\title{
Logros y desafíos de la integración centroamericana
}

Aportes de la CEPAL

JORGE MARIO MARTÍNEZ PIVA Editor

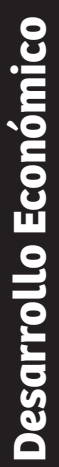

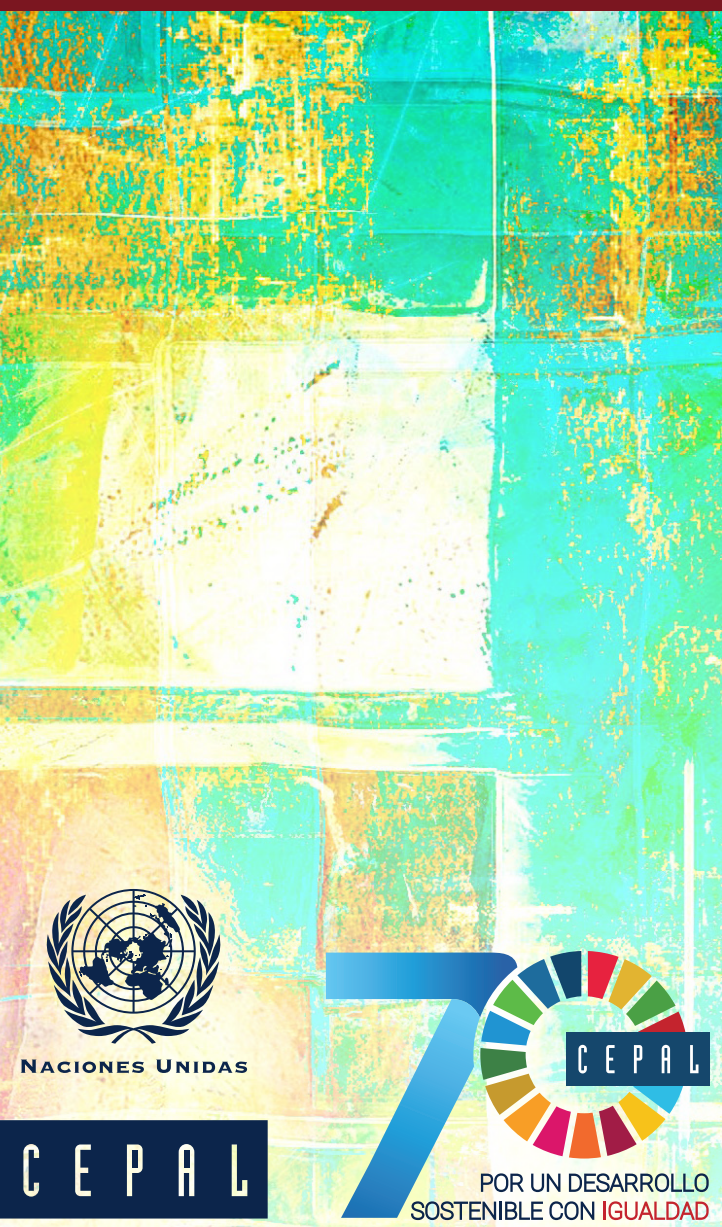




\section{Gracias por su interés en esta}

\section{publicación de la CEPAL}

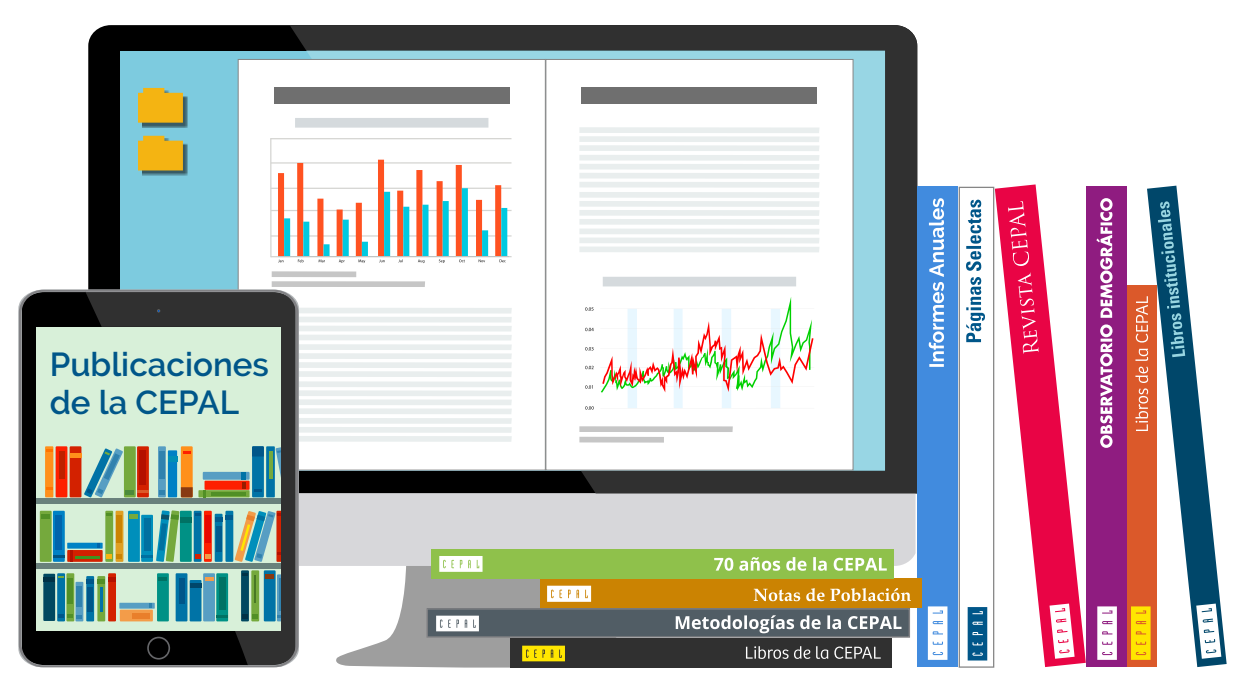

Si desea recibir información oportuna sobre nuestros productos editoriales y actividades, le invitamos a registrarse. Podrá definir sus áreas de interés y acceder a nuestros productos en otros formatos.

\section{Deseo registrarme}
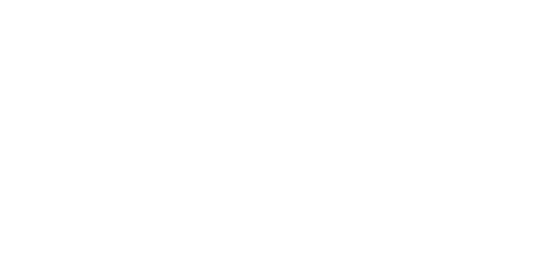

www.cepal.org/es/publications

facebook.com/publicacionesdelacepal

D.w.cepal.org/apps 


\section{Logros y desafíos de la integración centroamericana}

Aportes de la CEPAL

Jorge Mario Martínez Piva

Editor 


\section{Libros de la CEPAL}

156

Alicia Bárcena

Secretaria Ejecutiva

Mario Cimoli

Secretario Ejecutivo Adjunto

Raúl García-Buchaca

Secretario Ejecutivo Adjunto

para Administración y Análisis de Programas

Hugo E. Beteta

Director de la sede subregional de la CEPAL en México

Ricardo Pérez

Director de la División de Publicaciones y Servicios Web

La elaboración de este libro fue dirigida y coordinada por Jorge Mario Martínez Piva, Jefe de la Unidad de Comercio Internacional e Industria de la sede subregional de la Comisión Económica para América Latina y el Caribe (CEPAL) en México. Participaron en su elaboración, además de sus autores, los siguientes funcionarios de la CEPAL: Manuel Castillo, José Manuel Iraheta, Alan Méndez, Jaime Olivares, Diana Ramírez, Manuel Eugenio Rojas y Eugenio Torijano. Colaboraron también Eva Campos, Teófilo de la Torre, Juan Alberto Fuentes, Laura Michele Godoy, Jorge López, Martín Portillo, José Ángel Recinos y Adriana Velásquez. Se agradecen los valiosos comentarios de Jorge Máttar a la versión preliminar de algunos de los capítulos del libro.

Se agradece, además, la colaboración de Sebastián Herreros y Osvaldo Rosales, por la revisión y los comentarios sustantivos que hicieron durante el proceso de elaboración de este libro.

Los límites y los nombres que figuran en los mapas incluidos en este documento no implican su apoyo o aceptación oficial por las Naciones Unidas.

Publicación de las Naciones Unidas

ISBN: 978-92-1-122015-5 (versión impresa)

ISBN: 978-92-1-058654-2 (versión pdf)

ISBN: 978-92-1-358104-9 (versión ePub)

Número de venta: S.19.II.G.10

LC/PUB.2019/7-P

Distribución: $\mathrm{G}$

Copyright $\odot$ Naciones Unidas, 2019

Todos los derechos reservados

Impreso en Naciones Unidas, Santiago

S.18-01065

Esta publicación debe citarse como: J. M. Martínez Piva (ed.), Logros y desafíos de la integración centroamericana: aportes de la CEPAL, Libros de la CEPAL, N 156 (LC/PUB.2019/7-P), Santiago, Comisión Económica para América Latina y el Caribe (CEPAL), 2019.

La autorización para reproducir total o parcialmente esta obra debe solicitarse a la Comisión Económica para América Latina y el Caribe (CEPAL), División de Publicaciones y Servicios Web, publicaciones.cepal@un.org. Los Estados Miembros de las Naciones Unidas y sus instituciones gubernamentales pueden reproducir esta obra sin autorización previa. Solo se les solicita que mencionen la fuente e informen a la CEPAL de tal reproducción. 


\section{Índice}

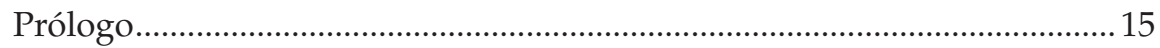

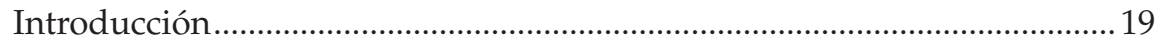

Jorge Mario Martínez Piva

Capítulo I

La Comisión Económica para América Latina y el Caribe (CEPAL) en la historia de la integración centroamericana ...............................................2 29

Rómulo Caballeros

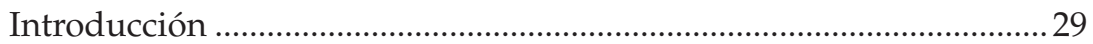

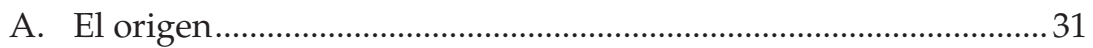

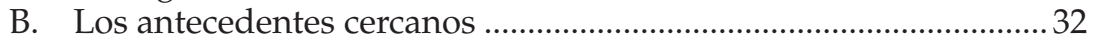

C. El inicio del actual proceso de integración ............................................33

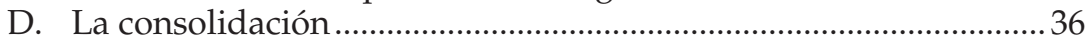

E. La anormalidad institucional y las raíces de la crisis....................... 40

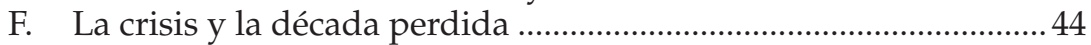

G. La reorientación y la consolidación .....................................................46

H. La recuperación y el redimensionamiento .........................................4 49

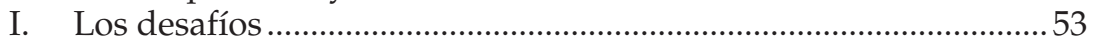

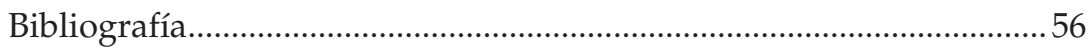

Capítulo II

El modelo de desarrollo subyacente de la integración centroamericana........61 Jorge Mario Martínez Piva

Introducción

A. La búsqueda de un modelo de desarrollo ........................................... 62

1. La industrialización por sustitución de importaciones. 
2. La integración como vía hacia el desarrollo .................................... 65

B. Del desarrollo hacia adentro al desarrollo hacia afuera ..................67 67

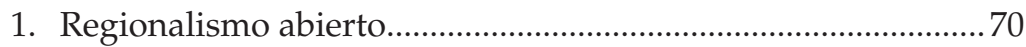

2. ¿Una nueva relación centro-periferia? .........................................75

C. El cambio estructural progresivo …………..................................... 76

1. Política industrial en el siglo XXI .................................................78

2. El desarrollo de cadenas regionales de valor.................................8 80

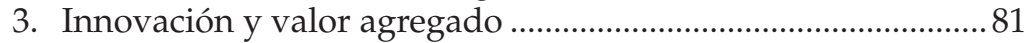

4. El desarrollo sostenible: un gran impulso ambiental .................83

5. La igualdad en el centro de la propuesta de desarrollo.............84 84

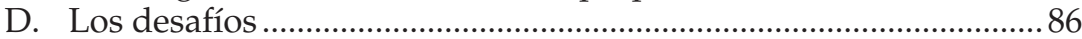

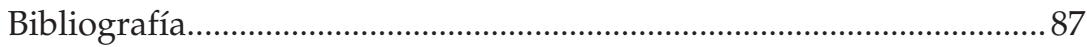

Capítulo III

Evolución del comercio de Centroamérica.

Martha Cordero Sánchez, Jorge Mario Martínez Piva

Introducción

A. El comercio centroamericano durante el período de sustitución de importaciones y fomento de la industrialización

B. El comercio centroamericano, de la crisis al regionalismo abierto

C. El comercio centroamericano en los años recientes (cambio estructural progresivo entre 2008 y 2017)

D. Conclusiones y perspectivas............................................................. 117

Bibliografía.

Capítulo IV

El potencial dinamizador de las exportaciones en Centroamérica

y la República Dominicana: evidencia empírica a partir

del análisis de matrices insumo-producto.....

Rodolfo Minzer Parnes, Roberto Carlos Orozco

Introducción

A. Marco conceptual: metodología y fuentes de información

B. Valor agregado nacional incorporado en las exportaciones y empleo inducido por estas.

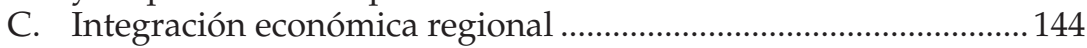

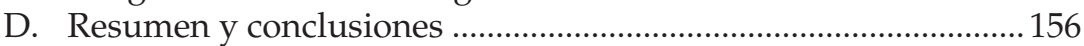

Bibliografía.

Capítulo V

Integración productiva regional: las cadenas regionales de valor Olaf de Groot

Introducción

A. Antecedentes.....

B. Las cadenas de valor. 


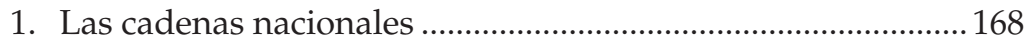

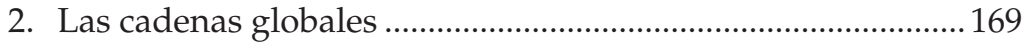

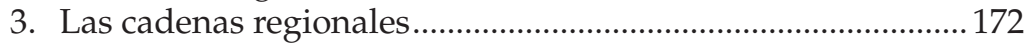

C. Las cadenas regionales de valor como un estímulo para la integración productiva de Centroamérica........................... 174

1. Metodología armonizada para el fortalecimiento de las cadenas regionales de valor ............................................ 176

2. Cooperación internacional con socios regionales .....................180

D. El futuro de las cadenas regionales en Centroamérica .................. 181

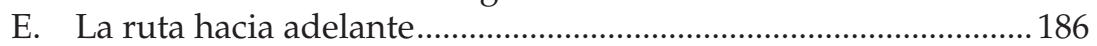

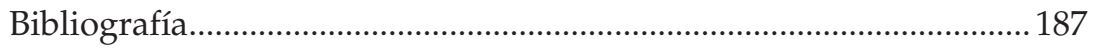

Capítulo VI

La Unión Aduanera Centroamericana: probables impactos económicos y sociales José Durán Lima

Introducción

A. Literatura sobre metodologías para evaluar el impacto de programas de facilitación del comercio....

1. Modelos gravitacionales para la estimación de costos administrativos

2. Modelos de equilibrio general computable y facilitación

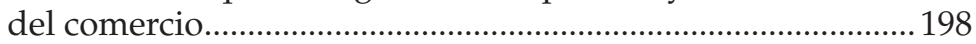

B. Estado actual de la Unión Aduanera Centroamericana ............... 201

1. Protección arancelaria y no arancelaria......................................2201

2. Cadenas de valor y comercio intrarregional...............................204

3. La Unión Aduanera Centroamericana y la facilitación del comercio.

C. Resultados esperados de la aplicación de programas de facilitación del comercio.

1. Resultados macroeconómicos .....................................................2. 214

2. Efectos sobre la recaudación tributaria......................................219

3. Efectos sobre el empleo, la pobreza y la distribución del ingreso.

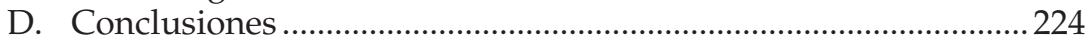

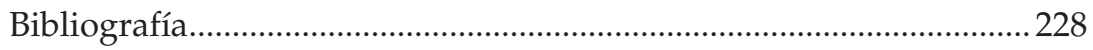

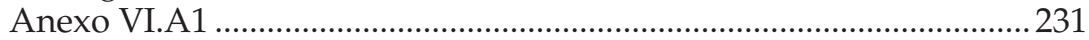

Capítulo VII

La coordinación fiscal como primer paso para el logro

de la integración fiscal en Centroamérica.......................................................237

María Concepción Castro Mazariegos, Juan Carlos Rivas Valdivia

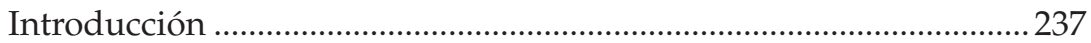

A. Situación fiscal de Centroamérica ..................................................240

B. La integración comercial como determinante de la integración fiscal 
1. Acompañamiento de la CEPAL y análisis de las implicaciones fiscales de algunos de los acuerdos comerciales de Centroamérica con otros países...............................................24 244

2. Área de Libre Comercio de las Américas ................................... 245

3. Tratado de Libre Comercio entre República Dominicana, Centroamérica y los Estados Unidos

4. Implicaciones fiscales de la construcción de la Unión Aduanera Centroamericana

5. Otros acuerdos relevantes donde el componente comercial ha predominado sobre los acuerdos fiscales...........250

C. La institucionalidad fiscal de la integración...................................2252

1. El COSEFIN: definición a partir del DR-CAFTA.......................253

2. El Grupo de Trabajo de Política Tributaria.................................253

3. El proceso de institucionalización del COSEFIN ......................255

4. Resultados más relevantes del trabajo del COSEFIN...............260

D. Conclusiones y desafíos de la integración centroamericana en materia fiscal: la visión de la CEPAL...........................................263

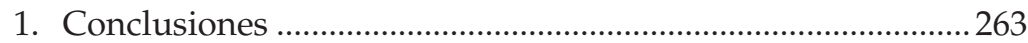

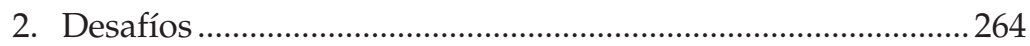

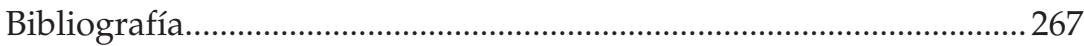

Capítulo VIII

Infraestructura logística y movilidad: las arterias

de la integración centroamericana.

Gabriel Pérez-Salas, Ricardo J. Sánchez

Introducción

A. Importancia de la infraestructura para los procesos de integración regional

B. Desde el concepto tradicional de transporte hacia un concepto más avanzado de logística y movilidad ....................2276

C. Políticas públicas integradas y sostenibles de logística

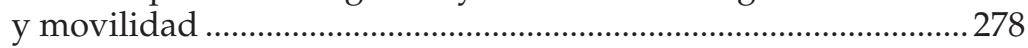

D. La integración regional como opción de desarrollo sostenible......280

E. Servicios logísticos y cadenas de valor vinculadas a los productos primarios.

F. El proceso de construcción de la política marco en Centroamérica.

G. Lecciones aprendidas del proceso centroamericano .......................290

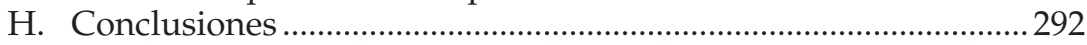

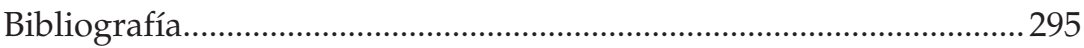

Capítulo IX

La energía en la integración centroamericana ..............................................297

Víctor Hugo Ventura Ruiz

Introducción

A. La energía en la agenda de la Comisión Económica para América Latina y el Caribe. 


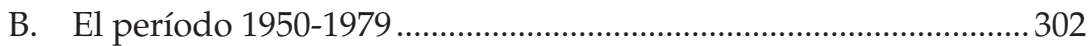

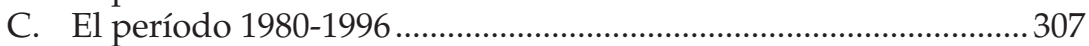

1. Avance de las interconexiones binacionales .............................309

2. El Plan Especial de Cooperación Económica

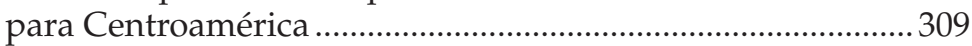

3. Institucionalización del Consejo de Electrificación de América Central......................................................................... 311

4. Relanzamiento de la interconexión eléctrica .............................311

5. El Tratado Marco del Mercado Eléctrico de América Central.

6. Otros acontecimientos importantes de la integración

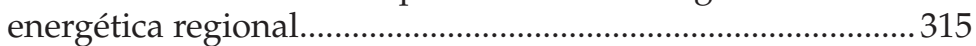

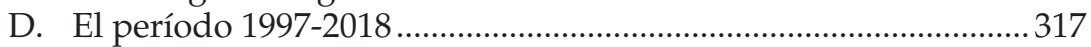

1. Asistencia técnica a los países ....................................................319

2. La cooperación de México ............................................................324

3. La Estrategia Energética Sustentable Centroamericana 2020........325

E. Reflexiones finales: las tareas pendientes de la integración

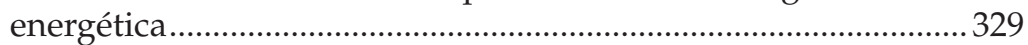

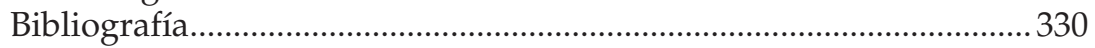

Capítulo X

La respuesta al cambio climático: transversalización sectorial en el Sistema de la Integración Centroamericana Julie Lennox

Introducción

A. La región del SICA frente al cambio climático: propuesta de adaptación sostenible e incluyente.

B. La iniciativa de la Economía del Cambio Climático en Centroamérica y la República Dominicana.

C. Experiencias de transversalización del cambio climático .............347

1. Transversalización con los Ministerios de Hacienda o Finanzas y el COSEFIN

2. Transversalización con los Ministerios de Agricultura y el CAC

3. Transversalización con los Ministerios de Salud ......................355

D. Lecciones aprendidas y camino por recorrer …………….............356

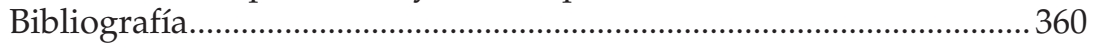

Capítulo XI

La dimensión social de la integración centroamericana. 365

Humberto Soto de la Rosa, Maria Luisa Marinho,

Citlalli Lamotte, Elsa Gutiérrez

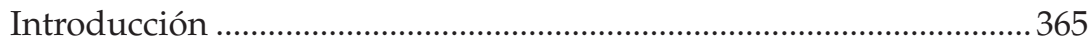

A. Institucionalidad de la integración social centroamericana..........367 
1. Secretaría de la Integración Social Centroamericana

2. Secretaría General de la Coordinación Educativa y Cultural Centroamericana.

3. Secretaría del Consejo de Ministros de Salud de Centroamérica.

4. Secretaría Técnica del Consejo de Ministras de la Mujer de Centroamérica y República Dominicana

5. Secretaría Técnica del Foro Centroamericano y República Dominicana de Agua y Saneamiento. 373

6. Otras instancias e instituciones.

B. Acciones realizadas a favor de la integración social centroamericana 373

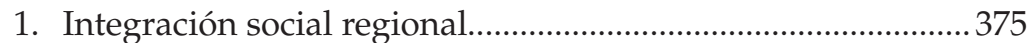

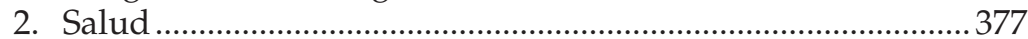

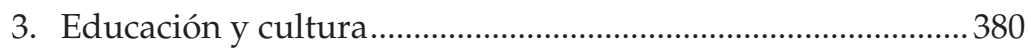

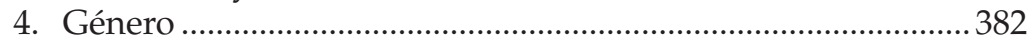

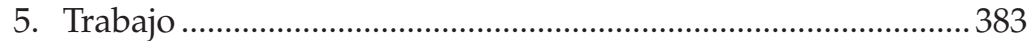

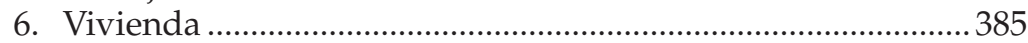

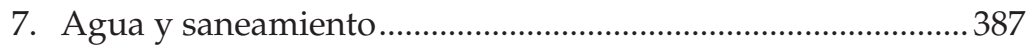

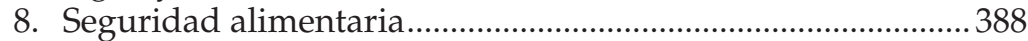

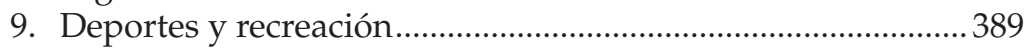

C. Los retos y desafíos para mejorar el proceso de la integración

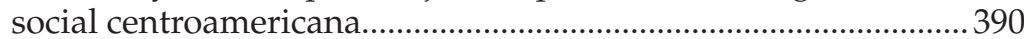

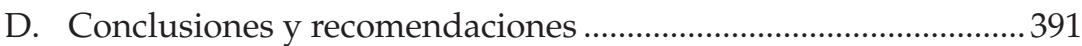

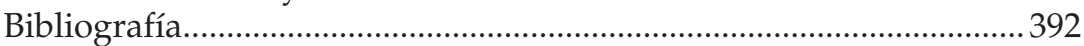

Capítulo XII

La integración centroamericana en materia de ciencia, tecnología e innovación.

Leda Peralta Quesada, Ramón Padilla Pérez

Introducción

A. Fundamento lógico de la integración en materia de ciencia, tecnología e innovación

B. Desarrollo histórico y estado actual de la integración centroamericana en materia de ciencia, tecnología e innovación

1. Coordinación para promover la ciencia, la tecnología y la innovación...

2. Integración mediante políticas públicas sectoriales ..................404

3. Cooperación para impulsar la investigación ...............................405

C. La contribución de la CEPAL a la integración en ciencia, tecnología e innovación.

1. Evolución del enfoque en ciencia, tecnología e innovación.........407

2. Hacia un sistema regional de innovación

3. Desarrollo productivo 
D. Conferencias y órganos subsidiarios de la CEPAL...........................416

1. Conferencia de Ciencia, Innovación y Tecnologías de la Información y las Comunicaciones ....................................416

2. Agenda Digital para América Latina y el Caribe.......................417

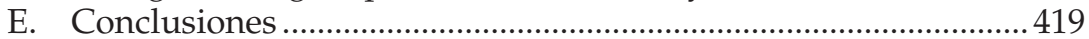

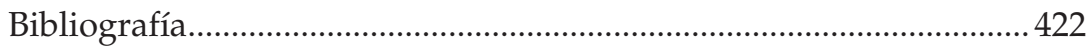

Capítulo XIII

A modo de conclusión: con la mirada puesta en el futuro

de la integración.....

Hugo E. Beteta, Jorge Mario Martínez Piva

A. Avances y acciones de trabajo identificadas....................................426

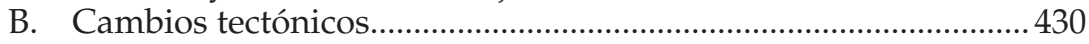

1. La consolidación de China como potencia económica

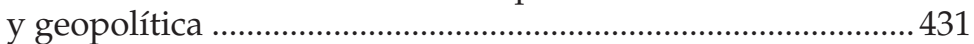

2. Los megaacuerdos crean mercados megarregionales .............. 432

3. El auge del nacionalismo económico y los vínculos

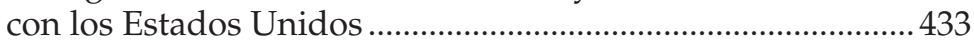

4. La población envejece y muchos jóvenes emigran ................... 435

5. La sostenibilidad del desarrollo y el cambio climático ............436

6. La nueva revolución tecnológica.................................................436

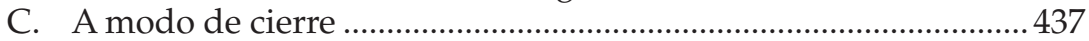

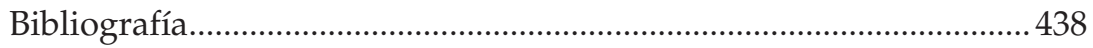

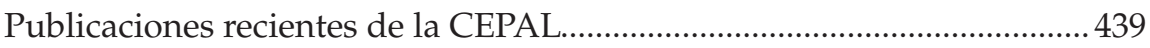

\section{Cuadros}

II.1 Centroamérica: tratados de libre comercio vigentes

y Organización Mundial del Comercio, 2017

IV.1 Centroamérica (4 países) y República Dominicana: valor agregado nacional incorporado en las exportaciones de bienes y servicios, y exportaciones brutas de bienes y servicios, por país, 2010-2013

IV.2 Centroamérica (4 países) y República Dominicana: valor agregado nacional incorporado en las exportaciones de bienes y servicios con respecto a las exportaciones brutas de bienes y servicios, por país, 2010-2013

IV.3 Centroamérica (4 países) y República Dominicana: valor agregado nacional incorporado en las exportaciones de bienes y servicios, y empleo que este induce, por país, 2010-2013

IV.4 Centroamérica (4 países) y República Dominicana: valor agregado por ocupado incorporado en las exportaciones de bienes y servicios, por país, 2010-2013

IV.5 Centroamérica (4 países) y República Dominicana: estructura porcentual del valor agregado nacional incorporado en las exportaciones de bienes y del empleo inducido por él, por sector económico y país, 2010-2013. 
IV.6 Centroamérica (4 países) y República Dominicana: valor agregado por ocupado incorporado en las exportaciones de bienes, por sector económico y país, 2010-2013.

IV.7 Centroamérica (4 países) y República Dominicana: estructura porcentual del valor agregado nacional incorporado en las exportaciones de servicios y del empleo inducido por él, por sector económico y país, 2010-2013

IV.8 Centroamérica (4 países) y República Dominicana: valor agregado por ocupado incorporado en las exportaciones de servicios, por sector económico y país, 2010-2013.

IV.9 Centroamérica (4 países) y República Dominicana: valor agregado por ocupado incorporado en las exportaciones de bienes y servicios, por país y destino comercial, 2010-2013 .......150

V.1 Conceptos y definiciones de cadena de valor ................................. 166

V.2 Centroamérica: comparación de las fortalezas de las cadenas nacionales, regionales y globales de valor.

VI.1 Centroamérica: protección arancelaria y equivalente arancelario de las medidas no arancelarias y administrativas aplicables a las importaciones intrarregionales, 2017 ....................204

VI.2 Centroamérica: equivalentes ad valorem estimados de las barreras administrativas, 2017

VI.3 Centroamérica (5 países): participación de empresas según tamaño y monto exportado, 2016

VI.4 Centroamérica: escenarios de profundización de la Unión Aduanera Centroamericana

VI.5 Centroamérica: escenario consolidado de la plena aplicación de la Unión Aduanera Centroamericana (todos los países miembros).

VI.6 Guatemala, Honduras y Triángulo del Norte de Centroamérica: cambio porcentual de variables macroeconómicas debido a reducciones de las barreras administrativas

VI.7 Guatemala, Honduras y Triángulo del Norte de Centroamérica: cambio porcentual en producción, importaciones y exportaciones a nivel sectorial, con un $60 \%$ de reducción de las barreras administrativas.

VI.8 Centroamérica: efectos macroeconómicos de una unión aduanera ampliada

VI.9 Centroamérica: aumento estimado de la recaudación tributaria resultante de programas alternativos de facilitación del comercio según los grupos de países que lo apliquen

VI.10 Resultados de las microsimulaciones: unión aduanera entre Guatemala y Honduras

VI.A1.1 Principales grupos de productos considerados en el modelo de equilibrio general computable empleado. 
VI.A1.2 Países y regiones que conforman el modelo de equilibrio general computable empleado

VI.A1.3 Centroamérica (6 países): distribución de las exportaciones según destino en regiones y socios seleccionados, 2016.

VI.A1.4 Centroamérica (6 países): distribución de las importaciones según origen en regiones y socios seleccionados, 2016 ................ 235

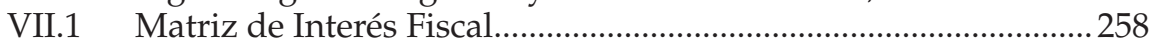

VIII.1 Centroamérica y México: inversión promedio en el sector del transporte, 2008-2015.

XI.1 Consejos ministeriales sociales centroamericanos, según el año de inicio de sus funciones

XI.2 Secretarías técnicas de los consejos ministeriales sociales centroamericanos, según su año de inicio de operaciones.

XI.3 Secretarías técnicas de los consejos ministeriales sociales centroamericanos, según su localización geográfica.....

XII.1 Centroamérica (6 países): indicadores de capacidades tecnológicas en comparación con economías grandes de América Latina y líderes en la materia

\section{Gráficos}

II.1 Centroamérica y República Dominicana: productividad laboral con relación a la productividad laboral de los Estados Unidos, 1990-2016

III.1 Costa Rica, Guatemala y Nicaragua: variación de la participación de socios seleccionados en su comercio total de bienes, 1960-1979

III.2 Mercado Común Centroamericano: evolución de las exportaciones intra- y extrarregionales, 1960-1979.

III.3 Mercado Común Centroamericano: composición de las exportaciones totales, 1970 y 1979

III.4 Mercado Común Centroamericano: evolución de las exportaciones e importaciones totales, 1960-1979

III.5 Mercado Común Centroamericano: evolución de la balanza comercial de bienes, 1960-2017.

III.6 Centroamérica: flujos de inversión extranjera directa, 1960-2016 ..... 99

III.7 Mercado Común Centroamericano: evolución del comercio intra- y extrarregional, 1980-1989.

III.8 Mercado Común Centroamericano: evolución del arancel ad valorem promedio de nación más favorecida, 1995-2016.

III.9 Centroamérica: número de acuerdos de libre comercio suscritos, 1995-2018

III.10 Centroamérica: evolución de las exportaciones e importaciones, 1994-2007

III.11 Centroamérica: índice de apertura comercial, 1990, 1995 y 2007 .......104 
III.12 Centroamérica: participación de mercado en las importaciones de mercados seleccionados, 1977, 1987, 1997, 2007 y 2017

III.13 Principales productos de importación desde Centroamérica y análisis de competitividad exportadora, 1990 y 2007

III.14 Centroamérica: principales productos en el comercio intrarregional, 1990 y 2007.

III.15 Centroamérica: exportaciones totales de bienes por intensidad tecnológica, 1986-2017

III.16 Centroamérica: exportaciones intrarregionales de bienes por intensidad tecnológica, 1986-2016.

III.17 Centroamérica: evolución de las exportaciones intrarregionales y extrarregionales, 1960-2016

III.18 Centroamérica: evolución de las exportaciones de bienes y servicios, 1980-2017

III.19 Centroamérica: número de productos y mercados de exportación, 1988-2016.

III.20 Centroamérica: matriz de competitividad de mercados, 2007-2016

III.21 Centroamérica: matriz de competitividad de productos en el mercado centroamericano, 2007-2016.

IV.1 Centroamérica (4 países) y República Dominicana: estructura porcentual del valor agregado nacional directo e indirecto incorporado en las exportaciones de bienes y del empleo inducido por él, por destino, 2010-2013.

V.1 Centroamérica: exportaciones internacionales por país, 1995 y 2016

V.2 Centroamérica (6 países): participación de las exportaciones a los países centroamericanos en las exportaciones totales de bienes, 1995 y 2016

V.3 Centroamérica (6 países): participación en las cadenas globales de valor, 2005 y 2018

V.4 Centroamérica (6 países): participación del valor agregado extranjero en las exportaciones, 2005 y 2018.

VI.1 Centroamérica: evolución de la protección arancelaria, 1995-2018

VI.2 Centroamérica: protección arancelaria y no arancelaria, alrededor de 2017

VI.3 Centroamérica: distribución de las exportaciones intrarregionales y coeficiente de comercio intrarregional, 2016.

VI.4 Centroamérica: evolución del número de acuerdos comerciales suscritos

VI.5 Triángulo del Norte de Centroamérica: importaciones sujetas al régimen de libre circulación de mercancías en el proceso de profundización de la Unión Aduanera Centroamericana, 2015-2016 
VI.6 Centroamérica (países y agrupaciones seleccionados): efectos sobre el producto interno bruto de diversos escenarios simulados.

VI.7 Centroamérica: efectos sobre el producto interno bruto de diversos escenarios simulados de unión aduanera.

VI.8 Nuevos socios en la Unión Aduanera Centroamericana: efectos sobre las exportaciones de bienes.

VI.9 Centroamérica: aumento estimado de la recaudación tributaria resultante de un programa ambicioso de facilitación del comercio

VI.10 Unión aduanera entre Guatemala y Honduras: efectos sobre empleo, pobreza y distribución del ingreso

VII.1 Centroamérica: balance fiscal del gobierno central, 2016-2017 ...... 241

VII.2 Centroamérica: ingresos y gastos totales del gobierno central, 2010-2017.

VIII.1 Centroamérica (7 países) y México: inversión promedio por tipo de infraestructura de transporte, 2008-2015

IX.1 Centroamérica: consumo de energía eléctrica por habitante, 1950-2016

IX.2 Centroamérica: participación por fuente en la producción total de energía eléctrica, 1950-2017

IX.3 Centroamérica: importaciones y exportaciones de electricidad, 1976-2017.

IX.4 Istmo centroamericano: participación por tipo de empresa e índices de concentración del mercado de diésel y gasolinas, 1996, 2006 y 2016

IX.5 Países del Sistema de la Integración Centroamericana: evolución del índice de electrificación, 1960-2016 326

\section{Recuadros}

V.1 La complejidad de las cadenas de valor .............................................167

V.2 El índice de selección de cadenas regionales de valor ......................183

VII.1 Las labores del Grupo de Trabajo de Política Tributaria ................... 254

IX.1 El Estudio Regional de Interconexión Eléctrica

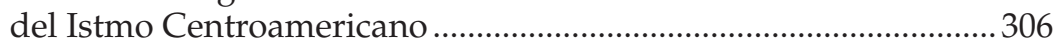

IX.2 El Programa de Actividades Regionales en el Subsector Eléctrico del Istmo Centroamericano.

IX.3 Desafíos actuales del Mercado Eléctrico Regional de Centroamérica.

IX.4 La transición energética de Centroamérica.........................................327

XI.1 Tendencias y desafíos relacionados con la migración en Centroamérica 


\section{Diagramas}

V.1 Las diferentes cadenas de valor. 166

V.2 Pasos del análisis de una cadena regional de valor

VI.1 Representación esquemática del modelo del Proyecto de Análisis del Comercio Global .....................................................2200

VII.1 Línea cronológica de la coordinación fiscal centroamericana .........239

VII.2 Organización del Consejo de Ministros de Hacienda o Finanzas de Centroamérica, Panamá y la República Dominicana (COSEFIN)....... 257

IX.1 Centroamérica: línea cronológica de la integración energética.......300

X.1 Adaptación sostenible e incluyente 339

X.2 Adaptación sostenible e incluyente y Objetivos de Desarrollo Sostenible (ODS)

XII.1 La triple hélice de la innovación.............................................................. 405

\section{Mapas}

IX.1 Sistema de Interconexión Eléctrica de los Países de América Central (SIEPAC), 2018

IX.2 Países del Sistema de la Integración Centroamericana: principales rutas de abastecimiento de hidrocarburos 


\section{Prólogo}

Desde la independencia de los países que la integran, Centroamérica ha emprendido diversos esfuerzos para mantenerse unida. El proyecto de integración más fructífero de esta región y de más larga vida de América Latina y el Caribe empezó en 1951, de la mano de las propuestas intelectuales y el apoyo técnico de la Comisión Económica para América Latina y el Caribe (CEPAL).

En junio de 1951, en el cuarto período de sesiones de la CEPAL, los delegados centroamericanos expusieron las dificultades que enfrentaban sus países y manifestaron su interés en desarrollar la producción agrícola e industrial y los sistemas de transporte de manera que promovieran la integración de sus economías y la formación de mercados más amplios, mediante el intercambio de sus productos, la coordinación de sus planes de fomento y la creación de empresas en las que todos o algunos de esos países tuvieran interés.

Desde entonces la CEPAL ha trabajado en conjunto con los países centroamericanos, formulando propuestas para su desarrollo que han ido siempre entrelazadas con el planteamiento de la integración regional. Mediante la resolución 9(IV), del cuarto período de sesiones de la CEPAL, se aprobó un programa de trabajo para fomentar el intercambio recíproco, lograr una mayor integración de sus economías y la coordinación de sus planes de fomento. También entonces se creó el Comité de Cooperación Económica del Istmo Centroamericano (CCE), como un órgano permanente de consulta, integrado por los Ministros de Economía de Costa Rica, El Salvador, Guatemala, Honduras y Nicaragua, al que posteriormente se sumó la participación del Ministro de Comercio e Industrias de Panamá. 
Las propuestas intelectuales de la CEPAL se han venido plasmando en reflexiones y propuestas de política pública y cooperación técnica en áreas diversas con alta incidencia en el desarrollo de Centroamérica, respondiendo así a la creciente complejidad técnica que la integración regional conlleva. Aunque el énfasis inicial estuvo en la integración gradual de las economías y la coordinación de los programas nacionales de desarrollo económico, la evolución natural de la integración condujo a nuevas áreas de trabajo como la integración energética, la coordinación de infraestructuras y logística, y el diseño de políticas para enfrentar amenazas naturales comunes, entre muchas otras. Sobre la base de su experiencia y con gran compromiso, la CEPAL ha colaborado en muchas de esas áreas emergentes.

Una mirada al camino recorrido y al estado actual del proceso de integración muestra una región que tiene el único mercado eléctrico integrado de todo el continente, que ha creado mecanismos de coordinación para el diseño de infraestructura que facilite el movimiento de mercancías, que ha logrado una unión aduanera entre tres de sus miembros y ha consensuado reglamentos y formularios que facilitan el comercio entre todos sus miembros, entre otros muchos hitos en este proceso. Entre estos hitos, hay que destacar que Centroamérica negoció el acuerdo de libre comercio con los Estados Unidos de manera conjunta, y lo mismo hizo con la República de Corea, y cuenta con el único acuerdo comercial que existe entre regiones, con la Unión Europea. La región tiene aún un camino importarte por recorrer, pero no se debe olvidar que la senda de la integración exhibe ya un conjunto de numerosos hitos que deben celebrarse.

En su septuagésimo aniversario, la CEPAL publica este libro en el que se analiza el proceso de integración centroamericana, poniendo énfasis en las áreas en que la Comisión colabora con la región, mostrando los avances más importantes y los desafíos para el futuro. Se subraya la existencia de bienes públicos regionales en los que resulta más provechosa la acción conjunta de la región y en los que la CEPAL puede prestar apoyo. Se trata de un repaso histórico necesario para observar, con visión renovada, los desafíos de Centroamérica y los aportes que la CEPAL puede realizar. En este libro se presenta un inventario de la contribución intelectual y técnica que la comisión regional de las Naciones Unidas ha hecho al proceso de integración centroamericana, al mismo tiempo que se muestra la actualidad y la relevancia del proyecto integracionista como instrumento de desarrollo.

El proceso de integración centroamericana es parte de la historia misma de la CEPAL, que ha ido adaptando su pensamiento a los requerimientos de los tiempos, manteniendo el foco en el cambio estructural. Este largo proceso ha permitido la generación de un importante cúmulo de conocimientos, desarrollo intelectual y apoyos técnicos, que hoy se presentan en este libro como un proceso de "continuidad con cambios". 
Con apego al método histórico-estructural, en el libro se analizan las transformaciones que han tenido lugar en las estructuras productivas centroamericanas y se identifican las transformaciones que aún son necesarias para impulsar un cambio estructural progresivo. La exposición se origina en el análisis histórico del proceso de integración centroamericana y en ella se examinan diversos temas en tres momentos cruciales del pensamiento cepalino: i) la fase de industrialización por sustitución de importaciones (modelo "hacia adentro"), ii) la etapa de integración con la economía global al mismo tiempo que se fortalecía la integración regional ("regionalismo abierto") y iii) los planteamientos más recientes para alcanzar una transformación productiva con énfasis en la igualdad, la innovación y la sostenibilidad ambiental ("cambio estructural progresivo").

Con este libro, la CEPAL busca contribuir, a partir de su bagaje histórico, a la permanente renovación de la propuesta de desarrollo e integración para Centroamérica. Esta propuesta pone el énfasis, en la actualidad, en un cambio estructural progresivo. Este cambio se puede impulsar desde los diversos frentes que se abordan en este trabajo: el sector social, la energía, los retos del cambio climático, la infraestructura, la coordinación fiscal, el comercio, la integración productiva y la innovación. Se subraya la importancia de un "gran impulso ambiental" para la igualdad y la sostenibilidad, apoyado en políticas públicas coordinadas que desvinculen el desarrollo de externalidades ambientales y mejoren la calidad de vida de la población. Las nuevas propuestas de la CEPAL al proceso de integración centroamericana permiten avanzar en el cumplimiento de los Objetivos de Desarrollo Sostenible (ODS) que las Naciones Unidas y los Estados se han propuesto a 2030. Estas nuevas ideas enmarcan los capítulos de este libro, para favorecer que se siga construyendo sobre la fructífera experiencia histórica y vislumbrando nuevas áreas de colaboración de la CEPAL con la integración centroamericana.

\author{
Alicia Bárcena \\ Secretaria Ejecutiva \\ Comisión Económica para \\ América Latina y el Caribe (CEPAL)
}





\section{Introducción}

El proceso de integración regional de Centroamérica es el más antiguo de América Latina. Nació en 1951, con la Carta de la Organización de Estados Centroamericanos (ODECA), y continuó en 1960, con la firma del Tratado General de Integración Económica Centroamericana, mediante el cual se creó el Mercado Común Centroamericano (MCCA). La Comisión Económica para América Latina y el Caribe (CEPAL) fue gestora y promotora de este proceso como instrumento clave para el desarrollo de la región, por lo que cuenta con abundante experiencia y material que se comparte y se pone en perspectiva a través de este libro.

El objetivo de esta publicación es presentar un análisis de algunos de los aportes más relevantes de la CEPAL al proceso de integración centroamericana, mostrar los avances más importantes y los desafíos para el futuro cercano. Si bien existen muchas áreas en las que la CEPAL ha aportado durante la historia de este proceso - como la integración financiera, el desarrollo turístico y el fortalecimiento de la capacidad de hacer modelizaciones macroeconómicas, entre otras-, no es posible abordarlas todas en este libro, por lo que solo se mencionan las que cuentan con una agenda de colaboración más reciente. Se muestra que existen bienes públicos regionales respecto de los cuales la acción conjunta resulta más provechosa, y que la CEPAL puede contribuir a optimizar el uso de dichos bienes. Se trata de un libro cepalino sobre la integración centroamericana en el que se arroja luz sobre este proceso y se subraya su relevancia como instrumento de desarrollo. 
La historia intelectual de la CEPAL ha sido, desde sus orígenes, una de "continuidad con cambios" (Bárcena, Bielschowsky y Torres, 2018), lo que se refleja tanto en su apoyo continuo a la integración centroamericana como en su adaptación a los requerimientos de los tiempos, sin perder de vista el foco en el cambio estructural. Como metodología de trabajo, en este libro se adoptan el enfoque investigativo de la CEPAL, denominado histórico-estructural, y la perspectiva del sistema centro-periferia. Se analizan los aportes de la CEPAL y los retos de la integración a la luz de las características periféricas de esta, condicionadas por la economía mundial que encabezan los países desarrollados.

El método histórico-estructural permite analizar las transformaciones de mediano y largo plazo de las estructuras productivas y sociales propias del subdesarrollo de América Latina y el Caribe (Bárcena, Bielschowsky y Torres, 2018). Se origina en el análisis del subdesarrollo de la región y el reto de transitar de las estructuras y los patrones de comportamiento económico típicos de la fase agroexportadora (modelo "hacia afuera") a la industrialización y la urbanización (modelo "hacia adentro"), así como a la integración con la economía mundial y el fortalecimiento de la integración regional ("regionalismo abierto"), y a la transformación productiva con énfasis en la igualdad ("cambio estructural progresivo"), que es el esfuerzo más reciente.

En la integración centroamericana también se ha vivido un proceso de continuidad con cambios en que del énfasis en la integración comercial se ha pasado a otras áreas de trabajo a nivel regional: infraestructura y movilidad, pesca, turismo, pequeñas y medianas empresas, medio ambiente, energía y otras. De esta manera, Centroamérica se ha adaptado al contexto político y económico internacional, al tiempo que sus instituciones han respondido a ese entorno. En las primeras décadas de la integración, la región se adaptó al espíritu desarrollista de la posguerra y, siguiendo la propuesta de industrialización de la CEPAL y el apoyo del sector empresarial, se emprendió la ampliación del mercado interno y la industrialización. Tras la crisis del petróleo, las tensiones de la guerra fría se reflejaron en conflictos armados en el contexto centroamericano, y en la región se redujo el comercio interno, pero se mantuvo firme el proyecto de integración. La pacificación, el fin de la guerra fría y el ascenso de las ideas comúnmente conocidas como el Consenso de Washington crearon el contexto para la apertura y el crecimiento de la mano del comercio internacional. Sin embargo, Centroamérica se adaptó de nuevo a los tiempos y se confió en el mercado interno y en nuevas áreas de integración más allá del comercio. Actualmente, en la segunda década del siglo XXI, se ha hecho evidente que el cambio climático y el escaso valor agregado de la oferta exportadora requieren de esfuerzos distintos, que permitan ejecutar nuevas políticas industriales en virtud de las cuales se 
descarbonice la economía y se aumente el valor agregado de la producción. En los países pequeños como los centroamericanos, estos retos se enfrentan mejor con políticas regionales que fortalezcan la labor nacional.

La CEPAL, de acuerdo con sus capacidades, experiencia y mandatos, colabora en algunas de las áreas de trabajo que se han propuesto en el proceso de integración. En este libro se expone el trabajo realizado hasta hoy. El número de países que participan en la integración ha cambiado, y se han sumado Belice, Panamá y la República Dominicana, en diversas áreas y con distintos niveles de profundidad, por lo que en este libro se da cuenta de ello en cada capítulo según sea relevante.

La presencia de la CEPAL en el proceso de integración centroamericano se ha expresado en múltiples intervenciones. Por una parte, a través de la influencia intelectual, que generó reflexiones y propuestas relativas a la industrialización, el comercio interno y externo, y la promoción del cambio estructural progresivo. Por otra parte, a través de asistencia técnica, a nivel nacional y regional, para crear instituciones, fortalecer capacidades, y formular planes y programas que se tradujeron en acciones que impulsaron la integración.

La influencia intelectual de la CEPAL se inicia con el planteamiento estructuralista de Raúl Prebisch. Se identificaron las características que predominaban en las relaciones comerciales que los países centroamericanos, y los latinoamericanos en general, mantenían con los países desarrollados. Estas relaciones se caracterizaron como de "centro-periferia", en las que los países del centro - los desarrollados- lograban obtener mayores beneficios al extraer rentas a través del comercio y perpetuar la condición de subdesarrollo - periferia - de los países latinoamericanos (Prebisch, 1958). Por ese motivo, se concluyó que la industrialización era una exigencia ineludible del desarrollo, que no podría alcanzarse en grado suficiente para acelerar el ritmo de crecimiento si no se acrecentaba el intercambio entre los países de la región (Prebisch, 1969).

Superar la condición de periferia suponía un nuevo modelo de desarrollo que promoviera el progreso técnico, una mejor distribución del ingreso y nuevas formas de relacionarse con el mundo. En los países se debían dirigir los esfuerzos a incrementar las capacidades industriales y escapar de la condición de periferia. La industrialización para sustituir importaciones era una exigencia del proceso de desarrollo, y para lograrla era necesario superar la limitación que imponía la estrechez de los mercados nacionales de los países centroamericanos. Ello se debía a que, a medida que se avanza en un proceso de industrialización, hay que desarrollar industrias cada vez más complejas y la dimensión del mercado es primordial para la productividad. Esto marcó la idea de lograr un mercado centroamericano integrado, que permitiera ampliar los mercados internos. 
Los trabajos de la CEPAL derivaron en propuestas de política pública que se presentaron a las autoridades nacionales y a las instituciones regionales recién creadas y se tradujeron en acciones que sostuvieron o impulsaron la integración. Otras de sus propuestas, si bien no cristalizaron, promovieron la reflexión o influyeron en acciones que profundizaron y ampliaron la temática de la interrelación entre los países.

El modelo de industrialización por sustitución de importaciones tuvo una serie de debilidades: pocos encadenamientos, alta dependencia de los insumos importados y una estructura fiscal ineficiente y regresiva que no permitió financiar el crecimiento de los servicios públicos, como los puertos y las carreteras necesarios para el modelo de desarrollo. Esto condujo al declive del modelo en la década de 1970. El panorama internacional de entonces ofreció oportunidades para superar las limitaciones del modelo, al tiempo que la CEPAL abrió un debate sobre cómo evitar la especialización en ramas de lento progreso técnico.

Dado que el mercado centroamericano seguía siendo limitado y aún sufría el estancamiento de la década de 1980, se propuso una nueva estrategia que aprovechara el dinamismo de los países desarrollados y lo conjugara con el aprovechamiento del mercado regional, que seguía siendo el principal destino de los productos industriales. En el mercado regional había una especialización productiva por país, redes creadas de proveedores y encadenamientos, $\mathrm{y}$ una institucionalidad que velaba por que el mercado funcionara, por lo que era importante aprovecharlo para mejorar la inserción internacional.

El planteamiento de la CEPAL sobre el regionalismo abierto aportó una estructura y permitió fundamentar las propuestas que se debatían en la región centroamericana para replantear la integración económica y el modelo de desarrollo, y darles un nuevo impulso. Se concilió la interdependencia nacida de los acuerdos comerciales, como el mismo proceso de integración, con la impulsada por las señales del mercado resultantes de la liberalización comercial en general (CEPAL, 1994). En Centroamérica se acogió el regionalismo abierto como parte de la política de desarrollo, se profundizó la integración comercial y se ampliaron las áreas de integración, al tiempo que se liberalizó el comercio con terceros países, se firmaron acuerdos comerciales con diversos socios extrarregionales y se promovió la inversión extranjera directa.

Durante el período del regionalismo abierto, en la región centroamericana se aprovecharon las tendencias mundiales de liberalización financiera, deslocalización productiva y crecientes flujos comerciales y de inversión extranjera directa. Sin embargo, la estructura productiva de la región siguió arrastrando viejos problemas característicos de las economías periféricas: una especialización en bienes y servicios de bajo valor agregado, escasa 
integración de los sectores exportadores con el tejido productivo local, débil creación y difusión de nuevas tecnologías, y niveles de productividad altamente heterogéneos, entre otros.

La CEPAL señaló entonces que en la región se debía promover otro tipo de cambio estructural: "El cambio estructural deseable se define y evalúa en función de sus efectos agregados sobre el sistema económico. No hay cambio estructural virtuoso si meramente se multiplican enclaves de alta tecnología o si solo hay cambios en la punta más eficiente del sistema productivo" (CEPAL, 2012). Sin embargo, el desarrollo de la región seguía incompleto y requería de nuevos énfasis en su política pública.

La CEPAL subraya que es necesario renovar la propuesta de desarrollo e integración para Centroamérica, sobre la base del cambio estructural progresivo. Se requiere un gran impulso ambiental que promueva la igualdad y la sostenibilidad, apoyado en políticas públicas coordinadas que permitan desvincular el desarrollo económico de las externalidades ambientales y mejorar la calidad de vida de la población con empleos y medios de vida dignos, así como bienes y servicios públicos de calidad y mayor cobertura.

Estas nuevas ideas enmarcan los capítulos del presente libro, en los que se repasan la historia, las propuestas y las nuevas áreas en que la CEPAL colabora con la integración centroamericana. El libro se organiza en 13 capítulos. En el primero, escrito por Rómulo Caballeros, se hace un recorrido histórico por las principales contribuciones y recomendaciones que la CEPAL ha hecho para fortalecer la integración centroamericana. Este recorrido va desde el aporte intelectual de Raúl Prebisch sobre la condición de periferia y su propuesta de industrialización hasta la suscripción de los principales instrumentos jurídicos de la integración y la creación del Mercado Común Centroamericano. Se analizan también las principales características del período de estancamiento de la integración en la década de 1970 y de la profunda crisis de la década de 1980, así como de la posterior consolidación de la institucionalidad de la integración en la década de 1990, y el trabajo de la CEPAL durante todo este tiempo. Al final del capítulo se identifican temas emergentes relacionados con la colaboración entre la CEPAL y la integración centroamericana.

En el segundo capítulo, Jorge Mario Martínez Piva expone el modelo de desarrollo que la CEPAL propuso a la región centroamericana y sus fundamentos analíticos y económicos, que condujeron a la integración regional como instrumento para el desarrollo. Al inicio del capítulo se describe el primer modelo de industrialización por sustitución de importaciones como producto del análisis de la condición de periferia de la región. La CEPAL recomendó que los mercados regionales se integraran más y fueran funcionales a las políticas de industrialización que ejecutaban los países, y 
apoyó técnicamente la creación del Mercado Común Centroamericano. El modo en que evolucionó la economía mundial condujo al diseño de un modelo basado en profundizar la integración y conciliarla con la participación de las corrientes internacionales de comercio e inversión. Se analizan brevemente los avances y resultados del regionalismo abierto hasta la crisis mundial de 2008-2009 y las nuevas ideas fuerza que la CEPAL propuso con miras a impulsar un cambio estructural progresivo.

En el tercer capítulo, Martha Cordero Sánchez y Jorge Mario Martínez Piva hacen un análisis sobre cómo evolucionaron el comercio internacional y los flujos de inversión extranjera directa en Centroamérica. Señalan el impacto que tuvo el establecimiento del mercado interno centroamericano en la composición del comercio regional y muestran la diversificación productiva alcanzada y el modo en que evolucionó el valor de los productos comercializados. Se llama a los países a diseñar políticas para insertarse mejor en los mercados internacionales, incrementar el valor de sus productos y alinearse con los nuevos requerimientos ambientales. Con ese fin se puede aprovechar el gran empuje ambiental como dinamizador de la economía regional.

En el cuarto capítulo, utilizando las matrices de insumo-producto de algunos países, Rodolfo Minzer Parnes y Roberto Carlos Orozco brindan evidencia empírica sobre la importancia del comercio intrarregional centroamericano para generar valor agregado y empleo inducido por las exportaciones. Con ese objetivo, los autores cuantifican el efecto de las exportaciones de algunos países seleccionados en términos de su capacidad para generar valor agregado y empleo, según los principales destinos comerciales de estas. Este tipo de información es de particular importancia en el análisis de las ganancias obtenidas como resultado del proceso de integración centroamericana.

En el quinto capítulo, escrito por Olaf de Groot, se analiza la integración productiva centroamericana a través de las cadenas regionales de valor. El autor señala la existencia de diferentes tipos de cadenas de valor y el nivel de impacto que estas pueden tener en las economías pequeñas e integradas como las centroamericanas. En el capítulo se muestra que las cadenas de valor ofrecen la oportunidad de fortalecer las actividades productivas en un país $y$, cuando son transfronterizas, en una región. En los países centroamericanos, las cadenas regionales de valor contribuyen al proceso de integrarlos, y profundizan la integración y la especialización productiva.

En el sexto capítulo, José Durán Lima muestra los efectos económicos y sociales de aplicar programas de facilitación del comercio entre los países que conforman la Unión Aduanera Centroamericana. En el trabajo de base se parte de los esfuerzos que vienen haciendo los países de la subregión, principalmente los tres del norte de Centroamérica (El Salvador, Guatemala y Honduras), para profundizar la unión aduanera existente. 
En el séptimo capítulo, María Concepción Castro Mazariegos y Juan Carlos Rivas Valdivia reflexionan sobre cómo ha evolucionado la integración centroamericana en materia fiscal, lo que tiene implicaciones que se relacionan directamente con la integración comercial. Se describe de forma sucinta la institucionalidad fiscal de la integración - el Consejo de Ministros de Hacienda o Finanzas de Centroamérica, Panamá y República Dominicana (COSEFIN) - y se identifican los principales retos que enfrentan los países de la subregión, entre ellos, aumentar la capacidad de recaudación tributaria y la eficiencia en el uso de los recursos públicos, así como aprobar reformas fiscales pendientes en varios países. Se hace también un análisis sobre el acompañamiento de la CEPAL en la evaluación de las consecuencias fiscales de algunos de los acuerdos comerciales más importantes que se han celebrado en la subregión.

En el octavo capítulo, escrito por Gabriel Pérez-Salas y Ricardo J. Sánchez, se analiza la integración en Centroamérica haciendo énfasis en el tema de la infraestructura logística y de movilidad. Se destacan las principales características del proceso que se llevó a cabo en la región para promulgar la política marco de logística y movilidad, sus fortalezas y los elementos pendientes para lograr una plena integración logística. En este contexto, se releva la magnitud del déficit de infraestructura carretera que hay en la región y la necesidad de hacer inversiones públicas en las que se contemplen el mantenimiento y la actualización de las vías, incorporando estándares adecuados de diseño y seguridad vial. También se destaca que en Centroamérica se deben actualizar las políticas públicas y los planes privados de inversión a fin de incorporar acciones tendientes a mejorar la eficiencia y la sostenibilidad de la infraestructura y los servicios logísticos para transitar hacia servicios más sostenibles.

En el noveno capítulo, Víctor Hugo Ventura Ruiz analiza la evolución histórica del sector energético de la subregión, y describe las principales acciones que la CEPAL ha emprendido para fomentar el aprovechamiento de los recursos hidroeléctricos y la armonización de la industria eléctrica mediante la regulación de los costos de producción, las tarifas y las interconexiones binacionales y regionales. Se destaca el papel de la CEPAL en la integración eléctrica de Centroamérica, subrayando los trabajos encaminados a reducir el consumo de hidrocarburos y analizar el papel del gas natural como producto energético de transición. Al final del capítulo se identifican tareas pendientes que son relevantes no solo para la seguridad energética, sino como eje para enfrentar los desafíos geopolíticos de la subregión.

En el décimo capítulo, escrito por Julie Lennox, se estudian los efectos adversos del cambio climático en la región, así como la exposición de esta a los fenómenos climáticos, y se indica que son una de las mayores amenazas para los países miembros del Sistema de la Integración Centroamericana (SICA). Debido a que el cambio climático es una falla de mercado que tiene un impacto 
directo en la economía, se trata este tema como un problema económico central y transversal, con serias implicaciones fiscales y económicas. Como respuesta a esta situación, la CEPAL ha colaborado con los países de la región para transversalizar el tema del cambio climático — que originalmente era tratado en las instituciones públicas relacionadas con el medio ambiente- $y$ lograr que se lo tome en cuenta en los planes y trabajos de otras instituciones, como las responsables de los asuntos agrícolas, fiscales y de salud.

En el capítulo XI, Humberto Soto de la Rosa, María Luisa Marinho, Citlalli Lamotte y Elsa Gutiérrez dan cuenta de la trascendencia, los avances y los desafíos de la dimensión social, considerada dentro del proceso de integración centroamericana. Los autores destacan la utilidad de potenciar las acciones nacionales para incrementar el bienestar social de la población regional en su conjunto, resaltan los esfuerzos que se han realizado para ello - con énfasis en los que han sido acompañados por la CEPAL - y señalan los retos y las limitantes que han impedido un mayor logro en este rubro. Se subraya el aporte intelectual de la CEPAL desde los inicios del proceso de integración en temas como la migración, la salud y la nutrición, y se destaca que en la década de 1990 se inició una etapa fructífera para el proceso de integración social de la región, en gran parte debido a la firma del Protocolo de Tegucigalpa a la Carta de la Organización de Estados Centroamericanos, del que se derivaron las bases para la firma del Tratado de la Integración Social Centroamericana (TISCA) en 1995. Debido a la amplia agenda y a la dispersión temática del área social, la CEPAL ha hecho recomendaciones para mejorar el modo en que se configura la institucionalidad de la integración, especialmente para consolidar políticas de carácter regional.

En el capítulo XII, Leda Peralta Quesada y Ramón Padilla Pérez analizan el aporte de la CEPAL al fortalecimiento de la ciencia, la tecnología y la innovación en el marco de la integración centroamericana. Se propone trabajar para que las agendas de investigación, desarrollo e innovación y las de proyectos de asistencia técnica se coordinen mejor entre los organismos regionales e internacionales que apoyan la integración. Este reto persiste desde la década de 1960, y la limitada disponibilidad de recursos para el desarrollo obliga a hacer más eficiente su uso. La CEPAL colabora para estructurar una agenda regional destinada a promover de forma integral la ciencia, la tecnología y la innovación, fortaleciendo y aprovechando las sinergias con organismos nacionales, regionales e internacionales. El trabajo realizado por la CEPAL con la Conferencia Ministerial sobre la Sociedad de la Información de América Latina y el Caribe ha fomentado la interacción entre los países al identificar oportunidades comunes de investigación, desarrollo e innovación, y ha promovido la integración regional en ciencia, tecnología e innovación. Estos espacios de diálogo, consenso y aprendizaje dan lugar a oportunidades para profundizar el trabajo realizado hasta el momento e identificar espacios de transversalización y trabajo multisectorial. 
Finalmente, en el capítulo XIII, Hugo E. Beteta y Jorge Mario Martínez Piva presentan las reflexiones finales del libro, en las que señala los principales retos a los que se enfrenta el proceso de integración regional en el entorno internacional actual. Es un ejercicio en que se reinterpreta el papel de la integración regional en un mundo donde existen cambios tectónicos profundos. Al comienzo de este ejercicio de reinterpretación se identifican los cambios y los retos que se deben abordar en la región centroamericana en el siglo XXI, subrayando los cambios tectónicos que alteran las relaciones mundiales y a los que Centroamérica es muy sensible: la consolidación de China como potencia económica y geopolítica; la evolución de los megaacuerdos comerciales; el creciente envejecimiento de la población; la crisis ambiental; la revolución tecnológica, y el auge del nacionalismo económico. Además, se indican los retos que los autores han señalado en los capítulos de este libro y se da también una visión puntual sobre los temas en los que se enfoca la cooperación de la CEPAL con Centroamérica.

En su conjunto, en este libro se hace un inventario del aporte intelectual y técnico de la CEPAL al proyecto de desarrollo centroamericano que se consolida a través del proceso de integración. Además, se apunta a nuevos horizontes de colaboración para lograr un cambio estructural progresivo, lo que evidencia el compromiso continuamente renovado de la CEPAL por apoyar a la región en su búsqueda del desarrollo.

\section{Bibliografía}

Bárcena, A., R. Bielschowsky y M. Torres (2018), “El séptimo decenio de la CEPAL: una reseña de su producción intelectual", Desarrollo e igualdad: el pensamiento de la CEPAL en su séptimo decenio. Textos seleccionados del período 2008-2018, Colección 70 años, $N^{\circ} 1$ (LC/PUB.2018/7-P), R. Bielschowsky y M. Torres (comps.), Santiago, Comisión Económica para América Latina y el Caribe (CEPAL), 2018.

CEPAL (Comisión Económica para América Latina y el Caribe) (2012), Cambio estructural para la igualdad: una visión integrada del desarrollo (LC/G.2524(SES.34/3), Santiago. (1994), El regionalismo abierto en América Latina y el Caribe: la integración económica al servicio de la transformación productiva con equidad (LC/G.1801/ REV.1-P), Santiago.

Prebisch, R. (1969), "La marcha hacia el Mercado Común Latinoamericano", La Nación, Buenos Aires, 13-14 de junio.

(1958), “Grupo de Expertos en Mercado Regional: exposición del Dr. Raúl Prebisch, a cargo de la Secretaria Ejecutiva de la CEPAL en la sesión inaugural, el día 3 de febrero de 1958", Documento de Sala de Conferencia, $N^{\circ} 1,3$ de febrero [en línea] https:/ / repositorio.cepal.org/bitstream/handle/11362/32862/058_ es.pdf? sequence $=1$ \&isAllowed $=\mathrm{y}$. 

Capítulo I

\section{La Comisión Económica para América Latina y el Caribe (CEPAL) en la historia de la integración centroamericana}

Rómulo Caballeros

\section{Introducción}

El objetivo de este capítulo es presentar de forma resumida las contribuciones más relevantes que la Comisión Económica para América Latina y el Caribe (CEPAL) ha hecho para impulsar o fortalecer el desarrollo de Centroamérica. La presentación se hará poniendo énfasis en los aportes al proceso de integración y haciendo referencia a las ideas fuerza y a las bases teóricas y conceptuales sobre las que esos aportes se asentaron.

Desde sus propios inicios, la CEPAL ha estado presente a lo largo de la historia de la integración centroamericana. Por una parte, se encuentra la influencia teórica del pensamiento cepalino, que se inspiró en las ideas de Raúl Prebisch y se desarrolló en el planteamiento estructuralista. Conforme fue progresando ese marco teórico, las actividades derivaron en estudios que se entregaron a las autoridades de la región y, posteriormente, constituyeron propuestas que se presentaron a las instituciones que se fueron organizando. Muchas de esas propuestas se tradujeron en acciones que sostuvieron o impulsaron la integración. Otras, aunque no cristalizaron, promovieron la reflexión e influyeron en acciones que ampliaron la temática de la interrelación entre los países. 
En las primeras décadas de la posguerra, los aportes de la CEPAL se centraron en la problemática que enfrentaban los países latinoamericanos para acceder a mayores niveles de desarrollo. Esas ideas indujeron a las autoridades económicas de la región a pensar que era posible "impulsar en forma deliberada el desarrollo de cada uno de los países" (CEPAL, 1992) y echar las bases de una modernización económica mediante políticas públicas activas. Los estudios e informes técnicos sirvieron de argumento para implementar políticas nacionales que paulatinamente se acoplaran a un escenario de dimensión regional, y contribuyeron a darle vida a los primeros instrumentos de la integración, mediante la asociación de mercados basada en acuerdos bilaterales que permitirían la existencia y expansión de nuevas actividades productivas, sobre todo industriales.

Desde otra perspectiva, la CEPAL también ha realizado esfuerzos para responder a preocupaciones de dimensión nacional, pero que, en el caso de Centroamérica, en muchas ocasiones han estado vinculadas con el proceso de integración. Dicha labor se ha traducido sobre todo en acciones de asistencia técnica.

Las actividades vinculadas con el desarrollo de Centroamérica que se realizaron a lo largo de 70 años son de tal magnitud que no es posible hacer un recuento exhaustivo de su contribución. Por ello, en este trabajo se hace referencia a una selección de documentos y acciones que se estima que han tenido especial relevancia.

La integración - lejos de evolucionar en etapas secuenciales determinadas según un programa definido- ha tenido períodos de auge y de crisis, así como tiempos de inestabilidad, desencuentros políticos, agitaciones sociales, recomposición institucional y consolidación. Por lo tanto, la división del análisis en períodos admite varias posibilidades según el tema dominante en cada estudio. En este capítulo se ha optado por definir ciclos relacionados con la intensidad de las actividades de la CEPAL, así como con el curso de los avances de la integración o con los hechos de mayor impacto.

La fisonomía de la integración también ha cambiado a lo largo de su existencia. Durante un período prolongado, sus integrantes fueron cinco países que compartían varios antecedentes históricos: Costa Rica, El Salvador, Guatemala, Honduras y Nicaragua. A partir de un cambio sobre la visión del alcance de la integración, se incorporó Panamá, que constituye una continuidad geográfica, y, más recientemente, Belice y la República Dominicana.

Dado que gran parte de las actividades de la CEPAL se realizaron sobre el proceso de integración original, cuando en este capítulo se hace referencia a ella, se pretende abarcar los cinco países originales, a menos que se mencione el actual sistema de integración de ocho países, denominado Sistema de la Integración Centroamericana (SICA). 
Finalmente, en este capítulo se analizan los hechos y los aportes de la CEPAL en el ámbito de las transformaciones institucionales y las macrotendencias derivadas de decisiones políticas de la integración. Las contribuciones que la CEPAL ha realizado en campos específicos y sectoriales están contenidas en los siguientes capítulos.

\section{A. El origen}

Desde su independencia en 1821 hasta 1940 hubo más de 20 iniciativas de los países centroamericanos por mantenerse unidos (Rodríguez, 2016), sin que ninguna perdurara. Ello debido a la inestabilidad política en que ha transcurrido la vida en la mayoría de los países de la región, con una cadena de golpes de Estado y de luchas por mantener los privilegios y las hegemonías de los grupos nacionales dominantes.

En 1823 se creó una República Federal compuesta por cinco Estados: Costa Rica, El Salvador, Guatemala, Honduras y Nicaragua, y en noviembre de 1824 se promulgó la Constitución de la República Federal de Centroamérica, pero intereses separatistas de algunos Estados condujeron a su disolución en 1838. Cuatro años después (en 1842), se dio la primera tentativa de integración de naturaleza militar, cuando cuatro países intentaron pacificar Centroamérica, que vivía las convulsiones políticas de la posindependencia; sin embargo, Guatemala se negó a suscribir el pacto. El segundo intento, también militar, fue en 1885, cuando el presidente de dicho país decretó unilateralmente la reconstitución de la unión y se propuso invadir a los cuatro países restantes, intento que fracasó por falta de legitimidad y de apoyo de la sociedad civil. Más adelante se realizaron ensayos de naturaleza política, entre los que se destaca el de 1895, en el que se acordó el Tratado de la Unión que creó la República Mayor de Centroamérica. No obstante, en El Salvador surgieron perturbaciones políticas que interrumpieron el proceso. Otro esfuerzo de naturaleza política ocurrió en 1921, cuando resurgió el espíritu político de unión en los cinco países y se aprobó la Constitución Política de Centroamérica. Sin embargo, un año después, otra vez un golpe de Estado en uno de los países interrumpió el intento (Pimentel, 2018).

Posteriormente se sucedieron esfuerzos integracionistas con base jurídica. El primero fue el de unificar las legislaciones sobre derecho civil, mercantil, penal y procesal; sin embargo, como el proyecto no fue aprobado por todas las legislaturas nacionales, nunca entró en vigor. Después se creó la Corte Centroamericana de Justicia, que a los pocos años se disolvió debido a que no se reconoció su actuación en una controversia entre países.

Los anteriores son ejemplos de los reiterados intentos que se hicieron para unificar a los países, sin que ninguno tuviera éxito. Ello se debió probablemente a que no hubo un plan basado en un andamiaje teórico que 
ofreciera estímulos para mantener esos esfuerzos estableciendo con claridad cuáles eran los beneficios que se perseguían. Además, los frecuentes golpes de Estado y los antagonismos por la preservación de privilegios, intereses económicos nacionales o protagonismos políticos provocaron la resistencia de algunos de los países.

\section{B. Los antecedentes cercanos}

A mediados de la década de 1940, los países de América Latina sufrían las consecuencias de la gran depresión de la década anterior y de la conflagración mundial, fenómenos que habían afectado seriamente el funcionamiento de la economía internacional. Sin embargo, conforme esta se fue normalizando $\mathrm{y}$, en consecuencia, también lo fueron haciendo las corrientes de comercio, mejoraron las perspectivas de las economías agroexportadoras menos desarrolladas. Al mismo tiempo comenzó a tomar forma la idea de impulsar el desarrollo de manera deliberada (CEPAL, 1966), lo que dio lugar a las primeras políticas que tenían por objeto diversificar la producción agrícola y las exportaciones ${ }^{1}$. Ambos factores contribuyeron a que en la región se experimentara una expansión en el período de posguerra, aun cuando se sucedieron descensos cíclicos de los precios de los principales productos de exportación, que se compensaron de forma parcial conforme en los países se lograron exportar nuevos productos y se abrieron las fuentes del incipiente financiamiento externo.

Durante esos años, se celebraron acuerdos bilaterales entre los cinco países, que favorecían el intercambio sobre la base de listas positivas de productos. Dichos acuerdos se caracterizaban por ser inflexibles, ya que se requerían complejas negociaciones para incluir un nuevo producto o excluir otro. Aun con esas dificultades, la existencia de acuerdos de cobertura parcial, como el de Guatemala-El Salvador en el período 1941-1943, el acuerdo de libre comercio e integración económica entre El Salvador y Guatemala en 1951, y otro acuerdo entre El Salvador y Nicaragua reflejaban la vocación de los países por estrechar las relaciones comerciales.

En medio de la preocupación de los países de América Latina por mejorar las condiciones de vida de la población, en 1947 se inició la gestación de la Comisión Económica para América Latina, cuando Hernán Santa Cruz, ilustre representante de Chile ante las Naciones Unidas, propuso crearla para atender los temas del desarrollo económico y social de la región. Después de un largo período de negociaciones, el " 25 de febrero de 1948, el Consejo Económico y Social de las Naciones Unidas, ECOSOC, decidió establecer la

“Una de las constantes en la historia de los cinco países centroamericanos es la búsqueda de un producto "líder de exportación que permita a las pequeñas economías de la región financiar sus requerimientos de importaciones" (CEPAL, 1992). 
Comisión Económica para América Latina, CEPAL, y la puso al servicio de los Gobiernos de América Latina para colaborar con ellos en el desarrollo económico de sus países, en el mejoramiento del nivel de vida de sus pueblos y en la ampliación y fortalecimiento de sus relaciones comerciales tanto dentro como fuera de la región" (CEPAL, 1978). Desde entonces, sus principios en esencia son los mismos, sobre todo el concepto de que la aceleración del crecimiento de los países de América Latina exige formular programas y políticas de desarrollo deliberados y de carácter dinámico, que deben fundamentarse en la realidad, en el análisis sistemático de las economías nacionales y en el estudio periódico de las perspectivas de crecimiento.

En 1949 la CEPAL contrató al insigne economista argentino Raúl Federico Prebisch Linares (1901-1986) para elaborar un informe en el que se esbozaron, por primera vez, los principales problemas que enfrentaban los países de la región para acceder al desarrollo (Prebisch, 1949). Desde la década de 1920 circulaban algunos escritos de Prebisch y, según algunos estudiosos, ya en 1929 este "habría comenzado a abandonar su neoclasicismo y buscar nuevas interpretaciones del proceso económico y políticas heterodoxas para reorientarlo" (Gurrieri, 2001). El informe que Prebisch elaboró para la CEPAL contenía las ideas originarias sobre centro y periferia, como semillas de la posterior propuesta cepalina de formular una política que promoviera la industrialización mediante los esfuerzos por sustituir importaciones, lo que significaba cierta protección selectiva y transitoria de la industria naciente. Ello se planteaba como una labor imprescindible para neutralizar las pérdidas debidas a los términos de intercambio, históricamente desfavorables para los países exportadores de productos primarios. Según Gurrieri (2001), "el contenido de ese trabajo provocó un gran impacto en los medios académicos y políticos de la región, siendo considerado un pilar fundacional del pensamiento estructuralista" (véase el capítulo II del presente documento).

\section{El inicio del actual proceso de integración}

Al principio de la década de 1950, la estructura de las economías de los países centroamericanos se basaba en el sector primario, y sus exportaciones las integraban unos pocos productos agrícolas, en un contexto internacional que mostraba tendencias hacia un nuevo deterioro de los términos de intercambio.

En ese período, el primer esfuerzo por concretar la integración fue fundar la Organización de Estados Centroamericanos (ODECA) el 14 de octubre de 1951. Esta enfrentó muchas dificultades, principalmente por diferencias y tensiones políticas entre los países y por el alto grado de generalidad con que se definieron sus principios y ámbitos de acción.

En junio de 1951, en el cuarto período de sesiones de la CEPAL, los delegados centroamericanos expusieron a la Secretaría Ejecutiva de dicho organismo la difícil perspectiva que enfrentaban sus países y su interés en 
desarrollar la producción agrícola e industrial y los sistemas de transporte, de forma que se promoviera la integración de sus economías y la formación de mercados más amplios, mediante el intercambio de sus productos, la coordinación de sus planes de fomento y la creación de empresas en que todos o algunos de dichos países tuvieran interés (CEPAL, 1956).

Lo anterior derivó en la resolución 9(IV) de la Comisión, gestionada por el Secretario Ejecutivo, que contenía un programa de acciones constituido por tres puntos básicos: i) ampliación del mercado en Centroamérica, ii) liberación del comercio y iii) coordinación de los programas de inversión de los Gobiernos. Esas fueron las primeras recomendaciones con respecto a las respuestas que los países de mercados y economías reducidos podrían instrumentar para neutralizar las pérdidas de ingreso real debidas al deterioro de los términos de intercambio y para adaptarse a las propuestas sobre la industrialización y la sustitución de importaciones.

Al mismo tiempo, en esa misma resolución se instituyó el Comité de Cooperación Económica del Istmo Centroamericano (CCE), como un órgano permanente de consulta integrado por los Ministros de Economía de los cinco países y, posteriormente, con la participación del Ministro de Industria y Comercio de Panamá. Asimismo, se encargó a la CEPAL un estudio para llevar a cabo el programa y se estableció una oficina que más adelante se transformó en la sede subregional de la CEPAL en México, con el objetivo de realizar los estudios necesarios para apoyar a la Secretaría Ejecutiva.

En la primera reunión del CCE, que tuvo lugar en agosto de 1952, se establecieron sus funciones. Entre ellas se destaca la de "proponer a los gobiernos respectivos medidas concretas tendientes a la integración gradual y progresiva de las economías de los países centroamericanos y a la coordinación de los programas nacionales de desarrollo económico", así como la de "orientar y encauzar la utilización de la ayuda técnica en materias atinentes a la integración de las economías centroamericanas" (CEPAL, 1956). Se determinó que la CEPAL ejercería la secretaría técnica de dicho foro y se encargaría de los trabajos e informes que servirían de soporte a las decisiones del ente intergubernamental. Finalmente, se contempló que el CCE podría crear los órganos subsidiarios que fueran necesarios para atender temas específicos, en los que la CEPAL también actuaría como secretaría.

En esa primera reunión, Prebisch, como Secretario Ejecutivo de la CEPAL, presentó el Informe preliminar del Secretario Ejecutivo de la Comisión Económica para América Latina sobre integración y reciprocidad económicas en Centroamérica (CEPAL, 1952a), junto con los documentos Nota del Secretario Ejecutivo sobre integración económica y cooperación tecnológica (CEPAL, 1952c), Nota del Secretario Ejecutivo sobre unificación de la nomenclatura arancelaria (CEPAL, 1952e) y Nota del Secretario Ejecutivo sobre el estudio de los transportes en Centroamérica (CEPAL, 1952d). 
En el primero de los documentos mencionados se analizaban las ventajas de una política que coadyuvaría a la integración, el alcance de esa política, los requisitos para instrumentarla y las opciones que ofrecía la industrialización. Entre las conclusiones que se derivaban del informe sobresalían las que se referían a los múltiples aspectos que justificaban una política de integración y reciprocidad económica. Primero, el hecho de que entonces empezaba a surgir en Centroamérica la noción de que era imprescindible disponer de una política de fomento deliberada, pues no podía esperarse que la aceleración del desarrollo económico surgiera espontáneamente. Segundo, el que existieran excedentes demográficos en ciertas áreas, y baja densidad poblacional y recursos naturales subutilizados en otras. Se sugería que podría inducirse la atracción de los excedentes demográficos hacia áreas menos pobladas, para potenciar el crecimiento. Tercero, el que la industrialización necesitara elevados volúmenes de inversiones de gran densidad de capital, y los mercados nacionales, considerados individualmente, fueran muy reducidos. Y cuarto, el hecho de que los mercados con frecuencia se encontraran aislados debido a las deficientes comunicaciones, por lo que no era posible hacer inversiones de gran densidad de capital.

Por otra parte, con respecto al alcance y los requisitos de una política de integración, en el informe se señalaba que la integración económica completa requeriría una unión aduanera total, el libre movimiento de mercancías, personas y capital, una administración común de las aduanas, los puertos y ciertos medios de transporte, la unificación de muchos aspectos de la legislación fiscal, bancaria, monetaria y aduanera, y posiblemente una unificación monetaria y de políticas crediticias, todas ellas metas que los países no estaban en posibilidad de cumplir. En consecuencia, era aconsejable plantearse objetivos inmediatos más modestos, que consistieran en una integración limitada basada en una política de reciprocidad comercial e industrial. La pieza central de este compromiso era la proliferación de tratados bilaterales que sirvieran como período de aprendizaje y que, a diferencia de los acuerdos del pasado, tendrían que tener características convergentes, de manera que pudieran homologarse con posterioridad.

Sobre la base de esos planteamientos, la CEPAL, como Secretaría Técnica del CCE, se abocó a elaborar estudios y propuestas que finalmente llevaron a la suscripción de los principales instrumentos jurídicos. Entre ellos se destacan los siguientes: el Tratado Multilateral de Libre Comercio e Integración Económica Centroamericana y el Convenio sobre el Régimen de Industrias Centroamericanas de Integración, suscritos el 10 de junio de 1958; el Convenio Centroamericano sobre Equiparación de Gravámenes a la Importación, del 1 de septiembre de 1959, y su Protocolo; el Tratado de Asociación Económica entre Guatemala, Honduras y El Salvador; el Acuerdo Regional para la Importación Temporal de Vehículos por Carretera; el Acuerdo Centroamericano sobre Circulación por Carreteras; el Convenio 
Centroamericano sobre Señales Viales Uniformes de 1958; el Protocolo sobre Preferencia Arancelaria Centroamericana; el Convenio Constitutivo del Banco Centroamericano de Integración Económica, suscrito el 13 de diciembre de 1960, y, por supuesto, el Tratado General de Integración Económica Centroamericana.

\section{La consolidación}

A partir del bienio 1959-1960, se dieron pasos decisivos para crear el Mercado Común Centroamericano (MCCA) en forma casi inmediata. El Comité de Cooperación Económica emitió la resolución 101 (CCE), del 2 de abril de 1960, en la cual solicitó a la CEPAL que elaborara un proyecto de convenio centroamericano de integración. Finalmente, una vez elaborados los documentos pertinentes para la equiparación de gravámenes - que fueron incorporados al Primer Protocolo al Convenio Centroamericano sobre Equiparación de Gravámenes a la Importación-,El Salvador, Guatemala, Honduras y Nicaragua suscribieron en Managua el Tratado General de Integración Económica Centroamericana el 13 de diciembre de 1960. Superados sus impedimentos constitucionales, Costa Rica se adhirió el 23 de julio de 1962, con base en la cláusula de adhesión de ese Tratado.

Con el objeto de aplicar y administrar el Tratado, así como de realizar todas las gestiones para llevar a la práctica la unión económica de Centroamérica, se crearon el Consejo Económico Centroamericano (CEC) y el Consejo Ejecutivo, así como su Secretaría Permanente que posteriormente se convertiría en la Secretaría de Integración Económica Centroamericana (SIECA).

En ese período, la CEPAL contribuyó con documentos, informes y propuestas relativas a las bases conceptuales y las prácticas sobre las cuales se apoyarían la cooperación y la integración económicas y el CCE como foro de carácter consultivo y asesor ${ }^{2}$.

La meta establecida en el Tratado virtualmente se cumplió en el período previsto de cinco años: se adoptó un arancel común para casi todos los artículos importados de terceros países; se acordó el libre comercio en relación con casi todos los productos originarios de la región; se estableció el andamiaje institucional para la consecución de los objetivos del Tratado, y se adoptaron algunos instrumentos de fomento industrial.

Téngase en cuenta que en el capítulo XX del Tratado General de Integración Económica Centroamericana se establece lo siguiente: “El Consejo Económico Centroamericano será el organismo encargado de facilitar la ejecución de las resoluciones del Comité de Cooperación Económica del Istmo Centroamericano relativas a la integración económica". 
Las actividades del CCE fueron intensas en ese período, y en el transcurso de él se crearon las principales instituciones de la integración. Entre ellas destacan las siguientes: la Escuela Superior de Administración Pública de América Central (ESAPAC), que posteriormente se transformó en el Instituto Centroamericano de Administración Pública (ICAP); el Instituto Centroamericano de Investigación y Tecnología Industrial (ICAITI); el Banco Centroamericano de Integración Económica (BCIE); la Corporación Centroamericana de Servicios de Navegación Aérea (COCESNA); la Comisión Técnica Regional de Telecomunicaciones (COMTELCA); la Cámara de Compensación Centroamericana; el Consejo Monetario Centroamericano (CMCA); el Programa Centroamericano para el Fomento de las Exportaciones (PROMECA), y el Instituto de Nutrición de Centro América y Panamá (INCAP) que, si bien había sido fundado en 1946, fue incorporado al sistema institucional de la integración. En todas esas actividades, la CEPAL estuvo involucrada directa o indirectamente, como secretaría del CCE³

En paralelo, se construyó una red centroamericana de carreteras; se organizó un sistema de transporte pesado; se creó un sistema centroamericano de telecomunicaciones, y se construyeron una serie de interconexiones eléctricas binacionales que fueron los antecedentes de la red de conexión eléctrica regional. El Banco Centroamericano de Integración Económica (BCIE) contribuyó a la construcción de esta infraestructura y otorgó apoyo financiero a la agricultura, la industria, el turismo, la construcción de vivienda de interés social y otras actividades. También se formó y consolidó un grupo de tecnócratas centroamericanos que tenían una visión regional, una especie de mística centroamericana, y una red de relaciones humanas que contribuyeron mucho a darle un sentido de dirección al proceso.

En síntesis, se puede considerar como un éxito que el mercado común, al que la CEPAL estuvo totalmente abocada, se estableciera en un período tan breve. Los resultados fueron inmediatos: el intercambio de bienes creció de forma espectacular y pasó de unos 32,7 millones de pesos centroamericanos en 1960 a 135,5 millones en 1965 y 300 millones en 19704. También aumentó la participación del comercio intrarregional en las exportaciones totales de la región, al pasar del 6,7\% en 1960 al 16,7\% en 1965 y al 25,8\% en 1970. Dicho intercambio estaba integrado por una proporción creciente de artículos manufacturados, que pasó de aproximadamente el 50\% en 1960 al $90 \%$ en 1970. Ello revela el dinamismo industrial derivado del efecto incipiente de la sustitución de importaciones que el mercado ampliado viabilizó. "El grado de industrialización se elevó, en efecto, de 13,9\% a 17,5\% entre 1960 y 1970 y se notó un creciente grado de complejidad de las manufacturas al aumentar la participación relativa de los [bienes] intermedios y de las metalmecánicas en la estructura de producción" (CEPAL, 1992).

Véase un detalle de los procesos de creación y de las funciones atribuidas en Pimentel (2018).

A los fines operativos, se definió como unidad de cuenta el peso centroamericano, equivalente al dólar. 
El movimiento integrador fue una fuente de considerable dinamismo para las economías nacionales, y no hay dudas de que, en su ausencia, estas hubieran crecido a tasas significativamente menores (CEPAL, 1966). Además, dicho movimiento permitió que surgiera una dinámica de crecimiento adicional a la de las exportaciones tradicionales de productos agrícolas. Su influencia fue de tal magnitud que son evidentes las modificaciones - tanto de carácter cuantitativo como cualitativo- que introdujo al comportamiento pretérito de la economía. En primer lugar, contribuyó a una rápida diversificación de las exportaciones. En segundo lugar, dado que dicha diversificación se relacionaba con artículos que no estaban sujetos a fluctuaciones cíclicas de precios, se moderaron las pérdidas debidas a los términos de intercambio. En tercer lugar, el Mercado Común Centroamericano constituyó un campo en el que se experimentó con la exportación de bienes manufacturados que posteriormente se exportarían a los mercados internacionales.

Por otra parte, la evolución de la economía se vio afectada por la diversificación ya no solo del comercio exterior, sino del aparato productivo implícito en el creciente grado de industrialización y por los efectos secundarios de esta: la urbanización, el surgimiento de un estrato de obreros capacitados, la incorporación de tecnologías modernas al aparato productivo y las altas tasas de formación de capital.

A partir de los resultados favorables que se obtuvieron en los inicios de la integración, se tenía la idea de que la dinámica de esta conduciría en forma automática a su ampliación y profundización; sin embargo, en la euforia de esa dinámica, se dejaron de lado actividades económicas importantes para el desarrollo de la región, como la agricultura y el desarrollo energético, así como algunos sectores sociales, como la educación y la salud. Es decir, hubo lo que en esa época la CEPAL definió como un "encapsulamiento" de la integración, tanto respecto a los sectores que se incluían, como a los actores que se beneficiaban de ella (CEPAL, 1992).

Por otra parte, desde el inicio la CEPAL advirtió el problema potencial de no considerar mecanismos que propendieran a una razonable distribución de los costos y los beneficios derivados de la integración entre los países. Un reflejo parcial, pero importante, de esta concentración de beneficios se encuentra en la participación desigual de los cinco países en el intercambio comercial intracentroamericano ${ }^{5}$.

En distintos documentos, la CEPAL señalaba que las principales dificultades y obstáculos que frenaron el avance de la integración pertenecían a las cuatro grandes categorías que se indican a continuación: i) los problemas distributivos; ii) los conflictos, reales o supuestos, entre las políticas nacionales

Véase la exposición del Gobierno de Honduras ante la XVII Reunión Extraordinaria del Consejo Económico Centroamericano, acta $\mathrm{N}^{\circ} 25$, Tegucigalpa, marzo de 1969, sobre los problemas que afrontaba ese país en el Mercado Común Centroamericano. 
y aquellas que suponía el programa regional; iii) el encapsulamiento de los temas relativos a la integración con respecto al resto del quehacer nacional en cada uno de los países, y iv) la lentitud y lo engorroso de la adopción de decisiones de carácter mancomunado (CEPAL, 1992).

Otro obstáculo para la buena marcha de la integración fue la cantidad de conflictos surgidos entre los intereses nacionales y los objetivos regionales. Los siguientes son algunos ejemplos de este tipo de conflictos: la aplicación de medidas para limitar el libre comercio de determinado producto manufacturado a fin de proteger una planta nacional; la promoción de proyectos industriales destinados a abastecer el mercado regional por parte de organismos nacionales de fomento, sin consulta con los demás países; la prohibición de exportar granos básicos con el fin de atender prioritariamente la demanda nacional; la alteración de la paridad cambiaria sin consultar a los demás países, y la tradicional renuencia a confiar responsabilidades a las instituciones regionales, porque ello de alguna forma "atentaba contra la soberanía nacional". Este conjunto de dificultades, cuyas consecuencias se acumularon en el tiempo, produjo un ambiente de escepticismo frente a las posibilidades prácticas de la integración.

Los órganos e instituciones de la integración centroamericana continuaron funcionando, aunque con irregularidades, sobre todo por el retiro parcial de uno de sus miembros (Honduras). Incluso se lograron avances en el perfeccionamiento del Mercado Común Centroamericano, como ciertos mecanismos ad hoc a nivel de los Gobiernos y los gremios privados para resolver controversias originadas en el libre comercio, o el establecimiento de acuerdos bilaterales para mantener el intercambio comercial.

A partir de esta etapa, el CCE desempeñó un papel muy importante como foro alterno de negociación o foro de "prenegociación". En él se proponían acciones concretas a los Gobiernos cuando los foros institucionales no funcionaban, primero a causa de la imposibilidad que impuso el retiro parcial de uno de los socios y, después, debido a los conflictos de diversa naturaleza que surgieron entre los países.

La CEPAL, al ser una institución de las Naciones Unidas, no representa intereses nacionales particulares; de allí que, actuando como secretaría del CCE, aportó la neutralidad y la oportunidad necesarias para que las propuestas fueran aceptadas aun por los Gobiernos que estaban enfrentados. En general, en los tiempos de anormalidad, sus actividades se centraron en elaborar propuestas transitorias buscando que los instrumentos continuaran funcionando, aunque fuese parcialmente.

En síntesis, si bien el movimiento de integración perdió dinamismo al final de la década de 1960, continuó revelando características de irreversibilidad. No obstante, se estaba lejos de aprovechar al máximo sus potencialidades para coadyuvar en el desarrollo económico de los cinco países de la región. 


\section{E. La anormalidad institucional y las raíces de la crisis}

A pesar de los notables resultados en materia de comercio intrarregional, persistieron algunas imperfecciones en el funcionamiento del sistema. Por una parte, los beneficios del comercio regional continuaban siendo muy desiguales. Por otra parte, la rigidez del arancel uniforme común hacía necesario un "mecanismo flexibilizante" para que los países pudieran hacer frente a las nuevas adversidades del sector externo, las estrecheces fiscales y las inestabilidades monetarias que venían manifestándose de forma creciente.

En el informe de la CEPAL titulado Evaluación de la integración económica en Centroamérica (CEPAL, 1966), que se presentó con el informe del noveno período de sesiones del Comité de Cooperación Económica del Istmo Centroamericano (Nueva York, 1966), se señalaba que, si bien el Mercado Común Centroamericano representaba, en ese entonces, el movimiento multilateral de integración económica más avanzado entre los países en desarrollo, en el informe se iban a analizar los problemas y factores críticos que habían ido manifestándose conforme avanzaba el programa de integración (CEPAL, 1966, pág. 3).

Se apuntaba que, al avanzar la integración hacia nuevas etapas, resultaba indispensable asegurar también una razonable y equitativa distribución de sus beneficios entre los países miembros, y propiciar por ese medio la continuada y voluntaria participación de todos en el esfuerzo multinacional (CEPAL, 1966, pág. 23). También se reconocía que los esfuerzos para promover un crecimiento equilibrado en la integración económica eran insuficientes.

Ante tantos apremios, en marzo de 1969 el CCE formuló el Plan de Acción Inmediata, con el que se impulsaría el crecimiento económico y la distribución de las obligaciones y beneficios en una nueva etapa de la integración económica cuyo objeto sería superar los problemas existentes, alcanzar mayores niveles de unión económica y evitar que en el mercado común se presentaran nuevas inestabilidades. Los objetivos centrales del Plan eran los siguientes: establecer una unión; coordinar y armonizar las políticas nacionales en las áreas industrial, agropecuaria, monetaria y de infraestructura; crear un mercado común de capitales, y facilitar y promover la libre movilidad de la mano de obra.

Poco tiempo después, la insatisfacción de Honduras con la integración, además de sus crecientes desencuentros con El Salvador, llevaron al conflicto armado entre ambos. Pese a lo breve del enfrentamiento, este tuvo consecuencias que afectaron la dinámica de la integración durante varios años. De forma inmediata se produjo una parálisis del sistema, puesto que se suspendieron las relaciones entre ambos países y, por consiguiente, la dinámica del intercambio regional y el tránsito de mercancías. Además, se 
paralizó el funcionamiento de los órganos e instituciones de la integración, incluidas las instancias superiores: el Consejo Económico Centroamericano y el Consejo Ejecutivo.

Gracias a la actividad del CCE, como órgano de las Naciones Unidas, el sistema continuó funcionando en el marco de la anormalidad jurídica tolerada por las partes, ya que Honduras pasó a operar con acuerdos bilaterales con los otros tres países, lo que permitió que continuara fluyendo el comercio intrarregional. Ello fue consecuencia de ingeniosas propuestas interinas elaboradas por la CEPAL, que permitieron al CCE desempeñar el papel de foro de prenegociación que ya habíamos mencionado. Es en el contexto de esos esfuerzos que se realizó una importante reunión de los Ministros de Relaciones Exteriores (San José, noviembre de 1969), en la que se definieron las rutas para resolver el conflicto, se generaron las grandes líneas políticas que permitirían restituir la paz y se fijaron los principios para retomar la vía de la integración.

A fin de lograr esos objetivos, los Ministros de Relaciones Exteriores de los cinco países acordaron lo siguiente: constituir un grupo bilateral de trabajo integrado por representantes de El Salvador y Honduras para proponer las fórmulas que permitieran solucionar las diferencias entre ambos países; crear una comisión ad hoc para reorganizar el sistema institucional centroamericano; constituirse en grupo de trabajo para dar seguimiento a los acuerdos, y solicitar a los Ministros de Economía que analizaran los alcances y las posibilidades de viabilizar el modus operandi que se propusiera, como sistema financiero que brindaría compensaciones a los países menos beneficiados.

Aunque se avanzó en las discusiones técnicas relativas al modus operandi y se diseñó un conjunto de medidas destinadas a restituir la normalidad del Mercado Común Centroamericano, dicho modus operandi desafortunadamente no cristalizó, porque los países en conflicto se negaron a firmar la paz en aquel momento, lo que era un requisito para que entrara en vigor.

Desde mediados de 1971, se identificaron tres tipos de desequilibrios macroeconómicos que amenazaban con desestabilizar las economías (CEPAL, 1971): los de las balanzas de pagos, los del financiamiento público y los del intercambio regional. La balanza de pagos de la región frente al resto del mundo se había deteriorado con el tiempo, y las importaciones se habían hecho cada vez menos flexibles, porque había variado su composición: los bienes terminados habían perdido peso frente a los insumos intermedios destinados a la producción sustitutiva de las importaciones y a los bienes de capital. Por otra parte, dado que los aranceles tenían un claro propósito fiscal, la reducción de las importaciones extrarregionales tenía un fuerte impacto en las finanzas públicas, lo que ampliaba los desequilibrios financieros internos. 
En octubre de 1973, los Gobiernos constituyeron el Comité de Alto Nivel para el Perfeccionamiento y la Reconstrucción del Mercado Común Centroamericano, integrado por representantes presidenciales, con el objetivo de buscar el consenso regional relativo a la amplitud, la profundidad y el cronograma del programa de restructuración que había propuesto la SIECA con el apoyo de la CEPAL.

Después de 20 sesiones celebradas en el transcurso de dos años, el Comité de Alto Nivel presentó un exhaustivo trabajo que contenía propuestas para instrumentar un verdadero desarrollo equilibrado: desde la sugerencia de un Tratado de la Comunidad Económica y Social Centroamericana hasta acciones detalladas relativas a diferentes temas. Desafortunadamente, las condiciones políticas no fueron adecuadas para ejecutar el audaz plan, en el que se abordaban temas que eran muy sensibles en aquel momento. Por lo tanto, esto quedó en otro muy buen intento por restructurar el proceso de integración.

El estancamiento de la integración se agudizó a lo largo de la década de 1970, al concatenarse varios factores que fueron afectando la realidad económica, política y social de los países. Por una parte, en tres de ellos se exacerbaron los conflictos y las tensiones de carácter político debido a la agudización de serios problemas nacionales de vieja data. Esos conflictos tendieron a asumir dimensiones regionales, cuando indirectamente amenazaron con rebasar las fronteras hacia el resto de la región, especialmente debido a la migración de refugiados que trasladaban las tensiones sociopolíticas a los países vecinos. Por otra parte, sucedieron lamentables catástrofes naturales, sobre todo el terremoto de Managua y el huracán Fifí en Honduras, que, además de la pérdida invaluable de vidas, provocaron graves efectos macroeconómicos y sociales. A ello se agregó el encarecimiento brusco de las importaciones, la alteración del sistema monetario y la tendencia al alza del precio del petróleo. Todo lo anterior determinó que se lograran pocos avances en los esfuerzos por restituir la dinámica de la integración, porque las autoridades nacionales privilegiaron la atención a los conflictos internos apremiantes.

Gradualmente, las gestiones del CCE se hicieron más esporádicas, en la medida en que se fueron enriqueciendo las capacidades técnicas de las instituciones de la integración. Sin embargo, el apremio de los acontecimientos demandaba respuestas más ágiles y oportunas en comparación con el ritmo al que reaccionaban los ministros dentro del seno del CCE. En consecuencia, en 1975 se decidió establecer la Comisión Interinstitucional para el Cumplimiento de las Decisiones del CCE, bajo la coordinación de la CEPAL 6 .

La Comisión Interinstitucional para el Cumplimiento de las Decisiones del CCE estaba integrada por las máximas autoridades de la Secretaría de Integración Económica Centroamericana (SIECA), el Banco Centroamericano de Integración Económica (BCIE), el Instituto Centroamericano de Administración Pública (ICAP), la Secretaría Ejecutiva del Consejo Monetario Centroamericano (CMCA) y el Instituto Centroamericano de Investigación y Tecnología Industrial (ICAITI). 
Dicha comisión actuaría como grupo de trabajo, con agilidad, y estaría a cargo de las siguientes tareas: i) formular sugerencias a los Gobiernos sobre la oportuna ejecución de las acciones que se requieren para el cumplimiento efectivo de las resoluciones aprobadas por el CCE; ii) coordinar las tareas que, de acuerdo con dichas resoluciones, debían realizar las instituciones regionales, y iii) presentar al CCE informes periódicos sobre la ejecución del programa para reactivar a corto plazo la integración.

En esas nuevas funciones, la CEPAL siguió acompañando el proceso, realizando investigaciones, evaluaciones y propuestas, y coordinando las actividades de las otras instituciones integrantes de la Comisión, para superar el cúmulo de problemas. Por ejemplo, a nivel global, la CEPAL elaboró informes sobre los problemas del mercado común (CEPAL, 1971), el perfeccionamiento de este, el planteamiento y la adopción de medidas relacionadas con el desarrollo equilibrado (CEPAL, 1974a y 1974c), la potencialidad de la integración para el desarrollo (CEPAL, 1976) y muchos otros temas. A nivel sectorial, se realizaron evaluaciones sobre el efecto de los desastres ${ }^{7}$, se efectuaron gestiones y consultas discretas ante los niveles más altos de los Gobiernos para restituir las relaciones políticas entre los países en conflicto, y se plantearon alternativas sobre políticas de productos energéticos (véase el capítulo IX).

Durante el segundo quinquenio de la década de 1970, el intercambio comercial siguió operando, pero con fuertes limitaciones. Asimismo, continuaron funcionando los instrumentos de integración, pero de forma anormal y con frecuencia respaldados por resoluciones provisionales, nada más por la fuerza intrínseca de la interdependencia y la vitalidad del sistema, apuntalada por la tenacidad de las instituciones de integración, especialmente de la SIECA. Por entonces empezó a surgir la convicción de que para reconstruir el programa de integración y regularizar las relaciones intergubernamentales de la región era necesario concluir los conflictos nacionales y lograr la paz.

En términos generales, la composición del comercio intrarregional no varió sustancialmente entre 1970 y 1980, ya que siguió centrado en las manufacturas de consumo final, sobre todo los productos textiles, los productos alimenticios y las sustancias químicas industriales. En 1970, estas ramas representaban más del $55 \%$ de las importaciones intrarregionales y, en 1980, la cifra todavía era del 51\%.

Incluso se elaboró un manual sobre evaluación de desastres. Esos trabajos fueron pioneros en materia de desarrollo sostenible y en cuanto a considerar la protección del medio ambiente para mitigar los desastres (Caballeros y Zapata, 1994; CEPAL, 1999a). 


\section{F. La crisis y la década perdida}

A principios de la década de 1980, diversos factores externos e internos, económicos y extraeconómicos, provocaron la crisis más profunda de la historia moderna centroamericana, que en algunos países se expresó en la exacerbación de los conflictos armados. En el plano socioeconómico, la crisis de la década de 1980 se tradujo en una caída significativa de la producción, gran inestabilidad financiera, aumento sostenido de la pobreza y la desigualdad, y deterioro de las condiciones generales de vida de la población centroamericana.

Varios factores contribuyeron a esa crisis. Entre los de origen estructural sobresale la concentración de los beneficios del comercio en algunos países. Entre los factores coyunturales se cuenta la turbulencia política y los posteriores enfrentamientos armados en tres países (Guatemala, El Salvador y Nicaragua), que determinaron condiciones inadecuadas para efectuar, con un mínimo de seguridad, las operaciones de transporte de personas y mercancías. Esos conflictos sociopolíticos fueron incidiendo gradualmente en los países vecinos, de manera indirecta, en la medida en que los grupos involucrados comenzaron a operar más allá de sus fronteras. Esta situación produjo distanciamientos y desconfianzas entre los Gobiernos y los dirigentes políticos, lo que dio lugar en muchos casos a la suspensión, aunque casi siempre de forma parcial, de los compromisos integracionistas (Caballeros, 2008).

Este fue otro elemento que deprimió las economías nacionales, al debilitar la demanda regional. Esta tendencia duró casi todo el decenio de 1980, que se denominó la "década perdida". La CEPAL advertía, con toda oportunidad, que los países del istmo centroamericano atravesaban en ese momento por una grave crisis económica, que en parte se inscribía en una tendencia recesiva de nivel mundial, y en mayor medida obedecía a causas particulares internas de origen muy complejo (CEPAL, 1981a, pág. V). La larga duración, la profundidad y el carácter generalizado de esta situación indican que se trató de una crisis estructural, ocasionada por el hecho de que se agotó el modelo de crecimiento agroexportador, unido a la propia crisis de la economía internacional, el deterioro del programa de integración, el debilitamiento del gobierno como fuente de dinamismo y el casi generalizado cuestionamiento del orden político-social (Caballeros, 1992).

El comercio intrarregional declinó en forma pronunciada en este período, y llegó a poco más de la mitad del monto alcanzado al final de la década de 1960 (véase el capítulo III). Nicaragua y El Salvador padecieron fuertes déficits intrarregionales y, en 1982, debido a la acumulación de deudas comerciales impagas, Costa Rica adoptó medidas restrictivas frente al primero de esos países. Se llegó así a un comercio intrarregional pagado bilateralmente en moneda extranjera, o a la adopción de procedimientos 
de trueque o créditos bilaterales. Se agotó el Fondo Centroamericano de Estabilización Monetaria (FOCEM), y a esto se sumaron las modificaciones cambiarias en la mayoría de los países, de manera que se redujo el impacto regional del Mercado Común Centroamericano y se generó una creciente desarmonización en materia de política monetaria y cambiaria.

Dado el debilitamiento de la idea fuerza de la integración, en las estrategias nacionales que se diseñaron en respuesta a la crisis se prescindió de esta como elemento neutralizador de la situación, sobre todo porque en ese período se intensificó la aplicación de programas de ajuste y estabilización a nivel nacional. Ello condujo al abandono casi total de los instrumentos de la integración, con lo que fue virtualmente imposible coordinar a nivel regional el ritmo, el plazo y el grado de ese ajuste. Como resultado, las finanzas públicas se vieron muy afectadas, hubo descoordinación de las políticas económicas y se desarmonizó el arancel externo común.

En 1986, el intercambio intrarregional llegó a su punto más bajo: 413,5 millones de dólares, lo que equivalía a apenas el 10,3\% de las exportaciones totales. Esto se debió a los fuertes desequilibrios en las balanzas del comercio intrarregional y al colapso del sistema regional de pagos a causa de la acumulación, hasta niveles insostenibles, de saldos deudores entre pares de países.

La labor de la CEPAL fue crucial en ese período, porque continuó apoyando con estudios, diagnósticos y propuestas los esfuerzos que realizaba la SIECA. Aquella labor está contenida en documentos donde se analizan, por ejemplo, la naturaleza de la crisis (CEPAL, 1983), los esfuerzos por incorporar a los Ministros de Finanzas en la búsqueda de las soluciones (CEPAL, 1984a), las perspectivas de largo plazo (CEPAL, 1989b) o las propuestas generales para la reactivación del desarrollo (CEPAL, 1990).

A partir de 1988, salió a la luz el valor intrínseco de la integración: el comercio intrarregional comenzó a recuperarse en forma leve pero sostenida, y se encontraron formas de compensar el comercio recíproco. Por una parte, se celebraron convenios entre pares de bancos centrales y, por otra, se efectuaron acuerdos entre empresas para recibir pagos en sus respectivas monedas nacionales.

A lo largo de toda la década, la comunidad internacional hizo esfuerzos para contribuir a desactivar los factores que producían la violencia, los enfrentamientos y la inestabilidad en la región, y para estimular el desarrollo, la justicia social y el respeto de los derechos humanos y la democracia. Esos esfuerzos se concretaron en la organización del Grupo de Contadora, integrado por Colombia, México, Panamá y Venezuela (República Bolivariana de), en 1983, a los que se adhirieron posteriormente España y Portugal ${ }^{8}$.

En 1985, la Argentina, el Brasil, el Perú y el Uruguay constituyeron el Grupo de Apoyo a Contadora. 
A continuación, los Gobiernos de Centroamérica y la antigua Comunidad Europea, reunidos en San José (1984), concordaron en la necesidad de dotar a la región centroamericana de instrumentos efectivos para lograr la paz y la democratización, y para ello se creó el Diálogo de San José.

Por su parte, los Gobiernos centroamericanos, respaldados por ese apoyo internacional, llevaron a cabo el trascendental Proceso de Esquipulas (1986 y 1987) ${ }^{9}$, por el que se comprometieron a consolidar la decisión política de los gobernantes para conseguir la paz firme y duradera en la región. En todas esas actividades de vinculación con la comunidad internacional, la CEPAL aportó trabajos que contribuyeron a fundamentar aquella labor. Ese fue el caso del memorándum dirigido a los ministros responsables de la integración económica centroamericana, en el que se presentaron los planteamientos económicos que los Gobiernos del istmo centroamericano podrían formular ante las autoridades de la Comunidad Europea (CEPAL, 1984b).

A pesar de que subsistieron los fuertes lazos de interdependencia construidos a través de la historia moderna, y de existir la voluntad política de aprovechar la integración como uno de los motores para reiniciar la senda del desarrollo, al final de este período aún permanecía la anormalidad jurídica y la debilidad de un andamiaje institucional diseñado para un modelo de integración pretérito.

\section{G. La reorientación y la consolidación}

Con el Proceso de Esquipulas se desactivaron los conflictos nacionales, que amenazaban con regionalizarse, se apaciguó la relación entre los países y resurgieron las reflexiones sobre el futuro de la integración. En ese nuevo ambiente, se presentaron varios estudios y evaluaciones que sugerían algunos posibles cursos de acción para relanzar el programa de integración ${ }^{10}$. Dichos documentos se referían principalmente al estado en el que esta se encontraba y a los desafíos que había que enfrentar para reactivarla, a la necesidad de introducir adaptaciones al modelo de desarrollo en función del nuevo escenario de globalización, a los retos que se deberían afrontar en los países para alcanzar y mantener el equilibrio financiero, y a la urgencia de recuperar los niveles de bienestar social, como requisito para consolidar la paz y fortalecer la democracia. También se presentaban reflexiones sobre la necesidad de revisar algunos componentes del paradigma de la integración, sobre la base de los acontecimientos regionales, pero también de los cambios que se estaban sucediendo en el ámbito internacional (CEPAL, 1989b).

\footnotetext{
9 El Proceso de Esquipulas consistió en dos reuniones trascendentales de alto nivel (Esquipulas Iy II) que se realizaron en 1986 y 1987, y en el conjunto de actividades desarrolladas en ese período.

10 Véase, por ejemplo, CEPAL (1985, 1988, 1989a, 1989b y 1990).
} 
Específicamente, se sostenía que podía combinarse la sustitución de exportaciones con las políticas de sustitución de importaciones y que, en lugar de promover un desarrollo "hacia adentro", Centroamérica bien podía promover uno "desde adentro", sin llegar al aperturismo absoluto. Con ello, se podría lograr una inserción más eficiente en una economía internacional cada vez más globalizada, sin renunciar a la proyección externa ni abandonar las ideas que dieron vida a la integración (véase el capítulo II).

Los compromisos asumidos por los Gobiernos en los acuerdos de Esquipulas fueron los siguientes: amnistía, cese al fuego, consolidación de la paz, limitación de los armamentos, democratización y elecciones libres, respeto de los derechos civiles y políticos, atención a los refugiados y desplazados, y aceleración del desarrollo. Una vez iniciadas las actividades para progresar en el cumplimiento de esos objetivos, los presidentes reafirmaron su convicción de que la paz, la democracia y el desarrollo eran inseparables, y que la consolidación de la democracia exigía enfrentar el desafío económico, tal como lo venía señalando la CEPAL en los documentos citados ${ }^{11}$.

La recuperación de los espacios de entendimiento entre los Gobiernos propició que Centroamérica se orientara hacia un ambiente de dinamismo y recomposición que se expresó en múltiples planos: en las relaciones sociales y productivas, en el orden político e institucional, en el proceso de integración regional y en las relaciones internacionales.

A solicitud de los presidentes, y en el marco de la Comisión Interinstitucional para el Cumplimiento de las Decisiones del Comité de Cooperación Económica del Istmo Centroamericano, la CEPAL presentó -en la reunión preparatoria de la Décima Cumbre de Presidentes de Centroamérica, realizada en La Antigua (Guatemala) en junio de 1990- un conciso informe que contenía un análisis de los seis principales desafíos que enfrentaba Centroamérica: i) corregir los desequilibrios macroeconómicos; ii) modernizar los sistemas productivos; iii) adaptarse al cambiante entorno internacional; iv) rescatar los niveles históricos de inversión productiva; v) mitigar la situación de pobreza extrema e impulsar la justicia distributiva, y vi) proteger el medio ambiente y los recursos naturales (CEPAL, 1990). A fin de responder a esos desafíos, en el documento se incluía un conjunto de orientaciones generales para reactivar el desarrollo. Asimismo, se formulaban consideraciones sobre el papel de la integración, el perfeccionamiento del mercado común centroamericano y las áreas prioritarias de la cooperación externa, y se presentaban sugerencias relacionadas con los aspectos institucionales.

11 Véase la Declaración de Montelimar, del 3 de abril de 1990 [en línea] http:/ /www.minex. gob.gt/MDAA/DATA/MDAA/201011081322143051990-4-2\%20\%20VII\%20REUNION\%20 ORDINARIA \%20(Nicaragua).pdf. 
De esa reunión presidencial surgió el Plan de Acción Económico de Centroamérica (PAECA), que se refería a múltiples temas, entre ellos, los siguientes: nuevo marco jurídico y operativo de la integración; programa de infraestructura e integración comercial; concertación regional para la coordinación del comercio exterior; participación activa de los sectores sociales; política de reconversión industrial; democratización económica de las empresas del Estado; coordinación de la política agrícola; política regional en ciencia y tecnología; coordinación de los programas de ajuste económico; programas de compensación social al ajuste económico, y foro de consulta sobre la deuda externa y la cooperación internacional.

Los principios se materializaron en un nuevo concepto integral de desarrollo en el que se contemplaban varias dimensiones - económica, política, social y ambiental一, mediante la interacción de cuatro ejes fundamentales: el desarrollo político institucional y la democracia; el desarrollo cultural; el desarrollo económico sostenible, y el manejo sostenible de los recursos naturales.

Como seguimiento a la Décima Cumbre de Presidentes de Centroamérica, la CEPAL presentó a las autoridades de la región una propuesta de reestructuración del sistema centroamericano de integración en la que se planteaban temas de importancia (CEPAL, 1991b). Por ejemplo, se proponía suscribir un nuevo tratado marco en el que los firmantes se limitaran a establecer las normas básicas que permitieran generar el derecho comunitario a través de la práctica en la interacción, así como crear la comunidad centroamericana. Por otra parte, se proponía actuar en dos planos simultáneos, a saber, la reactivación y la reestructuración del proceso, sobre la plataforma de principios esenciales que deberían tomarse en cuenta, sobre todo los siguientes: que la integración era suplementaria de los esfuerzos nacionales de desarrollo; que la integración regional y la inserción en la economía internacional debían ser complementarias; que el desarrollo tenía que significar un mejoramiento del bienestar de la población, y que la integración no debía sujetarse a etapas definidas o preconcebidas.

Si bien la ejecución del Plan de Acción Económico de Centroamérica (PAECA) fue diluyéndose en el tiempo, los mismos temas y propuestas fueron orientando las acciones posteriores, tanto en lo que se refiere al avance de la reforma institucional como en cuanto a la proliferación de temas que gradualmente fueron incorporándose en el quehacer de la integración. Además, el plan fue la guía para determinar las acciones destinadas a superar la crisis a nivel nacional.

En parte como resultado de esas propuestas, se fueron desarrollando las nuevas estructuras institucionales y la diversidad de temas y alcances de la integración. Algunos ejemplos de los avances en materia institucional que representan las transformaciones más importantes de los últimos tiempos son el Protocolo de Tegucigalpa a la Carta de la Organización de los Estados 
Centroamericanos (1991), que dio vida a la Corte Centroamericana de Justicia y al Sistema de la Integración Centroamericana (SICA) y su Secretaría General (SGSICA) - que son de particular trascendencia en la actualidad-, así como el Protocolo de Guatemala (1993), con el que se instituyó el subsistema económico de la integración.

A partir de entonces se inició un período de estabilidad, consolidación y desarrollo de la integración, ya que se incorporaron sistémicamente muchos temas más allá del económico, que había sido la esencia del proceso. Se crearon varias instituciones y secretarías especializadas y se activaron otras que ya se habían organizado, pero que enfrentaron dificultades institucionales para ponerse en funcionamiento. En 1994 se firmó la Alianza para el Desarrollo Sostenible de Centroamérica (ALIDES), y en 1995 el Tratado de la Integración Social Centroamericana y el Tratado Marco de Seguridad Democrática en Centroamérica, entre otros. También se crearon o fortalecieron secretarías como las de la Comisión Centroamericana de Ambiente y Desarrollo (CCAD), el Consejo de Ministros de Salud de Centroamérica (COMISCA), el Consejo de Ministros de Hacienda o Finanzas de Centroamérica, Panamá y República Dominicana (COSEFIN), el Consejo de Ministras de la Mujer de Centroamérica y República Dominicana (COMMCA), y el Comité Consultivo del SICA, entre otras.

En esta etapa, la CEPAL continuó realizando evaluaciones sobre el comportamiento de la evolución económica y de la integración ${ }^{12}$, además de responder con estudios sobre temas específicos, como el sector externo, la energía, la industria, la agricultura, los temas de género, la evaluación y mitigación de desastres, y el cambio climático. Una de las principales áreas de trabajo fue la institucional. Con base en diagnósticos y análisis sobre la dinámica que venía teniendo lugar debido a la proliferación de instituciones, instancias y niveles de decisión, se elaboraron varios documentos que contenían sugerencias acerca de acciones tendientes a ordenar el sistema o proponer alguna racionalidad ${ }^{13}$.

\section{H. La recuperación y el redimensionamiento}

Conforme se fue consolidando la institucionalidad de la integración y se fueron fortaleciendo los recursos humanos regionales al servicio de esta, las actividades de la CEPAL comenzaron a enfocarse en actividades de investigación, estudio y colaboración sobre los numerosos temas nuevos que se añadieron y, más que nada, sobre los desafíos que los organismos, las instituciones, las secretarías, los comités y las organizaciones sociales enfrentaban en variadas materias. Entre ellas, las que concentraron la

Véase, por ejemplo, CEPAL (1991a, 1991b, 1991c, 1992, 1993, 1994, 1999b y 2009b).

Véase CEPAL (1996 y 1997), y CEPAL y BID (1998). 
atención fueron las siguientes: la intensificación o el fortalecimiento de las relaciones externas y de la presencia de la región en los flujos de comercio; la articulación de temas diferentes y muy variados, sobre todo los sociales; el perfeccionamiento de los instrumentos reguladores del mercado común; el fortalecimiento de la participación de sectores no gubernamentales; la coordinación de las políticas públicas, y la búsqueda de espacios de convergencia de las políticas nacionales en torno a la identificación de un modelo compartido de desarrollo en el largo plazo.

En el ámbito de las relaciones comerciales, en Centroamérica se llevaron a cabo acciones que permitieron aumentar las vinculaciones externas, principalmente mediante la suscripción del Tratado de Libre Comercio entre la República Dominicana, Centroamérica y los Estados Unidos, el tratado comercial con México y, más recientemente, el Acuerdo de Asociación entre Centroamérica y la Unión Europea. Respecto de esos y otros acuerdos, la CEPAL proveyó a los países de la región con evaluaciones, datos y estudios ${ }^{14}$. Asimismo, se llevaron a cabo investigaciones y se elaboraron sistemas metodológicos propositivos sobre la construcción de cadenas regionales de valor (véase el capítulo V) y otras cuestiones ${ }^{15}$, y sobre las actividades vinculadas con el funcionamiento del mercado común, en particular el establecimiento de la unión aduanera (véase el capítulo VI) y los acuerdos sobre las reglamentaciones necesarias.

Después de un largo período de negociaciones, finalmente en 2012 la Unión Europea y Centroamérica, con inclusión de Panamá, lograron concretar el primer acuerdo de asociación de carácter birregional, que puede tener importantes consecuencias para la relación entre las dos regiones, pero sobre todo para el istmo centroamericano. Ya en 2008 la CEPAL se pronunciaba sobre las potencialidades y los desafíos que planteaba este acuerdo, y sugería diferentes alternativas de acción en el curso de las negociaciones (Caballeros, 2008). El acuerdo es un instrumento novedoso en el que se integran tres pilares interrelacionados: el diálogo político, la cooperación y el comercio. Los Estados de ambas regiones se comprometen a cumplir con requisitos, muchos de los cuales se vinculan directamente con actividades de integración y otros con derechos humanos, democracia y participación social. Cumplir con esos compromisos demandará trabajos y propuestas para que las instancias ejecutivas de la integración tomen decisiones y lleven a cabo múltiples acciones.

A pesar de que la construcción de la unión aduanera viene siendo una meta que desde la propia suscripción del Tratado General de Integración Económica Centroamericana se ha reiterado en las cumbres presidenciales,

14 CEPAL (2003), Cordero (2016), Cordero y Mata (2009), Durán y otros (2008), Pacheco y Valerio (2007), Sánchez (2007a y 2007b) y Schatan y otros (2008).

15 Por ejemplo, véase De Groot (2018), CEPAL y otros (2018) y García-Jiménez y Gandlgruber (2014). 
en los diferentes planes y agendas de trabajo de la integración y en fallidos intentos parciales, fue recién hace poco que se lograron algunos avances parciales. En 2002 los presidentes aprobaron el plan de acción en el que se determinaron plazos para concretar la creación de la Unión Aduanera Centroamericana, y en 2004 se definió el marco general para las negociaciones que condujeron a la aprobación del Convenio Marco para el Establecimiento de la Unión Aduanera en 2007. Sin embargo, los avances han sido acotados en el área de la armonización de las normas y la facilitación del comercio, y aún persisten resistencias y desconfianzas, sobre todo entre los sectores empresariales de algunos países. Más recientemente se logró un acuerdo de unión aduanera entre Guatemala y Honduras - en lo que se llamó "la integración profunda" (Cordero, 2017)—, al que en 2018 se sumó El Salvador.

Un acontecimiento importante fue la ampliación del alcance geográfico de la integración. En primer lugar, se avanzó hacia la incorporación plena y definitiva de Panamá, cuya adhesión se había iniciado con anterioridad y, en segundo lugar, más recientemente se incorporaron Belice (2000) y la República Dominicana (2013). Esto ha obligado a realizar estudios y a elaborar hojas de ruta en relación con esos acontecimientos, que ampliaron en casi un tercio la dimensión potencial del mercado regional.

Otras áreas que se han agregado a la agenda de la integración o cuya importancia se ha incrementado han sido, entre otras, las siguientes: los temas sociales, como la educación, la salud, la violencia intrafamiliar, la discriminación y los aspectos de género; las cuestiones ecológicas y las relativas a la sostenibilidad ambiental; los asuntos tecnológicos, y las cuestiones relacionadas con la seguridad ciudadana y la sostenibilidad de la democracia. Todo ello ha aumentado la cantidad de actividades y tareas pendientes de los diferentes entes especializados de la integración, y la CEPAL ha procurado contribuir a través de sus trabajos.

La importancia de fortalecer, diversificar e intensificar las relaciones interempresariales ha aumentado, al margen de las acciones gubernamentales y de los organismos de integración, y más allá de las transacciones comerciales del mercado común. En ese contexto, se han realizado estudios e investigaciones sobre el impacto de las coinversiones, la tecnología, la especialización productiva, las cadenas regionales de valor, el papel de las pequeñas y medianas empresas, así como el fortalecimiento de la presencia de las empresas regionales en el mercado internacional. En todos esos campos, la CEPAL ha aportado criterios y elementos de juicio con los que ha logrado desempeñar las funciones que le fueron asignadas, especialmente las que se le asignaron a la sede subregional de México, como organismo de las Naciones Unidas para el apoyo a la integración centroamericana. 
Reconociendo que en el tema de la integración social se había avanzado poco desde el lanzamiento de las bases para una política social centroamericana (CEPAL, 1996), los jefes de Estado y de Gobierno del Sistema de la Integración Centroamericana (SICA) aprobaron en 2008 la Agenda Estratégica Social. Esta constituye una hoja de ruta relativa al subsistema de integración social, que está estructurada en torno a los siguientes ejes de acción: aspectos institucionales con los que se pretende dar mayor precisión a las funciones, prioridades y mecanismos de coordinación y seguimiento de las acciones; mejoramiento del nivel de vida de la población por medio de acciones de cooperación horizontal, y formulación de políticas públicas mediante el fortalecimiento de las capacidades de desarrollo e implementación técnica (CEPAL, 2013). En estos temas, la CEPAL podrá hacer más aportes en el futuro en respuesta a las solicitudes de los países e instituciones de la región.

Tras sufrir los efectos de la crisis financiera internacional de 2008, que se combinó con la crisis política hondureña y las diferencias territoriales entre Costa Rica y Nicaragua, la integración retomó su regularidad. En la Cumbre Extraordinaria de Jefes de Estado y de Gobierno de los Países del Sistema de la Integración Centroamericana (SICA), celebrada en julio de 2010, los presidentes subrayaron los logros alcanzados en materia comercial e institucional, pero coincidieron en que no se habían cumplido algunos de los compromisos reconocidos en el marco de la integración. Además, se advirtió sobre los desafíos que enfrentaba la región como consecuencia de los veloces cambios en el ámbito internacional, las persistentes desigualdades económicas y sociales, tanto en el interior de los países como entre ellos, las amenazas del cambio climático y la fragilidad de la región, y el generalizado aumento del crimen organizado y la narcoactividad. En consecuencia, los presidentes acordaron el relanzamiento de la integración centroamericana, cuya agenda se centraría en los siguientes cinco pilares estratégicos y prioritarios: i) seguridad democrática, ii) cambio climático y gestión integral del riesgo, iii) integración económica, iv) integración social y v) fortalecimiento institucional de la integración. En la temática de las cumbres posteriores se incluyeron precisiones sobre agendas y actividades en torno a los cinco pilares prioritarios de la integración (Cordero, 2017).

A partir de la definición de los temas estratégicos y prioritarios, quedó establecida la agenda de trabajo de toda la institucionalidad de la integración, así como la prelación con que se debía gestionar la cooperación internacional que la región recibiera en el futuro. En la última reunión de presidentes (2017), a estas tareas se les agregaron la Agenda 2030 para el Desarrollo Sostenible y los Objetivos de Desarrollo Sostenible (ODS), con la indicación de que se los debería tomar en cuenta en el desarrollo de los trabajos relacionados con los objetivos prioritarios. Desde entonces, la Secretaría General del SICA precisa sus actividades y reorienta sus esfuerzos para responder a los desafíos que se le presentan, implementando una renovada visión estratégica cuyos objetivos finales responden plenamente a las indicaciones presidenciales. 


\section{Los desafíos}

En lo que va del presente siglo ha tenido lugar el período más prolongado de estabilidad en Centroamérica, y en él se han logrado importantes avances en cuanto al programa de integración. No obstante, "la región enfrenta enormes desafíos de cara a los elevados niveles de pobreza originada en la desigualdad de ingresos y la falta de inclusión social, para lo cual se debe estimular el crecimiento y la competitividad de la región, en un contexto en el que se ciernen otras amenazas, como son la violencia social, el crimen organizado y la vulnerabilidad, ante las amenazas derivadas del cambio climático" (SG-SICA, 2018, pág. 4). Para hacer frente a esos desafíos, debe promoverse la reflexión que permita lograr un consenso sobre un modelo de desarrollo sostenible y viable en el que se aborden las principales brechas socioeconómicas y se tomen en cuenta las áreas y los objetivos estratégicos establecidos en los cinco ejes prioritarios del relanzamiento de la integración y en la Agenda 2030 para el Desarrollo Sostenible. El macrodesafío es pensar en cómo la integración puede coadyuvar en el cumplimiento de los Objetivos de Desarrollo Sostenible. Es decir, se deben identificar áreas concretas en que los compromisos adquiridos o por adquirirse sean funcionales a la Agenda 2030.

Las máximas autoridades de la región ya han señalado las prioridades temáticas más generales, y estas se han venido indicando en las agendas específicas de sus reuniones posteriores. Sin embargo, parece importante señalar la urgencia con la que se deben atender algunos de esos temas e identificar otras tareas de carácter operativo o coyuntural que surgen en el devenir del mismo proceso.

La primera prioridad, por su impacto en la vida cotidiana de extensos grupos de la población, es la seguridad democrática. La violencia y el crimen organizado se han vuelto una de las principales fuentes de intranquilidad de la sociedad, y su carácter regional es una de las grandes preocupaciones de los Gobiernos. Por ese motivo, esta es un área en la que habrá que asignar recursos para realizar estudios, lograr la sistematización teórica del tema y poner a disposición las experiencias de otros países, para apoyar a las instancias de la integración.

Aunque todos los temas involucrados en el desarrollo social tienen un alto grado de prelación, la equidad, factor imprescindible en la consolidación de la democracia y en el desarrollo sostenible, demanda esfuerzos urgentes ${ }^{16}$. Hace varios años que se detuvo la tendencia al deterioro de la producción, a la ampliación de los desequilibrios macroeconómicos, a la recurrencia de fenómenos de inestabilidad y al empobrecimiento, y, más recientemente,

Véanse CEPAL (2008, 2010, 2012, 2013 y 2016) para obtener información más amplia acerca de las preocupaciones actuales de la CEPAL sobre el tema. 
se han logrado avances importantes en cuanto a la incorporación de varios sectores dinámicos en las estructuras productivas. Sin embargo, se han logrado pocas mejoras en materia de productividad y de capacidad para generar valor y, sobre todo, crear innovación (véase el capítulo II), porque no se han podido generar actividades dinámicas virtuosas que reduzcan los rezagos acumulados. Ello impide eliminar las inercias del deterioro del bienestar, sobre todo en los segmentos más empobrecidos.

Este tema tiene que ver con la actualización de los estudios sobre el origen de la pobreza, y su naturaleza, tipología y autorreproducción; no obstante, también está fuertemente ligado a la construcción de un modelo de desarrollo económico y social capaz de inducir a una mejor distribución de los beneficios, con efectos acumulativos. En consecuencia, será necesario redoblar esfuerzos en algunos de los temas que la CEPAL ha subrayado en los últimos tiempos, como la discusión sobre las características de un modelo deseable de desarrollo socialmente sostenible, la instrumentación de una política industrial que permita lograr un cambio estructural, el desarrollo de cadenas regionales de valor y el aporte de valor a la producción regional.

El siguiente tema en orden de urgencia es el del cambio climático y la gestión ambiental. El istmo centroamericano posee una gran riqueza biológica; sin embargo, es una región de alta vulnerabilidad debido a su ubicación geográfica y a su exposición a desastres que han tenido consecuencias graves en cuanto a la lamentable pérdida de vidas y las cuantiosas pérdidas de producción y capital que han provocado. Se han logrado importantes avances en varios frentes de este tema, pero es necesario redoblar esfuerzos para lograr lo siguiente: instrumentar políticas públicas nacionales y regionales encaminadas a incrementar las inversiones públicas, privadas y mixtas que tengan por objeto fortalecer la estructura ambiental, como la reforestación de las cuencas hidrográficas; generar una cultura de protección de los recursos ambientales; diseñar campañas educativas para evitar la exposición a los riesgos, y divulgar de manera profusa mapas de riesgo, leyes y regulaciones efectivas relacionados con el ordenamiento territorial, entre otros. Es necesario realizar estudios, evaluaciones e investigación sobre las mejores prácticas que se han utilizado en todos esos ámbitos.

En el campo específico de la integración económica, uno de los grandes asuntos pendientes que deberán tener prioridad es la construcción de la unión aduanera. Al respecto se han realizado numerosos trabajos, la mayoría de los cuales han estado centrados en definir instrumentos de facilitación de comercio y construcción de acuerdos sobre dichos instrumentos. Sin embargo, es necesario que la unión aduanera funcione de forma plena para estimular el crecimiento del comercio intrarregional y que se modifique la importancia relativa del comercio intrarregional con respecto al comercio exterior. Esto traería beneficios en lo que respecta a la actividad económica 
y a la reducción de las vulnerabilidades a los choques externos y, sobre todo, permitiría que se fortalecieran los encadenamientos productivos regionales que ya existen o que surgieran otros nuevos y más complejos.

También es prioritario fortalecer la institucionalidad regional. Aunque se han realizado importantes avances en cuanto a modernizar la institucionalidad de la integración, es necesario abordar temas como la adopción de un nuevo tratado único que responda a las necesidades del nuevo sistema de integración, más holístico y dinámico que el originario. A dicho tratado habrá que añadir otros tratados e instrumentos que abran el cauce para avanzar desde la estricta cooperación intergubernamental actual hacia la actuación comunitaria.

Para cumplir con los compromisos adquiridos en diversos foros internacionales, incluido el Acuerdo de Asociación entre Centroamérica y la Unión Europea, pero también para hacer más estables y profundas las relaciones entre los países, será necesario trabajar, por ejemplo, en lo siguiente: instrumentar mecanismos para evidenciar las actuaciones del Estado en materia de observancia de los derechos humanos, cumplimiento de los compromisos relativos al desarme de armas convencionales, combate o prevención del terrorismo y medidas para la protección de los migrantes; mejorar la administración de la cooperación regional y del seguimiento de su eficacia; homologar los procedimientos aduaneros y fitosanitarios; homogenizar las aduanas periféricas; armonizar la administración del comercio y los tratados; estandarizar los sistemas nacionales de calidad, así como las políticas de propiedad intelectual, comercio y medio ambiente, y la legislación laboral, y dar transparencia a las compras gubernamentales. En algunas de esas áreas, la CEPAL podrá hacer contribuciones sustantivas.

La CEPAL, en cumplimiento de su mandato fundacional, ha realizado una labor de apoyo al desarrollo de la región y de impulso a la integración centroamericana, como vehículo para mejorar las perspectivas de crecimiento y transformación de esta. Ese esfuerzo, basado en la reflexión, la investigación y el análisis de las realidades nacionales, se llevó a cabo en los tiempos más propicios - cuando prevalecía la armonía y el espíritu de unión-, para estimular los avances hacia el logro de aquellos objetivos, y también en los tiempos aciagos de divergencias y desencuentros, para ofrecer opciones destinadas a lograr acuerdos que permitieran retomar el camino del crecimiento y la integración. 


\section{Bibliografía}

Beteta, H. y J. C. Moreno-Brid (2014), Cambio estructural y crecimiento en Centroamérica y la República Dominica: un balance de dos décadas, 1990-2011, Libros de la CEPAL, No 122 (LC/G.2600-P), Santiago, Comisión Económica para América Latina y el Caribe (CEPAL).

Caballeros, R. (2008), “Centroamérica: los retos del Acuerdo de Asociación con la Unión Europea", serie Estudios y Perspectivas-Sede Subregional de la CEPAL en México, N 102 (LC/L.2925-P-LC/MEX/L.869), Ciudad de México, Comisión Económica para América Latina y el Caribe (CEPAL), julio.

(1992), "Reorientación de la integración centroamericana", Revista de la CEPAL, N 46 (LC/G.1717-P), Santiago, Comisión Económica para América Latina y el Caribe (CEPAL), abril.

(1990), "Centroamérica: perspectivas económicas de largo plazo", Comercio Exterior, vol. 20, $\mathrm{N}^{\circ}$ 7, Ciudad de México, julio.

Caballeros, R. y R. Zapata (1994), "The impacts of natural disasters on developing economies: implications for the international development and disaster community", documento presentado en la Conferencia Mundial sobre la Reducción de los Desastres Naturales, Banco Mundial/Academia Nacional de Ciencias de Estados Unidos, Yokohama, 23 al 27 de mayo.

Caldentey, P. (2014), "Los desafíos estratégicos de la integración Centroamericana”, serie Estudios y Perspectiva-Sede Subregional de la CEPAL en México, N 156 (LC/L.3897LC/MEX/L.1159), Ciudad de México, Comisión Económica para América Latina y el Caribe (CEPAL), septiembre.

CEPAL (Comisión Económica para América Latina y el Caribe) (2017), Posibles efectos económicos y sociales de la profundización de la Unión Aduanera entre Guatemala y Honduras (LC/ST.2017/53), Santiago.

(2016), Horizontes 2030: la igualdad en el centro del desarrollo sostenible(LC/G.2660/Rev.1), Santiago.

(2013), Integración social en Centroamérica: situación al 2012, tendencias y propuestas (LC/MEX/L.1094), Ciudad de México.

(2012), Cambio estructural para la igualdad: una visión integrada del desarrollo. Sintesis (LC/G.2604), Santiago.

(2010), La hora de la igualdad: brechas por cerrar, caminos por abrir. Sintesis (LC/G.2432(SES.33/3)).

(2009a), La integración económica centroamericana y sus perspectivas frente a la crisis internacional (LC/MEX/L.954), Ciudad de México

(2009b), Visión estratégica de Centroamérica y su inserción internacional (LC/MEX/L895), Ciudad de México.

(2008), La transformación productiva 20 años después: viejos problemas, nuevas oportunidades. Sintesis (LC/G.2368(SES.32/4)), Santiago.

(2003), Istmo Centroamericano: competitividad e integración regional, 2001-2003 (LC/MEX/L576), Ciudad de México.

(1999a), América Latina y el Caribe: el impacto de los desastres naturales en el desarrollo, 1972-1999 (LC/MEX/L.402-LC/MEX/R.701), Ciudad de México. (1999b), Integración, convergencia y coordinación de las políticas macroeconómicas en Centroamérica (LC/MEX/R.752), Ciudad de México.

(1997), Propuesta para el fortalecimiento y la racionalización de la institucionalidad regional centroamericana (LC/MEX/R.635), Ciudad de México. 
(1996), Bases para la evaluación de la institucionalidad regional centroamericana (versión revisada), Ciudad de México.

(1994), El regionalismo abierto en América Central: los desafíos de profundizar y ampliar la integración (LC/MEX/R. 493) (SEM. 68/2), Ciudad de México.

(1993), Centroamérica: el camino de los noventa (resumen) (LC/MEX/R.388), Ciudad de México.

(1992), Centroamérica: evolución económica desde la posguerra hasta fines de los años setenta (LC/MEX/L.211), Ciudad de México.

(1991a), Centroamérica: notas para una estrategia de desarrollo en los años noventa (LC/MEX/R.319(SEM.47/3)), Ciudad de México.

(1991b), Bases y propuestas para la reestructuración del sistema centroamericano de integración (LC/MEX/L.157), Ciudad de México.

(1991c), La integración en Centroamérica: su evolución desde los años setenta y perspectivas en los noventa (LC/MEX/R. 271/Rev.1), Ciudad de México.

(1991d), Reestructuración de sistema centroamericano de integración: bases y propuestas (LC/MEX/R.273/Rev.1), Ciudad de México.

(1990), Documento de discusión para la Cumbre Económica Centroamericana (LC/MEX/L.132, CCE/CICD/XXII/1), Ciudad de México, 23 de mayo.

(1989a), Reflexiones sobre politicas de ajuste e integración en Centroamérica: temario anotado (LC/MEX/R.184(SEM.32/2), Ciudad de México.

(1989b), Istmo centroamericano: perspectivas socioeconómicas de largo plazo (LC/MEX/R.175), Ciudad de México.

(1988), Centroamérica: crisis y políticas de ajuste, 1979-1986 (LC/MEX/L.81), Ciudad de México.

(1987), "Resúmenes de documentos sobre integración económica en América Latina y el Caribe", serie INFOPLAN: Temas Especiales del Desarrollo (LC/G.1474-P), Santiago, agosto.

(1985), Centroamérica: bases de una politica de reactivación y desarrollo (LC/L.331(SEM.22/5)-LC/MEX/G.1/Rev.2), Ciudad de México.

(1984a), Informe de la primera reunión de Ministros de Finanzas o de Hacienda de Centroamérica (E/CEPAL/CCE/L.419), Ciudad de México, 15 de octubre.

(1984b), Planteamientos económicos que los gobiernos del Istmo Centroamericano podrían formular ante las autoridades de la Comunidad Europea (E/CEPAL/CCE/L.416/Rev.1), Ciudad de México.

(1983), La crisis en Centroamérica: orígenes, alcances y consecuencias (E/CEPAL/ MEX/1983/R.3/Rev.1), Ciudad de México.

(1981a), Istmo Centroamericano: el carácter de la crisis económica actual, los desafíos que plantea y la cooperación internacional que demanda (E/CEPAL/CCE/402), Ciudad de México.

(1981b), Informe de la Secretaría del Comité de Cooperación Económica del Istmo Centroamericano (CCE) (E/CEPAL/CCE/398), Ciudad de México.

(1980), Notas sobre el trasfondo histórico del desarrollo centroamericano (CEPAL/ MEX/ODE/35), Ciudad de México.

(1978), "La CEPAL en la realidad económica de América Latina", Ciudad de México [en línea] https:/ / repositorio.cepal.org/bitstream/handle/11362/40634/ LaCEPALenlarealidadeconomicaAL.pdf?sequence $=1 \&$ isAllowed $=\mathrm{y}$. (1976), Algunos apuntes sobre la integración económica centroamericana (CEPAL/ MEX/76/14), Ciudad de México. 
(1974a), Planteamiento y posibles medidas en torno al problema del desarrollo equilibrado en Centroamérica (CEPAL/MEX/74/22), Ciudad de México.

(1974b), El Mercado Común Centroamericano, 1973-1974 (CEPAL/MEX/74/20/ Rev.1), Ciudad de México.

(1974c), El proceso de perfeccionamiento del Mercado Común Centroamericano: apuntes sobre la crisis de energéticos y su impacto en las economías centroamericanas (CEPAL/MEX/74/12), Ciudad de México.

(1973), Informe sobre los daños y repercusiones del terremoto de la ciudad de Managua en la economía nicaragüense (E/CN.12/AC.64/2/Rev.1), Nueva York.

(1971), El Mercado Común Centroamericano y sus problemas recientes (E/CN.12/ CCE/363), Ciudad de México.

(1968), Resoluciones del Comité de Cooperación Económica del Istmo Centroamericano (E/CN.12/CCE/358), Ciudad de México, julio.

(1966), Evaluación de la integración económica en Centroamérica (E/CN.12/762), Nueva York.

(1956), La integración económica de Centroamérica: su evolución y perspectivas (E/CN.12/422-E/CN.12/CCE/33/Rev.2), Ciudad de México.

(1955), Informe del Representante Regional de la Junta de Asistencia Técnica de las Naciones Unidas (E/CN.12/CCE/4), Ciudad de México, abril.

(1952a), Informe preliminar del Secretario Ejecutivo de la Comisión Económica para América Latina sobre integración y reciprocidad económicas en Centroamérica (E/CN.12/AC.17/3), Tegucigalpa, agosto.

(1952b), Integración y reciprocidad económica en Centroamérica (E/CN.12/AC.17/3), Tegucigalpa.

(1952c), Nota del Secretario Ejecutivo sobre integración económica y cooperación tecnológica, (E/CN.12/AC.17/4), Tegucigalpa, agosto.

(1952d), Nota del Secretario Ejecutivo sobre el estudio de los transportes en Centroamérica (E/CN.12/AC.17/6), Tegucigalpa.

(1952e), Nota del Secretario Ejecutivo sobre unificación de la nomenclatura arancelaria (E/CN.12/AC.17/5), Tegucigalpa.

(1952f), Primera reunión del Comité de Cooperación Económica de los Ministros de Economía del Istmo Centroamericano (E/CN.12/AC.17/1.S), Tegucigalpa, 23 de agosto.

(1952g), Problemas teóricos y prácticos del crecimiento económico (E/CN.12/221), Ciudad de México.

CEPAL/BID (Comisión Económica para América Latina y el Caribe/Banco Interamericano de Desarrollo) (1998), La integración centroamericana y la institucionalidad regional, Ciudad de México.

CEPAL (Comisión Económica para América Latina y el Caribe) y otros (2018), Articulación productiva y cadenas regionales de valor: una propuesta metodológica para la región SICA (LC/MEX/TS.2018/21), Ciudad de México.

Cordero, M. (2017), Integración económica centroamericana: base de datos 2016 (LC/MEX/TS.2017/24), Ciudad de México, Comisión Económica para América Latina y el Caribe (CEPAL).

(2016), El Acuerdo Transpacífico de Cooperación Económica (TPP) y sus implicaciones para Centroamérica en materia textil-confección (LC/MEX/L.1217), Ciudad de México, Comisión Económica para América Latina y el Caribe (CEPAL). 
Cordero, M. y H. Mata (2009), “El acuerdo de asociación económica entre Centroamérica y la Unión Europea: viabilidad, avances y perspectivas", serie Estudios y PerspectivasSede Subregional de la CEPAL en México, No 112 (LC/L.3110-P-LC/MEX/L.926), Comisión Económica para América Latina y el Caribe (CEPAL), octubre.

De Groot, O. (2018), La cadena regional de valor de la industria de lácteos en Centroamérica (LC/MEX/TS.2018/2), Ciudad de México, Comisión Económica para América Latina y el Caribe (CEPAL).

Delgado, P. (1964), “Evolución, estado actual y perspectivas del Mercado Común Centroamericano", Revista Conservadora del Pensamiento Centroamericano, vol. 9, $\mathrm{N}^{\circ} 49$, Managua, octubre.

Durán, J. y otros (2008), Acuerdo de Asociación Centroamérica-Unión Europea: evaluación utilizando equilibrio general computable y equilibrio parcial (LC/W.215), Santiago, Comisión Económica para América Latina y el Caribe (CEPAL).

García-Jiménez, H. y B. Gandlgruber (2014), Gobernanza y acuerdos institucionales en las cadenas del frijol y del maíz en Centroamérica (LC/MEX/W.10), Ciudad de México, Comisión Económica para América Latina y el Caribe (CEPAL)/Organización de las Naciones Unidas para la Alimentación y la Agricultura (FAO).

Gurrieri, A. (2001), "Las ideas del joven Prebisch", Revista de la CEPAL, N 75 (LC/G.2150-P), Santiago, Comisión Económica para América Latina y el Caribe (CEPAL), diciembre.

Ocampo, F. (2017), Acciones estratégicas para profundizar la integración económica en Centroamérica (LC/MEX/TS.2017/12), Ciudad de México, Comisión Económica para América Latina y el Caribe (CEPAL).

Pacheco, A. y F. Valerio (2007), “DR-CAFTA: aspectos relevantes seleccionados del Tratado y reformas legales que deben realizar a su entrada en vigor los países de Centroamérica y la República Dominicana", serie Estudios y Perspectivas-Sede Subregional de la CEPAL en México, N 76 (LC/L.2692-P-LC/MEX/L.765), Ciudad de México, Comisión Económica para América Latina y el Caribe (CEPAL), marzo.

Pellandra, A. y J. Fuentes (2011), "El estado actual de la integración en Centroamérica”, serie Estudios y Perspectivas-Sede Subregional de la CEPAL en México, N ${ }^{\circ} 129$ (LC/L.3360- LC/MEX/L.1017), Ciudad de México, Comisión Económica para América Latina y el Caribe (CEPAL), agosto.

Pimentel, A. (2018), La integración centroamericana desde sus orígenes hasta el Protocolo de Tegucigalpa 1951-1991, en prensa.

Prebisch, R. (1986), "Exposición del Dr. Raúl Prebisch en el vigesimoprimer período de sesiones de la CEPAL (México D. F., 24 de abril de 1986)", Revista de la CEPAL, N 29 (LC/G.1427), Santiago, Comisión Económica para América Latina y el Caribe (CEPAL), agosto.

(1983), "Centro y periferia en el origen y maduración de la crisis", Pensamiento Iberoamericano, $\mathrm{N}^{\circ}$ 3, Madrid, enero-junio.

(1981), Capitalismo periférico: crisis y transformación, Ciudad de México, Fondo de Cultura Económica.

(1976), "Crítica al capitalismo periférico", Revista de la CEPAL, N 1, Santiago, Comisión Económica para América Latina y el Caribe (CEPAL), primer semestre. (1960), "La CEPAL y los problemas del desarrollo económico en América Latina", Ciclo: El Mundo Subdesarrollado, conferencia N ${ }^{\circ}$ 2, Santiago, Universidad de Chile/Comisión Económica para América Latina y el Caribe (CEPAL). 
(1958), "El Mercado Común y los problemas de pagos", Panorama Económico, vol. 1, No 197, Santiago, noviembre.

(1955), "Problemas del desarrollo económico latinoamericano", Boletín Mensual, año 13, No 145-146, enero-febrero.

(1950), "Estudio económico de América Latina", Revista de Economía, vol. 3, No 17 , Montevideo, abril-mayo.

(1949), El desarrollo económico de la América Latina y sus principales problemas (E/CN.12/89), Santiago, Comisión Económica para América Latina y el Caribe (CEPAL).

Rodríguez, A. (2016), "La integración de Centroamérica: entre el vaivén y fallidas voluntades", La Razón Histórica, N³4, Instituto de Política Social (IPS).

Rosenthal, G. (1985), “Los nuevos rumbos de la integración”, documento presentado en el Seminario sobre Endeudamiento Externo y Políticas Económicas en América Latina, Universidad Estatal de Campinas, San Pablo, 6 al 8 de diciembre. (1982), “Algunas lecciones de la integración económica en América Latina: el caso de Centroamérica", Economía de América Latina, № 8, Ciudad de México, primer semestre.

Sánchez, M. (2007a), “Liberalización comercial en el marco del DR-CAFTA: efectos en el crecimiento, la pobreza y la desigualdad en Costa Rica", serie Estudios y Perspectivas-Sede Subregional de la CEPAL en México, N 80 (LC/L.2698-P-LC/ MEX/L.771/Rev.1), Ciudad de México, Comisión Económica para América Latina y el Caribe (CEPAL), marzo.

(2007b), "Apertura comercial y pobreza en Centroamérica: logros y desafíos", Revista CEPAL, N 98 (LC/G.2404-P), Santiago, Comisión Económica para América Latina y el Caribe (CEPAL), agosto.

Santa Cruz, H. (1987), "Recuerdos de la creación de la CEPAL, a guisa de introducción", Antecedentes sobre la creación de la CEPAL: fotocopias de documentos de la Asamblea General y del Consejo Económico y Social de las Naciones Unidas, Santiago, Comisión Económica para América Latina y el Caribe (CEPAL).

Schatan, C. y otros (2008), "Integración regional e integración con Estados Unidos: el rumbo de las exportaciones centroamericanas y de República Dominicana", serie Estudios y Perspectivas-Sede Subregional de la CEPAL en México, $\mathrm{N}^{\circ} 93$ (LC/L.2862-P-LC/MEX/L.831/Rev.1), Ciudad de México, Comisión Económica para América Latina y el Caribe (CEPAL).

SG-SICA (Secretaría General del Sistema de la Integración Centroamericana) (2018), Visión estratégica 2017-2021, SICA [en línea] https://www.sica.int/consulta/ documento.aspx?idn=111508\&idm=1.

SIECA/BID/INTAL (Secretaría de Integración Económica Centroamericana/Banco Interamericano de Desarrollo/Instituto para la Integración de América Latina) (1973), El desarrollo integrado de Centroamérica en la presente década: bases y propuestas para el perfeccionamiento y la reestructuración del Mercado Común Centroamericano, Buenos Aires, Secretaría de Integración Económica Centroamericana (SIECA).

Urbina, C. (2015), “Ensayo 60 años de integración centroamericana”, Universidad Nacional Autónoma de Honduras, Facultad de Ciencias Económicas, Tegucigalpa, abril [en línea] https://www.academia.edu/30738728/ENSAYO_60_A\%C3\%91OS_ DE_INTEGRACI\%C3\%93N_CENTROAMERICANA. 
Capítulo II

\section{El modelo de desarrollo subyacente de la integración centroamericana}

Jorge Mario Martínez Piva

\section{Introducción}

Desde sus inicios, la Comisión Económica para América Latina y el Caribe (CEPAL) ha elaborado y propuesto políticas para el desarrollo económico de América Latina como parte de su mandato institucional. Tales propuestas forman un conjunto de instrumentos e ideas sobre los roles del Estado y el sector privado que constituyen un modelo de desarrollo para la región.

Ese modelo propuesto por la CEPAL ha evolucionado y se ha actualizado según lo han requerido los cambios de la economía regional y mundial: la producción globalizada, los cambios geopolíticos globales o los retos ambientales, entre otros. No obstante, hay dos elementos que forman un continuo. En primer lugar, que el desarrollo se entiende como un cambio estructural que no solo ha de propiciar altas tasas de crecimiento, sino también cambios cualitativos en la estructura productiva y el patrón de especialización. En segundo lugar, que la integración es necesaria para el desarrollo de Centroamérica, toda vez que permite ampliar mercados por naturaleza pequeños, así como dinamizar el comercio industrial regional e incrementar el valor agregado de la producción. En este capítulo se analiza la propuesta de la CEPAL para el desarrollo de Centroamérica, desde el punto de vista de los dos elementos de continuidad y de sus adecuaciones a los cambios globales. 


\section{A. La búsqueda de un modelo de desarrollo}

En su búsqueda del desarrollo, los países centroamericanos han ensayado diversos modelos a lo largo de su historia. Cada uno enfrenta condiciones nacionales e internacionales, políticas y tecnológicas que transforman sus planteamientos sobre cómo alcanzar esa meta. Estas condiciones se acumulan y evolucionan, de modo que provocan cambios en la dirección, los énfasis y las opciones de políticas disponibles. Los cambios también implican transformaciones de los intereses de diversos grupos, de las justificaciones $\mathrm{y}$, por lo tanto, de los modelos políticamente viables.

Desde su independencia, los países centroamericanos exploraron diversos modelos de desarrollo, con características propias en cuanto a las relaciones económicas internas y externas ${ }^{1}$. Desde el punto de vista interno, estos modelos variaron en el trato que se daba a los sectores, el grado de competencia entre ellos y con el exterior, y las regulaciones que los afectaban. En sus relaciones de intercambio con las potencias extranjeras, la región centroamericana basó su comercio en exportaciones de productos primarios (por ejemplo, azúcar, cacao, café y banano) e importaciones de bienes industriales (prendas de vestir, maquinaria y bienes de consumo final, entre otros). Este modelo creó estructuras económicas dominadas por el sector primario, junto a un débil o inexistente sector secundario. También creó una economía política que favorecía a los sectores primarios, un sistema tributario consecuente con esa situación y una organización social mayoritariamente rural.

Durante más de 100 años, Centroamérica mantuvo un modelo de desarrollo basado en exportaciones de productos primarios e importaciones de bienes industriales. De este modo, la región se especializó en la producción de bienes agrícolas. Los países centroamericanos en general competían entre sí en los mercados externos y el comercio intrarregional era escaso. La CEPAL describió y subrayó algunas características que predominaban en las relaciones que mantenían los países centroamericanos, y los latinoamericanos en general, con el mundo desarrollado. Estas relaciones se denominaron de "centro-periferia" y su característica principal era que los países del centro (o sea, los desarrollados) lograban obtener mayores beneficios de dicha relación, mediante la extracción de rentas del comercio y la tendencia a perpetuar la condición de subdesarrollo (periferia) de los países latinoamericanos (Prebisch, 1958).

\footnotetext{
En este capítulo, Centroamérica se refiere a cinco países: Costa Rica, El Salvador, Guatemala, Honduras y Nicaragua. Panamá es miembro del Sistema de la Integración Centroamericana (SICA) desde que suscribió el Protocolo de Tegucigalpa a la Carta de la Organización de Estados Centroamericanos (ODECA), en 1991; Belice, desde 2000, y la República Dominicana, desde 2013. Sin embargo, solo Panamá se ha adherido al Subsistema de Integración Económica Centroamericana (en junio de 2012), que entró en vigor en mayo de 2013.
} 
La extracción de rentas por parte de los países del centro se basaba en el valor de los bienes que estos intercambiaban con los de la periferia. Los primeros exportaban bienes industriales cuyo valor y complejidad aumentaba con el tiempo, mientras que los segundos exportaban bienes primarios, cuyos precios relativos sufrían un deterioro constante. Raúl Prebisch, quien fuera Secretario Ejecutivo de la CEPAL, sostenía que existe una asimetría entre el escaso dinamismo de la demanda mundial de productos primarios y el gran dinamismo de la demanda de productos industriales (Bielschowsky, 2010). Esta situación conlleva recurrentes crisis del sector externo en los países periféricos, cuya balanza comercial se deteriora. Todo esto impone la necesidad de devaluaciones constantes, lo que a su vez provoca otros desequilibrios, como los procesos de inflación y la debilidad de las cuentas públicas.

Mediante el análisis estructuralista de la CEPAL, también se detallaron otras características de las relaciones centro-periferia que fueron parte del modelo que siguió la región hasta el fin de la Segunda Guerra Mundial. Se señaló que los países de la periferia se caracterizaban por: i) la especialización en bienes del sector primario y una baja diversificación productiva, con poca integración vertical en el tejido productivo; ii) la escasa integración entre la dinámica industrial y agrícola; iii) el atraso de los sectores difusores de tecnología, en particular los intensivos en bienes de capital; iv) los niveles de productividad muy dispares entre un sector y otro, lo que se describe como una gran "heterogeneidad estructural", entre cuyos efectos cabe mencionar una distribución de ingreso inequitativa; v) los bajos índices de inversión nacional debido a los exiguos niveles de ahorro, así como a la precariedad del empresariado industrial, con poca vocación de riesgo y de progreso técnico; vi) la gran penetración de empresas transnacionales en el tejido productivo y la escasa propensión de sus filiales a invertir en investigación, desarrollo e innovación, y vii) la gran concentración de las exportaciones en destinos y productos, lo que aumentaba la vulnerabilidad ante los choques externos (Bielschowsky, 2010; Sánchez y Martínez Piva, 2014).

El desarrollo económico centroamericano requería superar las relaciones centro-periferia. Con ese fin se planteó la necesidad de concertar acuerdos comerciales preferenciales para la formación de un mercado común. El razonamiento subyacente era el siguiente: debido a la baja elasticidad de la demanda de productos primarios y a políticas proteccionistas en el centro, la expansión continua de la producción de estos productos se traduce en una disminución de su precio y, por ende, en una pérdida de recursos. Si esta pérdida debida al deterioro de los términos del intercambio es superior a la

Aníbal Pinto denominaba heterogeneidad estructural a la existencia de sectores económicos con niveles de productividad muy diferentes (véase Pinto, 1970). Esta heterogeneidad se manifiesta en desempeños muy variados entre los agentes nacionales, transnacionales y estatales, y entre las empresas según su tamaño. 
que se produciría si se sustituyera la producción nacional por la importada, sería viable y más eficiente la opción de industrializar mediante un proceso de sustitución de importaciones.

\section{La industrialización por sustitución de importaciones}

Superar la condición de periferia suponía para la CEPAL un nuevo modelo de desarrollo que promoviera la introducción de progresos técnicos, la mejoría en la distribución del ingreso y una nueva forma de relacionarse con el mundo. También era necesario un conjunto de políticas económicas para la industrialización. Este modelo iba de la mano de un proceso de integración de mercados regionales que permitiría la sustitución de importaciones industriales.

Los países latinoamericanos debían dirigir sus esfuerzos de inversión y generación productiva hacia el sector industrial, de manera que las capacidades industriales se incrementaran y se redujera la condición de periferia. La industrialización para sustituir importaciones era una exigencia del proceso de desarrollo económico. A fin de no provocar una pérdida de riqueza, esa industrialización debía estar acompañada de la tecnificación de la agricultura (Prebisch, 1958).

La manera de corregir las restricciones existentes para el desarrollo de los países periféricos y promover la industrialización consistía en implementar una estrategia de sustitución de importaciones estimulada por una política de protección selectiva. El esfuerzo de sustitución de importaciones mediante la protección evitaría la asignación de recursos productivos a actividades primarias de exportación y los canalizaría hacia la producción industrial (Prebisch, 1969).

La industrialización por sustitución de importaciones no solo se justificaría con las diferencias entre las elasticidades de las importaciones y las elasticidades-precio de las exportaciones, sino también con los efectos multiplicadores de la manufactura, que son mayores que los de los bienes primarios. La industrialización en Centroamérica daría lugar a mayores externalidades a otros sectores, como sucedía entonces en los países del centro y no con los bienes primarios producidos en la periferia.

En Centroamérica, al igual que en el resto de América Latina y el Caribe, la estrategia aplicada se basaba en un conjunto de instrumentos de política pública que conformaron el modelo de desarrollo. Entre estos cabe mencionar la imposición de barreras arancelarias o cuotas a la importación de determinados bienes; los incentivos a la inversión (que muchas veces se realizaba mediante la participación de capital público o privado, o el establecimiento de filiales de empresas extranjeras que se beneficiaban de la protección comercial); los subsidios fiscales; los acuerdos comerciales 
que incluían reciprocidades industriales y los acuerdos de especialización productiva, que aseguraban la ampliación de los mercados nacionales para la colocación de la producción industrial. En palabras de Prebisch (1969):

Para acelerar la tasa de desarrollo es indispensable elevar también la tasa de crecimiento de las exportaciones y esto no podrá conseguirse sin un vigoroso aliento a las exportaciones industriales. Aquí está pues el punto decisivo. Estoy persuadido que, aún en la hipótesis más favorable de tratamiento de las exportaciones industriales latinoamericanas en los países desarrollados, ello no resolvería completamente este problema. Me parece pues indispensable desenvolver las exportaciones a otros países latinoamericanos; y si no se quiere caer en aquel esquema pretérito de intercambio prevaleciente en el siglo XIX, el país que logre dar gran vuelo a sus exportaciones tendrá también que admitir importaciones de productos industriales provenientes de los países latinoamericanos. Para cumplir este objetivo es indispensable dar impulso a la marcha hacia el mercado común, principalmente a través de los acuerdos de complementación o integración industrial en las actividades sustitutivas de importación.

\section{La integración como vía hacia el desarrollo}

Entre 1951 y 1958, la CEPAL realizó una intensa labor de apoyo a los gobiernos centroamericanos para fomentar la integración económica regional. Este esfuerzo culminó con la suscripción del Tratado Multilateral de Libre Comercio e Integración Económica Centroamericana (1958), al que siguieron el Convenio sobre el Régimen de Industrias Centroamericanas de Integración y el Convenio Centroamericano sobre Equiparación de Gravámenes a la Importación.

Desde el punto de vista de la CEPAL, el estímulo deliberado de la industrialización y del desarrollo de las actividades complementarias (transporte, comercio y servicios) era una política necesaria en la periferia para absorber el incremento de la población y mejorar la productividad y los niveles de vida. Se subrayó la limitación que supondría la estrechez del mercado para un proceso de industrialización eficiente. Ello se debe a que, a medida que se avanza en este proceso, hay que desarrollar industrias cada vez más complejas, donde la dimensión del mercado es primordial para la productividad. Una de las mayores debilidades del desarrollo en América Latina estribaba en que cada país intentaba hacer lo mismo que los otros, sin especialización ni comercio recíproco. De manera que, si la producción continuaba en compartimentos estancos como se hacía desde la independencia, el fruto de las nuevas inversiones de capital seguiría alejándose de los logros conseguidos en los centros industriales con amplios mercados. De ahí la racionalidad de un mercado común, ya que un proceso de industrialización eficiente requiere la ampliación permanente y sistemática de los mercados. 
La CEPAL propuso la creación de un mercado común como un esfuerzo negociado y racional de especialización y reciprocidad industrial, orientado a mejorar el intercambio tradicional de productos primarios y asegurar la industrialización. La sustitución eficiente de importaciones en un mercado común ampliado serviría de puente para pasar a una etapa de intercambio recíprocamente beneficioso de productos industriales con los centros. El mercado común contribuiría a mejorar la eficiencia. Por lo tanto, tendría efectos sobre los costos de producción, lo que podría dar impulso a la exportación de ciertos productos industriales. A su vez, la disminución de los costos justificaría una reducción de los aranceles frente al resto del mundo. Ello implica que un mercado común ofrecería la oportunidad de negociar en bloque la disminución recíproca de aranceles con socios comerciales concretos o frente al resto del mundo, lo que redundaría en beneficio del comercio internacional.

La creación de un mercado común debería contar con algunas características propuestas por la CEPAL, como la reciprocidad, el tratamiento diferencial, la forma de los compromisos de liberalización, un sistema de pagos y la progresividad. La reciprocidad se refiere a que las importaciones industriales de los países miembros se financien con el producto de sus propias exportaciones industriales adicionales. Así pues, el concepto vincula directamente el objetivo de la industrialización con el de la integración. Este principio implica que los países más competitivos deben tomar medidas para estimular sus importaciones industriales provenientes de los países de menor desarrollo relativo. En este sentido, el concepto de reciprocidad entraña un principio de balance comercial de largo plazo (o estructural) de bienes industriales.

El tratamiento diferencial para los países de desarrollo incipiente parte de la idea de que las economías menos desarrolladas requieren una mayor protección media que les permita un crecimiento y una actualización productiva más acelerados. Lo contrario se traduciría en desbalances en el proceso comercial y no conduciría a la industrialización. A fin de conjugar la necesidad de una mayor protección para los países de desarrollo incipiente y menor productividad con el proceso de liberación comercial entre los socios de la integración, se recomendó establecer un régimen de concesiones especiales. Contrariamente al principio de la nación más favorecida, esas concesiones no se extenderían a todos los demás miembros del mercado común.

La forma de los compromisos se refería principalmente a dos elementos. Un elemento cuantitativo, consistente en reducciones arancelarias promedio que buscaban que el nivel medio de aranceles entre los socios de la integración y entre ellos y el resto del mundo fuera uniforme para que existieran condiciones competitivas iguales para todos. El segundo elemento se refiere a la creación de listas de inclusión con el fin de promover la liberalización intrarregional. Esto significa que la liberalización no es para todos los sectores, sino solo para los que estén incluidos en dichas listas. 
La expansión del comercio intrarregional requeriría un sistema regional de pagos que redujera la intermediación monetaria de terceros países y favoreciera el uso de las monedas nacionales en el intercambio dentro de la región. Se trataría de un mecanismo multilateral de compensación y créditos recíprocos entre los bancos centrales centroamericanos, con el objetivo de facilitar los pagos y fomentar el uso de las monedas de la región en las transacciones intrarregionales. El sistema podría promover el uso de valores numerarios, cheques emitidos o certificados por los bancos, cartas de crédito, órdenes de pago, letras de cambio y otros documentos de pago, lo que facilitaría el comercio en la región.

Por último, la progresividad del proceso de industrialización por sustitución de importaciones subraya la necesidad de ampliar permanentemente los mercados. De acuerdo con Prebisch, a medida que se desarrollara una planta industrial nacional, se debían modificar los aranceles proteccionistas. Este escenario implicaba la revisión de los aranceles para que se abrieran a la competencia los sectores industriales maduros y se extendiera la protección a nuevas industrias sustitutivas. Así, un mercado común ampliado conduciría a una etapa de intercambios beneficiosos de productos industriales con los países del centro. "En la visión de Prebisch, el mercado común no es un fin en sí mismo, sino un instrumento para facilitar la industrialización y el avance hacia nuevas formas de integración en la economía mundial basadas en la competitividad internacional y el intercambio recíproco en productos industriales con los centros" (Salazar, 1990, págs. 175-176).

\section{B. Del desarrollo hacia adentro al desarrollo hacia afuera}

El modelo de industrialización por sustitución de importaciones, también conocido como modelo de desarrollo hacia adentro, condujo a la formación del mercado común centroamericano en 1960 y puso el acento en la demanda. Es decir, promovió la expansión del mercado interno y el reemplazo de los bienes importados por los de producción local (Sunkel, 1991). La estrategia descansaba en la ampliación del consumo interno y la reproducción de los patrones de consumo y producción de los países del centro. La estrategia de industrialización por sustitución de importaciones prevaleció desde la década de 1950 hasta la de 1980, y tuvo su correlato en el incremento del comercio intrarregional centroamericano.

En este período, el Estado jugó un papel fundamental al promover las inversiones a gran escala en infraestructura y en sectores productivos, al tiempo que protegió las industrias nacionales nacientes con aranceles de importación elevados, cuotas y restricciones sectoriales a la inversión extranjera directa (IED), cláusulas de desempeño y otras políticas. El modelo 
de desarrollo también se centró en el diseño de una política industrial encaminada a crear un sector manufacturero nacional que alejara a la región de su especialización en bienes primarios y sustituyera importaciones manufactureras (Bulmer-Thomas, 1998; Moreno-Brid, Pérez-Caldentey y Ruíz-Nápoles, 2004).

En la CEPAL se propusieron distintas ideas para guiar el proceso de industrialización y sustitución de importaciones, entre ellas, las relativas a los principios de gradualidad y reciprocidad. No obstante, estos principios fueron descartados a favor de una transición rápida al libre comercio intrarregional, que estaba protegido de la competencia externa por el arancel externo común. También se propusieron iniciativas para enfrentar el problema de los países de menor desarrollo relativo y que se revisaran con regularidad los incentivos, sobre todo los relacionados con la protección efectiva mediante los aranceles. Sin embargo, no se tomaron medidas al respecto, lo que enrareció el ambiente competitivo. No se promovieron las exportaciones industriales al resto del mundo y la estructura de incentivos se mantuvo prácticamente idéntica durante 25 años. Si bien la integración funcionó para crear una base industrial antes inexistente o incipiente, esta no fue competitiva ni se integró al comercio internacional, sino que tuvo que hacerlo como consecuencia de la crisis de los años ochenta y la posterior apertura comercial. Buena parte de dicha base industrial desapareció o fue adquirida por capital extranjero (Salazar, 1990).

El modelo de industrialización por sustitución de importaciones entró en declive en la década de 1970, debido a la acumulación de debilidades: pocos encadenamientos productivos; alta dependencia de insumos y productos intermedios extranjeros, y crecimiento acelerado de los servicios públicos (como carreteras, puertos y energía) basados en una estructura fiscal ineficiente y regresiva. La debilidad de las finanzas públicas y el excesivo uso de la deuda externa para financiar el impulso desarrollista produjeron desequilibrios en la balanza de pagos e hicieron que las cuentas fiscales entraran en crisis ante las conmociones externas, sobre todo el alza del precio del petróleo y de los intereses de la deuda externa (Moreno-Brid, Pérez-Caldentey y Ruíz-Nápoles, 2004).

En 1982 estalló la crisis de la deuda, con el anuncio del Gobierno de México de la moratoria de los pagos. Se inició así a la denominada "década perdida" ${ }^{\prime 3}$. Este período se caracterizó por caídas del PIB por habitante, la agudización de los desequilibrios macroeconómicos (alta inflación, déficit

\footnotetext{
Este término, que se utilizó en los informes de la CEPAL y de la Organización de Cooperación y Desarrollo Económicos (OCDE), ilustra la magnitud del retroceso sufrido en materia de desarrollo. En ocasiones se hace referencia a que en esa década hubo un gran avance en cuanto a libertades y derechos, pues se restableció la democracia en algunos países donde habían ocurrido golpes de Estado conducentes a dictaduras militares. Sin embargo, también cabe señalar que Centroamérica vivió complejos conflictos armados durante toda la década.
} 
fiscal, devaluación y enormes salidas de capital), la creciente obsolescencia de la planta de capital y de las infraestructuras, el aumento de la brecha entre la utilización de la tecnología en la región y su aplicación internacional, el deterioro financiero, el aumento de las tasas de paro, la extensión del sector informal y la sobreexplotación de los recursos naturales, entre otros (Sánchez y Martínez Piva, 2014).

La eficacia del Estado como diseñador y ejecutor de políticas de cambio estructural fue ampliamente cuestionada y coincidió con el ascenso de los defensores de los méritos del libre mercado. Al mismo tiempo, fue surgiendo un nuevo paradigma internacional, denominado "consenso de Washington"t. En el marco de dicho paradigma se hacía énfasis en medidas macroeconómicas de estabilización: reducción del déficit fiscal, control de la inflación, balance de las cuentas exteriores del Estado y pago de la deuda. El nuevo modelo económico tenía como objetivo estabilizar las debilitadas cuentas públicas y obtener recursos financieros para hacer frente a las obligaciones del Estado (Sunkel, 1991; Martínez Piva, 2001; Bulmer-Thomas, 1998; Ortiz, 2003; Moreno-Brid, Pérez-Caldentey y Ruíz-Nápoles, 2004).

Por su parte, la CEPAL propuso dar un giro importante en el modelo y promover el desarrollo desde dentro. Se trata de un "esfuerzo creativo interno por configurar una estructura productiva que sea funcional a las carencias y potencialidades específicas nacionales" (Sunkel, 1991, pág. 64). Esta estrategia no estaba necesariamente orientada a la demanda interna ni prejuzgaba en favor de la sustitución de importaciones. Más bien sostenía la relevancia de la industrialización desde dentro, para lo que era necesario establecer industrias pilares como núcleo endógeno que permitiera la generación, acumulación y difusión del progreso técnico. Se trataba de una propuesta con la que se intentaba superar las estrategias de desarrollo hacia adentro, así como las propuestas unilaterales de crecimiento hacia afuera. En Centroamérica, dicha propuesta se consagró en el principio de regionalismo abierto y coincidió con la suscripción del Protocolo de Tegucigalpa de 1991, por el que se creó el Sistema de la Integración Centroamericana (SICA). Según esta nueva estrategia, la integración centroamericana era compatible con la inserción internacional y podía contribuir a ese objetivo. Se consideraba que los mercados internacionales dinámicos podían proveer un impulso extra al sector productivo de la región.

Este surge a partir de contribuciones de la derecha liberal y de la escuela austríaca, el monetarismo, las expectativas racionales y la elección pública. En 1980, el Fondo Monetario Internacional (FMI) empezó a conceder préstamos de ajuste estructural que fueron modificados en 1986. En 1985, tuvo lugar una reunión de alto nivel entre el Banco Mundial y el FMI para que ambos organismos lideraran los ajustes que debían realizar los países altamente endeudados, siguiendo las directrices del denominado Plan Baker. El origen del término se debe a Williamson (1990). 


\section{Regionalismo abierto}

A mediados de la década de 1980, la región centroamericana se encontraba en una profunda crisis económica y política. Esta coincidía con cambios a nivel internacional sobre las políticas económicas dominantes, los paradigmas tecnológicos emergentes y la reorganización productiva.

Las propuestas del consenso de Washington encaminadas a sanear las economías se implementaron en Centroamérica a diferentes ritmos. Se subrayaba la necesidad de la apertura comercial y financiera, la desregulación de los mercados y la limitación de la acción del Estado en la actividad productiva con miras a sanear las cuentas públicas. Se puso énfasis en el control de la inflación y de las cuentas públicas, pero no se lograron acuerdos en temas como la necesidad de regulación y supervisión prudencial del sistema financiero, la secuencia de las reformas comerciales, la oportunidad de políticas de promoción de las exportaciones y otras políticas de incentivos a la industria, la agricultura y el desarrollo tecnológico, la estrategia de privatización ni la reforma laboral (CEPAL, 1995).

En la década de 1990 aparecieron acuerdos de diversa índole, alcance y configuración geográfica que permitían el comercio preferencial entre sus socios sin imponer necesariamente aranceles externos comunes ni el libre movimiento de mano de obra o capitales. Se consolidó la tendencia a la constitución de bloques comerciales que formaban ejes de producción y consumo. Dicha tendencia se reforzó con la integración de los países de Europa oriental a la cadena productiva occidental, al tiempo que Asia se constituía en otro bloque productivo. Esta forma de producción fue posible gracias a los cambios tecnológicos y las nuevas reglas comerciales: el abaratamiento relativo de los costos de transporte; la revolución tecnológica basada en la información, el conocimiento y la flexibilidad, y acuerdos comerciales y de inversión que favorecían la deslocalización productiva. En el marco de su adaptación a este entorno, los países centroamericanos acogieron favorablemente la propuesta del regionalismo abierto.

El nuevo panorama internacional ofreció oportunidades para superar las limitaciones que presentaba el modelo de industrialización por sustitución de importaciones y contribuyó a que se abriera un debate sobre cómo evitar la especialización en ramas de lento progreso técnico. El mercado intrarregional seguía siendo limitado y su dinamismo se estancó en la década de 1980, sobre todo en comparación con el tamaño y dinamismo de los mercados de países desarrollados. Para que los países de la región pudieran beneficiarse del dinamismo de los países desarrollados, debían aplicar una estrategia que conjugara, por una parte, el aprovechamiento del mercado regional (en el cual se comerciaban productos industriales, con una especialización productiva por país y redes de proveedores y encadenamientos creadas, y una institucionalidad que velaba por su funcionamiento) y, por otra, la mejora de la inserción internacional. 
La consolidación del mercado europeo y su proyecto de integración regional puso de relieve las ventajas que la integración podía aportar a sus miembros y cómo ese proceso podía ser funcional para su inserción internacional. El Tratado de Libre Comercio de América del Norte confirmó esa percepción y despertó cierto temor ante la aparición de bloques comerciales fragmentados de los que los países centroamericanos pudieran quedar aislados.

La región centroamericana vivía un replanteamiento de su integración económica y de su modelo de desarrollo, por lo que las ideas de la CEPAL sobre el regionalismo abierto vinieron a dar estructura y fundamento a sus propuestas. El regionalismo abierto permitió conciliar la interdependencia nacida de acuerdos especiales de carácter preferencial (como el proceso de integración centroamericano) con aquella impulsada por las señales del mercado resultantes de la liberalización comercial en general. Lo que se persigue con el regionalismo abierto es que las políticas explícitas de integración sean compatibles y complementen las políticas tendientes a elevar la competitividad internacional (CEPAL, 1994).

En el primer conjunto de medidas propuestas en el marco del regionalismo abierto se exigían compromisos con miras a la reducción gradual de la discriminación intrarregional y la estabilización macroeconómica. También se preveía la creación de mecanismos de pago y de facilitación de comercio, la construcción de infraestructura y la armonización de normas comerciales, regulaciones internas y estándares. Para aprovechar el dinamismo de la economía internacional se requerían acuerdos comerciales con terceros países, con condiciones de adhesión flexibles. Se promovía la conciliación de normas comerciales aprovechando las que surgían en el contexto multilateral, y se favorecía la inversión extranjera, dándole tratamiento nacional y amplias posibilidades de liberalización en términos de sectores (con listas negativas de bienes y servicios excluidos, a fin de establecer pocas excepciones).

Si bien se reconocía la heterogeneidad de los diversos compromisos integradores, el regionalismo abierto no descartaba la posibilidad de impulsar un proceso de integración que culminara con la constitución de una zona de libre comercio de alcance latinoamericano, y acaso hemisférico. Para llegar a esa meta era necesaria la estabilización macroeconómica y la creación de intereses comunes entre países y grupos de países. Todo esto facilitaría acuerdos de integración más amplios que multilateralizaran el proceso de integración.

Los países de Centroamérica acogieron el regionalismo como parte de su política de desarrollo, profundizaron su integración comercial y ampliaron las áreas del proceso de integración. Al mismo tiempo, liberalizaron su comercio, firmaron acuerdos comerciales con diversos socios extrarregionales y promovieron la inversión extranjera directa (véase el cuadro II.1). 


\section{Cuadro II.1 \\ Centroamérica: tratados de libre comercio vigentes y Organización Mundial del Comercio, 2017}

\begin{tabular}{|c|c|c|c|c|c|c|}
\hline & Costa Rica & El Salvador & Guatemala & Honduras & Nicaragua & Panamá \\
\hline $\begin{array}{l}\text { Asociación Europea } \\
\text { de Libre Comercio } \\
\text { (AELC) }\end{array}$ & $\begin{array}{l}\text { Agosto } \\
\text { de } 2014\end{array}$ & & $\begin{array}{l}\text { Julio de } \\
2015(F)\end{array}$ & & & $\begin{array}{l}\text { Agosto } \\
\text { de } 2014\end{array}$ \\
\hline Canadá & $\begin{array}{l}\text { Noviembre } \\
\text { de } 2002 \\
\text { (E.M.) }\end{array}$ & & & $\begin{array}{l}\text { Octubre } \\
\text { de } 2014\end{array}$ & & $\begin{array}{l}\text { Abril } \\
\text { de } 2013\end{array}$ \\
\hline $\begin{array}{l}\text { Comunidad del Caribe } \\
\text { (CARICOM) }\end{array}$ & $\begin{array}{l}\text { Noviembre } \\
\text { de } 2005^{\text {b }}\end{array}$ & & & & & \\
\hline Colombia & $\begin{array}{l}\text { Agosto } \\
\text { de } 2016\end{array}$ & $\begin{array}{l}\text { Febrero } \\
\text { de } 2010\end{array}$ & $\begin{array}{l}\text { Noviembre } \\
\text { de } 2009\end{array}$ & $\begin{array}{l}\text { Marzo } \\
\text { de } 2010\end{array}$ & & $\begin{array}{l}\text { Septiembre } \\
\text { de } 2013(F)\end{array}$ \\
\hline República de Corea & $\begin{array}{l}\text { Marzo de } \\
2017(F)\end{array}$ & $\begin{array}{l}\text { Marzo de } \\
2017(F)\end{array}$ & & $\begin{array}{l}\text { Marzo de } \\
2017(F)\end{array}$ & $\begin{array}{l}\text { Marzo de } \\
2017(F)\end{array}$ & $\begin{array}{l}\text { Marzo de } \\
2017(F)\end{array}$ \\
\hline Cuba & & & & & $\begin{array}{l}\text { Abril } \\
\text { de } 2014\end{array}$ & $\begin{array}{l}\text { Agosto } \\
\text { de } 2009\end{array}$ \\
\hline Chile y Centroamérica & $\begin{array}{l}\text { Febrero } \\
\text { de } 2002\end{array}$ & $\begin{array}{l}\text { Junio } \\
\text { de } 2002\end{array}$ & $\begin{array}{l}\text { Marzo } \\
\text { de } 2010\end{array}$ & $\begin{array}{l}\text { Julio } \\
\text { de } 2008\end{array}$ & $\begin{array}{l}\text { Octubre } \\
\text { de } 2012\end{array}$ & $\begin{array}{l}\text { Marzo } \\
\text { de } 2008\end{array}$ \\
\hline China & $\begin{array}{l}\text { Agosto } \\
\text { de } 2011\end{array}$ & & & & & \\
\hline Estados Unidos & & & & & & $\begin{array}{l}\text { Octubre } \\
\text { de } 2011\end{array}$ \\
\hline $\begin{array}{l}\text { República Dominicana, } \\
\text { Centroamérica y los } \\
\text { Estados Unidos }\end{array}$ & $\begin{array}{l}\text { Enero } \\
\text { de } 2009\end{array}$ & $\begin{array}{l}\text { Diciembre } \\
\text { de } 2004\end{array}$ & $\begin{array}{l}\text { Marzo } \\
\text { de } 2005\end{array}$ & $\begin{array}{l}\text { Abril } \\
\text { de } 2006\end{array}$ & $\begin{array}{l}\text { Octubre } \\
\text { de } 2005\end{array}$ & \\
\hline México & & & & & & $\begin{array}{l}\text { Julio } \\
\text { de } 2015\end{array}$ \\
\hline $\begin{array}{l}\text { México y } \\
\text { Centroamérica }\end{array}$ & $\begin{array}{l}\text { Julio } \\
\text { de } 2013\end{array}$ & $\begin{array}{l}\text { Septiembre } \\
\text { de } 2012\end{array}$ & $\begin{array}{l}\text { Septiembre } \\
\text { de } 2013\end{array}$ & $\begin{array}{l}\text { Enero } \\
\text { de } 2013\end{array}$ & $\begin{array}{l}\text { Septiembre } \\
\text { de } 2012\end{array}$ & \\
\hline $\begin{array}{l}\text { Organización Mundial } \\
\text { del Comercio (OMC) }\end{array}$ & $\begin{array}{l}\text { Mayo } \\
\text { de } 1995\end{array}$ & $\begin{array}{l}\text { Mayo } \\
\text { de } 1995\end{array}$ & $\begin{array}{l}\text { Julio } \\
\text { de } 1995\end{array}$ & $\begin{array}{l}\text { Enero } \\
\text { de } 1995\end{array}$ & $\begin{array}{l}\text { Septiembre } \\
\text { de } 1995\end{array}$ & $\begin{array}{l}\text { Septiembre } \\
\text { de } 1997\end{array}$ \\
\hline $\begin{array}{l}\text { Panamá y } \\
\text { Centroamérica }\end{array}$ & $\begin{array}{l}\text { Noviembre } \\
\text { de } 2008\end{array}$ & $\begin{array}{l}\text { Abril } \\
\text { de } 2003\end{array}$ & $\begin{array}{l}\text { Junio } \\
\text { de } 2009\end{array}$ & $\begin{array}{l}\text { Enero } \\
\text { de } 2009\end{array}$ & $\begin{array}{l}\text { Noviembre } \\
\text { de } 2009\end{array}$ & $\begin{array}{l}\text { Marzo } \\
\text { de } 2009\end{array}$ \\
\hline Perú & $\begin{array}{l}\text { Junio } \\
\text { de } 2013\end{array}$ & & $\begin{array}{l}\text { Diciembre } \\
\text { de } 2011 \mathrm{~F}\end{array}$ & $\begin{array}{l}\text { Enero } \\
\text { de } 2017\end{array}$ & & $\begin{array}{l}\text { Mayo } \\
\text { de } 2012\end{array}$ \\
\hline República Dominicana & & & & & & $\begin{array}{l}\text { Junio } \\
\text { de } 1987\end{array}$ \\
\hline $\begin{array}{l}\text { República Dominicana } \\
\text { y Centroamérica }\end{array}$ & $\begin{array}{l}\text { Marzo } \\
\text { de } 2002\end{array}$ & $\begin{array}{l}\text { Octubre } \\
\text { de } 2001\end{array}$ & $\begin{array}{l}\text { Octubre de } \\
2001\end{array}$ & $\begin{array}{l}\text { Diciembre } \\
\text { de } 2001\end{array}$ & $\begin{array}{l}\text { Septiembre } \\
\text { de } 2002\end{array}$ & \\
\hline Singapur & $\begin{array}{l}\text { Julio } \\
\text { de } 2013\end{array}$ & & & & & $\begin{array}{l}\text { Julio } \\
\text { de } 2006\end{array}$ \\
\hline Trinidad y Tabago & & $\begin{array}{l}\text { Octubre de } \\
2014(F)^{c}\end{array}$ & & & & $\begin{array}{l}\text { Julio } \\
\text { de } 2016\end{array}$ \\
\hline $\begin{array}{l}\text { Provincia china } \\
\text { de Taiwán }\end{array}$ & & $\begin{array}{l}\text { Enero } \\
\text { de } 2008\end{array}$ & $\begin{array}{l}\text { Julio } \\
\text { de } 2006\end{array}$ & $\begin{array}{l}\text { Julio } \\
\text { de } 2008\end{array}$ & $\begin{array}{l}\text { Enero } \\
\text { de } 2008\end{array}$ & $\begin{array}{l}\text { Enero } \\
\text { de } 2004\end{array}$ \\
\hline Unión Europea & $\begin{array}{l}\text { Octubre } \\
\text { de } 2013\end{array}$ & $\begin{array}{l}\text { Octubre de } \\
2013\end{array}$ & $\begin{array}{l}\text { Diciembre } \\
\text { de } 2013\end{array}$ & $\begin{array}{l}\text { Agosto } \\
\text { de } 2013\end{array}$ & $\begin{array}{l}\text { Agosto } \\
\text { de } 2013\end{array}$ & $\begin{array}{l}\text { Agosto de } \\
2013\end{array}$ \\
\hline
\end{tabular}

Fuente: Comisión Económica para América Latina (CEPAL) sobre la base de Organización de Estados Americanos (OEA), Sistema de Información sobre Comercio Exterior (SICE) [en línea] http://www. sice.oas.org/default_s.asp, y datos oficiales.

a Abreviaturas utilizadas en el cuadro: E.M. = en modernización; F = firmado.

b Tratado vigente con Barbados, Belice, Guyana, Jamaica y Trinidad y Tabago.

c Acuerdo de Alcance Parcial. 
En 1991, los países centroamericanos reafirmaron su voluntad de integración regional en un marco más abierto al comercio internacional. Suscribieron el Protocolo de Tegucigalpa, en el que se estableció y consolidó el Sistema de la Integración Centroamericana (SICA) ${ }^{5}$. Panamá se incorporó como Estado miembro y luego se adhirieron Belice y la República Dominicana, el primero como Estado miembro y el segundo como Estado asociado. Dos años más tarde, los países miembros suscribieron el Protocolo de Guatemala, en el que se comprometieron a alcanzar de manera voluntaria, gradual, complementaria y progresiva la Unión Económica Centroamericana. Además, el proceso de integración centroamericana se extendió a temas de políticas sectoriales ${ }^{6}$.

Como parte de la adopción de la política de regionalismo abierto, y el principio de voluntad expresado en el Protocolo de Guatemala, los participantes en el proceso de integración centroamericano no están obligados a firmar todos los acuerdos negociados, sino solo aquellos en que decidan participar 7 . Esta flexibilidad hizo que surgieran diversos ritmos de integración económica: algunos países han alcanzado acuerdos de unión aduanera y otros han conformado una región de libre comercio. La aplicación del regionalismo abierto también se ha visto plasmada en la firma de acuerdos bilaterales con terceros. Los países centroamericanos se adhirieron desde finales de la década de 1980 al Acuerdo General sobre Aranceles y Comercio (GATT) y luego pasaron a ser miembros de la Organización Mundial del Comercio (OMC), a mediados de la década de 1990. El primer socio con el que negociaron un tratado fue con México en la década de 1990. Todos lo hicieron por separado: Costa Rica en 1995, Nicaragua en 1998 y El Salvador, Honduras y Guatemala, en $2001^{8}$. Hacia 2017, han firmado bilateralmente diversos acuerdos y tratados comerciales con más de 12 países y grupos de países (véase el cuadro II.1) $)^{9}$ También han sido capaces de negociar y concluir acuerdos de modo conjunto con varios de sus principales socios

Esto fue resultado de la transformación de la Organización de Estados Centroamericanos (ODECA) creada en 1951. Su función principal sería dar seguimiento a las decisiones de la Reunión de Presidentes y coordinar su ejecución entre las diferentes instituciones regionales existentes.

6 A partir del Protocolo de Tegucigalpa, los países centroamericanos han firmado convenios generales, adoptado múltiples convenios sectoriales y emitido un gran número de mandatos específicos en diferentes áreas económicas, sociales y políticas.

7 Son ejemplo de ello la decisión de Panamá de excluirse de los acuerdos comerciales hasta 2012 y de participar solo en algunos acuerdos; la de Costa Rica de no formar parte del Parlamento Centroamericano (PARLACEN) ni de la Corte Centroamericana de Justicia, y la conformación de una unión aduanera entre Guatemala y Honduras en 2017.

8 Estos tres países conformaron en 1992 el Triángulo del Norte Centroamericano (TNCA) con el fin de acelerar la integración.

A pesar de que algunas negociaciones, como la del Tratado de Libre Comercio entre República Dominicana, Centroamérica y los Estados Unidos, el Canadá, Chile, México o la República de Corea se han realizado de manera conjunta, sus cláusulas se aplican de forma distinta para los países y otro tanto sucede con los calendarios de desgravación, la lista de productos sensibles, entre otros. 
extrarregionales (como los Estados Unidos y la Unión Europea, además de la sustitución de los acuerdos bilaterales con México por otro acuerdo de libre comercio único).

Como resultado de la activa integración de los países centroamericanos al comercio internacional, se incrementaron los flujos de inversión extranjera directa (IED) a la región. Estas corrientes fueron atraídas en gran medida por las privatizaciones de empresas estatales, la cercanía con el mercado de los Estados Unidos y las ganancias de eficiencia (asociadas a los bajos costos de producción). En este período se vivió un auge de los mecanismos de fomento de la industria manufacturera de exportación y maquiladora, como los regímenes de zonas francas y de perfeccionamiento activo que ofrecían condiciones fiscales y de infraestructura óptimas a la producción destinada a la exportación ${ }^{10}$. Además, a partir de grupos empresariales regionales creados durante la etapa de sustitución de importaciones, surgieron empresas transcentroamericanas que experimentaron una gran expansión desde los años noventa, pues aprovecharon el nuevo modelo de desarrollo, más abierto al comercio internacional (CEPAL, 2011).

En el período caracterizado por el regionalismo abierto, las exportaciones intrarregionales centroamericanas crecieron a un ritmo promedio del 13,8\% entre 1990 y 2007, mientras las exportaciones al resto del mundo lo hicieron al 8,7\%. La mayoría de las exportaciones intrarregionales siguieron siendo productos manufacturados a partir de recursos naturales y manufacturas de baja tecnología (un 53\% en 1990 y un 55\% en 2007). Las exportaciones al resto del mundo, sobre todo las dirigidas a los Estados Unidos, se componen principalmente de manufacturas. En algunos países, como Costa Rica, se trata de manufacturas de alto contenido tecnológico, aunque la mayor parte se confecciona en zonas francas. Los flujos de IED también aumentaron de forma significativa, pues pasaron de 216 millones de dólares anuales en promedio en la década de 1980 a 836 millones de dólares anuales en promedio en los años noventa, y 2.509 millones anuales en promedio entre 2000 y 2007.

En 1996, la CEPAL propuso que la integración económica contribuyera al proceso de transformación productiva. También indicó algunas líneas de política en los ámbitos de la inserción internacional, la articulación productiva y el fortalecimiento de la base institucional de la integración. De esta manera se incluyeron en la agenda regional algunas políticas orientadas al logro de una competitividad auténtica, al reforzamiento de la articulación productiva y a la interacción entre los agentes públicos y privados.

10 Este régimen aduanero permite el ingreso de mercancías en el territorio aduanero nacional con exoneración de toda clase de impuestos y con la condición de que los bienes sean reexportados, después de haberlos sometido a un proceso de transformación o ensamblaje. 


\section{2. ¿Una nueva relación centro-periferia?}

Las medidas adoptadas en Centroamérica a partir de la década de 1980, pero sobre todo en la de 1990, impulsaron la apertura comercial y financiera, promovieron la desregulación de los mercados y limitaron la participación del Estado en la actividad productiva. Se redujo la fuga de capitales nacionales y se incrementó la afluencia de capitales extranjeros atraídos por la apertura de la cuenta de capitales y los procesos de privatización. También se firmaron acuerdos de protección de la IED y la propiedad intelectual, con inclusión de áreas como las de las obtenciones vegetales y la protección de datos de prueba para medicamentos. De este modo la región se alineó con las tendencias de liberalización y protección de las inversiones de sus principales socios comerciales.

Las acciones públicas que más favorecieron la inserción internacional vinieron de la mano de la atracción de IED: incentivos fiscales en zonas francas que consolidaron a la región como plataforma exportadora; privatizaciones de empresas estatales, la mayoría de ellas creadas durante el proceso de sustitución de importaciones; apertura de la cuenta de capital y procesos de desregulación. El contexto global fue idóneo: se vivía una gran expansión de las empresas transnacionales y se iniciaba un notable proceso de deslocalización de la producción como parte de las estrategias empresariales y como consecuencia de los avances tecnológicos en las telecomunicaciones y transportes.

Los flujos de IED en Centroamérica se dirigen en gran medida a comprar activos existentes mediante fusiones y adquisiciones, sobre todo en el período 1990-2010. Las fusiones y adquisiciones llegaron a representar el 83\% del total de la IED en la región centroamericana en 2010. Esto respondía a una senda creciente desde la segunda mitad de la década de 1990, que pasó del 4\% en el período 1990-1994 al 30,2\% entre 1995 y 1999, y al 41,8\% en 2000-2004 y el 37,1\% en 2005-2010. Al menos en un primer momento, las fusiones y adquisiciones no suponen un incremento de la capacidad productiva. El ingreso del capital es el pago por un activo ya existente, aunque es común que la adquisición de activos conlleve procesos de reestructuración empresarial con miras a incrementar la productividad.

En la década de 1990, con la excepción de $1993^{11}$, se enajenaron esencialmente activos locales. Las operaciones de mayor envergadura fueron la venta de las empresas de servicios públicos que se traspasaron al sector privado (por ejemplo, la Empresa Eléctrica de Guatemala (EEGSA), la Tabacalera San Cristóbal en Honduras, la compañía de alumbrado ELEC, la Compañía de Telecomunicaciones de El Salvador y la Distribuidora de

${ }_{11}$ Debido al elevado importe de la compra de la filial de Chevron en Nicaragua por parte de Royal Dutch/Shell Group. 
Electricidad DELSUR, también de El Salvador). A partir de 2000, aunque con alguna irregularidad, tomó importancia la compra de activos localizados en Centroamérica y controlados por empresas extranjeras, muchos de ellos adquiridos en los años anteriores, en el marco de una reordenación de activos por parte de las transnacionales (Sánchez y Martínez Piva, 2014).

La recomposición de las inversiones a partir de 1990 ha contribuido a la subsistencia de gran parte de la industria desarrollada durante el período de industrialización sustitutiva de importaciones, así como al aumento de sus niveles de productividad y la modernización de su planta productiva, aunque ahora en manos de empresas transnacionales. Sumado a lo anterior, la IED que se estableció en la región para utilizarla como plataforma exportadora buscaba aprovechar sus bajos costos de producción. En la mayoría de los casos se trata de segmentos productivos de ensamblaje de escaso valor agregado. Esta recomposición productiva ha hecho que, en muchos casos, la región centroamericana desempeñe un papel como proveedora de insumos de bajo costo para las cadenas globales de valor. En otros, la región paga licencias y derechos de explotación y depende de los precios internacionales y de las decisiones tomadas en el extranjero.

Los cambios que han ido ocurriendo en la propiedad de los activos productivos, en la forma de generar y apropiarse del valor mediante la propiedad intelectual y en la forma de participar en las cadenas globales de valor sugieren la existencia de nuevos rasgos de las relaciones centro-periferia. Los países centroamericanos deben continuar sus esfuerzos por transformar su estructura productiva de modo que puedan transcender las relaciones de periferia que dificultan su desarrollo económico.

\section{El cambio estructural progresivo}

Los resultados económicos de Centroamérica en el período de regionalismo abierto (entre 1990 y 2007, el año anterior a la crisis económica mundial) muestran que la región aprovechó las tendencias favorables del contexto externo, expresadas en una mayor demanda internacional, así como un nivel más elevado de liquidez de los mercados financieros y deslocalización productiva. Entre 2000 y 2007, el crecimiento promedio de las exportaciones fue del 9,8\% y el de la IED, del 15\%. Esta situación tuvo un impacto en el crecimiento promedio anual del producto por habitante centroamericano, que alcanzó el 2,2\% en ese período.

Aunque la estructura productiva de la región centroamericana ha vivido cambios profundos en cuanto a la composición de su canasta exportadora y la naturaleza de los empleos generados, sigue arrastrando consigo viejos problemas característicos de las economías periféricas. La extracción de rentas se basa en la propiedad de los activos productivos, incluidos los pagos por 
el uso de la propiedad intelectual. Persiste una especialización en bienes y servicios de bajo valor agregado con escasa integración en el tejido productivo, así como una débil creación y difusión de nuevas tecnologías. También se mantienen niveles de productividad altamente heterogéneos; un elevado nivel de penetración de empresas transnacionales en el tejido productivo con escasa propensión a invertir en investigación, desarrollo e innovación, y una gran concentración de las exportaciones por destinos y por productos, lo que provoca un aumento de la vulnerabilidad a los choques externos (Bielschowsky, 2010; Sánchez y Martínez Piva, 2014). Como sostiene la CEPAL: "el cambio estructural deseable se define y evalúa en función de sus efectos agregados sobre el sistema económico. No hay cambio estructural virtuoso si meramente se multiplican enclaves de alta tecnología o si solo hay cambios en la punta más eficiente del sistema productivo" (CEPAL, 2012a, pág. 33).

El desarrollo de la región sigue incompleto y requiere un cambio en su estructura productiva. Es preciso reasignar recursos hacia sectores o actividades intensivas en conocimiento y en innovación tecnológica. También es necesaria la diversificación productiva hacia sectores y actividades que tengan un rápido crecimiento de la demanda, interna y externa, que pueda ser atendida con oferta interna, y que las exportaciones y las importaciones crezcan de forma equilibrada, sin crear presiones insostenibles sobre la balanza de pagos (CEPAL, 2012a).

El cambio estructural es un proceso gradual hacia una mayor productividad de los sectores existentes, así como un incremento de escala hacia sectores y procesos más complejos e intensivos en conocimientos. La CEPAL subraya que el cambio estructural es resultado de la innovación y el aumento de la productividad en sectores existentes. Añade que dicho cambio está asociado a ajustes de largo plazo en la composición de los sistemas económicos, lo que implica modificaciones significativas en el peso de diferentes sectores en términos de empleo, producción y comercio. Además, está asociado a la inserción exitosa en mercados globales de alto crecimiento, lo que conlleva el aumento de la demanda agregada, la actividad económica y la generación de empleo (CEPAL, 2012a).

A partir de la propuesta de promover una transformación productiva con equidad (CEPAL, 1996), la CEPAL ha promovido diversas ideas encaminadas a transformar la estructura productiva $\mathrm{y}$, al mismo tiempo, mejorar la equidad en las sociedades latinoamericanas. Sobre la base de estos conceptos, se ha impulsado un conjunto de ideas esenciales para acometer el cambio estructural progresivo. Dichas ideas se resumen en una propuesta de modelo de desarrollo que debería impulsar la política industrial del siglo XXI, el desarrollo de las cadenas de valor regionales, el incremento de la innovación y el valor agregado. También debería promover el desarrollo sostenible y la protección del medio ambiente, y colocar la igualdad en el centro de las acciones de política pública. 


\section{Política industrial en el siglo XXI}

Un balance del desarrollo alcanzado en las dos décadas previas a la crisis mundial de 2008 muestra que, a pesar del éxito con las exportaciones, Centroamérica registró pocos avances en materia de productividad (véase el gráfico II.1) o en su capacidad endógena de crear valor y promover las innovaciones. El valor agregado interno inducido por las exportaciones es muy bajo en países como Honduras, donde solo alcanza el 53,7\% (véase el capítulo IV). Los gastos en investigación y desarrollo tan solo alcanzan el 0,58\% del PIB en el caso más destacado de la región (Costa Rica) y apenas el 0,02\% en Honduras, situada en el otro extremo. Estos niveles son muy inferiores al promedio latinoamericano $(0,76 \%$ ) y al de la OCDE, del 2,38\% (véase el capítulo XII). Persiste en la región un modelo exportador basado en mano de obra de bajo costo que atrae inversiones orientadas al logro de la eficiencia y a las garantías de acceso a los mercados mediante acuerdos comerciales.

\section{Gráfico II.1}

Centroamérica y República Dominicana: productividad laboral con relación a la productividad laboral de los Estados Unidos, 1990-2016

(Estados Unidos=100)

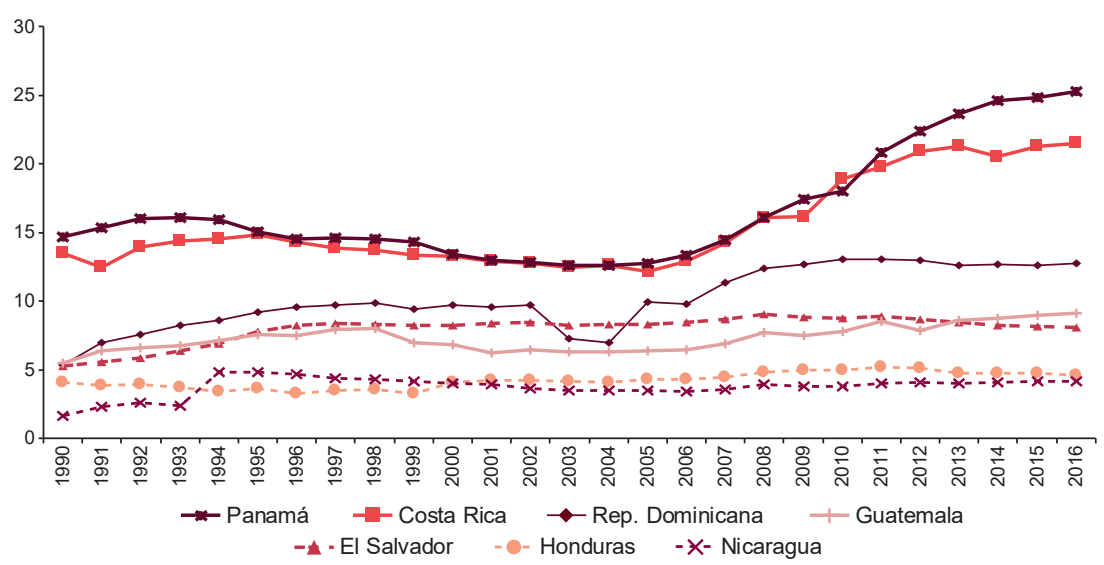

Fuente: Elaboración propia, sobre la base de datos oficiales.

La política industrial es un elemento central en la propuesta de la CEPAL para lograr un cambio estructural. En esta propuesta, publicada con motivo de su trigésimo cuarto período de sesiones (2012), se enfatiza la necesidad de avanzar hacia un cambio estructural que articule el desarrollo mediante la instrumentación de un nuevo conjunto integral de políticas públicas cuyo horizonte sea la igualdad. En ese sentido, la política industrial debe desempeñar un papel clave (CEPAL, 2012a). 
Las profundas transformaciones productivas y comerciales que ha vivido el mundo en las últimas décadas suelen resumirse en el concepto de globalización. Se basan en cambios que afectan el diseño de una nueva política industrial. Ello impone la necesidad de pensar en una política industrial para mercados abiertos en los que el conocimiento y la tecnología determinan en gran medida la capacidad de competir y de captar valor en las cadenas de producción globales y en la creación de nuevos sectores y empleos más productivos (CEPAL, 2012a).

Se entiende por política industrial la intervención del Estado para organizar y modificar la estructura y los sistemas de producción de su economía. Si bien originalmente el concepto se orientó a la creación de nuevas industrias en el sector secundario, en la actualidad se extiende a otros sectores como el primario y terciario. No obstante, el objetivo de densificar el tejido productivo de los países e incrementar la productividad sigue siendo fundamental. La política industrial consiste en un proceso dinámico en que el Estado aplica una serie de instrumentos encaminados a promover el desarrollo de actividades específicas o agentes económicos, sobre la base de las prioridades del desarrollo nacional (CEPAL, 2012a; Padilla Pérez y Alvarado, 2014).

Según afirma la CEPAL (2012b, pág. 243):

En América Latina y el Caribe, hay experiencias de diversos tipos de políticas industriales, que han sido resultado de los objetivos, la experiencia y las capacidades económicas e institucionales de cada país. En particular, se han concebido medidas que han ido desde la puesta en marcha de políticas sectoriales hasta la formulación de políticas horizontales, pasando por el fomento de los conglomerados productivos o cadenas productivas. Más aun, hay una creciente aceptación de la necesidad de desarrollar políticas de alcance sectorial, que hasta hace poco tiempo eran fuertemente resistidas en muchos países. Así, paulatinamente se ha reconocido que las políticas industriales son el núcleo de las estrategias de diversificación de la estructura productiva y de cambio estructural.

El reto que tiene el proceso de integración centroamericano es el de convertir los mercados de los países de la región en un mecanismo que impulse la demanda interna y contribuya a cambiar su patrón de especialización y su estructura productiva. En este sentido, la producción regional centroamericana y el comercio intrarregional intraindustrial pueden ser útiles para articular las demandas interna y externa, así como la capacidad de atenderlas mediante la producción local. "Una estructura productiva densa, con capacidad de innovación y tecnológicamente sofisticada, hace más factible que la producción local responda de manera dinámica a la expansión de las demandas interna y externa, y fortalece la especialización a partir de una base exportadora más diversificada" (CEPAL, 2012b, pág. 46). 
La estructura exportadora extrarregional ha hecho que surja un cierre o candado (lock-in) en una estructura productiva centrada en actividades poco intensivas en conocimiento, mientras que el comercio intrarregional se ha caracterizado por un mayor contenido tecnológico. Para superar ese candado se requiere impulsar el comercio intrarregional y las políticas orientadas a un cambio estructural progresivo. Es decir, habría que promover políticas industriales tendientes a crear nuevos sectores, sean manufactureros, primarios o de servicios, e incrementar la productividad y el valor agregado de los sectores existentes.

\section{El desarrollo de cadenas regionales de valor}

La deslocalización productiva ha permitido que distintas partes de un producto o servicio se realicen en diversos centros productivos dispersos por el mundo en busca de eficiencia. Centroamérica se insertó tempranamente en esta forma de producción a través de la maquila textil y de confección vinculada al mercado de los Estados Unidos. Sin embargo, se decantó por una oferta exportadora que ha hecho que la estructura productiva se especialice en actividades poco intensivas en conocimiento. Los países que han logrado una canasta exportadora con mayor participación de bienes o servicios de alto valor agregado (por ejemplo, dispositivos médicos, equipos electrónicos, servicios de salud) no han logrado articular dichas exportaciones con la producción local.

Las cadenas de valor globales comprenden todas las actividades que se requieren para hacer que un producto o servicio, desde su concepción, pase por las diversas fases o eslabones de la producción, hasta la entrega a los consumidores y la disposición final después de su uso (Kaplinsky y Morris, 2002). En cada fase se agrega valor al producto y, dependiendo de su grado de sofisticación y del conocimiento aplicado, así será el monto de valor agregado y la correspondiente remuneración al empleo. Las capacidades de los países, el tamaño de sus mercados internos, la normativa sobre importaciones y las reglas de acumulación de origen, entre otros elementos, condicionan el eslabón en que una economía se inserta en dichas cadenas.

El proceso de integración centroamericano ha facilitado la creación de cadenas de valor regionales en diversos sectores y la densificación del entramado productivo regional, lo que ha dado lugar a la conformación de redes centroamericanas de producción que ofrecen oportunidades de incremento de escala en la creación de valor a nivel regional. La CEPAL ha apoyado el análisis de dichos sectores con miras a encontrar los cuellos de botella que impiden su crecimiento y proponer políticas productivas regionales que permitan su fortalecimiento, con especial énfasis en la agregación de valor regional. En este contexto, la CEPAL diseñó una metodología para el fortalecimiento de las cadenas de valor regionales (véase el capítulo $\mathrm{V}$ ) y ha trabajado con diversas 
instancias de la integración en la identificación, análisis y presentación de propuestas de fortalecimiento. Con esta metodología se intenta promover el cambio estructural en la región, mediante la densificación de la estructura productiva regional, el incremento de la escala tecnológica y de valor, la promoción del mercado intraindustrial regional y el aprovechamiento de la demanda externa, que ha favorecido el establecimiento de una plataforma exportadora en Centroamérica.

\section{Innovación y valor agregado}

El desarrollo está asociado a una estructura productiva que muestra dos tipos de eficiencia dinámica, en el sentido de que representan trayectorias de más rápido crecimiento de la productividad, la producción y el empleo. La primera es la llamada "eficiencia schumpeteriana", dada por la presencia de sectores intensivos en conocimientos (con alta difusión de capacidades hacia el conjunto de la economía y que lideran el proceso de innovación) e incrementos de productividad, tanto internamente como en otros sectores. La segunda es la "eficiencia keynesiana" que se relaciona con el dinamismo de la demanda de los bienes producidos: si un país no produce bienes que tienen una demanda en rápido crecimiento, sus firmas no recibirán estímulos para elevar la inversión y la producción (CEPAL, 2012b).

El cambio estructural requiere niveles más altos de eficiencia dinámica (schumpeteriana y keynesiana). Para ello es fundamental que fortalezca sectores dinámicos desde el punto de vista tecnológico y de la demanda, ya que los aumentos de productividad sin un aumento paralelo de la demanda podrían provocar subocupación o desocupación (CEPAL, 2012b).

Ambas eficiencias incidirían en la composición de la producción e incrementarían su valor. Más allá de las dotaciones factoriales y las especificidades sectoriales, se reconoce que la especialización, la diferenciación de los productos y su valor están fundamentalmente determinados por la innovación y la calidad incorporadas. Los análisis de cadenas de valor muestran que es necesario transitar desde eslabones de bajo valor hacia los de mayor valor agregado. Esto solo se logra mediante la potenciación del recurso humano y el contenido tecnológico de los productos.

Un primer indicador para medir los esfuerzos orientados a la innovación a nivel agregado es el gasto en investigación y desarrollo (I+D), tanto en valores absolutos como en porcentajes del producto. La inversión mundial en investigación y desarrollo ha crecido sostenidamente, más del 40\% entre 1990 y 2003. Sin embargo, la región centroamericana sigue manteniendo niveles de gasto en I+D muy inferiores a los de países como los Estados Unidos o la República de Corea (3,1\% y 3,4\%, respectivamente). Los países de mayor gasto en ese rubro son los que poseen una estructura productiva más especializada 
en sectores de uso intensivo de tecnología y conocimientos. Dados los bajos niveles de inversión en I+D, el número de científicos y el volumen de patentes generadas en los países centroamericanos son también muy bajos.

Centroamérica debe hacer esfuerzos por incrementar el valor agregado de su producción y aumentar la escala en las cadenas de valor, y con ese fin necesita mejorar su capacidad de innovación. La CEPAL ha propuesto incidir desde la política pública sobre algunos factores con el fin de potenciar la innovación: elevar el gasto en actividades de investigación y desarrollo, mejorar la cooperación entre los agentes públicos y privados que realizan actividades de I+D y promover la cooperación regional para la innovación. Estos factores se desarrollan a continuación:

- Elevar el gasto en actividades de investigación y desarrollo: innovar es costoso y riesgoso, por lo que el acceso a financiamiento adecuado es de gran importancia. Para países pequeños como los centroamericanos es importante coordinar inversiones en I+D, emplear los recursos de la cooperación y de la banca de integración para financiar consorcios regionales y centrarse en áreas de interés regional en que existen políticas nacionales consolidadas.

- Mejorar la cooperación entre los agentes públicos y privados: el concepto de sistema nacional de innovación hace hincapié en que el progreso técnico es el resultado de la interacción entre los diversos agentes que crean, aplican, adaptan y mejoran las tecnologías, de manera que el nivel de innovación de cada país dependerá en gran medida del grado de cooperación que existe entre esos agentes. Existe un campo muy amplio para la aplicación de políticas orientadas a fortalecer las alianzas público-privadas con el fin de promover la innovación, teniendo presente que en este contexto las capacidades públicas y privadas de investigación son complementarias.

- La alianza público-privada es fundamental en la formulación e implementación de estrategias complejas y costosas. En países pequeños y en desarrollo, como los centroamericanos, las capacidades de investigación y desarrollo de productos suelen concentrarse en pocas instituciones, en su mayoría públicas, y algunas empresas privadas. El trabajo coordinado entre el sector público y privado permite aumentar su potencial individual para apoyar mecanismos que identifican oportunidades y restricciones y superan las principales fallas de mercado, así como las fallas derivadas de las políticas públicas de regulación y programas.

- La cooperación regional para la innovación: la integración de políticas a nivel regional no siempre es la solución más eficiente desde el punto de vista económico. No obstante, en los casos en que hay presencia potencial de economías de escala o externalidades gracias a la integración, y si de este modo se 
pueden coordinar eficientemente las políticas para crear beneficios regionales, entonces es conveniente formular una política regional. La integración regional es un mecanismo central que permite reducir la fragmentación de las iniciativas y aprovechar los recursos existentes. Una mayor integración permitiría lograr economías de escala y complementariedades en sectores en que hay una base sólida de conocimientos, instituciones y organizaciones. Las iniciativas deben partir de las capacidades existentes, con sistemas nacionales consolidados e intereses regionales comunes, como en el caso del sector agroproductivo. Este sector tiene una mayor solidez y concentra una parte significativa de la capacidad tecnológica de los países, por lo que las acciones conjuntas o coordinadas podrían tener un mayor impacto que las individuales y pequeñas (Padilla Pérez, 2012). Entre otras medidas que la región podría tomar en esta área, cabe mencionar la creación de un fondo regional que apoye la I+D y agrupe los recursos de la cooperación internacional, el establecimiento de consorcios público-privados, la coordinación de acciones con recursos nacionales disponibles y el fomento de las cadenas regionales de valor, entre otras (véase el capítulo XII).

\section{El desarrollo sostenible: un gran impulso ambiental}

Uno de los mayores retos a los que se enfrenta la humanidad es el cambio climático. Para superarlo, se requiere una respuesta colectiva y cambios profundos en el estilo de desarrollo actual. Los incentivos de ese desarrollo son tales que la contaminación se vuelve la estrategia dominante. Por ese motivo, la CEPAL concuerda con Nicholas Stern (Stern, 2006; CEPAL, 2016) al referirse a la contaminación y al cambio climático como la mayor falla de mercado de todos los tiempos. Por esta razón, los acuerdos internacionales orientados a cambiar el patrón de desarrollo han cobrado urgencia y las actuaciones regionales (como en Centroamérica) para hacer cambios en su modelo de desarrollo son de gran trascendencia.

El reto de diseñar un modelo de desarrollo sostenible requiere nuevas políticas productivas que a su vez abran nuevos espacios para la política pública y favorezcan el desarrollo económico. La necesidad de cambiar la matriz energética y el patrón de producción puede representar una oportunidad para implementar una nueva política industrial basada en un keynesianismo ambiental (CEPAL, 2016) en que los objetivos de pleno empleo y cuidado ambiental se armonicen en un bloque de inversiones con un sendero de crecimiento bajo en carbono. Esto, además, se alinea con los esfuerzos que realiza Centroamérica por cambiar su matriz energética (véase el capítulo IX). 
La política industrial necesaria para el desarrollo de la región centroamericana puede contribuir al surgimiento de nuevos sectores productivos si se aprovecha un gran impulso ambiental que estimule la innovación y el cambio estructural favorables al desacople de una economía basada en carbono. Las políticas en materia de ciencia y tecnología pueden crear las condiciones para el desacople entre crecimiento, empleo y emisiones. Una política industrial conjunta podría coordinar las economías y las inversiones regionales, mediante mecanismos de crédito y de inversiones públicas hacia sectores bajos en carbono, provocando un gran impulso (big push) ambiental.

Un modelo de desarrollo sostenible requiere alianzas públicas y coaliciones que lo sostengan e impulsen. En ese sentido, la región centroamericana puede avanzar, basada en sus instituciones nacionales y regionales, en la coordinación de políticas fiscales expansivas, la articulación de políticas ambientales, la coordinación de incentivos hacia una IED baja en carbono y el diseño de estándares ambientales regionales para los procesos productivos y normas ambientales para los productos de consumo, lo que contribuiría a la creación de una nueva matriz productiva e impulsaría nuevos sectores alineados con nuevas tendencias mundiales.

El desarrollo sostenible puede partir de un gran impulso ambiental regional que, con políticas industriales, promueva dos cosas. Por una parte, las capacidades y la competitividad de los sectores existentes con potencial de alinearse con una economía baja en carbono, incorporar progreso técnico y aprovechar el dinamismo de estos sectores a nivel global. Por otra, la creación de nuevos sectores de alta productividad, más sostenibles y eficientes. En suma, el desarrollo sostenible, además de ser un imperativo productivo, trae una oportunidad para el diseño de políticas industriales regionales que impulsen el crecimiento de Centroamérica.

\section{La igualdad en el centro de la propuesta de desarrollo}

La CEPAL ha señalado que la estrategia de desarrollo debe guiarse por la máxima de que la meta es la igualdad y el camino para lograrla es la transformación productiva (Bárcena, Bielschowsky y Torres, 2018). En línea con los objetivos de la integración centroamericana, orientada a construir una región de paz, libertad, democracia y desarrollo, la CEPAL ha indicado que la profundización de la democracia clama por una mayor igualdad de oportunidades y derechos. El valor de la igualdad es el corazón de la democracia. Esto supone hacer extensivas la participación y la deliberación pública a amplios sectores de la sociedad que se han visto secularmente marginados, pero también avanzar en cuanto a la efectiva titularidad de derechos económicos, sociales y culturales. La igualdad de derechos va más 
allá de la estructura meritocrática de las oportunidades y significa que la ciudadanía prescribe el pleno derecho de cada quien, por el solo hecho de ser parte de la sociedad e independientemente de sus logros individuales, a acceder a ciertos umbrales de bienestar social (Bárcena, Bielschowsky y Torres, 2018).

Los objetivos del Sistema de la Integración Centroamericana (SICA) coinciden con esta visión de la CEPAL. Se enfrenta el reto de crear instrumentos y mecanismos de colaboración regionales para alcanzarlos. La igualdad como meta sirve de guía a los pactos sociales a los que aspira la región centroamericana. Se trata de concertar acuerdos regionales en materia fiscal que contemplen una estructura y una carga tributaria con mayor efecto redistributivo, capaz de fortalecer el papel del Estado y la política pública de modo de garantizar umbrales de bienestar. Acuerdos regionales en materia ambiental que consideren el desarrollo de las futuras generaciones y que tengan que ver con la igualdad de oportunidades al inicio y en las trayectorias de los ciclos educativos y del empleo, así como en el acceso al bienestar material. Tales acuerdos también deberían promover la participación de todos en las decisiones y en el espacio público, así como la igualdad de oportunidades para acceder a los sistemas de justicia, a la seguridad ciudadana y a estilos de vida saludables, a múltiples fuentes de conocimiento e información y redes de apoyo social y de otra índole (CEPAL, 2010).

La región centroamericana puede impulsar y compartir experiencias sobre el diseño e implementación de políticas que procuren una sociedad más igualitaria, lo que a su vez consolidaría el cambio estructural progresivo y la estabilidad económica. El cambio estructural virtuoso requiere el desarrollo y fortalecimiento de instituciones económicas, sociales y públicas que aseguren el acceso a los factores de la producción, una mejor protección social y una amplia distribución de los frutos del progreso técnico, que prevengan su excesiva concentración e incrementen la productividad. Todo lo anterior conduce a una estructura distributiva orientada a la disminución de la desigualdad. La región puede avanzar de manera progresiva en la creación de los instrumentos y en la aplicación de políticas económicas que establezcan un piso de demanda agregada regional, la cual también constituiría un mecanismo anticíclico. Por otra parte, el acceso universal a la educación y la salud tendría un impacto positivo en la productividad regional.

La región de paz, libertad, democracia y desarrollo en que Centroamérica aspira a convertirse visualiza esas metas como bienes públicos regionales. La consolidación del aporte regional a esos objetivos y la puesta en marcha de estrategias y políticas nacionales con miras al cambio estructural progresivo deberán centrarse en la igualdad como requisito para alcanzarlas. 


\section{Los desafíos}

No obstante el éxito exportador de la región centroamericana y su favorable vinculación con mercados grandes y dinámicos a partir de la década de 1990, persisten grandes retos en materia de encadenamientos productivos y arrastre del resto de la economía. Las exportaciones a países desarrollados de mayor contenido industrial y tecnológico se concentran en las zonas francas, mientras que el resto de las exportaciones siguen siendo sobre todo de bienes primarios o de escaso valor agregado. La industrialización y el progreso técnico han llegado de la mano de las empresas exportadoras, muchas de ellas extranjeras, que deslocalizan parte de su producción en búsqueda de eficiencia, con poco impacto en el resto de la economía. La matriz de insumo-producto revela que los encadenamientos del sector exportador son débiles, sobre todo los de la industria manufacturera. Por ejemplo, en Costa Rica, los productos agrícolas y los servicios incorporan un alto valor agregado interno (el $80 \%$ y más del $90 \%$, respectivamente). Esto contrasta con las manufacturas de exportación, en las que el valor agregado importado es mucho más alto. Se destaca el sector de productos químicos, plásticos y de caucho, cuyas compras del exterior representan el 43,5\% de su valor agregado (Martínez Piva y Padilla, 2017).

La integración regional sigue siendo una opción relevante para promover el desarrollo conjunto. El comercio intrarregional tiene hoy un alto contenido industrial y es crecientemente intraindustrial, por lo que juega un papel destacado en el arrastre de otros sectores de la economía y como forma de inducir a la creación de empleos. Por esta razón, y de forma que representa un continuo en su pensamiento, la CEPAL ha alineado sus propuestas de desarrollo e integración económica con los objetivos del desarrollo sostenible, con miras a promover el crecimiento económico sostenido, inclusivo y sostenible, el empleo pleno y productivo y el trabajo decente para todos.

Es importante que la CEPAL, Centroamérica y sus instituciones reinterpreten el papel de la integración en un mundo donde han ido ocurriendo cambios tectónicos profundos (aumento de la importancia económica de Asia, digitalización, reto al liderazgo de los países que generaron el crecimiento desde la posguerra y a las instituciones multilaterales). La apuesta por un cambio estructural progresivo que tenga como metas el incremento de productividad, la diversificación, la modernización tecnológica y el aumento del valor añadido, en un marco de respeto al multilateralismo y a las reglas internacionales, conducirían al cumplimiento de las metas de los Objetivos de Desarrollo Sostenible y facilitarían el desarrollo económico y social de países pequeños como los centroamericanos. 


\section{Bibliografía}

Bielschowsky, R. (comp.) (2010), Sesenta años de la CEPAL: textos seleccionados del decenio 1998-2008, Buenos Aires, Comisión Económica para América Latina y el Caribe (CEPAL)/Siglo XXI.

Bárcena, A., R. Bielschowsky y M. Torres (2018), "El séptimo decenio de la CEPAL: una reseña de su producción intelectual", Desarrollo e igualdad: el pensamiento de la CEPAL en su séptimo decenio. Textos seleccionados del período 2008-2018, Colección 70 años, N 1 (LC/PUB.2018/7-P), R. Bielschowsky y M. Torres (comps.), Santiago, Comisión Económica para América Latina y el Caribe (CEPAL).

Bulmer-Thomas, V. (1998), La historia económica de América Latina desde la independencia, Ciudad de México, Fondo de Cultura Económica (FCE).

CEPAL (Comisión Económica para América Latina y el Caribe) (2016), Horizontes 2030: la igualdad en el centro del desarrollo sostenible (LC/G.2660/Rev.1), Santiago, julio. (2012a), Cambio estructural para la igualdad: una visión integrada del desarrollo. Sintesis (LC/G.2525(SES.34/4)), Santiago, agosto.

(2012b), Cambio estructural para la igualdad: una visión integrada del desarrollo (LC/G.2524(SES.34/3)), Santiago, julio.

(2011), La inversión extranjera directa en América Latina y el Caribe, 2010 (LC/G.2494-P), Santiago, junio.

(2010), La hora de la igualdad: brechas por cerrar, caminos por abrir. Sintesis (LC/G.2433(SES.33/4)), Santiago, mayo.

(2008), La transformación productiva 20 años después: viejos problemas, nuevas oportunidades. Sintesis (LC/G.2368(SES.32/4)), Santiago, junio.

(2007), La inversión extranjera directa en América Latina y el Caribe, 2006 (LC/G.2336-P), Santiago, mayo.

(2004), Desarrollo productivo en economias abiertas (LC/G.2234(SES.30/3)), Santiago, junio.

(1996), Transformación productiva con equidad: la tarea prioritaria del desarrollo de América Latina y el Caribe en los años noventa (LC/G.1601-P), Santiago, marzo. (1995), "Reformas económicas en América Latina: una síntesis de la experiencia en once países" (LC/R.1606), Santiago, diciembre.

(1994), El regionalismo abierto en América Latina y el Caribe: la integración económica al servicio de la transformación productiva con equidad, Libros de la CEPAL, N 39 (LC/G.1801/Rev.1), Santiago, septiembre.

Cimoli, M., G. Dosi y J. Stiglitz (eds.) (2009), Industrial Policy and Development: The Political Economy of Capabilities Accumulation, Oxford, Oxford University Press.

Cordero, M. (2017), "Integración económica centroamericana: base de datos 2016" (LC/MEX/TS.2017/24), Ciudad de México, Comisión Económica para América Latina y el Caribe (CEPAL), septiembre.

Cordero, M. y J. Martínez (2009), "Panamá y el proceso de integración centroamericana" (LC/MEX/L.946), Ciudad de México, Comisión Económica para América Latina y el Caribe (CEPAL), diciembre.

Fajnzylber, F. (1983), La industrialización trunca de América Latina, Ciudad de México, Editorial Nueva Imagen.

(1990), Industrialización en América Latina: de la "caja negra" al "casillero vacío", Cuadernos de la CEPAL, N 60 (LC/G.1534/Rev.1-P), Santiago, Comisión Económica para América Latina y el Caribe (CEPAL), agosto. 
Ffrench-Davis, R. (1988), "Esbozo de un planteamiento neoestructuralista", Revista CEPAL, N 34 (LC/G.1521-P), Santiago, Comisión Económica para América Latina y el Caribe (CEPAL), abril.

Giner, S. (1984), Historia del pensamiento social, Barcelona, Editorial Ariel.

Govaere, V. (2017), “Prolegómenos de procesos e impactos de los tratados de libre comercio de Costa Rica", tesis de doctorado en derecho, San José, Universidad Estatal a Distancia (UNED), diciembre.

Guerra-Borges, A. (1996), “El sistema regional de pagos en Centroamérica 1961-1992 y la cooperación financiera de la Comunidad Europea", Managua, Coordinadora Regional de Investigaciones Económicas y Sociales (CRIES) [en línea] http:/ / www.obela.org/system/files/SistPagosMCCA1961-92.doc.

Kaplinsky, R. y M. Morris (2002), A Handbook for Value Chain Research, Brighton, Universidad de Sussex.

Krugman, P. (1997), Desarrollo, geografía y teoría económica, Barcelona, Antoni Bosch.

Martínez, J. (2011), “La estructura teórica centro/periferia y el análisis del sistema económico global: ¿obsoleta o necesaria?", Revista de Economía Mundial, № 29, Huelva, Sociedad de Economía Mundial.

Martínez Piva, J. y R. Padilla (2017), "Política industrial y cambio estructural en Costa Rica", Políticas industriales y tecnológicas en América Latina (LC/TS.2017/91), Santiago, Comisión Económica para América Latina y el Caribe (CEPAL), noviembre.

Martínez Piva, J. (2015), "Política industrial en el siglo XXI", Estrategias empresariales, política industrial y competitividad en las mipymes, M. López (coord.), Ciudad de México, Pearson.

(2001), "El desarrollo local en América Latina", Revista de Comercio Exterior, vol. 51, $\mathrm{N}^{\circ}$ 8, Ciudad de México, Banco Nacional de Comercio Exterior (Bancomext), agosto.

Moreno-Brid, J., E. Pérez-Caldentey y P. Ruíz-Nápoles (2004), “The Washington consensus: a Latin American perspective fifteen years later", Journal of Post Keynesian Economics, vol. 27, N², Hoboken, Taylor and Francis.

Ortiz, G. (2003), "Latin America and the Washington Consensus: overcoming reform fatigue", Finance and Development, vol. 40, N³, Washington, D.C., Fondo Monetario Internacional (FMI), septiembre.

Padilla, R. (ed.) (2013), Sistemas de innovación en Centroamérica: fortalecimiento a través de la integración regional, Libros de la CEPAL, N 118 (LC/G.2559-P), Santiago, febrero.

Padilla, R. y J. Alvarado (2014), "El resurgimiento de la política industrial", Fortalecimiento de las cadenas de valor como instrumento de la política industrial: metodología y experiencia de la CEPAL en Centroamérica, R. Padilla (ed.), Libros de la CEPAL, N 123 (LC/G.2606-P), Santiago, Comisión Económica para América Latina y el Caribe (CEPAL).

Pellandra, A. y J. Fuentes (2011), "El estado actual de la integración en Centroamérica", serie Estudios y Perspectivas - sede subregional de la CEPAL en México, $\mathrm{N}^{\circ} 129$ (LC/L.3360 - LC/MEX/L.1017), Ciudad de México, Comisión Económica para América Latina y el Caribe (CEPAL), agosto.

Pinto, A. (1970), "Naturaleza e implicaciones de la 'heterogeneidad estructural' de la América Latina”, Trimestre Económico, vol. 37, N 1, Ciudad de México, Fondo de Cultura Económica (FCE), enero-marzo.

Prebisch, R. (1969), "La marcha hacia el mercado común latinoamericano", La Nación, Buenos Aires, 13 y 14 de junio. 
(1958), "Exposición del Dr. Raul Prebisch, director principal a cargo de la Secretaría Ejecutiva de la CEPAL en la Sesión Inaugural, el día 3 de febrero de 1958", Documento de Sala de Conferencia, N $^{\circ}$, Santiago, Comisión Económica para América Latina y el Caribe (CEPAL), febrero.

Salazar, J. (1990), "Presente y futuro de la integración centroamericana", Revista CEPAL, N 42 (LC/G,1642-P), Santiago, Comisión Económica para América Latina y el Caribe (CEPAL), diciembre,

Sánchez, A. y J. Martínez Piva (2014), “Centroamérica: ¿una nueva relación centroperiferia basada en el control de los activos productivos?", Documentos de Proyectos (LC/W.578), Santiago, Comisión Económica para América Latina y el Caribe (CEPAL), marzo.

Stern, N. (2006), The Economics of Climate Change: The Stern Review, Nueva York, Cambridge University Press.

Sunkel, O. (1991), "Del desarrollo hacia adentro al desarrollo desde dentro", El desarrollo desde dentro: un enfoque neoestructuralista para la América Latina, Ciudad de México, Fondo de Cultura Económica (FCE).

Williamson, J. (1990), Latin American Adjustment: How Much Has Happened?, Washington, D.C., Institute of International Economics. 



\title{
Capítulo III \\ Evolución del comercio de Centroamérica
}

\author{
Martha Cordero Sánchez \\ Jorge Mario Martínez Piva
}

\section{Introducción}

A lo largo del proceso de integración centroamericano, el pensamiento de la Comisión Económica para América Latina y el Caribe (CEPAL) ha promovido la aplicación de diversas estrategias comerciales en los países de la región. En los primeros años de creación del Mercado Común Centroamericano (MCCA), la CEPAL fomentó la aplicación de una política sustitutiva de importaciones y el impulso al comercio intrarregional mediante la consolidación de un aparato productivo nacional. Sin embargo, después de la crisis interna centroamericana y de los shocks petroleros de los años setenta, la CEPAL apoyó una mayor apertura al mercado internacional, la atracción de inversión extranjera directa (IED) y una integración regional flexible y gradual. Por último, tras la crisis económica de 2008 y 2009, la CEPAL se replanteó la estrategia de desarrollo propuesta desde una perspectiva de mayor inclusión e igualdad y sobre la base de una mejor inserción internacional.

El reciente pensamiento de la CEPAL enfatiza que no basta con identificar los rubros de mayor demanda, sino que hay que construir capacidades productivas, humanas y tecnológicas que permitan alcanzar un posicionamiento competitivo en mercados más dinámicos y en productos y servicios de mayor 
valor agregado e incorporación tecnológica. ¿Hasta qué punto ha reflejado el comercio intrarregional centroamericano los cambios en el pensamiento de la CEPAL? ¿Ha logrado el comercio intrarregional ayudar a los países centroamericanos a insertarse mejor en el mercado internacional? ¿Tiene el comercio intracentroamericano mayor valor agregado y mayor contenido industrial? Estas son algunas de las interrogantes que se responden en este capítulo, dividido en tres partes de acuerdo con la historia del pensamiento de la CEPAL y de la integración económica centroamericana.

\section{A. El comercio centroamericano durante el período de sustitución de importaciones y fomento de la industrialización}

Entre los años 1960 y 1980, el pensamiento de la CEPAL se pronunció por el fomento a la industrialización mediante la sustitución de importaciones externas. La idea era que Centroamérica reemplazara algunos de los bienes adquiridos externamente por productos de la región, política que implementaron la mayoría de los países centroamericanos ${ }^{1}$. En 1960, más del 80\% de las importaciones de Costa Rica, Guatemala y Nicaragua ${ }^{2}$ provenían de los Estados Unidos y de Europa. La creación del MCCA y la puesta en marcha de sus diferentes instrumentos promovieron la sustitución de esas importaciones por compras intrarregionales ${ }^{3}$.

En el gráfico III.1 se observa cómo Costa Rica, Guatemala y Nicaragua redujeron el peso de los Estados Unidos y Europa en su comercio, al mismo tiempo que aumentó la participación de los países del MCCA. En el eje vertical de las matrices incluidas en este gráfico se ha medido el cambio en la participación de las importaciones entre 1960 y 1979, mientras que en el eje horizontal se mide el cambio en la participación de las exportaciones durante el mismo período. En todos los casos se observa que los mercados de los Estados Unidos y Europa se ubican en el cuadrante inferior izquierdo, lo que implica una reducción de la participación de ambos mercados tanto en las importaciones como en las exportaciones de Costa Rica, Guatemala y

\footnotetext{
En este capítulo, al referirse a Centroamérica, se incluyen los seis países de la región: Costa Rica, El Salvador, Guatemala, Honduras, Nicaragua y Panamá. Cuando se refiere al Mercado Común Centroamericano (MCCA) se incluyen solo los primeros cinco países, excluido Panamá, que vino a incorporarse al Sistema de Integración Económica Centroamericano el 29 de junio de 2012. Sin embargo, a lo largo del capítulo se intenta referirse a Centroamérica para incluir la evolución de todos los países del Sistema, excepto cuando la información estadística disponible no lo permita. Países sobre los que existe esta información desde 1960.

El MCCA fue creado en 1960 por Costa Rica, El Salvador, Guatemala, Honduras y Nicaragua.

Véase más información sobre su creación e instrumentos en el capítulo I de este libro.
} 
Nicaragua. La mayor reducción de importaciones desde los Estados Unidos se observa en Nicaragua, que redujo en 44 puntos porcentuales sus compras desde ese país en 1979, con respecto a 1960. En el caso de Europa, tanto Guatemala como Nicaragua redujeron 15 puntos porcentuales sus compras desde ese mercado en igual período.

\section{Gráfico III.1 \\ Costa Rica, Guatemala y Nicaragua: variación de la participación de socios seleccionados en su comercio total de bienes, 1960-1979 \\ (En puntos porcentuales)}

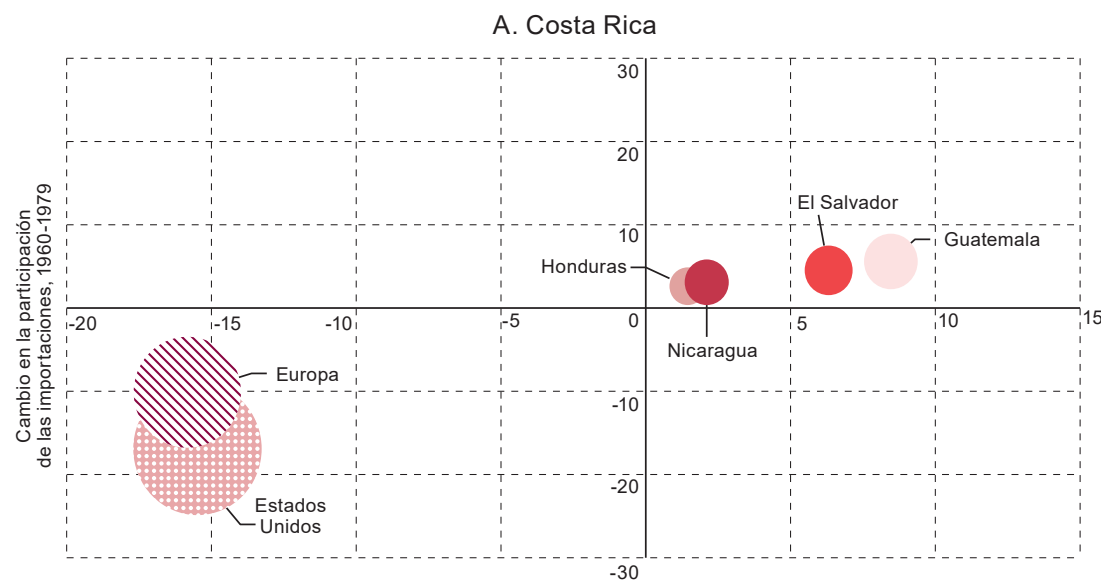

Cambio en la participación de las exportaciones, 1960-1979

B. Guatemala

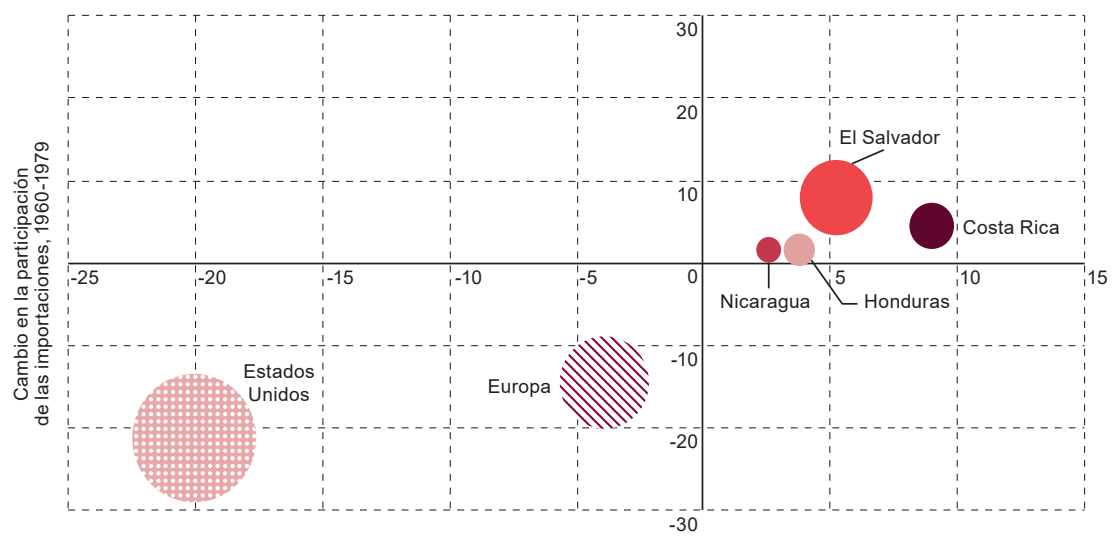

Cambio en la participación de las exportaciones, 1960-1979 
Gráfico III.1 (conclusión)

C. Nicaragua

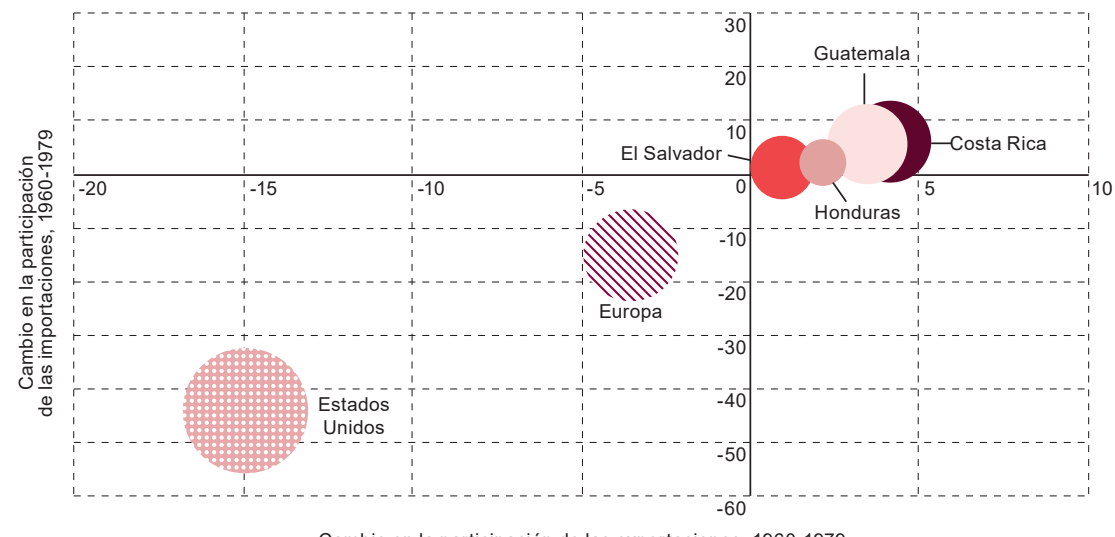

Fuente: Comisión Económica para América Latina y el Caribe (CEPAL) sobre la base de información del Consejo Monetario Centroamericano (CMCA).

Nota: El tamaño de los círculos corresponde a la importancia porcentual de esos países en el comercio de Costa Rica, Guatemala y Nicaragua.

Por el contrario, todos los mercados del MCCA se ubican en el cuadrante superior derecho, lo que implica un aumento de su participación tanto en las exportaciones como en las importaciones de Costa Rica, Guatemala y Nicaragua durante el período objeto de estudio. En el caso de Costa Rica, los mayores incrementos de sus importaciones desde el MCCA se observan en Guatemala y El Salvador, con un cambio de 6 y 5 puntos porcentuales, respectivamente. En el caso de Guatemala, sus mayores aumentos se registraron en El Salvador (8 puntos porcentuales) y Costa Rica (5 puntos porcentuales). Por último, en Nicaragua, sus mayores cambios se registraron en importaciones desde Guatemala y Costa Rica (ambos con un aumento de 6 puntos porcentuales).

Este cambio en el comercio centroamericano condujo a un aumento de las exportaciones intrarregionales, sobre todo durante la primera década de este período, como se observa en el gráfico III.2. En 1960, las exportaciones destinadas al mercado intracentroamericano representaron el 6,7\% del total de las ventas del MCCA, la participación más baja de la historia del MCCA. Sin embargo, para 1969, esas exportaciones representaron el 25,5\% del total exportado por los países del grupo. Entre 1960 y 1969, las exportaciones intrarregionales crecieron a un ritmo del $27 \%$ como promedio anual. Esto es cuatro veces más que las extrarregionales, que crecieron a un ritmo promedio anual del 6\% en el mismo período. No obstante, en la década de 1970, el ritmo de crecimiento y la participación de las exportaciones intrarregionales disminuyeron como resultado de la situación económico-política en el seno del MCCA, la situación económica mundial y las alzas del precio del petróleo. 
Entre 1970 y 1979, la tasa de crecimiento de las exportaciones intrarregionales fue menor que la de las extrarregionales ( $14 \%$ y $18 \%$, respectivamente), lo que hizo que el peso de las primeras se redujera a un 19\% en 1979.

Gráfico III.2

Mercado Común Centroamericano: evolución de las exportaciones intra- y extrarregionales, 1960-1979

(En porcentajes con respecto al total exportado)

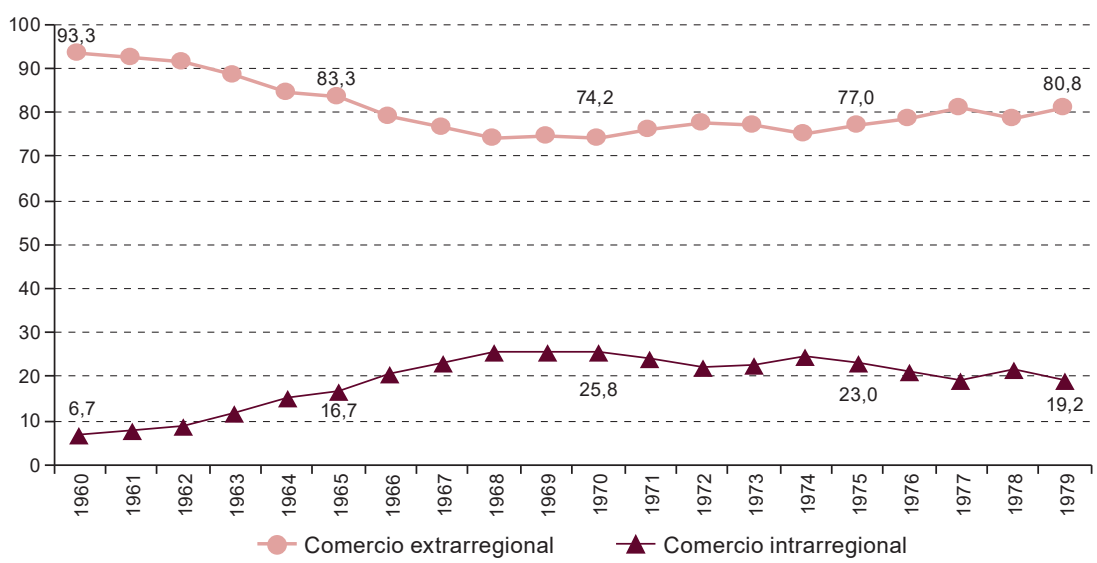

Fuente: Comisión Económica para América Latina y el Caribe (CEPAL), sobre la base de información del Consejo Monetario Centroamericano (CMCA).

A inicios de la década de 1960, las exportaciones de los países centroamericanos hacia terceros mostraban una alta concentración en unos pocos productos, sobre todo primarios: café, banano, carne, azúcar, algodón, mariscos, harina de pescado, cardamomo, madera y algunos metales, entre otros. De acuerdo con las estadísticas disponibles, en la década de 1970, cerca del $68 \%$ de las exportaciones totales del MCCA correspondían a productos primarios. Pese a la pérdida de dinamismo del comercio intrarregional en los años setenta, al final del período de la política sustitutiva de importaciones, los países centroamericanos habían logrado diversificar parcialmente sus mercados y productos de exportación. La mayor diversificación hacia bienes manufacturados se observó en el MCCA, donde las manufacturas llegaron a representar el 95\% del comercio intrarregional en $1978^{4}$.

En el gráfico III.3 se puede observar el peso de las exportaciones de materias primas y productos alimenticios en el total de las exportaciones de cada uno de los países centroamericanos. Honduras y Panamá eran los países de mayor concentración de sus exportaciones en ese tipo de bienes

Este es el primer año en que se tiene referencia estadística sobre el porcentaje de importaciones intrarregionales manufactureras. 
en 1970. Sin embargo, para 1979 ambos habían disminuido ese porcentaje por efecto del incremento de sus exportaciones de productos manufacturados. De manera similar, Costa Rica aumentó el porcentaje de sus exportaciones manufactureras. El Salvador y Guatemala siguieron siendo los países con mayor peso de exportaciones de productos manufacturados, aun cuando durante el decenio 1970-1979 vieron aumentar ligeramente el peso de las materias primas y los productos alimenticios en sus ventas externas.

\section{Gráfico III.3}

\section{Mercado Común Centroamericano: composición de las exportaciones totales, 1970 y 1979}

(En porcentajes con respecto al total exportado)

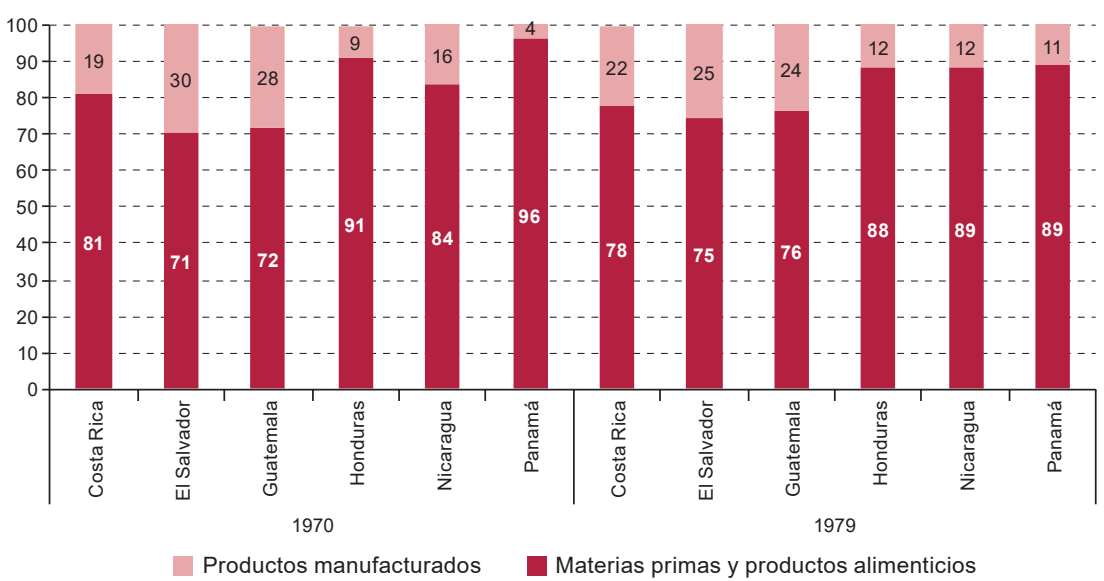

Fuente: Comisión Económica para América Latina y el Caribe (CEPAL), sobre la base de información del Consejo Monetario Centroamericano (CMCA).

De acuerdo con la información disponible sobre el período estudiado, en 1958 el 57,5\% del comercio intrarregional estaba compuesto por productos de la industria manufacturera. En ese año, los principales cinco tipos de productos que se intercambiaban dentro del MCCA eran los alimenticios elaborados (16,4\% del total intrarregional); los textiles (5,2\%); los productos de madera y corcho, excepto muebles $(4,3 \%)$; la construcción de maquinaria y equipos (3,8\%), y las prendas de vestir $(3,4 \%)$.

Para 1970 y 1980, el peso de los productos manufactureros había aumentado a más del $90 \%$ del total intercambiado entre los miembros del MCCA. En ese último año los principales cinco productos comercializados fueron las prendas de vestir $(14,8 \%)$, los productos químicos y cosméticos $(13,7 \%)$, las sustancias químicas industriales $(8,6 \%)$, los productos alimenticios elaborados $(7,6 \%)$ y el papel y sus productos $(4,5 \%)$. Todas esas industrias siguen siendo hasta la fecha las más importantes en el comercio intrarregional. 
Los cambios ya reseñados en la estructura exportadora de Centroamérica, en la diversificación de sus mercados y en la mayor importancia del mercado intrarregional coadyuvaron a mantener un ritmo similar en la dinámica de sus exportaciones e importaciones hasta mediados de la década de 1970. En 1960, el valor de las importaciones de bienes de los países del MCCA era ligeramente superior al de sus exportaciones de bienes (498 millones de dólares y 439 millones de dólares, respectivamente). Este cuasi equilibrio en el comercio de mercancías se mantuvo a lo largo del período 1960-1979, en consonancia con el pensamiento de la CEPAL de implementar políticas tendientes a reducir las importaciones y sustituirlas por productos centroamericanos. Solamente en 1974, como consecuencia del alza del precio del petróleo en 1973, y en 1978 y 1979, a inicios de la crisis económica de la década de 1980, el valor de las importaciones del MCCA superó el equilibrio mostrado durante las dos primeras décadas del proceso de integración (véase el gráfico III.4).

Gráfico III.4

Mercado Común Centroamericano: evolución de las exportaciones e importaciones totales, 1960-1979

(En millones de dólares)

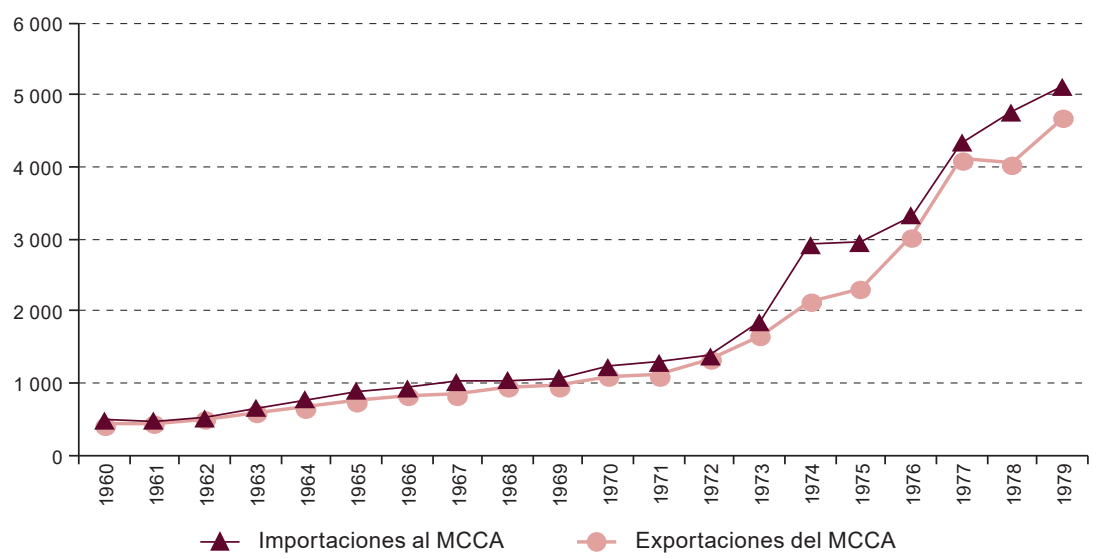

Fuente: Comisión Económica para América Latina y el Caribe (CEPAL), sobre la base de información de la Secretaría de Integración Económica Centroamericana (SIECA) y del Consejo Monetario Centroamericano (CMCA).

Los ajustes realizados en materia de política comercial permitieron a los países del MCCA mantener un saldo comercial estable y cercano al equilibrio durante los primeros años del MCCA, como se observa en el gráfico III.5. Sin embargo, a partir de la década de 1980, período que la CEPAL denominó la década perdida, se incrementó el déficit comercial, sobre todo a partir de la apertura comercial de la década de 1990. 
Gráfico III.5

Mercado Común Centroamericano: evolución de la balanza

comercial de bienes, 1960-2017

(En millones de dólares)

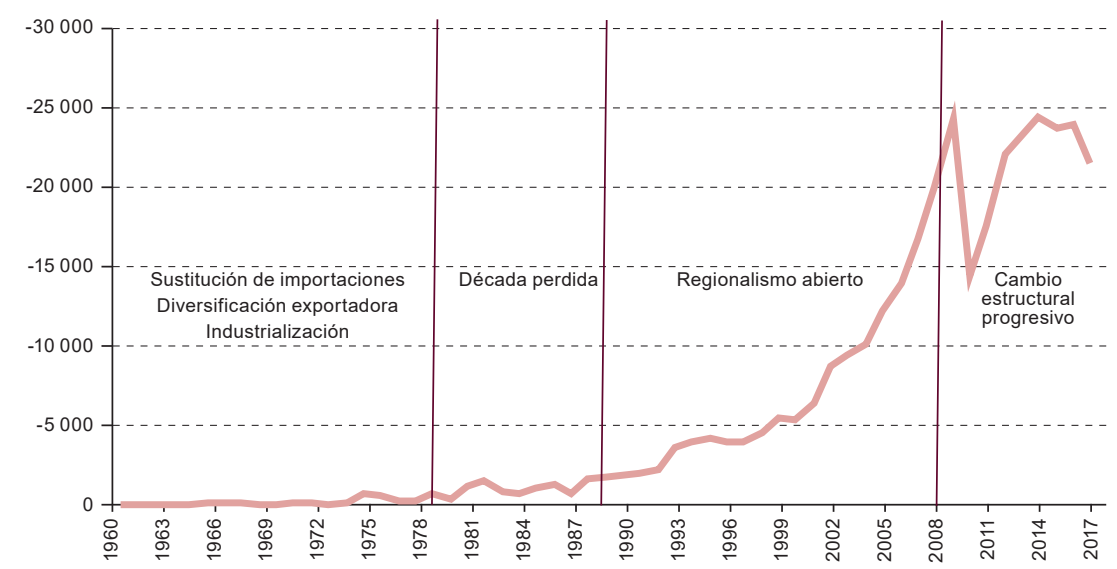

Fuente: Comisión Económica para América Latina y el Caribe (CEPAL), sobre la base de información de la Secretaría de Integración Económica Centroamericana (SIECA) y del Consejo Monetario Centroamericano (CMCA).

Debido a que uno de los objetivos de la aplicación de la política sustitutiva de importaciones era la creación de una masa empresarial nacional, durante este período se protegió a la industria nacional de los competidores internacionales, lo que incluyó la protección de las nuevas industrias mediante regulaciones restrictivas de la IED. En este período también se crearon empresas públicas que actuaron a menudo en régimen de monopolio en sectores clave, como los del transporte, las telecomunicaciones y la energía. Por esas razones, las empresas transnacionales que se fueron estableciendo en Centroamérica lo hicieron para acceder al mercado nacional y regional (el Mercado Común Centroamericano), más que para crear vinculaciones con el aparato productivo nacional o aumentar la eficiencia de sus procesos productivos. Lo anterior explica los bajos flujos de IED que llegaron a Centroamérica hasta comienzos de los años noventa (véase el gráfico III.6).

En resumen, las acciones llevadas a cabo y los resultados obtenidos a fines de la década de 1960 permiten concluir que los países centroamericanos aplicaron exitosamente las recomendaciones de política de sustitución de exportaciones, diversificación exportadora e industrialización, sobre la base de la consolidación de un aparato productivo nacional. 
Gráfico III.6

Centroamérica: flujos de inversión extranjera directa, 1960-2016

(En millones de dólares corrientes)

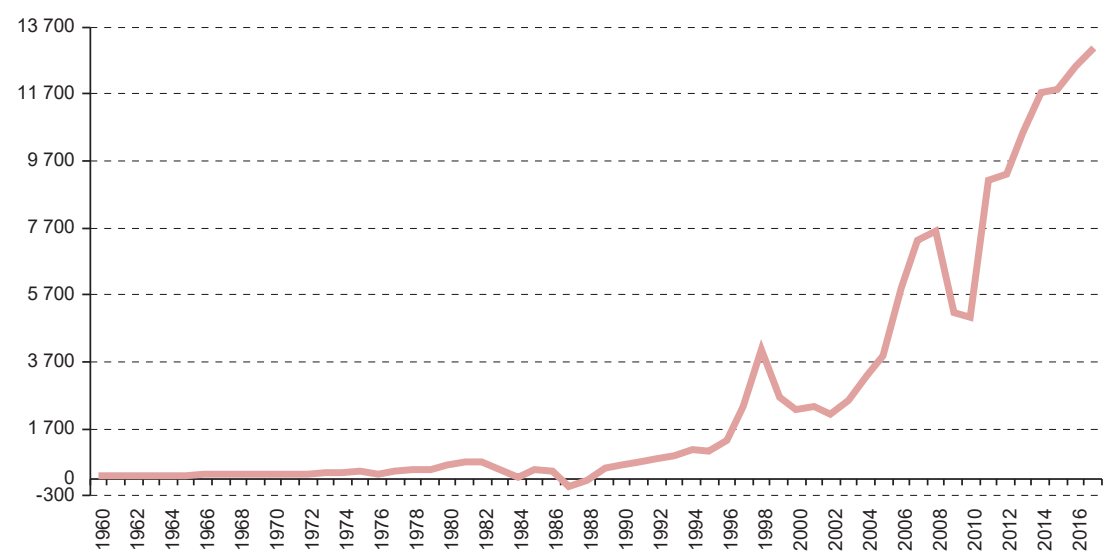

Fuente: Comisión Económica para América Latina y el Caribe (CEPAL), sobre la base de datos oficiales.

\section{B. El comercio centroamericano, de la crisis al regionalismo abierto}

El período de 1980 a 1989 se distinguió por la caída del valor del comercio centroamericano, sobre todo del intrarregional. Como se observa en el gráfico III.7, el peso de este último en las exportaciones totales centroamericanas se redujo de forma paulatina entre 1980 y 1986, para luego repuntar levemente en los últimos cuatro años de esa década, sin alcanzar los niveles de 1980. De 1980 a 1989, el valor de las exportaciones totales centroamericanas cayó a una tasa promedio del $-1,7 \%$ anual. Las exportaciones extrarregionales cayeron en menor medida que las intrarregionales $(-0,5 \%$ anual y $6,3 \%$ anual, respectivamente), por lo que aumentó su participación en las exportaciones totales. Mientras que en 1980 las ventas extrarregionales representaban el $76,8 \%$ de las ventas totales centroamericanas, en 1986 su peso llegó al 89,7\% del total. En tanto, las exportaciones intrarregionales disminuyeron su participación del 23,2\% al 10,3\% durante el mismo período.

Durante la década de 1980, Centroamérica (y, en general, toda América Latina) enfrentó una ralentización económica debido a la disminución de los precios y del consumo de sus principales materias primas de exportación. Además, el incremento de las tasas de interés hizo que aumentara el costo del servicio de la deuda externa, lo que dejó a los países en una situación económicamente delicada. Por otra parte, surgieron nuevos conflictos políticos y sociales en Centroamérica, todo lo cual contribuyó a configurar lo que la CEPAL denominó la década perdida. 
Gráfico III.7

Mercado Común Centroamericano: evolución del comercio

intra- y extrarregional, 1980-1989

(En porcentajes con respecto al total exportado)

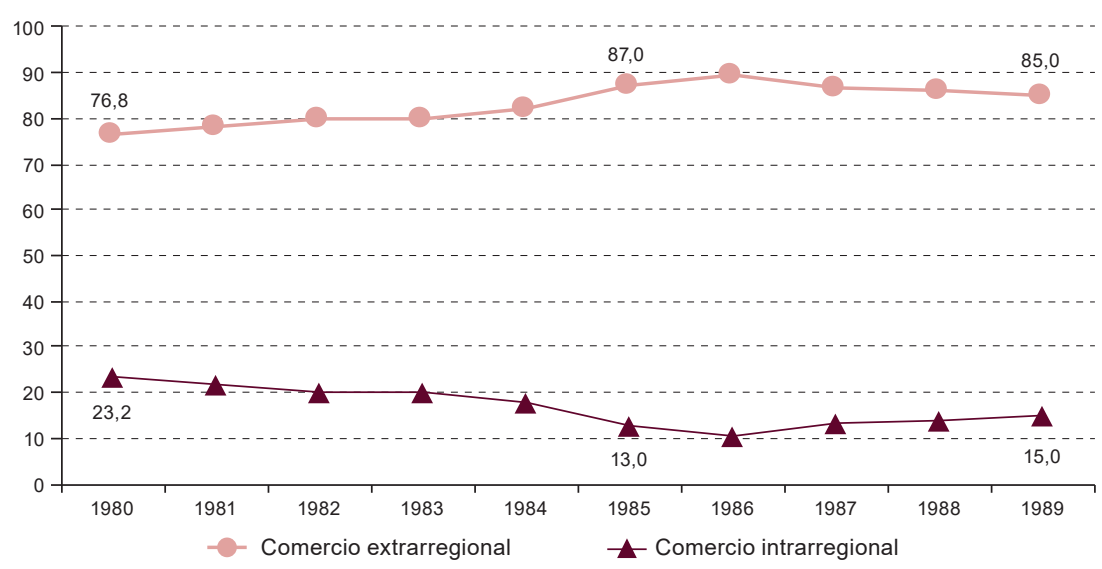

Fuente: Comisión Económica para América Latina y el Caribe (CEPAL), sobre la base de información de la Secretaría de Integración Económica Centroamericana (SIECA).

En un intento por salir de la crisis, la CEPAL propuso la aplicación de una política de regionalismo abierto al inicio de la década de $1990^{5}$. De esa forma se intentaba lograr un equilibrio entre la política externa y la política regional. Al mismo tiempo que los países se abrían al mercado internacional, se les recomendaba continuar con sus políticas de integración económica regional de forma flexible, gradual y progresiva, a fin de alcanzar sus objetivos iniciales de integración y tener un contrapeso frente a la volatilidad del mercado internacional. En seguimiento al pensamiento de la CEPAL de las décadas de 1960 y 1970, se recomendaba seguir reforzando las políticas de industrialización, pero haciendo hincapié en la competitividad productiva y de los mercados. Mediante esta nueva política se buscaba incursionar competitivamente en los mercados internacionales y utilizar el comercio intrarregional como primer paso antes de su mayor internacionalización.

La primera acción de apertura económica que llevaron a cabo los países centroamericanos fue su adhesión a la Organización Mundial del Comercio (OMC). Esta dio continuidad al Acuerdo General sobre Aranceles Aduaneros y Comercio (GATT), al que los países centroamericanos se habían adherido previamente y en cuyo marco se había registrado su proceso de integración económico regional en la década de 1960. La mayoría de los países centroamericanos se adhirieron a la OMC en 1995, año en que esta comenzó a funcionar.

5 Véase más información sobre el regionalismo abierto en los capítulos I y II de este libro. 
El ingreso a la OMC marcó el inicio de una política unilateral de apertura económica en la que se observaría una notable reducción de los aranceles centroamericanos. Como se aprecia en el gráfico III.8, en 1995 el arancel promedio de los países del MCCA era de un $10 \%$ ad valorem. Un año después, este promedio bajaría a un $9 \%$ y seguiría su descenso progresivo, con algunos altibajos. Después de la firma del Tratado de Libre Comercio entre República Dominicana, Centroamérica y los Estados Unidos en 2004, el promedio del arancel externo de los países del MCCA bajó a niveles inferiores al $6 \%$. Esta cifra se estabilizaría alrededor del 5,7\%, en promedio, tras la firma del Acuerdo de Asociación entre Centroamérica y la Unión Europea en 2012.

\section{Gráfico III.8 \\ Mercado Común Centroamericano: evolución del arancel ad valorem promedio de nación más favorecida, 1995-2016 \\ (En porcentajes)}

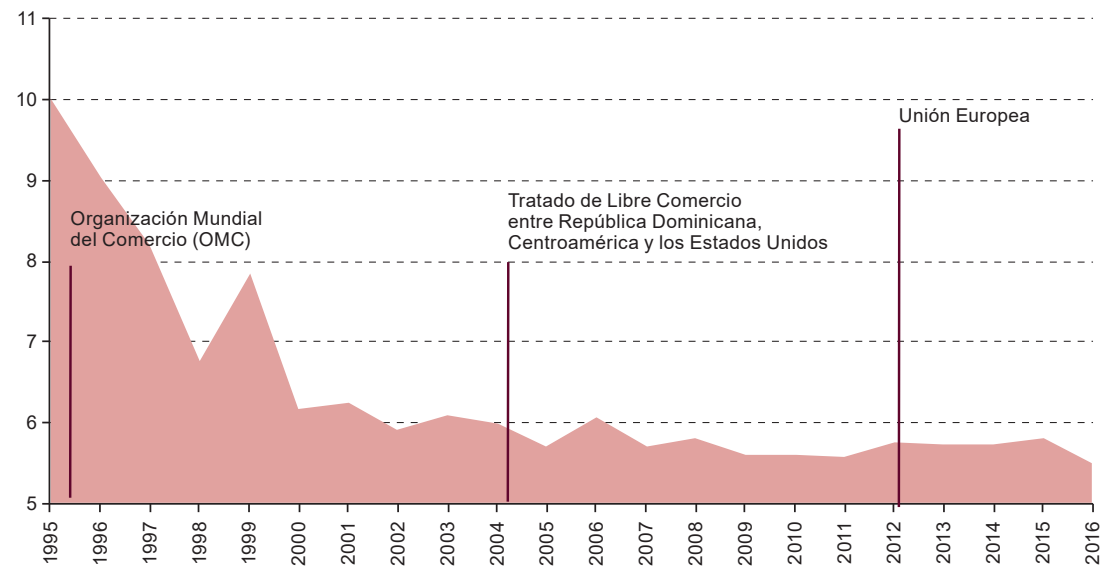

Fuente: Comisión Económica para América Latina y el Caribe (CEPAL), sobre la base de información del Banco Mundial.

De forma paralela a la apertura unilateral, los países centroamericanos buscaron la firma de acuerdos preferenciales con sus principales socios comerciales tradicionales y con otros socios emergentes, sobre todo de Asia. Ya a finales de la década de 1980, algunos países de Centroamérica firmaron varios acuerdos de complementación económica con países latinoamericanos, en el marco de la Asociación Latinoamericana de Integración (ALADI). En 1994, México firmó un tratado de libre comercio con Costa Rica y, en 1998, otro con Nicaragua 6 . Sin embargo, su mayor inserción en el comercio internacional se inició en 1995 con su adhesión a la OMC.

Posteriormente, México renegoció todos los tratados de libre comercio que había suscrito con los países centroamericanos en la década de 1990. Con el nuevo tratado México-Centroamérica, suscrito en 2011, se unificaron todos los tratados bilaterales previos, además de modernizarse las normativas, tanto en comercio de bienes como de servicios. 
En ese último año, los países del MCCA también firmaron un tratado de libre comercio con la República Dominicana de forma bilateral ${ }^{7}$. En 1999 firmaron otro con Chile. En 2000, El Salvador, Guatemala y Honduras suscribieron un tratado similar con México; en 2001, Costa Rica con el Canadá; en 2002, los países del MCCA con Panamá (y en 2004, con los Estados Unidos y la República Dominicana); en 2005, Costa Rica con la Comunidad del Caribe (CARICOM) y Guatemala con la provincia china de Taiwán; en 2006, Guatemala con Belice, Nicaragua con la provincia china de Taiwán y Panamá con Chile y Singapur, y en 2007, El Salvador, Guatemala y Honduras con Colombia, y Panamá con los Estados Unidos. En el gráfico III.9 se observa la acumulación de estos acuerdos desde 1995 y hasta la primera mitad de 2018. En el período caracterizado por el regionalismo abierto, los países centroamericanos firmaron más del $50 \%$ del total de acuerdos que tienen hasta la fecha.

Gráfico III.9

Centroamérica: número de acuerdos de libre comercio suscritos, 1995-2018 (Suma del número de acuerdos firmados)

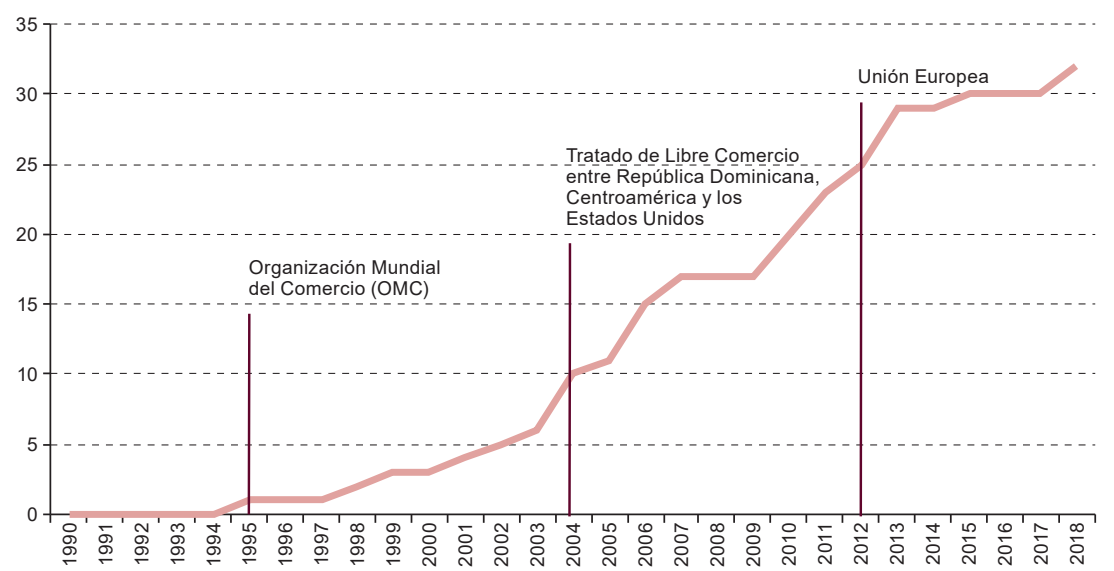

Fuente: Comisión Económica para América Latina (CEPAL), sobre la base de información del Sistema de Información sobre Comercio Exterior (SICE) de la Organización de los Estados Americanos (OEA) e información oficial.

La apertura comercial unilateral de los países centroamericanos, junto con su mayor apertura mediante la firma de acuerdos bilaterales, se reflejó en la reactivación de su comercio exterior e intrarregional. Entre 1994 y 2007, las exportaciones totales centroamericanas crecieron a una tasa promedio anual del 10\%, como se observa en el gráfico III.10. Sin embargo, las importaciones crecieron en mayor medida durante el mismo período, a una tasa promedio anual del 11\%. La diferencia en las dinámicas entre ambos flujos trajo consigo un

Aunque las negociaciones se llevaron a cabo de manera conjunta, cada uno de los países del MCCA firmaron acuerdos específicos con la República Dominicana. Este tipo de negociación sería recurrente en todos los acuerdos negociados, a excepción del acuerdo firmado con la Unión Europea, de bloque económico a bloque económico. 
aumento del déficit comercial de los países centroamericanos, como se observa en el gráfico III.5. De este modo, en la etapa de regionalismo abierto, el crecimiento del déficit comercial fue constante y llegó a los 24.455 millones de dólares en 2007.

Gráfico III.10

Centroamérica: evolución de las exportaciones e importaciones, 1994-2007 (En millones de dólares y tasas promedio anuales de variación)

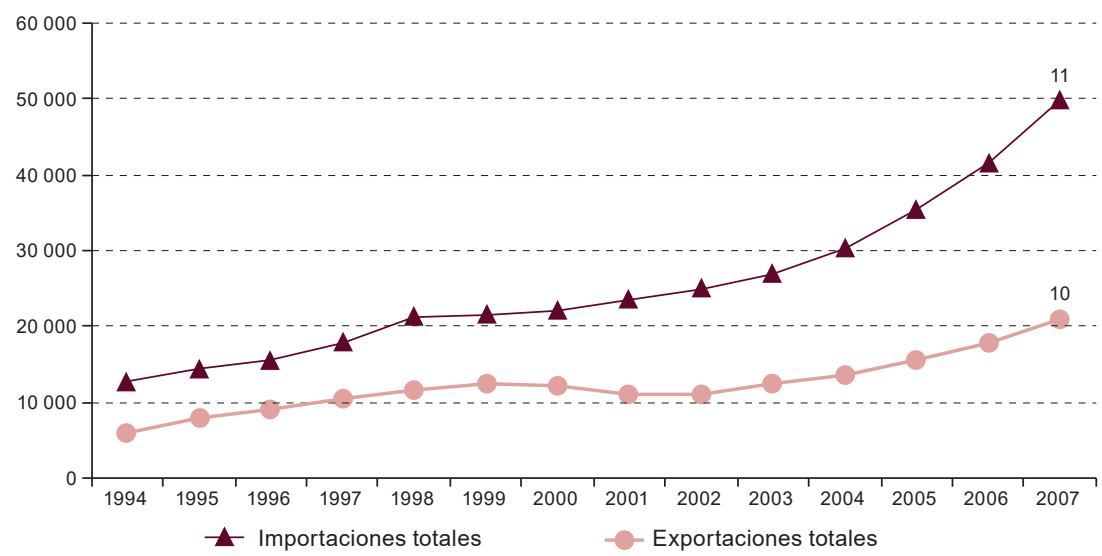

Fuente: Comisión Económica para América Latina y el Caribe (CEPAL), sobre la base de información de la Secretaría de Integración Económica Centroamericana (SIECA).

La mayor apertura comercial de los países centroamericanos durante el período de regionalismo abierto se puede observar también en la evolución de su índice de apertura. Este muestra la proporción de la suma de las exportaciones e importaciones de bienes y servicios de cada país, con respecto a su producto interno bruto (PIB). Como se aprecia en el gráfico III.11, en 1990 todos los países del MCCA mostraban un índice de apertura comercial inferior al 80\%, siendo el más alto el de Honduras (77\%). En 2007, este índice rebasó el 100\% en Honduras y en todos los otros países del MCCA se incrementó de manera importante con respecto a 1990. En el caso de Panamá, esta apertura fue aún mayor, lo que refleja la importancia del comercio de bienes y servicios en su economía. En 2007, su índice de apertura llegó a 146 puntos porcentuales, el mayor de toda Centroamérica.

En materia de competitividad exportadora (entendida como la capacidad de incrementar la participación en mercados determinados), los países centroamericanos buscaron incrementar su presencia en varios mercados internacionales, al mismo tiempo que trataban de comerciar productos con mayor demanda en esos mercados. Sin embargo, su participación en el mercado mundial disminuyó durante el período de regionalismo abierto con respecto a la que se observaba antes de $1980^{\circ}$. En efecto, mientras que en 1977 la participación de Centroamérica en las importaciones mundiales

\footnotetext{
8 Se refiere a la proporción que representan las importaciones provenientes de los países
} centroamericanos en las importaciones totales de cada uno de los mercados a los que se hace referencia. 
de bienes alcanzó el 0,4\%, desde 1987 se ha mantenido en un 0,3\% (véase el gráfico III.12). La misma tendencia se observó en el mercado de los países industrializados, en el que la participación centroamericana en el total de sus importaciones bajó del 3\% en 1977 al 1,3\% en 1997 y al 0,7\% en 2007.

Gráfico III.11

Centroamérica: índice de apertura comercial, 1990, 1995 y 2007 (En porcentajes del PIB)

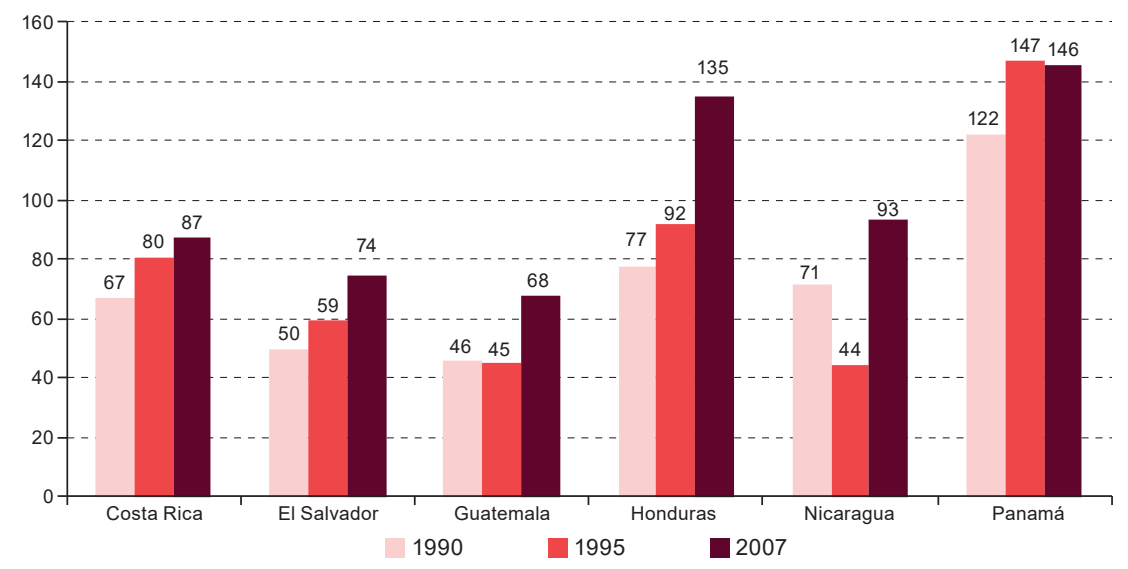

Fuente: Comisión Económica para América Latina y el Caribe (CEPAL), sobre la base de Banco Mundial, Solución Comercial Integrada Mundial (WITS); Conferencia de las Naciones Unidas sobre Comercio y Desarrollo (UNCTAD); Comisión de Estadística de las Naciones Unidas; Organización Mundial del Comercio (OMC) y Centro de Comercio Internacional UNCTAD/OMC.

\section{Gráfico III.12}

\section{Centroamérica: participación de mercado en las importaciones de mercados seleccionados, 1977, 1987, 1997, 2007 y 2017}

(En porcentajes)

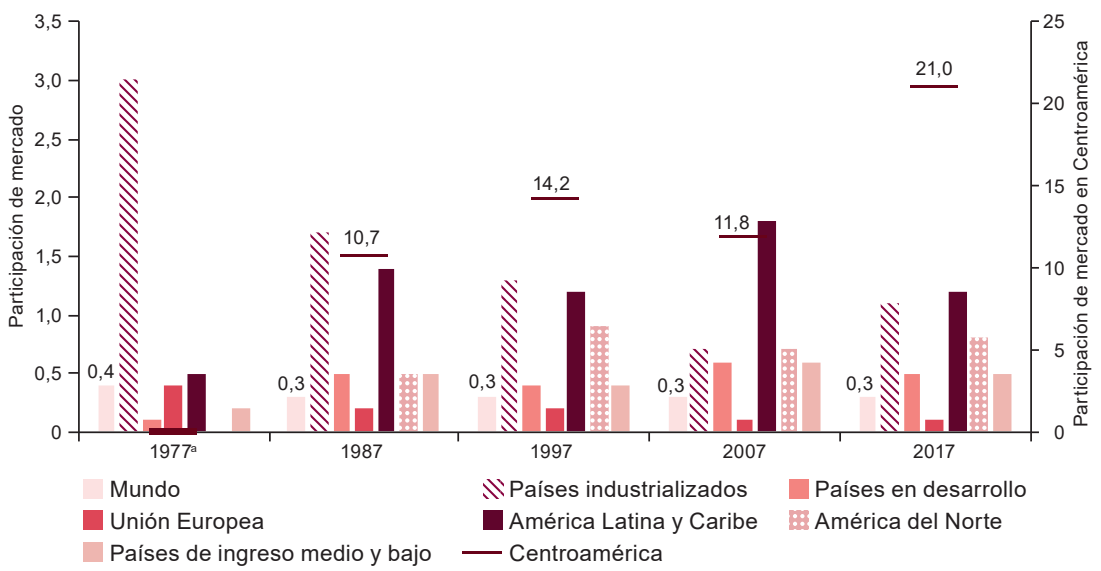

Fuente: Comisión Económica para América Latina y el Caribe (CEPAL), base de datos para el análisis de la competitividad de los países (TradeCAN).

a No hay datos referentes a Centroamérica en 1977. 
Por el contrario, la participación de mercado centroamericana se incrementó en los países en desarrollo, sobre todo en los demás países de América Latina y el Caribe, así como en el propio mercado centroamericano. En América Latina, se incrementó en más de 1 punto porcentual, mientras que su participación en las importaciones centroamericanas se ubicó, en promedio, alrededor de los 13 puntos porcentuales.

Respecto a los productos centroamericanos comercializados a nivel mundial, se observa un cambio entre 1990 y 2007. En el primer año, el 55\% de los bienes centroamericanos exportados eran productos alimenticios $\mathrm{y}$ animales vivos, seguidos por los artículos manufacturados diversos (13\% del total) y la maquinaria y equipo de transporte (9\%). Para 2007, los artículos manufacturados diversos se convirtieron en el principal producto de exportación centroamericano con el 32\% del total, seguidos por los productos alimenticios y animales vivos (cuya participación se redujo al $26 \%$ del total) y la maquinaria y equipo de transporte (18\% del total). Este cambio de la estructura exportadora se puede ver en el gráfico III.13, donde también se refleja la menor concentración en una sola clase de productos debido a una mayor diversificación productiva. No obstante, más del 75\% de las exportaciones centroamericanas siguieron concentrándose en los tres primeros sectores productivos en 1990 y 2007.

Gráfico III.13

\section{Principales productos de importación desde Centroamérica y análisis de competitividad exportadora, 1990 y 2007 (En porcentajes)}

\section{A. Competitividad exportadora de Centroamérica}

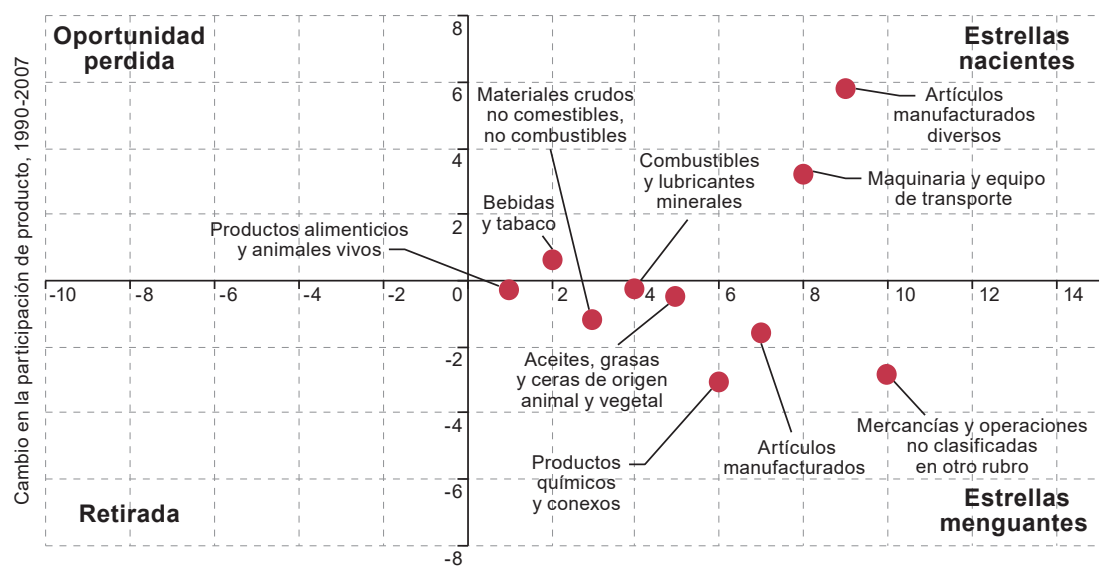


Gráfico III.13 (conclusión)

B. Principales productos de importación desde Centroamérica

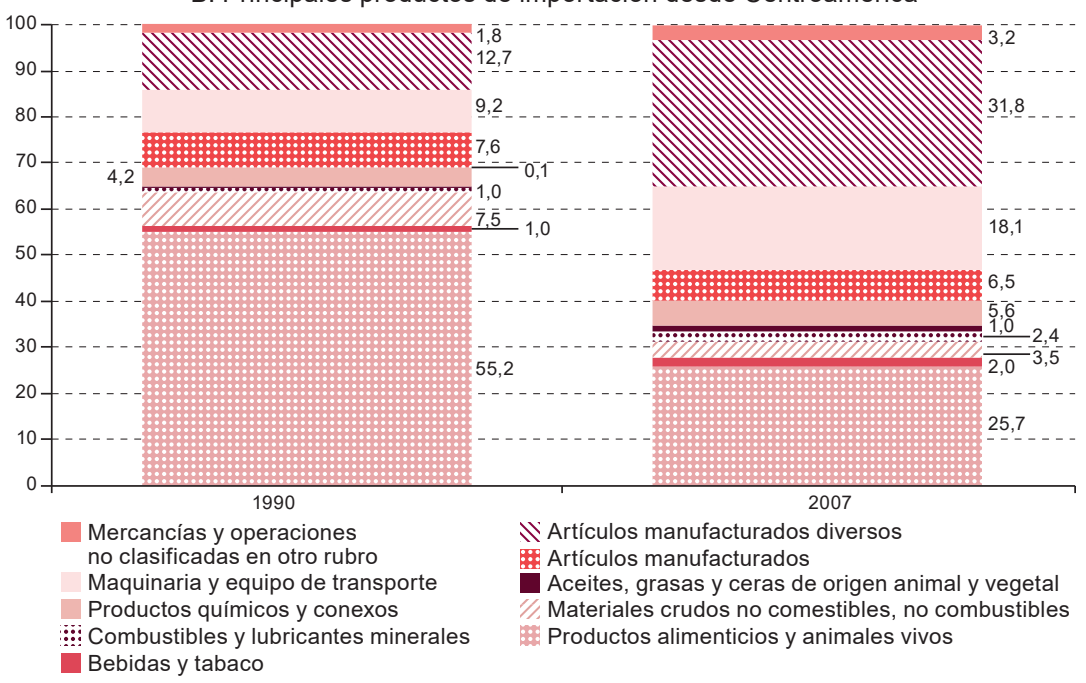

Fuente: Comisión Económica para América Latina y el Caribe (CEPAL), base de datos para el análisis de la competitividad de los países (TradeCAN).

La competitividad de los productos centroamericanos registró un cambio positivo en su participación de mercado entre 1990 y 2007, como se observa en la matriz del gráfico III.13. En el eje horizontal se mide el cambio en la participación de mercado de cada producto centroamericano en el total de las importaciones mundiales, es decir, el mejor posicionamiento de esos bienes en el mercado internacional. En el eje vertical se mide el cambio en la participación de cada uno de los productos comercializados en 1990 y 2007, es decir, su mayor demanda en el mercado internacional. De acuerdo con estos datos (véase el gráfico III.14), las exportaciones centroamericanas fueron competitivas en el mercado internacional, aunque en su mayor parte correspondieron a sectores de escaso o nulo crecimiento en la demanda internacional, como las manufacturas de caucho, los textiles y las manufacturas de cartón. En la terminología de la CEPAL, estos productos se clasifican como estrellas menguantes ${ }^{9}$. Sin embargo, en ese mismo período la región también aprovechó la mayor demanda de artículos como material eléctrico, ropa, calzado y otras manufacturas de mayor valor agregado, que se clasificaron como estrellas nacientes (véase el gráfico III.13) ${ }^{10}$.

Los productos centroamericanos comercializados en el mercado intrarregional también mostraron un cambio en su estructura entre 1990 y 2007. En 1990, una cuarta parte de ellos eran productos químicos y conexos (un $26 \%$

9 Denota un producto competitivo y estancado, cuya participación de mercado se incrementa a la vez que disminuye su demanda global.

10 Se refiere a un producto competitivo y dinámico, cuya participación de mercado y demanda global se incrementan. 
del total importado desde Centroamérica) y otro tanto correspondía a artículos manufacturados (un 26\% del total). Algunos de los bienes incluidos en estas categorías son los medicamentos, artículos de perfumería, jabones, insecticidas, desinfectantes, fertilizantes y preparaciones químicas. En 2007, los alimentos y los animales vivos se convirtieron en los principales productos comercializados en el mercado intrarregional (un $26 \%$ del total importado desde Centroamérica), aun cuando la importación de artículos manufacturados (un 20\% del total) y productos químicos (19\%) siguió teniendo un volumen considerable, como se observa en el gráfico III.14. Entre los principales productos alimenticios comercializados se encuentran las preparaciones comestibles, las bebidas no alcohólicas, los productos de panadería, el aceite de palma y la carne de bovino. Es decir, productos primarios, algunos con cierto grado de transformación.

En este período, la competitividad de los bienes comerciados en el mercado intracentroamericano fue inferior a la observada en el mercado mundial. En este caso la mayoría de los productos se ubicaron en sectores estancados, con poco crecimiento de su demanda en el mercado centroamericano, como los productos alimenticios, los aceites y grasas y los productos manufacturados, como se observa en la matriz del gráfico III.14. Por otra parte, el crecimiento de la oferta en productos centroamericanos de mayor demanda en ese mercado fue escaso, sobre todo en lo que respecta a artículos manufacturados diversos y maquinaria y equipo de transporte. Entre estos se encuentran los refrigeradores, las baterías, los televisores, otros aparatos eléctricos, la maquinaria de construcción y los vehículos automotores. Una vez realizada la apertura comercial, la mayoría de estos productos provinieron de mercados externos, lo que explica una parte del crecimiento del volumen de importaciones y el incremento del déficit comercial en mercancías.

Gráfico III.14

Centroamérica: principales productos en el comercio intrarregional, 1990 y $2007^{\text {a }}$ (En porcentajes)

A. Competitividad del comercio intrarregional

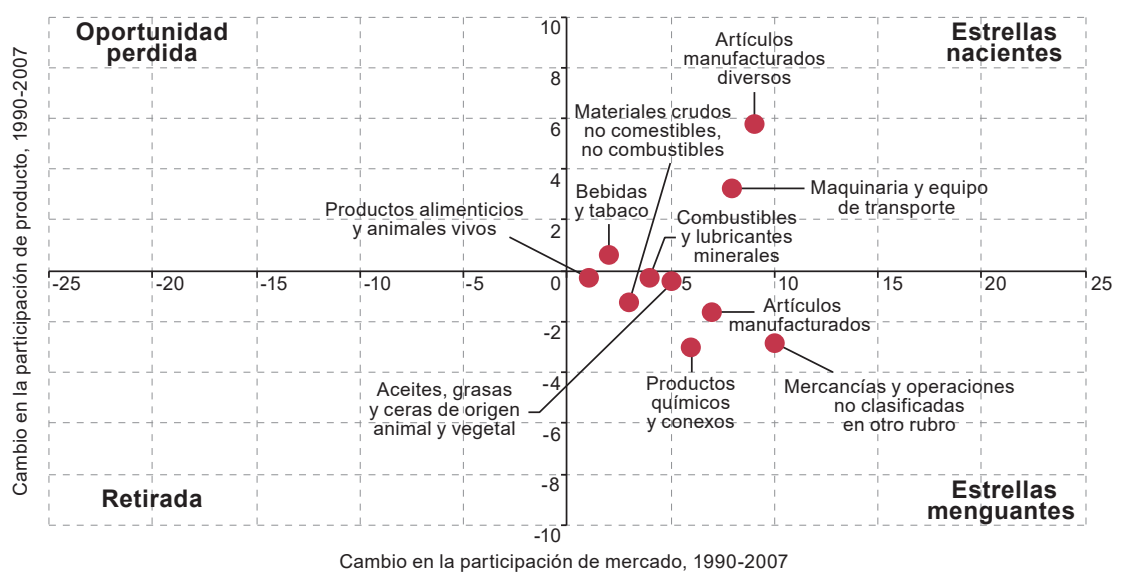


B. Principales importaciones intrarregionales

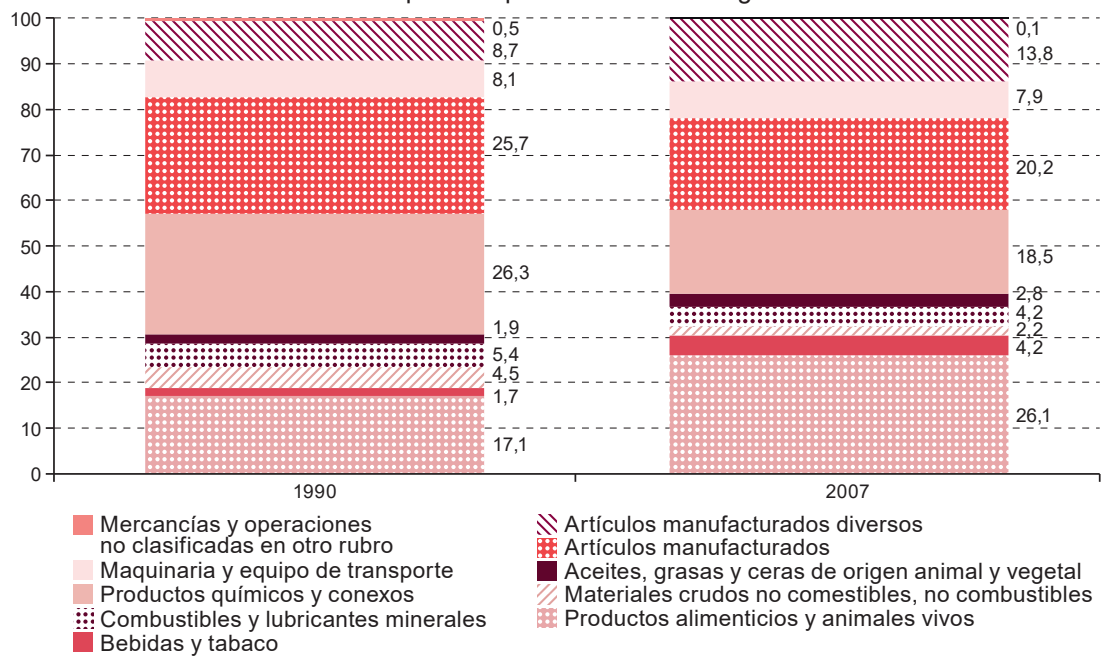

Fuente: Comisión Económica para América Latina y el Caribe (CEPAL), base de datos para el análisis de la competitividad de los países (TradeCAN).

a Medidos a través de los productos importados desde el mismo MCCA.

En los primeros años de la década de 1990, la región se consolidó como plataforma de exportaciones gracias a los segmentos productivos que fueron instalando las transnacionales, entre los que cabe destacar las inversiones en el sector de los textiles y las confecciones. Otros sectores de manufactura también comenzaron a exportar desde Centroamérica de la mano de la IED, en especial la manufactura liviana y la electrónica. A partir de la primera década de este siglo, las inversiones en el sector de los servicios crecieron de tal manera que actualmente superan a las inversiones en el sector secundario. Destacan las inversiones en los sectores de turismo, transporte, telecomunicaciones, finanzas y servicios de negocios (externalización de procesos empresariales o business process outsourcing). En este sentido, al igual que sucedió con las exportaciones de manufacturas, los flujos de IED contribuyeron al creciente aporte de los servicios a las exportaciones de la región.

A diferencia del período de sustitución de importaciones, en el regionalismo abierto se impulsó la atracción de IED con el objetivo de equilibrar las cuentas externas, suplir el ahorro nacional y generar empleo y divisas a través de las exportaciones. Por ese motivo, se promovió la IED que contribuyera al aumento de las exportaciones. Las empresas estatales, creadas en el período anterior, se privatizaron, de modo que se incentivó la llegada de IED en sectores como los de energía y telecomunicaciones. A partir de 1990 los flujos de IED han crecido de manera notable, excepto en contadas ocasiones vinculadas con crisis internacionales (véase el gráfico III.6). 
Las nuevas legislaciones sobre IED en Centroamérica, al igual que en el conjunto de la región casi sin excepciones, introdujeron una serie de cambios con el fin de promover la llegada de la IED, entre los que destacan los siguientes: i) aplicación del mismo tratamiento a las empresas de origen extranjero que a las inversiones nacionales (trato nacional); ii) eliminación de los controles sobre la repatriación de los beneficios y los dividendos de las IED; iii) permisos para llevar la IED a sectores antes prohibidos, como los bancos, los servicios públicos, entre otros; iv) establecimiento de agencias de promoción de inversiones con miras a estimular la IED, y v) firma de acuerdos bilaterales en materia de protección de inversiones (Sánchez Díez, 2002).

En resumen, en el período de regionalismo abierto, los países centroamericanos lograron el cometido de diversificar sus mercados mediante una política de mayor apertura comercial, aun cuando su balanza comercial se vio afectada por esto. Los productos comercializados al exterior también incrementaron su valor agregado y lograron insertarse de manera más competitiva que en el mercado interno. En esta época, la firma de diversos acuerdos bilaterales con socios externos dinamizó esas relaciones comerciales sin que por ello disminuyera la importancia del comercio intrarregional. La IED en la región contribuyó al cambio en la estructura de las exportaciones regionales, que pasó a ser fundamentalmente de bienes manufacturados, con especialización en los eslabones de menor valor agregado de la cadena de valor.

\section{El comercio centroamericano en los años recientes (cambio estructural progresivo entre 2008 y 2017)}

Después de la crisis económica internacional de 2008, la CEPAL planteó la necesidad de incorporar la igualdad y la sostenibilidad ambiental en el eje de todas las políticas de desarrollo económico implementadas en los países de América Latina y el Caribe. Dentro de este pensamiento, el comercio exterior es un elemento importante para lograr un cambio estructural que permita elevar los niveles de desarrollo. La recomendación es hacer que los sectores y actividades más intensivos en conocimiento adquieran un mayor peso en el comercio y en la producción nacional, de modo que los países puedan insertarse mejor en los mercados de rápido crecimiento. La idea es que la demanda de productos de mayor valor agregado en esos mercados promovería la producción nacional, incrementaría la productividad y, por consiguiente, el empleo mejor remunerado.

Si bien la política de inserción internacional sigue la línea del regionalismo abierto y la política de competitividad exportadora impulsada desde inicios de la década de 1990, en la nueva recomendación de política se enfatiza que no basta con identificar los rubros de mayor demanda. También es necesario 
desarrollar las capacidades productivas, humanas y tecnológicas que permitan alcanzar un posicionamiento competitivo en ellos. De acuerdo con esta nueva recomendación de política, las economías deberían impulsar el desarrollo de productos de mayor grado de incorporación tecnológica. Además, deberían diversificarse hacia sectores de rápido crecimiento en la demanda interna y externa, de tal forma que esta pueda ser atendida con oferta interna, y que las exportaciones e importaciones crezcan de forma equilibrada sin crear presiones insostenibles en la balanza de pagos (CEPAL, 2012).

Como se observa en el gráfico III.15, los países centroamericanos han tomado medidas significativas con miras a incorporar mayor valor agregado a sus exportaciones de bienes. La política sustitutiva de importaciones los ayudó a dar los primeros pasos hacia un cambio de la estructura exportadora. Sin embargo, la disminución de las ventas de productos primarios y el incremento de las ventas de manufacturas se observan con mayor vigor a partir de finales de la década de 1990. En los últimos diez años las exportaciones de productos primarios muestran sus niveles mínimos en términos relativos, aunque experimentaron un leve repunte del $5 \%$ a partir de 2014. En 2013 estos productos representaron el 18\% de las ventas totales de los países centroamericanos, 60 puntos porcentuales menos que en 1986. También en 2013, las manufacturas representaron un $81 \%$ del total exportado, 60 puntos porcentuales más que en 1986.

Gráfico III.15

Centroamérica: exportaciones totales de bienes por intensidad tecnológica, 1986-2017

(En porcentajes con respecto al total exportado)

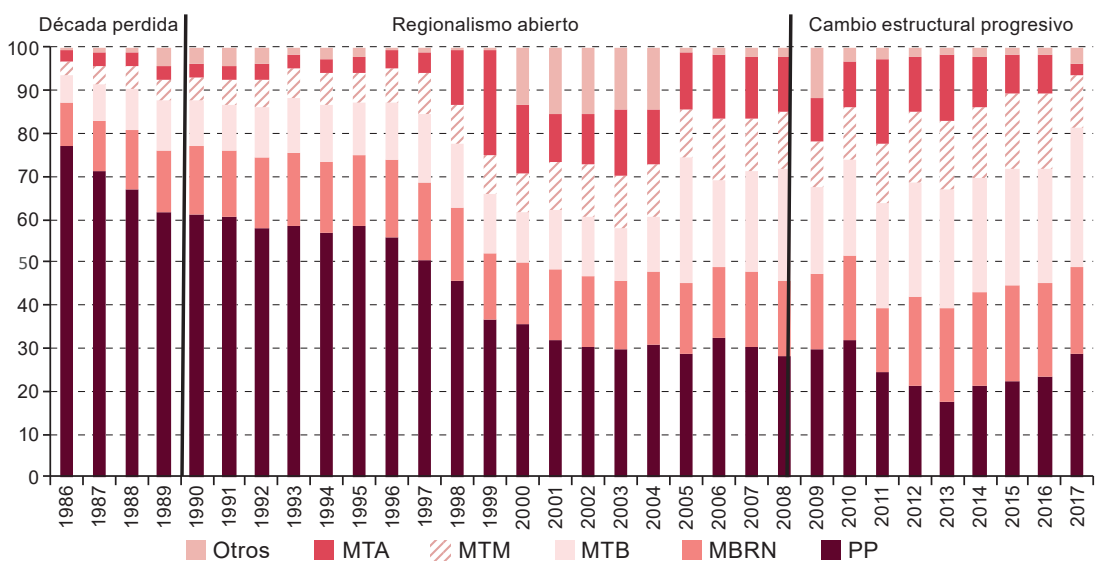

Fuente: Comisión Económica para América Latina y el Caribe (CEPAL), sobre la base de información de la Base de Datos Estadísticos de las Naciones Unidas sobre el Comercio de Productos Básicos (COMTRADE).

Nota: Abreviaturas utilizadas en la leyenda: $\mathrm{PP}=$ productos primarios, $\mathrm{MBRN}=$ manufacturas basadas en recursos naturales, $\mathrm{MTB}=$ manufacturas de tecnología baja, $\mathrm{MTM}=$ manufacturas de tecnología media y MTA = manufacturas de tecnología alta. 
En suma, entre mediados de los años ochenta y de la presente década se observa un cambio completo en la estructura exportadora de la región hacia productos de más valor agregado y cuya demanda en los mercados internacionales es también superior. Sin embargo, la mayor parte de las exportaciones centroamericanas de manufacturas se clasifican como productos basados en recursos naturales y de tecnología baja (el $49 \%$ del total de las exportaciones en 2016). En tanto, las exportaciones de manufacturas de media tecnología suman el 16\% del total y las de alta tecnología, el 15\%. Lo anterior indica que la región necesita seguir trabajando en su inserción en sectores que tengan un mayor nivel de incorporación tecnológica y de conocimientos. En este sentido, la CEPAL ha señalado la relevancia de diseñar políticas industriales que incrementen el valor de la producción regional.

El cambio estructural de las exportaciones centroamericanas también se observa en el comercio intrarregional. Las exportaciones de bienes primarios dentro del mercado regional han sido inferiores a las que se hacen al mercado global. En 1986, los productos primarios representaron el 11\% de las exportaciones intrarregionales, mientras que las manufacturas sumaron el $89 \%$ restante ${ }^{11}$. Esta relación es similar a la observada en 2016: el 9\% de las ventas intrarregionales está compuesto por productos primarios y el $91 \%$, por manufacturas. La mayor diferencia que se observa en el mercado centroamericano desde 2008 es el aumento del peso de las manufacturas de alta tecnología comercializadas en la región. No obstante, la mayoría de los productos comercializados intrarregionalmente siguen siendo manufacturas basadas en recursos naturales y manufacturas de baja tecnología (56\% en 2016) (véase el gráfico III.16).

\section{Gráfico III.16 \\ Centroamérica: exportaciones intrarregionales de bienes por intensidad tecnológica, 1986-2016 \\ (En porcentajes con respecto al total exportado)}

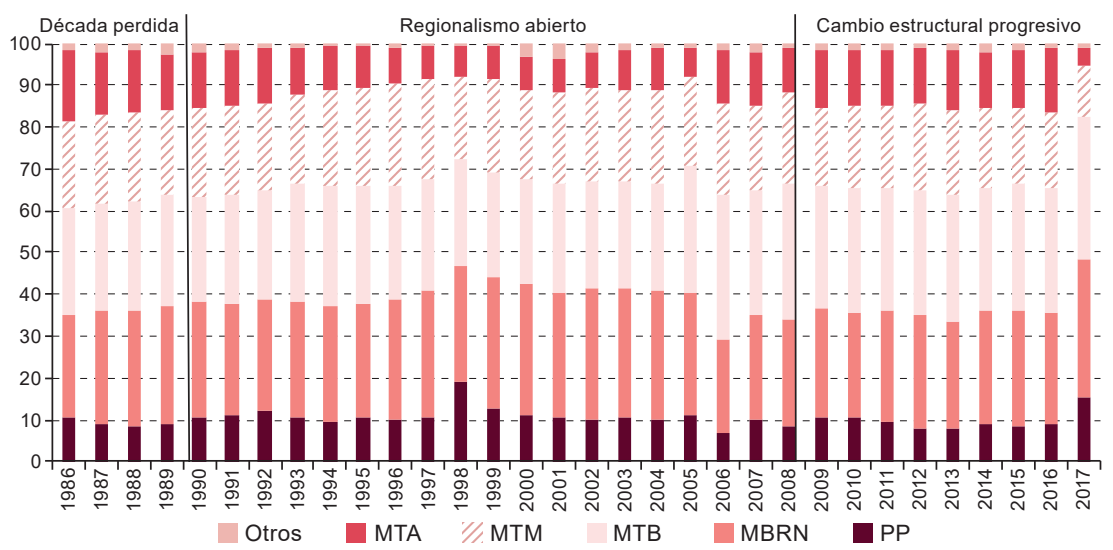

Fuente: ComisiónEconómicaparaAméricaLatinayelCaribe(CEPAL), sobrelabasedeinformacióndelaBase deDatosEstadísticos delas NacionesUnidassobreelComerciodeProductosBásicos(COMTRADE).

Nota: Abreviaturas utilizadas en la leyenda: $\mathrm{PP}=$ productos primarios, $\mathrm{MBRN}=$ manufacturas basadas en recursos naturales, MTB = manufacturas de tecnología baja, MTM = manufacturas de tecnología media y MTA = manufacturas de tecnología alta.

11 Primer año del que se tiene información. 
La crisis de 2008 mostró los beneficios del mercado intrarregional centroamericano para afrontar la desaceleración del mercado internacional, así como la necesidad de profundizar aún más en su integración y diversificar más sus mercados y exportaciones hacia terceros países (Martínez y Cordero, 2009). La proporción de las exportaciones intrarregionales en las exportaciones totales nunca había sido tan elevada como la alcanzada en 2016, cuando el $32 \%$ del total exportado por los países centroamericanos tuvo como destino el propio mercado centroamericano (véase el gráfico III.17). Esto ayudó a compensar la disminución de la demanda de los principales socios comerciales extrarregionales en los años posteriores a la crisis de 2008 y 2009.

\section{Gráfico III.17}

\section{Centroamérica: evolución de las exportaciones intrarregionales y extrarregionales, 1960-2016 \\ (En porcentajes del total exportado)}

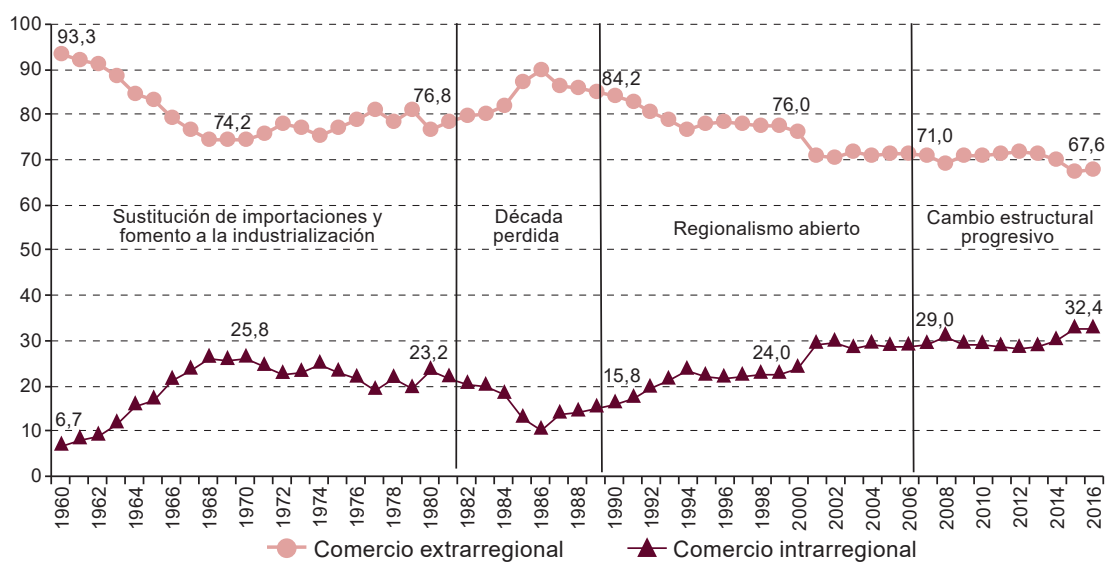

Fuente: Comisión Económica para América Latina y el Caribe (CEPAL), sobre la base de información oficial.

Por primera vez desde mediados de la década de 1990, en 2009 se observó una disminución del déficit comercial centroamericano, seguido de una progresiva mejoría en los últimos años. Ello ha permitido mantener dicho déficit por debajo de sus mayores niveles, alcanzados en 2008 (24.000 millones de dólares), como se observa en el gráfico III.5.

En la balanza de pagos, los servicios han jugado un papel importante en lo que respecta a equilibrar el sector externo centroamericano. En la región, el comercio de servicios ha crecido con mayor intensidad desde principios de la década de 1990. Se ha acercado paulatinamente al monto de las exportaciones de bienes en los últimos años, como se observa en el gráfico III.18. Entre 1990 y 2004, el comercio de servicios de los países centroamericanos creció a un 
ritmo promedio anual del $9 \%$, y entre 2007 y 2017 , lo hizo al $8 \%{ }^{12}$. Esta es una tendencia similar a la observada en el comercio mundial en el mismo rubro. Sin embargo, en 2017 los servicios representaron el 38\% de las exportaciones centroamericanas de bienes y servicios, es decir, 15 puntos porcentuales más que el peso de ese rubro específico en las exportaciones mundiales ( $23 \%$ del total) (Cordero, 2018).

Gráfico III.18

Centroamérica: evolución de las exportaciones de bienes y servicios, 1980-2017a (En millones de dólares)

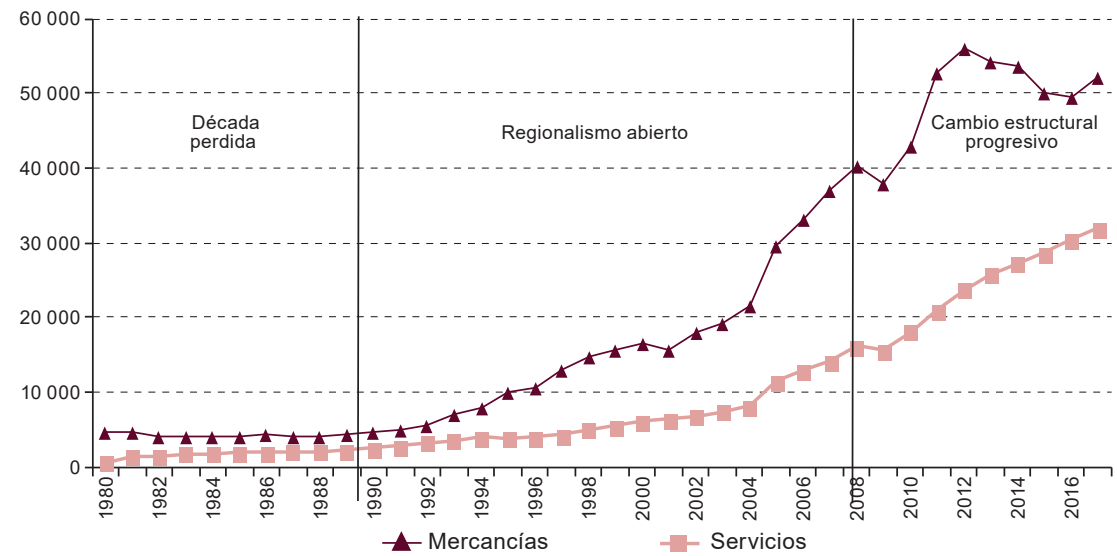

Fuente: Comisión Económica para América Latina y el Caribe (CEPAL), sobre la base de información de la Conferencia de las Naciones Unidas sobre Comercio y Desarrollo (UNCTAD).

a Los datos de 1980 a 2004 siguieron la metodología de Manual de Balanza de Pagos y Posición de Inversión Internacional, quinta edición (MBP5) (FMI, 1993) y a partir de 2005 aplicó el Manual de Balanza de Pagos y Posición de Inversión Internacional, sexta edición (MBP6) (FMI, 2009) para la recopilación de datos de comercio internacional de servicios.

En las exportaciones centroamericanas de servicios aún no ha habido un cambio notable en cuanto a la incorporación de valor agregado como el observado en las mercancías. La CEPAL promueve el impulso de los servicios modernos que aporten un mayor valor agregado y sean intensivos en el uso de tecnologías de la información y las comunicaciones (CEPAL, 2017, capítulo II). No obstante, en 2016, el 75\% del valor de las exportaciones centroamericanas de servicios correspondió a servicios tradicionales. Esa categoría comprende servicios relacionados con el turismo (viajes), servicios de transporte y otros relacionados con la transformación de bienes. Solo el

12 A partir de 2005, en la metodología de recopilación y procesamiento de datos se utilizó el Manual de Balanza de Pagos y Posición de Inversión Internacional, sexta edición (MBP6). Una de las principales diferencias de este manual es que los servicios de transformación (maquila) pasan de la balanza de bienes a la balanza de servicios, ahora bajo el rubro de servicios de reparación y mantenimiento. Este cambio afecta especialmente la contabilidad del comercio de los países centroamericanos. Por tal razón, en la comparación de los datos se debe tener en cuenta esta diferencia. 
$25 \%$ restante corresponde a servicios modernos, entre los que se incluyen servicios empresariales, servicios de telecomunicaciones, de informática e información y servicios financieros (Cordero, 2018).

En este punto, es importante tener presente que el fortalecimiento de los servicios tradicionales y el desarrollo de nuevos servicios son factores cruciales para el desarrollo de las cadenas de valor en Centroamérica. Los servicios permiten a las cadenas conjugar la eficiencia operacional con la innovación mediante el incremento del valor agregado de sus productos. En el ámbito operacional están presentes los servicios de logística, de información y de comunicación, con tecnologías que hacen más eficientes las cadenas de valor. En lo que se refiere al valor agregado, los servicios profesionales y de soporte juegan un papel decisivo en la mejora de los procesos y las innovaciones (Oddone y Padilla, 2014).

La incorporación de nuevas normas que impulsan y regulan los nuevos tipos de servicios y de mercancías se observa en los diversos acuerdos que han seguido firmando los países centroamericanos con terceros países a lo largo de este nuevo período. Uno de los más relevantes para el avance de la integración centroamericana y el impulso del comercio de los nuevos servicios ha sido el firmado por la Unión Europea en 2012 con todos los países centroamericanos como bloque económico. También se han firmado otros acuerdos bilaterales con países asiáticos como China, la República de Corea y Singapur, así como otros países latinoamericanos que muestran un notable crecimiento en sus importaciones mundiales, como Colombia y el Perú. Además, se han modernizado los tratados con México y el Canadá para incorporar los nuevos lineamientos de comercio exterior e impulsar más el mercado intrarregional centroamericano con normas que permiten la acumulación de origen regional y el comercio de servicios modernos.

La firma de acuerdos comerciales ha sido constante desde el período de regionalismo abierto (véase el gráfico III.9), lo que ha coadyuvado a que los países centroamericanos diversifiquen sus mercados y productos de exportación (véase el gráfico III.19). En 1990, eran 18 los mercados a los que los países centroamericanos enviaban sus exportaciones de bienes. En 2008, este número se había elevado a 86. En 2013 registró su máximo nivel, con 95 mercados alrededor del mundo. A partir de 2014 se nota un cambio en la tendencia y una leve reducción de mercados de destino y productos de exportación. La mayor inserción en los mercados internacionales ha ido de la mano con la mayor diversificación de los productos comercializados. En 1990, el número promedio de productos exportados era de 92. Países como El Salvador y Nicaragua comercializaban menos de 32 productos. En 2008, este número se elevó a 800 productos, hasta llegar a su máximo nivel en 2012 con 868 productos exportados diferentes, que también han tenido una mayor incorporación de valor agregado que en los años anteriores, como ya se ha observado. 
Gráfico III.19

Centroamérica: número de productos y mercados de exportación, 1988-2016ª

(Número de productos y mercados por año)

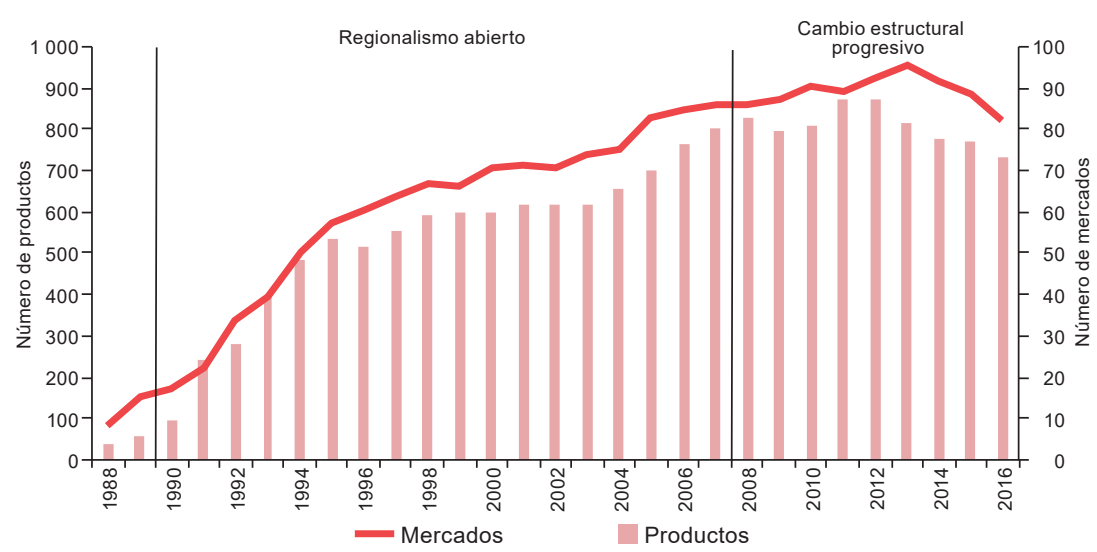

Fuente: Comisión Económica para América Latina y el Caribe (CEPAL), sobre la base de Banco Mundial, Solución Comercial Integrada Mundial (WITS); Conferencia de las Naciones Unidas sobre Comercio y Desarrollo (UNCTAD); Comisión de Estadística de las Naciones Unidas; Organización Mundial del Comercio (OMC) y del Centro de Comercio Internacional UNCTAD/OMC.

a Los productos corresponden a los bienes clasificados a seis dígitos del Sistema Armonizado.

Siguiendo las recomendaciones de la CEPAL, no basta solo con lograr una mayor diversificación de productos y mercados, sino que es necesario insertarse en los mercados y productos de mayor crecimiento en su demanda. En el eje vertical del gráfico III.20 se ha medido la demanda de los mercados a partir de la tasa de crecimiento promedio de las importaciones totales de los principales socios comerciales de Centroamérica durante el período 2007-2016 $6^{13}$. En el eje horizontal, se ha medido la respuesta centroamericana a la demanda de sus socios comerciales, utilizando la tasa de crecimiento promedio de sus exportaciones a esos socios. La matriz de competitividad permite observar que, a excepción del Japón y la Unión Europea, cuya demanda de importaciones ha disminuido en el período objeto de estudio, el resto de los principales socios comerciales muestran un aumento en su demanda de importaciones. Sin embargo, los países centroamericanos no han logrado aprovechar con eficacia la mayor demanda observada en los casos de los mercados de la República de Corea y China. De ahí que estos mercados se clasifiquen como oportunidades perdidas para Centroamérica. También se ven otros mercados que Centroamérica ha aprovechado poco y que tienen una mayor dinámica en su demanda de importaciones, como la India, México, el Perú y la República Dominicana.

13 Estos países y grupos de países suman el $92 \%$ del total de las exportaciones centroamericanas de bienes en 2016.

14 En este ejercicio se ha elegido el período 2007-2016, en lugar del correspondiente al período de estudio (2008-2016), a fin de no seleccionar un año base atípico como lo fue 2008. 


\section{Gráfico III.20}

Centroamérica: matriz de competitividad de mercados, 2007-2016

(Tasas de crecimiento promedio anual)

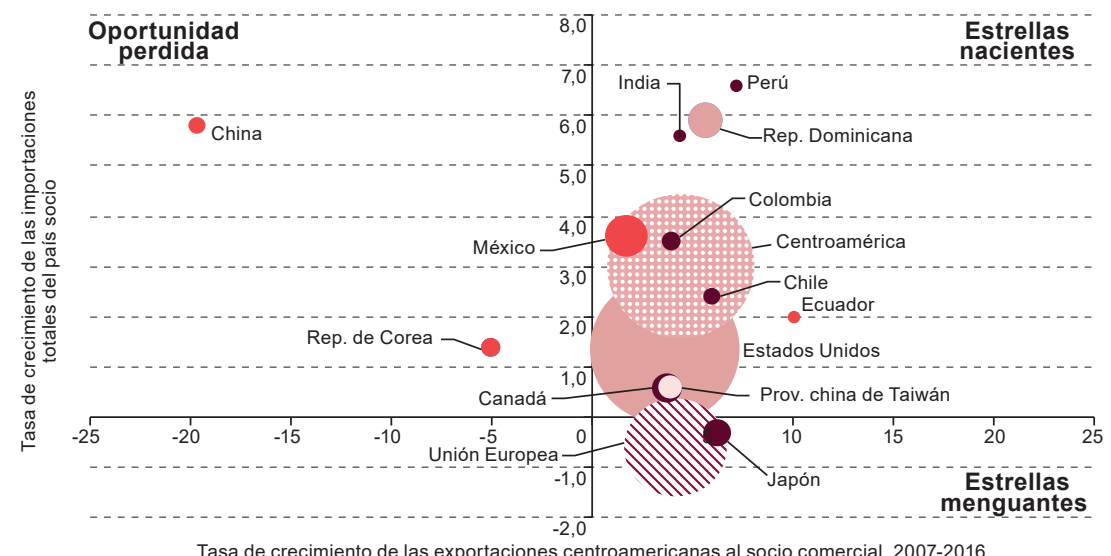

Fuente: Comisión Económica para América Latina y el Caribe (CEPAL), sobre la base de información de TradeMap y Magic Plus.

Si bien la mayor demanda en el mercado intrarregional es atendida por los propios países centroamericanos, cuando se hace un análisis pormenorizado en términos de productos comercializados, se observa que varios de los principales productos muestran una demanda mayor que la oferta de los países centroamericanos y que ellos mismos podrían aprovechar. En el eje vertical del gráfico III.21 se ha medido la demanda del producto mediante el cambio de la participación de los principales productos importados en el mercado intrarregional durante el período 2007-2016 ${ }^{15}$. En el eje horizontal se ha medido la respuesta centroamericana a esa demanda a través del cambio en su participación de mercado durante el mismo período. También se observa que la mayoría de esos productos muestran un aumento en su demanda, pero que en seis de ellos el cambio en la oferta de los países centroamericanos ha sido inferior al de la demanda, por lo que se clasifican como oportunidades perdidas. Entre estos están los jabones, los productos de pastelería, las preparaciones alimenticias, los productos farmacéuticos, las bebidas y la fundición de hierro y acero.

En resumen, las políticas implementadas por los países centroamericanos para lograr una mejor inserción en los mercados internacionales parecen ir por un cauce positivo. Sin embargo, aún se debe impulsar la aplicación de políticas que coadyuven a una mejor inserción en esos mercados mediante el incremento del valor de los productos de la región y la alineación de su

15 Estos diez productos suman el 50\% de las exportaciones intrarregionales centroamericanas.

16 En este ejercicio también se ha elegido el período 2007-2016, en lugar del correspondiente al período de estudio (2008-2016), a fin de no seleccionar un año base atípico como lo fue 2008. 
oferta con los requisitos ambientales del planeta. Además, en esas políticas se debería considerar el efecto que la IED ejerce sobre los exportadores nacionales, ya sea mediante el desarrollo de nuevas capacidades productivas o por efecto de los encadenamientos positivos. Centroamérica sigue siendo una región dinámica en la recepción de IED, aun en momentos en que el resto de América Latina ve contraerse dichos flujos ${ }^{17}$. Sin embargo, para aprovechar ese aumento constante de la inversión es necesario que los países mejoren las condiciones de su ingreso en las economías nacionales, de manera que se potencien externalidades que estimulen a los productores nacionales y propicien el desarrollo de nuevas capacidades tecnológicas.

\section{Gráfico III.21}

Centroamérica: matriz de competitividad de productos en el mercado centroamericano, 2007-2016

(Cambios en las participaciones de producto y mercado)

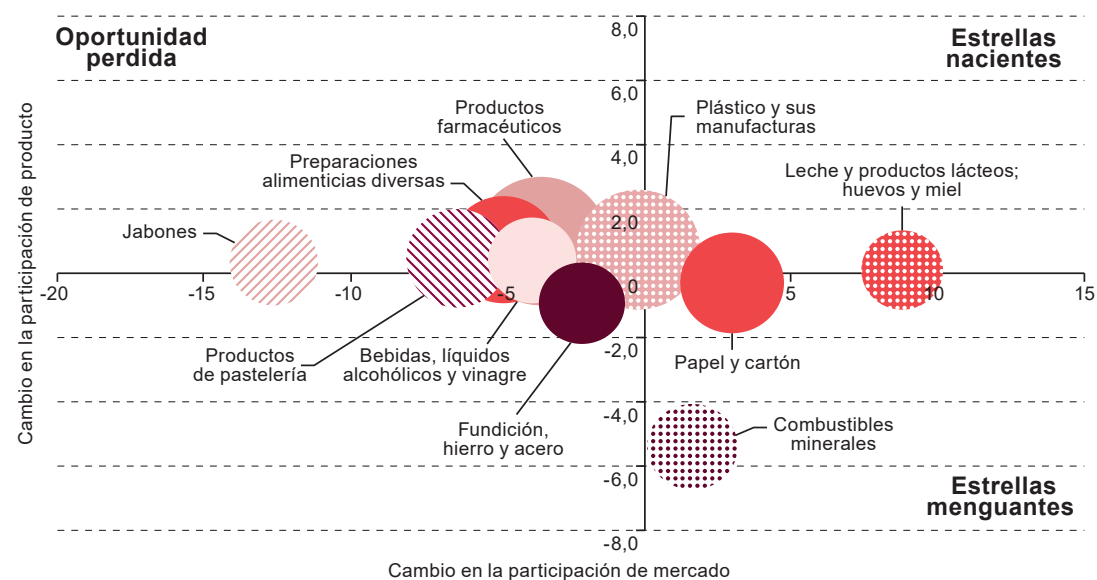

Fuente: Comisión Económica para América Latina y el Caribe (CEPAL), sobre la base de información de Magic Plus.

\section{Conclusiones y perspectivas}

Tras la creación del mercado común centroamericano, y en línea con las propuestas de la CEPAL de procurar la industrialización mediante la sustitución de importaciones, el comercio intrarregional avanzó significativamente, de modo que se creó un mercado intrarregional y se conformó una masa empresarial nacional con crecientes capacidades industriales. El alza de los precios del petróleo, la crisis de la deuda externa y las crisis políticas internas condujeron a un cambio en el modelo de desarrollo con la adopción

17 Como consecuencia de la crisis económica mundial, en 2008 los flujos de IED cayeron hasta niveles similares a 2005, pero pronto se retomó la senda del crecimiento, lo que permitió alcanzar un récord histórico en 2017: 13.083 millones de dólares. 
del regionalismo abierto. En ese nuevo marco, Centroamérica se abrió a los mercados externos sin olvidar el avance en su mercado regional, como lo sugería la CEPAL. Los países centroamericanos reforzaron sus políticas y acciones con miras a incrementar la competitividad de sus productos e incursionar mejor en sus principales mercados. Para ello fue primordial aumentar las exportaciones y diversificar los productos y los mercados de exportación. La inversión extranjera directa jugó un papel muy importante en este proceso, pues el crecimiento de las exportaciones vino de la mano de los crecientes flujos de IED.

A pesar de ese aumento y del éxito exportador, la región centroamericana mantuvo serios problemas para su desarrollo: economías altamente heterogéneas, amplios sectores de la población en estado de pobreza y elevados índices de desigualdad. En este contexto, la CEPAL subrayó que era necesario un cambio estructural progresivo, haciendo hincapié en la incorporación de mayor valor agregado tanto en productos como en servicios, al tiempo que se mantenía la importancia del mercado intrarregional como medio para facilitar el cambio estructural. La región centroamericana deberá prestar más atención a la calidad de la IED que atrae, al valor agregado de su producción y a la importancia de las actividades endógenas de investigación y desarrollo como medio para lograr el desarrollo económico y social.

Durante la crisis económica internacional de 2008, los países centroamericanos aumentaron su comercio intrarregional, con lo que lograron contrarrestar parcialmente la contracción del mercado internacional. Esta reacción del sector productivo centroamericano fue diferente a la observada en la década de 1970, cuando sus intercambios comerciales intrarregionales disminuyeron tras la crisis de los precios del petróleo. Ello pone de relieve el avance del mercado intrarregional como alternativa a las exportaciones al resto del mundo, además de la importancia de la estabilidad política regional. El mercado intrarregional es hoy el segundo más importante para Centroamérica en su conjunto y ha servido de plataforma de arranque para muchas empresas pequeñas y medianas de la región que han decidido exportar. Después de fortalecerse en los mercados más cercanos, muchas empresas han comenzado a exportar a mercados más grandes, competitivos y dinámicos, como los de los Estados Unidos, Europa y México.

La estructura exportadora centroamericana cambió de forma profunda desde el inicio del proceso de integración regional, tanto en el comercio intrarregional como en el extrarregional. Los países centroamericanos han pasado de ser exportadores de materias primas y recursos naturales a exportadores de manufacturas y, más recientemente, de servicios. La estructura económica de la región también experimentó un gran cambio de la mano del comercio y de la integración, hacia un mayor peso de la industria y los servicios y un menor peso del sector primario. Sin embargo, aún se requieren 
mayores esfuerzos para pasar de la exportación de manufacturas ligeras a manufacturas de mayor valor agregado y mayor demanda internacional. También se requieren políticas de innovación que permitan a la región transitar de la exportación de servicios tradicionales a la de servicios modernos, lo que será relevante para dar un mayor impulso al desarrollo y fortalecimiento de las cadenas de valor en Centroamérica. La región sigue siendo muy heterogénea y enfrenta profundos retos para incrementar su productividad. Ello pone de manifiesto la importancia de implementar políticas públicas que conduzcan al cambio estructural progresivo que propone la CEPAL.

\section{Bibliografía}

CEPAL (Comisión Económica para América Latina y el Caribe) (2018a), La inversión extranjera en América Latina y el Caribe, 2018 (LC/PUB.2018/13-P), Santiago. (2018b), La ineficiencia de la desigualdad (LC/SES.37/3-P), Santiago.

(2017), Perspectivas del Comercio Internacional de América Latina y el Caribe, 2017 (LC/PUB.2017/22-P), Santiago.

(2016a), Horizontes 2030: la igualdad en el centro del desarrollo sostenible (LC/G.2660 (SES.36/3)), Santiago.

(2016b), La protección social de cara al futuro: acceso, financiamiento y solidaridad (LC/G.2294(SES.31/3)), Santiago, marzo.

(2014), Pactos para la igualdad: hacia un futuro sostenible (LC/G.2586 (SES.35/3)), Santiago.

(2012), Cambio estructural para la igualdad: una visión integrada del desarrollo (LC/G.2524(SES.34/3)), Santiago, julio.

(2011), La inversión extranjera directa en América Latina y el Caribe, 2010 (LC/G.2494-P), Santiago.

(2010), La hora de la igualdad: brechas por cerrar caminos por abrir (LC/G.2432 (SES.33/3)), Santiago.

(2008a), La transformación productiva 20 años después. Viejos problemas, nuevas oportunidades (LC/G.2367(SES.32/3)), Santiago.

(2008b), Sesenta años con América Latina y el Caribe (LC/L.2890-P), Santiago, mayo. (2000), Equidad, desarrollo y ciudadanía (LC/G.2071/Rev.1-P/E), Santiago.

(1996), Transformación productiva con equidad: la tarea prioritaria del desarrollo de América Latina y el Caribe en los años noventa, Libros de la CEPAL, N 25 (LC/G.1601-P), Santiago.

(1994), El regionalismo abierto en América Latina y el Caribe. La integración económica en servicio de la transformación productiva con equidad (LC/G.1801/Rev.1-P), Santiago. (1963), Segundo compendio estadístico centroamericano (E/CN.12/597), Nueva York, enero.

CEPAL/CCE (Comisión Económica para América Latina y el Caribe/Comité de Cooperación Económica del Istmo Centroamericano) (1994), El regionalismo abierto en Centroamérica: los desafíos de profundizar y ampliar la integración (LC/MEX/R.493), Ciudad de México, octubre.

(1991a), Evolución de la integración centroamericana en 1990 (LC/MEX/L.162), Ciudad de México, octubre. 
(1991b), Bases y propuestas para la reestructuración del sistema centroamericano de integración (LC/MEX/L.157), Ciudad de México, septiembre.

(1991c), La integración en Centroamérica: su evolución desde los años setenta y perspectivas en los noventa (LC/MEX/R.271/Rev.1), Ciudad de México, mayo. (1974), El Mercado Común Centroamericano, 1973-74 (CEPAL/MEX/74/20/ Rev.1), Ciudad de México, noviembre.

(1971), El Mercado Común Centroamericano y sus problemas recientes (E/CN.12/ CCE/363), Ciudad de México, enero.

CEPAL/Subcomité de Comercio Centroamericano (1967), Información estadística comercial y de financiamiento de los países Centroamericanos, (CCE/SC.1/XIII/DI.1), Ciudad de México, diciembre.

Cordero, M. (2018), El comercio de servicios en la integración económica centroamericana (LC/MEX/TS.2018/16), Ciudad de México, Comisión Económica para América Latina y el Caribe (CEPAL), agosto.

(2017), Integración Económica Centroamericana: base de datos 2016 (LC/MEX/TS.2017/24), Ciudad de México, Comisión Económica para América Latina y el Caribe (CEPAL), agosto.

FMI (Fondo Monetario Internacional) (2009), Manual de Balanza de Pagos y Posición de Inversión Internacional, sexta edición (MBP6), Washington, D.C. [en línea] https:/ / www.imf.org/external/spanish/pubs/ft/bop/2007/bopman6s.pdf.

(1993), Manual de Balanza de Pagos y Posición de Inversión Internacional, quinta edición (MBP5), Washington, D.C.

Hernández, R. y otros (2016c), Innovation and internationalization of Latin American services (LC/L.4177), Santiago, El Colegio de la Frontera Norte/Comisión Económica para América Latina y el Caribe (CEPAL).

Martínez Piva, J. y R. Hernández (2012), “La inversión extranjera directa en Costa Rica: principales determinantes y efectos en el desarrollo nacional y regional", Serie Aportes para el Análisis del Desarrollo Humano Sostenible, San José, Programa Estado de la Nación.

Martínez Piva, J. y M. Cordero (2009), La integración económica centroamericana y sus perspectivas frente a la crisis internacional (LC/MEX/L.954), Ciudad de México, Comisión Económica para América Latina y el Caribe (CEPAL), diciembre.

Ocampo, J. A. (1998), "Cincuenta años de la CEPAL", Revista de la CEPAL, $N^{o}$ Extraordinario (LC/G.2037-P), Santiago, Comisión Económica para América Latina y el Caribe (CEPAL), octubre.

Oddone, N. y R. Padilla (2014), Upgrading value chains through profesional and supporting services: lessons from three agro-industry chains in El Salvador and Guatemala (LC/MEX/L.1151), Ciudad de México, Comisión Económica para América Latina y el Caribe (CEPAL).

Sánchez Díez, A. (2002), La internacionalización de la economía española hacia América Latina: elementos determinantes en el inicio y consolidación del proceso, Burgos, Servicio de Publicaciones de la Universidad de Burgos.

Sánchez Díez, A. y J. Martínez Piva (2014), “Centroamérica: ¿Una nueva relación centro-periferia basada en el control de los activos productivos?", Documentos de Proyectos (LC/W.578), Santiago, Comisión Económica para América Latina y el Caribe (CEPAL). 
Capítulo IV

\section{El potencial dinamizador de las exportaciones en Centroamérica y la República Dominicana: evidencia empírica a partir del análisis de matrices insumo-producto}

Rodolfo Minzer Parnes

Roberto Carlos Orozco

\section{Introducción}

Hace cuatro décadas, en América Latina se abandonó el proceso de industrialización dirigida por el Estado y se inició una transición hacia un nuevo modelo orientado al fomento de las exportaciones. Los países centroamericanos, México y la República Dominicana han seguido un patrón común, caracterizado por la atracción de empresas de capital extranjero que establecen plantas exportadoras de productos manufacturados dirigidos principalmente a los Estados Unidos ${ }^{1}$.

Los encargados de formular la política económica centroamericana apostaron por la apertura comercial y el fomento de las exportaciones como pilares del crecimiento. Los países centroamericanos, relativamente pequeños, encuentran en el mercado externo una oportunidad para impulsar la demanda de sus bienes y servicios, y alcanzar mayores tasas de crecimiento económico

Véase un análisis de las consecuencias de este proceso en la industria maquiladora de exportación en Padilla y otros (2008). 
y generación de empleo. Para alcanzar esos objetivos, se han utilizado diferentes formas de inserción en los mercados externos, que se traducen en distintas capacidades para crear valor agregado y empleo a partir de las exportaciones. Un primer objetivo del presente capítulo es analizar dichas formas de inserción en términos comparativos y cuantificar la forma en que se traducen en capacidad para generar valor agregado nacional y empleo a partir de las exportaciones.

En este capítulo basado en matrices de insumo-producto nacionales se brinda evidencia empírica sobre la importancia del comercio intrarregional centroamericano para crear valor agregado y empleo a partir de las exportaciones. Con ese fin, se cuantifica el efecto de las exportaciones de los países seleccionados en términos de su capacidad para generar valor agregado y empleo, de acuerdo con los principales destinos comerciales. Esta información es de particular importancia en la discusión sobre las ganancias del proceso de integración centroamericana.

El resto del capítulo se estructura como sigue. En la sección A se exponen el marco conceptual, los aspectos metodológicos y las fuentes de información. La información existente se basa en estudios que se han llevado a cabo en los últimos años en la sede subregional de la Comisión Económica para América Latina y el Caribe (CEPAL) en México, utilizando el instrumental basado en matrices de insumo-producto nacionales. Esto ha derivado en un proceso de cooperación técnica entre la CEPAL y los bancos centrales e institutos de estadísticas de los países, a los efectos de construir las bases de datos necesarias para realizar dichos estudios. En la sección B se calcula y se analiza, respecto de cada país seleccionado, el valor agregado nacional producido e incorporado en las exportaciones, así como el empleo que estas inducen, diferenciando entre las exportaciones de bienes y las de servicios. Como se explicará más adelante, esta diferenciación es clave para comprender los efectos de la forma de inserción comercial exportadora de cada país. Asimismo, en esa sección se estiman indicadores, como el valor agregado por ocupado, que se puede interpretar como la productividad del factor trabajo. Estas estimaciones se realizan en relación con las exportaciones de bienes y las de servicios. El resultado puede interpretarse como una medida del éxito del tipo de inserción comercial de cada país, ya que los indicadores más elevados muestran una mayor capacidad para crear valor agregado por ocupado como producto de la actividad exportadora. En la sección C se aborda la integración económica centroamericana utilizando el instrumental analítico y empírico desarrollado. A tales efectos, se amplía el nivel de detalle del análisis y se distingue entre los distintos destinos de exportación y entre los sectores exportadores. En esa sección se presentan además recomendaciones sobre política pública para los países estudiados. En la sección D, que es la última, se resumen los principales hallazgos y conclusiones. 


\section{A. Marco conceptual: metodología y fuentes de información}

La principal herramienta que se utiliza para evaluar la capacidad dinamizadora del sector externo de los países estudiados es la matriz de insumo-producto de cada uno. Esta matriz constituye una representación sintética de la economía de un país, que proporciona datos detallados sobre la producción y la utilización de los bienes y servicios producidos e importados del resto del mundo, así como el ingreso nacional que los diversos sectores económicos generan a partir de dicha producción. Este instrumento permite conocer la importancia relativa de los sectores y el nivel de articulación intersectorial, mediante la identificación de los principales flujos de producción e intercambio $\mathrm{y}$ de los bienes que se necesitan para uso intermedio y final.

En un modelo de insumo-producto, una variación de la demanda de exportaciones de cualquier sector económico se traduce en un cambio en el nivel de producción del sector directamente afectado, así como de los sectores restantes de la economía nacional que se encuentran encadenados con él y que le proveen insumos intermedios. El empleo y el valor agregado inducidos por el incremento de las exportaciones siguen una lógica similar. Ante un incremento de la demanda de exportaciones de un determinado sector, se requieren más empleos directos para aumentar el nivel de producción del sector inicialmente afectado. Asimismo, se necesitan más empleos indirectos en los sectores económicos restantes, para satisfacer la mayor demanda de insumos generada por los encadenamientos del sistema productivo nacional.

El aumento del nivel de producción de bienes y servicios exportables provoca también un aumento del valor agregado nacional que se reparte entre los factores de producción responsables de su creación: remuneraciones y sueldos, excedente bruto de explotación (utilidades de las empresas) e impuestos. Finalmente, el incremento de la demanda de productos exportables requiere insumos intermedios de los mercados internacionales, si estos no se producen en la economía nacional. En resumen, en un modelo de insumoproducto, un aumento inicial de la demanda de exportaciones da lugar a un aumento de la demanda de insumos intermedios nacionales (directos e indirectos) que produce un mayor nivel de empleo. A este efecto se añade la generación de valor agregado nacional directo e indirecto (sueldos, excedente bruto de explotación e impuestos), que sumado a los insumos importados equivale al aumento de las exportaciones brutas.

En el presente capítulo se enfatizan dos componentes que se relacionan de forma directa con las exportaciones de una economía: el valor agregado nacional (directo e indirecto) incorporado en dichas exportaciones y el empleo inducido por estas. El primero puede interpretarse como el aporte de las exportaciones a la creación del producto interno bruto, y el segundo como el aporte de estas a la dinamización del mercado laboral. 
Las matrices de insumo-producto se elaboran a partir de los cuadros de oferta y utilización, que conforman un sistema contable organizado que permite relacionar coherentemente los productos, los sectores económicos y las industrias. Los cuadros de oferta y utilización forman parte del sistema integral de cuentas nacionales y permiten cuantificar una serie de variables que son importantes en el análisis productivo. En primer lugar, permiten cuantificar la oferta de bienes y servicios a nivel sectorial y total, ya sea que se produzcan en la economía nacional o que se obtengan a través de importaciones. Segundo, muestran el uso intermedio de dichos bienes y servicios en los distintos sectores de la economía nacional. Tercero, proporcionan una estimación de la demanda de bienes y servicios finales de los distintos factores de demanda, a saber, los hogares, las exportaciones, la formación bruta de capital fijo y el sector gubernamental. Los cuadros de oferta y utilización proporcionan información detallada respecto del uso que en cada sector se hace de insumos intermedios provenientes de los sectores restantes, así como de la dinámica de generación de valor agregado nacional y su repartición entre los actores de la economía nacional. Así, los cuadros de oferta y utilización proporcionan un marco analítico sistematizado mediante el cual se asegura que las formas alternativas de medición del PIB, contabilizado bien desde el punto de vista de la producción, bien desde el punto de vista del gasto, converjan en un mismo valor.

A pesar de las importantes aplicaciones que las matrices de insumoproducto tienen en el análisis económico — como el análisis de reformas fiscales, la distribución funcional del ingreso, los tratados comerciales, las cadenas globales de valor, el medio ambiente, la energía y el empleo-, las instituciones de la región responsables de las cuentas nacionales de los países y, en particular, de sus cuadros de oferta y utilización, no han construido matrices de insumo-producto como parte de su labor cotidiana, salvo en contadas excepciones. De los diez países a los que la sede subregional de la CEPAL en México da seguimiento, solo en México se cuenta con una larga tradición en la elaboración de matrices de insumo-producto, aun cuando esta se interrumpió por más de dos décadas². Por su parte, en Costa Rica, Honduras y, muy recientemente, la República Dominicana, se comenzaron a elaborar matrices de insumo-producto, en tanto que en los restantes países centroamericanos se elaboran cuadros de oferta y utilización cuya publicación tiene un rezago que varía según el país.

Los países a los que se da seguimiento en la sede subregional de la CEPAL en México son los siguientes: El Salvador, Costa Rica, Cuba, Guatemala, Haití, Honduras, México, Nicaragua, Panamá y la República Dominicana. 
Como parte de la cooperación de la CEPAL, en 2013 se inició un proceso de colaboración con los departamentos de cuentas nacionales de los bancos centrales centroamericanos. En Panamá esta colaboración se canalizó a través del Instituto de Estadística y Censo (INEC). Como resultado, se elaboraron matrices de insumo-producto de Nicaragua, Panamá y la República Dominicana. En lo que respecta a Costa Rica y Honduras no fue necesario elaborarlas, debido a que sus bancos centrales ya las habían construido. En el caso de Guatemala y El Salvador no se contó a tiempo con la información necesaria para llevar a cabo este estudio; no obstante, la CEPAL está trabajando con los bancos centrales de esos países y en un futuro cercano se contará con ella. Sobre la base de las matrices de insumo-producto nacionales se realizaron estudios relacionados con el mercado laboral y el sector exportador de los países seleccionados. Estos estudios se publicaron recientemente ${ }^{3}$. También se elaboró un documento metodológico sobre cómo construir matrices de insumo-producto a partir de cuadros de oferta y utilización ${ }^{4}$.

En el presente capítulo se da un paso adicional y se hace un análisis comparativo de los cinco países de la región sobre los cuales se disponía de matrices de insumo-producto: Costa Rica, Honduras, Nicaragua, Panamá y la República Dominicana. A los efectos de esta comparación, se utilizaron los datos más actualizados disponibles sobre cada país en el momento de llevarse a cabo el estudio. Así, en la República Dominicana se empleó la información de 2010, en Costa Rica y Nicaragua, de 2011, en Panamá, de 2012, y en Honduras, de 2013. Debido a su carácter estructural, analizar información con un rezago temporal de entre cuatro y siete años no limita las conclusiones esenciales del presente capítulo. Además, y dado el mismo carácter estructural y la complejidad de la información, las matrices de insumo-producto suelen elaborarse con un rezago y se actualizan cada varios años.

Las variables clave que se utilizaron como base de comparación son el valor agregado nacional incorporado en las exportaciones de bienes y servicios, y el empleo inducido por estas, lo que se traduce en diferencias entre la capacidad para crear valor agregado nacional por ocupado. Debido a que en los países centroamericanos se han adoptado distintas formas de insertarse en el comercio internacional, ya que algunos se orientan más a la exportación de bienes y otros a las de servicios, resulta de interés caracterizar cómo estas diferencias se reflejan en distintas capacidades de generación respecto de las variables mencionadas.

Véase Comisión Económica para América Latina y el Caribe/Fondo Internacional de Desarrollo Agrícola (CEPAL/FIDA). "Crecimiento inclusivo, política industrial rural y cadenas de valor participativas en América Latina y el Caribe" [en línea] https:/ /www.cepal.org/es/proyectos/ cepal-fida.

$4 \quad$ Véase Minzer y otros (2017). 


\section{B. Valor agregado nacional incorporado en las exportaciones y empleo inducido por estas}

Como se mencionó, el análisis del presente capítulo gira en torno a tres ejes centrales: el valor agregado nacional incorporado en las exportaciones, el empleo inducido por estas, y el cociente de valor agregado por ocupado.

En las tres primeras columnas del cuadro IV.1 se muestra, respectivamente y en relación con los cinco países estudiados, el valor agregado nacional incorporado en las exportaciones de bienes, el incorporado en las exportaciones de servicios y la suma de ambos valores. En términos de cada columna, la primera se desglosa en dos componentes: el valor agregado nacional que se incorpora a las exportaciones de bienes (en forma directa) proveniente de los sectores asociados con los bienes y el valor agregado nacional que se incorpora a las exportaciones de bienes (en forma indirecta) proveniente de los sectores asociados con los servicios. Por ejemplo, en las exportaciones de bienes panameños se incorpora en forma directa un valor agregado de 491 millones de dólares provenientes de los sectores asociados con los bienes, y además se incorpora en forma indirecta un valor agregado de 123 millones de dólares provenientes de los sectores asociados con los servicios. Una explicación análoga se aplica a la segunda y a la tercera columna. Finalmente, en las tres columnas siguientes se muestran las exportaciones brutas de bienes, las de servicios y las totales.

En Panamá hay una notoria diferencia entre el valor agregado incorporado en las exportaciones a partir de los sectores asociados con los bienes y el incorporado a partir de los relacionados con los servicios. En 2012, en la economía panameña se generó un valor agregado nacional total de 10.159 millones de dólares, a partir de 11.792 millones de dólares anuales de exportaciones brutas. Del total, un 94\% correspondía al valor agregado nacional creado en las exportaciones de servicios y un $6 \%$ al valor agregado nacional creado en las exportaciones de bienes.

Este hallazgo coincide con la forma de inserción comercial que se utiliza en el país, en la que se han privilegiado los servicios relacionados con la logística. El sector logístico, que es el pilar más importante de la economía panameña y uno de los más dinámicos, constituye uno de los principales motores de crecimiento del país. El clúster marítimo tiene como eje el Canal de Panamá, en tanto que el clúster logístico y de comercio terrestre y aéreo incluye los servicios de transporte y carga, así como la Zona Libre de Colón. Ambos clústeres tienen como infraestructura común los puertos, a partir de los cuales se desarrolla una cadena de interacciones entre los centros logísticos, el sistema de transporte, la comercialización y el conjunto de servicios asociados. El sector exportador de bienes, por el contrario, es incipiente, y se focaliza en el pescado, los productos del mar y las frutas. 


\section{Cuadro IV.1}

Centroamérica (4 países) y República Dominicana: valor agregado nacional incorporado en las exportaciones de bienes y servicios, y exportaciones brutas de bienes y servicios, por país, 2010-2013

(En millones de dólares nominales anuales)

\begin{tabular}{|c|c|c|c|c|c|c|c|}
\hline \multirow{2}{*}{ País } & \multirow{2}{*}{$\begin{array}{l}\text { Grupo de } \\
\text { sectores }^{a}\end{array}$} & \multicolumn{3}{|c|}{$\begin{array}{l}\text { Valor agregado nacional incorporado } \\
\text { en las exportaciones de bienes y servicios }\end{array}$} & \multicolumn{3}{|c|}{ Exportaciones brutas } \\
\hline & & Bienes & Servicios & Total & Bienes & Servicios & Total \\
\hline \multirow{3}{*}{$\begin{array}{l}\text { Panamá, } \\
2012\end{array}$} & Bienes & 491 & 239 & 698 & & & \\
\hline & Servicios & 123 & 9306 & 9461 & & & \\
\hline & Total & 614 & 9545 & 10159 & 820 & 10972 & 11792 \\
\hline \multirow{3}{*}{$\begin{array}{l}\text { Costa Rica, } \\
2011\end{array}$} & Bienes & 4128 & 246 & 4374 & & & \\
\hline & Servicios & 1418 & 4026 & 5445 & & & \\
\hline & Total & 5547 & 4272 & 9819 & 8081 & 4784 & 12865 \\
\hline \multirow{3}{*}{$\begin{array}{l}\text { República } \\
\text { Dominicana, } \\
2010\end{array}$} & Bienes & 2299 & 328 & 2627 & & & \\
\hline & Servicios & 447 & 4438 & 4885 & & & \\
\hline & Total & 2746 & 4767 & 7512 & 4210 & 5289 & 9499 \\
\hline \multirow{3}{*}{$\begin{array}{l}\text { Nicaragua, } \\
2011\end{array}$} & Bienes & 1833 & 37 & 1870 & & & \\
\hline & Servicios & 289 & 474 & 763 & & & \\
\hline & Total & 2122 & 511 & 2633 & 3010 & 627 & 3636 \\
\hline \multirow{3}{*}{$\begin{array}{l}\text { Honduras, } \\
2013\end{array}$} & Bienes & 2771 & 89 & 2860 & & & \\
\hline & Servicios & 530 & 970 & 1499 & & & \\
\hline & Total & 3301 & 1059 & 4360 & 6681 & 1438 & 8119 \\
\hline
\end{tabular}

Fuente: Elaboración propia, sobre la base de cuadros de oferta y utilización de los bancos centrales e institutos de estadística de los respectivos países.

En las filas correspondientes al grupo de sectores de los bienes y al de los servicios se indica al valor agregado nacional que se incorpora a las exportaciones provenientes de dichos sectores.

Por su parte, el valor agregado nacional total incorporado en las exportaciones costarricenses alcanzó los 9.819 millones de dólares anuales en 2011, obtenidos a partir de 12.865 millones de dólares anuales de exportaciones brutas. La composición del valor agregado nacional difiere significativamente de la de Panamá en cuanto al valor que se incorpora en las exportaciones de bienes y el que se incorpora en las de servicios. Se aprecia un mayor equilibrio comparado con el caso panameño: el grupo de los sectores de los bienes aportó el 56,5\% del total, y el de los sectores de los servicios aportó el $43,5 \%$. Este hallazgo está en línea con la política comercial que se ha seguido en Costa Rica en las últimas décadas. La composición de las exportaciones del país se transformó y pasó de los productos primarios a la manufactura de tecnología media, como dispositivos médicos y componentes electrónicos, y a servicios de mayor sofisticación, como los empresariales. Esta evolución explica que este país exhiba la mayor interacción entre los sectores asociados con los bienes y los relacionados con los servicios. En este sentido, es interesante notar el importante aporte de las exportaciones de bienes costarricenses proveniente de los sectores asociados con los servicios (1.418 millones de dólares anuales), que es bastante superior al que se alcanzó en los restantes países, como se verá más adelante. 
En el caso de la República Dominicana, el valor agregado nacional incorporado en las exportaciones totalizó 7.512 millones de dólares anuales en 2010, alrededor de un 25\% menos que en Panamá y Costa Rica, y se generó a partir de 9.499 millones de dólares anuales de exportaciones brutas. Un 63,5\% del valor agregado se originó en las exportaciones de los sectores asociados a los servicios y un 36,5\% en las de los sectores relacionados con los bienes. Al igual que en el caso costarricense, el modelo dominicano de fomento de las exportaciones recibió un importante impulso en 1990, con la Ley núm. 8-90 sobre Fomento de Zonas Francas. La Ley creó incentivos para las exportaciones, como la reintegración de los derechos y gravámenes aduaneros, los bonos de compensación tributaria y el reembolso del impuesto al valor agregado, entre otros. Posteriormente, el proceso de liberalización del comercio exterior de bienes y servicios tuvo un impulso adicional en 2007 con la incorporación de la República Dominicana al acuerdo de libre comercio con los Estados Unidos y Centroamérica. El sector exportador de servicios ha registrado un importante dinamismo en las tres últimas décadas y, en el período 1990-2015, su valor aumentó un 8,2\% anual. Esta evolución obedece sobre todo al dinamismo del sector turístico y del sector del transporte y el almacenamiento. Los cálculos de valor agregado que se ilustran en el cuadro IV.1 son reflejo de la política comercial dominicana, debido a la cual en el sector de los servicios se concentran casi dos tercios del valor agregado generado en las exportaciones totales.

El valor agregado nacional incorporado en las exportaciones hondureñas totalizó 4.360 millones de dólares anuales en 2013 y se generó a partir de 8.119 millones de dólares de exportaciones brutas. Un $75,7 \%$ provenía del grupo de los sectores asociados con los bienes, y un $24,3 \%$ provenía de los relacionados con los servicios. La economía hondureña es muy abierta y, al igual que en el resto de los países de la región, se ha beneficiado gracias al acuerdo de libre comercio con los Estados Unidos. Las exportaciones tradicionales del país se basan en el café, el banano y los camarones, y en las últimas cuatro décadas se ha sumado la maquila de productos textiles. En el cuadro IV.1 sobresale el valor agregado relativamente bajo que se origina en las exportaciones de servicios de la economía hondureña (1.059 millones de dólares en 2013), que es resultado del peso reducido del sector del turismo y de la poca presencia de otros servicios de exportación.

Finalmente, el valor agregado nacional incorporado en las exportaciones nicaragüenses alcanzó los 2.633 millones de dólares en 2011, el más bajo de los cinco países analizados. Respecto de su composición, un $80,6 \%$ provenía del grupo de los sectores asociados con los bienes y solo un $19,4 \%$ provenía de los sectores relacionados con los servicios. De modo similar a lo sucedido en Honduras y la República Dominicana, durante la década de 1990 se introdujeron 
cambios en la política económica de Nicaragua, que pasó de ser una política basada en el intervencionismo del Estado, con una fuerte inclinación al desarrollo hacia adentro, a ser una política orientada al mercado, con una progresiva apertura comercial. A pesar de esta evolución y del acuerdo de libre comercio firmado con los Estados Unidos y la República Dominicana, que consolidó y amplió el acceso del país a estos mercados, el rendimiento de las exportaciones nicaragüenses continúa siendo frágil. El sector externo del país refleja un fuerte contraste: por un lado, dominan las exportaciones de productos agropecuarios, y, por el otro, sobresalen las exportaciones de zonas francas, principalmente las de productos textiles. El poco valor agregado de las exportaciones se debe, entre otras razones, al escaso proceso de diversificación exportadora, el bajo nivel de inserción en las cadenas de valor y el reducido nivel tecnológico de los procesos productivos. Donde se aprecian las mayores diferencias con respecto a los países restantes es en el valor agregado generado en las exportaciones de servicios, que en Nicaragua solo alcanzó los 511 millones de dólares en 2011. Como se verá en la sección $\mathrm{C}$, este hecho obedece a la existencia de un rezago generalizado en la infraestructura y la logística de los principales sectores de servicios ligados con las exportaciones, entre ellos, los servicios de redes, comercio, finanzas, seguros y turismo ${ }^{5}$.

En el cuadro IV.2 se exhibe un índice que se define como el valor agregado nacional incorporado en las exportaciones sobre las exportaciones brutas. Este índice puede interpretarse como el retorno, en términos de valor agregado, sobre cada dólar exportado. Independientemente del país que se considere, en las exportaciones de servicios se genera un porcentaje de valor agregado por cada dólar exportado que es muy superior al que se observa en las exportaciones de bienes. No obstante, es necesario destacar que, si bien una economía focalizada en la prestación de servicios producirá un mayor valor agregado por cada dólar exportado, esto implicará un menor nivel de encadenamientos $\mathrm{y}$, por lo tanto, una menor capacidad de derrame hacia el resto del sistema productivo nacional ${ }^{6}$.

Los servicios de redes incluyen el suministro de electricidad, gas, agua y saneamiento, el transporte terrestre, aéreo y acuático, y los servicios postales y de telecomunicaciones.

6 El motivo por el que eso ocurre es el siguiente. Según una identidad contable básica, el valor bruto de la producción es igual a la suma del gasto intermedio nacional intersectorial, el valor agregado nacional y las importaciones intermedias. Dado un determinado valor de las importaciones intermedias, un mayor valor agregado implicará un menor nivel de compras intermedias nacionales intersectoriales, $\mathrm{y}$, por lo tanto, un menor nivel de encadenamiento productivo nacional interindustrial. 


\section{Cuadro IV.2}

Centroamérica (4 países) y República Dominicana: valor agregado nacional incorporado en las exportaciones de bienes y servicios con respecto a las exportaciones brutas de bienes y servicios, por país, 2010-2013

(En porcentajes)

\begin{tabular}{|c|c|c|c|c|}
\hline \multirow[b]{2}{*}{ País } & \multirow[b]{2}{*}{$\begin{array}{l}\text { Grupo } \\
\text { de sectores }\end{array}$} & \multicolumn{3}{|c|}{$\begin{array}{l}\text { Proporción de valor agregado generado por cada dólar de bienes } \\
\qquad y \text { servicios exportados }\end{array}$} \\
\hline & & $\begin{array}{c}\text { Valor agregado } \\
\text { incorporado en las } \\
\text { exportaciones de } \\
\text { bienes/exportaciones } \\
\text { de bienes }\end{array}$ & $\begin{array}{c}\text { Valor agregado } \\
\text { incorporado en las } \\
\text { exportaciones de } \\
\text { servicios/exportaciones } \\
\text { de servicios }\end{array}$ & $\begin{array}{l}\text { Valor agregado } \\
\text { incorporado en } \\
\text { el total de las } \\
\text { exportaciones/total } \\
\text { de exportaciones }\end{array}$ \\
\hline \multirow{3}{*}{$\begin{array}{l}\text { Panamá, } \\
2012\end{array}$} & Bienes & 59,9 & 2,2 & 5,9 \\
\hline & Servicios & 15,0 & 84,8 & 80,2 \\
\hline & Total & 74,9 & 87,0 & 86,2 \\
\hline \multirow{3}{*}{$\begin{array}{l}\text { Costa Rica, } \\
2011\end{array}$} & Bienes & 51,1 & 5,1 & 34,0 \\
\hline & Servicios & 17,5 & 84,2 & 42,3 \\
\hline & Total & 68,6 & 89,3 & 76,3 \\
\hline \multirow{3}{*}{$\begin{array}{l}\text { República } \\
\text { Dominicana, } \\
2010\end{array}$} & Bienes & 54,6 & 6,2 & 27,7 \\
\hline & Servicios & 10,6 & 83,9 & 51,4 \\
\hline & Total & 65,2 & 90,1 & 79,1 \\
\hline \multirow{3}{*}{$\begin{array}{l}\text { Nicaragua, } \\
2011\end{array}$} & Bienes & 60,9 & 5,9 & 51,4 \\
\hline & Servicios & 9,6 & 75,6 & 21,0 \\
\hline & Total & 70,5 & 81,5 & 72,4 \\
\hline \multirow{3}{*}{$\begin{array}{l}\text { Honduras, } \\
2013\end{array}$} & Bienes & 41,5 & 6,2 & 35,2 \\
\hline & Servicios & 7,9 & 67,4 & 18,5 \\
\hline & Total & 49,4 & 73,6 & 53,7 \\
\hline
\end{tabular}

Fuente: Elaboración propia, sobre la base de cuadros de oferta y utilización de los bancos centrales e institutos de estadística de los respectivos países.

En términos del total de exportaciones, se observa que Panamá es el país que muestra el mayor índice y genera 0,86 dólares de valor agregado por cada dólar de exportaciones brutas. Este resultado se debe a la alta ponderación que en dicho país tienen las exportaciones de servicios, que constituyen un $94 \%$ del valor agregado total creado en las exportaciones brutas. Por su parte, Costa Rica, la República Dominicana y Nicaragua exhiben un índice que varía entre 0,72 y 0,79 dólares de valor agregado por cada dólar exportado, en tanto que en las exportaciones brutas de Honduras se generan solo 0,53 dólares por cada dólar exportado. Este resultado obedece al bajo valor agregado que se produce en las exportaciones de bienes hondureños, en las que solo se generan 0,49 dólares por cada dólar exportado. Esta última cifra, que en Honduras es sensiblemente menor comparada con el resto de los países analizados, se explica sobre todo por el sector de la fabricación de prendas de vestir, que representa un 35,5\% del total de las exportaciones de bienes hondureños. Las exportaciones brutas de ese sector alcanzaron los 2.376 millones de dólares en 2013, en tanto que el valor agregado nacional 
incorporado en dichas exportaciones totalizó 558 millones de dólares anuales, lo que significa que, por cada dólar exportado, el sector produjo solo 0,23 dólares 7 .

En el cuadro IV.3 se muestra el valor agregado incorporado en las exportaciones y se agrega una estimación del número de empleos que ellas indujeron. En las primeras tres columnas aparecen el valor agregado nacional incorporado en las exportaciones de bienes, el incorporado en las de servicios y el incorporado en el total de las exportaciones, que ya se mencionaron. En la cuarta y la quinta columna figuran el número de empleos inducidos por las exportaciones de bienes y el inducido por las exportaciones de servicios. La sexta columna representa la suma de las dos anteriores, es decir, el número de empleos generado por las exportaciones totales de cada país. Al igual que ocurre con el valor agregado, visto en términos de columnas, el número de empleos inducidos por las exportaciones de bienes se desglosó en dos componentes, a saber, el inducido en los sectores asociados con los bienes (efecto directo) $\mathrm{y}$ el inducido en los sectores asociados con los servicios (efecto indirecto). Por ejemplo, en el caso de Panamá, las exportaciones de bienes indujeron en forma directa 56.154 empleos en los sectores asociados con los bienes, $\mathrm{y}$, en forma indirecta, 2.951 empleos en los sectores de los servicios, lo que da como resultado un total de 59.106 empleos inducidos por las exportaciones totales de bienes. Una descomposición análoga se aplica en la quinta columna (número de empleos inducidos por las exportaciones de servicios) y en la sexta (número de empleos inducidos por las exportaciones totales).

Como se señaló, en las exportaciones de Panamá y Costa Rica se crea un valor agregado similar: alrededor de 10.000 millones de dólares anuales en cada país. Sin embargo, Panamá utiliza alrededor de 256.000 ocupados para generarlo y Costa Rica casi 427.000, es decir, un 167\% más. La principal diferencia se debe a las exportaciones de servicios: en Panamá se genera un valor agregado que es un $123 \%$ superior al de Costa Rica, pero se ocupa un $6 \%$ menos de personal. Esta disparidad, que como se verá a continuación da como resultado una importante diferencia en el valor agregado por ocupado, se debe a diferencias en la naturaleza de los sectores exportadores de servicios de cada país. Mientras que Panamá se especializa en servicios que suponen procesos de transporte logístico con un elevado grado de mecanización y automatización, y un uso intensivo de capital fijo (maquinaria, equipos e infraestructura), Costa Rica lo hace en servicios de exportación orientados a los centros de llamadas y el turismo, que son intensivos en mano de obra y producen menos valor agregado ${ }^{8}$. Otra comparación interesante surge al

En el sector se realizan importaciones intermedias equivalentes a un $38,6 \%$ del total de las importaciones intermedias efectuadas en la economía hondureña y hay muy pocos encadenamientos intersectoriales nacionales.

8 Las diferencias en la orientación exportadora de cada país y sus consecuencias en términos de valor agregado y empleo se analizarán más adelante a nivel sectorial. 
contrastar el valor agregado que se produce en el sector de los servicios de la República Dominicana y el de Costa Rica. En las exportaciones del primero se genera un $11,6 \%$ más de valor agregado, pero para lograrlo se requiere un $80,6 \%$ adicional de personal ocupado.

\section{Cuadro IV.3}

Centroamérica (4 países) y República Dominicana: valor agregado nacional incorporado en las exportaciones de bienes y servicios, y empleo que este induce, por país, 2010-2013

(En millones de dólares nominales anuales y en número de ocupados)

\begin{tabular}{|c|c|c|c|c|c|c|c|}
\hline \multirow{3}{*}{ País } & \multirow{3}{*}{$\begin{array}{l}\text { Grupo de } \\
\text { sectores }\end{array}$} & \multicolumn{6}{|c|}{ Efecto de las exportaciones de bienes y servicios sobre la economía } \\
\hline & & \multicolumn{3}{|c|}{$\begin{array}{c}\text { Valor agregado incorporado } \\
\text { en las exportaciones de bienes } \\
\text { y servicios }\end{array}$} & \multicolumn{3}{|c|}{$\begin{array}{c}\text { Empleo inducido por el valor } \\
\text { agregado incorporado en las } \\
\text { exportaciones de bienes y servicios }\end{array}$} \\
\hline & & Bienes & Servicios & Total & Bienes & Servicios & Total \\
\hline \multirow{3}{*}{$\begin{array}{l}\text { Panamá, } \\
2012\end{array}$} & Bienes & 491 & 239 & 730 & 56154 & 15949 & 72103 \\
\hline & Servicios & 123 & 9306 & 9429 & 2951 & 181205 & 184156 \\
\hline & Total & 614 & 9545 & 10159 & 59106 & 197154 & 256259 \\
\hline \multirow{3}{*}{$\begin{array}{l}\text { Costa Rica, } \\
2011\end{array}$} & Bienes & 4128 & 246 & 4374 & 165893 & 9637 & 175530 \\
\hline & Servicios & 1418 & 4026 & 5445 & 52090 & 199283 & 251372 \\
\hline & Total & 5547 & 4272 & 9819 & 217983 & 208920 & 426902 \\
\hline \multirow{3}{*}{$\begin{array}{l}\text { República } \\
\text { Dominicana, } \\
2010\end{array}$} & Bienes & 2299 & 328 & 2627 & 147058 & 23416 & 170474 \\
\hline & Servicios & 447 & 4438 & 4885 & 25348 & 353990 & 379337 \\
\hline & Total & 2746 & 4767 & 7512 & 172406 & 377406 & 549812 \\
\hline \multirow{3}{*}{$\begin{array}{l}\text { Nicaragua, } \\
2011\end{array}$} & Bienes & 1833 & 37 & 1870 & 511408 & 9398 & 520806 \\
\hline & Servicios & 289 & 474 & 763 & 39189 & 80035 & 119224 \\
\hline & Total & 2122 & 511 & 2633 & 550596 & 89433 & 640029 \\
\hline \multirow{3}{*}{$\begin{array}{l}\text { Honduras, } \\
2013\end{array}$} & Bienes & 2771 & 89 & 2860 & 374748 & 14151 & 388899 \\
\hline & Servicios & 530 & 970 & 1499 & 43154 & 101613 & 144767 \\
\hline & Total & 3301 & 1059 & 4360 & 417901 & 115764 & 533665 \\
\hline
\end{tabular}

Fuente: Elaboración propia, sobre la base de cuadros de oferta y utilización de los bancos centrales e institutos de estadística de los respectivos países.

Para realizar una comparación más sistemática de la relación entre el valor agregado nacional incorporado en las exportaciones y el número de empleos inducido por estas, en el cuadro IV.4 se muestra el cociente entre ambas variables, que puede interpretarse como un índice de productividad laboral.

Se observa que Panamá tiene la mayor productividad laboral, con un cociente de valor agregado incorporado en sus exportaciones de 39.642 dólares anuales por ocupado. Este valor se debe al alto índice de productividad originado en las exportaciones de servicios (48.414 dólares anuales por ocupado), que supera en alrededor de 28.000 dólares anuales (137\%) el valor que se alcanza en Costa Rica, país que le sigue en orden decreciente. Como se señaló antes, este resultado obedece a diferencias en el tipo de servicios de 
exportación que cada país ofrece. En Costa Rica y la República Dominicana se registra un cociente de valor agregado incorporado en sus exportaciones de 23.000 y 13.663 dólares anuales por ocupado, respectivamente. En ambos países se observa un fenómeno contrario al caso panameño, ya que son las exportaciones de bienes las que dan lugar a un mayor cociente de productividad laboral. Esto se debe a que las exportaciones de bienes de los dos países, especialmente de Costa Rica, se posicionan en un nivel de las cadenas de valor que es superior al que se alcanza en las exportaciones de bienes panameños, que se concentran en el sector primario.

\section{Cuadro IV.4}

Centroamérica (4 países) y República Dominicana: valor agregado por ocupado incorporado en las exportaciones de bienes y servicios, por país, 2010-2013

(En dólares nominales anuales)

\begin{tabular}{|c|c|c|c|c|}
\hline País & $\begin{array}{l}\text { Grupo de } \\
\text { sectores }\end{array}$ & $\begin{array}{c}\text { Valor agregado por } \\
\text { ocupado incorporado } \\
\text { en las exportaciones } \\
\text { de bienes }\end{array}$ & $\begin{array}{c}\text { Valor agregado por } \\
\text { ocupado incorporado } \\
\text { en las exportaciones } \\
\text { de servicios }\end{array}$ & $\begin{array}{l}\text { Valor agregado } \\
\text { por ocupado } \\
\text { incorporado en las } \\
\text { exportaciones totales }\end{array}$ \\
\hline \multirow{3}{*}{$\begin{array}{l}\text { Panamá, } \\
2012\end{array}$} & Bienes & 8745 & 14989 & 10126 \\
\hline & Servicios & 41550 & 51356 & 51199 \\
\hline & Total & 10383 & 48414 & 39642 \\
\hline \multirow{3}{*}{$\begin{array}{l}\text { Costa Rica, } \\
2011\end{array}$} & Bienes & 24885 & 25520 & 24920 \\
\hline & Servicios & 27227 & 20204 & 21659 \\
\hline & Total & 25445 & 20449 & 23000 \\
\hline \multirow{3}{*}{$\begin{array}{l}\text { República } \\
\text { Dominicana, } \\
2010\end{array}$} & Bienes & 15631 & 14015 & 15409 \\
\hline & Servicios & 17631 & 12538 & 12878 \\
\hline & Total & 15925 & 12630 & 13663 \\
\hline \multirow{3}{*}{$\begin{array}{l}\text { Nicaragua, } \\
2011\end{array}$} & Bienes & 3584 & 3929 & 3590 \\
\hline & Servicios & 7383 & 5924 & 6403 \\
\hline & Total & 3854 & 5714 & 4114 \\
\hline \multirow{3}{*}{$\begin{array}{l}\text { Honduras, } \\
2013\end{array}$} & Bienes & 7395 & 6309 & 7355 \\
\hline & Servicios & 12271 & 9545 & 10358 \\
\hline & Total & 7898 & 9150 & 8170 \\
\hline
\end{tabular}

Fuente: Elaboración propia, sobre la base de cuadros de oferta y utilización de los bancos centrales e institutos de estadística de los respectivos países.

Por último, Honduras y Nicaragua exhiben los menores índices de valor agregado incorporado en las exportaciones por ocupado: 8.170 y 4.114 dólares anuales, respectivamente. Dada la alta ponderación de las exportaciones de bienes en ambos países, que representan alrededor de un $82 \%$ de las exportaciones totales, son estas las que determinan en mayor medida el valor del índice. El valor agregado incorporado por ocupado en las exportaciones de bienes de Honduras constituye alrededor de la mitad del que se estima en relación con la República Dominicana y solo un 30\% del de Costa Rica. Por su parte, el incorporado en las exportaciones de bienes de Nicaragua 
equivale a alrededor de la cuarta parte del de la República Dominicana y solo un $15 \%$ del que se calcula respecto a Costa Rica. Hay varios factores que explican lo anterior, y se resumen en la menor intensidad tecnológica de los procesos productivos y en los bienes y servicios exportados.

Para profundizar el análisis, en el cuadro IV.5 se ilustra la estructura porcentual del valor agregado (directo e indirecto) incorporado en las exportaciones de bienes, así como del empleo inducido por él, por sector económico y país ${ }^{9}$. Ambas variables se expresan en porcentajes del valor agregado y del empleo total generado en las exportaciones, así como en valores absolutos (en millones de dólares nominales y en número de empleos, respectivamente) ${ }^{10}$.

Se observa que, en los cinco países considerados, la participación del sector agrícola en el valor agregado total generado en las exportaciones de bienes de la economía en su conjunto es notoriamente inferior a la participación de dicho sector en el número de empleos que dichas exportaciones inducen. En otras palabras, en los cinco países analizados, las exportaciones del conjunto de sectores de bienes generan proporcionalmente mucho más empleo que valor agregado en el sector agrícola, lo que implica una baja capacidad de creación de valor agregado por ocupado en ese sector. Por el contrario, el efecto de las exportaciones del conjunto de sectores de bienes en el sector de los alimentos, las bebidas y el tabaco, así como en el sector del petróleo, los productos químicos, los plásticos y los productos de caucho, es proporcionalmente mayor en la producción de valor agregado nacional que en el empleo, lo que implica que el valor agregado por ocupado en ambos sectores es alto en términos relativos. Esta última relación se encontró también en el sector de la maquinaria general y el de los otros productos eléctricos y electrónicos en el caso de Costa Rica; en el de las minas y canteras en Panamá y Nicaragua; en el de los textiles, el cuero y el calzado en Honduras y Nicaragua, y en el de los equipos de transporte en Honduras. En términos generales, este hallazgo significa que en estos sectores dichos países participan en eslabones relativamente avanzados de las cadenas de valor.

El valor agregado directo se deriva de las compras de insumos que los integrantes de un determinado sector hacen dentro del mismo sector, en tanto que el valor agregado indirecto se obtiene a partir de las compras que los integrantes de dicho sector hacen a los sectores restantes de la economía nacional. Los cálculos realizados en el presente capítulo incluyen tanto el valor agregado directo como el indirecto. Un concepto similar se aplica al número de empleos (directos e indirectos) generados a partir de las compras de insumos entre los sectores.

10 Como se infiere a partir de los datos del cuadro IV.5, los sectores exportadores de bienes de la economía hondureña generan 869 millones de dólares de valor agregado en el sector agrícola e inducen 248.651 empleos en ese sector. La participación del sector agrícola en el valor agregado, derivada del total de exportaciones de bienes hondureños, alcanza un 26,3\%, en tanto que la participación en el número de empleos llega a un 59,5\% del total de empleos inducidos por las exportaciones de bienes hondureños. 


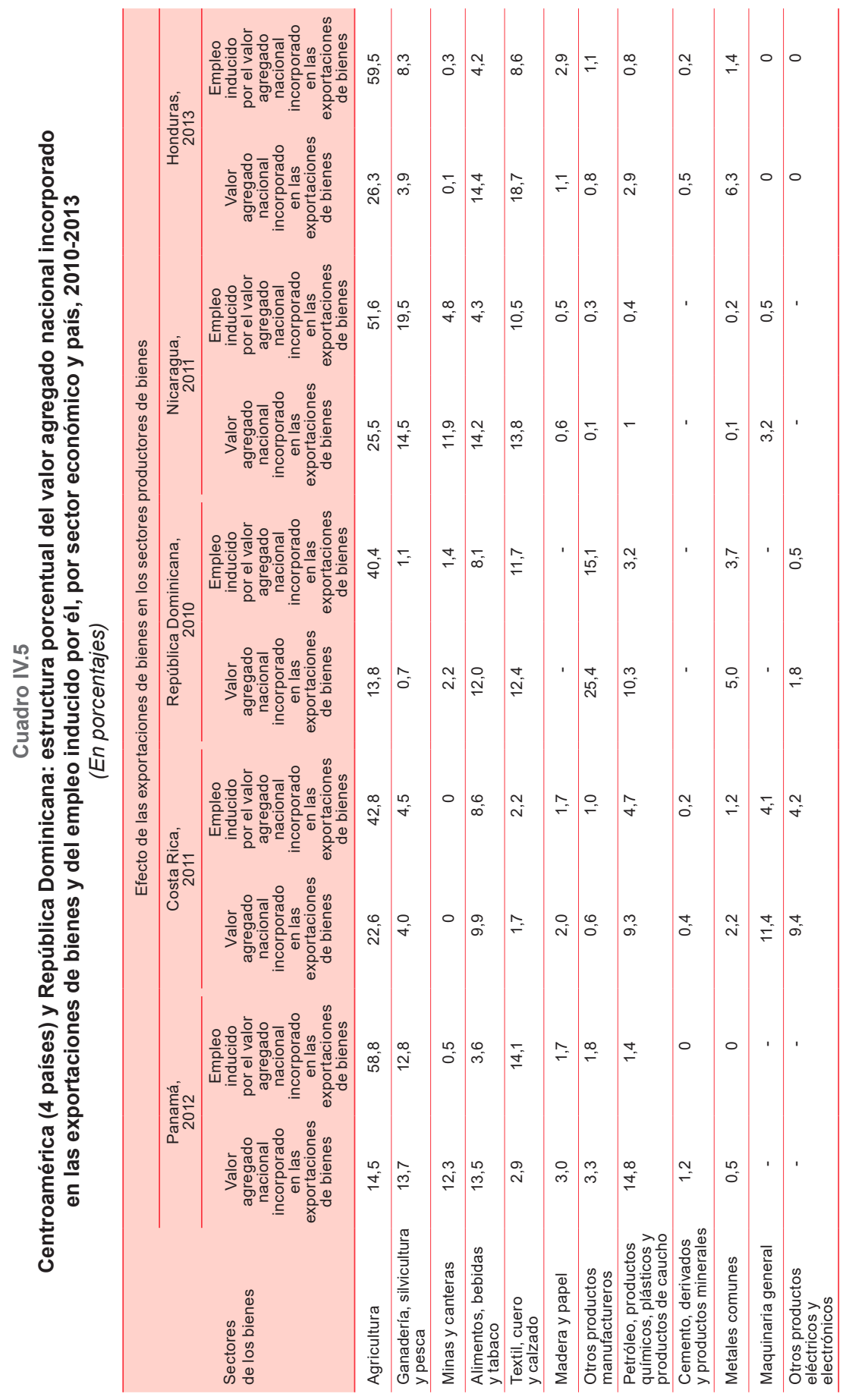




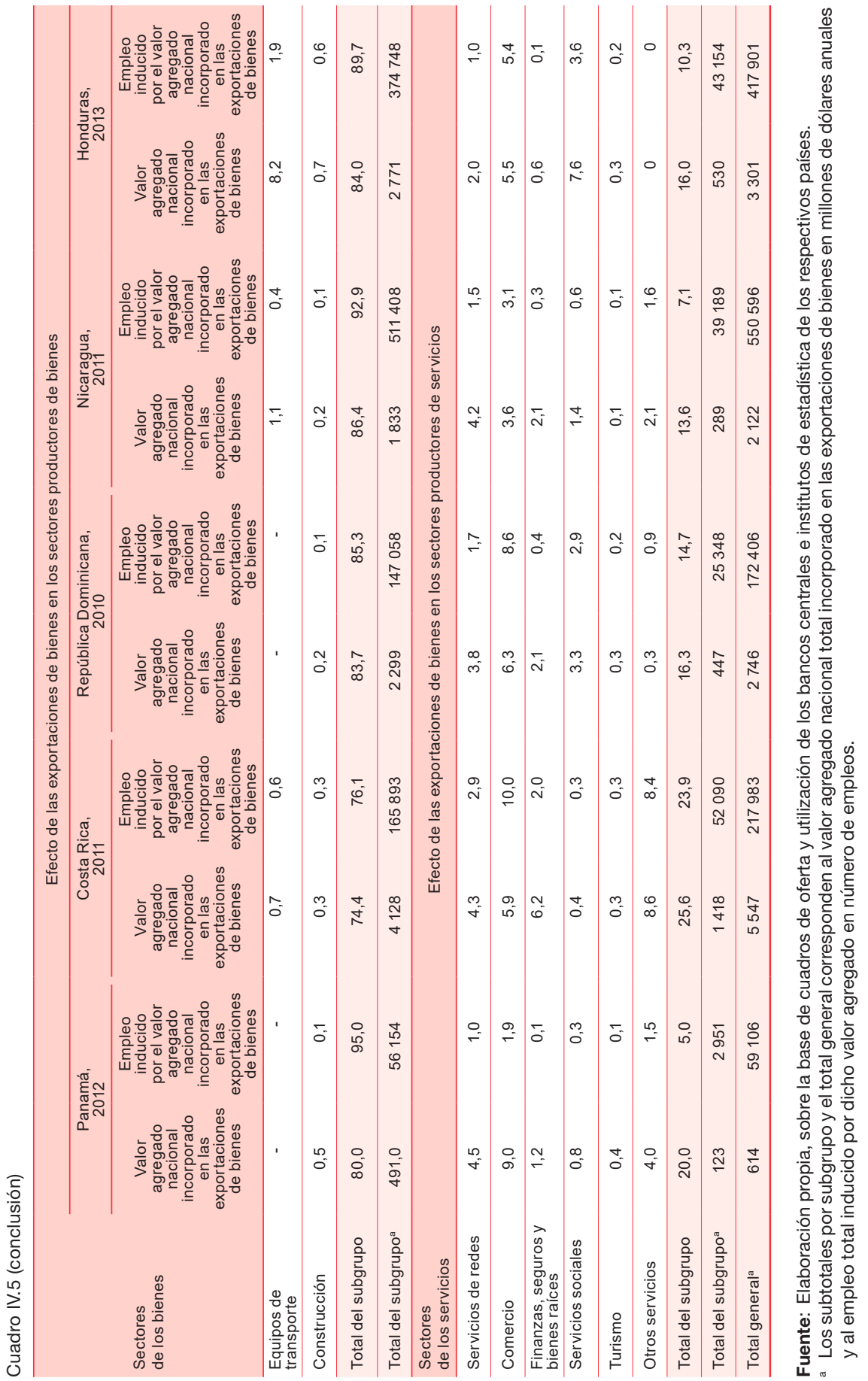


En la parte inferior del cuadro IV.5 se muestra el efecto de las exportaciones de bienes sobre los sectores asociados con los servicios. Costa Rica es el país donde se observa la mayor sinergia entre los sectores de servicios y las exportaciones de bienes, con una generación de 1.418 millones de dólares anuales de valor agregado y alrededor de 52.000 empleos en 2011, principalmente gracias al sector de los servicios de redes, el del comercio, el de las finanzas, los seguros y los bienes raíces, y el de otros servicios. Este hallazgo sugiere que el equilibrio entre el valor agregado que se crea en las exportaciones de bienes y el que se crea en las exportaciones de servicios, sumado a una mayor diversificación exportadora y a una inserción en niveles más avanzados de las cadenas de valor, produce una mayor sinergia entre ambos grupos de sectores. Por el contrario, Panamá exhibe la menor sinergia entre los sectores asociados con los bienes y los relacionados con los servicios, ya que las exportaciones de bienes generan 123 millones de dólares de valor agregado y alrededor de 3.000 empleos en los sectores de los servicios. Esto se debe al incipiente nivel de desarrollo del sector productor y exportador de bienes panameños. Los restantes países se encuentran en el medio de estos dos extremos.

El cuadro IV.6 complementa el cuadro IV.5: en la parte superior se exhibe el valor agregado que las exportaciones totales de bienes de cada país inducen por ocupado de cada sector exportador de bienes, en tanto que en la parte inferior se muestra el valor agregado que inducen por ocupado de cada sector exportador de servicios.

Se observa el escaso valor agregado por ocupado que las exportaciones totales de bienes inducen en el sector agrícola, evolución que viene acompañada por una gran heterogeneidad en dicho valor. En el sector agrícola de cuatro de los cinco países estudiados, las exportaciones de bienes inducen un valor agregado por ocupado que va desde 1.900 dólares en Nicaragua hasta 5.400 dólares en la República Dominicana. Estos se encuentran entre los valores sectoriales más bajos de los respectivos países. Aun en el caso de Costa Rica, en cuyo sector agrícola se registra un valor significativamente superior que asciende a 13.427 dólares por ocupado, este se ubica en el último lugar entre los sectores exportadores de bienes del país. Esto es relevante por tratarse de un sector cuya participación en las exportaciones de cada país es importante, que además genera un porcentaje significativo del empleo inducido por las exportaciones en todos ellos. Existen varias razones que podrían explicar el mayor valor agregado por ocupado que las exportaciones de bienes costarricenses inducen en el sector agrícola en comparación con los restantes países. Entre ellas, se podría citar la mayor diversificación exportadora intrasectorial orientada a productos de mayor valor agregado, que daría como resultado un nivel superior de inserción en las cadenas de valor. Asimismo, es posible que en el país se use más tecnología en los procesos productivos agrícolas, lo que liberaría mano de obra hacia otros sectores. 


\section{Cuadro IV.6 \\ Centroamérica (4 países) y República Dominicana: valor agregado por ocupado incorporado en las exportaciones de bienes, por sector económico y país, 2010-2013}

(En dólares anuales)

\begin{tabular}{|c|c|c|c|c|c|}
\hline \multirow[b]{2}{*}{ Sectores de los bienes } & \multicolumn{5}{|c|}{$\begin{array}{l}\text { Valor agregado por ocupado incorporado en las exportaciones } \\
\text { de bienes en los sectores productores de bienes }\end{array}$} \\
\hline & $\begin{array}{l}\text { Panamá, } \\
2012\end{array}$ & $\begin{array}{l}\text { Costa Rica, } \\
\quad 2011\end{array}$ & $\begin{array}{c}\text { República } \\
\text { Dominicana, } \\
2010\end{array}$ & $\begin{array}{l}\text { Nicaragua, } \\
2011\end{array}$ & $\begin{array}{l}\text { Honduras, } \\
2013\end{array}$ \\
\hline Agricultura & 2556 & 13427 & 5421 & 1909 & 3491 \\
\hline Ganadería, silvicultura y pesca & 11094 & 22499 & 10436 & 2868 & 3741 \\
\hline Minas y canteras & 248983 & 40056 & 24904 & 9630 & 3749 \\
\hline Alimentos, bebidas y tabaco & 38586 & 29441 & 23550 & 12871 & 27223 \\
\hline Textil, cuero y calzado & 2148 & 19183 & 16802 & 5088 & 17191 \\
\hline Madera y papel & 17928 & 29320 & - & 4538 & 3059 \\
\hline Otros productos manufactureros & 18814 & 14960 & 26853 & 1497 & 5744 \\
\hline $\begin{array}{l}\text { Petróleo, productos químicos, } \\
\text { plásticos y productos de caucho }\end{array}$ & 106257 & 50263 & 50943 & 9638 & 28634 \\
\hline $\begin{array}{l}\text { Cemento, derivados } \\
\text { y productos minerales }\end{array}$ & 682420 & 44760 & - & - & 20036 \\
\hline Metales comunes & 110417 & 45697 & 21621 & 3053 & 35648 \\
\hline Maquinaria general & - & 71251 & - & 26916 & - \\
\hline $\begin{array}{l}\text { Otros productos eléctricos } \\
\text { y electrónicos }\end{array}$ & - & 57405 & 57574 & - & - \\
\hline Equipos de transporte & - & 29519 & - & 12340 & 34615 \\
\hline Construcción & 44831 & 27725 & 26517 & 4715 & 9096 \\
\hline $\begin{array}{l}\text { Valor agregado por ocupado } \\
\text { del subgrupo }\end{array}$ & 8745 & 24885 & 15631 & 3584 & 7395 \\
\hline Sector de los servicios & \multicolumn{5}{|c|}{$\begin{array}{l}\text { Valor agregado por ocupado incorporado en las exportaciones } \\
\text { de bienes en los sectores productores de servicios }\end{array}$} \\
\hline Servicios de redes & 46618 & 36781 & 36027 & 10829 & 15439 \\
\hline Comercio & 49866 & 15101 & 11767 & 4600 & 8052 \\
\hline $\begin{array}{l}\text { Finanzas, seguros } \\
\text { y bienes raíces }\end{array}$ & 104593 & 77477 & 80607 & 29201 & 75524 \\
\hline Servicios sociales & 23407 & 35537 & 18565 & 8872 & 16502 \\
\hline Turismo & 31457 & 23832 & 22784 & 5129 & 12226 \\
\hline Otros servicios & 27948 & 26066 & 5732 & 5283 & - \\
\hline $\begin{array}{l}\text { Valor agregado por ocupado } \\
\text { del subgrupo }\end{array}$ & 41550 & 27227 & 17631 & 7383 & 12271 \\
\hline $\begin{array}{l}\text { Valor agregado por ocupado } \\
\text { de la economía }\end{array}$ & 10383 & 25445 & 15925 & 3854 & 7898 \\
\hline
\end{tabular}

Fuente: Elaboración propia, sobre la base de cuadros de oferta y utilización de los bancos centrales e institutos de estadística de los respectivos países. 
La importante heterogeneidad sectorial que existe en el valor agregado por ocupado que las exportaciones totales de bienes inducen no es una característica exclusiva del sector agrícola, sino que se extiende a la mayoría de los demás sectores. Por ejemplo, un sector importante de la economía costarricense - el del petróleo, los productos químicos, los plásticos y los productos de caucho - exhibe un alto valor (50.263 dólares anuales), que es similar al que se alcanza en la República Dominicana, pero es mucho mayor que el de Nicaragua (9.638 dólares anuales) y el de Honduras (28.634 dólares anuales). En otro sector de importancia en la economía costarricense - el de la maquinaria general- se observa un valor mucho mayor que en Nicaragua, en tanto que en los tres países restantes dicho sector es inexistente. Algo similar ocurre con el sector de los otros productos eléctricos y electrónicos, que en Costa Rica y en la República Dominicana alcanza un alto valor, pero en Panamá, Nicaragua y Honduras es inexistente. En el caso del sector de los alimentos, las bebidas y el tabaco, se observa cierta homogeneidad en el valor agregado por ocupado inducido por las exportaciones totales de bienes, salvo en Nicaragua, país que exhibe un valor marcadamente inferior al de los restantes países. Por su parte, en lo que respecta a las exportaciones del sector de los productos textiles, el cuero y el calzado, que son de especial importancia en la República Dominicana, Honduras y Nicaragua, el valor de este último país es significativamente inferior al de los otros dos países.

Estos hallazgos apuntan a que las diferencias en el valor agregado por ocupado inducido por las exportaciones totales de bienes en las economías de los países estudiados se explican fundamentalmente por las diferencias que se encuentran a nivel sectorial, sumadas al hecho de que algunos sectores que generan un alto valor agregado por ocupado en determinados países son inexistentes en otros.

En la parte inferior del cuadro IV.6 se muestra el efecto de las exportaciones de bienes en el valor agregado que se crea por ocupado en los sectores asociados con los servicios. En Panamá, las exportaciones de bienes dan lugar al mayor cociente de valor agregado por ocupado en los sectores productores de servicios (41.550 dólares). Como se señaló, esto se debe a la importante inversión en infraestructura logística automatizada puesta al servicio de las exportaciones de dicho país. Este resultado positivo se encuentra limitado debido al incipiente desarrollo del sector exportador de bienes del país. En otras palabras, aun cuando las exportaciones de bienes producen un alto valor agregado por ocupado en los sectores de los servicios, dado que el sector exportador de bienes es incipiente en Panamá, esto se traduce en la obtención de solo 123 millones de dólares en términos absolutos (véase el cuadro IV.5). En cuanto al efecto de las exportaciones de bienes en el valor agregado por ocupado generado en los sectores de los servicios, a Panamá le siguen, en orden decreciente, Costa Rica (27.227 dólares), la República Dominicana (17.631 dólares), Honduras (12.271 dólares) y Nicaragua (7.383 dólares). 
Es interesante notar que, en los cinco países estudiados, el sector de los servicios más beneficiado a partir de las exportaciones de bienes es el de las finanzas, los seguros y los bienes raíces. Sin embargo, también en este aspecto se advierte una importante heterogeneidad. Mientras que en Panamá las exportaciones de bienes inducen en este sector un valor agregado por ocupado de 104.593 dólares anuales, en Nicaragua esta cifra llega a solo 29.201 dólares anuales. Otros sectores asociados con los servicios que se benefician de las exportaciones de bienes son el de los servicios de redes, el del comercio y el del turismo.

En el cuadro IV.7 se muestra la estructura porcentual del valor agregado (directo e indirecto) incorporado en las exportaciones de servicios y la del empleo inducido por él, por sector económico y país. Dado que la parte superior del cuadro, en la que se muestra el efecto de las exportaciones de servicios sobre los sectores productores de bienes, no resulta muy significativa, la discusión se centrará en la parte inferior, que exhibe el efecto de las exportaciones de servicios sobre los propios sectores productores de servicios.

A nivel agregado, el mayor efecto se registra en Panamá, donde el valor agregado incorporado en las exportaciones de servicios totaliza 9.306 millones de dólares anuales en los sectores de los servicios; los dos sectores más beneficiados son el de los servicios de redes $(38,6 \%)$ y el del comercio $(36,2 \%)^{11}$. Le sigue en orden decreciente la República Dominicana, con un valor de 4.438 millones de dólares anuales que se centran principalmente en el turismo $(29,9 \%)$, los servicios de redes $(24,5 \%)$ y el comercio $(16,2 \%)$. En tercer lugar, se ubica Costa Rica, con 4.026 millones de dólares anuales focalizados en el sector de los otros servicios (51,5\%) y, en menor medida, en el del turismo $(14,1 \%)$ y el de los servicios de redes $(11,3 \%)^{12}$. El cuarto lugar lo ocupa Honduras, cuyas exportaciones de servicios generan en el propio sector un valor agregado de 970 millones de dólares anuales: los que más se benefician son los servicios de redes $(29,2 \%)$, el comercio $(24,3 \%)$, el turismo $(19,1 \%)$ y los servicios sociales (18\%). Finalmente, las exportaciones nicaragüenses de servicios generan 474 millones de dólares anuales de valor agregado en el propio sector, principalmente en el comercio (30,9\%) y los servicios de redes $(28,5 \%)$.

11 Como ya se mencionó, los servicios de redes incluyen el suministro de electricidad, gas, agua y saneamiento, el transporte terrestre, aéreo y acuático, y los servicios postales y de telecomunicaciones.

12 El sector de los otros servicios incluye una gran variedad de servicios profesionales, entre los que se cuentan los servicios de contabilidad, consultoría, publicidad, medicina, alquiler, agencias de empleo, viajes, seguridad, investigación, administración, reparación, peluquería, servicios domésticos y otros. 


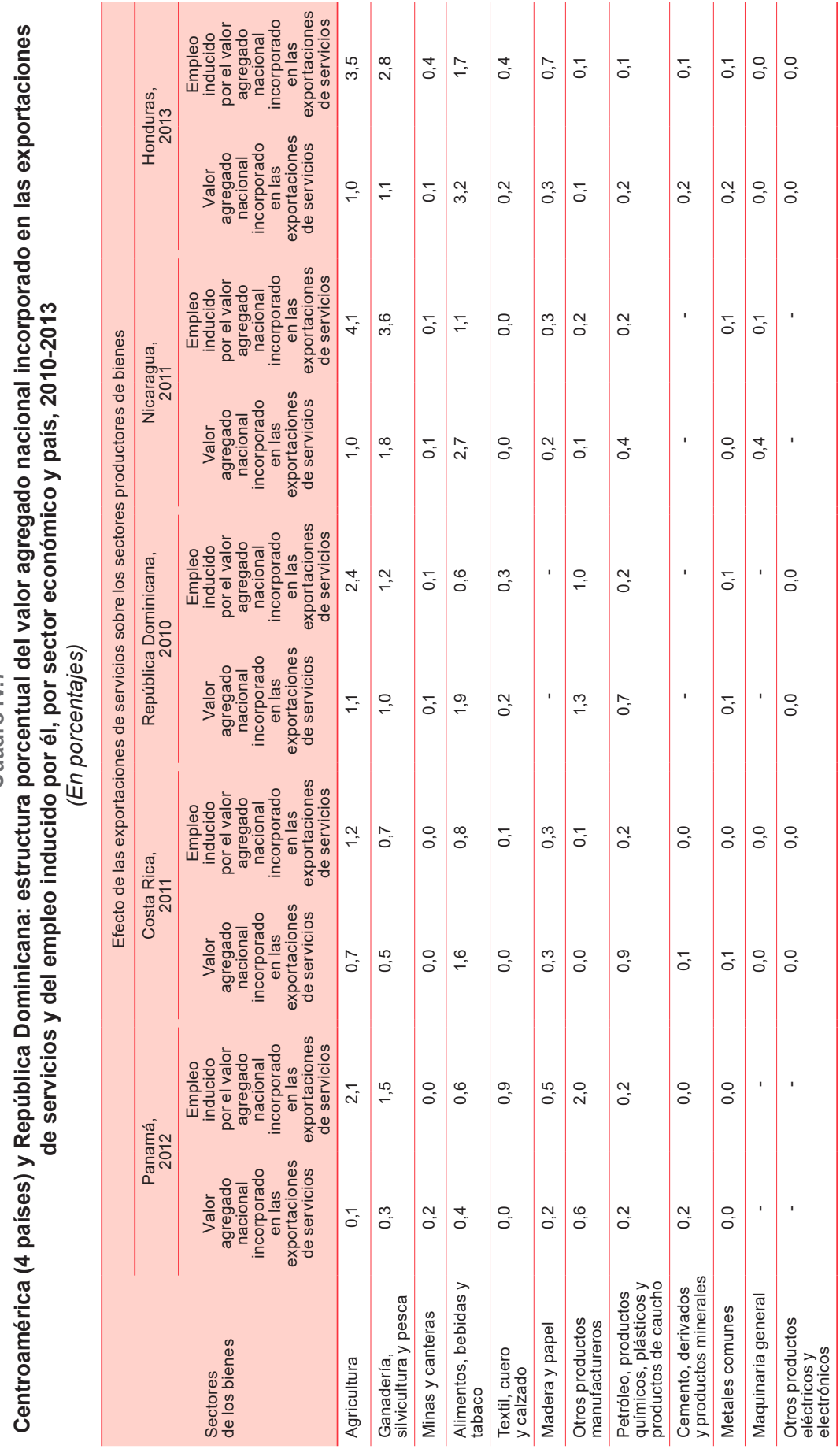




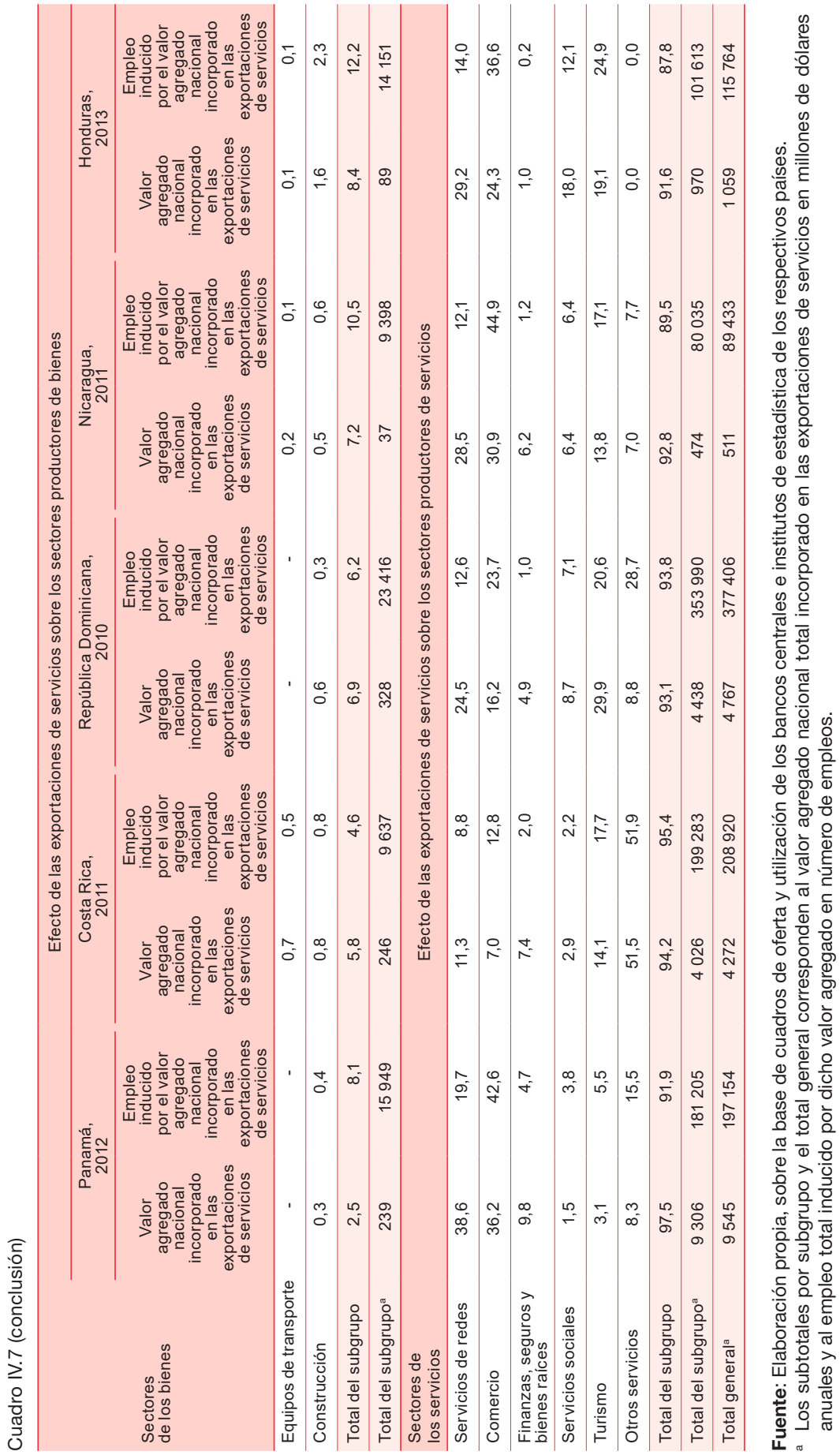


El cuadro IV.8 complementa el cuadro IV.7. En la parte superior se exhibe el valor agregado por ocupado inducido por las exportaciones de servicios de cada país en los sectores de bienes, en tanto que en la parte inferior se muestra el valor inducido por esas exportaciones en los propios sectores de servicios de cada país. Por las razones señaladas, el análisis se focalizará en la parte inferior del cuadro. Se aprecia que el sector de los servicios que más se beneficia en la economía panameña es el de las finanzas, los seguros y los bienes raíces, con un valor agregado por ocupado de 100.621 dólares anuales. Este sector ocupa también el primer lugar en los restantes países, pero con diferencias que es importante destacar. En la República Dominicana y Costa Rica, el valor agregado por ocupado del sector alcanza 64.880 y 77.856 dólares anuales, respectivamente, cifras bastante superiores a las que se registran en Honduras (46.233 dólares anuales) y Nicaragua (29.144 dólares anuales). En el segundo sector de los servicios que exhibe el mayor valor agregado por ocupado, a saber, el de los servicios de redes, también se observa una gran heterogeneidad entre los países. El valor promedio por ocupado en Panamá alcanza los 94.820 dólares anuales, lo que supera ampliamente al valor alcanzado en Costa Rica (26.275 dólares anuales), la República Dominicana (24.615 dólares anuales), Honduras (19.120 dólares anuales) y Nicaragua (13.416 dólares anuales). Aun cuando la participación del sector del comercio en el valor agregado total inducido por las exportaciones de servicios resulta de importancia tanto en Nicaragua (30,9\%) como en Honduras $(24,3 \%)$, el valor agregado producido por ocupado en ambos países es bajo y se sitúa en solo 3.928 y 6.081 dólares anuales, respectivamente. Algo similar se puede señalar respecto del sector de los servicios de redes y el sector del turismo en ambos países.

\section{Cuadro IV.8 \\ Centroamérica (4 países) y República Dominicana: valor agregado por ocupado incorporado en las exportaciones de servicios, por sector económico y país, 2010-2013 \\ (En dólares anuales)}

\begin{tabular}{|c|c|c|c|c|c|}
\hline \multirow[b]{2}{*}{ Sectores de los bienes } & \multicolumn{5}{|c|}{$\begin{array}{l}\text { Efecto de las exportaciones de servicios sobre los sectores } \\
\text { productores de bienes }\end{array}$} \\
\hline & $\begin{array}{l}\text { Panamá, } \\
2012\end{array}$ & $\begin{array}{l}\text { Costa Rica, } \\
2011\end{array}$ & $\begin{array}{c}\text { República } \\
\text { Dominicana, } \\
2010\end{array}$ & $\begin{array}{l}\text { Nicaragua, } \\
2011\end{array}$ & $\begin{array}{l}\text { Honduras, } \\
2013\end{array}$ \\
\hline Agricultura & 2711 & 12264 & 5848 & 1448 & 2665 \\
\hline $\begin{array}{l}\text { Ganadería, silvicultura } \\
\text { y pesca }\end{array}$ & 10025 & 15615 & 9856 & 2758 & 3622 \\
\hline Minas y canteras & 239834 & 29242 & 20278 & 9245 & 2519 \\
\hline $\begin{array}{l}\text { Alimentos, bebidas } \\
\text { y tabaco }\end{array}$ & 31771 & 41744 & 36990 & 14301 & 16816 \\
\hline Textil, cuero y calzado & 1835 & 12005 & 7545 & 2619 & 6309 \\
\hline Madera y papel & 19890 & 18443 & - & 4083 & 3954 \\
\hline
\end{tabular}


Cuadro IV.8 (conclusión)

\begin{tabular}{|c|c|c|c|c|c|}
\hline \multirow[b]{2}{*}{ Sectores de los bienes } & \multicolumn{5}{|c|}{$\begin{array}{l}\text { Efecto de las exportaciones de servicios sobre los sectores } \\
\text { productores de bienes }\end{array}$} \\
\hline & $\begin{array}{l}\text { Panamá, } \\
2012\end{array}$ & $\begin{array}{l}\text { Costa Rica, } \\
2011\end{array}$ & $\begin{array}{l}\text { República } \\
\text { Dominicana, } \\
2010\end{array}$ & $\begin{array}{l}\text { Nicaragua, } \\
2011\end{array}$ & $\begin{array}{l}\text { Honduras, } \\
2013\end{array}$ \\
\hline $\begin{array}{l}\text { Otros productos } \\
\text { manufactureros }\end{array}$ & 14960 & 10458 & 17137 & 1250 & 8397 \\
\hline $\begin{array}{l}\text { Petróleo, productos } \\
\text { químicos, plásticos } \\
\text { y productos de caucho }\end{array}$ & 52984 & 96285 & 43666 & 12323 & 15134 \\
\hline $\begin{array}{l}\text { Cemento, derivados } \\
\text { y productos minerales }\end{array}$ & 605201 & 37253 & - & - & 16802 \\
\hline Metales comunes & 60689 & 34718 & 16077 & 1807 & 23435 \\
\hline Maquinaria general & - & 46094 & - & 16946 & - \\
\hline $\begin{array}{l}\text { Otros productos } \\
\text { eléctricos y electrónicos }\end{array}$ & - & 44975 & 35113 & - & - \\
\hline Equipo de transporte & - & 27818 & - & 11474 & 22242 \\
\hline Construcción & 41552 & 21863 & 21630 & 4102 & 6318 \\
\hline $\begin{array}{l}\text { Valor agregado por } \\
\text { ocupado del subgrupo }\end{array}$ & 14989 & 25520 & 14015 & 3929 & 6309 \\
\hline Sectores de los servicios & \multicolumn{5}{|c|}{$\begin{array}{l}\text { Efecto de las exportaciones de servicios sobre los sectores } \\
\text { productores de servicios }\end{array}$} \\
\hline Servicios de redes & 94820 & 26275 & 24615 & 13416 & 19120 \\
\hline Comercio & 41135 & 11229 & 8635 & 3928 & 6081 \\
\hline $\begin{array}{l}\text { Finanzas, seguros } \\
\text { y bienes raíces }\end{array}$ & 100621 & 77856 & 64880 & 29144 & 46233 \\
\hline Servicios sociales & 19023 & 27103 & 15393 & 5661 & 13587 \\
\hline Turismo & 27126 & 16277 & 18328 & 4631 & 7024 \\
\hline Otros servicios & 25827 & 20269 & 3876 & 5155 & - \\
\hline $\begin{array}{l}\text { Valor agregado por } \\
\text { ocupado del subgrupo }\end{array}$ & 51356 & 20204 & 12538 & 5924 & 9545 \\
\hline $\begin{array}{l}\text { Valor agregado por } \\
\text { ocupado de la economía }\end{array}$ & 48414 & 20449 & 12630 & 5714 & 9150 \\
\hline
\end{tabular}

Fuente: Elaboración propia, sobre la base de cuadros de oferta y utilización de los bancos centrales e institutos de estadística de los respectivos países.

\section{Integración económica regional}

En esta sección se analizan aspectos relacionados con la integración centroamericana, desde una perspectiva del valor agregado y el empleo. Si bien este análisis arroja luces sobre la generación de valor agregado nacional y de empleo como resultado de la integración regional, no está exento de limitaciones metodológicas, que se exponen a continuación. 
Como se señaló en la introducción, el análisis que se presenta en este capítulo se basa en una elaboración previa de matrices de insumo-producto nacionales, a partir de cuadros de oferta y utilización elaborados por los bancos centrales e institutos de estadística de los países ${ }^{13}$. A partir de los datos disponibles en la Solución Comercial Integrada Mundial (WITS), se obtuvieron las exportaciones de bienes de cada país a nivel sectorial, y por país o región de destino. Este proceso se llevó a cabo cuadrando el total exportado de cada sector según el WITS con el que se indicaba en los cuadros de oferta y utilización de cada país estudiado. Debido a la falta de datos sobre las exportaciones de los sectores de los servicios por destino comercial, el análisis se limitó a las exportaciones de bienes. Esta limitante es importante en los casos de Panamá y la República Dominicana, países en los que solo un 6\% y un $36,5 \%$ del valor agregado inducido por las exportaciones, respectivamente, se deriva de los bienes, y en los que la mayor parte del valor agregado se crea a través de las exportaciones de servicios. La limitante es menos grave en los tres países restantes - Costa Rica, Honduras y Nicaragua-, en los que un $56,5 \%$, un $75,7 \%$ y un $80,6 \%$ del valor agregado, respectivamente, se origina a partir de las exportaciones de bienes.

Otra limitación metodológica es que el análisis de la integración regional que se presenta en lo que sigue se basa en matrices de insumoproducto nacionales y no en una matriz de insumo-producto regional, que proporcionaría un marco analítico ideal para analizar la integración centroamericana ${ }^{14}$. En particular, en este análisis no se diferencia entre los insumos intermedios importados provenientes de Centroamérica y los originarios de otras regiones, y por lo tanto no es posible abordar aspectos relacionados con el grado de integración productiva centroamericana.

Considerando lo anterior, en el gráfico IV.1 se muestra el destino exportador responsable de crear el valor agregado incorporado en las exportaciones y el empleo inducido por estas.

13 Como se señaló en la sección A, en el caso de Costa Rica y Honduras los bancos centrales elaboraron sus propias matrices de insumoproducto.

14 La CEPAL construye actualmente una matriz de insumo-producto latinoamericana, con la participación de todos los países sudamericanos y centroamericanos, así como de México y la República Dominicana. 


\section{Gráfico IV.1}

Centroamérica (4 países) y República Dominicana: estructura porcentual del valor agregado nacional directo e indirecto incorporado en las exportaciones de bienes y del empleo inducido por él, por destino, 2010-2013

(En porcentajes)

\section{A. Panamá, 2012}

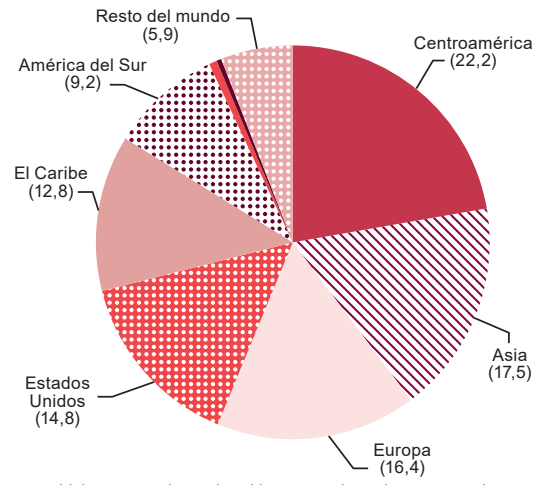

Valor agregado nacional incorporado en las exportaciones de bienes: 613,7 millones de dólares

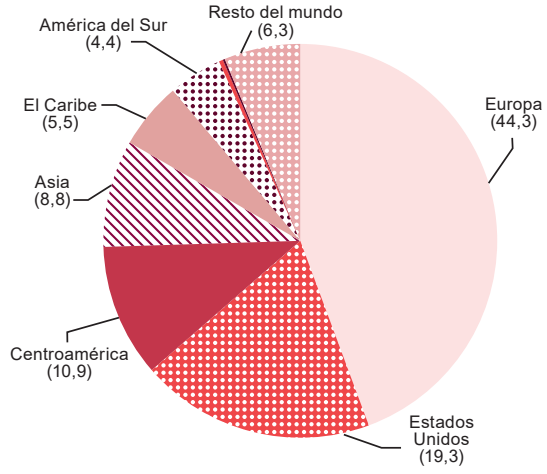

Empleo inducido por el valor agregado nacional incorporado en las exportaciones de bienes: 59106 empleos

B. Costa Rica, 2011

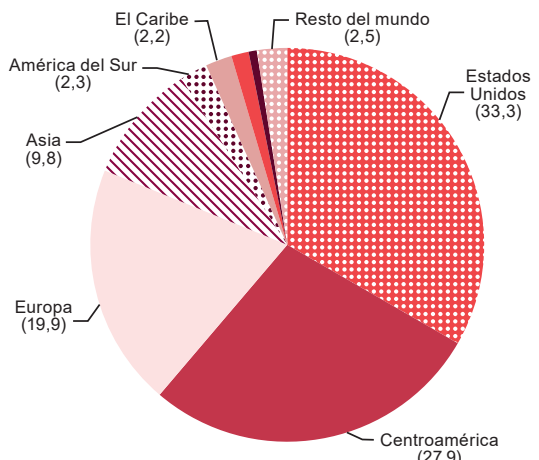

$(27,9)$

Valor agregado nacional incorporado en las exportaciones de bienes: 5 546,5 millones de dólares

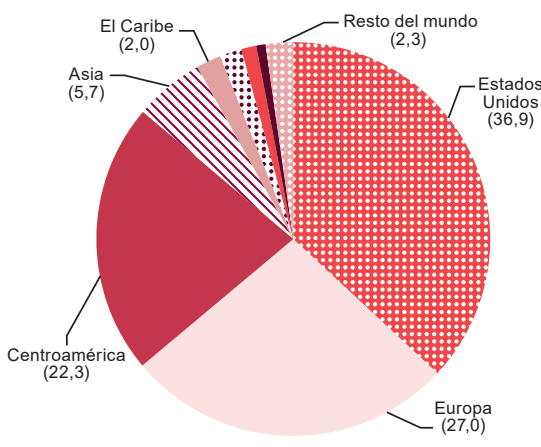

Empleo inducido por el valor agregado nacional incorporado en las exportaciones de bienes: 217983 empleos

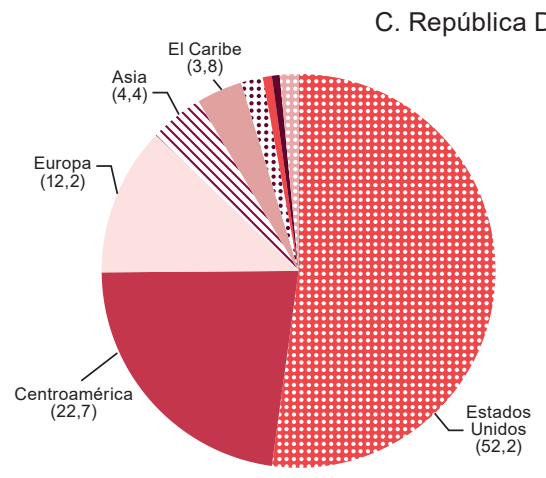

Valor agregado nacional incorporado en las exportaciones de bienes: 2745,6 millones de dólares

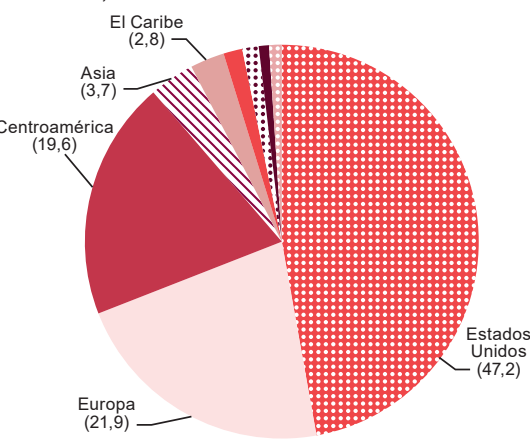

Empleo inducido por el valor agregado nacional incorporado en las exportaciones de bienes: 172406 empleos 
Gráfico IV.1 (conclusión)

D. Nicaragua, 2011

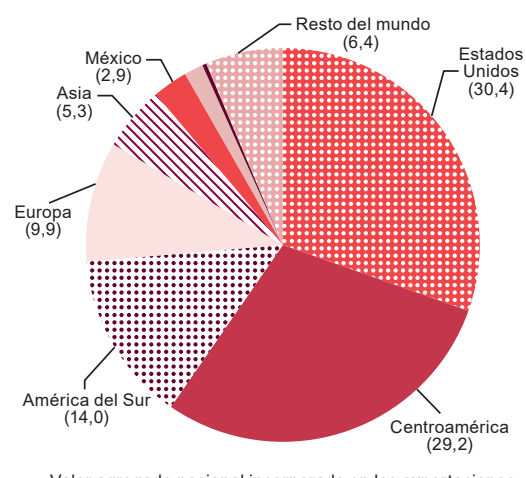

Valor agregado nacional incorporado en las exportaciones de bienes: 2 121,9 millones de dólares

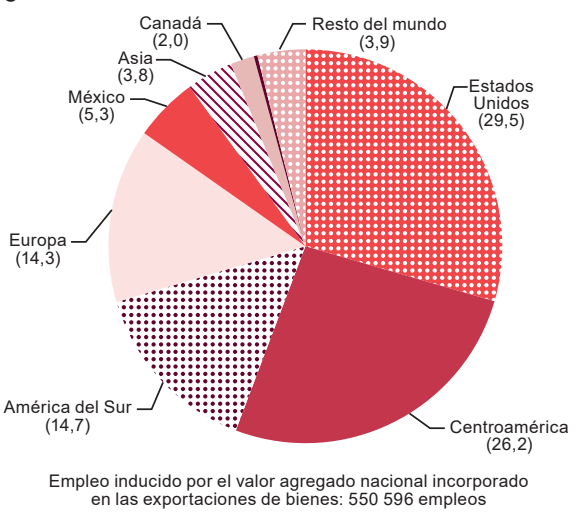

en las exportaciones de bienes: 550596 empleos

E. Honduras, 2013

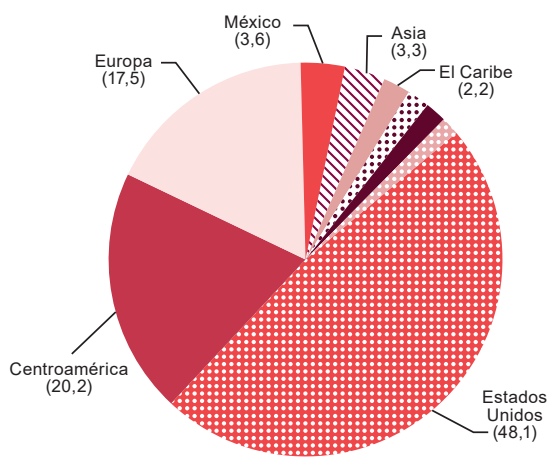

Valor agregado nacional incorporado en las exportaciones de bienes: 3 300,6 millones de dólares

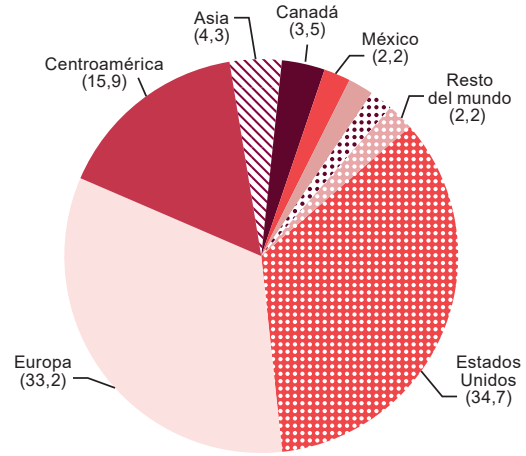

Empleo inducido por el valor agregado nacional incorporado en las exportaciones de bienes: 417900 empleos

Fuente: Elaboración propia, sobre la base de cuadros de oferta y utilización de los bancos centrales e institutos de estadística de los respectivos países y la Base de Datos Estadísticos de las Naciones Unidas sobre el Comercio de Productos Básicos (COMTRADE).

Nota: En los gráficos solo se muestran las etiquetas de los socios comerciales con participaciones porcentuales iguales o mayores a dos.

Los destinos comerciales que generan la mayor parte del valor agregado de los cinco países estudiados son los Estados Unidos, Centroamérica y Europa, aun cuando la importancia de cada uno varía de acuerdo con el país. En Honduras y la República Dominicana, las exportaciones a los Estados Unidos producen alrededor de la mitad del valor agregado total de las exportaciones de bienes. Le siguen en importancia las exportaciones de bienes destinadas a Centroamérica (20,2\% y $22,7 \%$, respectivamente) y a Europa (17,5\% y $12,2 \%$, respectivamente). Es interesante notar que tanto en Honduras como en la República Dominicana la participación de los Estados Unidos y Centroamérica en el total de los empleos inducidos por las exportaciones de bienes es inferior a la participación de esos destinos en el valor agregado, mientras que en las exportaciones de bienes destinadas a 
Europa se observa una relación opuesta, es decir, la participación en el total de empleos es superior a la participación en el valor agregado. Como se señalará más adelante, este fenómeno, que es indicativo de una mayor capacidad de creación de valor agregado por ocupado en las exportaciones dirigidas a los Estados Unidos y a Centroamérica comparadas con las destinadas a Europa, se debe a diferencias sectoriales en la composición de las exportaciones a estos tres destinos comerciales. En el caso de Costa Rica se aprecia una distribución más balanceada en el valor agregado producido por las exportaciones, ya que los Estados Unidos representa un tercio del total, Centroamérica un 27,9\%, Europa un $20 \%$ y Asia un 9,8\%. Asimismo, se observa que la participación de las exportaciones a los Estados Unidos, y sobre todo a Europa, en el número de empleos inducidos supera la participación en el valor agregado, en tanto que lo contrario sucede con las exportaciones destinadas a Centroamérica y Asia. Esto sugiere que el valor agregado por ocupado que producen las exportaciones de bienes costarricenses destinadas a Centroamérica y Asia es superior al que producen las de los Estados Unidos y Europa.

En Nicaragua también se observa una distribución bastante equitativa en la generación de valor agregado, según la cual alrededor de un 30\% de este se crea en las exportaciones a los Estados Unidos, un porcentaje similar en las destinadas a Centroamérica, un $14 \%$ en las dirigidas a América del Sur y un $10 \%$ en las que van a Europa. La distribución porcentual del número de ocupados es similar a la del valor agregado, pero sobresale que las exportaciones dirigidas a Europa generan alrededor de cuatro puntos porcentuales más de empleos que de valor agregado, y lo contrario sucede con las que se dirigen a Centroamérica.

En el caso de Panamá se observa la mayor diversificación del valor agregado generado en las exportaciones de bienes. Los principales destinos exportadores son los siguientes: Centroamérica (22,2\%), Asia (17,5\%), Europa (16,4\%), los Estados Unidos (14,8\%), El Caribe (12,8\%) y América del Sur $(9,2 \%)$. Respecto del empleo que inducen las exportaciones, el hecho más sobresaliente es la alta participación de Europa, con un 44,3\%.

En el análisis anterior llama la atención la reducida participación de México en el valor agregado que producen las exportaciones de los países estudiados, lo que muestra la débil integración comercial de dicho país con la región centroamericana.

En el cuadro IV.9 se muestra el valor agregado por ocupado que se incorpora en las exportaciones de bienes, por país y destino comercial. Sobresale que aun cuando los Estados Unidos constituye el principal destino comercial en términos de su participación en el valor agregado incorporado en las exportaciones de bienes de cuatro de los cinco países estudiados (excluido Panamá), el valor agregado promedio por ocupado que se incorpora en las exportaciones de bienes dirigidos a Centroamérica es mayor (salvo en el caso 
de Honduras). El caso más notable es el de Costa Rica. La participación de los Estados Unidos en el valor agregado total incorporado en las exportaciones de bienes costarricenses es de un 33,3\%, en tanto que la participación de Centroamérica alcanza un $27,9 \%$. No obstante, el valor agregado por ocupado incorporado en las exportaciones de bienes costarricenses a Centroamérica es de 31.863 dólares anuales, en tanto que en las dirigidas a los Estados Unidos es de 22.962 dólares anuales, una diferencia significativa de 8.900 dólares anuales por ocupado a favor de las exportaciones orientadas a Centroamérica ${ }^{15}$. Esto indica que, en promedio, en todos los países estudiados excepto en Honduras, las exportaciones de bienes dirigidas al mercado centroamericano tienen una mayor productividad que las orientadas al mercado estadounidense, lo que se refleja en un mayor valor agregado por ocupado. Es interesante resaltar que, en el caso costarricense, esta diferencia se debe en mayor medida al efecto de las exportaciones de bienes sobre los sectores asociados con los bienes (11.168 dólares anuales por ocupado) y, en menor medida, al efecto de las exportaciones de bienes sobre los sectores asociados con los servicios (2.782 dólares anuales por ocupado). En las exportaciones de bienes costarricenses destacan las orientadas al mercado asiático, que representan casi un $10 \%$ del valor agregado total generado por las exportaciones totales de bienes de dicho país y un valor agregado por ocupado de 43.621 dólares anuales, muy superior al promedio registrado en las exportaciones de esos bienes (25.445 dólares anuales).

En los cinco países analizados, el valor agregado por ocupado que se observa en las exportaciones dirigidas a Europa es uno de los más bajos. Como se explicará más adelante, esto obedece a que dichas exportaciones se focalizan principalmente en el sector agrícola. Nótese que aun en este caso se aprecia una importante heterogeneidad entre los países. Mientras que en Panamá, Nicaragua y Honduras el valor agregado por ocupado varía entre 2.000 y 4.000 dólares anuales, en la República Dominicana alcanza casi 9.000 dólares anuales y en Costa Rica llega a casi 19.000 dólares anuales.

Finalmente, en algunos de los países estudiados existen varios destinos comerciales que exhiben un significativo cociente de valor agregado por ocupado. Ese es el caso, por ejemplo, de las exportaciones de Panamá, Costa Rica y la República Dominicana a América del Sur, las exportaciones de Panamá y Honduras a México, y las exportaciones de Panamá y Costa Rica a El Caribe. Sin embargo, en esos casos se trata de volúmenes menores de exportación, que no influyen en forma significativa a nivel nacional.

15 Esta diferencia es mayor en el caso de Panamá (13.200 dólares anuales por ocupado). Sin embargo, se ejemplifica el caso costarricense porque las exportaciones de bienes de Panamá representan solo un $6 \%$ del valor agregado total que se crea las exportaciones panameñas, y por lo tanto son menos representativas que las exportaciones de bienes costarricenses, que generan un $56,5 \%$ del valor agregado total. 


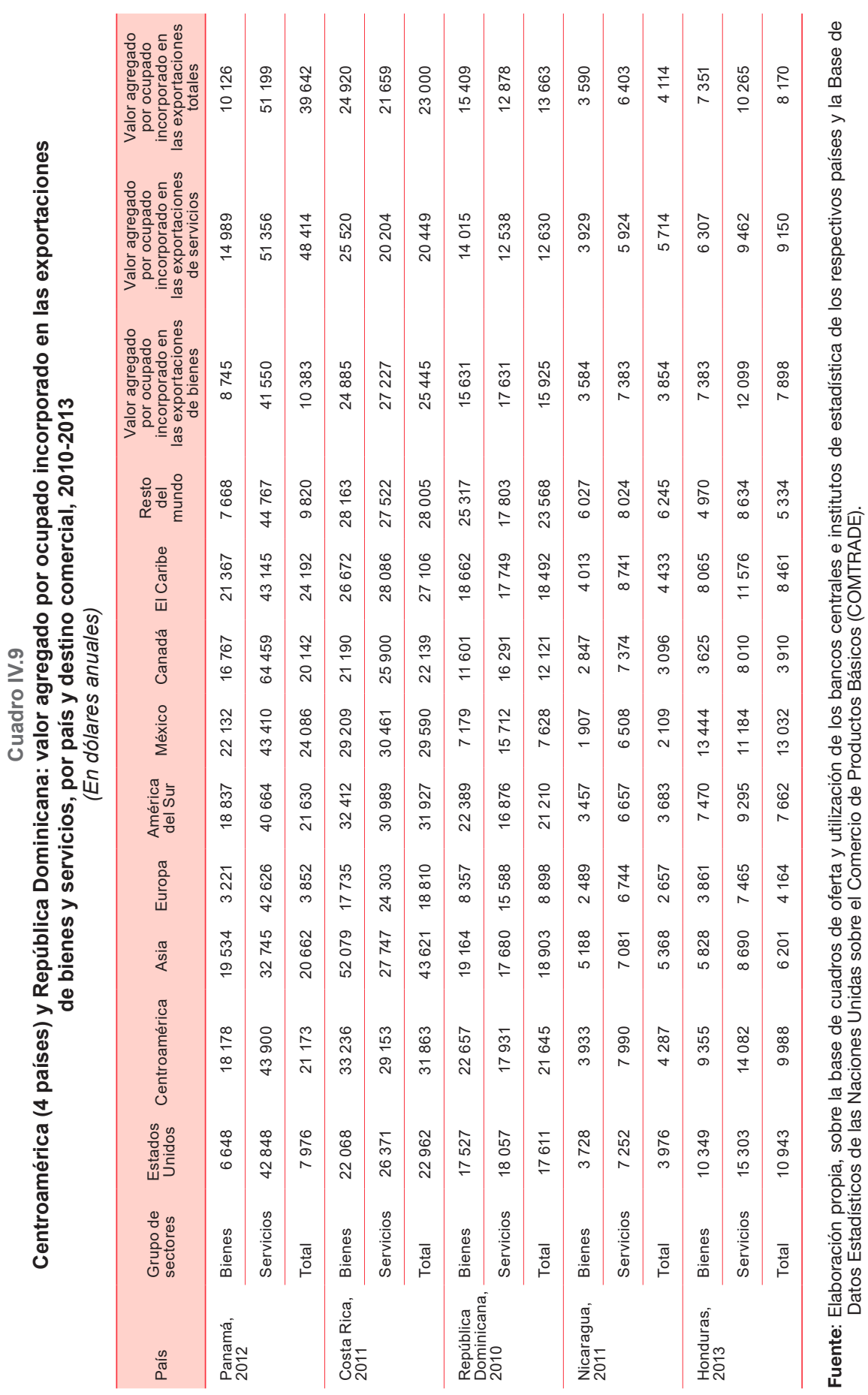


En lo que resta del capítulo se analizarán los hallazgos anteriores para entender las diferencias en el valor agregado por ocupado a nivel del total de las exportaciones, en función de las diferencias sectoriales entre los países analizados (para obtener más información sobre el valor agregado y el empleo generado por las exportaciones de bienes de los países centroamericanos, véase Minzer y Orozco, 2018). También se sugieren algunas recomendaciones relacionadas con las políticas públicas.

En el caso de Honduras, los Estados Unidos es el principal destino comercial y aporta el mayor valor agregado promedio por ocupado (10.939 dólares anuales), seguido de cerca por Centroamérica ( 9.982 dólares anuales); ambos valores superan el correspondiente a Europa (4.162 dólares anuales). El valor agregado promedio por ocupado relacionado con las exportaciones de bienes a los Estados Unidos se ve favorecido por dos sectores, a saber, el de las prendas de vestir y la peletería, y el de la maquinaria, los equipos de transporte y los aparatos de uso doméstico, que suman la mitad del valor agregado total generado por las exportaciones de bienes hondureños a ese país. En el primero de los dos sectores, el valor agregado por ocupado alcanza 19.233 dólares anuales y, en el segundo, 24.104 dólares anuales. Ambos valores superan el promedio nacional del total de las exportaciones de bienes hondureños (7.898 dólares anuales).

Los sectores que sobresalen debido al alto valor agregado por ocupado en las exportaciones a Centroamérica pueden clasificarse en dos grupos. El primero está conformado por los hilados e hilos y los tejidos de fibras textiles (18.804 dólares anuales por ocupado), los textiles, el cuero y el calzado (14.263 dólares anuales), y las prendas de vestir y la peletería (19.233 dólares anuales); en conjunto, estos representan un 38,3\% del valor agregado total generado por las exportaciones de bienes hondureños. El segundo grupo está conformado por las sustancias y los productos químicos (24.678 dólares anuales por ocupado), el caucho y el plástico (24.433 dólares anuales), los productos metálicos (21.694 dólares anuales), y la maquinaria, los equipos de transporte y los aparatos de uso doméstico (24.104 dólares anuales); en conjunto, estos suman un $25,5 \%$ del valor agregado total generado por las exportaciones de bienes. Finalmente, en el caso de las exportaciones a Europa, un $72,3 \%$ del valor agregado se concentra en el sector del café oro, que induce 116.288 empleos, lo que da como resultado un valor agregado promedio por ocupado de 3.588 dólares anuales.

Estos datos proporcionan evidencia empírica para diseñar una estrategia que permita incrementar el valor agregado por ocupado en Honduras. Por ejemplo, las exportaciones del sector agrícola (excluidas las del café en uva), dirigidas principalmente al mercado estadounidense, así como las del sector del café oro, focalizadas en el mercado europeo, exhiben un bajo valor agregado por ocupado. Considerando el importante tamaño de ambos sectores en la economía hondureña, se deberían estudiar las formas de aumentar el valor 
agregado que generan los productos que se ofrecen en ambos sectores, de manera que se incremente la productividad. Por otra parte, existen sectores de alto valor agregado por ocupado, como el de las sustancias y los productos químicos, el del caucho y el plástico, el de los productos metálicos, y el de la maquinaria, los equipos de transporte y los aparatos de uso doméstico, cuyas exportaciones a Centroamérica crean un alto valor agregado por ocupado, cercano a los 25.000 dólares anuales. Sin embargo, dado el volumen reducido de las ventas de esos sectores, estos inciden poco en la economía nacional. En este caso, se podrían estudiar estrategias para aumentar el volumen que estos sectores ofrecen al mercado centroamericano y hallar nuevos destinos comerciales. Otro ejemplo de este fenómeno lo constituyen las exportaciones del sector de los metales comunes al mercado asiático, cuyo valor agregado por ocupado alcanza los 22.360 dólares anuales, pero cuyo volumen es muy reducido como para influir significativamente en la economía hondureña.

Aun cuando el mercado norteamericano representa el principal destino comercial de la República Dominicana (con un 52,2\% del valor agregado total inducido por las exportaciones), el aporte en términos del valor agregado promedio por ocupado es inferior al que se observa en las exportaciones dominicanas destinadas a Centroamérica, y ambos valores superan el que se alcanza en las exportaciones al mercado europeo. El valor agregado por ocupado correspondiente a las exportaciones dominicanas dirigidas a los Estados Unidos se beneficia sobre todo de tres sectores que tienen un importante volumen de exportaciones: la elaboración de productos textiles, prendas de vestir y productos de cuero y calzado (zonas francas) (22.036 dólares anuales por ocupado); otras industrias manufactureras locales (19.460 dólares anuales), y la fabricación de equipos médicos y quirúrgicos (zonas francas) (41.987 dólares anuales). En su conjunto, estos sectores representan un $45,4 \%$ del valor agregado total generado por las exportaciones de bienes dominicanos a los Estados Unidos.

En el caso de las exportaciones dirigidas a Centroamérica, sobresale un grupo más amplio de sectores, entre los que se cuentan los siguientes: la elaboración de productos textiles, prendas de vestir y productos de cuero y calzado (zonas francas) (22.036 dólares anuales por ocupado); el petróleo, la química y los productos minerales no metálicos (45.355 dólares anuales); la fabricación de sustancias y productos químicos (28.735 dólares anuales); la fabricación de metales comunes (37.946 dólares anuales), y otras industrias manufactureras locales (19.460 dólares anuales). En forma conjunta, estos sectores representan un $61,3 \%$ del valor agregado inducido por las exportaciones de bienes dominicanos con destino a Centroamérica. Finalmente, en el caso de las exportaciones a Europa, un 54,6\% del valor agregado se concentra en el sector agrícola e induce 30.442 empleos, lo que da como resultado un valor agregado promedio por ocupado de solo 5.956 dólares anuales, muy por debajo del promedio del total de las exportaciones de bienes dominicanos. 
Esta información permite extraer conclusiones para mejorar el valor agregado por ocupado del sector exportador de bienes en la República Dominicana. Las exportaciones de los sectores de la fabricación de joyas y artículos conexos, y la fabricación de motores eléctricos, generadores, transformadores eléctricos, distribución de la electricidad y aparatos de control (zonas francas), que se orientan sobre todo al mercado estadounidense, exhiben un alto valor agregado por ocupado que supera los 40.000 dólares anuales. Sin embargo, el volumen de operaciones de estos sectores es reducido, por lo que tienen un impacto limitado en la economía dominicana. Resultaría importante ampliar el volumen de las exportaciones de estos sectores al mercado estadounidense, e incluso buscar nuevos mercados que tengan la capacidad de dar lugar a niveles similares de valor agregado por ocupado. Algo similar se puede señalar respecto de las exportaciones de los sectores del petróleo, la química y los productos minerales no metálicos, y de la fabricación de sustancias y productos químicos (locales y de zonas francas) —dirigidas principalmente a los Estados Unidos y Centroamérica-, y también respecto de las exportaciones de los sectores de la minería y la extracción, así como de la fabricación de metales comunes, que están dirigidas al mercado asiático. En todos esos casos se observa un elevado valor agregado por ocupado, pero un volumen reducido de exportación que no permite sacarles provecho. Es necesario aumentar el valor agregado incorporado en las exportaciones agrícolas, destinadas sobre todo a Europa, desafío que es común a los cinco países estudiados.

En el caso de las exportaciones costarricenses se presenta un fenómeno similar al dominicano, en el sentido de que su principal destino comercial, los Estados Unidos, país que representa un tercio del valor agregado total inducido por las exportaciones, ocupa solo el segundo lugar en términos del valor agregado por ocupado, por debajo de las exportaciones destinadas a Centroamérica, pero muy por encima de las destinadas a Europa. El hecho de que el valor agregado por ocupado de las exportaciones de bienes costarricenses a los Estados Unidos sea relativamente alto obedece más que nada a cuatro sectores cuyas exportaciones tienen un volumen significativo: los productos químicos, los plásticos y los productos de caucho; los equipos de cómputo electrónico; los otros productos eléctricos y electrónicos, y las máquinas de precisión. El valor agregado de cada uno de estos sectores, que en su conjunto representan un 33,2\% del valor agregado total generado por las exportaciones de bienes costarricenses a los Estados Unidos, sobrepasa los 43.000 dólares anuales por ocupado.

Por su parte, en el caso de las exportaciones destinadas a Centroamérica, el segundo destino comercial más importante, sobresalen los primeros tres sectores señalados anteriormente, a los que se añade el sector del cemento, los derivados y los productos minerales. En su conjunto, estos sectores representan un $52,8 \%$ del valor agregado generado por las exportaciones 
de bienes costarricenses a Centroamérica, y cada uno de ellos exhibe un valor agregado por ocupado que supera los 40.000 dólares anuales. Respecto del mercado asiático, destaca el sector de las máquinas de precisión, que representa un $69 \%$ del valor agregado total a ese destino comercial, con un valor agregado por ocupado de 52.098 dólares anuales. Finalmente, las exportaciones a Europa se focalizan en el sector agrícola, que representa un $57,4 \%$ del valor agregado total generado en ese destino comercial, e induce 43.499 empleos. Lo anterior se traduce en un valor agregado por ocupado de 14.623 dólares anuales, que corresponden al menor valor agregado por ocupado alcanzado entre los sectores exportadores de bienes costarricenses.

$\mathrm{Al}$ igual que ocurre en los casos anteriores, se pueden extraer conclusiones para aumentar el valor agregado por ocupado del sector exportador de bienes costarricenses. En el sector de la madera, los muebles y los derivados, así como en el de los metales y las maquinarias, se observa un valor agregado por ocupado relativamente elevado; no obstante, el volumen exportado a los dos principales destinos comerciales, Centroamérica y los Estados Unidos, es demasiado bajo como para influir de forma significativa en la economía costarricense. Asimismo, dos sectores de dicha economía - el de los alimentos, las bebidas y el tabaco, y, sobre todo, el de la agricultura- representan un volumen importante de las exportaciones costarricenses, pero un escaso valor agregado por ocupado. Es necesario continuar trabajando para que los productos comercializados en estos sectores sean más sofisticados, a fin de incrementar el valor por ocupado.

Con respecto a Nicaragua, el principal destino comercial es los Estados Unidos, que registra un valor agregado por ocupado inferior al que exhibe Centroamérica, segundo destino comercial más importante. Otros dos destinos comerciales de importancia para las exportaciones de bienes nicaragüenses son América del Sur y Europa. El valor agregado por ocupado relativamente bajo de las exportaciones nicaragüenses a los Estados Unidos se debe al valor reducido que exhiben los dos sectores exportadores principales, a saber, el del cultivo de café y el de los alimentos, las bebidas y el tabaco, que representan en forma conjunta un $63,8 \%$ del valor agregado total generado por las exportaciones nicaragüenses a ese país. En el caso del cultivo del café, el valor agregado por ocupado es de 2.603 dólares anuales, en tanto que, en los alimentos, las bebidas y el tabaco, este valor llega a 4.124 dólares anuales. Respecto a las exportaciones nicaragüenses a Centroamérica, los principales dos sectores exportadores - los alimentos, las bebidas y el tabaco, y la elaboración de tejidos de punto o ganchillo (zona franca)— que en conjunto representan un $57,7 \%$ del valor agregado total generado por las exportaciones de bienes nicaragüenses a ese destino comercial, también registran poco valor agregado por ocupado. Por su parte, las exportaciones nicaragüenses a Europa provienen sobre todo del sector del cultivo de café, cuyo valor agregado por ocupado es de solo 2.603 dólares anuales. Por último, 
respecto de las exportaciones nicaragüenses a América del Sur, estas se centran en el sector de los alimentos, las bebidas y el tabaco, que dan lugar a un escaso valor agregado por ocupado.

Como se aprecia, en la mayoría de los sectores exportadores nicaragüenses, particularmente en los que tienen un volumen importante de exportaciones, se crea poco valor agregado por ocupado. Algunos ejemplos emblemáticos los constituyen el sector de la agricultura (incluido el del cultivo de café) y el de los alimentos, las bebidas y el tabaco, que representan un $60,7 \%$ del valor agregado generado por la totalidad de las exportaciones nicaragüenses. Respecto del sector agrícola se observa que, mientras este produce 14.623 dólares anuales de valor agregado por ocupado en Costa Rica, 5.956 dólares anuales en la República Dominicana y 5.708 dólares anuales en Honduras (incluido el café uva), en Nicaragua genera tan solo 2.092 dólares anuales (incluido el cultivo de café). Otro ejemplo lo constituye el sector de los alimentos, las bebidas y el tabaco. En tanto que en Costa Rica el valor agregado por ocupado del sector llega a 22.784 dólares anuales, en la República Dominicana a 13.857 dólares anuales ${ }^{16}$ y en Honduras a 5.162 dólares anuales (incluido el café oro), en Nicaragua solo alcanza los 4.124 dólares anuales. Resulta evidente la necesidad de aumentar el valor agregado que se produce en estos sectores y de modernizar los procesos de producción para lograr una mayor eficiencia y productividad. Por su parte, existen algunos sectores que dan lugar a un alto valor agregado por ocupado, a saber, el de la minería y la extracción, el del petróleo y la química, el de la elaboración de tejidos de punto o ganchillo (industria local), el de la maquinaria y los equipos (excepto el de transporte-zona franca), y el de la manufactura de maquinaria y equipos de transporte; no obstante, el volumen de las exportaciones de dichos sectores es demasiado reducido como para incidir de forma significativa a nivel nacional. Se sugiere entonces estudiar las formas de lograr un mayor nivel de penetración internacional en estos mercados atractivos para la economía nicaragüense.

Por último, Panamá difiere significativamente de los casos anteriores debido a que, como ya se señaló, las exportaciones de bienes representan solo un $6 \%$ del valor agregado generado por las exportaciones de ese país, que se basan en servicios. De cualquier modo, los destinos más atractivos son Centroamérica, Asia, El Caribe y América del Sur, todos ellos con un valor agregado por ocupado superior a 20.000 dólares anuales. Las exportaciones de productos químicos y de caucho - dirigidas a Centroamérica, El Caribe y América del Sur - y las de minas y canteras —orientadas principalmente al mercado asiático - resultan particularmente atractivas y dan lugar a un alto valor agregado por ocupado. No obstante, dado el escaso volumen exportado no causan un impacto significativo en la economía nacional.

16 Incluye los sectores de los alimentos y la elaboración de bebidas alcohólicas, no alcohólicas y derivados del tabaco, tanto locales como de zona franca. 
En resumen, la principal conclusión que emerge del análisis de esta sección es que el comercio intrarregional de bienes ha sido un elemento importante en la integración centroamericana. Esto se ha reflejado en una importante participación del mercado centroamericano en el valor agregado que crearon las exportaciones de los países estudiados: la subregión ocupa el segundo lugar después de los Estados Unidos. También se ha reflejado en el hecho de que las exportaciones destinadas a Centroamérica dieron lugar a un alto índice promedio de valor agregado por ocupado; en este aspecto, la subregión ocupa el primer lugar.

\section{Resumen y conclusiones}

En este capítulo se analizó la creación de valor agregado y empleo a partir de las exportaciones en algunos países centroamericanos y en la República Dominicana. El enfoque, basado en matrices de insumo-producto nacionales, permitió cuantificar la importancia del comercio internacional para estos países y, en particular, la del comercio intrarregional centroamericano. Las dos principales variables que se estimaron utilizando el modelo de insumo-producto, a saber, el valor agregado generado por las exportaciones y el empleo inducido por estas, se combinaron para calcular el cociente de valor agregado por ocupado, que puede interpretarse o bien como un indicador de la productividad laboral, o bien como el retorno de la actividad exportadora por ocupado.

Una primera conclusión es que en los países se han adoptado distintas formas de inserción comercial, que se reflejan en los resultados de las actividades exportadoras. En Panamá, las exportaciones se basan en los servicios logísticos, que se han constituido en uno de los principales motores exportadores del país. Por su parte, en Costa Rica se ha seguido una forma de inserción más balanceada, en la que se combina la creación de valor agregado que se incorpora en las exportaciones tanto de bienes como de servicios. En el caso de la República Dominicana se observa un modelo más similar al costarricense, pero con una menor producción de valor agregado y un mayor sesgo exportador hacia los servicios, sobre todo el turismo. Por último, la inserción comercial exportadora utilizada tanto en Nicaragua como en Honduras se ha basado principalmente en los sectores relacionados con los bienes.

Se encontró que en los países analizados las exportaciones de servicios generan una mayor proporción de valor agregado por cada dólar exportado que las exportaciones de bienes. No obstante, hay importantes diferencias entre los países. Panamá sobresale como el país que más valor agregado crea por cada dólar exportado, en tanto que Honduras es el que crea menos. Otro hallazgo surge de comparar el valor agregado por ocupado. Una vez más, 
Panamá destaca debido al alto valor que se observa en los sectores asociados con los servicios logísticos ligados a sus exportaciones. Por su parte, el menor valor lo obtiene Nicaragua, debido al bajo índice que se observa tanto en los bienes como en los servicios.

La evidencia apunta a una alta heterogeneidad sectorial en el índice de valor agregado por ocupado. Esta se refleja en los diferentes valores que se encuentran en los distintos sectores de un mismo país y en los que un determinado sector exhibe en diferentes países. Por ejemplo, en el sector agrícola de la economía costarricense se registra el menor valor agregado por ocupado de todos los sectores de dicho país. Simultáneamente, ese valor es más de seis veces superior al que se alcanza en Nicaragua. Otros sectores que exhiben una gran heterogeneidad son el del petróleo, los productos químicos, los plásticos y los productos de caucho, y el de la maquinaria general, entre otros. Asimismo, otro factor que explica la heterogeneidad sectorial entre los países es que algunos sectores en los que se observa un alto valor agregado por ocupado en determinados países son inexistentes en otros.

En la sección C se profundizó el análisis de las diferencias sectoriales en el valor agregado por ocupado entre los países, para explicar las diferencias que se encontraron a nivel nacional. Esta apertura sectorial permite examinar aspectos relacionados con la integración económica regional, en particular la integración centroamericana, desde una perspectiva del valor agregado y el empleo.

Resalta que Centroamérica constituye el segundo destino más importante de los países estudiados en cuanto a la generación de valor agregado, precedido por los Estados Unidos. Más aun, el valor agregado por ocupado que se incorpora en las exportaciones dirigidas a Centroamérica es superior al que se observa en las dirigidas a los Estados Unidos, lo que sugiere que las exportaciones intracentroamericanas crean empleo de mayor calidad.

La evidencia empírica presentada ofrece lineamientos para formular políticas públicas. Por una parte, las diferencias sectoriales en el interior de los países ilustran las capacidades distintas que tienen los sectores orientados a la exportación en términos de generación de valor agregado y creación de empleo. De lo anterior se desprende la importancia de contar con una política industrial activa que permita distinguir un sector de otro de acuerdo con el aporte actual y el deseado de cada uno. En el caso de los sectores que constituyen un porcentaje importante de las exportaciones totales pero aportan poco valor agregado, las acciones se encaminarían a fomentar una mayor incorporación de conocimientos tecnológicos, incrementar la productividad y lograr un escalamiento dentro de la cadena de valor. En los sectores cuyas exportaciones generan un alto valor agregado por ocupado en ciertos destinos comerciales, pero cuyo volumen exportado no es suficiente como para provocar efectos significativos en la economía nacional, el apoyo 
estaría dirigido a incrementar la escala y alcanzar un mayor volumen de exportación. Desde una perspectiva regional, las políticas de innovación que se analizan en el capítulo XIII de este libro contribuirían a estos propósitos.

Por otra parte, en ciertos sectores las exportaciones dirigidas al mercado centroamericano generan mayor valor agregado nacional que las dirigidas a otros mercados y además se caracterizan por una creación significativa de empleo. En este sentido, es deseable formular una política productiva que promueva el fortalecimiento de la integración comercial regional.

El cambio estructural progresivo que propone la CEPAL para la región puede tener una expresión significativa en Centroamérica a la luz de los resultados de esta investigación. Se han citado casos de sectores que tienen potencial para incorporar mayor valor agregado en las exportaciones, producir efectos significativos en la creación de empleo o, mejor aún, incidir en la creación de empleos de mejor calidad y, por tanto, aumentar la productividad y mejorar las remuneraciones. La evidencia ofrece insumos para diseñar políticas públicas que encaminen la región hacia el cambio estructural progresivo, es decir, hacia las transformaciones necesarias para que surjan nuevas actividades productivas de alta demanda internacional, y para que las existentes se vuelvan a lanzar con mejores parámetros de innovación, eficiencia, productividad y progreso técnico, estableciendo el cuidado del medio ambiente como requisito y propósito.

En la región centroamericana se enfrenta el desafío de construir bases de datos armonizadas a los efectos de estudiar de manera sistemática y con mayor detalle los flujos de comercio internacional entre los países de la región. La CEPAL continuará apoyando a los países en este sentido y liderará un esfuerzo para construir una matriz de insumo-producto regional que permita analizar los multiplicadores del comercio intrarregional y diseñar políticas comerciales e industriales a partir de escenarios y simulaciones de crecimiento basados en dichos datos.

La evidencia empírica es un aporte relevante para que las autoridades nacionales y regionales tomen decisiones en el marco de los procesos de integración, y proporciona insumos para los propios actores productivos, exportadores e inversionistas, nacionales, regionales y extrarregionales. En cada país existen prioridades diversas que en un momento determinado pueden favorecer una inserción externa o una política de integración regional más o menos agresiva. Los factores e indicadores estimados en este trabajo, como el valor agregado nacional y el empleo inducido por las exportaciones, son criterios importantes para esa toma de decisiones, como también lo pueden ser otros criterios, por ejemplo, la contribución de la actividad en cuestión al crecimiento global de la economía, la prioridad que se otorgue a ciertas actividades productivas, la contribución al avance de los objetivos de la Agenda 2030 para el Desarrollo Sostenible, la necesidad de que el desarrollo 
territorial sea más armónico, la creación de empleos (se podrían priorizar los que supongan una mayor calificación y sean mejor remunerados), las implicaciones sobre las necesidades de inversión, o el impacto que estas decisiones puedan tener en el abatimiento de la pobreza y la desigualdad. Son muchos los criterios que se pueden emplear en los procesos de análisis, selección, diseño e implementación de las políticas públicas y, por tanto, en la asignación de recursos públicos. En ese universo, el presente capítulo aporta un enfoque metodológico moderno y poco explorado en la región; se espera que enriquezca la discusión sobre esquemas que permitan impulsar el desarrollo sostenible de los países centroamericanos.

\section{Bibliografía}

Miller, R. y P. Blair (2009), Input-Output Analysis: Foundations and Extensions, Cambridge, Cambridge University Press.

Minzer, R. y V. Solís (2016), “Análisis estructural de la economía costarricense: el mercado laboral", Documentos de Proyectos (LC/MEX/W.14), Ciudad de México, Comisión Económica para América Latina y el Caribe (CEPAL), enero.

Minzer, R. y R. Orozco (2018), “El potencial dinamizador de las exportaciones en Centroamérica y la República Dominicana: evidencia empírica a partir del análisis de matrices insumo-producto", serie Estudios y Perspectivas-Sede Subregional de la CEPAL en México, N 177 (LC/MEX/TS.2018/22-LC/TS.2018/76), Ciudad de México, Comisión Económica para América Latina y el Caribe (CEPAL), octubre. (2017), "Análisis estructural de la economía panameña: el mercado laboral", Documentos de Proyectos (LC/MEX/TS.2017/5), Ciudad de México, Comisión Económica para América Latina y el Caribe (CEPAL), abril.

Minzer, R., R. Orozco y I. Romero (2017a), “Análisis estructural de la economía dominicana: el mercado laboral", Documentos de Proyectos (LC/MEX/TS.2017/16), Ciudad de México, Comisión Económica para América Latina y el Caribe (CEPAL), julio.

(2017b), "Análisis estructural de la economía nicaragüense: el mercado laboral", Documentos de Proyectos (LC/MEX/TS.2017/14), Ciudad de México, Comisión Económica para América Latina y el Caribe (CEPAL), junio.

Minzer, R. y otros (2017), “Descripción del marco metodológico para la construcción de matrices de insumo-producto a partir de los cuadros de oferta y utilización: una aplicación para el caso de Panamá", Documentos de Proyectos (LC/MEX/ TS.2017/17), Ciudad de México, Comisión Económica para América Latina y el Caribe (CEPAL), julio.

Monge, R. y otros (2016), "El potencial dinamizador del sector exportador costarricense: encadenamientos productivos, valor agregado y empleo", Documentos de Proyectos (LC/MEX/W.19), Ciudad de México, Comisión Económica para América Latina y el Caribe (CEPAL), septiembre.

Padilla, R. y otros (2008), "Evolución reciente y retos de la industria manufacturera de exportación en Centroamérica, México y República Dominicana: una perspectiva regional y sectorial", serie Estudios y Perspectivas-Sede Subregional de la CEPAL en México, No 95 (LC/L.2868-P-LC/MEX/L.839/REV.1), Ciudad de México, Comisión Económica para América Latina y el Caribe (CEPAL), febrero. 



\section{Capítulo V \\ Integración productiva regional: las cadenas regionales de valor}

Olaf de Groot

\section{Introducción}

Desde su fundación, la sede subregional de la CEPAL en México ha trabajado intensamente en promover mejoras de la capacidad productiva de Centroamérica. La concepción misma del proceso de integración regional respondía a la propuesta de industrialización y cambio de las estructuras productivas nacionales (véase el capítulo II del presente documento). Hace algunos años, la CEPAL diseñó una metodología para fortalecer las cadenas productivas nacionales como una forma de política industrial (Padilla Pérez, 2014). Dicha metodología ha sido adaptada para impulsar cadenas productivas regionales, buscando con ello aprovechar las fortalezas que existen en la región (incluido el propio proceso de integración), para promover el cambio estructural y conducir al desarrollo económico. El trabajo de fortalecer las cadenas regionales de valor se ha beneficiado inestimablemente de la colaboración con diversos organismos de la integración regional. En este capítulo se reseña el trabajo de la CEPAL en el ámbito del fortalecimiento de las cadenas regionales de valor y se detallan los trabajos futuros con los que la CEPAL y sus socios buscarán apoyar la integración productiva en Centroamérica ${ }^{1}$.

Este capítulo se enfoca en los siguientes países miembros de la Secretaría de Integración Económica Centroamericana (SIECA): Costa Rica, El Salvador, Guatemala, Honduras, Nicaragua y Panamá. 


\section{A. Antecedentes}

El concepto de cadena de valor surgió en 1985, cuando Michael Porter propuso dividir el proceso de producción y distinguir los diferentes elementos que lo componen. Antes de que surgiera el concepto analítico de Porter, el comercio intrarregional (dentro de Centroamérica) y el extrarregional (con el resto del mundo) se enfocaba en productos finales, a pesar de que las políticas de promoción de las exportaciones y de integración económica tenían que ver con crear cadenas regionales de valor aun antes de que este concepto se utilizara. De la mano de las políticas de integración, en el comercio de bienes y servicios de la región centroamericana se fue creando poco a poco una integración productiva regional que es especialmente fuerte en algunos sectores industriales.

El comercio centroamericano, siguiendo las tendencias del comercio mundial, ha crecido rápidamente en los últimos años. Entre 1995 y 2016, las exportaciones de Centroamérica aumentaron un 250\%, lo que representa un 6,0\% anual en promedio (CEPAL, 2018a). Sin embargo, el crecimiento no ha sido igualitario entre los diferentes países, por lo que ha dado como resultado una creciente concentración de las exportaciones en unos pocos. Como se muestra en el gráfico V.1, en 1995 Costa Rica era el principal exportador de la región, con un $34 \%$ del total de las exportaciones, y los tres principales exportadores (Costa Rica, Guatemala y El Salvador) representaban el 71\% del total de los envíos regionales. En 2016, la participación conjunta de esos tres países aumentó al 76\%.

\section{Gráfico V.1}

Centroamérica: exportaciones internacionales por país, 1995 y 2016 (En porcentajes)

A. 1995

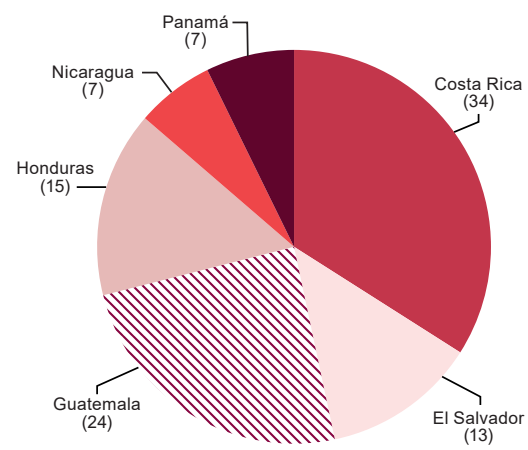

B. 2016

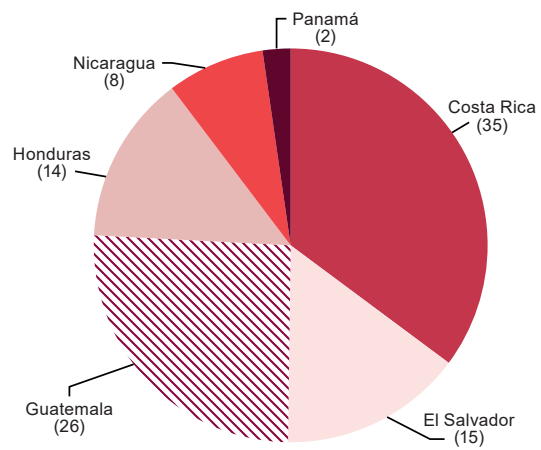

Fuente: Comisión Económica para América Latina y el Caribe (CEPAL), sobre la base de información de la Base de Datos Estadísticos de las Naciones Unidas sobre el Comercio de Productos Básicos (COMTRADE). 
Un dato aún más importante es el crecimiento de la participación del comercio intrarregional. El peso de las exportaciones intrarregionales en las exportaciones de Centroamérica en su conjunto aumentó del 22\% en 1995 al 32\% en 2016. En este caso también se observan diferencias importantes entre los países. Como se muestra en el gráfico V.2, Panamá es el único país en que el peso del mercado regional disminuyó ligeramente en ese período, al pasar del 14\% al 13\%; el peso de dicho mercado aumentó en todos los demás países. En 1995, el país en cuyas exportaciones se observaba la mayor participación de Centroamérica era El Salvador, con un 44\%; en 2016, dicha participación aumentó al 51\%. En el otro extremo se encuentra Honduras, en cuyos envíos totales las exportaciones a Centroamérica representaban la menor fracción en 1995 (solo el 10\%). Sin embargo, en 2016 el peso de la región en las exportaciones de ese país aumentó al $24 \%$ y se situó en un rango similar al de Costa Rica y Nicaragua.

\section{Gráfico V.2}

Centroamérica (6 países): participación de las exportaciones a los países centroamericanos en las exportaciones totales de bienes, 1995 y 2016

(En porcentajes)

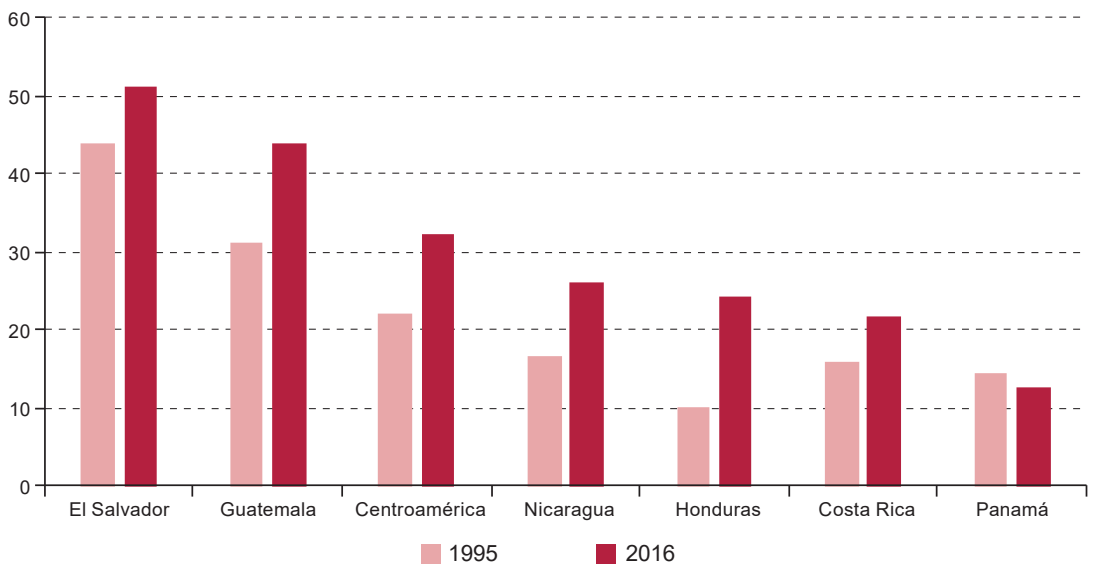

Fuente: Comisión Económica para América Latina y el Caribe (CEPAL), sobre la base de información de la Base de Datos Estadísticos de las Naciones Unidas sobre el Comercio de Productos Básicos (COMTRADE).

A partir de la década de 1990, desde la CEPAL se subrayó la importancia del comercio tanto intrarregional como extrarregional. Willmore (1997) destaca el proceso en que los países centroamericanos cambiaron su estrategia para pasar de una política de desarrollo "hacia adentro" (véase el capítulo II sobre el modelo de desarrollo subyacente) a una más abierta, que empezó a finales de la década de 1980. Sin embargo, en el afán de promover las exportaciones, 
en algunos países se apoyaron las exportaciones extrarregionales de diversas formas, lo que inhibió el desarrollo del mercado intrarregional (Willmore, 1997).

Dado el éxito económico que se vivió en la región en la década de 1960 y la primera mitad de la década de 1970 de la mano del fortalecimiento del mercado intrarregional, el nuevo contexto mundial sugería aprovechar el mercado internacional sin abandonar el primero, por lo que era necesaria una estrategia que fortaleciera el mercado interno y favoreciera la inserción internacional (Willmore, 1989). Las estrategias productivas requerían fomentar la especialización y las cadenas de carácter regional, de manera que la integración de la región también pudiera impulsar la inserción de Centroamérica en la economía mundial (Salazar, 1990).

En la década de 1990, la CEPAL propuso una estrategia en la que se subrayaba que la integración centroamericana era compatible y funcional con la inserción internacional, y que los mercados internacionales dinámicos podían brindar un impulso extra al sector productivo de la región. Desde la promoción de las exportaciones manufactureras (CEPAL, 1983) hasta la promoción de las de frutas, hortalizas y plantas ornamentales como un sector que ofrecía posibilidades de exportar fuera de la región (CEPAL, 1993), las exportaciones extrarregionales comenzaron a valorarse no solo por su aporte al equilibrio de las cuentas nacionales, sino también como una forma de integrar el comercio intrarregional con el internacional, es decir, como una manera de promover la integración productiva centroamericana para fortalecer la capacidad de competir en los mercados internacionales.

A pesar de lo anterior, Zapata y Pérez (2001) consideran que el proceso de integración comercial de Centroamérica sigue estando incompleto y que la región aún debe crecer y distribuir mejor, por lo que se requieren más esfuerzos para que este proceso sea exitoso. Di Filippo (1998) sugiere que la integración comercial de la región puede ser parte de un proceso vinculado con los procesos de paz y democratización que surgieron a fines de la década de 1980, y reconoce que el regionalismo abierto se alineaba con las propuestas comerciales liberales de los Estados Unidos y las políticas asociadas.

La idea estadounidense de ampliar el Tratado de Libre Comercio de América del Norte (TLCAN) a todo el continente americano (Whalley, 1998) nunca se puso en práctica, pero ayudó a consolidar el concepto de que el comercio es el motor fundamental del crecimiento y que la integración comercial de Centroamérica es un engranaje de dicho motor. La integración centroamericana se ve como un proceso integral encaminado a aumentar el crecimiento económico y fomentar la industrialización basada en el comercio intraindustrial, para lo que hay que mejorar la coordinación intrarregional (Cáceres, 1994). Gracias al fortalecimiento de varias instituciones regionales, la coordinación intrarregional ha venido desarrollándose desde entonces, lo que se ve reflejado en las cifras comerciales de la región. 
La CEPAL ha trabajado activamente con otros actores regionales que también promueven la integración productiva centroamericana a través de la formación de cadenas regionales de valor. La Secretaría de Integración Económica Centroamericana (SIECA) es una voz importante en este tema y uno de los socios principales de la CEPAL. En el trabajo que afecta a las micro, pequeñas y medianas empresas (mipymes), su otro socio fundamental es el Centro Regional de Promoción de la MIPYME (CENPROMYPE), que lidera a nivel regional la participación de este tipo de empresas en la integración internacional. Otras instituciones sectoriales de la región también juegan un papel importante, entre otras, el Consejo Agropecuario Centroamericano (CAC), en el sector agrícola, y la Secretaría de Integración Turística Centroamericana (SITCA), en el del turismo. La cooperación con dichos actores ofrece a la CEPAL la oportunidad de aumentar el impacto de su trabajo y fortalecer las capacidades de esas instituciones para que lideren futuros proyectos.

\section{B. Las cadenas de valor}

En esencia, la economía de las cadenas de valor es muy sencilla: existen agentes económicos que producen ciertos bienes y hay consumidores que demandan los bienes producidos. Si los dos participantes del mercado se identifican, sigue una transacción en la que el consumidor compra el bien mencionado al productor, y todos los participantes del mercado aumentan su utilidad. Sin embargo, el mundo de hoy es más complejo: son pocos los productos que provienen directamente de un agente económico individual, sin que se empleen insumos de otros, y son pocos los que se venden directamente al consumidor, sin involucrar a ningún intermediario. Hoy en día es más probable que exista cooperación entre diferentes agentes para elaborar un producto de mayor complejidad, mejor calidad o menor costo. Por ejemplo, un empresario produce un insumo para un segundo productor, quien lo combina con otros insumos que ha comprado a otros productores para elaborar un bien final que vende a un intermediario, quien a su vez lo vende a un consumidor.

En suma, hoy en día la producción suele tener la forma de una cadena o red, como lo reconoció y describió Porter (1985). Hay diversas definiciones y tipologías relativas a las cadenas de valor. En el cuadro V.1 se resaltan algunas de las definiciones que usan diferentes autores e instituciones. Un aspecto clave que aparece en todas las definiciones es que las cadenas de valor son una serie de actividades que incluye diferentes etapas. Gracias a Kaplinsky (2000), las etapas se conocen como "eslabones"; el número de eslabones cambia con la complejidad de la cadena. 


\section{Cuadro V.1 \\ Conceptos y definiciones de cadena de valor}

\begin{tabular}{|c|c|}
\hline $\begin{array}{l}\text { Gereffi (2001), UNCTAD (2006), } \\
\text { OCDE (2013) }\end{array}$ & $\begin{array}{l}\text { Una cadena de valor es toda la serie de actividades de las } \\
\text { empresas, desde la concepción del producto hasta su uso final } \\
\text { y más allá. Esto incluye actividades como el diseño, la producción, } \\
\text { el marketing, la distribución y el soporte posventa. }\end{array}$ \\
\hline $\begin{array}{l}\text { Kaplinsky y Morris (2001), } \\
\text { CEPAL (Anlló, Bisang } \\
\text { y Salvatierra, 2010), } \\
\text { Unión Europea (Sturgeon, 2013), } \\
\text { Comisión Europea (2018) }\end{array}$ & $\begin{array}{l}\text { Una cadena de valor es toda la gama de actividades que se } \\
\text { precisan para que un producto o servicio avance desde su } \\
\text { concepción, a través de las diferentes fases productivas, hasta } \\
\text { su entrega a los consumidores y la disposición final después } \\
\text { de su utilización. }\end{array}$ \\
\hline GIZ (2007) & $\begin{array}{l}\text { Una cadena de valor es una secuencia de actividades o funciones } \\
\text { empresariales que van desde el suministro de insumos específicos } \\
\text { para la producción primaria, la transformación y la mercadotecnia } \\
\text { de un producto en particular, hasta la venta final al consumidor. }\end{array}$ \\
\hline USAID (2008) & $\begin{array}{l}\text { Una cadena de valor es el flujo de creación de valor de un bien, } \\
\text { desde la materia prima, la producción y la comercialización, hasta } \\
\text { la entrega a los usuarios finales o consumidores. }\end{array}$ \\
\hline BID (Blyde, 2014) & $\begin{array}{l}\text { Una cadena de valor se define como un grupo de unidades } \\
\text { económicas que proporciona una gama de actividades tangibles } \\
\text { e intangibles que agregan valor y son necesarias para la entrega } \\
\text { de un bien o servicio, desde su concepción, pasando por diferentes } \\
\text { etapas de producción, hasta la entrega final a los consumidores. }\end{array}$ \\
\hline
\end{tabular}

Fuente: Comisión Económica para América Latina y el Caribe (CEPAL), Articulación productiva y cadenas regionales de valor: una propuesta metodológica para la región SICA (LC/MEX/TS.2018/21), Ciudad de México, sede subregional de la CEPAL en México, 2018.

El análisis de las cadenas de valor ofrece una oportunidad para estudiar las actividades productivas de un país o una región, así como el modo en que estas aportan valor a los productos intermedios y finales. Con el análisis de las cadenas de valor es posible determinar el impacto de un sector específico y buscar nuevas oportunidades para ampliar el número de beneficiarios de una cadena. En el caso de Centroamérica, existen tres tipos de cadenas de valor que son relevantes, como se muestra en el diagrama V.1.

\section{Diagrama V.1 \\ Las diferentes cadenas de valor}
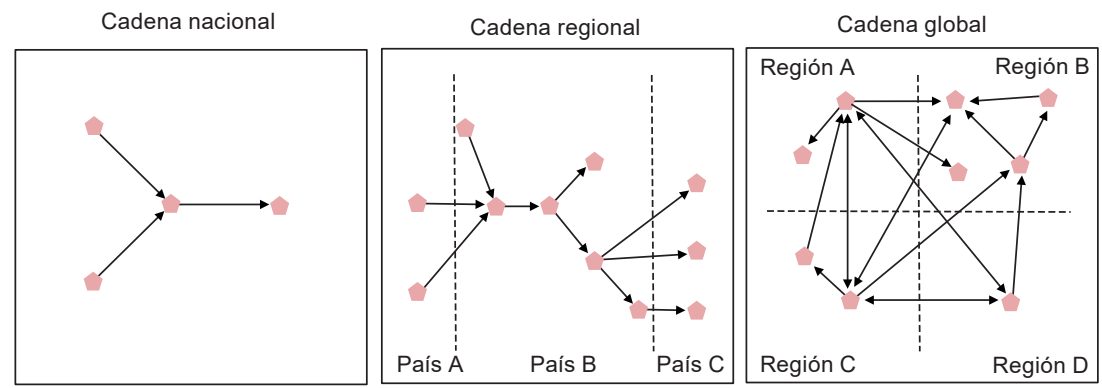

Fuente: Elaboración propia. 
La cadena más sencilla es el primer caso que aparece en el diagrama V.1: la cadena nacional ${ }^{2}$. Todos los participantes de esa cadena son nacionales, y la cadena suele tener pocos eslabones porque la producción puede estar verticalmente integrada. En el otro extremo existen las cadenas globales de valor. Estas son redes internacionales de producción, en general dominadas por empresas transnacionales extrarregionales, que involucran a varias regiones del mundo y que tienen como objetivo producir bienes o servicios de alta complejidad (véase una descripción de la complejidad de las cadenas de valor en el recuadro V.1). En el medio existe la cadena regional de valor. En una cadena de este tipo se combinan las ventajas de las cadenas nacionales (menor nivel de complejidad, cercanía geográfica y cultural, y conocimiento de los agentes económicos entre sí, por ejemplo) con las ventajas de las cadenas globales de valor (como la mayor eficiencia que se puede lograr). Como se explica más adelante, en el caso de Centroamérica existen amplias oportunidades de desarrollar cadenas regionales de valor.

\section{Recuadro V.1 \\ La complejidad de las cadenas de valor}

No existe una definición exacta de la complejidad de las cadenas de valor, pero se pueden describir algunos elementos relevantes que la determinan. Es importante tomar en cuenta que la definición que se usa aquí se basa en las características del entorno productivo centroamericano y por ello no se puede extrapolar a otras regiones.

Los factores que contribuyen al nivel de complejidad de una cadena son el tipo de producto y el proceso productivo:

- Con referencia al tipo de producto, los menos complejos son los que se basan en bienes primarios, como los productos agroindustriales, que suponen poca transformación. La presencia de este tipo de productos es abundante en las cadenas nacionales y regionales de Centroamérica. La forma de elaborar los productos de menor complejidad es menos sofisticada y el valor agregado suele ser relativamente bajo.

- Con referencia al proceso productivo, los elementos clave son la tecnología que se requiere para la producción (que en el caso de las cadenas de menor complejidad no suele ser tecnología de punta), el grado de coordinación entre los diferentes eslabones de la cadena y el grado en que se puede agregar valor al producto durante su procesamiento.

Tomando en cuenta estos diferentes criterios, las cadenas nacionales de Centroamérica se definen como cadenas de menor complejidad (aunque existen excepciones), mientras que las cadenas globales de valor suelen ser de mayor complejidad (con sus propias excepciones). De hecho, algunas de las cadenas globales de valor que tienen una fuerte presencia en la región, como las de productos textiles o agroindustriales, suelen tener un grado de complejidad menor que algunas cadenas regionales

Fuente: Elaboración propia.

Si bien esta es la cadena más sencilla, su complejidad puede variar mucho dependiendo del número de eslabones y agentes productivos que participan en la elaboración del bien o servicio. 


\section{Las cadenas nacionales}

En Centroamérica, la producción más común es aquella en la que se encadenan diversos actores locales para elaborar bienes que se venden en el mercado local. Este tipo de cadenas (cadenas nacionales de valor) tienen ciertas fortalezas. Primero, los actores locales se conocen, existen relaciones productivas e institucionales comunes y, en muchos casos, la complejidad tecnológica es relativamente baja, lo que facilita el desarrollo de la cadena. Su estudio (y su fortalecimiento) también tiende a ser menos complejo, porque participa un número reducido de agentes productivos que están geográficamente cercanos. Segundo, en muchos casos las cadenas nacionales corresponden a sectores que dependen menos del extranjero: los insumos se producen dentro del país y los principales consumidores están en él. Tercero, las cadenas nacionales pueden ser útiles porque crean trabajo basado en fuentes locales y suelen tener un impacto directo en la mejora de la eficiencia de la producción local.

Sin embargo, el desarrollo de las cadenas nacionales de valor puede tener un menor impacto macroeconómico que el de las cadenas productivas internacionales, y la ganancia en términos de eficiencia puede ser menor. Además, si bien una de las ventajas importantes de las cadenas de valor es el aprendizaje que los participantes obtienen de los demás de la cadena, es posible que dicho aprendizaje sea limitado en el caso de las cadenas nacionales, por el hecho de que solo hay participantes del país.

Recientemente la CEPAL ha tenido la oportunidad de ofrecer apoyo al fortalecimiento de algunas cadenas nacionales de valor en la región. A través de diversos proyectos de cooperación, se diseñó una metodología para fortalecer dichas cadenas que se aplicó en El Salvador (camarones y fibras sintéticas) y Guatemala (hortalizas no tradicionales y productos maderables) (Padilla Pérez, 2014). La CEPAL publicó un manual sobre la aplicación de una metodología de fortalecimiento de las cadenas nacionales de valor (Padilla Pérez y Oddone, 2016) y, con base en ese manual, se llevaron a cabo nuevos trabajos en la región: lácteos en la República Dominicana (Gomes Nogueira y Oddone, 2017); turismo en la República Dominicana (Alvarado y Oddone, 2017), Guatemala (Oddone y Alarcón, 2017) y El Salvador (Garry y Martínez, 2017); tomate y chile verde dulce (Oddone y otros, 2017) y snacks nutritivos con base en fruta deshidratada en El Salvador (Romero, Díaz y Aguirre, 2016); chips fritos al vacío (Cordero y Padilla Pérez, 2017) y miel y papaya en Costa Rica (Garry, Martínez Piva y Salido Marcos, 2017), entre otros. El fortalecimiento de las cadenas nacionales de valor juega un papel relevante en el desarrollo rural a nivel local, pero su impacto en el desarrollo productivo regional es limitado.

En el resto de América Latina, la CEPAL también ha apoyado el desarrollo de varias cadenas nacionales de valor (Aghón, Alburquerque y Cortés, 2001; Durán Lima y Zaclicever, 2013; Cornejo Díaz, 2018). Sin embargo, dado el 
tamaño de los países sudamericanos, la escala de este tipo de intervención tiende a ser mayor. La singularidad de los países centroamericanos estriba en su menor tamaño y su grado de integración regional y productiva, por lo que no es conveniente hacer una comparación directa entre los programas de fortalecimiento de las cadenas de valor en los países de Centroamérica y en los países latinoamericanos más grandes.

\section{Las cadenas globales}

Las cadenas globales de valor forman parte del escenario internacional desde hace mucho tiempo, pero su complejidad y escala han aumentado desde los años noventa. De acuerdo con la UNCTAD (2018), las cadenas globales de valor representan cerca del $57 \%$ del comercio mundial. En el gráfico V.3 se muestra que los números son mucho menores en el caso de Centroamérica. Además, en la mayoría de los países centroamericanos la tendencia es negativa, motivo por el cual la participación de las cadenas globales de valor es menor en 2018 que en 2005. El Salvador y Guatemala son la excepción, pues en ellos se observa un ligero aumento.

\section{Gráfico V.3}

Centroamérica (6 países): participación en las cadenas globales de valor, 2005 y 2018 ${ }^{\text {a }}$ (En porcentajes de las exportaciones)

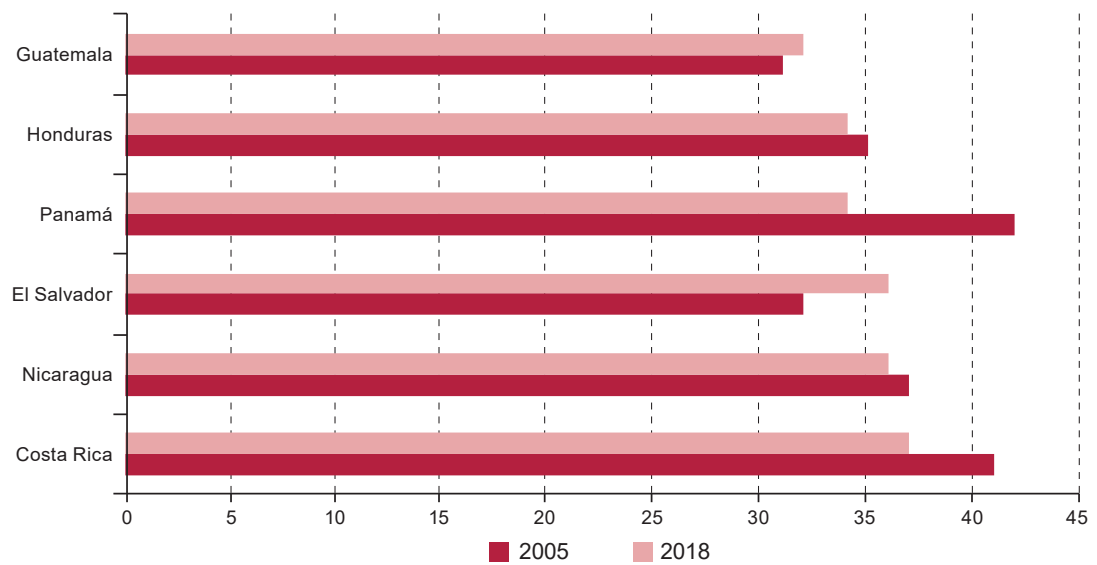

Fuente: Comisión Económica para América Latina y el Caribe (CEPAL), sobre la base de Conferencia de las Naciones Unidas sobre Comercio y Desarrollo (UNCTAD), "UNCTAD-Eora Global Value Chain Database", 2018 [base de datos en línea] http:// worldmrio.com/unctadgvc.

a Cifras estimadas.

Las cadenas globales de valor causan grandes dificultades a la hora de medir el comercio internacional, debido a lo complejo que es contabilizar los flujos transfronterizos de insumos intermedios que se incorporan en los bienes finales. Un indicador que se usa para este fin es el valor agregado 
extranjero contenido en las exportaciones brutas de un país, que en el mundo en su conjunto alcanza el $28 \%$, de acuerdo con lo que ha informado la UNCTAD (2018). Como se muestra en el gráfico V.4, también en lo que respecta a esta medida la región se comporta de modo diferente al mundo. En todos los países centroamericanos se observan resultados menores que el promedio mundial, y, con la notable excepción de El Salvador, también en este aspecto la región presenta una tendencia negativa.

\section{Gráfico V.4 \\ Centroamérica (6 países): participación del valor agregado extranjero en las exportaciones, 2005 y 2018 \\ (En porcentajes)}

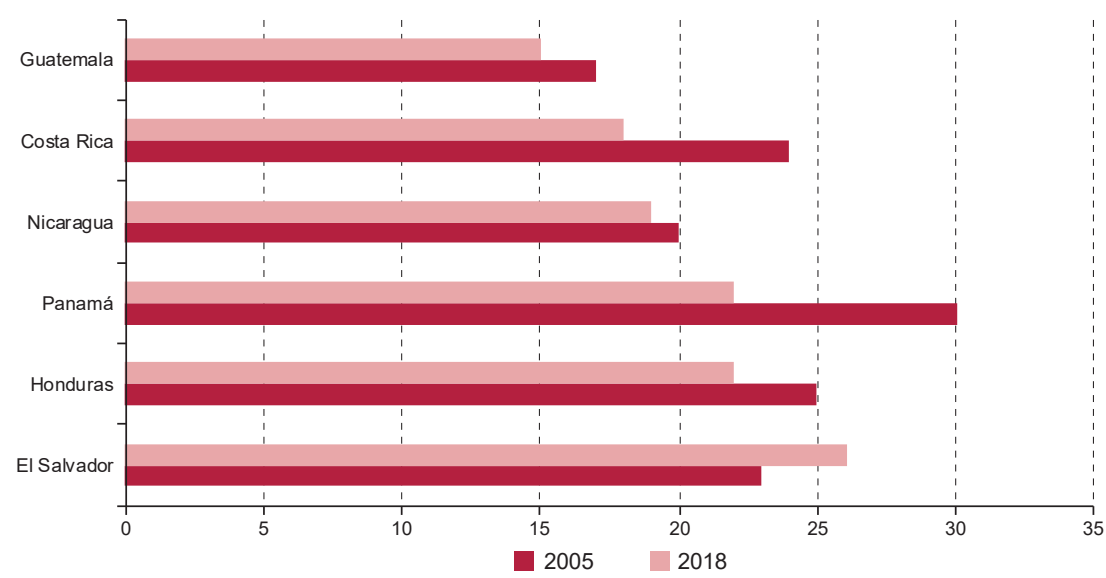

Fuente: Comisión Económica para América Latina y el Caribe (CEPAL), sobre la base de Conferencia de las Naciones Unidas sobre Comercio y Desarrollo (UNCTAD), "UNCTAD-Eora Global Value Chain Database", 2018 [base de datos en línea] http:// worldmrio.com/unctadgvc.

a Cifras estimadas.

Las cadenas globales de valor son redes complejas en las que participan múltiples regiones para producir bienes o servicios; estas cadenas tienen eslabones en diversos países y su gobernanza generalmente se controla en una casa matriz ubicada en países desarrollados. Por ejemplo, los productos de Apple son ensamblados por productores especializados, y su manufactura contiene cientos de diferentes componentes que elaboran distintos proveedores. En la fabricación del iPhone $X$ se recurre a más de 200 proveedores mundiales concentrados en algunos países asiáticos. El ensamblaje final lo hace una empresa taiwanesa especializada en la manufactura (The New York Times, 2016). El sector automotriz es otro de los sectores en que hay amplias cadenas globales de valor, y tiene una especial importancia en México y en la zona que abarca el TLCAN. 
Las cadenas globales de valor tienen características diferentes de las que se observan en las cadenas nacionales. Primero, su objeto es producir bienes o servicios que no es factible elaborar de manera eficiente en un solo país $^{3}$. Segundo, aunque es posible que las mipymes participen en eslabones concretos de la cadena, los líderes son empresas multinacionales que buscan recursos o eficiencia. Tercero, las cadenas globales de valor se caracterizan por cierta inflexibilidad en cuanto a los proveedores y la localización, dadas las inversiones y las decisiones logísticas y de aprovisionamiento que se han tomado para establecerlas. Cuarto, las cadenas globales de valor son frecuentes en industrias maduras que suelen contar con redes de proveedores establecidos, por lo que ofrecen pocas oportunidades de inserción para las empresas nuevas. La creación de nuevas cadenas globales de valor suele traer consigo un proceso schumpeteriano de destrucción creativa que no sucede a menudo, por lo que las oportunidades de crearlas son escasas y costosas.

Las características específicas de las cadenas globales de valor implican que es un gran desafío insertarse en ellas. Aunque en la producción de un automóvil se utilizan insumos provenientes de muchos países del mundo, insertarse en esta cadena solo es posible si un país o una región ofrecen algo relevante para la cadena. Varios países de América del Sur, por ejemplo, participan en dichas cadenas principalmente a través de su producción de materias primas, mientras que México lo hace gracias a sus bajos costos de producción, su ubicación geográfica y la amplia presencia de empresas transnacionales.

En Centroamérica se deben construir fortalezas que ofrecer para aumentar la participación en determinadas cadenas globales de valor, y se deben identificar los eslabones en los que la región pueda insertarse y sacar provecho de esa participación. Insertarse al inicio (con recursos naturales) o en el medio (ensamblaje) de una cadena de valor tiende a ser menos beneficioso, porque los beneficios de los efectos secundarios (spillovers) relacionados con el conocimiento y el valor agregado suelen concentrarse en los eslabones avanzados de las cadenas globales de valor. Por ese motivo, también es importante hacer lo posible por escalar en ellas.

Lo anterior no quiere decir que no haya cadenas globales de valor puntuales en las que la región juegue un papel relevante. Por ejemplo, la planta de manufactura de Intel en Costa Rica (que cerró en 2014) formó parte de las cadenas globales de valor en las tecnologías de la información y las comunicaciones. Sin embargo, el traslado de la producción a plantas de

La factibilidad tiene que ver con los desafíos tecnológicos (procesos en los que el conocimiento no existe en solo un lugar), los recursos (los insumos se producen solo en países específicos, por ejemplo) o la eficiencia (cuando la producción mundial es una forma de disminuir los costos de la producción). 
China, Malasia y Viet Nam muestra la dificultad que enfrenta Centroamérica para encontrar su propio nicho en estas cadenas. En este caso, Costa Rica perdió su lugar en dicha cadena global. Sin perjuicio de ello, Intel es un buen ejemplo de una de las ventajas principales que ofrecen las cadenas globales de valor: el potencial de generar efectos secundarios. Durante su presencia en Costa Rica, la planta de Intel creó oportunidades de aprendizaje para sus trabajadores y proveedores. Así, se formaron expertos en el sector de la computación y la alta tecnología que podrían ofrecer nuevas oportunidades para el desarrollo del sector en ese país.

En algunos nichos específicos existen otros ejemplos más allá de Intel. En Nindirí (Nicaragua) hay una planta de arneses para autos de la empresa alemana DRÄXLMAIER, y empresas de software y reparación de aviones, así como una larga experiencia en el sector textil y de prendas de vestir. El mayor reto que plantea la participación en estas cadenas globales es incrementar el valor que el país aporta en los eslabones en que participa e incrementar los efectos secundarios sobre el resto de la economía.

\section{Las cadenas regionales}

Las cadenas regionales de valor son el modelo que ofrece, en muchos casos, oportunidades más factibles y accesibles de inserción para las empresas locales, como se observa en el centro del cuadro V.2, en el que se muestran las distintas fortalezas de las cadenas de valor en diferentes niveles. En las cadenas regionales de valor se combinan las ventajas de las cadenas nacionales con las de las globales. En términos generales, las cadenas regionales se orientan a aumentar la integración y la eficiencia de diferentes eslabones ubicados en países vecinos. Participar en estas cadenas permite acceder a nuevas tecnologías, habilidades empresariales y redes de innovación que tienden a incrementar la productividad y deberían mejorar la calidad del empleo y los salarios (CEPAL, 2018b). En el caso de los países pequeños como los centroamericanos, para que algunas industrias se desarrollen y sean competitivas es necesario que tengan una escala regional y que en ellas participen actores públicos y privados regionales (transportes, logística, seguros, créditos, capitales, insumos y consumidores finales).

Como se muestra en el cuadro V.2, las cadenas regionales de valor se ubican entre las cadenas nacionales y las cadenas globales en muchos aspectos. Por ejemplo, las cadenas regionales no ofrecen la simplicidad de manejo de una cadena nacional, pero tampoco son tan complejas como las cadenas globales (véase el recuadro V.1). De forma similar, el bono potencial de eficiencia que la región puede aprovechar queda también entre esos extremos. Una excepción importante se observa en las oportunidades que ofrece este tipo de cadena para Centroamérica. 
Cuadro V.2

Centroamérica: comparación de las fortalezas de las cadenas nacionales, regionales y globales de valor

\begin{tabular}{llll}
\hline & Cadenas nacionales & Cadenas regionales & Cadenas globales \\
\hline Grado de complejidad & Bajo & Mediano & Alto \\
\hline Bono potencial de eficiencia & Bajo & Mediano & Alto \\
\hline Factibilidad & Alta & Alta & Baja \\
\hline Oportunidades & Medianas & Altas & Bajas \\
\hline Requisitos institucionales & Bajos & Medianos & Altos \\
\hline Impacto potencial & Mediano & Mediano & Alto \\
\hline Efectos secundarios potenciales & Bajos & Medianos & Altos \\
\hline
\end{tabular}

Fuente: Elaboración propia.

Dado lo complejo que es insertarse en las cadenas globales de valor y el menor impacto potencial de las cadenas nacionales, las cadenas regionales ofrecen a Centroamérica más oportunidades de mejorar, tanto en eficiencia como en productividad. Además, estas cadenas se fundamentan en el proceso de integración regional y contribuyen a él, con lo que profundizan la integración y la especialización productiva. En resumen, las cadenas regionales de valor ofrecen una oportunidad alternativa para escalar y crear valor a nivel regional.

Por su capacidad de agregar valor y fortalecer la integración productiva regional y la competitividad internacional, las cadenas regionales de valor han llamado la atención de los encargados de tomar decisiones en Centroamérica. La CEPAL está cooperando con el CENPROMYPE y la SIECA en el desarrollo de una metodología armonizada para fortalecer las cadenas regionales de valor (CEPAL, 2018b). Esta metodología se explica en detalle más adelante. Sin embargo, las cadenas regionales de valor no solo se aplican dentro de Centroamérica; de hecho, en el Proyecto de Integración y Desarrollo de Mesoamérica (Proyecto Mesoamérica), que reúne a los países centroamericanos con Belice, Colombia, México y la República Dominicana, se ha expresado interés en fortalecer cadenas regionales de escala mesoamericana. El encadenamiento con países como Colombia o México es una oportunidad de acceder a mercados más grandes.

La CEPAL realizó un primer estudio de una cadena regional de valor en Centroamérica que se enfocó en el sector lácteo y mostró la factibilidad de analizar y fortalecer cadenas de naturaleza regional (De Groot, 2018). El sector lácteo es un sector primario con un alto grado de integración en Centroamérica. La producción está concentrada en pocos países (principalmente en Costa Rica y Nicaragua), y existen varios vínculos entre los países, ya que en el proceso de producción se unen eslabones de varios de ellos. Las conclusiones del estudio indicaron que el sector enfrenta desafíos nacionales y regionales, y que, para fortalecer una cadena regional, los esfuerzos puramente nacionales pueden ser tan relevantes como los de carácter regional. 
Los cuellos de botella del sector lácteo a nivel nacional tienen que ver con los diferentes desafíos que cada país enfrenta. En un país, el desafío principal puede ser la inocuidad del producto primario, mientras que en otro puede ser la formalización de las empresas. Los desafíos principales de la región tienen que ver con las reglas fitosanitarias y los retos asociados con la integración regional. A pesar del proceso de integración centroamericana, el sector de los lácteos sigue teniendo controles fitosanitarios estrictos en los que los procesos de certificación no están homologados. Lograrlo mejoraría sustancialmente el grado de confianza intracentroamericano, y aumentaría la eficiencia productiva y el comercio intrarregional.

\section{Las cadenas regionales de valor como un estímulo para la integración productiva de Centroamérica}

La relación entre las cadenas regionales de valor y la integración económica en Centroamérica es estrecha y compleja. Por una parte, la integración económica ha permitido la integración productiva regional y, por lo tanto, es la base del surgimiento de las cadenas regionales de valor. Por otra parte, mediante el estudio de estas cadenas se pueden identificar desafíos que subsisten en la integración regional y los cuellos de botella que la región debe enfrentar. Tanto la integración regional como el estudio de las cadenas regionales de valor tienen el mismo metaobjetivo: impulsar el desarrollo productivo de la región.

El mercado centroamericano ya cuenta con un elevado nivel de integración en algunos servicios. Los servicios financieros y el sector de las telecomunicaciones, por ejemplo, están muy integrados y en ellos hay actores internacionales que consideran el mercado centroamericano como uno solo, lo que da lugar a una mayor competencia y a precios más bajos para los consumidores. Hasta ahora, la integración de los servicios ha sido liderada por empresas transnacionales, que dominan en el sector de las telecomunicaciones, aunque han surgido actores pancentroamericanos en el sector financiero.

El esfuerzo por estimular el desarrollo productivo a través de encadenamientos regionales y de la integración regional tiene una extensa historia. Durante el período de sustitución de importaciones se promovió la industrialización y la especialización productiva de los países centroamericanos, de manera que en el interior de cada uno se integraban los eslabones productivos de industrias concretas. Posteriormente, con la propuesta del regionalismo abierto, se promovieron los encadenamientos productivos regionales para aumentar la competitividad de la región a nivel internacional (véanse los capítulos I y II). 
En 1999, el Centro Latinoamericano para la Competitividad y el Desarrollo Sostenible (CLACDS) de INCAE Business School (INCAE), en colaboración con el Instituto de Desarrollo Internacional de Harvard (HIID), lanzó la agenda para la competitividad y el desarrollo sostenible de Centroamérica en el siglo XXI. Esta es una propuesta de carácter prospectivo en la que se determinó el potencial de la región centroamericana en cuanto al desarrollo de clústeres, entendidos como un grupo geográficamente próximo de compañías e instituciones asociadas que operan en un campo empresarial particular y que están vinculadas por características comunes y complementarias (INCAE/HIID, 1999). En el estudio se identificaron varios sectores de alto potencial que pueden funcionar como un motor económico del desarrollo productivo de la región. Los sectores señalados fueron el turismo, los agronegocios, los textiles y las prendas de vestir, así como la manufactura de componentes electrónicos y los servicios relacionados con el software y la computación. De esta manera, y sin planteárselo de manera directa, en el análisis de INCAE y el HIID se reconocieron sectores con potencial para crear cadenas regionales de valor.

Por otra parte, en un análisis del Programa Regional de Apoyo a la Calidad y a la Aplicación de Medidas Sanitarias y Fitosanitarias en Centroamérica (PRACAMS), se identificaron productos específicos de la región que tienen un alto potencial para la exportación extrarregional. Los principales productos reconocidos son la carne, la miel natural, el follaje, el cardamomo, las tilapias y los camarones. Algunos de ellos ofrecen posibilidades de encadenamiento regional, pero también es posible trabajar con ellos a nivel nacional.

Dada la relevancia que las cadenas regionales de valor tienen para la integración productiva de la región, el Consejo de Ministros de Integración Económica (COMIECO) de la SIECA definió el fortalecimiento de las cadenas de valor de carácter transfronterizo como una de sus áreas de acción. En cooperación con socios regionales, la CEPAL impulsa una labor que tiene por objeto profundizar el trabajo en este tema. La primera parte de este impulso es diseñar una metodología de análisis y fortalecimiento de las cadenas regionales de valor. Además, la CEPAL está promoviendo el desarrollo de estas cadenas para fomentar el desarrollo productivo a nivel regional. Es una forma de crecimiento natural en que la región puede mostrar su liderazgo sin depender de países desarrollados y grandes empresas transnacionales.

Para disminuir la dependencia respecto de las empresas transnacionales y aumentar los beneficios de las cadenas regionales de valor, la CEPAL trabaja en conjunto con instituciones regionales, como el CAC, el CENPROMYPE, la SIECA y la SITCA, entre otras. En su Estrategia Regional de Articulación Productiva MIPYME, el CENPROMYPE también reconoce el desarrollo de cadenas regionales de valor como un punto clave para el desarrollo productivo de la región (CENPROMYPE, 2017). Esta estrategia está organizada en torno a los siguientes cinco ejes principales: 
i) Gobernanza y coordinación institucional.

ii) Metodología armonizada.

iii) Instrumentos de acceso a los mercados.

iv) Inclusión de las mipymes en las cadenas de valor.

v) Infraestructura y servicios para las mipymes.

El CENPROMYPE también identifica algunos sectores puntuales que pueden ser la vanguardia del desarrollo productivo de la región. Como respuesta al eje ii), el CENPROMYPE ha buscado la cooperación de la CEPAL y la SIECA, y las tres instituciones han trabajado en el diseño de una metodología armonizada para investigar y fortalecer las cadenas regionales de valor. En la siguiente sección se presenta dicha metodología.

\section{Metodología armonizada para el fortalecimiento de las cadenas regionales de valor ${ }^{4}$}

Como se planteó en las secciones anteriores, analizar las cadenas regionales de valor es de gran importancia para formular políticas de transformación y articulación productivas en la región del Sistema de la Integración Centroamericana (SICA). La metodología que propone la CEPAL en cooperación con el CENPROMYPE y la SIECA tiene sus raíces en el Manual para el fortalecimiento de cadenas de valor de la CEPAL y el Fondo Internacional de Desarrollo Agrícola (FIDA) (Padilla Pérez y Oddone, 2016), que se orienta al fortalecimiento de las cadenas nacionales de valor. La metodología armonizada se enfoca en las diferencias entre las cadenas nacionales y las regionales, y en ella se pone el énfasis en los elementos debido a los cuales la intervención a escala regional se debe planificar de una forma diferente.

En el diagrama V.2 se presentan los principales pasos del análisis de una cadena regional de valor. Para analizar de forma completa este tipo de cadenas es necesario seguir los pasos sugeridos, aunque también es importante tener en cuenta que tal vez haya que adaptarlos a la situación específica de la región o el caso concreto. Los pasos forman una guía integral para lograr resultados completos en cuanto al análisis y el fortalecimiento de las cadenas regionales de valor, y se explican con mayor detalle en esta subsección. La metodología se enfoca en promover un alto nivel de participación sectorial intrarregional y en ella hay varios puntos de reflexión y retroalimentación cuyo propósito es mejorar los resultados finales. La participación del sector objeto del análisis permite lograr buenos resultados, tanto en lo que respecta al diagnóstico como a las propuestas relacionadas con las políticas públicas. Otro punto que la CEPAL considera importante es que las autoridades

Esta sección se basa en gran parte en el manual que la CEPAL ha elaborado en cooperación con el CENPROMYPE y la SIECA (CEPAL, 2018b). 
nacionales y regionales participen en todo el proceso, de manera que se transfiera conocimiento hacia las autoridades locales para que estas puedan emprender futuros trabajos de fortalecimiento por su propia cuenta.

Diagrama V.2

Pasos del análisis de una cadena regional de valor

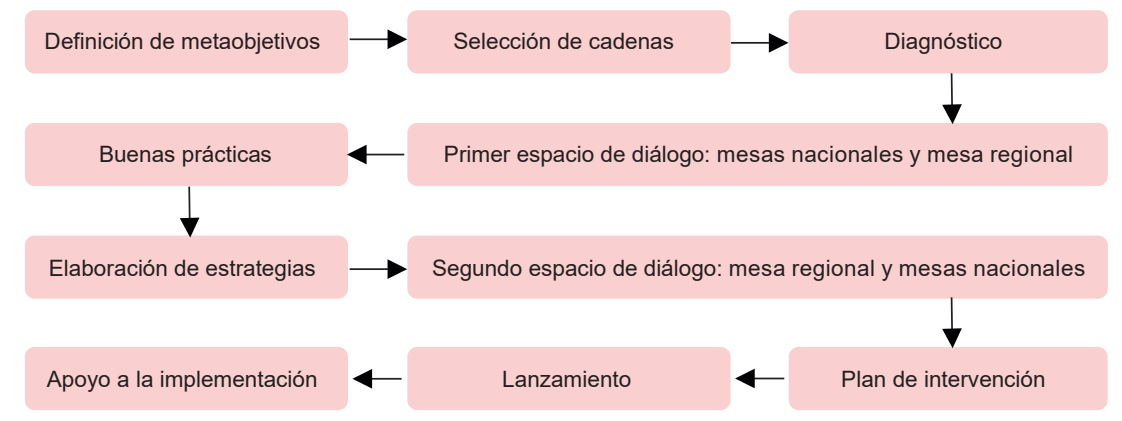

Fuente: Comisión Económica para América Latina y el Caribe (CEPAL), Articulación productiva y cadenas regionales de valor: una propuesta metodológica para la región SICA (LC/MEX/TS.2018/21), Ciudad de México, sede subregional de la CEPAL en México, 2018.

El primer paso para analizar las cadenas regionales de valor es definir los metaobjetivos, lo que es fundamental para el ejercicio de selección. Los metaobjetivos no solo afectan la selección de las cadenas, sino también los resultados de las sucesivas etapas del proceso, y se entienden como la finalidad última, en materia de desarrollo económico y social, que se persigue con el fortalecimiento de una cadena. Se espera que los metaobjetivos estén alineados con el plan nacional de desarrollo y las políticas públicas más relevantes, como la industrial y la de ciencia, tecnología e innovación. Algunos metaobjetivos que se pueden mencionar a modo de ejemplo son aumentar el empleo y los salarios reales, impulsar las exportaciones, provocar una creciente participación de las mipymes o incrementar la producción nacional.

Con los metaobjetivos ya definidos, se puede empezar un proceso cuidadoso de selección para decidir, entre todas las potenciales cadenas, con cuáles trabajar. En este proceso se tienen que combinar criterios cuantitativos y cualitativos, además de consideraciones de carácter político. Las circunstancias de la investigación determinan el universo de cadenas potenciales que serán objeto de análisis: o bien se incluirá la totalidad de los sectores, o bien se hará una selección previa para acotar el proceso de decisión.

La metodología propuesta consiste en un proceso durante el cual se agrega información en dos etapas, y concluye con un espacio de consulta que tiene por objeto fomentar el diálogo político entre las autoridades encargadas de tomar la decisión. Los metaobjetivos se instrumentalizan, en una primera instancia, mediante indicadores cuantitativos que se asocian a 
un conjunto de criterios de decisión. Estos indicadores permiten construir un índice compuesto que genera una primera jerarquización de los sectores de acuerdo con la información cuantitativa disponible.

En una segunda etapa se incorporan las dimensiones cualitativas, por lo que se sugiere definir criterios que se ponderen de acuerdo con su relevancia estratégica y política. Finalmente, el ciclo del proceso de selección culmina con un espacio de diálogo entre los actores políticos encargados del proceso de tomar la decisión, quienes representan los intereses específicos de cada país y validan la información obtenida y la metodología aplicada.

Una vez seleccionada la cadena, sigue la etapa de diagnóstico, que no difiere mucho del de una cadena nacional de valor. Los pasos principales son los mismos, pero con un enfoque ampliado y con mayor atención a los temas transfronterizos. El primer paso del diagnóstico es mapear la industria a nivel nacional en cada uno de los países objeto del análisis, seguido por un mapeo que contiene la información a nivel regional. En el mapeo se tiene que presentar el funcionamiento de la cadena con cada uno de sus eslabones.

La identificación de los actores principales (el segundo paso) es parte fundamental del análisis. Además de los actores directos, como los productores de los insumos principales y los consumidores, también es importante reconocer que existen actores indirectos que crean el entorno de una cadena. El sector público y la academia forman parte de dicho entorno y pueden jugar un papel clave en su organización. El tercer paso del diagnóstico consiste en analizar los aspectos económicos. Se reconocen puntos importantes, como la rentabilidad de la cadena y los eslabones en los cuales se concentran las ganancias. Es importante determinar el valor agregado existente y las posibilidades de aumentar ese valor mediante intervenciones en el proceso productivo, ganancias de calidad e incorporación de servicios, entre otras medidas. El cuarto paso del diagnóstico abarca diferentes temas transversales: el papel de las mujeres, el impacto ambiental de la cadena, las restricciones de financiamiento o la desigualdad económica territorial, por ejemplo.

Al finalizar el diagnóstico se identifican las principales restricciones o cuellos de botella que hay en la cadena. Estos son los obstáculos que enfrentan los eslabones de la cadena o la cadena en su conjunto (restricciones sistémicas), que impiden su buen funcionamiento o articulación y, por consiguiente, el escalamiento económico y social. A su vez, estos cuellos de botella tendrán un carácter regional o nacional, dependiendo del caso.

De acuerdo con el diagrama V.2, la siguiente etapa son los espacios de diálogo. En la metodología para el fortalecimiento de las cadenas de valor es medular construir espacios de diálogo entre los actores de la cadena, como se explica en Padilla Pérez y Oddone (2016). El objetivo de estos espacios es que el diagnóstico y las estrategias se validen de manera participativa, y de esta manera se creen los consensos necesarios para solucionar los cuellos 
de botella que se hayan encontrado. Los espacios de diálogo se organizan con el apoyo de las instituciones nacionales y de los actores relevantes de la cadena. La experiencia previa muestra la fortaleza de este diálogo en lo que respecta a la creación de consensos y la adopción común de las estrategias propuestas en el análisis.

En el caso de las cadenas regionales de valor, los espacios de diálogo son más complejos debido a que, por su naturaleza, comprenden múltiples países y múltiples actores, pero se trata de un paso indispensable. En su desarrollo se debe tener prevista la participación de actores tanto locales (principalmente a nivel nacional) como regionales, con el fin de brindar un abordaje integral al espacio de diálogo creado.

En la metodología de fortalecimiento de las cadenas nacionales (Padilla Pérez y Oddone, 2016) se contemplan dos mesas de diálogo. La primera tiene por objeto validar los hallazgos principales (el mapeo de los actores de la cadena, su gobernanza y las principales restricciones que enfrenta la cadena a nivel sistémico y por eslabón). La segunda es para generar consenso sobre las estrategias que permitirán resolver los cuellos de botella identificados en el diagnóstico.

Debido a que las cadenas regionales de valor comprenden múltiples países, es necesario subdividir ambos espacios de diálogo en mesas separadas a nivel nacional y regional: un primer espacio de diálogo que empieza con las mesas nacionales en cada país participante, seguidas por una mesa regional. De esta forma se incluyen las opiniones de todos los participantes de la cadena con el objetivo de validar el diagnóstico. El segundo espacio de diálogo consiste en las mismas mesas, pero en el orden opuesto, empezando con la mesa regional.

Después de realizar las primeras mesas de diálogo (tanto las nacionales como la regional), se elaboran estrategias que incidan en los cuellos de botella identificados. Afortunadamente, no es necesario diseñar nuevas políticas a partir de cero, dado que existen experiencias previas que pueden servir de guía como buena práctica. Existen muchas experiencias con diferentes tipos de cadenas y en diferentes contextos que podrían constituir aportes de fondo para la elaboración de estrategias que permitan abordar los desafíos del sector. Por ello, es importante identificar buenas prácticas en otras cadenas o en experiencias anteriores relacionadas con políticas de transformación y articulación productivas. Los ejemplos pueden originarse en el mismo país, en la región o en otras partes del mundo que han enfrentado un desafío similar. No es necesario que se trate de la misma industria: ciertos desafíos ocurren en diferentes cadenas y se puede valorar el aprendizaje y su aplicación. Aunque es deseable que haya una comparabilidad elevada y es cierto que esta puede ser útil, no es estrictamente necesaria. En el proceso de análisis se puede adaptar una solución en la medida que corresponda. 
Luego de identificar diferentes ejemplos, se tiene que determinar la pertinencia y la aplicabilidad de estos en lo que respecta al caso vigente. Al reconocer los factores clave del éxito de ciertos programas, y al adaptarlos a la situación vigente, es posible armar una estrategia de fortalecimiento dirigida a una cadena regional de valor. Se usan las diferentes soluciones posibles para resolver los cuellos de botella ya identificados y se organiza el segundo espacio de diálogo para presentar un plan de intervención en la cadena. Es probable que durante las mesas de diálogo se reciba retroalimentación para mejorar el plan de intervención. La participación y el compromiso del sector privado son fundamentales, por lo que incorporar dicha retroalimentación es importante para obtener un resultado óptimo.

Finalmente, se llega a las últimas etapas del proceso de acompañar el fortalecimiento de la cadena regional de valor: el plan de intervención, el lanzamiento y el apoyo a la implementación. Antes del lanzamiento regional, se diseña un plan de intervención en el que se toman en cuenta todos los resultados encontrados anteriormente y la retroalimentación recibida en los espacios de diálogo. Con dicho plan en la mano, se organiza el lanzamiento de la estrategia propuesta. Algunas experiencias previas con cadenas nacionales de valor indican que este es un elemento clave para escalar las cadenas.

El lanzamiento es un evento participativo y mediático en el que se convoca a todos los participantes de la cadena a una última reunión. El objetivo principal de esta es consolidar el compromiso de todos los participantes, incluso del sector público y sus autoridades, para lograr una cooperación fructífera. La ejecución del plan de intervención tiene lugar tras el lanzamiento y es parte de la responsabilidad funcional de las autoridades nacionales y regionales que han estado involucradas en el proceso.

\section{Cooperación internacional con socios regionales}

Para que la intervención en una cadena regional de valor sea un éxito, es muy importante que participe el sector a nivel nacional y regional. Sin embargo, la participación de la institucionalidad pública en los dos niveles también juega un papel muy relevante. El CENPROMYPE desempeña una función significativa en el fortalecimiento de las mipymes en la región y también es de su interés fortalecer las cadenas regionales de valor. Como resultado, cooperar con esta institución es importante para fortalecer las cadenas regionales. Similarmente, la SIECA tiene interés en desarrollar las cadenas regionales de valor como forma de profundizar el comercio regional. Dado su papel en la integración regional, la SIECA es un foro lógico donde resolver los cuellos de botella que tienen que ver con el comercio internacional.

La CEPAL ha cooperado con el CENPROMYPE y la SIECA en el desarrollo de una metodología armonizada para analizar las cadenas regionales de valor, y también trabaja con ambas instituciones a los efectos 
de aplicar la metodología en diferentes cadenas. Existen también otras instituciones regionales que pueden jugar un papel importante en este tema. Por ejemplo, el CAC busca fortalecer cadenas tanto nacionales como regionales en el sector agropecuario, y la SITCA es una de las instituciones especializadas de la región que tiene como objetivo desarrollar el turismo a nivel regional.

Además de la institucionalidad pública, en la región hay un amplio rango de gremios privados a nivel sectorial. Por ejemplo, en trabajos previos (De Groot, 2018), la CEPAL ha cooperado con la Federación Centroamericana del Sector Lácteo (FECALAC), organización que tiene un gran interés en el fortalecimiento de su propia cadena. Otros ejemplos incluyen la Federación de Cámaras y Asociaciones de Exportadores de Centroamérica y el Caribe (FECAEXCA) y la Federación de Entidades Privadas de Centroamérica, Panamá y República Dominicana (FEDEPRICAP), entre otros.

Cooperar con los socios tanto nacionales como internacionales también ofrece la oportunidad de que se transfiera conocimiento. Uno de los objetivos de la CEPAL es fortalecer las capacidades de las autoridades nacionales y regionales para que continúen por sí mismas con diversos trabajos relativos a las cadenas regionales de valor. El objetivo final es que esos actores realicen sus propios trabajos con el objeto de fortalecer dichas cadenas. Por ello, es crucial incorporar representantes del sector público nacional y regional en el proceso, para fomentar la transferencia de conocimiento.

\section{El futuro de las cadenas regionales en Centroamérica}

El análisis de las cadenas regionales de valor, como el de las nacionales, forma parte de un proceso enfocado en el fortalecimiento de la articulación productiva. Analizar los dos tipos de cadena puede aclarar los diferentes arquetipos de desafíos que existen en las economías centroamericanas. Sin embargo, el análisis de las cadenas regionales es más amplio y tiene un mayor potencial articulador. Con un análisis completo y profundo, se pueden identificar las necesidades que hay en el proceso productivo de la región, incluidas las que se pueden abordar desde el proceso de integración y las que requieren otros tipos de estrategias nacionales e internacionales.

Además, el trabajo de la CEPAL se alinea con otros esfuerzos destinados a fomentar el desarrollo industrial. El análisis a escala regional puede ayudar a identificar clústeres especiales en los que la región puede especializarse. Por ejemplo, la CEPAL trabaja en el fortalecimiento de la cadena regional de animación digital, un sector con grandes oportunidades, pero que, hasta el momento, desempeña un papel menor en la economía de la región. 
Mediante el análisis, las recomendaciones y el plan que la CEPAL ha hecho en relación con el sector, se puede impulsar no solo esta cadena misma, sino también los sectores relacionados, tanto en los eslabones iniciales como en los finales.

Con la identificación de estas oportunidades y el reconocimiento de los desafíos a nivel regional, se abre la puerta a nuevas posibilidades. Otro sector que tiene un alto potencial para el desarrollo a nivel regional es el turismo. Aunque en la región se ha desarrollado una buena oferta turística destinada a los visitantes internacionales, la creación de un producto conjunto ofrecería nuevas oportunidades. Reconocerlas y formular un plan que permita superar los desafíos asociados ofrecerá nuevas áreas potenciales de desarrollo para la región. La CEPAL considera que ofrecer un producto a nivel regional puede ser un gran impulso para el turismo. Además, puede dar lugar a oportunidades que son diferentes de las que ofrecen los países actualmente, con una mayor cantidad de efectos secundarios que favorezcan a los pequeños proveedores de servicios, en vez de que los productores grandes de nivel internacional concentren las ganancias, como ocurre hoy en día.

Detectar los cuellos de botella que inhiben el fortalecimiento de las cadenas regionales de valor puede requerir soluciones que se atienden mejor en el marco de la integración y la cooperación regionales. De hecho, algunos desafíos solo tienen solución por medio de la cooperación entre los países. Por ejemplo, el reconocimiento mutuo de los estándares fitosanitarios requiere concordancia regional, no solo en lo que respecta a la identificación del problema, sino también a la solución. El proceso de integración centroamericana es, por lo tanto, un instrumento fundamental para buscar soluciones a estos problemas y también puede contribuir a resolver otros desafíos. Por ejemplo, el tema de la escala, que podría beneficiar a ciertos sectores, también se puede resolver reconociendo a Centroamérica como un mercado integrado. De manera similar, la atracción de inversionistas internacionales se simplificaría gracias al aumento de escala que ofrece la integración centroamericana.

Mediante la aplicación de la misma metodología que la CEPAL concibió para analizar la cadena de lácteos a nivel regional, el CENPROMYPE ha iniciado el proceso de análisis del sector pesquero en varios países centroamericanos, y la CEPAL trabajará en el sector de la animación digital. El trabajo preliminar en el sector lácteo permitió identificar varias cadenas constituidas en Centroamérica que muestran un grado de integración productiva relevante, lo que subraya la importancia de incrementar la labor destinada a fortalecer las cadenas regionales de valor. En esa línea, el COMIECO indicó su interés en fortalecer dichas cadenas y, con ese fin, identificó dos metaobjetivos orientadores: fortalecer los patrones de complementariedad 
comercial y productiva de los países, y promover la inserción competitiva de Centroamérica en los mercados internacionales.

La CEPAL y la SIECA crearon un índice de selección de cadenas regionales de valor en el que se combinan dichos metaobjetivos (véase el recuadro V.2). Entre los sectores que tienen mayor potencial de acuerdo con el análisis cuantitativo se encuentran varios de tecnología baja a intermedia, en los que ya hay fortalezas y cadenas regionales constituidas en la región, como las harinas y los productos de la molienda, y los cosméticos y los aceites esenciales. Sin embargo, también hay sectores como el de las preparaciones alimenticias, que incluye un rango amplio de diferentes tipos de cadenas y productos, y en el que, para determinar una cadena específica, se requiere una selección más detallada. Este índice en sí mismo muestra el grado de integración productiva que existe en algunos sectores de Centroamérica.

Recuadro V.2

El índice de selección de cadenas regionales de valor

Dado que existen varias cadenas regionales de valor, la Comisión Económica para América Latina y el Caribe (CEPAL) y la Secretaría de Integración Económica Centroamericana (SIECA) crearon un índice de selección que responde a los dos metaobjetivos establecidos por el Consejo de Ministros de Integración Económica (COMIECO) de la SIECA, a saber: fortalecer los patrones de complementariedad comercial y productiva de los países, y promover la inserción competitiva de Centroamérica en los mercados internacionales. El propósito de este índice es identificar las cadenas regionales de valor que tienen mayor potencial en Centroamérica. En relación con los dos metaobjetivos hay una serie de indicadores que se combinan en un resultado que constituye el primer paso para identificar las cadenas. Las cadenas regionales de valor que se identifican tienen características que cumplen con los metaobjetivos del COMIECO, pero la elección de una cadena u otra siempre tiene un componente de oportunidad política que contribuye a garantizar el apoyo institucional tanto del sector privado como del público.

\section{Metaobjetivo 1: Fortalecer los patrones de complementariedad comercial}

Los indicadores relacionados con el primer metaobjetivo se refieren a la capacidad exportadora a nivel intrarregional, la complementariedad comercial y la vinculación intrasectorial y transfronteriza. Para cuantificar dichos criterios, se propuso usar el nivel absoluto del comercio intrarregional, el peso relativo del comercio intrarregional en comparación con las exportaciones totales, el índice de complementariedad comercial, el índice de Grubel y Lloyd, y el índice de Herfindahl-Hirschman con respeto a las exportaciones.

\section{Metaobjetivo 2: Promover la inserción competitiva de Centroamérica en los mercados internacionales}

Los indicadores relacionados con este metaobjetivo se enfocan en la especialización exportadora y el potencial de crecimiento de la demanda externa. Más en detalle, se usa el índice de ventaja comparativa revelada, el crecimiento relativo de las exportaciones extrarregionales y el crecimiento de las importaciones mundiales. 
Recuadro V.2 (conclusión)

Los diferentes indicadores se combinaron en el índice de selección de cadenas regionales de valor para identificar las cadenas con el mayor potencial y para presentar a los encargados de tomar decisiones un caso balanceado. Los resultados del análisis indican que en Centroamérica hay una serie de cadenas regionales de valor que tienen un gran potencial, como se muestra en el cuadro que figura abajo y que contiene los resultados del análisis cuantitativo de la selección.

\begin{tabular}{rlc}
\hline & Sector & $\begin{array}{c}\text { Índice de selección de cadenas regionales } \\
\text { de valor (de 0 a 1) }\end{array}$ \\
\hline 1 & Harinas y productos de la molienda & 0,59 \\
\hline 2 & Preparaciones alimenticias & 0,57 \\
\hline 3 & Cosméticos y aceites esenciales & 0,52 \\
\hline 4 & Industria papelera & 0,51 \\
\hline 5 & Lácteos y derivados & 0,51 \\
\hline 6 & Plásticos & 0,51 \\
\hline 7 & Agua embotellada & 0,51 \\
\hline 8 & Sal & 0,50 \\
\hline 9 & Videojuegos & 0,48 \\
\hline 10 & Grasas y aceites vegetales & 0,48 \\
\hline
\end{tabular}

Los resultados muestran que existen varios sectores con alto potencial cuyas cadenas de valor regionales se pueden fortalecer. La CEPAL ha trabajado en el sector de los lácteos y sus derivados, y está trabajando con el sector de la animación digital (muy vinculado al de los videojuegos). Algunos sectores son muy amplios, como el de las preparaciones alimenticias, por lo que sería importante dividirlo en subsectores más específicos.

Fuente:Elaboración propia, sobre la base de Comisión Económica para América Latina y el Caribe (CEPAL), Articulación productiva y cadenas regionales de valor: una propuesta metodológica para la región SICA (LC/MEX/TS.2018/21), Ciudad de México, sede subregional de la CEPAL en México, 2018.

Para optimizar el análisis de las cadenas regionales de valor y potenciar sus efectos, es de gran importancia cooperar con socios regionales. Esto es así no solo porque dicha cooperación permite ampliar la labor destinada a las diferentes cadenas, sino también porque cada institución regional tiene sus propias fortalezas para solucionar diferentes cuellos de botella. Las organizaciones gremiales de los diferentes sectores también cuentan con capacidades para enfrentar los desafíos identificados en los análisis y, por ello, también desempeñan un papel clave.

Para resaltar el objetivo del trabajo de fortalecer las cadenas regionales de valor, es importante recordar que el análisis no es el punto final. Los resultados y las recomendaciones se deben convertir en planes de implementación y, a tales efectos, la cooperación con socios nacionales y regionales juega un papel significativo. El CENPROMYPE y su red regional de cooperación desempeñarán una función clave en lo que respecta a coordinar actividades enfocadas en la implementación de los planes. Si bien implementar los planes de fortalecimiento de una cadena es tarea de las autoridades nacionales o regionales, en trabajos recientes a nivel nacional la CEPAL ha contribuido 
al proceso de poner en práctica las recomendaciones y desarrollar nuevos productos en los sectores de la miel y la papaya en Costa Rica (Garry y Salido, 2016; Garry y Martínez, 2017). En cooperación con socios nacionales y regionales, el objetivo de la CEPAL es buscar la forma óptima de llevar a cabo la implementación.

El trabajo de las cadenas regionales de valor ofrece una oportunidad de mejorar la coordinación internacional con el objetivo de estimular el proceso de integración regional y buscar un cambio estructural progresivo. La identificación de cuellos de botella relevantes a nivel regional puede indicar la existencia de grandes posibilidades de mejorar. Por otra parte, la integración regional también puede funcionar como catalizador del desarrollo de cadenas regionales de valor. En un mercado más integrado, los beneficios de escala y de aprovechamiento de las complementariedades intrarregionales pueden ser más obvios. De esta manera, las cadenas regionales de valor y el proceso de integración son dos elementos que se refuerzan entre sí.

Una parte importante de fortalecer las cadenas transfronterizas es mejorar la gobernanza regional. Por las características propias de las cadenas regionales de valor, en su fortalecimiento intervienen múltiples instituciones del quehacer público y privado, tanto nacionales como regionales, que contribuyen a generar y agregar valor, y que tienen su propio esquema de gobernanza. No es posible proponer y definir un modelo único y consolidado de gobernanza que se aplique a cualquier cadena regional de valor, pero se pueden plantear algunos lineamientos y recomendaciones con el fin de motivar una intervención más integral en dicho ámbito.

A nivel regional, los cuellos de botella más relevantes en lo que respecta a los encadenamientos regionales requieren de la acción articulada de dos o más autoridades, dada la estructura de regulación y gestión pública vinculada con el comercio de la región. Eso significa que en Centroamérica se deben promover fórmulas de trabajo en materia de las cadenas regionales de valor que involucren la coordinación intrainstitucional y técnico-administrativa. Además, es importante que el sector privado participe, por lo que es necesario integrar a nivel horizontal (entre quienes llevan la rectoría de los temas vinculados con la cadena a nivel nacional) y también vertical (entre los participantes de espacios regionales donde se concilian los intereses de diversos países) (CEPAL, 2018b). La existencia de este tipo de espacios a nivel sectorial es de gran apoyo para el proceso de integración.

Finalmente, en un contexto internacional voluble como el actual, fortalecer la integración productiva a nivel regional puede ofrecer un espacio de crecimiento alternativo menos incierto que el que ofrecen otros socios que no pertenecen a la región. En una época turbulenta, profundizar las buenas relaciones con los países vecinos es una forma de garantizar el desarrollo estable y confiable. 


\section{E. La ruta hacia adelante}

El proceso de integración centroamericana se ve reflejado en el comercio intraindustrial que ha generado cadenas de valor regionales. El reto actual es doble: crear más cadenas regionales que incrementen los flujos intrarregionales de comercio, y aumentar el valor agregado de las que ya existen. Al diseñar la metodología para el fortalecimiento de las cadenas regionales de valor se ha dado un primer paso importante, pero la mayor parte del trabajo aún está por hacerse. La experiencia con las cadenas de lácteos, pescado y animación digital ha permitido confirmar la utilidad de la metodología y ahora es posible buscar otras oportunidades para aplicarla. Al mismo tiempo, como parte del proceso de análisis, la CEPAL capacita a otros agentes de la región para que empiecen sus propios procesos de análisis y fortalecimiento. El objetivo tiene que ser analizar y fortalecer las cadenas regionales de valor que tienen mayor potencial, a través de acciones que conduzcan a cambios en su estructura y a productos y servicios de mayor valor.

Al mismo tiempo, es importante seguir comunicándose e interactuando con la institucionalidad de la integración centroamericana, para apoyar dicho proceso y utilizarlo a los efectos de solucionar cuellos de botella. Esto último es fundamental para aumentar el apoyo del sector productivo al proceso de integración.

El fortalecimiento de las cadenas regionales de valor tiene potencial para favorecer no solo el proceso de integración, sino también el cambio estructural que requiere la región para avanzar hacia una economía más productiva y eficiente. Identificar cadenas que tengan un alto potencial y políticas que las promuevan puede jugar un papel importante. Sin embargo, fortalecer las cadenas regionales de valor no es una panacea que resuelve todos los desafíos de la región. En Centroamérica también es necesario formular políticas públicas que fortalezcan el desarrollo sostenible de diversas cadenas nacionales y, en algunos casos, la integración en cadenas globales de valor.

La CEPAL seguirá apoyando el proyecto de integración centroamericana por diversas vías, y la integración productiva regional es una de ellas. En este contexto, el fortalecimiento de las cadenas regionales de valor es un instrumento de política de desarrollo productivo que ofrece excelentes oportunidades. Además, la cooperación interinstitucional a nivel regional estimula futuras cooperaciones y proyectos. 


\section{Bibliografía}

Aghón, G., F. Alburquerque y P. Cortés (comps.) (2001), Desarrollo económico local y descentralización en América Latina: un análisis comparativo (LC/L.1549), Comisión Económica para América Latina y el Caribe (CEPAL)/Deutsche Gesellschaft für Technische Zusammenarbeit (GTZ).

Alvarado, J. y N. Oddone (2017), "Fortalecimiento de la cadena de valor de turismo en Pedernales (República Dominicana)", Fortalecimiento de cadenas de valor rurales (LC/TS.2017/24), N. Oddone y R. Padilla Pérez (eds.), Santiago, Comisión Económica para América Latina y el Caribe (CEPAL).

Anlló, G., R. Bisang y G. Salvatierra (eds.) (2010), “Cambios estructurales en las actividades agropecuarias: de lo primario a las cadenas globales de valor", Documentos de Proyectos (LC/W.350-LC/BUE/W.50).

Blyde, J. S. (coord.) (2014), Fábricas sincronizadas: América Latina y el Caribe en la era de las cadenas globales de valor, Washington, D.C., Banco Interamericano de Desarrollo (BID).

Cáceres, L. (1994), “Costos y beneficios de la integración centroamericana”, Revista de la CEPAL, N 54 (LC/G. 1845-P), Santiago, Comisión Económica para América Latina y el Caribe (CEPAL).

CENPROMYPE (Centro Regional de Promoción de la MIPYME) (2017), Estrategia Regional de Articulación Productiva MIPYME, San Salvador.

CEPAL (Comisión Económica para América Latina y el Caribe) (2018a), "MagicPlus" [en línea] https:/ / www.cepal.org/magic.

(2018b), Articulación productiva y cadenas regionales de valor: una propuesta metodológica para la región SICA (LC/MEX/TS.2018/21), Ciudad de México, sede subregional de la CEPAL en México.

(1993), Centroamérica: el fomento de las exportaciones de frutas, hortalizas y plantas ornamentales (LC/MEX/R.438), Santiago, Comisión Económica para América Latina y el Caribe (CEPAL).

(1983), Centroamérica: la exportación de productos industriales y las políticas de promoción en el contexto del proceso de integración económica (E/CEPAL/ MEX/1983/L.10), Ciudad de México, sede subregional de la CEPAL en México.

Comisión Europea (2018), “Análisis de cadenas de valor para mejorar nuestra intervención", Bruselas [en línea] https: / / europa.eu/capacity4dev/value-chainanalysis-for-development-vca4d-/documents/vca4ddescripcion-es.

Cordero, M. y R. Padilla Pérez (2017), “Creación de una cadena de valor: chips fritos al vacío en Costa Rica", Fortalecimiento de cadenas de valor rurales (LC/TS.2017/24), N. Oddone y R. Padilla Pérez (eds.), Santiago, Comisión Económica para América Latina y el Caribe (CEPAL).

Cornejo Díaz, R. (2018), “Las cadenas logísticas mineras en el Perú: oportunidades para una explotación más sostenible de los recursos naturales", Documentos de Proyectos (LC/TS.2017/146), Santiago, Comisión Económica para América Latina y el Caribe (CEPAL).

De Groot, O. (2018), La cadena regional de valor de la industria de lácteos en Centroamérica (LC/MEX/TS.2018/2), Ciudad de México, sede subregional de la CEPAL en México.

Di Filippo, A. (1998), Integración regional latinoamericana, globalización y comercio Sur-Sur (LC/R.1820), Santiago, Comisión Económica para América Latina y el Caribe (CEPAL). 
Durán Lima, J. y D. Zaclicever (2013), “América Latina y el Caribe en las cadenas internacionales de valor", serie Comercio Internacional, No 124 (LC/L.3767), Santiago, Comisión Económica para América Latina y el Caribe (CEPAL).

Garry, S., J. M. Martínez Piva y J. Salido Marcos (2017), Herramientas para la transformación productiva en las cadenas de valor: los casos de la miel y la papaya en el Pacífico Central costarricense (LC/MEX/TS.2017/27), Ciudad de México, sede subregional de la CEPAL en México.

Garry, S. y R. Martínez (2017), “Fortalecimiento de la cadena de turismo en el departamento de La Libertad en El Salvador", Fortalecimiento de cadenas de valor rurales (LC/TS.2017/24), N. Oddone y R. Padilla Pérez (eds.), Santiago, Comisión Económica para América Latina y el Caribe (CEPAL).

Garry, S. y J. Salido (2016), "Ejercicio de identificación y selección de cadenas de valor para su fortalecimiento en el Pacífico Central costarricense", Documentos de Proyecto (LC/MEX/W.20), Ciudad de México, sede subregional de la CEPAL en México.

Gereffi, G. (2001), "Shifting governance structures in global commodity chains, with special reference to the Internet", American Behavioral Scientist, vol. 44, No 10 , Thousand Oaks, SAGE Publications.

GIZ (Deutsche Gesellschaft für Internationale Zusammenarbeit) (2007), ValueLinks Manual: The Methodology of Value Chain Promotion, Eschborn [en línea] http:/ / www2.giz.de/wbf/4tDx9kw63gma/ValueLinks_Manual.pdf.

Gomes Nogueira, C. y N. Oddone (2017), "Fortalecimiento de la cadena de valor de los lácteos en la República Dominicana", Documentos de Proyectos (LC/MEX/ TS.2017/15), Ciudad de México, sede subregional de la CEPAL en México.

INCAE/HIID (INCAE Business School/Instituto de Desarrollo Internacional de Harvard) (1999), Centroamérica en el siglo XXI: una agenda para la competitividad y el desarrollo sostenible, Alajuela, Centro Latinoamericano para la Competitividad y el Desarrollo Sostenible (CLACDS) [en línea] http:/ /www.incae.edu/ES/ clacds/publicaciones/pdf/cen1000agenda.pdf.

Kaplinsky, R. (2000), “Globalisation and unequalisation: What can be learned from value chain analysis?" Journal of Development Studies, vol. 37, N² 2, ABI/INFORM Global.

Kaplinsky, R. y M. Morris (2001), A handbook for value chain research, Ottawa, Centro de Investigaciones para el Desarrollo Internacional (IDRC).

Naciones Unidas (2017), "UN Comtrade" [base de datos en línea] https:/ / comtrade. un.org/db.

OCDE (Organización de Cooperación y Desarrollo Económicos) (2013), Interconnected Economies: Benefiting from Global Value Chains, París, OECD Publishing.

Oddone, N. y P. Alarcón (2017), "Fortalecimiento de la cadena de turismo de La Antigua Guatemala y de los municipios rurales del departamento de Sacatepéquez", Fortalecimiento de cadenas de valor rurales (LC/TS.2017/24), N. Oddone y R. Padilla Pérez (eds.), Santiago, Comisión Económica para América Latina y el Caribe (CEPAL).

Oddone, N. y otros (2017), "La cadena de valor de tomate y chile verde dulce en El Salvador", Fortalecimiento de cadenas de valor rurales (LC/TS.2017/24), N. Oddone y R. Padilla Pérez (eds.), Santiago, Comisión Económica para América Latina y el Caribe (CEPAL).

Padilla Pérez, R. (ed.) (2014), Fortalecimiento de las cadenas de valor como instrumento de la política industrial: metodología y experiencia de la CEPAL en Centroamérica, Libros de la CEPAL, N 123 (LC/G.2606-P), Santiago, Comisión Económica para América Latina y el Caribe (CEPAL). 
Padilla Pérez, R. y N. Oddone (2016), Manual para el fortalecimiento de cadenas de valor (LC/MEX/L.1218), Santiago, Comisión Económica para América Latina y el Caribe (CEPAL) / Fondo Internacional de Desarrollo Agrícola (FIDA).

Porter, M. E. (1985), Competitive advantage: creating and sustaining superior performance, Nueva York, Free Press.

Romero, I., V. Díaz y A. Aguirre (2016), “Fortalecimiento de la cadena de valor de los snacks nutritivos con base en fruta deshidratada en El Salvador", Documentos de Proyectos (LC/MEX/W.16), Ciudad de México, Comisión Económica para América Latina y el Caribe (CEPAL).

Salazar, J. M. (1990), "Presente y futuro de la integración centroamericana", Revista de la CEPAL, Nº 42 (LC/G.1642-P), Santiago, Comisión Económica para América Latina y el Caribe (CEPAL).

Sturgeon, T. J. (2013), Global Value Chains and Economic Globalization: Towards a New Measurement Framework, Oficina Estadística de la Unión Europea (Eurostat).

The New York Times (2016), "How China built 'iPhone City' with billions in perks for Apple's partner", 29 de diciembre [en línea] https:/ / www.nytimes.com/2016/12/29/ technology/apple-iphone-china-foxconn.html.

UNCTAD (Conferencia de las Naciones Unidas sobre Comercio y Desarrollo) (2018), "UNCTAD-Eora Global Value Chain Database" [base de datos en línea] http:/ / worldmrio.com/unctadgvc/. (2006), Global value chains for building national productive capacities. Note by the UNCTAD secretariat (TD/B/COM.3/79), Ginebra.

USAID (Agencia de los Estados Unidos para el Desarrollo Internacional) (2008), "Finance in value chain analysis - A synthesis paper", microREPORT, No 132, Washington D. C., octubre.

Whalley, J. (1998), "Why do countries seek regional trade agreements?", The Regionalization of the World Economy, J. A. Frankel (ed.), Chicago, The University of Chicago Press.

Willmore, L. (1997), "Políticas de promoción de exportaciones en Centroamérica", Revista de la CEPAL, N 62 (LC/G.1969-P), Santiago, Comisión Económica para América Latina y el Caribe (CEPAL). (1989), "La promoción de exportaciones y la sustitución de importaciones en la industria centroamericana", Revista de la CEPAL, N 38 (LC/G.1570-P), Santiago, Comisión Económica para América Latina y el Caribe (CEPAL).

Zapata, R. y E. Pérez (2001), "Pasado, presente y futuro del proceso de integración centroamericano", serie Estudios y Perspectivas-Sede Subregional de la CEPAL en México, No 6 (LC/L.1643-P-LC/MEX/L.500), Ciudad de México, Comisión Económica para América Latina y el Caribe (CEPAL). 



\section{Capítulo VI \\ La Unión Aduanera Centroamericana: probables impactos económicos y sociales}

José Durán Lima

\section{Introducción}

El comercio exterior es hoy más abierto a nivel mundial que a fines del siglo pasado. La mayoría de los países han reducido unilateralmente sus niveles de protección arancelaria y muchos han suscrito acuerdos comerciales preferenciales que reducen los aranceles a las importaciones provenientes de sus socios.

Entre los países de Centroamérica, el arancel promedio aplicado para las importaciones de bienes es bajo $(2 \%)^{1}$. Sin embargo, existen costos asociados a carencias de infraestructura, así como a barreras administrativas que dificultan el aprovechamiento del mercado ampliado (cumplimentación de formularios aduaneros, tramitación de certificaciones fito- y zoosanitarias, requisitos de empaque, inspecciones en diversos puntos del proceso exportador, entre otras).

La persistencia de barreras no arancelarias al comercio intrarregional ha sido uno de los ejes centrales de la agenda centroamericana de integración en los últimos años. Esta tiene como prioridades, entre otras: la implementación

A los efectos de este capítulo, Centroamérica está compuesta por los seis miembros de la SIECA que forman parte del Mercado Común Centroamericano (MCCA): Costa Rica, El Salvador, Guatemala, Honduras, Nicaragua y Panamá. 
de la Hoja de ruta para avanzar en la Unión Aduanera 2015-2024, el fortalecimiento de la conectividad física regional y la puesta en marcha de una Estrategia Centroamericana de Facilitación del Comercio. Como parte del acompañamiento a dicho proceso, la Comisión Económica para América Latina y el Caribe (CEPAL) ha apoyado a los países centroamericanos en la evaluación del costo asociado a la inexistencia de un programa de facilitación del comercio y a la evaluación de un programa que permita la reducción de las barreras administrativas al comercio.

En 2015, a petición del Ministerio de Comercio Exterior de Costa Rica (COMEX), se realizaron los primeros ejercicios para determinar los sobrecostos ocasionados por diversas barreras administrativas. Los resultados constituyeron un insumo valioso para los equipos técnicos que venían perfilando la Estrategia Centroamericana de Facilitación del Comercio. Además, sirvieron para evaluar el costo asociado a la falta de tal estrategia. Se determinó la existencia de un costo adicional promedio en el caso de las importaciones subregionales, equivalente a un arancel del $24 \%$ sobre el valor unitario de los productos comerciados.

Durante 2016, a pedido de la Secretaría de Integración Económica Centroamericana (SIECA), el Ministerio de Economía de Guatemala y la Secretaría de Desarrollo Económico de Honduras, la CEPAL evaluó el costo asociado a la eliminación de las barreras administrativas calculadas. Se analizó el plan de facilitación del comercio que contempla el uso de aduanas exclusivas entre ambos países. El proceso de negociaciones concluyó con la puesta en marcha, en junio de 2017, de aduanas binacionales en tres de los principales pasos de frontera entre Honduras y Guatemala. De este modo, ambos territorios aduaneros se integraron en un único territorio de poco más de $221.000 \mathrm{~km}^{2}$, lo que equivale al $44 \%$ de la superficie total de Centroamérica. Los trámites aduaneros del $80 \%$ de la carga binacional se redujeron, de 11 horas en promedio, a menos de 6 minutos (SIECA, 2019). Tras la puesta en marcha de la unión aduanera binacional entre ambos países, El Salvador, por conducto de su banco central y su Ministerio de Hacienda, solicitó a la CEPAL apoyar un nuevo proceso de evaluación, esta vez, de la inclusión de El Salvador a la unión aduanera que ya estaban aplicando Guatemala y Honduras.

En este capítulo se consolidan los principales resultados del trabajo técnico que la CEPAL ha desarrollado para los Gobiernos de Costa Rica, Guatemala, Honduras y El Salvador y la Secretaría de Integración Económica Centroamericana (SIECA). Por motivos de confidencialidad, se presentan resultados generales y referenciales con el propósito de ilustrar la temática abordada: la determinación de los efectos macroeconómicos, sociales e impositivos derivados de programas de facilitación del comercio. 
La motivación de este capítulo es múltiple. En primera instancia, presenta los equivalentes ad valorem asociados a las barreras administrativas que se interponen al comercio en Centroamérica. En segundo lugar, expone los efectos económicos y sociales de la reducción de tales barreras entre los países del Triángulo del Norte de Centroamérica (El Salvador, Guatemala y Honduras). En tercer término, describe nuevos escenarios en los que se tiene en cuenta la posible ampliación de la unión aduanera al conjunto de los países de Centroamérica (con inclusión de Costa Rica, Nicaragua y Panamá).

En la segunda sección se presenta una revisión de la literatura sobre dos de las metodologías principales aplicadas a las mediciones de impacto de la facilitación del comercio: los modelos gravitacionales y los modelos de equilibrio general computable. La primera metodología se aplica a la evaluación del costo asociado a las múltiples barreras administrativas existentes en el comercio intrarregional. La segunda se aplica a la evaluación de los efectos de los programas de facilitación del comercio.

En la tercera sección se revisa el estado de la integración regional en el ámbito económico. Se considera la cuantificación de las barreras administrativas mediante el cálculo de equivalentes ad valorem y las iniciativas emprendidas para profundizar la unión aduanera. En la cuarta se muestran los resultados de los principales escenarios considerados para evaluar el efecto de programas de facilitación del comercio entre Guatemala y Honduras, y entre ambos países y El Salvador, en lo que sería la unión aduanera entre los tres integrantes del Triángulo del Norte de Centroamérica. Además, se describen las implicancias para los países que no se han adherido a tales programas, así como el resultado que tendría un programa de facilitación aduanera que incluya a todos los países centroamericanos. Por último, en la quinta sección se presentan algunas conclusiones.

\section{A. Literatura sobre metodologías para evaluar el impacto de programas de facilitación del comercio}

En esta sección se hace un breve repaso de algunos de los principales trabajos sobre la cuantificación de las medidas de facilitación del comercio y sus dos vertientes principales: los modelos gravitacionales y los modelos de equilibrio general computable. El objetivo es doble. Por una parte, se buscan antecedentes de estudios que evalúan y estiman el costo asociado a las barreras no arancelarias de tipo administrativo, mediante el cálculo de equivalentes arancelarios ad valorem. Por otra, se intenta definir la principal metodología analítica que contempla la evaluación del impacto esperado en la producción y el comercio ante la eliminación de dichas barreras. 
Las medidas de facilitación del comercio comprenden diversas actividades, entre las que cabe mencionar los esfuerzos por reducir los procesos administrativos en aduana al mismo tiempo que se aumenta la transparencia y se reduce el contrabando y la construcción de sistemas electrónicos para el procesamiento de cargamentos y el desarrollo de sistemas modernos que agilicen el transporte intrarregional (por ejemplo, el uso de códigos de respuesta rápida $(\mathrm{QR})$ para escanear los documentos aduaneros mediante la tecnología de identificación por radiofrecuencia (radio frequency identification (RFID)). La Estrategia Centroamericana de Facilitación del Comercio incluye medidas como la automatización de los procesos de tránsito de mercancías, la reducción del tiempo necesario para exportar e importar y la automatización de la circulación de personas. En este análisis, se incluyen solamente las dos primeras medidas. Su implementación requiere inversiones sustanciales en infraestructura y reformas de los procesos de comercio.

La aplicación de un modelo económico que permita evaluar el costo de la eliminación de las barreras administrativas y los cuellos de botella que entorpecen el pleno funcionamiento de una unión aduanera requiere, en primera instancia, cuantificar tales barreras mediante su arancelización. Posteriormente, exige la incorporación de tales estimaciones en un modelo que permita simular choques de política que eliminen esos costos. De este modo, se derivan los impactos económicos sobre la producción y el comercio y los impactos sociales sobre el bienestar y el empleo. A continuación, se presenta una revisión de literatura sobre trabajos en los que se han seguido los lineamientos aquí descritos, así como una breve descripción metodológica de los modelos aplicados al cálculo de los equivalentes ad valorem de las barreras administrativas y de las simulaciones de impacto presentadas más adelante.

\section{Modelos gravitacionales para la estimación de costos administrativos}

Dada la notable reducción de los aranceles a nivel mundial a causa de los procesos unilaterales de apertura y del gran número de acuerdos de libre comercio vigentes, la facilitación del comercio ha pasado a ser un importante tema de análisis, en particular tras la entrada en vigor en 2017 del Acuerdo sobre facilitación del comercio de la Organización Mundial del Comercio. Hoy los factores no arancelarios que afectan el comercio de mercancías suelen tener mayor peso que los aranceles. La importancia de las cadenas globales de valor incrementa de manera significativa el comercio de bienes intermedios, por lo que la reducción de barreras no arancelarias tiene efectos multiplicadores significativos. Según un estudio del Foro Económico Mundial, una modesta mejora en la facilitación del comercio haría que el producto interno bruto (PIB) mundial aumentara en un 2,6\% y que las exportaciones mundiales se incrementaran en un 9,4\% (Foro Económico Mundial, 2013). 
La facilitación del comercio, entendida de una forma acotada como la mejora de los procesos de gestión de fronteras con el fin de agilizar y facilitar las operaciones de importación y exportación, tiene un efecto directo en la reducción del costo del comercio (OMC, 2015)2. Dichas medidas (es decir, el uso de ventanillas únicas, la reducción del uso del papel o la utilización de puestos fronterizos especiales) son fundamentales para impulsar el comercio, la diversificación de las exportaciones y el bienestar económico. En su definición más amplia, la facilitación del comercio incluye también las medidas de política que afectan la eficiencia de los servicios de transporte y logística (APEC, 2007).

Desde inicios de la década de 2000, se desarrolló en varios trabajos la metodología de estimación de barreras no arancelarias al comercio. El método utilizado con mayor regularidad es el de la estimación de una ecuación gravitacional, que se complementa con el enfoque de economía espacial (Fujita, Krugman y Venables, 2001) y con el trabajo de Anderson y Wincoop (2003). De este modo se tienen en cuenta la distancia y otros factores que determinan las exportaciones (permisos de exportación, inspecciones, número de documentos requeridos para exportar, entre otros). A partir de ese enfoque, en varios trabajos se ha estimado el impacto de la facilitación del comercio mediante la evaluación de las elasticidades de comercio con respecto a diferentes medidas, sobre todo la reducción de los tiempos por trámites en frontera.

Wilson, Mann y Otsuki (2003) fueron de los primeros investigadores que desarrollaron medidas de facilitación del comercio con el fin de estimar aspectos de la logística en frontera para los 19 países miembros de la Organización de Cooperación y Desarrollo Económicos (OCDE). Posteriormente, Wilson, Mann y Otsuki (2004 y 2005) extendieron su labor a un conjunto más amplio de países (75). A partir de sus estimaciones econométricas, calcularon ganancias debidas a la facilitación del comercio del orden de los 377.000 millones de dólares.

En diversos análisis econométricos se utilizan distintas medidas de facilitación del comercio, aunque todas resultan significativas al determinar el mayor o menor flujo de comercio bilateral. Hummels y Schaur (2013) y Djankov, Freund y Pham (2010) estudian el efecto del tiempo de tramitación en el comercio. Traca y Dutt (2010) analizan las consecuencias de la corrupción. Limão y Venables (1999) evalúan el uso eficiente de la infraestructura.

Según se concluye en varios trabajos, la mejora de los indicadores de facilitación del comercio aumenta el comercio de un país o de un conjunto de países. A la inversa, las barreras no arancelarias imputables a la inexistencia

En OMC (2015) se presenta un conjunto de definiciones que tienen como denominador común hacer más eficientes los procesos comerciales, así como el control y el tránsito de mercaderías. Véase la introducción de ese estudio. 
de medidas de facilitación del comercio reducen el comercio. Saslavsky y Shepherd (2012) proporcionan evidencias adicionales en el caso de las cadenas globales de valor. Respecto de la región de Asia oriental y sudoriental, Cheewatrakoolpong y Ariyasajjakorn (2012) concluyen que la facilitación del comercio (medida en función de los menores tiempos de procesamiento y menores costos asociados) tiene un impacto significativo en la mejora de los flujos de comercio. Este efecto es más pronunciado en las exportaciones de alimentos y productos agrícolas.

Entre todos los trabajos revisados destacan los de Zaki (2010a y 2015), en los que, a partir de un modelo teórico con fundamentos microeconómicos, se deriva un modelo gravitacional en dos etapas. Tal estimación permite el cálculo de aranceles equivalentes correspondientes a un conjunto de medidas de facilitación del comercio. De las especificaciones de Zaki se destaca la que realiza estimaciones a nivel sectorial. En particular, los resultados obtenidos muestran que los productos perecederos (alimentos y bebidas), estacionales (prendas de vestir y calzado) y los de un alto valor agregado son los más sensibles a retrasos en los tiempos de tránsito. Esto se refleja en estimaciones de equivalentes ad valorem más elevados en ese tipo de productos.

En los países centroamericanos, hay estudios que evalúan la incidencia de las medidas no arancelarias en los precios de algunos productos importantes en el comercio intrarregional: carne, productos de panadería, productos lácteos y carne de pollo. En estos trabajos se estiman altos costos asociados a dichas medidas (Banco Mundial, 2013). Kelleher y Reyes (2014) concluyeron que la existencia de al menos una medida no arancelaria, en un conjunto de 33 países, aumentaba los precios internos entre un $8 \%$ y un $11 \%$. Asimismo, determinaron que una barrera sanitaria acarrearía aumentos de precio equivalentes a un arancel promedio del $21,4 \%$. En algunos productos, las alzas podrían ser especialmente pronunciadas. Tal es el caso de la carne de vacuno, los productos de panificación y la carne de pollo, respecto de los que se estimaron aranceles equivalentes del $68,4 \%$, el $51,4 \%$ y el $22 \%$, respectivamente.

A partir de un modelo gravitacional, Kelleher y Reyes (2014) estimaron el equivalente ad valorem de las barreras sanitarias en cinco países centroamericanos. Encontraron un costo promedio de un $28 \%$ adicional al valor de los productos centroamericanos importados, con efectos más altos en el caso de las importaciones de Guatemala, donde el equivalente ad valorem llegó al 55\% del valor del producto. Por su parte, Costa Rica obtuvo una estimación de equivalentes ad valorem menor que el resto de los países del istmo centroamericano, en cuyo caso superó el $20 \%$.

CEPAL (2017), siguiendo a Cheewatrakoolpong y Ariyasajjakorn (2012), utilizó un modelo gravitacional aumentado para determinar la sensibilidad de los intercambios a diversas dimensiones de facilitación del comercio. Tal 
especificación se vio complementada con el enfoque de Zaki (2010b y 2015), que estimó una regresión utilizando el tiempo para exportar o importar como variable dependiente de sus principales determinantes: el número de documentos para exportar o importar (Doc), el número de trámites necesarios para exportar o importar (Proc) y el costo de exportaciones en dólares por contenedor (Cont). Esa primera etapa de la estimación se definió como sigue:

$$
\begin{gathered}
\ln \left(\operatorname{Time}_{\text {exp }, i}\right)=\alpha_{0}+\alpha_{1} \ln \left(\operatorname{Doc}_{\text {exp }, i}\right)+\alpha_{2} \ln \left(\operatorname{Proc}_{\text {exp }, i}\right)+\alpha_{2} \ln \left(\operatorname{Cont}_{\text {exp }, i}\right)+\omega_{i} \\
\ln \left(\text { Time }_{i m p, j}\right)=\alpha_{0}+\alpha_{1} \ln \left(\operatorname{Doc}_{i m p, j}\right)+\alpha_{2} \ln \left(\operatorname{Proc}_{\text {exp }, j}\right)+\alpha_{2} \ln \left(\operatorname{Cont}_{\text {exp, }, j}\right)+\omega j
\end{gathered}
$$

Las estimaciones de tiempo obtenidas en 1 y 2 se introdujeron en la ecuación aumentada:

$$
\ln \left(X_{i j k}\right)=A+\beta_{1} \ln \left(Y_{i k}\right)+\beta_{2} \ln \left(Y_{j k}\right)+\lambda_{j}+\chi_{i}-\gamma_{i j k} \ln \left(D_{i j}\right)+\omega_{i j k}+e_{i j k}
$$

donde $k$ representa una clasificación de grupos de productos; $X_{i j}$ las exportaciones del país $i$ al país $j ; Y_{i}\left(Y_{j}\right)$ representa el PIB del país $i(j) ; D$ es un vector que representa las variables vinculadas a la distancia (incluido el tiempo, principal variable utilizada para definir el costo debido a barreras administrativas) entre países; las variables $\chi_{i}$ y $\lambda_{j}$ son efectos fijos asociados a cada país; $\tau_{t}$ es el efecto fijo del año; $\omega_{i j}$ es la variable asociada a la probabilidad de comerciar entre países y un socio $j$, y $e_{i j}$ es el error estocástico asociado a las variables no observables.

Siguiendo a Zaki (2014 y 2015), los resultados del parámetro estimado $Y_{i j k}$ que expresa los cambios en niveles de comercio se transformaron en una variable de política. De este modo la ganancia o pérdida de comercio derivada del tiempo se convirtió a un arancel equivalente para el comercio bilateral de cada uno de los países considerados en el modelo.

La transformación del parámetro estimado en equivalentes ad valorem se realizó mediante el cómputo de la razón entre el coeficiente predicho de la variable de tiempo para exportar (importar) y la elasticidad de la demanda, valor que se multiplicó por el tiempo expresado por el número de días necesarios para completar el trámite, como sigue:

$$
E A V_{f, i-j}^{k}=\left(\frac{\gamma_{i}^{k}}{\varepsilon_{i k}} * t_{f}\right)
$$

donde:

$\gamma$ es el coeficiente asociado al tiempo en la ecuación gravitacional, frepresenta el flujo de comercio que puede ser una exportación o importación; $i$ es el país exportador o importador; $k$ identifica el grupo de productos; $t$ equivale al tiempo expresado en número de días, y $\varepsilon_{i j k}$ es la elasticidad de demanda del país $i$ para el producto $k$. 
Por último, el resultado obtenido es el equivalente ad valorem asociado a las exportaciones e importaciones de bienes del $k$-ésimo sector de la economía. En la sección B se presentan los resultados de las estimaciones en relación con los países de Centroamérica. Estos resultados serán insumos principales para la determinación de los escenarios de política que se utilizarán en la evaluación de un programa de facilitación del comercio, primero entre Guatemala y Honduras, luego entre los tres países del Triángulo del Norte de Centroamérica (El Salvador, Guatemala y Honduras) y, por último, en un escenario que incluye a todos los países centroamericanos.

\section{Modelos de equilibrio general computable y facilitación del comercio}

El uso de los modelos de equilibrio general computable para el análisis de la facilitación del comercio es relativamente reciente. Estos modelos permiten cuantificar los beneficios de la facilitación del comercio a nivel mundial, regional y nacional.

Varios de los análisis de equilibrio general computable simulan la reducción de los costos del comercio mediante choques de productividad. A partir de la versión dinámica del modelo del Proyecto de Análisis del Comercio Global (GTAP, por sus siglas en inglés), APEC (1999) encontró que la reducción del 1\% de los costos de transacción del comercio en países industrializados y del $2 \%$ en los países en desarrollo produciría ganancias de bienestar de 46.000 millones de dólares para los países miembros del Foro de Cooperación Económica de Asia y el Pacífico (APEC). Por otro lado, Francois, van Meil y van Tongeren (2003), con una versión de competencia imperfecta del modelo GTAP en el sector de manufacturas y suponiendo una reducción del 1,5\% en los costos de transacción, estiman beneficios globales cercanos a los 72.000 millones de dólares. Esta cifra es similar a la obtenida por la OCDE (2003) cuando evaluó una reducción del 1\% en los costos de transacción mediante el modelo estándar del GTAP. Un aspecto común a estas investigaciones y otras similares (Hertel, Walmsley e Itakura, 2001; Fox, Francois y Londoño-Kent, 2003) es que aplican reducciones únicas en todos los productos, sin diferenciar entre países o grupos de países. Además, los shocks de productividad no son modelados endógenamente, es decir, las ganancias de eficiencia vienen sin un costo asociado. Esto significa que no se tienen en cuenta los ajustes, por lo que se sobreestiman los beneficios de la facilitación del comercio.

Walkenhorst y Yasui (2009) tratan de incluir los costos de ajuste (por ejemplo, la reducción del número de empleados requeridos para realizar trámites) y analizan el impacto que tendría en la economía mundial la reducción de costos de comercio en frontera y los costos de transacción, para lo cual se valen del modelo GTAP. Este análisis incluye costos directos 
asociados con aduanas complejas y burocráticas, documentación compleja y no transparente, y largos tiempos de espera para cumplir requisitos del despacho de aduana, así como costos indirectos asociados con el tiempo adicional de espera en frontera y las demoras no anticipadas debido a huelgas y situaciones políticas. Mirza (2007 y 2009) realiza un análisis de equilibrio general de costo-beneficio de la facilitación del comercio, mediante la endogeneización de los costos de inversión necesarios para implementar las medidas de facilitación. Por otro lado, Minor y Tsigas (2008), sobre la base de Hummels y Schaur (2013), estiman equivalentes ad valorem respecto del tiempo requerido para comerciar a nivel de producto y región. A partir de estos equivalentes, simulan los efectos de reducir costos de tiempo en precios y estiman los impactos sobre el comercio.

El uso de equivalentes ad valorem en modelos de equilibrio general para estimar los impactos de la facilitación del comercio se contempla en varias investigaciones (Mirza, 2007; Zaki, 2010b; Durán, 2015; entre otros). Durán (2015), a partir de un modelo de equilibrio general computable, evaluó los efectos de un programa de facilitación del comercio que redujera los equivalentes ad valorem calculados (en promedio, un $24 \%$ para todo el comercio centroamericano) hasta el 2,2\%, de manera similar a las mejoras aplicadas por Zaki (2010b) y que considerara una reducción del $90 \%$ en todos los países centroamericanos. Según los resultados, en términos de efectos sobre el producto, el impacto podría significar un alza promedio del 3\%, cifra que se reducía a poco más de un 1,4\% en el caso de una reducción de únicamente un $50 \%$. Es decir, el equivalente ad valorem se reduciría de un $24 \%$ a un $12 \%$.

La CEPAL ha utilizado entre 2015 y 2019 el modelo de equilibrio general computable del Proyecto de Análisis del Comercio Global. Se trata de un modelo multirregional y multisectorial que emplea bases de datos de las matrices de insumo-producto de las oficinas nacionales de estadísticas de cada país, o de académicos expertos en cuentas nacionales. Así se garantiza que el modelo responda a la estructura productiva de los países y regiones analizados. La información de las matrices de insumo-producto se complementa con datos internacionales de comercio y transporte. Todos los países del modelo se conectan entre sí a partir de los flujos comerciales bilaterales. De esta manera, se consideran las múltiples cadenas de valor en la economía global y, sobre todo, la interconexión entre las economías centroamericanas, ya que todas forman parte de la base de datos y del modelo GTAP.

El modelo se representa como un conjunto de ecuaciones simultáneas y se puede esquematizar mediante la interacción entre los hogares, las empresas y el gobierno, todos agentes económicos de cada región o país del modelo. Se supone que cada firma produce un único bien y que para ello requiere factores primarios (trabajo calificado, no calificado, tierra, capital y 
recursos naturales) y los respectivos insumos intermedios. En el diagrama VI.1 se muestra esquemáticamente la interacción del flujo de valor entre los diferentes elementos del modelo. En cada economía, el comportamiento de la producción se caracteriza por la maximización de ganancias de la empresa. Esta combina recursos o factores con insumos intermedios en una estructura anidada de elasticidad de sustitución constante (CES, por sus siglas en inglés), con sustitución imperfecta en cada etapa de producción (entre factores de producción e insumos intermedios, y entre insumos intermedios nacionales e insumos intermedios importados desde diversas regiones del modelo).

\section{Representación esquemática del modelo del Proyecto de Análisis del Comercio Global}

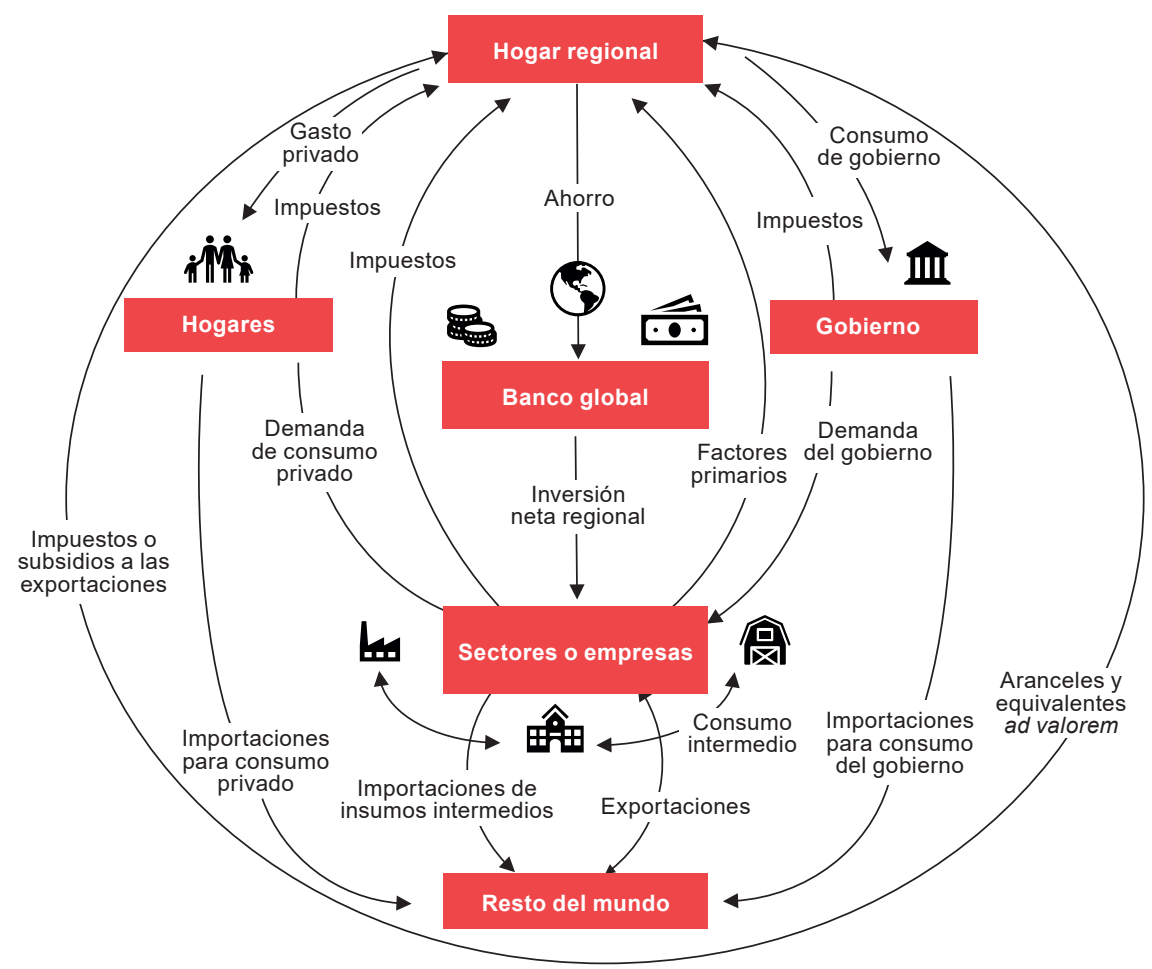

Fuente: Elaboración propia, sobre la base de A. Schuschny, J. Durán y C. de Miguel, "El modelo GTAP y las preferencias arancelarias en América Latina y el Caribe: reconciliando su año base con la evaluación reciente de la agenda de liberalización regional”, serie Manuales, N 54 (LC/L.2679-P), Santiago, Comisión Económica para América Latina y el Caribe (CEPAL), 2007.

El modelo incluye un hogar regional en cada economía. Los ingresos se reparten mediante el consumo del hogar privado, el consumo público se realiza a través del gobierno y el consumo futuro se contempla en forma de 
ahorro. Los ahorros de cada región son recolectados por un banco global y se distribuyen entre las regiones en forma de inversiones de capital dictadas por las tasas de rentabilidad.

En las decisiones de consumo de los hogares y las empresas se distingue entre bienes nacionales e importados, y entre bienes importados según su procedencia (Armington, 1969). Este supuesto permite modelar los flujos de un mismo bien en dos direcciones, pues se puede exportar e importar simultáneamente. Sin embargo, de esta manera las importaciones se interpretan como sustitutos perfectos de los productos nacionales ${ }^{3}$.

La línea de base de la estructura del modelo empleado para las simulaciones presentadas en este capítulo corresponde al año 2011. En cuanto a la protección arancelaria, se procedió a la revisión de aranceles hasta 2017, incluido el estado de las preferencias arancelarias recibidas por los países de otros socios comerciales, y viceversa, hasta diciembre de 2017 (Estados Unidos, Unión Europea y otros) y las estimaciones ad valorem calculadas según el método descrito.

En el modelo aplicado se presupone una apertura de 33 sectores de bienes y uno de servicios, y un conjunto de 34 regiones y países, que considera a todos los países centroamericanos de manera individual. En los cuadros VI.A1.1 y VI.A1.2 del anexo VI.A1 se presentan los sectores y países analizados.

\section{B. Estado actual de la Unión Aduanera Centroamericana}

En esta sección se presenta la evolución de la protección arancelaria en cada país y en el conjunto de Centroamérica, así como la participación del comercio exterior en las cadenas de valor intrarregionales. Se describe también la evolución y el estado de la Unión Aduanera Centroamericana en el ámbito de la facilitación del comercio, elemento clave del proceso emprendido para consolidar la Unión Aduanera Centroamericana. La sección se cierra con la descripción de diversos escenarios que se simularán para derivar impactos económicos y sociales.

\section{Protección arancelaria y no arancelaria}

Aunque el arancel promedio centroamericano (de nación más favorecida) es cercano al $6 \%$, cuando se consideran todos los acuerdos de libre comercio suscritos por la región en conjunto, así como los suscritos individualmente por algunos países, el arancel aplicado promedio se reduce al $2 \%$ (véase el gráfico VI.1). Ello pone de relieve el alto nivel de apertura comercial de estos países.

Véase en Schushny, Durán y de Miguel (2007) un análisis detallado del modelo GTAP. 


\section{Gráfico Vl.1}

Centroamérica: evolución de la protección arancelaria, 1995-2018

(En porcentajes ad valorem)

A. Aranceles de nación más favorecida promedio

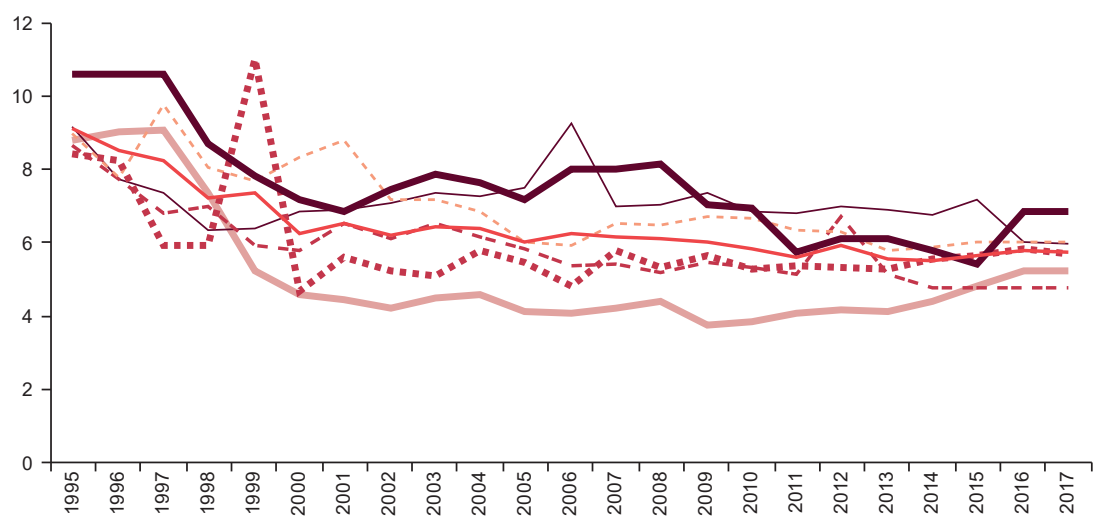

B. Aranceles preferenciales

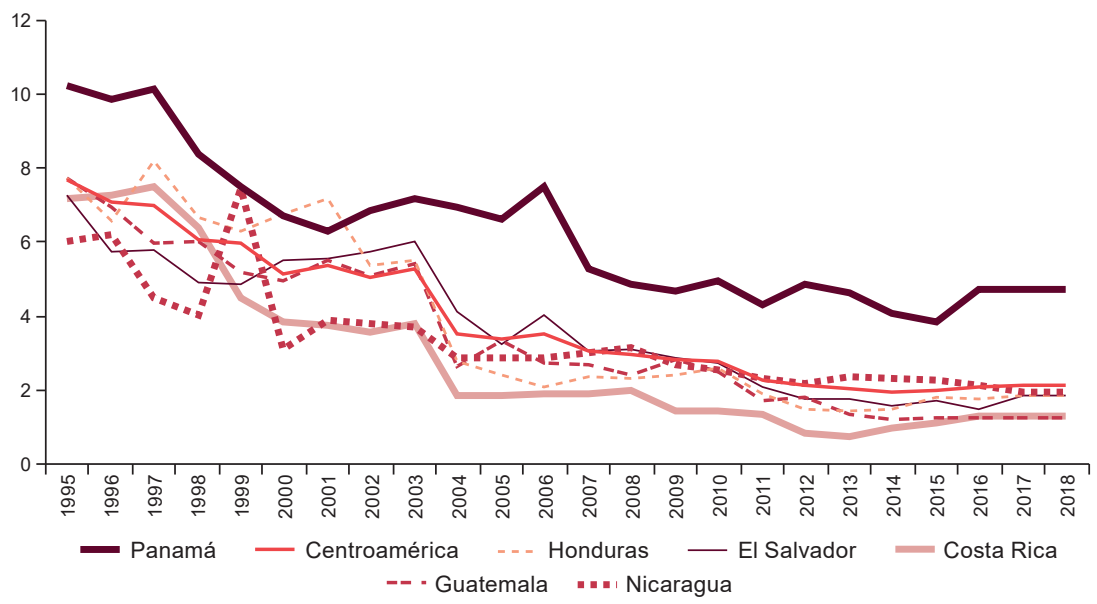

Fuente: Elaboración propia, sobre la base de Banco Mundial, "Tasa arancelaria, nación más favorecida, media simple, todos los productos (\%)" [base de datos en línea] https://datos.bancomundial.org/ indicador/TM.TAX.MRCH.SM.FN.ZS?view=chart; Organización Mundial del Comercio (OMC), Función de Descarga de Aranceles [base de datos en línea] http://tariffdata.wto.org/Default. aspx?culture=es-ES; Secretaría de Integración Económica Centroamericana (SIECA).

Debido a la vigencia de la zona de libre comercio respecto del $99 \%$ de los productos de la canasta exportadora centroamericana, la protección arancelaria del comercio intrarregional es muy reducida. El arancel promedio que se 
aplica a los flujos intrarregionales es del 0,8\%, siendo más alto en alimentos, bebidas y tabaco, sobre todo por algunas excepciones contempladas en el Anexo "A" del Tratado General de Integración Económica Centroamericana.

Aunque la protección arancelaria es muy baja, las barreras administrativas al comercio, que se reflejan en el tiempo necesario para exportar e importar, así como otras medidas no arancelarias, hacen que, en promedio, las importaciones centroamericanas enfrenten un arancel adicional del 18\% (véase el gráfico VI.2). Este es más elevado en el caso de productos agrícolas y agropecuarios, textiles, confecciones y calzado, así como de los productos agroindustriales. Al estimar los equivalentes ad valorem de las medidas no arancelarias, se determinó que estas representaron en promedio un monto similar al promedio del arancel intrarregional $(0,8 \%)$. Es mayor la incidencia en los productos químicos y petroquímicos, la agroindustria y la agricultura, aunque no tanto como en el caso de las barreras administrativas (véase el cuadro VI.1). Es evidente que el principal problema para un exportador promedio en Centroamérica radica en las elevadas barreras administrativas al comercio.

\section{Gráfico VI.2}

Centroamérica: protección arancelaria y no arancelaria, alrededor de $2017^{\text {a }}$ (En porcentajes ad valorem)

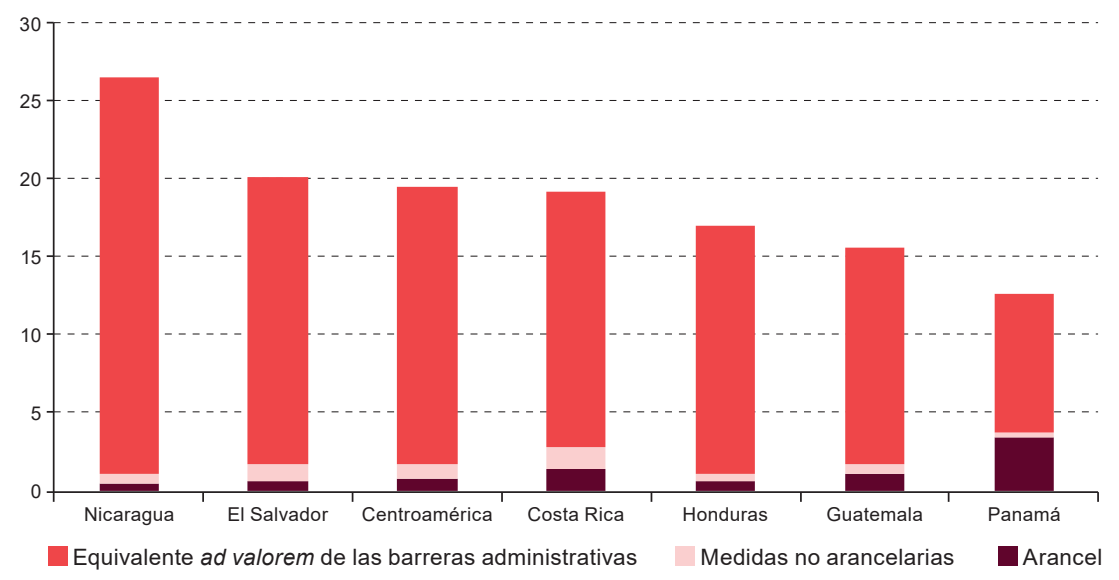

Fuente: Elaboración propia, sobre la base de Organización Mundial del Comercio (OMC) y datos oficiales de los respectivos países.

a Los detalles metodológicos se describen en la nota al pie del cuadro VI.1, y detalladamente en la sección A.1 de este capítulo. 


\section{Cuadro VI.1}

Centroamérica: protección arancelaria y equivalente arancelario de las medidas no arancelarias y administrativas aplicables a las importaciones intrarregionales, 2017 (En porcentajes)

\begin{tabular}{lcccc}
\hline Sectores económicos & $\begin{array}{c}\text { Arancel intra- } \\
\text { centroamericano } \\
(1)\end{array}$ & $\begin{array}{c}\text { Equivalentes ad } \\
\text { valorem debido } \\
\text { a medidas no } \\
\text { arancelarias }^{\mathrm{b}} \\
(2)\end{array}$ & $\begin{array}{c}\text { Equivalentes ad } \\
\text { valorem debido a } \\
\text { barreas administrativas } \\
\text { al comercio } \\
(3)\end{array}$ & $\begin{array}{c}\text { Protección } \\
\text { arancelaria y } \\
\text { no arancelaria } \\
(4)=(1+2+3)\end{array}$ \\
\hline $\begin{array}{l}\text { Agricultura, caza } \\
\text { y pesca }\end{array}$ & 0,8 & 0,9 & 31,7 & 33,4 \\
\hline Petróleo y minería & 0,0 & 0,1 & 4,8 & 4,8 \\
\hline $\begin{array}{l}\text { Alimentos, bebidas } \\
\text { y tabaco }\end{array}$ & 2,1 & 0,9 & 17,1 & 20,1 \\
\hline $\begin{array}{l}\text { Textiles, confecciones } \\
\text { y calzado }\end{array}$ & 0,6 & 0,0 & 43,0 & 43,6 \\
\hline $\begin{array}{l}\text { Química y } \\
\text { petroquímica }\end{array}$ & 0,4 & 1,9 & 10,5 & 12,8 \\
\hline $\begin{array}{l}\text { Metales y productos } \\
\text { derivados }\end{array}$ & 0,1 & 0,6 & 13,6 & 14,3 \\
\hline Maquinaria y equipo & 0,4 & 0,0 & 10,0 & 10,5 \\
\hline Otras manufacturas & 0,3 & 0,0 & 19,6 & 19,5 \\
\hline Promedio & 0,8 & 0,8 & 17,8 & \\
\hline
\end{tabular}

Fuente: Elaboración propia, sobre la base de Organización Mundial del Comercio (OMC), Naciones Unidas, Base de Datos Estadísticos de las Naciones Unidas sobre el Comercio de Productos Básicos (COMTRADE) [en línea] https://comtrade.un.org/, y datos oficiales de los respectivos países.

a Aranceles ponderados para las relaciones bilaterales centroamericanas a un nivel de seis dígitos del Sistema Armonizado. Se consideraron las preferencias arancelarias concedidas en el Tratado General de Integración Económica Centroamericana.

b Cálculos a partir de un modelo de gravedad en que se consideró la base de notificaciones de medidas no arancelarias de la OMC, además de un conjunto de variables de control (distancia, arancel promedio, pertenencia a un acuerdo comercial, entre otras). Se consideró el período 2001-2015.

c Las estimaciones se realizaron mediante un modelo de gravedad ampliado con el que se estimó la elasticidad asociada al tiempo para exportar e importar. A partir de dicha elasticidad se obtuvieron equivalentes arancelarios a nivel bilateral y sectorial entre los países de la región. En el cuadro se presentan los promedios ponderados centroamericanos.

\section{Cadenas de valor y comercio intrarregional}

Diversos estudios sobre la presencia de cadenas intracentroamericanas muestran que a nivel industrial existe un amplio potencial en las relaciones bilaterales de Costa Rica, El Salvador y Guatemala. Les siguen en importancia la relación bilateral entre Guatemala y Honduras y, en menor medida, las que existen entre los cuatro países referidos y el resto de los socios de la región (Nicaragua y Panamá). Las principales industrias vinculadas a cadenas regionales en Centroamérica son la petroquímica, la química, la farmacéutica y la agrícola, además de la industria del hilado, el papel y el cartón, así como la de equipos de telecomunicaciones (Durán y Zaclicever, 2013). En 
los últimos tiempos se ha ampliado el espectro hacia el sector del hierro y el acero y la metalmecánica. Estos rubros representan la columna vertebral de muchas de las industrias nacionales en los seis países de la región, por la cantidad de insumos intermedios necesarios en su producción exportable (por ejemplo, envases metálicos, bienes intermedios, material y equipo para la conformación y renovación de nuevas plantas).

Una proporción considerable del comercio intrarregional involucra comercio de doble vía de insumos intermedios en las industrias antes mencionadas. En la mayoría de ellas (salvo en la de textiles, confecciones y calzado), el coeficiente de comercio intrarregional es superior al promedio $(25,4 \%)$ y alcanza su nivel máximo ( $44 \%$ ) en la química y petroquímica (véanse el gráfico VI.3 y los cuadros VI.A1.3 y VI.A1.4 del anexo VI.A1). Aunque el comercio intrarregional es alto en algunos sectores, se encuentra por debajo de su potencial, toda vez que hay evidencia empírica de que los elevados costos impiden el aprovechamiento del potencial (CEPAL, 2017). El comercio intracentroamericano podría superar su nivel actual, sobre todo en productos de tecnología baja y media y en manufacturas basadas en recursos naturales. En todos los sectores, el potencial calculado es cercano al 30\% (Durán y Lo Turco, 2010). La existencia de un conjunto de barreras administrativas que encarecen el costo de exportación y aumentan el tiempo de tránsito de las mercancías es uno de los motivos que impiden alcanzar dicho nivel.

\section{Gráfico VI.3}

Centroamérica: distribución de las exportaciones intrarregionales y coeficiente de comercio intrarregional, 2016

(En porcentajes del total)

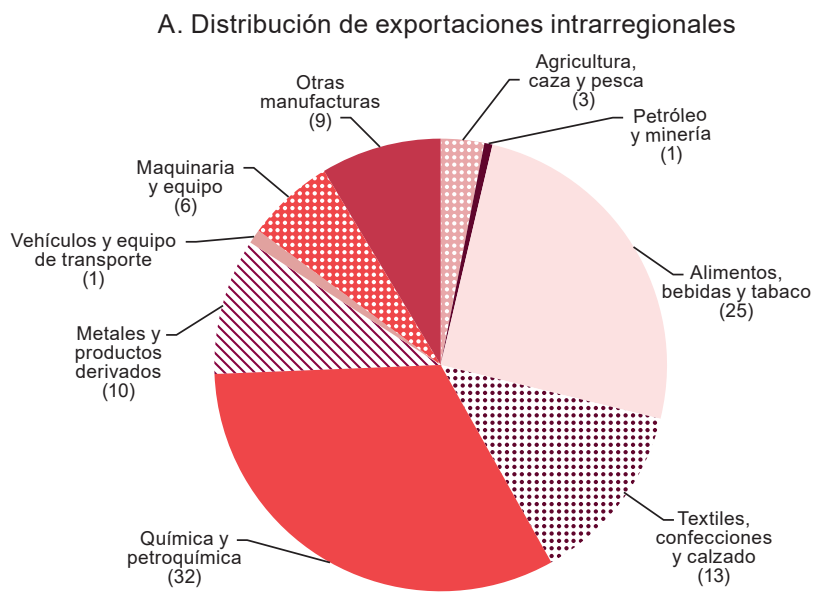


Gráfico VI.3 (conclusión)

B. Coeficiente de exportaciones intrarregionales

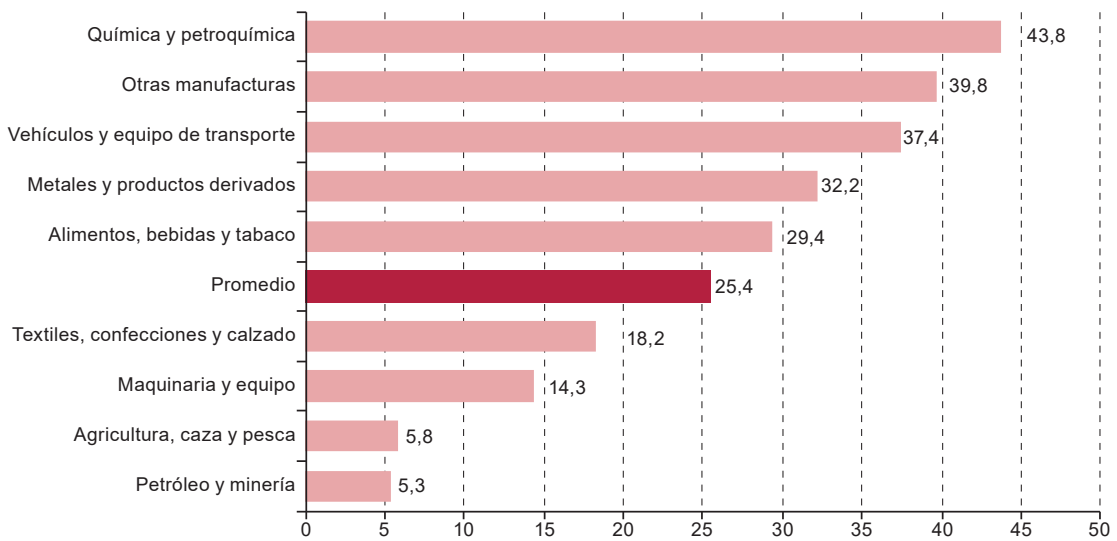

Fuente: Elaboración propia, sobre la base de Naciones Unidas, Base de Datos Estadísticos de las Naciones Unidas sobre el Comercio de Productos Básicos (COMTRADE) [en línea] https://comtrade.un.org/. a El cálculo del coeficiente de comercio intrarregional incluye las exportaciones de maquila y zonas francas.

Las dificultades asociadas a cuellos de botella de tipo administrativo y logístico (altos costos de transporte, problemas de información, comunicación, carencia de servicios, entre otros) no son un problema nuevo y son de carácter transversal en todos los países de Centroamérica (Aráuz, 2012; Kelleher y Reyes, 2014). Tales barreras afectan con mayor intensidad a las importaciones de Nicaragua y El Salvador, donde equivalen a aranceles ad valorem del 25,3\% y el 18,3\%, respectivamente. En el caso de Panamá, los aranceles ad valorem son del $9 \%$ en promedio. Por sectores, los textiles, las confecciones y el calzado, así como los productos agroindustriales, presentan sobrecostos mayores en todos los países centroamericanos (véase el cuadro VI.2). Estas barreras afectan negativamente la competitividad de las empresas exportadoras de la región, aproximadamente el $50 \%$ de las cuales exporta al mercado intrarregional ${ }^{4}$. Las pequeñas y medianas empresas exportadoras se ven especialmente afectadas por este tipo de barreras, ya que representan cerca del $75 \%$ del total de empresas que operan en los circuitos intracentroamericanos (véase el cuadro VI.3). De estas, a su vez, las medianas exportadoras son las que tienen un mayor aporte al proceso exportador subregional (CENPROMYPE, 2017). De igual forma, estos costos inciden negativamente en el precio final que pagan los consumidores, lo que afecta el bienestar de los hogares (Banco Mundial, 2013). Por ese motivo, los países centroamericanos hacen esfuerzos

\footnotetext{
4 Este guarismo resulta de dividir el número de empresas exportadoras registradas a nivel centroamericano en 2017 (7.751) por el total de empresas exportadoras reportadas por cada país, que se estimó en torno a las 15.200 (alrededor de 2015).
} 
por impulsar programas de facilitación del comercio tendientes a reducir los cuellos de botella logísticos mediante la simplificación y modernización de las operaciones aduaneras.

\section{Cuadro VI.2 \\ Centroamérica: equivalentes ad valorem estimados de las barreras administrativas, $2017^{\mathrm{a}}$}

(En porcentajes del valor del producto importado)

\begin{tabular}{lrrrrrr}
\hline Principales sectores & Costa Rica & Guatemala & El Salvador & Honduras & Nicaragua & Panamá \\
\hline Agricultura, caza y pesca & 26,4 & 26,8 & 36,6 & 26,8 & 33,4 & 11,3 \\
\hline Petróleo y minería & 5,1 & 1,1 & 1,0 & 0,6 & 7,0 & 2,0 \\
\hline $\begin{array}{l}\text { Alimentos, bebidas } \\
\text { y tabaco }\end{array}$ & 14,6 & 17,8 & 15,6 & 17,8 & 19,6 & 7,3 \\
\hline $\begin{array}{l}\text { Textiles, confecciones } \\
\text { y calzado }\end{array}$ & 33,8 & 30,1 & 36,5 & 28,3 & 61,7 & 21,8 \\
\hline Química y petroquímica & 12,3 & 6,2 & 3,3 & 14,2 & 20,0 & 7,7 \\
\hline $\begin{array}{l}\text { Metales y productos } \\
\text { derivados }\end{array}$ & 12,3 & 13,0 & 13,0 & 10,4 & 19,7 & 9,0 \\
\hline Maquinaria y equipo & 8,1 & 9,7 & 7,5 & 9,4 & 19,0 & 6,2 \\
\hline Otras manufacturas & 21,0 & 15,6 & 17,4 & 15,6 & 31,2 & 11,5 \\
\hline Todos los sectores & 16,3 & 14,0 & 18,3 & 15,8 & 25,3 & 9,0 \\
\hline
\end{tabular}

Fuente: Comisión Económica para América Latina y el Caribe (CEPAL).

a Estimaciones realizadas a partir de un modelo de gravedad ampliado que permite calcular la elasticidad asociada al tiempo para exportar e importar. Se presentan los promedios ponderados de los equivalentes ad valorem bilaterales de cada país centroamericano con el resto de los socios de la región.

\section{Cuadro VI.3 \\ Centroamérica (5 países): participación de empresas según tamaño y monto exportado, 2016}

(En porcentajes del total exportado a Centroamérica, millones de dólares y número)

\begin{tabular}{lccc}
\hline País & $\begin{array}{c}\text { Grandes exportadores } \\
\text { (en porcentajes del total) }\end{array}$ & $\begin{array}{c}\text { Microexportadores y } \\
\text { pequeños y medianos } \\
\text { exportadores } \\
\text { (en porcentajes del total) }\end{array}$ & $\begin{array}{c}\text { Montos totales } \\
\text { (en número de empresas } \\
\text { y millones de dólares) }\end{array}$ \\
\hline Costa Rica & 18,3 & 81,7 & 1343 \\
\hline Empresas & 86,4 & 13,6 & 825 \\
\hline Monto exportado & & & 3317 \\
\hline Guatemala & 22,4 & 77,6 & 2187 \\
\hline Empresas & 87,1 & 12,9 & 804 \\
\hline Monto exportado & & & 654 \\
\hline Honduras & 32,0 & 68,0 & \\
\hline Empresas & 93,1 & 6,9 & 2950 \\
\hline Monto exportado & & & \\
\hline Nicaragua & 30,5 & 69,5 & \\
\hline Empresas & 92,5 & 7,5 & \\
\hline Monto exportado & & & \\
\hline
\end{tabular}


Cuadro VI.3 (conclusión)

\begin{tabular}{lccc}
\hline País & $\begin{array}{c}\text { Grandes exportadores } \\
\text { (en porcentajes del total) }\end{array}$ & $\begin{array}{c}\text { Microexportadores y } \\
\text { pequeños y medianos } \\
\text { exportadores } \\
\text { (en porcentajes del total) }\end{array}$ & $\begin{array}{c}\text { Montos totales } \\
\text { (en número de empresas } \\
\text { y millones de dólares) }\end{array}$ \\
\hline El Salvador & & & \\
\hline Empresas & 32,8 & 67,2 & 1737 \\
\hline Monto exportado & 94,7 & 5,3 & 7751 \\
\hline Centroamérica (sin Panamá) & & & 5218 \\
\hline Empresas & 25,6 & 74,4 & 1255 \\
\hline Monto exportado & 89,9 & 10,1 & \\
\hline
\end{tabular}

Fuente: Comisión Económica para América Latina y el Caribe (CEPAL), sobre la base de Secretaría de Integración Económica Centroamericana (SIECA), Observatorio de Inteligencia Económica [base de datos en línea] http://estadisticas.sieca.int/.

a Para la determinación de la tipología de cada empresa y su comparabilidad entre países se normalizó a partir del tamaño relativo de cada país medido como la proporción del PIB y la población económicamente activa (PEA), y un índice de corrección que estandariza los umbrales de ventas de exportaciones en función de la propensión a exportar bienes. Véase una revisión de la metodología empleada en M. Álvarez y J. Durán, Manual de la micro, pequeña y mediana empresa: una contribución a la mejora de los sistemas de información y el desarrollo de las políticas públicas. Segunda edición, Santiago, Comisión Económica para América Latina y el Caribe/Deutsche Gesellschaft für Internationale Zusammenarbeit (GIZ/CEPAL), 2019, en prensa.

\section{La Unión Aduanera Centroamericana y la facilitación del comercio}

Todos los países de Centroamérica son signatarios del Acuerdo sobre Facilitación del Comercio de la OMC, que tiene como objetivo primordial agilizar el despacho, el movimiento y el tránsito de mercaderías a nivel mundial. Los países se comprometieron a adoptar medidas como la aplicación de mecanismos de ventanilla única, la implementación del operador único autorizado, el uso de medios electrónicos para el intercambio de datos (declaraciones aduaneras, emisión de licencias, envío de manifiestos de carga marítima y aérea), la publicación electrónica de procedimientos aduaneros regulatorios, el intercambio electrónico de certificados (de origen, sanitarios y fitosanitarios) y datos de aduana, la reducción de inspecciones físicas y la cooperación entre agencias de aduana, entre otras.

Paralelamente a dicho Acuerdo, los países centroamericanos se han centrado en la facilitación del comercio intrarregional y, para ello, cuentan con normativa complementaria. En consonancia con lo anterior, los presidentes del Sistema de la Integración Centroamericana (SICA) a mediados de 2014 instruyeron al Consejo de Ministros de Integración Económica (COMIECO) que trabajara en una Estrategia Centroamericana de Facilitación del Comercio y la Competitividad, con énfasis en la gestión coordinada de fronteras en el corredor logístico centroamericano. Desde 2015, los países cuentan con un plan de acción que contiene cinco medidas concretas: i) la declaración 
anticipada de mercancías; ii) la agilización y coordinación de controles migratorios; iii) la emisión de certificados fito- y zoosanitarios electrónicos; iv) el registro por medio de dispositivos de identificación de radiofrecuencia, y v) la utilización de sistemas de cámaras en los pasos de frontera. La plena aplicación de la Unión Aduanera Centroamericana es todavía un proceso en desarrollo, que se espera culminar a fines de 2024, con tres líneas de acción a seguir: i) la libre circulación de bienes y la facilitación del comercio; ii) la modernización y convergencia normativa, y iii) el desarrollo institucional (COMIECO, 2015).

En los últimos años, los países han promovido iniciativas tendientes a la plena aplicación de la Unión Aduanera (prevista en 1960 tras la firma del Tratado General de Integración Económica Centroamericana, pero aún sin concretarse). Los acuerdos comerciales bilaterales han hecho que la región aumente el acervo de acuerdos comerciales suscritos (34). También se ha incrementado el número de socios (67). Esto ha retrasado la aplicación del arancel aduanero unificado, que debía compatibilizarse con diferentes calendarios de desgravación arancelaria por cada acuerdo de libre comercio suscrito. En los acuerdos se fue modificando el arancel promedio que los países venían aplicando, por lo que es inviable una armonización plena del arancel comunitario (véase el gráfico VI.4). El caso más emblemático es el Tratado de Libre Comercio entre Costa Rica y China, vigente desde 2011. En el marco de ese tratado, Costa Rica ha liberalizado el 68\% de las líneas arancelarias (COMEX, 2010) y, en 2021, esa cifra aumentará al 88,5\%. Debido a la inexistencia de un acuerdo similar con el resto de los países centroamericanos, la aplicación plena de la Unión Aduanera Centroamericana en materia arancelaria es más difícil que con los acuerdos suscritos con los Estados Unidos o la Unión Europea, cuyos calendarios de desgravación convergerán con el pasar de los años.

En 2000, hubo un primer intento por consolidar la Unión Aduanera Centroamericana, bajo el impulso de El Salvador y Guatemala, y la adhesión de Nicaragua y Honduras a dicho esfuerzo. Con esta base, plasmada en un Convenio Marco para el Establecimiento de la Unión Aduanera Centroamericana, los países negociaron el Acuerdo de Asociación con la Unión Europea. Tras el cierre de las negociaciones con la Unión Europea, cinco países (Costa Rica, El Salvador, Guatemala, Honduras y Nicaragua) ratificaron su voluntad de alcanzar la Unión Aduanera Centroamericana, aunque sin planes concretos sobre cómo proceder ${ }^{5}$. El mayor avance se dio con el establecimiento de la unión aduanera entre Guatemala y Honduras en junio de 2017. En la sección

En Cordero (2017) se detallan los esfuerzos bilaterales con miras a implementar la Unión Aduanera Centroamericana: El Salvador y Honduras en 2011, Guatemala y El Salvador en 2012, y Costa Rica y Panamá en 2005. 
siguiente se presentan los resultados de la evaluación que hizo la CEPAL de dicho proceso sobre la base de escenarios de política que consideran la reducción de los costos administrativos desde su nivel estimado (en un $60 \%$ en un escenario ambicioso y, alternativamente, en un 30\%, en otro de menor ambición). Se aclara que en los ejercicios no se considera la plena aplicación del arancel externo común a terceros países. Además, se presentan resultados de la inclusión de El Salvador en la unión aduanera antes referida. En este caso, el programa de facilitación del comercio aplicado prevé la ampliación del territorio aduanero unificado a los tres países del Triángulo del Norte de Centroamérica. Se consideran escenarios similares a los arriba señalados, con la salvedad de que en este caso se incluyen tres países (El Salvador, Guatemala y Honduras).

\section{Gráfico VI.4}

Centroamérica: evolución del número de acuerdos comerciales suscritos

(En número de acuerdos, países y porcentajes)

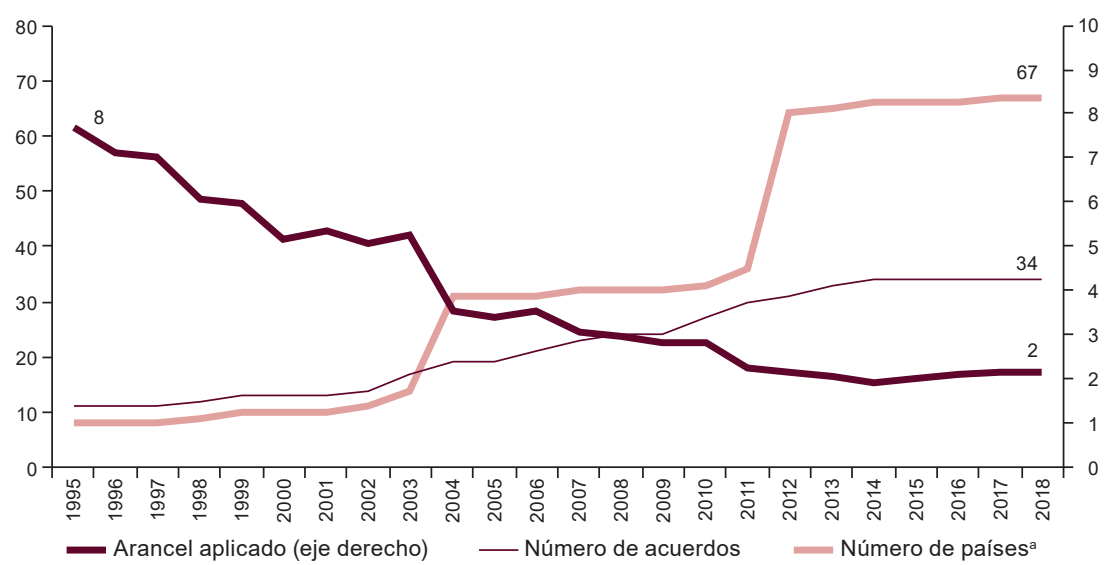

Fuente: Elaboración propia, sobre la base de Banco Mundial, "Tasa arancelaria, nación más favorecida, media simple, todos los productos (\%)" [base de datos en línea] https://datos.bancomundial.org/ indicador/TM.TAX.MRCH.SM.FN.ZS?view=chart; Organización Mundial del Comercio (OMC), Función de Descarga de Aranceles [base de datos en línea] http://tariffdata.wto.org/Default. aspx?culture=es-ES; Secretaría de Integración Económica Centroamericana (SIECA); Organización de los Estados Americanos (OEA), "Acuerdos comerciales en vigor" [base de datos en línea] http:// www.sice.oas.org/agreements_s.asp.

a En el número de países se consideran todos aquellos con los que al menos un país de la subregión mantiene un acuerdo comercial preferencial vigente (véase el cuadro II.1 del capítulo II).

En el cuadro VI.4 se presentan los equivalentes ad valorem calculados respecto de los escenarios simulados considerando el statu quo (situación inicial). También se plasman las reducciones de los escenarios (ambicioso y moderado) respecto de la liberalización bilateral entre Guatemala y Honduras, y las del Triángulo del Norte de Centroamérica (que incluye a El Salvador). 


\section{Cuadro VI.4}

Centroamérica: escenarios de profundización de la Unión Aduanera Centroamericana ${ }^{a}$ (Equivalentes ad valorem en porcentajes del valor del producto)

\begin{tabular}{|c|c|c|c|c|c|c|}
\hline \multirow[t]{2}{*}{ Sectores o escenarios } & \multicolumn{3}{|c|}{$\begin{array}{c}\text { Profundización de la unión } \\
\text { aduanera Honduras-Guatemala } \\
\text { (17\% del comercio } \\
\text { intracentroamericano })\end{array}$} & \multicolumn{3}{|c|}{$\begin{array}{l}\text { Profundización de la unión } \\
\text { aduanera en el Triángulo } \\
\text { del Norte de Centroamérica } \\
\text { (52\% del comercio } \\
\text { intracentroamericano) }\end{array}$} \\
\hline & Statu quo & $\begin{array}{c}\text { Escenario } \\
\text { ambicioso } \\
(60 \%)\end{array}$ & $\begin{array}{l}\text { Escenario } \\
\text { moderado } \\
(30 \%)\end{array}$ & Statu quo ${ }^{c}$ & $\begin{array}{l}\text { Escenario } \\
\text { ambicioso } \\
(60 \%)\end{array}$ & $\begin{array}{l}\text { Escenario } \\
\text { moderado } \\
(30 \%)\end{array}$ \\
\hline Agricultura, caza y pesca & 29,0 & 11,6 & 20,3 & 35,5 & 15,5 & 25,5 \\
\hline Petróleo y minería & 47,5 & 19,0 & 33,3 & 0,8 & 0,3 & 0,6 \\
\hline $\begin{array}{l}\text { Alimentos, bebidas } \\
\text { y tabaco }\end{array}$ & 15,6 & 6,2 & 10,9 & 18,2 & 10,9 & 14,6 \\
\hline $\begin{array}{l}\text { Textiles, confecciones } \\
\text { y calzado }\end{array}$ & 48,4 & 19,3 & 33,8 & 34,2 & 13,7 & 23,9 \\
\hline Química y petroquímica & 22,5 & 9,0 & 15,7 & 9,7 & 3,9 & 6,8 \\
\hline $\begin{array}{l}\text { Metales y } \\
\text { productos derivados }\end{array}$ & 3,7 & 1,5 & 2,6 & 12,0 & 6,1 & 9,0 \\
\hline Maquinaria y equipo & 34,3 & 13,7 & 24,0 & 11,3 & 5,5 & 8,4 \\
\hline Otras manufacturas & 23,5 & 9,4 & 16,5 & 16,1 & 6,7 & 11,4 \\
\hline Todos los sectores & 28,2 & 8,3 & 14,4 & 17,8 & 8,4 & 13,0 \\
\hline
\end{tabular}

Fuente: Comisión Económica para América Latina y el Caribe (CEPAL), sobre la base de estimaciones de equivalentes ad valorem y criterios de ejecución del programa de facilitación del comercio entre los países intervinientes.

En las cifras del cuadro se consolidan las estimaciones bilaterales de todos los países incluidos en cada simulación. En el modelo de equilibrio general computable aplicado, los choques arancelarios se incluyen a nivel bilateral y por grupo de productos.

b Considera únicamente los equivalentes ad valorem calculados para los intercambios bilaterales entre Guatemala y Honduras.

c Incluye todas las relaciones bilaterales entre los tres países del Triángulo del Norte de Centroamérica (El Salvador, Guatemala y Honduras).

Para la definición de los escenarios simulados se consideraron las listas oficiales de productos exceptuados del programa de facilitación del comercio, que alcanzan el $25 \%$ del monto del intercambio bilateral entre Honduras y Guatemala y el 19\% en el caso del intercambio comercial entre todos los miembros del Triángulo del Norte de Centroamérica. Por grupos, las mayores excepciones están en productos químicos y petroquímicos, principalmente derivados del petróleo, así como algunos productos agroalimentarios (aceites vegetales, alimentos para animales, embutidos de cerdo, arroz, levaduras, entre otros) (véase el gráfico VI.5).

En el cuadro VI.5 se muestran los cambios que tendrían lugar en la protección arancelaria en Centroamérica si entrara en vigor un programa de facilitación del comercio que involucrara a todos los países centroamericanos miembros de la Secretaría de Integración Económica Centroamericana (SIECA). Al igual que en las situaciones antes mencionadas, en este caso se 
consideran dos escenarios: uno ambicioso en el que se aplican niveles de reducción de las barreras administrativas del $60 \%$ y uno moderado, con una reducción del 30\%. A diferencia de los ejercicios anteriores, en este caso no se consideraron listas de excepción al definir los escenarios, por lo que se asumen reducciones uniformes al equivalente ad valorem calculado.

\section{Triángulo del Norte de Centroamérica: importaciones sujetas al régimen de libre circulación de mercancías en el proceso de profundización de la Unión Aduanera Centroamericana, 2015-2016 \\ (En porcentajes del total de las importaciones totales)}

A. Excepciones bilaterales

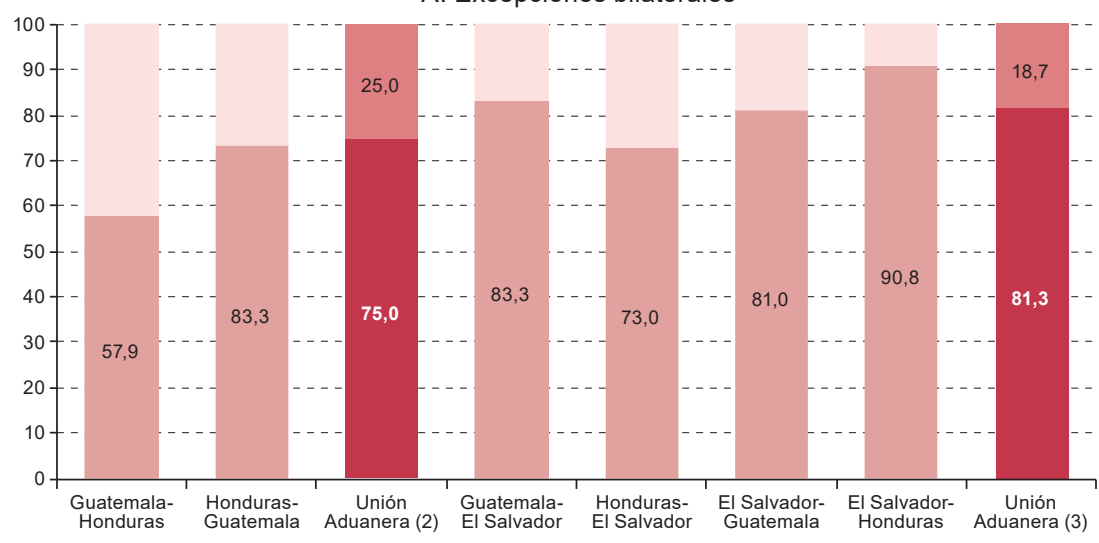

B. Excepciones sectoriales

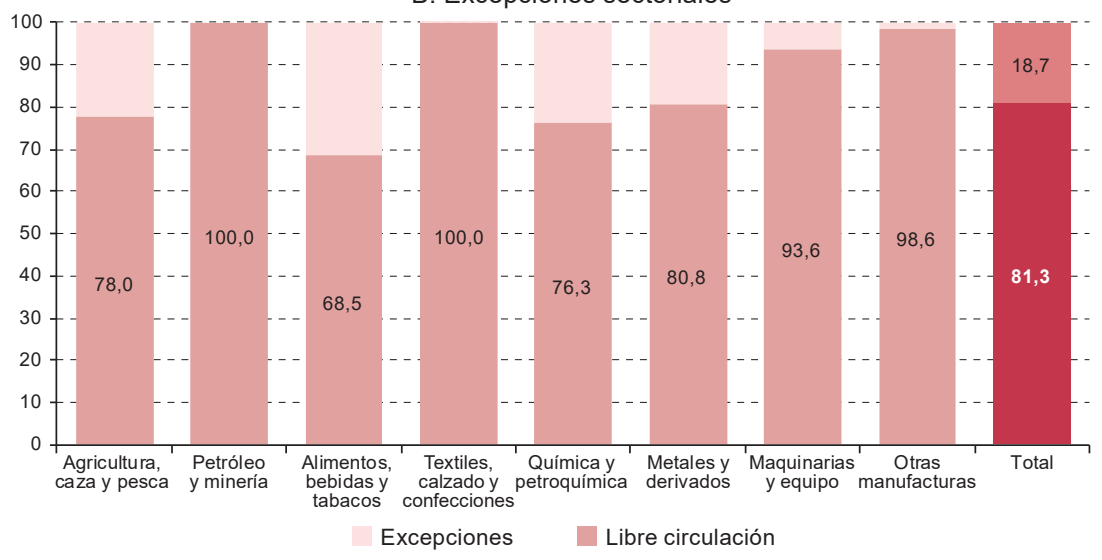

Fuente: Comisión Económica para América Latina y el Caribe (CEPAL), sobre la base de Naciones Unidas, Base de Datos Estadísticos de las Naciones Unidas sobre el Comercio de Productos Básicos (COMTRADE) [en línea] https://comtrade.un.org/. 


\section{Cuadro VI.5}

\section{Centroamérica: escenario consolidado de la plena aplicación de la Unión Aduanera}

Centroamericana (todos los países miembros)

(En equivalentes ad valorem como porcentaje del valor del producto)

\begin{tabular}{lccc}
\hline Sectores & Statu quo & $\begin{array}{r}\text { Escenario ambicioso } \\
(60 \%)\end{array}$ & $\begin{array}{c}\text { Escenario moderado } \\
(30 \%)\end{array}$ \\
\hline Agricultura, caza y pesca & 33,4 & 13,4 & 23,4 \\
\hline Petróleo y minería & 4,8 & 1,9 & 3,4 \\
\hline Alimentos, bebidas y tabaco & 20,1 & 8,0 & 14,1 \\
\hline Textiles, confecciones y calzado & 43,6 & 17,5 & 30,5 \\
\hline Química y petroquímica & 12,8 & 5,1 & 8,9 \\
\hline Metales y productos derivados & 14,3 & 5,7 & 10,0 \\
\hline Maquinaria y equipo & 10,5 & 4,2 & 7,3 \\
\hline Otras manufacturas & 19,9 & 8,0 & 13,6 \\
\hline Total & 19,5 & 7,8 & \\
\hline
\end{tabular}

Fuente: Comisión Económica para América Latina y el Caribe (CEPAL), sobre la base de estimaciones de equivalentes ad valorem y criterios de ejecución del programa de facilitación del comercio entre los países intervinientes.

Nota: En las cifras presentadas se consolidan las estimaciones bilaterales de todos los países incluidos en cada simulación. En el modelo de equilibrio general computable aplicado, los choques arancelarios se incluyen a nivel bilateral y por grupo de productos.

La CEPAL desarrolló un conjunto de ejercicios para simular los escenarios descritos en esta sección, de modo que se pudieran evaluar los costos y beneficios de su implementación. Con ese fin, se introdujeron los cambios esperados en un modelo de equilibrio general computable. A partir de un escenario central calibrado en una situación definida como statu quo, se realizaron simulaciones para derivar las ganancias o pérdidas sectoriales tras la aplicación de los escenarios descritos.

Los principales resultados del primer conjunto de escenarios fueron presentados a las autoridades de los países con el propósito de apoyar el proceso de negociaciones seguido por Guatemala y Honduras. Luego fueron publicados con el título "Posibles efectos económicos y sociales de la profundización de la unión aduanera entre Guatemala y Honduras". En el caso de la unión aduanera entre los países del Triángulo del Norte de Centroamérica, el trabajo de evaluación y los escenarios resultantes son parte de un proceso en desarrollo conjunto con la SIECA, el Banco Central de Reserva de El Salvador y el Ministerio de Hacienda de El Salvador.

En este capítulo se comparan los resultados de ambos trabajos, incluidas las simulaciones de la unión aduanera ampliada. Se presupone que los países avanzan hacia la plena aplicación de medidas de facilitación del comercio tendientes a reducir el tiempo de tránsito y los costos extra asociados a un conjunto de barreras administrativas. Entre estas cabe mencionar la implementación de puestos especiales de frontera con facilitación del comercio, el intercambio electrónico en línea de certificados de origen y el uso de códigos de respuesta rápida $(\mathrm{QR})$ para el escaneo de documentos y vehículos, principalmente camiones, mediante la tecnología de identificación 
por radiofrecuencia (RFID). De este modo es posible considerar no solo los impactos aplicables a los países que se han adherido a tales procesos, sino también a los que aún se encuentran excluidos, pero que se adherirían en el futuro. Se aclara que las simulaciones no incluyen la reducción ni el aumento de los aranceles aplicados y comprometidos en acuerdos bilaterales comerciales, ni la revisión de la protección remanente de la lista " $\mathrm{A}$ " del Protocolo de Guatemala. Estos se mantienen vigentes.

Los resultados incluirán efectos sobre producción, comercio y empleo y, cuando sea posible, también sobre pobreza y distribución del ingreso. Se incluyen estimaciones de los efectos sobre la recaudación arancelaria debido al cambio esperado en las importaciones de bienes y sobre la recaudación de impuesto al valor agregado asociada al consumo final de tales bienes.

\section{Resultados esperados de la aplicación de programas de facilitación del comercio}

En esta sección se comparan los resultados de tres conjuntos de escenarios, a fin de derivar conclusiones generales que pudieran servir de retroalimentación en el proceso de integración centroamericana. Los cambios macroeconómicos proyectados son indicativos del impacto en cada economía tras la aplicación de un programa de facilitación del comercio más o menos ambicioso. A partir del cambio en la actividad económica también se producen efectos en los ingresos fiscales y los indicadores sociales.

\section{Resultados macroeconómicos}

A fin de analizar el impacto de las diversas iniciativas y compromisos asumidos por los países con miras a reducir los costos administrativos del comercio, se presentan comparativamente los resultados macroeconómicos en el escenario de unificación aduanera de los territorios de Guatemala y Honduras, y el de un proceso similar que incluya a El Salvador (escenario del Triángulo del Norte de Centroamérica). En ambos casos se separan los resultados según el nivel de ambición.

La unión aduanera entre Guatemala y Honduras muestra un cambio del PIB de entre el 0,2\% y el 0,8\%, con una variación mayor en el escenario ambicioso. Honduras recibiría una variación mayor $(0,7 \%$ en el escenario ambicioso), en tanto que Guatemala recibiría una variación positiva menor $(0,4 \%$ en el mismo escenario). De igual forma, los cambios del comercio son mayores en el caso de Honduras, aunque la actividad económica y exportadora se vería impulsada en ambos países. Los impactos son positivos y mayores en el escenario ambicioso, con aumentos del bienestar de los consumidores e impacto positivo en el empleo, sobre todo el de mano de obra no calificada (véanse el cuadro VI.6 y el gráfico VI.6). 


\section{Cuadro VI.6}

Guatemala, Honduras y Triángulo del Norte de Centroamérica: cambio porcentual de variables macroeconómicas debido a reducciones de las barreras administrativas (En variaciones porcentuales con respecto a la línea de base y millones de dólares)

\begin{tabular}{|c|c|c|c|c|}
\hline \multirow{2}{*}{ Variable } & \multicolumn{2}{|c|}{$\begin{array}{l}\text { Unión aduanera entre } \\
\text { Guatemala y Honduras }\end{array}$} & \multicolumn{2}{|c|}{$\begin{array}{l}\text { Unión aduanera del } \\
\text { Triángulo del Norte } \\
\text { de Centroamérica }\end{array}$} \\
\hline & $\begin{array}{c}\text { Menos } \\
\text { ambicioso } \\
(30 \%)\end{array}$ & $\begin{array}{c}\text { Ambicioso } \\
(60 \%)\end{array}$ & $\begin{array}{c}\text { Menos } \\
\text { ambicioso } \\
(30 \%)\end{array}$ & $\begin{array}{c}\text { Ambicioso } \\
(60 \%)\end{array}$ \\
\hline PIB & 0,2 & 0,5 & 0,3 & 0,8 \\
\hline Exportaciones & 0,7 & 1,8 & 0,7 & 2,1 \\
\hline Importaciones & 0,5 & 1,7 & 0,9 & $1, .8$ \\
\hline Empleo total & 0,4 & 0,5 & 0,4 & 1,0 \\
\hline Empleo (mano de obra no calificada) & 0,6 & 0,8 & 0,4 & 1,0 \\
\hline Bienestara (en millones de dólares) & 162 & 377 & 187 & 419 \\
\hline Porcentaje del PIB & 0,2 & 0,6 & 0,2 & 0,5 \\
\hline
\end{tabular}

Fuente: Comisión Económica para América Latina y el Caribe (CEPAL), sobre la base del modelo y base de equilibrio general del Proyecto de Análisis del Comercio Global (GTAP), versión 9.

a El bienestar mide la cantidad de riqueza en términos de ingreso que el consumidor percibe (o pierde) cuando su nivel de utilidad se incrementa (o reduce), suponiendo que los precios no cambian.

\section{Gráfico VI.6}

Centroamérica (países y agrupaciones seleccionados): efectos sobre el producto interno bruto de diversos escenarios simulados

(En variaciones porcentuales con respecto a la línea de base)

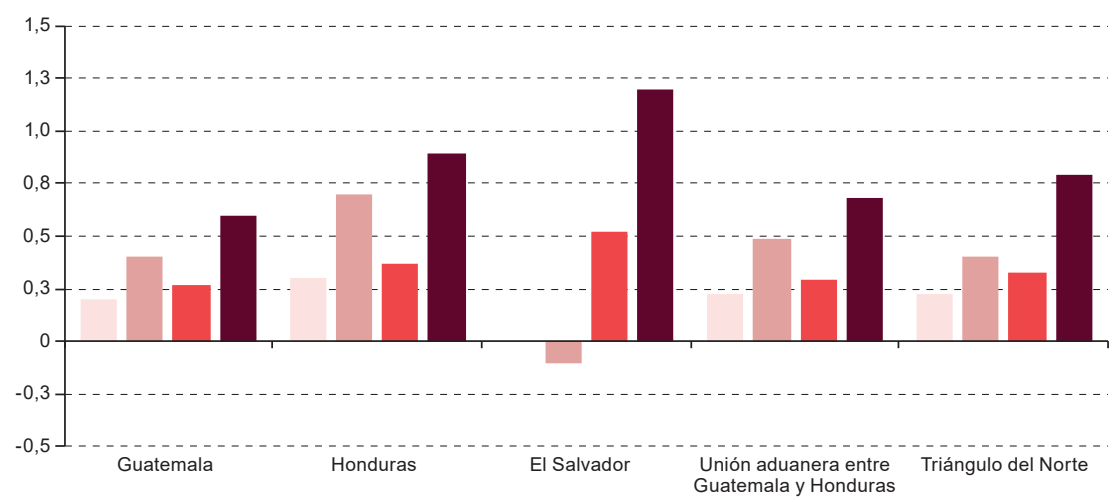

Unión aduanera entre Guatemala y Honduras moderado

Unión aduanera entre Guatemala y Honduras ambicioso

Unión aduanera del Triángulo del Norte de Centroamérica moderado

Unión aduanera del Triángulo del Norte de Centroamérica ambicioso

Fuente: Comisión Económica para América Latina y el Caribe (CEPAL), sobre la base del modelo y base de equilibrio general del Proyecto de Análisis del Comercio Global (GTAP), versión 9.

La variación positiva sobre el bienestar (entre 73 y 171 millones de dólares en Honduras, y entre 89 y 206 millones de dólares en Guatemala, según el escenario considerado) se explica principalmente por el aumento de la recaudación de impuestos debido al mayor volumen importado y al mayor empleo de la mano de obra no calificada (CEPAL, 2017). A esto se suma el efecto de los menores costos administrativos sobre los términos 
de intercambio, que hacen más competitivos los productos comerciados entre ambos países. La ampliación de esta unión aduanera a El Salvador aumenta las diferencias en todas las variables macroeconómicas, sobre todo una mejora del bienestar de los individuos en los tres países. El monto se eleva a 419 millones de dólares en el escenario ambicioso y a 187 millones de dólares en uno más moderado (véase el cuadro VI.6).

$\mathrm{Al}$ igual que en cualquier escenario de cambio en el comercio exterior, hay sectores ganadores y perdedores. Los mayores impactos sectoriales positivos se producen en química y petroquímica, alimentos, bebidas y tabacos, textiles, confección y calzado, agricultura, caza y pesca, además de maquinarias y equipos y otras manufacturas. Entre los sectores que ven disminuida su producción en el escenario de unión aduanera entre Guatemala y Honduras están principalmente los de petróleo y minería $(0,8 \%)$, y los de agricultura, silvicultura, caza y pesca $(-0,2 \%)$. La inclusión de El Salvador en la unión aduanera tiene mayores efectos positivos sobre el comercio, al tiempo que permite moderar los efectos negativos en la agroindustria y la producción de metales y productos derivados. En ambos casos se expanden la producción y el comercio (véase el cuadro VI.7). La mayor demanda de otros sectores, como los de textiles, confecciones y calzado, alimentos, bebidas y tabaco, metales y productos derivados, química y petroquímica y otras manufacturas, permiten que la mano de obra no calificada empleada en sectores primarios con crecimiento bajo o nulo (agropecuario y petróleo y minería) sea absorbida por los sectores antes mencionados.

\section{Cuadro VI.7}

Guatemala, Honduras y Triángulo del Norte de Centroamérica: cambio porcentual en producción, importaciones y exportaciones a nivel sectorial, con un $60 \%$ de reducción de las barreras administrativas

(En variaciones porcentuales con respecto a la línea de base)

\begin{tabular}{|c|c|c|c|c|c|c|}
\hline \multirow[t]{2}{*}{ Sectores } & \multicolumn{3}{|c|}{$\begin{array}{c}\text { Unión aduanera entre Guatemala } \\
\text { y Honduras }\end{array}$} & \multicolumn{3}{|c|}{$\begin{array}{c}\text { Unión aduanera en Triángulo del Norte } \\
\text { de Centroamérica }\end{array}$} \\
\hline & Producción & Importaciones & Exportaciones & Producción & Importaciones & Exportaciones \\
\hline $\begin{array}{l}\text { Agricultura, } \\
\text { silvicultura, pesca }\end{array}$ & $-0,2$ & 1,2 & 0,2 & 0,1 & 1,5 & $-0,3$ \\
\hline Petróleo y minería & $-0,8$ & 2,8 & $-1,4$ & $-0,6$ & 1,6 & $-0,9$ \\
\hline $\begin{array}{l}\text { Alimentos, bebidas } \\
\text { y tabaco }\end{array}$ & $-0,1$ & 2,4 & 0,1 & 0,6 & 3,7 & 3,7 \\
\hline $\begin{array}{l}\text { Textiles, calzado } \\
\text { y confección }\end{array}$ & 2,8 & 4,5 & 5,3 & 1,4 & 2,6 & 3,2 \\
\hline $\begin{array}{l}\text { Química y } \\
\text { petroquímica }\end{array}$ & 1,5 & 1,1 & 6,3 & 1,7 & 0,9 & 6,7 \\
\hline $\begin{array}{l}\text { Metales y productos } \\
\text { derivados }\end{array}$ & $-0,2$ & 1,6 & $-1,8$ & 0,8 & 2,4 & 3,0 \\
\hline $\begin{array}{l}\text { Maquinarias } \\
\text { y equipos }\end{array}$ & 0,5 & 1,9 & 4,0 & 0,0 & 1,5 & 0,5 \\
\hline $\begin{array}{l}\text { Otras } \\
\text { manufacturas }\end{array}$ & 0,9 & 2,7 & 4,7 & 1,6 & 3,1 & 8,6 \\
\hline Servicios & 0,4 & $-1,9$ & $-0,9$ & 0,9 & 1,2 & $-1,6$ \\
\hline Total & 0,5 & 1,7 & 1,8 & 0,8 & 1,8 & 2,1 \\
\hline
\end{tabular}

Fuente: Comisión Económica para América Latina y el Caribe (CEPAL), sobre la base del modelo y base de equilibrio general del Proyecto de Análisis del Comercio Global (GTAP), versión 9. 
Las simulaciones de una unión aduanera ampliada a todos los países centroamericanos muestran una variación positiva del PIB que supera las variaciones descritas en los escenarios precedentes (véase el gráfico VI.7). La inclusión de más países en el programa de facilitación del comercio, sea este moderado o ambicioso, deriva en una variación positiva del producto de entre un $1 \%$ y un $2,4 \%$, respectivamente. Estos cambios superan todos los resultados obtenidos bajo los escenarios de la unión aduanera entre Guatemala y Honduras, y de la unión aduanera del Triángulo del Norte de Centroamérica. La variación del PIB en toda Centroamérica pasa desde un $0,2 \%$ cuando solo opera la unión aduanera entre Guatemala y Honduras, hasta un $1 \%$ si se conforma la unión aduanera tripartita entre El Salvador, Guatemala y Honduras, a una variación promedio del 2,4\% en el caso de la Unión Aduanera Centroamericana ampliada. Además, en todos los grupos de países y en cada país por separado, los impactos son favorables, siendo más altos en los casos de Guatemala y Honduras, que alcanzarían tasas de variación del PIB del 2,9\% y el 4,5\%, respectivamente, en el escenario ambicioso. En el menos ambicioso, aunque todos los países reciben efectos positivos, estos son mayores en el caso de Guatemala. En todas las simulaciones de la unión aduanera ampliada, Costa Rica recibe los menores impactos, aunque revierte la desviación de comercio que se produce en los escenarios precedentes, en los que presenta una expansión nula, o levemente negativa, de sus exportaciones totales. Se aprecia un patrón similar en las exportaciones de Nicaragua y Panamá (véase el gráfico VI.8).

\section{Gráfico VI.7}

Centroamérica: efectos sobre el producto interno bruto de diversos escenarios simulados de unión aduanera

(En variaciones porcentuales con respecto a la línea de base)

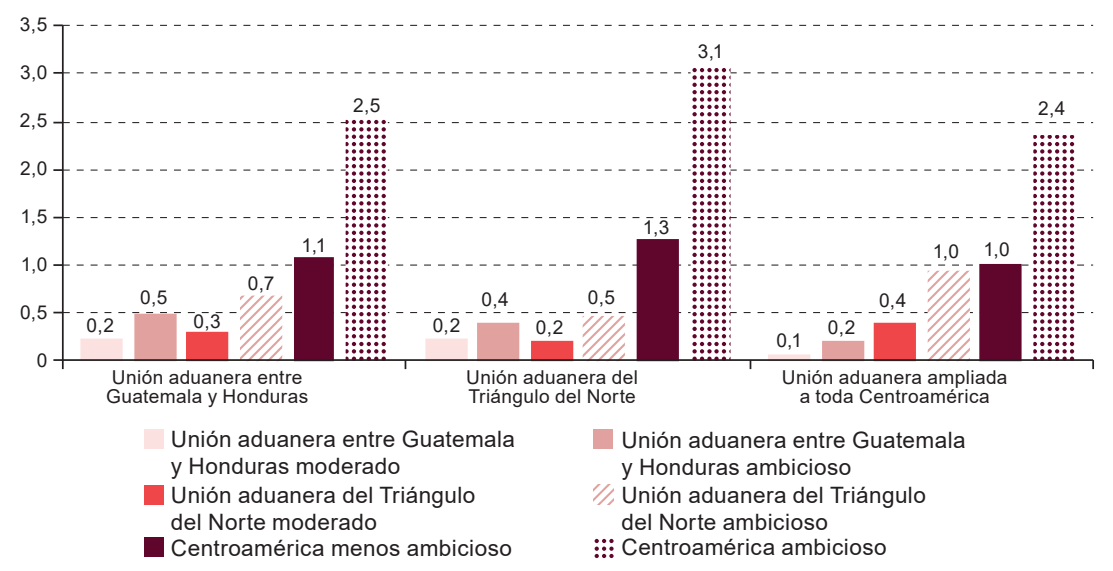

Fuente: Comisión Económica para América Latina y el Caribe (CEPAL), sobre la base del modelo y base de equilibrio general del Proyecto de Análisis del Comercio Global (GTAP), versión 9. 
Gráfico VI.8

Nuevos socios en la Unión Aduanera Centroamericana: efectos

sobre las exportaciones de bienes

(En variaciones porcentuales con respecto a la línea de base)

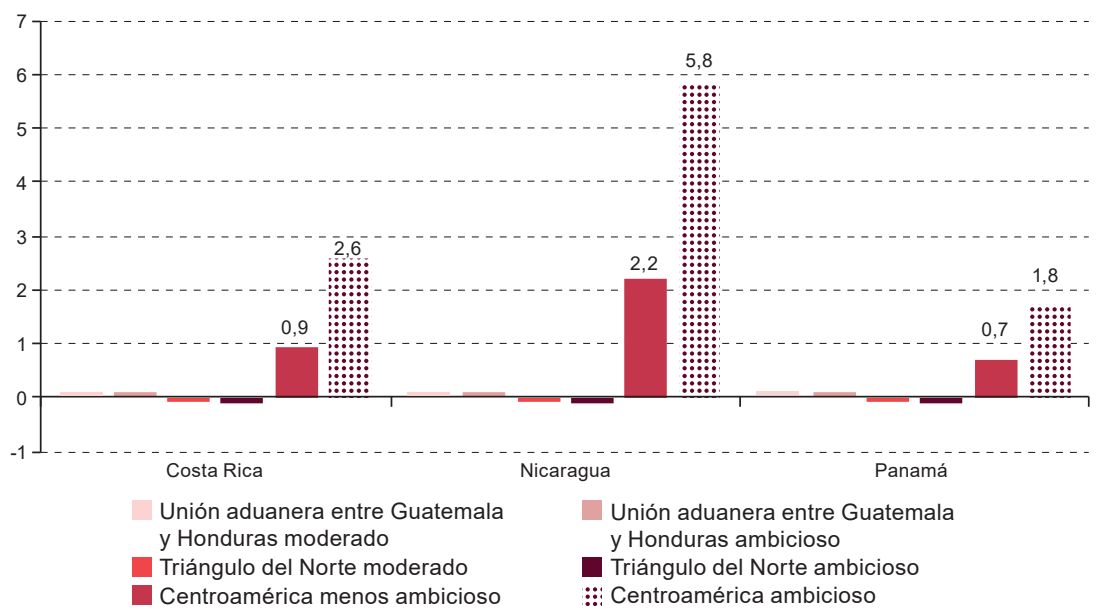

Fuente: Comisión Económica para América Latina y el Caribe (CEPAL), sobre la base del modelo y base de equilibrio general del Proyecto de Análisis del Comercio Global (GTAP), versión 9.

En todas las simulaciones se destaca el efecto favorable de la unión aduanera ampliada sobre el empleo, en particular de mano de obra no calificada, cuyas remuneraciones aumentan. El cambio en el bienestar de los consumidores, medido en términos del PIB, también resulta positivo en todos los países (véase el cuadro VI.8). Esto se explica principalmente por el aumento de la competitividad de las operaciones de comercio exterior debido a los mejores precios. Destaca el efecto favorable de esos precios sobre el comercio, sobre todo por la expansión de las importaciones. Al tratarse de resultados transversales a todos los agentes económicos, las pequeñas y medianas empresas exportadoras recibirían estímulos para impulsar operaciones de comercio exterior en los mercados vecinos. En este segmento, las mejoras administrativas son más favorables que en las empresas de mayor tamaño, que disponen de más herramientas para resolver cuellos de botella en sus trámites aduaneros. Otro efecto importante es el aumento del consumo de bienes importados, lo que repercute favorablemente en la recaudación fiscal debido al mayor impuesto al valor agregado recaudado por el fisco. 


\section{Cuadro VI.8}

Centroamérica: efectos macroeconómicos de una unión aduanera ampliada (En variaciones porcentuales con respecto a la línea de base y millones de dólares)

\begin{tabular}{|c|c|c|c|c|c|c|}
\hline Principales sectores & Costa Rica & Guatemala & El Salvador & Honduras & Nicaragua & Panamá \\
\hline \multicolumn{7}{|c|}{ Escenario ambicioso ( $60 \%$ de reducción de los equivalentes ad valorem) } \\
\hline PIB & 1,0 & 4,5 & 2,4 & 2,9 & 2,4 & 2,1 \\
\hline Exportaciones & 2,6 & 12,0 & 5,9 & 6,7 & 5,8 & 1,8 \\
\hline Importaciones & 2,9 & 9,0 & 5,1 & 6,3 & 5,5 & 2,0 \\
\hline Empleo total & 1,0 & 2,0 & 1,0 & 2,4 & 2,7 & 1,6 \\
\hline $\begin{array}{l}\text { Empleo (mano de obra } \\
\text { no calificada) }\end{array}$ & 2,1 & 3,4 & 1,8 & 3,9 & 4,2 & 2,5 \\
\hline $\begin{array}{l}\text { Bienestara } \\
\text { (en millones de dólares) }\end{array}$ & 518 & 614 & 627 & 592 & 299 & 625 \\
\hline Porcentaje del PIB & 1,2 & 2,5 & 1,3 & 3,1 & 2,8 & 1.9 \\
\hline \multicolumn{7}{|c|}{ Escenario moderado ( $30 \%$ de reducción de los equivalentes ad valorem) } \\
\hline PIB & 0,5 & 1,8 & 1,1 & 1,1 & 1,1 & 0,9 \\
\hline Exportaciones & 0,9 & 4,6 & 2,3 & 2.5 & 2,2 & 0,7 \\
\hline Importaciones & 1,0 & 3,5 & 2,0 & 2,3 & 2,1 & 0,8 \\
\hline Empleo total & 0,4 & 0,8 & 0,4 & 0,9 & 1,1 & 0,7 \\
\hline $\begin{array}{l}\text { Empleo (mano de obra } \\
\text { no calificada) }\end{array}$ & 0,8 & 1,3 & 0,7 & 1,5 & 1,7 & 1,0 \\
\hline $\begin{array}{l}\text { Bienestara } \\
\text { (en millones de dólares) }\end{array}$ & 238 & 255 & 284 & 209 & 135 & 257 \\
\hline Porcentaje del PIB & 0,6 & 1,0 & 0,6 & 1,1 & 1,3 & 0,8 \\
\hline
\end{tabular}

Fuente: Comisión Económica para América Latina y el Caribe (CEPAL), sobre la base del modelo y base de equilibrio general del Proyecto de Análisis del Comercio Global (GTAP), versión 9.

a El bienestar mide la cantidad de riqueza en términos de ingreso que el consumidor percibe (o pierde) cuando su nivel de utilidad se incrementa (o reduce), suponiendo que los precios no cambian.

\section{Efectos sobre la recaudación tributaria}

Una preocupación del análisis de los posibles impactos de los escenarios simulados se concentra en los resultados esperados sobre los ingresos tributarios y en la posibilidad de que la profundización de una unión aduanera erosione la recaudación de los países participantes. En los resultados de esta sección no se considera una disminución de los aranceles aplicados hacia terceros países, ni tampoco desembolsos por inversiones en infraestructuras aduaneras. Únicamente se refleja el impacto de las medidas de facilitación del comercio sobre los flujos de bienes comerciados, que luego son objeto de recaudación mediante impuestos al valor agregado o impuestos especiales. Es decir, la recaudación tributaria analizada se calcula como los efectos fiscales derivados del aumento de las importaciones tras la aplicación de un programa de facilitación del comercio. 
La aplicación de un programa ambicioso de facilitación del comercio entre Honduras y Guatemala aumentaría su recaudación fiscal en 37 y 41 millones de dólares, respectivamente (el 0,2\% y el 0,1\% del PIB). En un programa menos ambicioso, el efecto positivo esperado sobre la recaudación fiscal es menor: de 21 y 27 millones de dólares para Honduras y Guatemala, respectivamente (véase el cuadro VI.9).

\section{Cuadro VI.9}

Centroamérica: aumento estimado de la recaudación tributaria resultante de programas alternativos de facilitación del comercio según los grupos de países que lo apliquen

(En millones de dólares y porcentajes del PIB)

\begin{tabular}{|c|c|c|c|c|c|}
\hline \multirow[b]{2}{*}{ Países o grupos de países } & \multicolumn{3}{|c|}{ Millones de dólares corrientes } & \multicolumn{2}{|c|}{ Porcentajes del PIB } \\
\hline & $\begin{array}{l}\text { Programa } \\
\text { ambicioso }\end{array}$ & $\begin{array}{c}\text { Programa } \\
\text { menos } \\
\text { ambicioso }\end{array}$ & PIB (2017) & $\begin{array}{l}\text { Programa } \\
\text { ambicioso }\end{array}$ & $\begin{array}{c}\text { Programa } \\
\text { menos } \\
\text { ambicioso }\end{array}$ \\
\hline $\begin{array}{l}\text { Unión Aduanera entre Guatemala } \\
\text { y Honduras }\end{array}$ & 78 & 48 & 93481 & 0,1 & 0,1 \\
\hline Guatemala & 41 & 27 & 70806 & 0,1 & 0,0 \\
\hline Honduras & 37 & 21 & 22675 & 0,2 & 0,1 \\
\hline $\begin{array}{l}\text { Unión Aduanera del Triángulo } \\
\text { del Norte de Centroamérica }\end{array}$ & 160 & 101 & 120888 & 0,1 & 0,1 \\
\hline El Salvador & 52 & 34 & 27407 & 0,2 & 0,1 \\
\hline Guatemala & 59 & 40 & 70806 & 0,1 & 0,0 \\
\hline Honduras & 49 & 27 & 22675 & 0,2 & 0,1 \\
\hline Unión Aduanera Centroamericana & 652 & 324 & 252540 & 0,3 & 0,1 \\
\hline El Salvador & 127 & 56 & 27407 & 0,5 & 0,2 \\
\hline Guatemala & 151 & 71 & 70806 & 0,2 & 0,1 \\
\hline Honduras & 113 & 52 & 22675 & 0,5 & 0,2 \\
\hline Costa Rica & 115 & 68 & 58909 & 0,3 & 0,1 \\
\hline Nicaragua & 91 & 47 & 13692 & 0,7 & 0,3 \\
\hline Panamá & 55 & 30 & 59051 & 0,1 & 0,1 \\
\hline
\end{tabular}

Fuente: Comisión Económica para América Latina y el Caribe (CEPAL), sobre la base de microsimulaciones de incrementos del IVA tras la aplicación de un programa de facilitación del comercio. EI PIB de los países se obtuvo de la base de datos oficial de la Secretaría de Integración Económica Centroamericana (SIECA), "Herramienta de consulta de indicadores" [base de datos en línea] http://www.oie.sieca.int/Indicadores; y legislaciones tributarias de los respectivos países.

Nota: Para el cálculo de la recaudación arancelaria simulada se consideró en cada caso la tasa impositiva del impuesto sobre el valor añadido declarado en la Legislación Tributaria de cada país, incluidos, según correspondiera, algunos impuestos especiales, así como las excepciones particulares referidas a medicamentos o alimentos. Las tasas impositivas generalmente aplicadas fueron: Costa Rica: 13\%, El Salvador: 13\%, Guatemala: 12\%, Honduras: 15\%, Nicaragua: 15\%, y Panamá: $7 \%$. Entre los casos especiales se cuentan una tasa del $20 \%$ a los autos en Guatemala, del $18 \%$ a las bebidas y el tabaco en Honduras y del 10\% a las bebidas alcohólicas en Panamá. Véanse más detalles en Comisión Económica para América Latina y el Caribe (CEPAL), "Posibles efectos económicos y sociales de la profundización de la unión aduanera entre Guatemala y Honduras", Documentos de Proyectos (LC/TS.2017/53), Santiago, 2017. La información de base para el cálculo de los impuestos se obtuvo a partir del incremento de importaciones por sector y país, derivada del modelo de equilibrio general computable.

En todos los escenarios que incluyen a El Salvador se estiman aumentos un poco mayores de la recaudación fiscal, especialmente en los casos con reducciones arancelarias más ambiciosas. Guatemala y Honduras alcanzarían 
aumentos de recaudación mayores que cuando se trata de una unión aduanera bilateral. Los aumentos de recaudación fiscal en el conjunto de los países del Triángulo del Norte de Centroamérica se mantienen en torno al 0,1\% del PIB.

En las simulaciones de una unión aduanera ampliada, el impacto también es positivo. Se estima un aumento de la recaudación entre 324 y 652 millones de dólares según se trate de un programa menos o más ambicioso. En términos del PIB, la participación se eleva al 0,3\% en el escenario ambicioso. El mayor impacto en términos de recaudación se daría en Nicaragua, Honduras y El Salvador. En Nicaragua, el aumento de la recaudación alcanzaría un $0,7 \%$ del PIB. Esto se debe a que la tasa impositiva en ese país es de las más altas de Centroamérica. Los otros países con aumentos estimados de recaudación en el escenario ambicioso son Honduras y Guatemala. El primero porque tiene una gran carga impositiva de IVA $(15 \%)$ y el segundo porque recibe un mayor aumento de las importaciones (9\%). En todos los países por separado, la recaudación impositiva estimada tras la profundización de la unión aduanera es más elevada por los beneficios que produce la expansión del territorio aduanero (véanse el gráfico VI.9 y el cuadro VI.9).

\section{Gráfico VI.9}

Centroamérica: aumento estimado de la recaudación tributaria resultante de un programa ambicioso de facilitación del comercio

(En porcentajes del PIB)

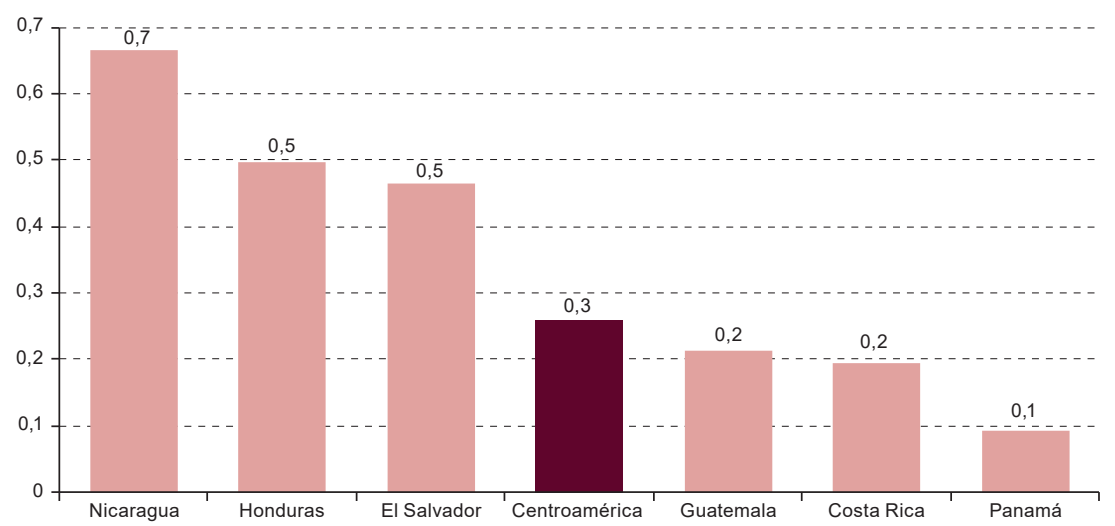

Fuente: Comisión Económica para América Latina y el Caribe (CEPAL), sobre la base de microsimulaciones efectuadas según los resultados de un modelo de equilibrio general computable.

Durán (2015) estimó un ejercicio similar al aquí presentado en un escenario de drástica reducción de los equivalentes ad valorem, del orden del $95 \%$ de los valores calculados. Se estimó que el aumento de la recaudación tributaria para toda Centroamérica sería del orden de 364 millones de dólares en 2015 y de 1.044 millones de dólares en un escenario ambicioso, con lo que la recaudación tributaria esperada rondaría entre un $0,2 \%$ y un $0,5 \%$ del PIB combinado en toda Centroamérica. 


\section{Efectos sobre el empleo, la pobreza y la distribución del ingreso}

En esta sección se presentan los resultados de ejercicios sobre la unión aduanera bilateral entre Guatemala y Honduras. El efecto de la facilitación del comercio en los escenarios simulados sobre el desempleo, la pobreza y la distribución del ingreso estará determinado por diversos factores. En primer lugar, por el dinamismo de los sectores exportadores que hayan recibido los impactos positivos tras la reducción de las barreras administrativas. En segundo lugar, por la estructura sectorial del empleo y el nivel de calificación de la mano de obra vinculada a tales actividades.

La estructura del empleo de Honduras (2010) y Guatemala (2011) muestra que el sector de mayor empleo es el de servicios, que abarca el $50 \%$ de la ocupación. También se destacan los sectores del transporte, las telecomunicaciones, los servicios empresariales y los financieros, que son actividades vinculadas al comercio exterior. En ambos países hay un predominio de la mano de obra no calificada, sobre todo en los sectores primarios (más del 90\% del total), con más incidencia de la mano de obra de mayor calificación en los sectores de maquinarias y equipo (36\%) y de servicios (33\%) (CEPAL, 2017).

En Honduras, en los escenarios ambicioso y menos ambicioso se obtendría una reducción de la desocupación de 1,5 y de 0,4 puntos porcentuales, respectivamente (véanse el cuadro VI.10 y el gráfico VI.10). Tal resultado se deriva de una baja del nivel de desempleo, del 3,9\% al 2,4\%, y al 3,51\% en los casos ambicioso y menos ambicioso, respectivamente. La reducción del desempleo en Honduras equivale a un aumento de la ocupación de 51.000 empleos nuevos en el caso de mejoras ambiciosas en la facilitación del comercio y 15.000 en el escenario menos ambicioso.

\section{Cuadro VI.10}

Resultados de las microsimulaciones: unión aduanera entre Guatemala y Honduras (En porcentajes)

\begin{tabular}{|c|c|c|c|c|c|c|}
\hline & \multicolumn{3}{|c|}{ Honduras } & \multicolumn{3}{|c|}{ Guatemala } \\
\hline & \multirow{2}{*}{$\begin{array}{c}\text { Línea } \\
\text { de base }\end{array}$} & \multicolumn{2}{|c|}{ Escenario } & \multirow{2}{*}{$\begin{array}{c}\text { Línea } \\
\text { de base }\end{array}$} & \multicolumn{2}{|c|}{ Escenario } \\
\hline & & Ambicioso & $\begin{array}{c}\text { Menos } \\
\text { ambicioso }\end{array}$ & & Ambicioso & $\begin{array}{c}\text { Menos } \\
\text { ambicioso }\end{array}$ \\
\hline Indigencia & 45,71 & 42,87 & 44,68 & 16,89 & 15,78 & 16,42 \\
\hline Pobreza ${ }^{a}$ & 69,29 & 68,04 & 68,94 & 42,46 & 40,36 & 41,56 \\
\hline Desempleo $^{b}$ & 3,95 & 2,44 & 3,51 & 3,10 & 1,80 & 2,60 \\
\hline $\begin{array}{l}\text { Coeficiente } \\
\text { de Gini }\end{array}$ & 0,5638 & 0,5621 & 0,5629 & 0,5165 & 0,5123 & 0,5145 \\
\hline
\end{tabular}

Fuente: Elaboración propia, sobre la base de Comisión Económica para América Latina y el Caribe (CEPAL), "Posibles efectos económicos y sociales de la profundización de la unión aduanera entre Guatemala y Honduras", Documentos de Proyectos (LC/TS.2017/53), Santiago, 2017; Banco de Datos de Encuestas de Hogares (BADEHOG).

a El porcentaje de personas pobres incluye las personas bajo la línea de indigencia.

b El desempleo comprende las zonas rurales y urbanas. 
Gráfico VI.10

Unión aduanera entre Guatemala y Honduras: efectos sobre empleo, pobreza y distribución del ingreso

(En cambios porcentuales respecto de la línea de base)

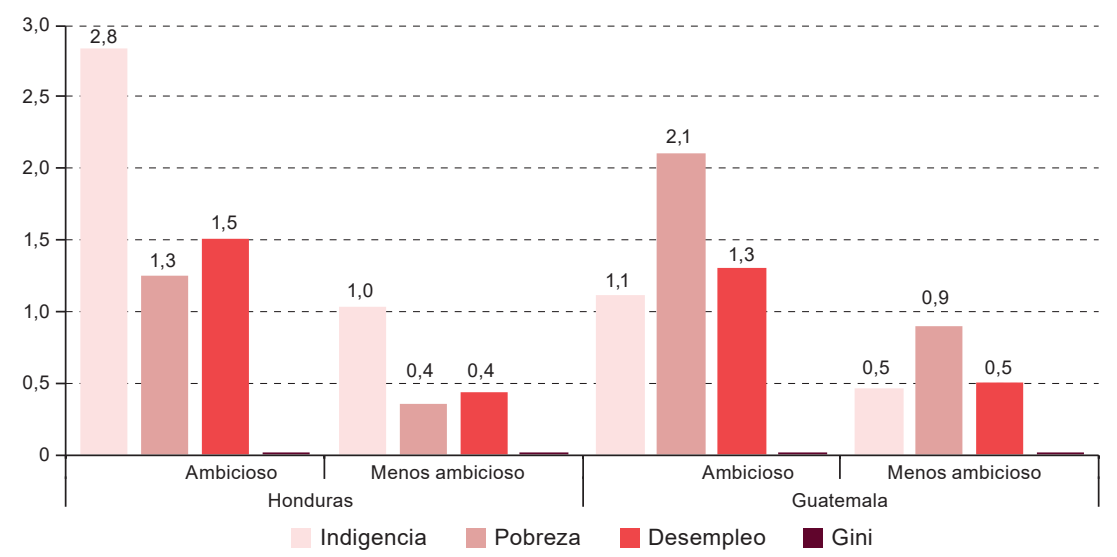

Fuente: Elaboración propia, sobre la base de Comisión Económica para América Latina y el Caribe (CEPAL), "Posibles efectos económicos y sociales de la profundización de la unión aduanera entre Guatemala y Honduras", Documentos de Proyectos (LC/TS.2017/53), Santiago, 2017.

Nota: En todos los casos, los valores indican reducción de las variables de análisis. Siempre en relación con la línea de base considerada.

En el caso de Guatemala, la reducción de la tasa de desempleo es de 1,3 puntos porcentuales en el escenario ambicioso y de 0,5 puntos porcentuales en el menos ambicioso. El nivel de desempleo pasa del 3,1\% al 1,8\% en el escenario ambicioso y al 2,6\% en uno menos ambicioso. En un escenario ambicioso de reducción de las barreras no arancelarias, Guatemala crearía cerca de 80.000 nuevos empleos. Dicha cifra se reduce hasta 30.000 si se simulan reducciones más moderadas. Dada la mayor incidencia de la mano de obra no calificada en el empleo, los sectores donde se concentran los nuevos empleos son principalmente los intensivos en mano de obra no calificada.

Los efectos sobre la pobreza y la distribución del ingreso, medidos en función de los cambios en los indicadores de pobreza e indigencia, muestran que la facilitación del comercio tendrá un efecto favorable a los pobres, al reducirse ambos indicadores en los dos escenarios. En Honduras, es mayor el descenso esperado de la indigencia, pero en el caso de Guatemala se reduce más la pobreza (véase el gráfico VI.10). Esta diferencia se explica en parte porque en Honduras hay proporcionalmente más indigentes que en Guatemala. En consecuencia, quienes aumentan su ingreso en Honduras contribuyen en mayor medida a que los hogares salgan de la indigencia que de la pobreza.

Los cambios en cuanto a desigualdad son marginales, ya que el coeficiente de Gini se mantiene prácticamente en el nivel de la línea de base. Los cambios solo son perceptibles al tercer decimal, como puede apreciarse en el gráfico VI.10 y el cuadro VI.10 precedentes. 


\section{Conclusiones}

En este capítulo se ha abordado uno de los desafíos pendientes en la investigación sobre integración económica: la determinación de los posibles efectos económicos y sociales de la aplicación de programas de facilitación del comercio como los que impulsan Honduras, Guatemala y El Salvador y a la que aspiran todos los países centroamericanos cuando pongan en marcha una unión aduanera ampliada. Con este fin, y a partir de un conjunto de indicadores de facilitación del comercio (costo de exportar e importar, tiempo requerido para exportar e importar, entre otras variables), se estimó el costo asociado a las barreras al comercio en un conjunto de ocho sectores económicos mediante la aplicación de un modelo de gravedad aumentado.

Los resultados mostraron que el comercio centroamericano en 2017 enfrentó una protección promedio (con inclusión de barreras arancelarias y no arancelarias) cercana al $20 \%$, con una importante incidencia de barreras administrativas, que serían particularmente elevadas en Nicaragua y El Salvador. A nivel bilateral, estas barreras serían muy altas en el comercio bilateral entre Guatemala y Honduras. Por sectores, los costos más elevados están en los productos agrícolas y agroindustriales, y los textiles, las confecciones y el calzado. Todo ello deriva en una retracción del comercio y en pérdidas económicas y sociales asociadas a menores flujos de comercio y al pago de precios unitarios más altos por los consumidores.

A partir de las estimaciones de equivalentes ad valorem sectoriales en el comercio bilateral, se calibró un modelo de equilibrio general computable, utilizando la base de datos del Proyecto de Análisis del Comercio Global (GTAP). Sobre esa base se realizaron algunas simulaciones que recogen los posibles cambios en la política comercial en materia de facilitación del comercio sobre las relaciones comerciales entre ambos países. Se buscaba dar respuesta a la pregunta de cuál sería el efecto probable de la aplicación de una política concertada que unificara el territorio aduanero. Se comenzó por analizar la unión aduanera entre Honduras y Guatemala, incorporando progresivamente a El Salvador y, por último, a toda la región, en una unión aduanera ampliada. El trabajo se desarrolló para observar los efectos macroeconómicos y sociales de la aplicación de un programa de facilitación aduanera.

A nivel macroeconómico, se determinó que un programa de facilitación del comercio con un nivel de ambición alto (estimado como cortes del $60 \%$ en los equivalentes ad valorem de las barreras administrativas) permitiría aumentos en el PIB de Honduras y Guatemala del $0,4 \%$ y el 0,7\%, respectivamente. Tal programa conduciría al aumento de las importaciones de bienes del 2,2\% y el $1,4 \%$ en Honduras y Guatemala, respectivamente. Se producirían aumentos de las exportaciones de bienes del 2,2\% y el 1,5\% para los mismos países. 
Un menor nivel de ambición del programa de facilitación, con una reducción de los equivalentes ad valorem de un $30 \%$, todavía traería aumentos del PIB de un $0,3 \%$ y un $0,2 \%$ en Honduras y Guatemala, respectivamente, con alzas de los flujos de comercio más acotadas, del 0,6\% y el 0,8\% en el caso de las exportaciones de Guatemala y Honduras, y del 0,4\% y el 0,8\% en el caso de las importaciones.

Según las estimaciones de bienestar calculadas para un escenario ambicioso, se obtendrían mejoras de 171 y 206 millones de dólares, equivalentes al 0,9\% y el 0,4\% del PIB en Honduras y Guatemala, respectivamente. El mayor beneficio de bienestar se verifica en una mejora de la eficiencia distributiva, así como en los términos del intercambio y el aumento del empleo de mano de obra no calificada.

La incorporación de El Salvador a la unión aduanera entre Guatemala y Honduras mostró variaciones positivas en las estimaciones para los tres países, con una variación del PIB combinado de entre un $0,3 \%$ y un $0,8 \%$ según se tratase un escenario menos o más ambicioso. De igual forma, el modelo reportó cambios positivos para el comercio, el empleo y el bienestar, incluso un tanto mayores en Guatemala y Honduras. En todos los casos las variaciones fueron mayores que en los escenarios de una unión aduanera sin El Salvador. Los sectores que reciben las mayores variaciones fueron los manufactureros, principalmente la agroindustria, la química y la petroquímica, los metales y productos derivados, las maquinarias y equipos, y otras manufacturas. Se destaca que gran parte de estos sectores son los que poseen mayor incidencia en el comercio intracentroamericano. En el escenario ambicioso, Guatemala aumenta la variación positiva en el PIB del 0,4\% al 0,6\% y Honduras, del 0,7\% al 0,9\%. Por su parte, El Salvador aumenta su PIB entre un $0,5 \%$ y un $1,2 \%$, según se trate de un programa de facilitación del comercio menos o más ambicioso.

Las simulaciones de una unión aduanera ampliada a todos los países centroamericanos resultan en una variación positiva del PIB que supera a las uniones aduaneras con menor número de socios. La inclusión de más países en el programa de facilitación del comercio, sea este moderado o ambicioso, deriva en una variación positiva del PIB de entre un $1 \%$ y un 2,4\%. La unión aduanera ampliada produciría efectos virtuosos al ampliar el territorio aduanero a todos los miembros del Mercado Común Centroamericano. Además, se advierte que los países nuevos (Costa Rica, Nicaragua y Panamá) alcanzan tasas de variación positivas y mayores que si no se adhieren a la unión aduanera. En esos escenarios, llegan a revertir tasas de crecimiento nulo o negativas.

Los resultados fiscales esperados tras la aplicación de un programa ambicioso aumentarían la recaudación fiscal de Honduras y Guatemala en 37 y 41 millones de dólares, es decir, un $0,2 \%$ y un $0,1 \%$ del PIB, respectivamente, 
en el caso de una unión aduanera bilateral. Con la ampliación de esta unión, primero a El Salvador y luego al resto de socios de Centroamérica, el efecto fiscal es mayor. Llega a totalizar un monto recaudado de entre 324 y 652 millones de dólares, según se trate de un programa menos o más ambicioso. En términos del PIB, la participación se eleva al 0,3\% en el caso de tratarse de un programa de facilitación del comercio ambicioso. Los aumentos de recaudación en el escenario de unión aduanera ampliada se producen en todos los países considerados. La recaudación impositiva estimada tras la profundización de la unión aduanera es más alta debido a los beneficios obtenidos de la expansión del territorio aduanero. Este resultado se deriva del impacto positivo sobre el flujo bilateral de comercio y desde terceros mercados. Por ende, el reforzamiento de la unión aduanera derivado de la aplicación de un programa de facilitación del comercio produce un aumento de la recaudación de los impuestos internos al expandirse la actividad económica derivada del comercio.

Las estimaciones del empleo asociado a la expansión de la ocupación en un escenario ambicioso en el caso de la unión aduanera bilateral entre Guatemala y Honduras (el único sobre el que se realizan tales cálculos) producirían un descenso de los niveles de desocupación, pobreza e indigencia. La reducción del desempleo equivale a aumentos en la ocupación en ambos países de 45.000 empleos en el escenario moderado (15.000 en Honduras y 50.000 en Guatemala), a 131.000 en un escenario ambicioso (51.000 en Honduras y 80.000 en Guatemala).

En cuanto a los efectos simulados sobre la pobreza, la indigencia y la distribución del ingreso, se verificó la existencia de un claro efecto favorable a los pobres. Este se reflejaría principalmente en una reducción de la indigencia en Honduras y de la pobreza en Guatemala. Estos resultados se explican por el bajo nivel de los salarios en ambos países, sobre todo en Honduras.

Se concluye que la unificación de los territorios aduaneros de Honduras y Guatemala impulsaría la producción y el comercio y entrañaría una mayor recaudación tributaria por el aumento de las importaciones. Los efectos esperados sobre el empleo, la pobreza y la indigencia también serían favorables, al aumentar la ocupación y reducirse el número de hogares en situación de pobreza e indigencia en ambos países. Estos resultados se amplían cada vez que los territorios aduaneros se expanden. De modo que una unión aduanera entre los tres países del Triángulo del Norte de Centroamérica resultaría de mayor beneficio en términos de producción y bienestar para todos los países miembros. De la misma forma, una expansión de dicha unión aduanera hacia todos los países centroamericanos tendría impactos positivos más amplios en beneficio de todos los miembros de dicha Unión en términos macroeconómicos, sociales y tributarios. 
Tras la puesta en marcha de la Unión Aduanera entre los tres países del Triángulo del Norte de Centroamérica, quedan como desafíos pendientes, en primera instancia, avanzar hacia la plena aplicación de la política marco regional de movilidad y logística de Centroamérica (PMRML), que incluye a toda Centroamérica. La CEPAL, que ha acompañado dicho proceso más amplio de definición de la política de logística regional, considera que los tres países pueden ser pioneros en la obtención de mayores avances en la ejecución de la PMRML, lo que preparará a estos países y sus vecinos para la plena vigencia de la Unión Aduanera en toda la subregión.

Entre los pasos concretos a seguir en esta dirección se sugiere: i) avanzar hacia el fortalecimiento institucional del tema logístico y de políticas públicas en general, a nivel nacional, a fin de apuntalar el esfuerzo subregional; ii) establecer metodologías y procedimientos comunes para el diseño, financiamiento y operación de las infraestructuras, que sean capaces de articular las distintas iniciativas nacionales en torno a la convergencia regional; iii) definir mecanismos para priorizar y financiar el costo de las infraestructuras subregionales, distribuyendo equitativamente los costos y beneficios entre los países participantes; iv) crear un fondo de cohesión contra asimetrías o fondos de inversión regionales que permitan la construcción, el mantenimiento o el mejoramiento de infraestructura económica, y v) establecer un sistema de indicadores cuantitativos, que muestre los progresos alcanzados y desafíos aún pendientes, poniendo el foco en los beneficios para la población en un contexto de desarrollo sostenible.

Finalmente, la cuantía de los beneficios de la aplicación de políticas de facilitación del comercio dependerá del grado de ambición que las autoridades de los países adherentes pongan en el impulso de los trabajos tendientes a alcanzar la libre circulación en los pasos fronterizos con facilitación del comercio, así como la culminación y el seguimiento de la convergencia normativa y el desarrollo institucional asociado al proceso. Para ello es importante que los países refuercen sus acciones, tanto a nivel individual en sus propias agendas nacionales como de manera coordinada a nivel regional, para resolver de forma prioritaria los cuellos de botella que suponen costos asociados a las barreras administrativas del comercio. 


\section{Bibliografía}

Anderson, J. y E. van Wincoop (2003), “Gravity with gravitas: a solution to the border puzzle", American Economic Review, vol. 93, N¹, Pittsburgh, Asociación Estadounidense de Economía, marzo.

APEC (Foro de Cooperación Económica de Asia y el Pacífico) (2007), APEC's Second Trade Facilitation Plan, Singapur.

(1999), "Assessing APEC trade liberalization and facilitation: 1999 update", Singapur, septiembre [en línea] https: / / www.apec.org/Publications/1999/09/ Assessing-APEC-Trade-Liberalization-and-Facilitation---1999-Update.

Aráuz, A. (2012), "ALCA y tratados de libre comercio: oportunidades y retos para la integración centroamericana", Managua, Fundación Friedrich Ebert, diciembre [en línea] http:/ / library.fes.de/pdf-files/bueros/nicaragua/01572.pdf.

Armington, P. (1969), "A theory of demand for products distinguished by place of production", Staff Papers, vol. 16, N 1, Basingstoke, Fondo Monetario Internacional (FMI)/Palgrave Macmillan.

Banco Mundial (2013), "Medidas no arancelarias en Centroamérica: incidencia económica e incrementación de precios", Washington, D.C., inédito [en línea] http://www.bancomundial.org/content/dam/Worldbank/document/LAC/ ResumenJDR.pdf.

CENPROMYPE (Centro Regional de Promoción de la MIPYME) (2017), Estrategia Regional de Articulación Productiva MIPYME, San Salvador.

CEPAL (Comisión Económica para América Latina y el Caribe) (2017), "Posibles efectos económicos y sociales de la profundización de la unión aduanera entre Guatemala y Honduras", Documentos de Proyectos (LC/TS.2017/53), Santiago, junio. (2014), Integración regional: hacia una estrategia de cadenas de valor inclusivas (LC/G.2594(SES.35/11), Santiago, mayo.

Cheewatrakoolpong, K. y D. Ariyasajjakorn (2012), "The quantitative assessment of trade facilitation benefits in the ASEAN+6", presentación realizada en la Octava Conferencia Anual de la Asociación Económica de Asia y el Pacífico (APEA), Singapur, 28 y 29 de junio.

COMEX (Ministerio de Comercio Exterior) (2010), “Tratado de Libre Comercio Costa Rica-China: documento explicativo", San José, marzo [en línea] http:/ / www.comex.go.cr/media/2676/doc_explicativo_china.pdf.

COMIECO (Consejo de Ministros de Integración Económica) (2015), “Acuerdo No 01-2015 (COMIECO LXXIII)", San Salvador, octubre [en línea] https:/ / sde.gob. hn/wp-content/uploads/2017/08/Acuerdo-No.-01-2015-COMIECO-LXXIII.pdf.

Cordero, M. (2017), Integración económica centroamericana: base de datos 2016 (LC/MEX/ TS.2017/24), Ciudad de México, Comisión Económica para América Latina y el Caribe (CEPAL), septiembre.

Dennis, A. y B. Shepherd (2011), "Trade facilitation and export diversification", The World Economy, vol. 34, N 1, Hoboken, Wiley, enero.

Djankov, S., C. Freund y C. Pham (2010), "Trading on Time", Review of Economics and Statistics, vol. 92, $\mathrm{N}^{\circ}$ 1, Cambridge, The MIT Press, febrero.

Durán, J. (2015), “Evaluación de los efectos de la aplicación de un programa centroamericano de facilitación del comercio", Santiago, Comisión Económica para América Latina y el Caribe (CEPAL), mayo, inédito. 
Durán, J. y A. Lo Turco (2010), “El comercio intrarregional en América Latina: patrón de especialización y cálculo de potencial exportador", Los impactos de la crisis internacional en América Latina: ¿hay margen para el diseño de políticas regionales?, M. Terra y J. Durán (coords.), Montevideo, Red MERCOSUR de Investigaciones Económicas.

Durán, J. y D. Zaclicever (2013), “América Latina y el Caribe en las cadenas internacionales de valor", serie Comercio Internacional, № 124 (LC/L.3767), Santiago, Comisión Económica para América Latina y el Caribe (CEPAL), diciembre.

Fontagné, L. y S. Zignago (2007), "A re-evaluation of the impact of regional agreements on trade patterns", Economie Internationale, N 109, París, Cairn.

Foro Económico Mundial (2013), Enabling Trade: Valuing Growth Opportunities, Ginebra.

Fox, A., J. Francois y P. Londoño-Kent (2003), "Measuring border crossing costs and their impact on trade flows: the United States-Mexican trucking case", West Lafayette, Purdue University [en línea] https:/ / www.gtap.agecon.purdue.edu/ resources/download/1492.pdf.

Francois, J., H. van Meil y F. van Tongeren (2003), "Economic Benefits of the Doha Round for The Netherlands", Project Report, La Haya, Agricultural Economics Research Institute, enero.

Fujita, M., P. Krugman y A. Venables (2001), The Spatial Economy: Cities, Regions, and International Trade, Cambridge, The MIT Press.

Hertel, T., T. Walmsley y K. Itakura (2001), "Dynamic effects of the "new age" free trade agreement between Japan and Singapore", Journal of Economic Integration, vol. 16, N 4, Seúl, Sejong University.

Hummels, D. y G. Schaur (2013), "Time as trade barrier", American Economic Review, vol. 103, N 7, Pittsburgh, Asociación Estadounidense de Economía, diciembre.

Ivanic, M., C. Mann y J. Wilson (2006), “Aid-for-trade facilitation: global welfare gains and developing countries", París, Organización de Cooperación y Desarrollo Económicos (OCDE), inédito.

Kelleher, S. y J. Reyes (2014), "Technical measures to trade in Central America: incidence, price effects, and consumer welfare", Policy Research Working Paper, $\mathrm{N}^{\circ}$ 6857, Washington, D.C., Banco Mundial, mayo.

Limão, N. y A. Venables (1999), "Infrastructure, geographical disadvantage, and transport costs", Policy Research Working Paper, N 2257, Washington, D.C., Banco Mundial, diciembre.

Minor, P. y M. Tsigas (2008), "Impacts of better trade facilitation in developing countries: analysis with a new GTAP database for the value of time in trade", GTAP Resource, N²762, West Lafayette, Purdue University.

Mirza, T. (2009), "A cost-benefit analysis of trade facilitation in an applied general equilibrium model", Working Paper, West Lafayette, Purdue University, inédito. (2007), "Estimating the impact of trade facilitation on global trade flows", GTAP Resource, No. 2401, West Lafayette, Purdue University.

Moïsé, E. y S. Sorescu (2013), “Trade facilitation indicators: the potential impact of trade facilitation on developing countries' trade", OECD Trade Policy Paper, $\mathrm{N}^{\circ} 144$, París, Organización de Cooperación y Desarrollo Económicos (OCDE), marzo.

OCDE (Organización de Cooperación y Desarrollo Económicos) (2003), "The Doha Development Agenda: welfare gains from further multilateral trade liberalisation with respect to tariffs", París, junio [en línea] http://www.oecd. org/officialdocuments / publicdisplaydocumentpdf/?doclanguage=en\&cote= td/tc/wp(2003)10/final. 
OMC (Organización Mundial del Comercio) (2015), Informe sobre el Comercio Mundial 2015, Ginebra.

Portugal-Pérez, A. y J. Wilson (2009), "Why trade facilitation matters to Africa", World Trade Review, vol. 8, №3, Cambridge, Cambridge University Press.

Saslavsky, D. y B. Shepherd (2012), "Facilitating international production networks: the role of trade logistics", Policy Research Working Paper, Nº 6224, Washington, D.C., Banco Mundial, octubre.

Schuschny, A., J. Durán y C. de Miguel (2007), “El modelo GTAP y las preferencias arancelarias en América Latina y el Caribe: reconciliando su año base con la evaluación reciente de la agenda de liberalización regional", serie Manuales, N 54 (LC/L.2679-P), Santiago, Comisión Económica para América Latina y el Caribe (CEPAL), febrero.

SIECA (Secretaría de Integración Económica Centroamericana) (2019), “Identificación de necesidades para el funcionamiento y perfeccionamiento de la Unión Aduanera del Triángulo Norte" [en línea] https://www.cepal.org/sites/default/files / events/files/presentacion_sieca_0.pdf.

(2015), Hoja de ruta para avanzar en la Unión Aduanera 2015-2024, Ciudad de Guatemala, junio [en línea] https://www.sieca.int/index.php/integracioneconomica/integracion-economica/hoja-de-ruta-union-aduanera-2015-2024/.

Soloaga, I., J. Wilson y A. Mejía (2006), "Moving forward faster: trade facilitation reform and Mexican competitiveness", Policy Research Working Paper, N 3953, Washington, D.C., Banco Mundial, junio.

Traca, D. y P. Dutt (2010), "Corruption and bilateral trade flows: extortion or evasion?", The Review of Economics and Statistics, vol. 92, N 4, Cambridge, The MIT Press.

Walkenhorst, P. y T. Yasui (2009), "Quantitative assessment of the benefits of trade facilitation", Overcoming Border Bottlenecks: The Costs and Benefits of Trade Facilitation, París, Organización de Cooperación y Desarrollo Económicos (OCDE), enero.

Wilson, J., C. Mann y T. Otsuki (2005), "Assessing the benefits of trade facilitation: a global perspective", The World Economy, vol. 28, N 6, Hoboken, Wiley-Blackwell. (2004), "Assessing the potential benefit of trade facilitation: a global perspective", Policy Research Working Paper, N 3224, Washington, D.C., Banco Mundial, febrero. (2003), "Trade facilitation and economic development: measuring the impact", Policy Research Working Paper, N²988, Washington, D.C., Banco Mundial, marzo.

Zaki, C., (2015), "How does trade facilitation affect international trade?", European Journal of Development Research, vol. 27, N 1, Berlín, Springer, enero.

(2014), "An empirical assessment of the trade facilitation initiative: econometric evidence and global economic effects", World Trade Review, vol. 13, $\mathrm{N}^{\circ} 1$, Cambridge, Cambridge University Press, enero.

(2010a), "Does trade facilitation matter in bilateral trade?", París, Paris School of Economics, julio [en línea] https: / / www.parisschoolofeconomics.eu/IMG/ pdf/JobMarket-1paper-ZAKI-PSE.pdf.

(2010b), "Towards an explicit modeling of trade facilitation in CGE models: evidence from Egypt", Working Paper, N 515, El Cairo, Economic Research Forum (WEF), abril. 


\section{Anexo VI.A1}

Cuadro VI.A1.1

Principales grupos de productos considerados en el modelo de equilibrio general computable empleado

\begin{tabular}{|c|c|c|}
\hline Número & Sectores individuales & Grandes grupos de productos \\
\hline 1 & Arroz & Agricultura, caza y pesca \\
\hline 2 & Trigo & \\
\hline 3 & Otros cereales & \\
\hline 4 & Frutas y vegetales & \\
\hline 5 & Oleaginosas & \\
\hline 6 & Fibras vegetales & \\
\hline 7 & Otros cultivos & \\
\hline 8 & Ganadería & \\
\hline 9 & Forestal & \\
\hline 10 & Pesca & \\
\hline 11 & Petróleo crudo, gas y carbón & Petróleo y minería \\
\hline 12 & Minería no energética & \\
\hline 13 & Carne & Alimentos, bebidas y tabaco \\
\hline 14 & Lácteos & \\
\hline 15 & Aceites vegetales & \\
\hline 16 & Azúcar & \\
\hline 17 & Otros alimentos & \\
\hline 18 & Bebidas y tabacos & \\
\hline 19 & Textiles & Textiles, confecciones y calzado \\
\hline 20 & Confecciones & \\
\hline 21 & Cuero y calzado & \\
\hline 22 & Petróleo y derivados & Química y petroquímica \\
\hline 23 & Productos químicos & \\
\hline 24 & Hierro y acero & Metales y productos derivados \\
\hline 25 & Productos de metal & \\
\hline 26 & Vehículos & Maquinaria y equipo \\
\hline 27 & Equipos de transporte & \\
\hline 28 & Equipo eléctrico & \\
\hline 29 & Maquinarias y equipo & \\
\hline 30 & Productos de papel & Otras manufacturas \\
\hline 31 & Productos de madera & \\
\hline 32 & Minerales no metálicos & \\
\hline 33 & Otras manufacturas & \\
\hline 34 & Servicios & Servicios \\
\hline
\end{tabular}

Fuente: Elaboración propia, sobre la base del modelo y base de equilibrio general del Proyecto de Análisis del Comercio Global (GTAP), versión 9. 


\section{Cuadro VI.A1.2 \\ Países y regiones que conforman el modelo de equilibrio general computable empleado}

\begin{tabular}{|c|c|c|}
\hline Número & Regiones o países individuales & $\begin{array}{l}\text { Agrupaciones subregionales } \\
\text { o países }\end{array}$ \\
\hline 1 & Costa Rica & \multirow[t]{6}{*}{ Mercado Común Centroamericano } \\
\hline 2 & El Salvador & \\
\hline 3 & Guatemala & \\
\hline 4 & Honduras & \\
\hline 5 & Nicaragua & \\
\hline 6 & Panamá & \\
\hline 7 & Argentina & \multirow{5}{*}{$\begin{array}{l}\text { Mercado Común } \\
\text { del Sur (MERCOSUR) }\end{array}$} \\
\hline 8 & Brasil & \\
\hline 9 & Paraguay & \\
\hline 10 & Uruguay & \\
\hline 11 & Venezuela (República Bolivariana de) & \\
\hline 12 & Chile & Chile \\
\hline 13 & Bolivia (Estado Plurinacional de) & \multirow[t]{4}{*}{ Comunidad Andina } \\
\hline 14 & Colombia & \\
\hline 15 & Ecuador & \\
\hline 16 & Perú & \\
\hline 17 & República Dominicana & \multirow[t]{4}{*}{ Países del Caribe } \\
\hline 18 & Jamaica & \\
\hline 19 & Trinidad y Tabago & \\
\hline 20 & Resto del Caribe & \\
\hline 21 & México & \multirow{3}{*}{$\begin{array}{l}\text { Tratado de Libre Comercio } \\
\text { de América del Norte }\end{array}$} \\
\hline 22 & Canadá & \\
\hline 23 & Estados Unidos & \\
\hline 24 & Unión Europea & \\
\hline 25 & Japón & \multirow[t]{7}{*}{ Asia y el Pacífico } \\
\hline 26 & China & \\
\hline 27 & Australia & \\
\hline 28 & Nueva Zelanda & \\
\hline 29 & República de Corea & \\
\hline 30 & Asociación de Naciones del Asia Sudoriental (ASEAN) & \\
\hline 31 & Otros, Asia y el Pacífico & \\
\hline 32 & Oriente Medio y Norte de África & \multirow[t]{2}{*}{ Oriente Medio y África } \\
\hline 33 & África Subsahariana & \\
\hline 34 & Resto del mundo & Resto del mundo \\
\hline
\end{tabular}

Fuente: Elaboración propia, sobre la base del modelo y base de equilibrio general del Proyecto de Análisis del Comercio Global (GTAP), versión 9. 


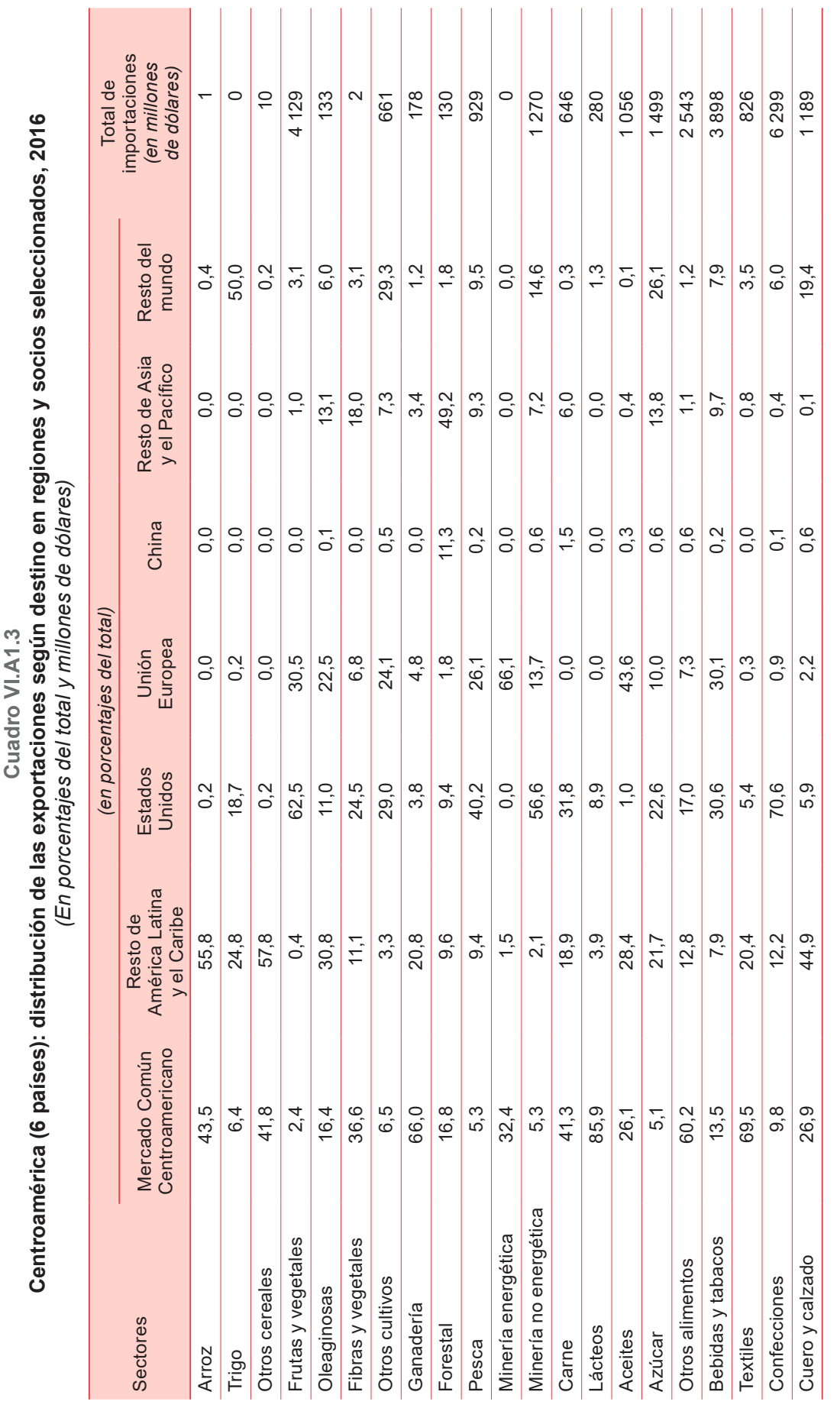




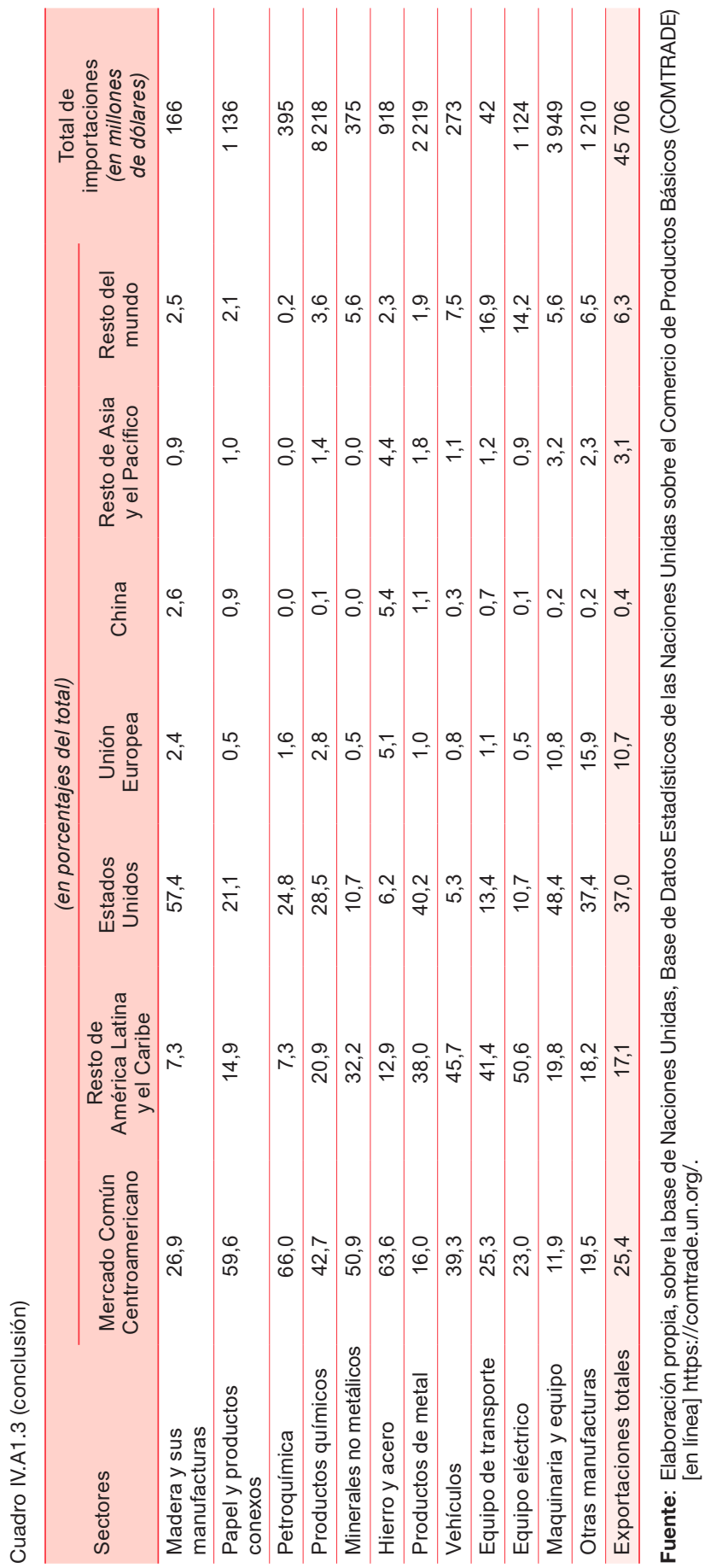




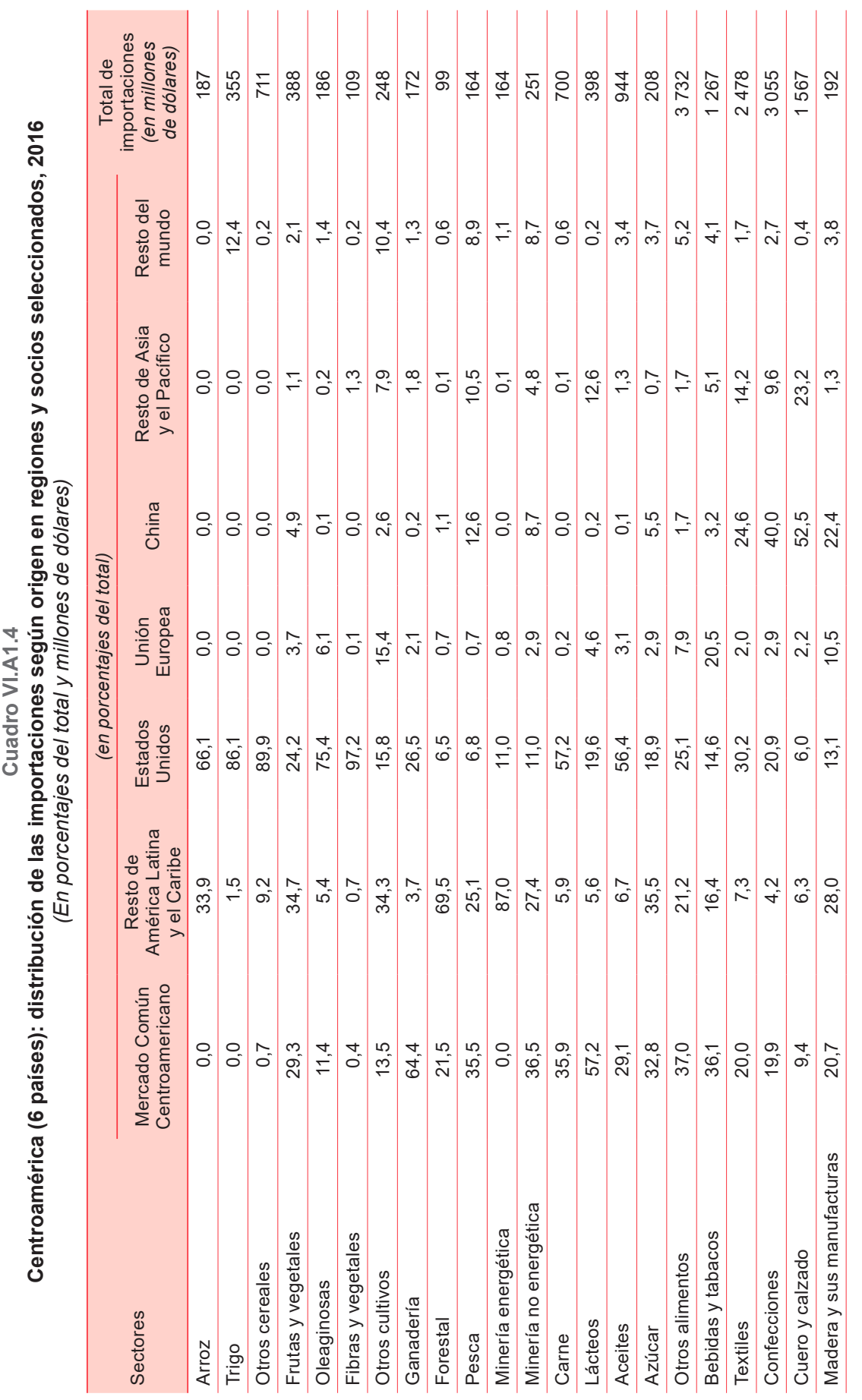




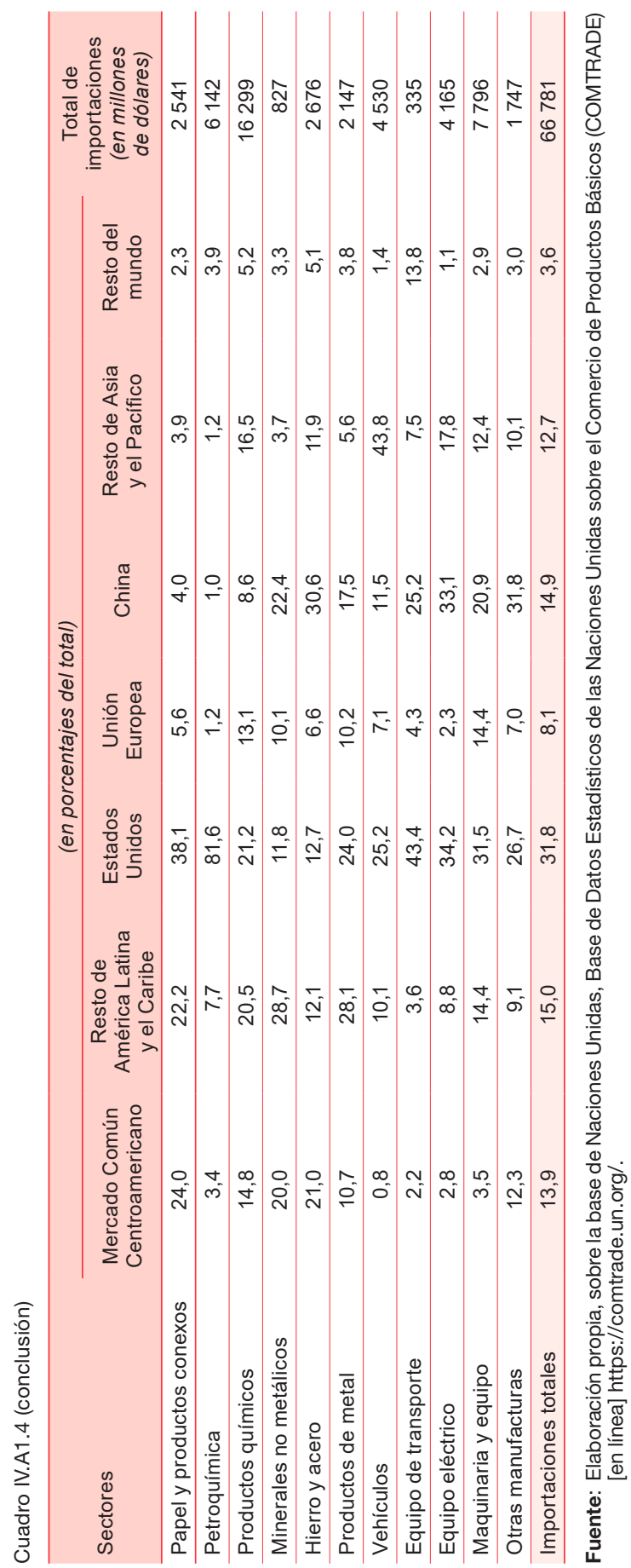




\title{
La coordinación fiscal como primer paso para el logro de la integración fiscal en Centroamérica
}

\author{
María Concepción Castro Mazariegos \\ Juan Carlos Rivas Valdivia
}

\section{Introducción}

La integración centroamericana ${ }^{1}$ es la más dinámica de América Latina en cuanto al intercambio comercial. Sin embargo, la coordinación en materia fiscal es aún incipiente. La potenciación de la integración como mecanismo de desarrollo pasa por articular mejor los aspectos logísticos relacionados con la tributación (principalmente aduaneros), pero también por el establecimiento de reglas a fin de evitar la evasión y elusión tributaria internacional (manipulación de precios de transferencia, utilización de paraísos fiscales y utilización de la heterogeneidad de incentivos).

El objetivo del capítulo es ofrecer un panorama general de la evolución de la integración centroamericana en materia fiscal. A esos efectos, se describe brevemente su situación fiscal, las implicaciones fiscales de la integración

A los efectos de este capítulo, al hablar de Centroamérica se hace referencia a los seis países del istmo centroamericano que se adhirieron a la iniciativa integracionista durante la segunda mitad del siglo XX (de norte a sur: Guatemala, El Salvador, Honduras, Nicaragua, Costa Rica y Panamá) y a la República Dominicana, salvo que se indique otra cosa. 
comercial, la institucionalidad fiscal de la integración centroamericana y algunos desafíos que esta plantea en materia fiscal, todo desde una visión crítica y de acompañamiento de la CEPAL.

Durante la última década, una de las características de los países centroamericanos es el logro de pequeños déficits del gobierno central, gracias a una política fiscal ortodoxa que percibe la estabilidad como objetivo primario. Sin embargo, el principal reto en materia fiscal de estos países sigue siendo la necesidad de aumentar la capacidad de recaudación tributaria y de eficiencia en el uso de los recursos públicos, a fin de superar los retos del desarrollo y el crecimiento económico.

Las primeras acciones encaminadas hacia la coordinación fiscal se iniciaron en 1966 con la aprobación de la resolución núm. 138, del Comité de Cooperación Económica del Istmo Centroamericano, de 27 de enero de 1966. Con dicha resolución se perseguía el objetivo de iniciar cuanto antes la armonización gradual de los sistemas fiscales de los países miembros, para lo cual se recomendó crear una comisión de asuntos fiscales. Sin embargo, este paso vital hacia la integración centroamericana no se concretó (véase el diagrama VII.1).

Más recientemente, en 2006, se creó el Consejo de Ministros de Hacienda o Finanzas de Centroamérica, Panamá y la República Dominicana (COSEFIN), a partir de la visión clave de que la coordinación de la política fiscal y la progresiva armonización tributaria entre los países de la región son indispensables para avanzar en la integración centroamericana. Desde entonces, el Consejo ha ido avanzando en la consolidación de su institucionalidad y, en 2017, aprobó una Matriz de Interés Fiscal (MIF), que establece las áreas prioritarias de trabajo. La Secretaría ha realizado un llamado a diferentes cooperantes (incluida la CEPAL) para que apoyen la concreción de áreas de trabajo de la Matriz. A partir de esta, los Ministros establecieron un modelo de articulación técnica (delegados) diferente para llevar a cabo los trabajos regionales. Se creó el Grupo de Trabajo de Política Fiscal (GTPF) y se le asignó un rol técnico asesor entre las labores regionales y su incidencia en el ámbito nacional, así como una función coordinadora ante los diferentes grupos especializados.

El camino hacia el logro de una plena integración fiscal y comercial también implica la superación de desafíos relacionados con los Objetivos de Desarrollo Sostenible (ODS). Uno de los principales problemas de Centroamérica es la desigualdad (contemplada en el ODS 10), por lo que es importante que tanto el aspecto comercial como el fiscal del proceso de integración sean medios para reducir las desigualdades de la región. En este sentido, la CEPAL desempeña un papel sustancial al ejercer una labor de acompañamiento intelectual y apoyo técnico a los diferentes gobiernos en materia de políticas para alcanzar los objetivos de la Agenda 2030. 


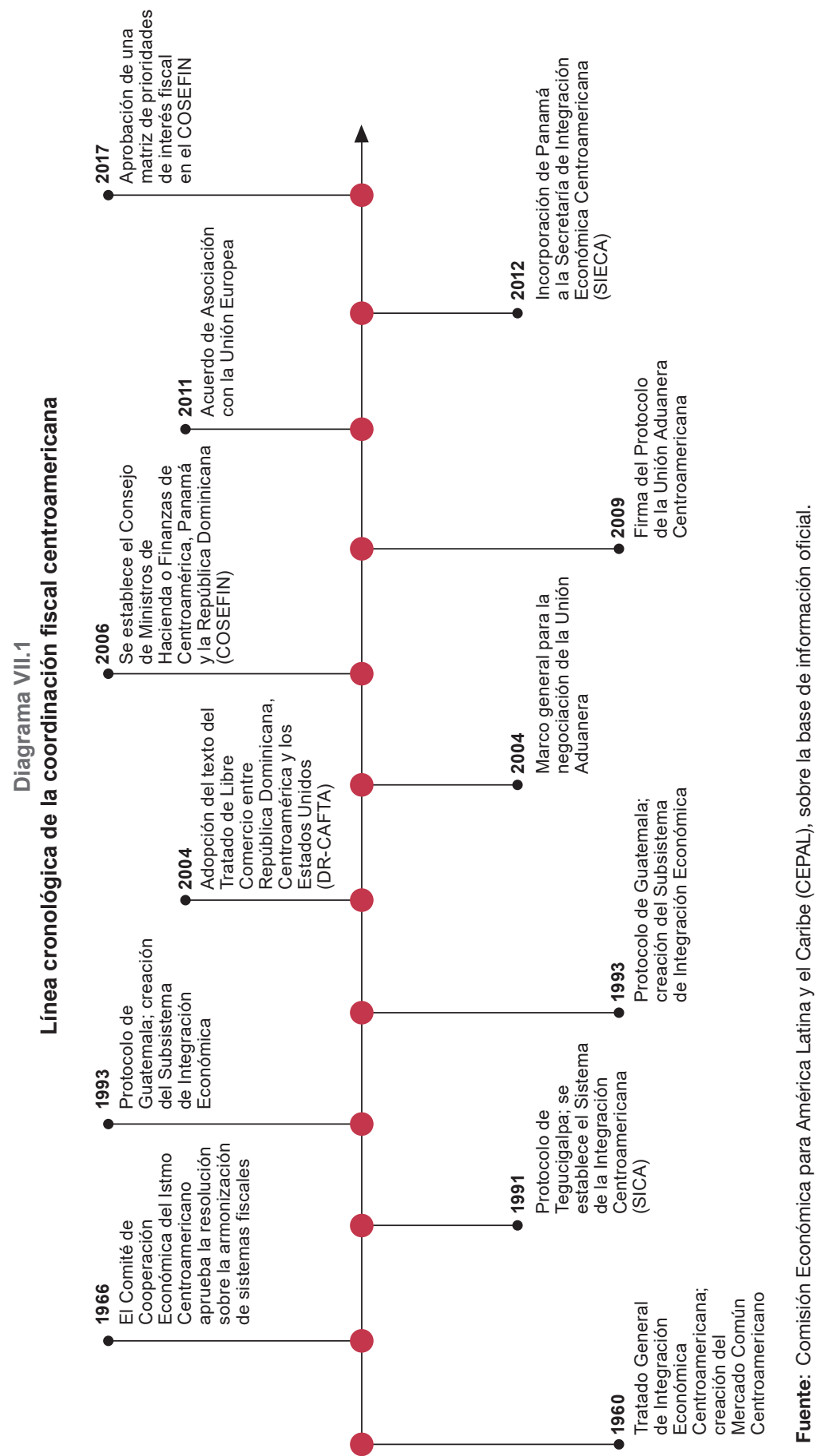




\section{A. Situación fiscal de Centroamérica ${ }^{2}$}

El desempeño fiscal de Centroamérica se ha caracterizado en los últimos diez años por déficits del gobierno central relativamente bajos. Esto se debe a una política fiscal ortodoxa que percibe la estabilidad como objetivo primario. En consecuencia, en el período referido, el déficit fiscal promedio del gobierno central nunca ha sido superior al 3\% del producto interno bruto (PIB).

La mayoría de los países de la región han sabido moderar sus gastos y han puesto en marcha reformas fiscales con miras a incrementar los ingresos públicos de manera recurrente. En ese sentido, como punto de referencia, se observó que en 2017 los niveles medios de los gastos e ingresos públicos totales, como porcentaje del PIB, fueron similares a los registrados al cierre de 2016. El déficit fiscal de la región alcanzó un 2,5\% del PIB (2,6\% en 2016). Este resultado se debe en parte a un alza de los pagos de intereses (de un 2,0\% del PIB en 2016 a un 2,2\% del PIB en 2017), evolución que dificultó los esfuerzos por contener las erogaciones públicas. Cabe destacar que el déficit fiscal registrado en los países de la región se comparó favorablemente con el déficit fiscal promedio de todos los países de América Latina y el Caribe, que se ubicó en un 2,8\% del PIB.

En 2017, tres de las siete economías de la región (El Salvador, Panamá y Honduras) lograron una reducción del déficit fiscal de los gobiernos centrales en comparación con 2016. El resto mostró un leve deterioro. El Salvador, Nicaragua y Guatemala registraron los menores déficits, equivalentes al $0,1 \%$, el $0,6 \%$ y el 1,3\% del PIB, respectivamente. Por su parte, Costa Rica y la República Dominicana alcanzaron los mayores balances negativos, con un $6,2 \%$ y un $4,0 \%$ del PIB, respectivamente (véase el gráfico VII.1).

En cuanto al resultado fiscal primario, en el que no se considera el pago de intereses de la deuda, el déficit fiscal de los países de la región en 2017 fue de un $0,1 \%$ del PIB. Con ello se habría alcanzado el equilibrio por segundo año consecutivo, ya que en 2016 el déficit fiscal llegó al 0,0\% del PIB. Este resultado fue similar al promedio observado en 2017 en América Latina y el Caribe (también del 0,0\% del PIB).

Los ingresos totales del gobierno central, en promedio en los países de la región, aumentaron levemente de un 15,8\% del PIB en 2016 a un 16,1\% del PIB en 2017, mientras que los gastos totales lo hicieron de un $18,2 \%$ a un 18,4\% del PIB (véase el gráfico VII.2). Los factores centrales que explican este desempeño fueron un aumento de los ingresos tributarios y la contención del crecimiento del gasto, sobre todo mediante la reducción de la inversión pública. Además, se registró un alza en los pagos de intereses (de un 2,0\% del PIB en 2016 a un 2,2\% en 2017), evolución que dificultó los esfuerzos por contener las erogaciones públicas.

2 Gran parte de la información de este apartado es una actualización del estudio "Centroamérica y la República Dominicana: evolución económica en 2017 y perspectivas para 2018” (CEPAL, 2018). 


\section{Gráfico VII.1}

Centroamérica: balance fiscal del gobierno central, 2016-2017

(En porcentajes del PIB)

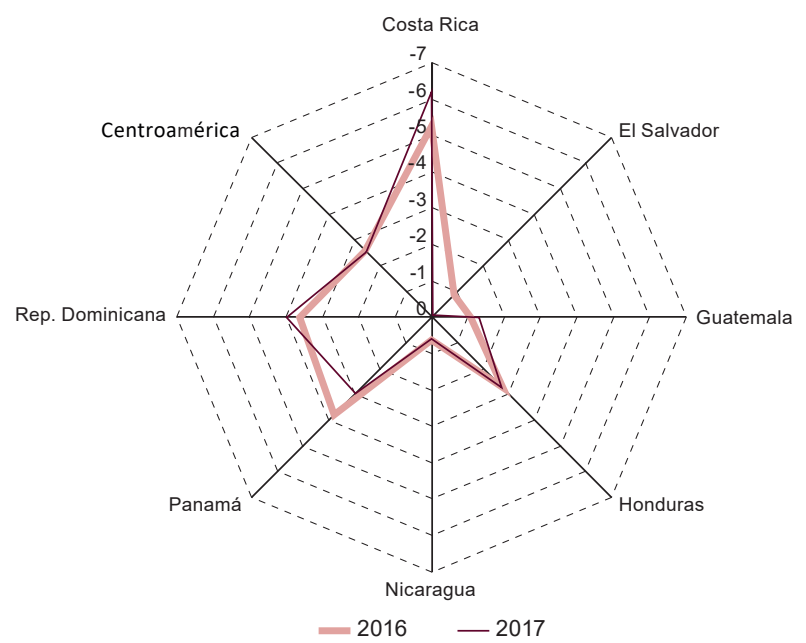

Fuente: Comisión Económica para América Latina y el Caribe (CEPAL), sobre la base de cifras oficiales.

\section{Gráfico VII.2}

Centroamérica: ingresos y gastos totales del gobierno central, 2010-2017 (En porcentajes del PIB)

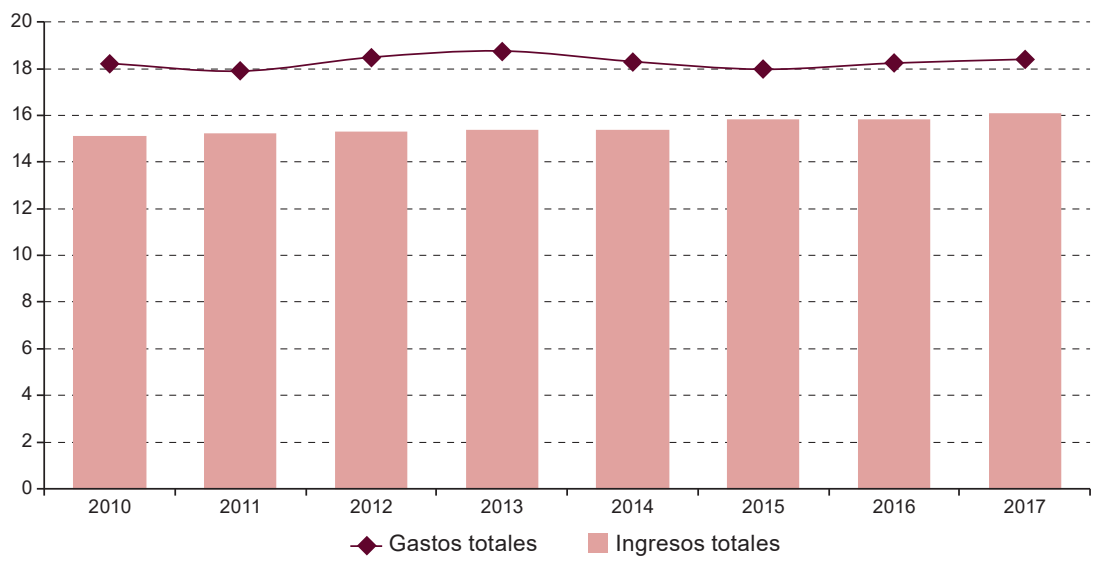

Fuente: Comisión Económica para América Latina y el Caribe (CEPAL), sobre la base de cifras oficiales.

El saldo total de la deuda del sector público no financiero de los países de la región se situó en un equivalente al 42,6\% del PIB en 2017 (42,3\% en 2016). El resultado global tuvo una evolución dispar de un país a otro. Costa Rica y Honduras registraron los mayores aumentos de su cociente 
de deuda pública como porcentaje del PIB, al pasar el primer país de un 62,5\% al cierre de 2016 a un $64,6 \%$ al término de 2017, y el segundo, de un $41,2 \%$ a un $43,5 \%$ en el mismo período.

Otros cuatro países que exhibieron aumentos en su cociente de deuda, aunque más moderados que los dos anteriores, fueron la República Dominicana, Nicaragua, El Salvador y Panamá. En la República Dominicana, la relación de deuda a PIB aumentó del 37,0\% al término de 2016 al 38,6\% a fines de 2017. En el caso de Nicaragua, la relación se expandió del 45,0\% a fines de 2016 al 46,3\% al cierre de 2017. En El Salvador, país que exhibe el mayor nivel de endeudamiento de los países de la región, el incremento de la razón de deuda a PIB fue más moderado, de un 73,2\% en diciembre de 2016 a un $74,1 \%$ a finales del año siguiente. En el caso de Panamá, se aprecia una ligera expansión de su relación de deuda a PIB, al pasar de un 37,4\% al cierre de 2016 a un 37,8\% al finalizar 2017. Por último, Guatemala, que tiene la menor relación de deuda sobre PIB, fue el único país que redujo dicha proporción en el transcurso de 2017, al pasar de un 24,3\% en diciembre de 2016 a un 22,4\% un año después.

Desde una perspectiva de más largo plazo, durante el último decenio los países de la región han registrado un incremento de su relación de deuda a PIB de 9 puntos porcentuales. Sobresalen en este sentido Costa Rica y El Salvador, que no solo han registrado grandes aumentos de sus niveles de deuda, sino que además han sobrepasado el umbral del $60 \%$ de su relación de deuda a PIB, muy por encima de los restantes países de la región.

El acceso al endeudamiento externo seguirá siendo un tema complejo en los próximos años, debido a los factores que se enumeran a continuación. En primer lugar, cabe mencionar la tendencia al aumento de las tasas de interés en los mercados internacionales, sobre todo en los Estados Unidos. En segundo lugar, a pesar de una menor volatilidad, se mantiene la incertidumbre en los mercados internacionales. Será más difícil el acceso al crédito, sobre todo en el caso de los países que no llegan al grado de inversión, como sucede por lo general en la región. En tercer lugar, vistos en su conjunto, estos países no han logrado poner en marcha reformas fiscales significativas ni coordinadas que conduzcan a un aumento sustancial de sus ingresos, lo que supone una presión desde el punto de vista del endeudamiento.

De acuerdo con Fuentes (2006, pág. 5), "el limitado gasto público, condicionado por los reducidos recursos tributarios, y por diversos choques externos, ha tenido un carácter procíclico, y se lo ha ajustado por el lado de la inversión. Otro rasgo del gasto público es la rigidez resultante de disposiciones legales, que en algunos países se suma al abultado pago de remuneraciones y al constante incremento de la deuda pública".

Dado el desempeño económico de los países de la región en los últimos diez años, existen riesgos latentes en materia de política fiscal. Prevalece una 
alta volatilidad en los precios internacionales de los derivados del petróleo, lo que en un futuro puede conducir a una mayor presión sobre las cuentas públicas vinculadas a los subsidios de la energía, debido a la gran dependencia de los combustibles fósiles en la mayor parte de la región. Además, existe escaso margen de acción para aplicar medidas contracíclicas. Asimismo, hay un gran trabajo pendiente en materia de reducción de la evasión y elusión fiscal en la mayoría de los países. Si estas situaciones no se atienden, se torna más vulnerable la viabilidad de las cuentas fiscales a mediano y largo plazo. En este contexto, el reto principal en materia fiscal sigue siendo el desarrollo de una mayor capacidad de recaudación tributaria y de eficiencia en el uso de los recursos públicos.

Mediante la coordinación de políticas fiscales regionales se podrían establecer mecanismos que sirvan como estabilizadores automáticos de las presiones internas y externas que se ejercen sobre los sistemas impositivos. Es decir, mecanismos que, en situaciones de tensión económica, como crisis o choques externos, puedan utilizarse de forma conjunta. Entre otros, podrían consistir en el establecimiento de fondos regionales contracíclicos, la participación como bloque en negociaciones con organismos financieros internacionales, el fortalecimiento de la institucionalidad fiscalizadora de las administraciones tributarias en materia de tributación internacional (con el fin de perseguir delitos fiscales a nivel regional) y la transferencia de conocimientos para modernizar las administraciones tributarias.

\section{B. La integración comercial como determinante de la integración fiscal}

De acuerdo con Fuentes (2006, pág. 7):

Los cambios de la política fiscal en los últimos 15 años en el Istmo Centroamericano [Costa Rica, El Salvador, Guatemala, Honduras, Nicaragua y Panamá] están marcados por una estrategia de desarrollo dirigida a promover una creciente inserción de estas economías en la economía mundial. Esta estrategia le ha planteado a la política fiscal un dilema. Por una parte, se ha debilitado la generación de recursos tributarios por la vía de la reducción de aranceles y el incremento de exenciones y exoneraciones para atraer inversiones extranjeras $\mathrm{y}$, por otra, se requiere aumentar los recursos públicos disponibles para favorecer el desarrollo de una mayor competitividad con equidad social, al tiempo que se garantice la estabilidad económica y se enfrenten con éxito los shocks externos. El resultado de esta tensión ha sido una carga tributaria que ha crecido, pero de manera insuficiente, mientras que los desafíos resultantes de una cambiante inserción en la economía mundial se han incrementado sin que se disponga de los recursos idóneos para enfrentarlos. 
Los datos indican que la evolución de la integración centroamericana en materia fiscal ha sido impulsada por la necesidad de acuerdos en el ámbito comercial. Sin embargo, cabe preguntarse si en realidad las acciones puestas en marcha hasta hoy por los países de Centroamérica han promovido verdaderamente una agenda de integración fiscal o si solamente se ha buscado esa coordinación para facilitar las transacciones comerciales.

Este capítulo aporta una perspectiva crítica sobre el proceso de integración fiscal centroamericana a partir del recuento y análisis de las implicaciones fiscales de diversos acuerdos y tratados comerciales. En primer lugar, habría que referirse al Área de Libre Comercio de las Américas (ALCA) que, si bien no se concretó, despejó importantes incógnitas y dio lugar a la realización de estudios que siguen siendo referentes. En segundo lugar, se aborda el Tratado de Libre Comercio entre República Dominicana, Centroamérica y los Estados Unidos (DR-CAFTA). En tercer lugar, se examina la construcción de la Unión Aduanera Centroamericana. Por último, se analizan el Acuerdo de Asociación con la Unión Europea y el Tratado de Libre Comercio Único entre Centroamérica y México. La CEPAL acompañó a los países de Centroamérica en la elaboración de estudios sobre el impacto fiscal de dichos acuerdos a corto y largo plazo. Parte de los resultados y las propuestas presentadas fueron esenciales en los procesos de negociación y puesta en marcha de los acuerdos. El análisis de esas negociaciones pone de relieve de forma muy clara la predominancia de los temas comerciales sobre los fiscales en cada acuerdo.

\section{Acompañamiento de la CEPAL y análisis de las implicaciones fiscales de algunos de los acuerdos comerciales de Centroamérica con otros países}

Las reformas económicas emprendidas desde mediados de los años ochenta en los países en desarrollo, sobre todo en América Latina, cambiaron el entorno en que se desenvolvían los procesos económicos. En el ámbito comercial proliferaron procesos de apertura unilaterales, bilaterales y multilaterales, al mismo tiempo que se fortalecieron los procesos de integración regional. Los países se abocaron directa o indirectamente a promover un modelo de desarrollo liderado por las exportaciones.

Antes de la década de 1980, las finanzas públicas de la mayoría de las economías en desarrollo dependían de los impuestos al comercio exterior. Sin embargo, los procesos de apertura de los últimos 30 años erosionaron esta fuente de ingresos fiscales. La erosión de los ingresos fiscales a inicios de los años noventa, que en principio se explicaba por las aperturas unilaterales, ahora se explica por reducciones arancelarias acordadas en los tratados de libre comercio. De este modo, a comienzos del nuevo siglo, los países de Centroamérica enfrentaron varios procesos de apertura de manera 
simultánea. Por una parte, se seguían realizando esfuerzos orientados a la integración centroamericana mediante las negociaciones de la Unión Aduanera Centroamericana. Por otra, se sumaron las negociaciones del Área de Libre Comercio de las Américas (que no pudo concretarse), del DR-CAFTA (que entró en vigor en 2006) y del Tratado de Libre Comercio entre México y la Unión Europea (TLCUE), entre otros.

Todos los procesos de negociación comercial mencionados dieron lugar a reducciones de la base recaudatoria, lo que incidió en los ingresos tributarios, en los resultados fiscales en términos macroeconómicos y en la capacidad del Estado de cumplir sus funciones de manera satisfactoria. Esta situación hizo que los países de Centroamérica solicitaran el apoyo de la CEPAL con el objetivo de evaluar la magnitud del impacto fiscal de estos procesos de liberalización comercial, a fin de poder reaccionar con tiempo y preparar medidas que compensaran los efectos fiscales adversos. A tal efecto, la CEPAL realizó varios estudios mediante los que se estimó el impacto fiscal del ALCA y el DR-CAFTA en los países de la región. Los resultados de esos estudios estuvieron muy cercanos a la realidad experimentada. La CEPAL también llevó a cabo una labor de acompañamiento en lo referente a los acuerdos comerciales con la Unión Europea (UE) y la construcción de la unión aduanera, y estuvo atenta a las negociaciones del Tratado de Libre Comercio entre Centroamérica y México.

\section{2. Área de Libre Comercio de las Américas}

En la Primera Cumbre de las Américas, celebrada en Miami (Estados Unidos) en diciembre de 1994, se acordó establecer un área de libre comercio en las Américas, a fin de crear un espacio continental de libre comercio antes de 2005. De acuerdo con CEPAL (1999), desde una perspectiva institucional, el Área de Libre Comercio de las Américas (ALCA) reconocía sus antecedentes en la Iniciativa de las Américas, que privilegiaba las negociaciones entre grupos de países, en detrimento de las bilaterales. En un principio este acuerdo buscaba profundizar las reformas económicas puestas en marcha en los países latinoamericanos con objeto de abrir sus economías a la competencia externa y permitir que el mercado se transformara en el principal asignador de recursos.

En su momento, el ALCA representaba el más importante acuerdo de integración regional que firmarían países desarrollados y en desarrollo (se trataba de un mercado compuesto por 757 millones de personas, con un PIB conjunto de más de 8 billones de dólares y un comercio total de 2,4 billones de dólares), con miras a establecer el libre flujo comercial entre sus economías. De forma coherente con las disposiciones multilaterales de la Organización Mundial del Comercio (OMC), mediante este acuerdo se pretendía incorporar a la negociación la inversión en bienes y servicios, siguiendo reglas 
comerciales definidas y transparentes. También se incorporarían las compras del sector público y las políticas de competencia, y se sentarían las bases para la inclusión de temas tales como la agricultura y el acceso a mercados, los servicios y la inversión, las políticas de competencia y los subsidios, así como los procedimientos antidumping y los derechos compensatorios.

A fin de medir el potencial de intensidad comercial que se alcanzaría con el ALCA, la CEPAL (Rivas y Paunovic, 2005) elaboró varios documentos en que se analizaba la institucionalidad del ALCA y el potencial del comercio vinculado con dicho tratado. El examen de los aspectos económicos se centraba en el cálculo de indicadores de similitud en los flujos comerciales de los países, a partir de una muestra de 15 miembros que integrarían el ALCA. Se decidió no incluir a los Estados Unidos entre ellos, dado que su estrecha relación comercial con los miembros latinoamericanos podría sesgar los resultados obtenidos. La metodología de análisis siguió la propuesta de Van Beers y Linnemann (1991).

Las estimaciones del impacto fiscal del ALCA dieron como resultado que efectivamente habría una pérdida de ingresos fiscales en el escenario de base. Sin embargo, también se advertía que la pérdida no sería muy pronunciada, aun considerando el caso de un escenario pesimista de crecimiento económico, pues no sobrepasaría el 1\% del PIB en promedio en los últimos años del período de transición en los países centroamericanos. En el escenario de crecimiento optimista, habría una pérdida de ingresos fiscales de un 0,3\% del PIB en promedio al final del período de transición. Incluso se estimaba que, en los primeros años de vigencia del ALCA, en el escenario de crecimiento optimista, podría presentarse una ganancia de ingresos fiscales del $0,1 \%$ del PIB en promedio.

El ALCA nunca llegó a concretarse, debido principalmente a la falta de una política definida de "vía rápida" y a la imposibilidad de conciliar las posiciones de los Estados Unidos con las de algunas de las principales economías latinoamericanas. Sin embargo, la participación de la CEPAL fue valorada por el apoyo que prestó para el análisis de la viabilidad fiscal de este tipo de acuerdos.

\section{Tratado de Libre Comercio entre República Dominicana, Centroamérica y los Estados Unidos}

En 1984 se aprobó en Estados Unidos la Ley de Recuperación Económica de la Cuenca del Caribe (LRECC), conocida como la Iniciativa de la Cuenca del Caribe (ICC). En mayo de 2000 se dio una ampliación de la ICC mediante la aprobación de la Ley de Asociación Comercial entre los Estados Unidos y la Cuenca del Caribe (CBTPA). La CBTPA confirió al Presidente de los Estados Unidos el mandato de convenir reuniones con el propósito de llegar a un acuerdo sobre la oportunidad y los procedimientos para iniciar negociaciones de libre comercio con los Estados Unidos. 
En octubre de 2002, el Gobierno de los Estados Unidos notificó al Congreso su intención de iniciar negociaciones para suscribir un tratado de libre comercio con Centroamérica (con excepción de Panamá). Las negociaciones concluyeron en diciembre de 2003 en el caso de El Salvador, Guatemala, Honduras y Nicaragua, y en enero de 2004 en el caso de Costa Rica. La incorporación de la República Dominicana se negoció entre junio y julio de 2004 y, en agosto de 2005, se suscribió el DR-CAFTA entre los siete países. En ese momento, se dio inicio al período para que cada país emprendiera el proceso de someter el acuerdo a discusión y votación en sus congresos respectivos. Todos aprobaron el acuerdo comercial, entre diciembre de 2004 (El Salvador) y octubre de 2008 (Costa Rica), aunque en algunos entró en vigor en 2006 y, en el caso concreto de Costa Rica, la entrada en vigor fue en enero de 2009.

Dado que los Estados Unidos son el principal socio comercial de los países centroamericanos, hubo muchos estudios respecto a diferentes temas relacionados con el tratado. En el ámbito del impacto fiscal, cabe destacar los elaborados por la CEPAL en 2003 y en 2005. En el primer estudio de la CEPAL (Paunovic y Martínez, 2003) se abordó el tema del impacto fiscal durante el primer año del tratado, la eliminación de aranceles y la reducción de impuestos indirectos recaudados sobre las importaciones (por ejemplo, el impuesto sobre el valor agregado (IVA)). Se evaluaron tres escenarios diferentes, desde una declinación moderada hasta un hipotético caso de profunda reducción de aranceles.

Luego se elaboró un estudio más completo (Paunovic, 2005) en que se estimaron las implicaciones fiscales del acuerdo de libre comercio firmado entre los Estados Unidos, Costa Rica, El Salvador, Guatemala, Honduras, Nicaragua y la República Dominicana. Entre los cinco posibles efectos sobre los ingresos fiscales (directo, indirecto, de elasticidad, de sustitución e inducido) solo se analizaron los tres primeros. El cuarto podría ser insignificante, mientras que la evaluación del quinto era tan incierta que no se realizó. En este estudio se utilizó el método de la estática comparativa. Se determinó que el impacto negativo, a partir de la sumatoria de los efectos positivos y negativos directos e indirectos por la eliminación de aranceles, afectaría en menor medida a Costa Rica, y en mayor medida a Honduras, durante el primer año de operación del DR-CAFTA.

Después de contabilizar las implicaciones positivas y negativas de los ingresos, se llegó a la conclusión de que habría una pérdida neta de ingresos fiscales en todos los países debido al DR-CAFTA. Dado que en la mayor parte de los casos la pérdida era pequeña, el único país que podría tener problemas en ese sentido sería Honduras, en vista de su mayor vulnerabilidad, por lo que estaba menos preparada para mitigar las implicaciones fiscales del Tratado. Incluso en el escenario de crecimiento más optimista, se estimaba 
que ese país experimentaría una pérdida al comienzo del período de transición de 20 años. En el documento se proponía una serie de acciones y políticas públicas encaminadas a mitigar los efectos negativos del Tratado y aprovechar el aumento del comercio tras la puesta en marcha del DR-CAFTA. Entre las principales propuestas estaban el aumento de la base impositiva (y la reducción de la informalidad), el cobro de un impuesto a la propiedad, la homogenización regional del IVA y el impuesto sobre la renta (ISR), entre otros.

Como se analizará más adelante, en esta etapa (2005) fue cuando los Ministerios de Hacienda o Finanzas de los siete países iniciaron las reuniones técnicas que dieron como resultado la creación del COSEFIN. La agenda del grupo de Ministros, y luego del COSEFIN, estuvo estrechamente relacionada con los retos que planteaba el DR-CAFTA en materia tributaria.

\section{Implicaciones fiscales de la construcción de la Unión Aduanera Centroamericana}

Desde la suscripción del Tratado General de Integración en 1960, firmado por Costa Rica, El Salvador, Guatemala, Honduras y Nicaragua, se buscó la constitución formal de una unión aduanera. Su finalidad era alcanzar una mayor fluidez del comercio; reducir los costos de transporte, de logística y de la administración pública; utilizar de forma racional la infraestructura y robustecer la posición negociadora de la región frente a terceros.

Aunque con el Tratado General de Integración Económica Centroamericana se intentó constituir una unión aduanera en Centroamérica, el Protocolo de Guatemala (1993), que permitió la geometría variable en el avance de los procesos, hizo que disminuyeran las probabilidades de lograr un arancel externo común. Además, hasta ahora no se ha establecido uno de los requisitos básicos para su constitución, a saber, la creación de un territorio aduanero único.

En los últimos seis años se han registrado avances concretos en la coordinación de procedimientos y regulaciones aduaneras, y en la armonización de normas (como las fitosanitarias) que se aplican a los productos importados y que son indispensables para la facilitación del comercio. También se ha profundizado la armonización en materia aduanera en Centroamérica, ya que se han alcanzado consensos que se plasmaron en legislación interna y en regulaciones de observancia regional. Sin embargo, los avances son asimétricos y sus alcances, heterogéneos.

$\mathrm{Al}$ igual que en otros procesos de integración, la unión aduanera ha tenido avances y retrocesos en relación con sus dimensiones comerciales y fiscales. De acuerdo con Funes (2011), la condición de libre movilidad comercial de las mercancías en Centroamérica se otorga a los bienes originarios de 
los países centroamericanos, salvo un número muy pequeño de productos que están incluidos en el Anexo A del Tratado General de Integración Económica Centroamericana.

Los tratados de libre comercio negociados bilateralmente por los países centroamericanos han impedido que a corto plazo se logre aplicar un arancel externo común. No obstante, en la medida en que la mayor parte de las importaciones realizadas por la región se efectúan al amparo de tratados de libre comercio, que implican una eliminación de aranceles a corto o mediano plazo, se logrará una armonización arancelaria de facto.

Funes (2011, pág. 5) apunta que "mientras importantes avances se han tenido en la coordinación de procedimientos y regulaciones para facilitar la libre circulación de bienes y servicios, persisten desafíos en el ámbito fiscal". En los pasados diez años, los países centroamericanos se han centrado en el logro de avances concretos en la facilitación del comercio. En las reuniones de Directores de Aduanas de Centroamérica (tanto en el formato de Comité Aduanero, bajo el amparo del Consejo de Ministros de Integración Económica (COMIECO), como en el del Grupo Aduanero y Tributario, bajo la coordinación del COSEFIN), con la cooperación técnica de la Secretaría de Integración Económica Centroamericana (SIECA) y la CEPAL, se discutió la definición de las visiones general y específica sobre las aduanas. Debido a ello, en 2015 se dio inicio al proceso de facilitación del comercio mediante una aduana electrónica. Su implementación fue posible gracias a la evolución de los mecanismos de control aduanero hacia un sistema fundamentado en la gestión de riesgo y a la redefinición del papel de las aduanas intrafronterizas.

De manera concreta, por ejemplo, la Unión Aduanera entre Guatemala y Honduras ya rinde frutos. Además de lograrse una reducción significativa de los tiempos de entrega de las mercancías, los empresarios que comercializan sus productos entre ambos países informan sobre un incremento del volumen comercializado. A partir del 1 de marzo de 2018 se hizo obligatorio el uso de la Factura y Declaración Única Centroamericana (FYDUCA) para el tránsito de mercadería en los puestos fronterizos entre Guatemala y Honduras. En el caso de las mercancías que tengan como destino Nicaragua, Costa Rica y Panamá, se utilizará el Formulario Aduanero Único Centroamericano (FAUCA). En abril de 2018, se llevó a cabo la cuarta ronda de negociaciones con miras a la incorporación de El Salvador al proceso de unión aduanera con Guatemala y Honduras. En esos encuentros se discutieron temas como los tributos internos, las medidas fitosanitarias y los aranceles, entre otros. En agosto de 2018, el Congreso de El Salvador ratificó el protocolo de adhesión al proceso de unión aduanera.

Además, Centroamérica ha convenido un mecanismo que permite eliminar el múltiple pago del derecho arancelario a la importación, en el marco del Acuerdo de Asociación con la Unión Europea, con cuya aplicación 
se han ido reduciendo las limitaciones a la libre circulación de mercancías. Está en proceso de discusión el establecimiento de un mecanismo para evitar el cobro del IVA o de impuestos sobre la venta en las aduanas a bienes que circulan dentro de la región.

La CEPAL (2017) hizo algunas estimaciones sobre los impactos económicos y sociales que tendría la implementación de la profundización de la Unión Aduanera entre Guatemala y Honduras mediante un programa de facilitación del comercio ${ }^{3}$. En particular, se calcularon los efectos fiscales derivados del aumento de las importaciones tras la aplicación de un programa de este tipo. Según los resultados fiscales que se prevén tras la aplicación de un programa ambicioso, podría producirse un aumento de la recaudación fiscal en Honduras y Guatemala, de 37 millones de dólares (0,2\% del PIB) y 41 millones de dólares (0,1\% del PIB), respectivamente. En el caso de las simulaciones realizadas a partir de un programa de facilitación del comercio menos ambicioso, el efecto positivo esperado sobre la recaudación fiscal es menor, de 21 millones de dólares (0,1\% del PIB) y 27 millones de dólares $(0,04 \%$ del PIB) en Honduras y Guatemala, respectivamente.

Estos resultados y otros análisis elaborados por la CEPAL se han tenido en cuenta en las discusiones en torno al fortalecimiento de la unión aduanera en Centroamérica.

\section{Otros acuerdos relevantes donde el componente comercial ha predominado sobre los acuerdos fiscales}

De acuerdo con Caballeros (2008), durante los últimos 20 años los países centroamericanos han buscado estrechar sus vínculos económicos y comerciales con varios de sus socios naturales y tradicionales. En el marco de esa estrategia, se propuso la negociación de un Acuerdo de Asociación con la Unión Europea que les garantizara una relación mayor y más estable con ese mercado. Por su parte, los países europeos manifestaron su interés en colaborar con Centroamérica a fin de consolidar el proceso de integración y estimular el crecimiento con equidad, como vehículos que contribuyeran a consolidar la paz y la democracia en la región.

Tras varios años de intensas negociaciones comerciales binacionales (es decir, de la Unión Europea con cada país del bloque) que evidenciaron

\footnotetext{
Un programa de facilitación del comercio entre distintos países incluye normalmente tres componentes principales: i) la automatización de los procesos de tránsito de mercancías; ii) la reducción del tiempo necesario para exportar e importar, y iii) la automatización del tránsito de personas. De estos tres, el estudio de la CEPAL (2017) solo incluye los dos primeros, asociados principalmente al comercio. En los resultados presentados no se considera una disminución de los aranceles aplicados, ni tampoco los desembolsos por inversiones en infraestructuras aduaneras. Solo se refleja el impacto de las medidas de facilitación del comercio sobre los flujos de bienes comerciados que luego son objeto de recaudación por la vía de impuestos al valor añadido e impuestos especiales.
} 
las dificultades de la región para ejercer la fuerza que podría conferirle la negociación colectiva, los países de Centroamérica (excepto la República Dominicana) establecieron en diciembre de 2012 el Acuerdo de Asociación con la Unión Europea. Sin embargo, esas negociaciones dieron lugar a múltiples excepciones al Arancel Externo Común (AEC), con lo que se debilitaron los logros que ya se habían alcanzado en la materia.

La UE presionó para lograr un alto grado de liberalización, basada en sus mayores ventajas competitivas estáticas y dinámicas. Además, se insistió en la consolidación de la Unión Aduanera Centroamericana con el fin de homologar las reglas y registros intracomerciales. Mientras tanto, en el tema de los derechos de propiedad intelectual, se negoció la adopción de una legislación homogénea a nivel regional. También se asumieron compromisos respecto de la contratación pública y de la adopción de una política de fomento de la competencia. La UE consiguió que se definiera una normativa regional en ambos temas y se estableciera una autoridad regional de defensa de la competencia. En materia institucional, se diseñaron mecanismos de administración y aplicación del Acuerdo de Asociación con la Unión Europea, incluido un sistema de solución de controversias. Sin embargo, no hubo acuerdos que fortalecieran la posición fiscal de los países de Centroamérica y tampoco se hicieron estudios con el fin de evaluar su impacto fiscal.

Otro tratado relevante fue el Tratado de Libre Comercio Único entre Centroamérica (Costa Rica, El Salvador, Guatemala, Honduras, Nicaragua) y México. Antes existían los tratados de libre comercio entre: i) México y Costa Rica, vigente desde el 1 de enero de 1995; ii) México y Nicaragua, vigente desde el 1 de julio de 1998, y iii) México y El Salvador, Guatemala y Honduras, vigente desde el 15 de marzo de 2001. Después de intensas mesas de diálogo, los países participantes concluyeron las negociaciones técnicas relativas a la convergencia de lo que sería el Tratado de Libre Comercio Único entre Centroamérica y México el 20 de octubre de 2011. El TLC Único se firmó el 22 de noviembre de 2011 y entró plenamente en vigor en 2013, después de las correspondientes aprobaciones en los congresos de los países.

El TLC Único, además de beneficiar al sector exportador en varios aspectos (debido primordialmente a que se acordaron reglas de origen comunes para los productos que se exporten entre los países de la región), contempla la aplicación de un trato arancelario preferencial a las prendas y complementos de vestir que se clasifiquen en el capítulo 62 del Sistema Armonizado y que incorporen en su producción insumos originarios de los Estados Unidos. Es decir, las exportaciones de este tipo de mercancías que incorporen tales insumos pueden ingresar en el mercado mexicano haciendo uso de las mismas preferencias arancelarias que si hubiesen sido producidas con insumos de cualquier país centroamericano. También se 
acordó establecer formatos únicos para el certificado de origen y la declaración de origen, que sirven para certificar que una mercancía que se exporte de territorio de una de las partes se considera originaria, lo que simplifica los trámites administrativos y fiscales entre los países firmantes. Sin embargo, el tratado no aborda los temas fiscales desde el punto de vista de la región en su conjunto y, en su negociación, no se realizaron evaluaciones del impacto fiscal de su implementación.

Para concluir este apartado, se puede decir que tanto el DR-CAFTA como el Acuerdo de Asociación con la Unión Europea y la Unión Aduanera Centroamericana, además de eliminar aranceles y reducir barreras no arancelarias, introdujeron grandes cambios en los marcos legales de los países miembros. De este modo, se facilitó el comercio de servicios, se promovió la transparencia y se establecieron las bases de una discusión profunda sobre el diseño, creación y puesta en marcha de mecanismos que permitieran una mayor coordinación fiscal regional. También cabe destacar que, a pesar de la existencia de múltiples acuerdos comerciales entre Centroamérica y otros países y regiones del mundo, no hay suficientes acuerdos que promuevan el fortalecimiento de la integración fiscal en la región.

Todo lo anterior, junto con la información vertida en este apartado, refuerza la idea de que la integración comercial ha sido uno de los factores determinantes de la integración fiscal. Lo que es aún más importante, en Centroamérica no existe la integración fiscal, sino una mera coordinación en algunos de los temas de ámbito fiscal que más han interesado a los países de la región.

\section{La institucionalidad fiscal de la integración}

El Consejo de Ministros de Hacienda o Finanzas de Centroamérica, Panamá y la República Dominicana (COSEFIN) se creó en 20064 . Esa decisión se enmarcó en lo establecido tanto por el Protocolo de Tegucigalpa (por el que se creó el Sistema de la Integración Centroamericana (SICA)) como por el Protocolo de Guatemala (de 1993), cuyo objetivo es la creación "voluntaria, gradual, complementaria y progresiva" de una unión económica centroamericana.

El COSEFIN es una de las instituciones más jóvenes del proceso de integración centroamericana. Si bien en el Protocolo de Guatemala se señaló la necesidad de la convergencia de las políticas económicas como uno de los mecanismos para impulsar el proyecto económico regional (CEPAL, 2000), el COSEFIN no se creó hasta 13 años después. Su creación tuvo dos antecedentes. El primero fue una reunión celebrada en 1984 en Guatemala, como seguimiento

Resolución núm. 1 del Consejo de Ministros de Hacienda o Finanzas de Centroamérica, Panamá y la República Dominicana. 
de una reunión informal que había tenido lugar en Costa Rica ese mismo año, cuyo objetivo fue la revisión de la política arancelaria y aduanera de la región (CEPAL, 1984). El segundo fue la creación de un Grupo de Apoyo Técnico organizado en la Secretaría Permanente del Tratado General de Integración Económica Centroamericana (SIECA), cuyo objetivo era realizar los estudios de base necesarios con miras a lograr la armonización tributaria. Se estableció que el proyecto debía entrar en vigor a más tardar en diciembre de 1991, pero ese plazo no se cumplió y no fue reprogramado.

\section{EI COSEFIN: definición a partir del DR-CAFTA}

Los considerandos o antecedentes que se describen en la resolución de creación del COSEFIN hacen alusión a la necesidad de coordinar las políticas fiscales y emprender de forma progresiva la armonización tributaria. Ello se enmarca en el proceso de unión aduanera y en la liberalización e integración comercial derivadas de los acuerdos comerciales, entre los que cabía destacar el DR-CAFTA, que en ese momento se encontraba ya suscrito por los países de la región.

\section{El Grupo de Trabajo de Política Tributaria}

El antecedente técnico que precedió a la formación del COSEFIN fue la creación del Grupo de Trabajo de Política Tributaria (GTPT) (en agosto de 2005) ${ }^{5}$. Este grupo fue establecido por los Ministros de Hacienda o Finanzas, que le asignaron la tarea de proponer medidas de coordinación tributaria en la región. Para los trabajos del GTPT, los Ministros comenzaron por solicitar apoyo al Fondo Monetario Internacional (FMI). Luego contaron con un proyecto del Banco Interamericano de Desarrollo (BID) ejecutado con fondos del Banco Centroamericano de Integración Económica (BCIE) y el Gobierno de España. El GTPT fue creado en reunión con los Directores del Departamento de Finanzas Públicas (FAD) y el Departamento del Hemisferio Occidental (WHD) del FMI y recibió apoyo técnico del Departamento Jurídico de la misma institución financiera.

El GTPT estaba conformado por especialistas tributarios (un titular y un alterno) de los Ministerios de cada uno de los países. Sus integrantes establecieron algunos acuerdos de trabajo relacionados con los desafíos que la región enfrentaría con la entrada en vigor del DR-CAFTA. Los principales acuerdos de la primera reunión fueron los siguientes (véase el recuadro VII.1):

- Se definieron los objetivos del trabajo del GTPT: evitar que las normas tributarias distorsionen el comercio regional yo la localización de las inversiones debido a la alteración de las tasas de rentabilidad. 
- Se estableció una secretaría técnica, a cargo de Guatemala.

- Se decidió iniciar la coordinación con la SIECA para evitar la duplicación de los trabajos. Esto respondió principalmente al proyecto del establecimiento de un Grupo de Apoyo Técnico, en el seno de la SIECA, para trabajar con miras a una armonización tributaria.

- Se definieron los aspectos prioritarios de las labores: i) el análisis de los regímenes de incentivos y de exoneraciones y exenciones tributarias, sin incluir entre ellos, en esta etapa, el tratamiento tributario de las zonas francas; ii) los principios jurisdiccionales aplicables en la imposición a la renta, y iii) los convenios para evitar la doble imposición.

- La alternancia del lugar de reuniones entre la sede del FMI (en Washington, D.C.) y los países participantes.

\section{Recuadro VII.1 \\ Las labores del Grupo de Trabajo de Política Tributaria}

EI GTPT realizó un intenso trabajo durante los cuatro primeros años (desde su creación en 2005 hasta 2009). Las detalladas minutas de las reuniones dan cuenta de la concreción de estudios técnicos y propuestas regionales. Se plantearon dos objetivos: i) evitar distorsiones del comercio (vinculado con la imposición al consumo, general o selectivo), y ii) lograr la neutralidad en la radicación de inversiones (vinculado a la renta corporativa y a gravámenes complementarios).

En cuanto al primer objetivo, se reconocía que, dados los procesos de ajuste estructural implementados durante la década de 1990 y debido a la aplicación del principio exclusivo de imposición en destino, ya había un grado considerable de avance en su coordinación, por lo que pasó a ser una segunda prioridad. En cambio, el segundo objetivo se priorizó, al reconocerse que la falta de coordinación estimularía la competencia por captar inversiones adicionales, lo que daría lugar a una guerra fiscal.

EI GTPT estableció las siguientes líneas de trabajo:

- Código de conducta sobre incentivos fiscales a la inversión.

- Tratamiento impositivo de las zonas francas.

- Precios de transferencia.

- Subcapitalización de empresas.

- Convenios para evitar la doble tributación en la renta.

- Principios jurisdiccionales para evitar la doble tributación.

- Impuesto a los inmuebles y otros tributos locales, a los vehículos y al consumo.

- Tratamiento de las instituciones financieras.

En una de las últimas minutas de las reuniones del grupo se realizó un recuento de los trabajos técnicos finalizados, en el siguiente orden (se indica entre paréntesis si fue aprobado o presentado al COSEFIN):

- Modelo de convenio para evitar la doble tributación (aprobado).

- Código de conducta sobre incentivos fiscales a la inversión (presentado). 
Recuadro VII.1 (conclusión)

- Unión Aduanera Centroamericana: análisis de documentos sobre su establecimiento (presentado).

- Modelo de normas para tratamiento de precios de transferencia (aprobado).

- Matriz regional de incentivos fiscales (aprobada).

- Nota técnica sobre la negociación de tratados para evitar la doble tributación (presentada).

- Estudio descriptivo de los incentivos contenidos en la matriz (presentado).

- Norma de subcapitalización de empresas (aceptada).

- Modelo legal de impuesto sobre la renta, basado en los principios jurisdiccionales de renta mundial y renta territorial (aceptado).

De especial relevancia fue la elaboración del código de conducta sobre incentivos fiscales a la inversión. Sobre esa base se planteó la elaboración de un convenio regional que sería asumido por los Jefes de Estado de los países. Sin embargo, el esfuerzo se vio frenado por la falta de acuerdo de un país miembro del COSEFIN.

Muchos de los trabajos técnicos desarrollados en el GTPT sirvieron de base, años después, para proyectos de reformas tributarias ejecutados en algunos países. En el seno de este grupo se planteó también la necesidad de implementar unidades de investigación de precios de transferencia, en preparación para la apertura financiera y la aplicación de los mecanismos que las empresas transnacionales pueden utilizar en sistemas abiertos.

Fuente:Comisión Económica para América Latina y el Caribe (CEPAL), sobre la base de minutas del Grupo de Trabajo de Política Tributaria (GTPT).

\section{El proceso de institucionalización del COSEFIN}

El COSEFIN se establece en virtud de la resolución correspondiente como un "foro permanente de Ministros de Hacienda y Finanzas [...] para discutir consistentemente temas asociados a la información, armonización, convergencia, desarrollo y coordinación de políticas fiscales" (COSEFIN, 2012, pág. 1) de estos países. En el momento de su creación (2006), se definieron como miembros los titulares del Ministerio de Finanzas Públicas de Guatemala, el Ministerio de Hacienda de El Salvador, la Secretaría de Finanzas de Honduras, el Ministerio de Hacienda de Costa Rica, el Ministerio de Hacienda de la República Dominicana, el Ministerio de Hacienda y Crédito Público de Nicaragua y el Ministerio de Economía y Finanzas de Panamá.

En la primera resolución se establecieron las bases mínimas de funcionamiento tanto del Consejo como de la Secretaría Ejecutiva: la selección de un presidente y un vicepresidente durante un año (los primeros en ocupar dichos cargos fueron el Ministro de Hacienda de la República Dominicana y su homólogo de Costa Rica). Posteriormente se decidió que dichos cargos se asumirían según el orden de la presidencia del SICA, por períodos de seis meses. Se estableció la necesidad de elaborar el Reglamento Interno del Consejo, pero este no fue aprobado por el COSEFIN hasta 2012. La Secretaría 
Ejecutiva tendría su sede en Guatemala. Por decisión del COSEFIN en 2008, se cambió la sede a El Salvador y se estableció que la Secretaría Ejecutiva se financiaría con los aportes de los Estados miembros. Sin embargo, no fue sino en 2012 que los Estados, por conducto de los Ministerios respectivos, iniciaron sus aportes ${ }^{6}$.

La Secretaría Ejecutiva dio inicio a sus labores en 2008. Durante sus primeros años, funcionó mediante el apoyo del BCIE, que asignó los primeros recursos para financiar los honorarios y gastos de traslado del Secretario Ejecutivo, pero sin haberse definido una estructura de apoyo al Secretario Ejecutivo.

En 2012 se aprobó el Reglamento de Organización y Funcionamiento del COSEFIN. Con ello se inició una etapa de fortalecimiento institucional, al hacerse posible de esta manera una organización clara y acordada por todos. Además, a partir de ese año los Estados miembros comenzaron a realizar sus aportes para el funcionamiento de la Secretaría Ejecutiva.

De acuerdo con el COSEFIN (2012), la finalidad del reglamento es "establecer un marco regulatorio interno que norme la organización y funcionamiento del COSEFIN, para contar con un instrumento de gestión administrativa que oriente el esfuerzo institucional al logro de su finalidad y objetivo, estableciendo campos funcionales y precisando responsabilidades, de forma ordenada y transparente para alcanzar la eficiencia y eficacia del Consejo y sus relaciones con el resto de órganos del Sistema de Integración, secretarías e instituciones". En él se definen también las instancias que lo conforman: el Consejo de Ministros, la presidencia pro tempore del Consejo y la Secretaría Ejecutiva.

Según el reglamento, el Consejo podrá establecer unidades asesoras, comités técnicos de enlace y grupos de trabajo, entre otras instancias. En la práctica, el Consejo ha trabajado designando dentro de los Ministerios a los especialistas que se encargan de conformar un grupo que pueda enlazarse a nivel regional. Los grupos que se integraron en los primeros años fueron el GTPT y el Grupo Aduanero Tributario (GAT).

El reglamento define las atribuciones del Consejo:

- En el marco regional de integración, establece su ámbito de acción y su relación con el sistema de integración, sobre todo con el SICA y la SIECA.

- En el marco operativo, define principalmente las atribuciones del Consejo con la Secretaría y las responsabilidades de esta última.

6 En principio, 25.000 dólares, que se incrementaron a 30.000 dólares en 2014. 
Por otro lado, se precisan las atribuciones tanto de la presidencia pro tempore como de la Secretaría Ejecutiva. Esto último ha permitido establecer un estándar para la evaluación del Secretario Ejecutivo, mediante la presentación de informes anuales, tanto financieros como de gestión, a partir de 2013.

Podría señalarse que, en los tres últimos años, el proceso de institucionalización del COSEFIN se ha visto marcado por dos elementos: i) la implementación de una agenda de trabajo consensuada y priorizada, llamada Matriz de Interés Fiscal (MIF), y ii) la definición de una estructura con la identificación de los órganos del consejo y de los diferentes grupos de trabajo.

En el diagrama VII.2 se refleja la organización del COSEFIN con la MIF como elemento articulador del trabajo del Consejo y de sus instancias. Se estableció un Grupo de Trabajo de Política Fiscal, que se encargará de la coordinación con los Ministerios y los especialistas en cada área para integrar los requisitos técnicos en función de los temas. Luego se conforman cuatro grupos técnicos más (además del GTPT y el GAT): i) el Grupo de Trabajo de Presupuestos Públicos (GTPP); ii) el Grupo de Trabajo de Estadísticas en Finanzas Públicas (GTEFP); iii) el Grupo de Trabajo de Crédito e Inversión Pública (GTCIP), y iv) el Comité Técnico Regional (CTR).

\section{Diagrama VII.2 \\ Organización del Consejo de Ministros de Hacienda o Finanzas de Centroamérica, Panamá y la República Dominicana (COSEFIN)}

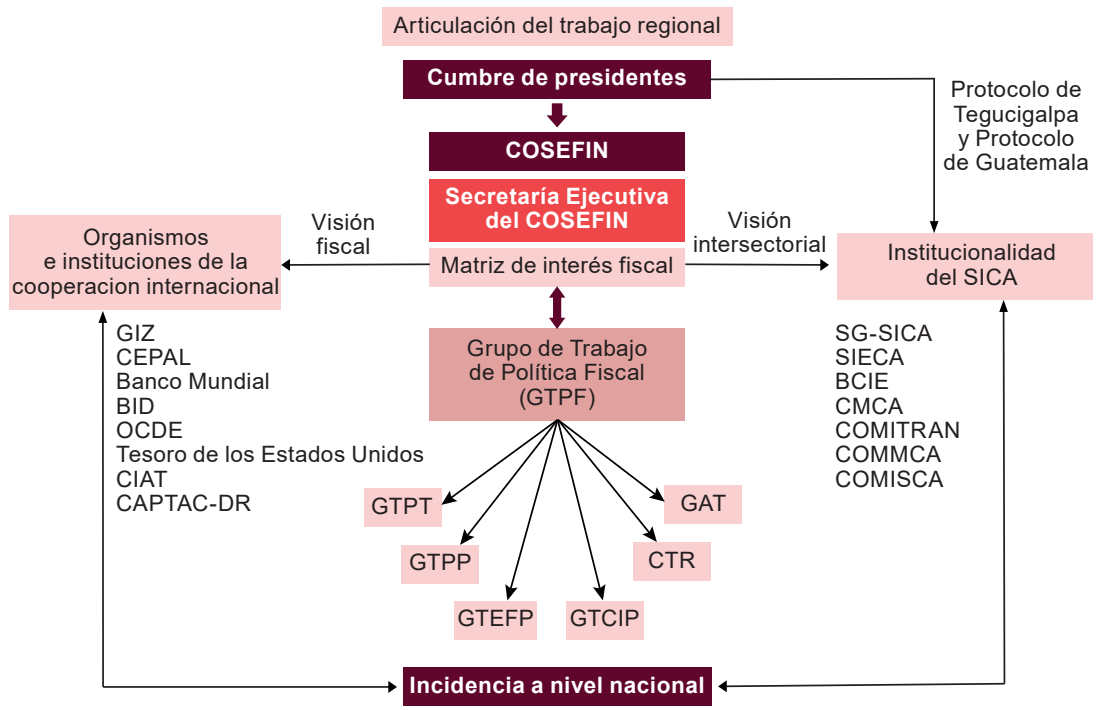

Fuente: Secretaría Ejecutiva del Consejo de Ministros de Hacienda o Finanzas de Centroamérica, Panamá y la República Dominicana (SE-COSEFIN). 
La MIF (véase el cuadro VII.1) se origina en la 37ª Reunión Ordinaria del Consejo de Ministros de Hacienda o Finanzas de Centroamérica, Panamá y la República Dominicana (San Salvador, 2015). En ese encuentro, a petición de los Ministros, el Secretario Ejecutivo presentó una matriz de mandatos que conciernen al consejo derivado de las cumbres presidenciales. A partir de entonces, y dada la amplitud de mandatos y la recomendación de algunos miembros de definir prioridades concretas de trabajo, se inició un proceso de consulta con los Ministerios para establecer una agenda de trabajo del Consejo que guiara la gestión de la Secretaría Ejecutiva.

\section{Cuadro VII.1}

\section{Matriz de Interés Fiscal}

\begin{tabular}{|c|c|c|c|}
\hline & $\begin{array}{l}\text { Área temática } \\
\text { de interés }\end{array}$ & $\begin{array}{l}\text { Objetivo de } \\
\text { Desarrollo Sostenible }\end{array}$ & Resultado esperado \\
\hline 1 & $\begin{array}{l}\text { Exoneraciones } \\
\text { fiscales }\end{array}$ & $\begin{array}{l}\text { Objetivo } 8 \text {. Trabajo decente } \\
\text { y crecimiento económico }\end{array}$ & $\begin{array}{l}\text { Integración de políticas públicas a nivel } \\
\text { regional para el otorgamiento y control } \\
\text { de las exoneraciones fiscales, evaluando } \\
\text { e incorporando "mejores prácticas" de } \\
\text { evaluación de impactos (costo-beneficio), } \\
\text { registro contable y presupuestario del } \\
\text { sacrificio fiscal. }\end{array}$ \\
\hline
\end{tabular}

2 Estrategia BEPS Objetivo 8. Trabajo decente Análisis para Centroamérica de la iniciativa y crecimiento económico Objetivo 10. Reducción de las desigualdades sobre la erosión de la base imponible y el traslado de beneficios (BEPS), relativo a las estrategias de las empresas multinacionales para eludir o evadir el pago de impuestos mediante el traslado de sus beneficios a países de escasa o nula tributación.

3 Evaluación física $y$ financiera de la ejecución de los programas de inversión pública

4 Riesgos fiscales
Objetivo 8. Trabajo decente y crecimiento económico Objetivo 9. Industria, innovación e infraestructura Objetivo 10. Reducción de las desigualdades

Objetivo 8. Trabajo decente y crecimiento económico Objetivo 9. Industria, innovación e infraestructura Objetivo 10. Reducción de las desigualdades Objetivo 11. Ciudades y comunidades sostenibles Objetivo 12. Producción y consumo responsables Objetivo 13. Acción por el clima

Objetivo 15. Vida de ecosistemas terrestres Objetivo 16. Paz, justicia e instituciones sólidas

5 Desarrollo y modernización de la administración tributaria y aduanera

Objetivo 8. Trabajo decente y crecimiento económico Objetivo 10. Reducción de las desigualdades
Estudio regional de estado de ejecución de proyectos de inversión pública, problemas y recomendaciones. Estudio de metodologías de éxito a nivel mundial.

Conocimiento de las políticas públicas con respecto a la identificación, análisis y registro contable de los riesgos y contingencias fiscales, conocimiento de los derivados de las asociaciones público-privadas, desastres naturales, sistema de pensiones, rescate financiero de municipalidades, garantías soberanas y otros.

Continuación o ampliación de las iniciativas de las "economías del cambio climático". Análisis de instrumentos financieros de protección ante el riesgo de eventos catastróficos y de adaptación al cambio climático bajo el contexto de políticas y estrategias regionales y complementarias para los Estados de Centroamérica.
Coordinación de programas de cooperación comunes en materia arancelaria, aduanera, impositiva y de fronteras periféricas. 
Cuadro VII.1 (conclusión)

\begin{tabular}{|c|c|c|c|}
\hline & $\begin{array}{l}\text { Área temática } \\
\text { de interés }\end{array}$ & $\begin{array}{l}\text { Objetivo de } \\
\text { Desarrollo Sostenible }\end{array}$ & Resultado esperado \\
\hline 6 & $\begin{array}{l}\text { Procesos } \\
\text { presupuestarios }\end{array}$ & $\begin{array}{l}\text { Objetivo 1. Fin de la pobreza } \\
\text { Objetivo } 5 . \text { Igualdad } \\
\text { de género } \\
\text { Objetivo } 8 \text {. Trabajo decente } \\
\text { y crecimiento económico }\end{array}$ & $\begin{array}{l}\text { Conocimiento de los procesos de } \\
\text { descentralización a nivel regional o municipal } \\
\text { de la formulación y ejecución de planes y } \\
\text { presupuestos, considerando y evaluando el } \\
\text { grado de participación ciudadana; continuación } \\
\text { o ampliación de la iniciativa de asistencia y } \\
\text { cooperación técnica para la elaboración de } \\
\text { marcos presupuestarios de mediano plazo; } \\
\text { prestación de asistencia técnica a la región } \\
\text { para evaluar herramientas de planificación y } \\
\text { presupuestos a fin de aplicar un presupuesto } \\
\text { por programas de largo plazo que garantice el } \\
\text { cumplimiento de los objetivos trazados en los } \\
\text { planes nacionales y regionales. }\end{array}$ \\
\hline 7 & $\begin{array}{l}\text { Mercado } \\
\text { unificado regional } \\
\text { de deuda pública }\end{array}$ & $\begin{array}{l}\text { Objetivo } 8 \text {. Trabajo decente } \\
\text { y crecimiento económico }\end{array}$ & $\begin{array}{l}\text { Continuación de los esfuerzos de organización } \\
\text { de los mercados internos de deuda pública } \\
\text { con el fin de propiciar su desarrollo o } \\
\text { profundización y luego pasar a la construcción } \\
\text { de un mercado regional. }\end{array}$ \\
\hline
\end{tabular}

Fuente: Secretaría Ejecutiva del Consejo de Ministros de Hacienda o Finanzas de Centroamérica, Panamá y la República Dominicana (SE-COSEFIN).

En 2016 se acuerda la MIF con siete áreas de trabajo, de las que se priorizaron las siguientes: las exoneraciones fiscales, la iniciativa de erosión de la base imponible y el traslado de beneficios (BEPS) y la eficiencia en la ejecución de la inversión pública. A partir de esto, la Secretaría Ejecutiva invitó a los diferentes organismos de cooperación a colaborar con las áreas de su especialidad. En marzo de 2017 el COSEFIN aprobó la MIF mediante una resolución. La CEPAL determinó los ámbitos en que podría colaborar con asistencia técnica, capacitación o investigaciones, y organizó un taller para compartir información en junio de 2017, al que asistieron los técnicos especialistas de los Ministerios.

La CEPAL ya había colaborado con el COSEFIN por conducto del Comité Técnico Regional, como contraparte de la Iniciativa Economía del Cambio Climático en Centroamérica y la República Dominicana (ECC-CARD) que se inició en 2008 (véase el capítulo X). Uno de los objetivos de la ECC-CARD fue establecer las bases para fomentar una inversión pública resiliente a los efectos del cambio climático. El proyecto, de acuerdo con la CEPAL (2011), se emprendió en colaboración con el Consejo de Ministros de Medio Ambiente, bajo la iniciativa de la Comisión Centroamericana de Ambiente y Desarrollo (CCAD). Luego el trabajo se ha ido extendiendo a otros sectores de la institucionalidad centroamericana, entre ellos los Ministerios de Hacienda o Finanzas. Por la vía del COSEFIN, se ha formado una comunidad de práctica relacionada específicamente con la inversión pública.

La Secretaría Ejecutiva, con el apoyo del Ministerio de Hacienda de El Salvador, elaboró un documento base del plan operativo de la MIF. Dicho documento fue elevado posteriormente al plano regional, con la participación 
del GTPF. Los integrantes de este grupo consensuaron y validaron técnicamente el plan operativo, que fue aprobado por el Consejo en julio de 2018. Además, varias organizaciones internacionales han respondido al llamado de la Secretaría Ejecutiva.

\section{Resultados más relevantes del trabajo del COSEFIN}

Durante los primeros años (entre 2006 y 2011), la agenda del COSEFIN estuvo marcada por la discusión en los ámbitos tributarios de la entrada en vigor del DR-CAFTA (el tratado entró en vigor entre 2006 y 2008). En esta primera etapa, que es cuando surge el Consejo, se concretaron trabajos técnicos y discusiones sobre temas regionales, entre los que destacan los que se enumeran a continuación.

\section{a) La elaboración y discusión del código de conducta sobre incentivos fiscales a la inversión}

La elaboración de este código de conducta dejó varias lecciones con respecto a la institucionalidad y la manera de deliberar del Consejo, así como un valioso trabajo realizado por un grupo de técnicos que se formaron en el proceso en temas especializados de política tributaria internacional. Esa labor requirió la implementación de la matriz regional de incentivos fiscales y la revisión de la legislación conexa en cada uno de los países miembros. Este esfuerzo, en vista de la decisión adoptada por el Consejo en 2018 respecto del tema de las exenciones y privilegios fiscales, debería retomarse a fin de tener una visión fundamentada de los costos y beneficios que ha tenido para los países y la región la guerra de incentivos que en 2007 condujo a la falta de consenso sobre la implementación del código.

\section{b) Los análisis realizados para el establecimiento de la Unión Aduanera Centroamericana}

Estos análisis han servido de base para dos elementos recientes en los que ha habido acuerdo a nivel intersectorial con el COMIECO: el establecimiento del mecanismo de devolución del derecho arancelario a la importación (compromiso derivado del Acuerdo de Asociación con la Unión Europea) y la Unión Aduanera entre Guatemala y Honduras.

\section{c) Modelo de normas para el tratamiento de precios de transferencia}

La discusión en el seno del COSEFIN de diversos marcos tributarios a nivel internacional desencadenó reformas institucionales en los países, con la implementación de unidades de análisis de precios de transferencia. En algunos países, estos precios se han incorporado en proyectos de reformas tributarias y algunas normas conexas. 
El COSEFIN dejó a un lado la discusión de temas relacionados con política tributaria internacional, que habían dado origen al Consejo, debido a que hubo un desgaste dentro de este órgano al no lograrse consenso respecto del código de conducta sobre incentivos fiscales a la inversión, antes de la entrada en vigor del DR-CAFTA. Después, los países se enfrascaron en una guerra de incentivos para atraer inversión extranjera directa y mantener zonas francas. El apoyo financiero del FMI y el BID comenzó a disminuir y la comunidad de aprendizaje creada en los Ministerios para realizar los trabajos técnicos empezó a carecer de asistencia técnica y financiamiento que les permitieran seguir celebrando reuniones con la intensidad de los primeros años.

En 2009 se comenzaron a sentir los efectos de la crisis financiera internacional de 2008 y se redujeron drásticamente los ingresos tributarios, que en su mayoría dependen de los tributos indirectos. También cayeron las importaciones y, con ello, el IVA relacionado con estas. Se inició entonces una nueva etapa para el Consejo, que exigía respuestas sobre la forma de enfrentar los efectos de la crisis y las propuestas que podrían plantearse a nivel regional. Además, se terminó de negociar el Acuerdo de Asociación Comercial con la Unión Europea, que tenía implicaciones tributarias. Estos dos últimos elementos fueron primordiales en la discusión y los trabajos del COSEFIN en esta segunda etapa. A continuación se enumeran los resultados más relevantes de este período, derivados de las discusiones en el seno del COSEFIN.

\section{d) Acción conjunta ante el FMI}

El Consejo solicitó análisis técnicos sobre el impacto de la crisis en las finanzas públicas de los países miembros. Lo anterior derivaría en una acción conjunta ante el FMI, con una presentación de los Ministros agrupados en el COSEFIN ante el Director Gerente del FMI en Washington, D.C., en vista de la crisis financiera mundial de 2008-2009. Específicamente, se solicitó que el tradicional apoyo de balanza de pagos de este organismo pudiera ser en forma de apoyo presupuestario. Esta gestión conjunta, respaldada por un mandato presidencial centroamericano y por el Departamento del Tesoro de los Estados Unidos, condujo a que al menos un país, la República Dominicana, lograra que el apoyo de balanza de pagos fuera en forma de apoyo presupuestario directo (Fuentes, 2017).

\section{e) Mecanismo de reembolso del Arancel Centroamericano de Importación (derechos a la importación)}

En el contexto de la entrada en vigor del Acuerdo de Asociación Comercial con la Unión Europea, se inició en este período la discusión sobre este acuerdo, que después sería uno de los primeros mecanismos convenidos en el Comité Intersectorial COMIECO-COSEFIN. 


\section{f) Fondo de seguro contra riesgos de catástrofe para el Caribe}

Ante el incremento de los costos asociados con los impactos de las amenazas naturales, se dio inicio en este período a la discusión sobre la incorporación al Fondo de seguro contra riesgos de catástrofe para el Caribe (CCRIF) del bloque de países que conforman el COSEFIN. Esta entidad solicitó al Banco Mundial que estableciera opciones de financiamiento de riesgos soberanos ante desastres, a partir de lo cual el bloque recurrió a la alternativa de adherirse al CRIFF. En abril de 2015 se firmó un memorándum de entendimiento entre el CCRIF y el COSEFIN, que permitió a los países integrantes de este último tener acceso al seguro de riesgo de catástrofe proporcionado por el CCRIF. Los miembros del COSEFIN podrían tener incidencia en la orientación de estos recursos (con un representante ante el consejo directivo de este mecanismo) en la medida en que varios Gobiernos centroamericanos tomaran la decisión de adherirse. Nicaragua ha sido el único país centroamericano que ha aprovechado esta oportunidad, al firmar un Acuerdo de Participación en 2015, con lo que adquirió cobertura contra ciclones tropicales y terremotos (Fuentes, 2017).

En la medida en que los países fueron saliendo de la crisis, las reuniones del COSEFIN retomaron una amplia gama de temas. La falta de continuidad en algunos de los temas se ha debido en parte a la escasa frecuencia de las reuniones del Consejo (en 2012, 2013 y 2014 se reunieron una vez al año y apenas en 2015 fue que se celebró más de una reunión anual). Discurría en paralelo el proceso de fortalecimiento financiero de la Secretaría Ejecutiva mediante el aporte de sus miembros y el inicio de la sistematización del trabajo del Consejo en esa nueva etapa.

En este período, que comenzó en 2012, se discutieron temas variados: el proyecto mesoamericano del BID de gestión coordinada de fronteras, la iniciativa BEPS y el mercado regional de deuda, entre otros. Sin embargo, podría señalarse que los aspectos más relevantes del período han sido los siguientes:

- La aprobación del reglamento de organización y funcionamiento del Consejo. Este instrumento le ha permitido al Consejo gestionar mejor sus reuniones, realizar el seguimiento de acuerdos y comenzar las labores relacionadas con el Sistema de Integración Centroamericana, por conducto del Consejo de Ministros de Relaciones Exteriores y el COMIECO.

- La aprobación conjunta por el COMIECO y el COSEFIN del mecanismo de reembolso del derecho arancelario a la importación, después de un trabajo técnico conjunto entre especialistas de los Ministerios de Hacienda o Finanzas y los de Economía. 
- La disposición de Panamá y la República Dominicana a formar parte del Convenio de Asistencia Mutua y Cooperación Técnica entre las Administraciones Tributarias y Aduaneras de Centroamérica, que los demás países habían firmado en 2006.

- El inicio de dos debates que ponen de relieve la ventaja de actuar conjuntamente: uno relacionado con la conveniencia de presentar una posición conjunta en la Junta de Gobernadores del Banco Mundial, ante su recapitalización, y otro presentado por el BCIE al COSEFIN sobre la incorporación de Chile y la República de Corea.

- Por último y no menos importante, esta etapa está marcada por la definición de un tema prioritario en la agenda de trabajo: la Matriz de Interés Fiscal.

\section{Conclusiones y desafíos de la integración centroamericana en materia fiscal: la visión de la CEPAL}

\section{Conclusiones}

La integración centroamericana es la más dinámica de América Latina en cuanto al intercambio comercial. Sin embargo, la coordinación fiscal en la región es aún incipiente. La pregunta a la que se trata de dar respuesta en este capítulo, es decir, si la integración centroamericana en materia fiscal ha sido impulsada por los acuerdos comerciales, puede responderse de manera afirmativa. El COSEFIN surge como consecuencia de los retos previstos en materia de incentivos para atraer inversión extranjera directa, ante la entrada en vigor del DR-CAFTA.

El inicio de las negociaciones del Acuerdo de Asociación con la Unión Europea encontró una institucionalidad fiscal centroamericana creada, pero con insuficiencias que le impidieron formar parte de las negociaciones. A pesar de ello, se da en este marco el primer trabajo intersectorial entre el COMIECO y el COSEFIN con la definición del mecanismo único de devolución del derecho arancelario a la importación.

Por otro lado, la Unión Aduanera Centroamericana se ha centrado en los últimos diez años en la facilitación del comercio. Se han registrado avances concretos en la coordinación de procedimientos y regulaciones aduaneras y en la armonización de las normas (como las fitosanitarias) que se aplican a los productos importados, indispensables para alcanzar la facilitación del comercio. La entrada en vigor de la Unión Aduanera entre Guatemala y Honduras (2017) y la adhesión de El Salvador (2018) representan una gran oportunidad para la región. Sin embargo, se ha avanzado a un ritmo más lento en los esfuerzos encaminados a la coordinación e integración fiscal. 
Si bien el COSEFIN surgió de las preocupaciones en materia de impuestos derivadas de los acuerdos comerciales, con el tiempo ha ido consolidando una institucionalidad que le ha permitido conocer una gama más amplia de temas, más allá de los tributarios, y contribuir a la concertación de acuerdos sobre esos temas. El compromiso de financiar la SE-COSEFIN con aportes de los Estados, la aprobación del reglamento, el establecimiento de una agenda de trabajo (la MIF) y la definición de prioridades dentro de ella demuestran que poco a poco la institucionalidad se ha ido consolidando.

\section{Desafíos}

De acuerdo con Fuentes (2006, pág. 48),

[...] la integración, o la coordinación fiscal centroamericana, puede visualizarse desde dos ángulos. Uno, acorde con la magnitud de los desafíos existentes, puede conducir a concebir acciones de integración y cooperación ambiciosas, donde la propia integración puede servir para darle un impulso fuerte a las políticas fiscales nacionales en cada país, conformando así una amplia agenda centroamericana de política fiscal. Otro enfoque es avanzar con algunos de los componentes de esta agenda más amplia de manera independiente, logrando avances parciales en la medida de lo posible.

La primera concepción llevaría a colocar la política fiscal como uno de los temas fundamentales de la agenda centroamericana de integración. Ello implicaría asumir compromisos políticos comunes que pudieran servir de asideros para políticas o acuerdos nacionales, $\mathrm{o}$ que representaran una armonización de políticas nacionales, sin dejar de reconocer que verdaderos "pactos fiscales" nacionales duraderos generalmente involucran un cambio en la correlación interna de las fuerzas políticas y sociales de un país [...].

Desde su creación, y más recientemente en 1998, la CEPAL ha propuesto un pacto fiscal, entendido como un acuerdo sociopolítico básico que legitime el papel del Estado y el ámbito y el alcance de las responsabilidades gubernamentales en las esferas económica y social. Los cinco pilares del pacto se sustentan en: i) consolidar el ajuste fiscal en marcha en los países de América Latina y el Caribe; ii) elevar la productividad de la gestión pública; iii) dotar de mayor transparencia la acción fiscal; iv) promover la equidad, y v) favorecer el desarrollo de la institucionalidad democrática. Aunque su puesta en marcha sigue siendo un reto para los países de la región, puede servir de guía a los futuros trabajos centroamericanos en materia fiscal.

La integración comercial del sector privado regional es profunda, por lo que un desafío común es iniciar un diálogo regional que establezca mínimos para la realización de reformas fiscales nacionales que estén coordinadas. 
Esto implicaría la creación de compromisos de promover en cada país el desarrollo de recursos que contribuyan a la equidad y no únicamente a la competitividad en un sentido restringido (Fuentes, 2006). Lo anterior podría iniciarse con una evaluación de las tensiones entre los resultados positivos de la apertura comercial, sus efectos negativos en la recaudación y sus implicaciones para el financiamiento de los Estados.

Entre los principales desafíos que podrían contemplarse en el marco de la cooperación centroamericana en el ámbito fiscal están los siguientes:

- Evaluar el costo y el beneficio de las exenciones y exoneraciones fiscales en la región, y determinar los mecanismos (más allá de los tributarios) que mejor respondan a los objetivos de generación de empleo decente y atracción de la inversión extranjera directa, sin afectar la carga tributaria de los países y contribuyendo al inicio de una armonización del impuesto sobre la renta. Este esfuerzo debe ser regular y debería promoverse su discusión continua en el marco de la institucionalidad centroamericana.

- Armonizar la tributación indirecta, incluidos los impuestos sobre la venta o el IVA, los aranceles (con calendario para el arancel externo común) y los impuestos selectivos, con tasas convergentes y con excepciones comunes que reduzcan su regresividad.

- Acordar acciones y resultados comunes, fortalecidos mediante reformas de la política fiscal en cada país, con miras a impulsar el desarrollo o la protección de los bienes públicos regionales. Entre estos cabría mencionar la seguridad ciudadana y la protección de la democracia, un mercado único de bienes y servicios en la región, la protección del medio ambiente y la prevención de desastres.

- Establecer un mecanismo que permita captar y distribuir los ingresos resultantes de los aranceles externos recaudados en las aduanas centroamericanas periféricas, con el fin de garantizar la existencia de un territorio aduanero común.

- Establecer reglas para evitar mecanismos de evasión y elusión tributaria internacional, tales como la manipulación de los precios de transferencia, los paraísos fiscales y la competencia de incentivos para atraer flujos de inversión extranjera directa. La formación de cuadros profesionales en los Ministerios o Secretarías de Finanzas o Hacienda y las instituciones encargadas de la recaudación de impuestos podría ser un primer paso en esa dirección.

Para alcanzar la armonización fiscal plena en el camino a una integración fiscal, es recomendable que los grupos técnicos de trabajo realicen una serie de tareas, como:

- la revisión de los mecanismos de registro para que las estadísticas regionales de comercio sean coherentes; 
- la definición de un instrumento que permita institucionalizar el intercambio automático de información relevante entre los sistemas aduaneros de los países de la región y reforzar los mecanismos existentes de intercambio de información tributaria, y

- la evaluación de mecanismos de devolución del crédito del IVA aplicado a transacciones que se llevan a cabo dentro de Centroamérica.

Por el lado institucional, aunque la Secretaría Ejecutiva del COSEFIN y el Consejo de Ministros no han celebrado reuniones con la frecuencia deseada, su institucionalidad ha ido consolidándose. La experiencia del COSEFIN sugiere mayor potencial de acción cuando converge el interés de todos los países (o de la mayoría) en torno a temas importantes (por ejemplo, las consecuencias tributarias de la unión aduanera, la implementación de reformas del impuesto sobre la renta, el acceso a recursos del FMI o la participación en un mecanismo para enfrentar riesgos catastróficos) en que la acción conjunta añade valor a la acción nacional. La iniciativa de erosión de la base imponible y el traslado de beneficios (BEPS) podría representar un tema de interés regional con estas características.

La acción regional se potencia con el acompañamiento técnico continuo. En ese sentido, la cooperación internacional puede desempeñar un papel decisivo, sobre todo cuando fortalece el trabajo conjunto y el intercambio de técnicos especializados de cada país. Con ello, la cooperación técnica pone de relieve el valor agregado de la acción regional. De este modo va surgiendo una comunidad regional de aprendizaje que se beneficiaría al contar con una secretaría ejecutiva que tuviera la capacidad de dar seguimiento técnico especializado a los temas de trabajo. Una secretaría ejecutiva con capacidad técnica en los temas de interés de los Ministros de Hacienda o Finanzas de la región garantizaría la continuidad y la memoria institucional, así como una visión consolidada a nivel regional, lo que no siempre se logra con los grupos de trabajo conformados por técnicos nacionales. En este contexto, la CEPAL mantiene su compromiso de acompañar los esfuerzos de los países centroamericanos con miras a una plena integración regional. 


\section{Bibliografía}

Agosin, M., A. Barreix y R. Machado (eds.) (2005), Recaudar para crecer: bases para la reforma tributaria en Centroamérica, Washington, D.C., Banco Interamericano de Desarrollo (BID).

Baldinelli, E. (1993), "Políticas monetarias y fiscales en la integración regional", Integración Latinoamericana, mayo-junio.

Barreix, A., M. Bès y J. Roca (2009), Equidad fiscal en Centroamérica, Panamá y República Dominicana, Washington, D.C., Banco Interamericano de Desarrollo (BID)/Eurosocial.

Caballeros, R. (2008), “Centroamérica: los retos del Acuerdo de Asociación con la Unión Europea", serie Estudios y Perspectivas-Sede Subregional de la CEPAL en México, N 102 (LC/L.2925-P-LC/MEX/L.869), Ciudad de México, Comisión Económica para América Latina y el Caribe (CEPAL), julio.

Cáceres, L. (2007), "Los retos de la integración centroamericana”, Comercio Exterior, vol. $57, \mathrm{~N}^{\circ} 1$.

Caldentey, P. (2014), "Los desafíos estratégicos de la integración centroamericana", serie Estudios y Perspectivas-Sede Subregional de la CEPAL en México, $\mathrm{N}^{\circ} 156$ (LC/L.3897-LC/MEX/L.1159), Ciudad de México, Comisión Económica para América Latina y el Caribe (CEPAL).

CEMLA (Centro de Estudios Monetarios Latinoamericanos) (2012), La cooperación entre bancos centrales a principios del siglo XXI, Ciudad de México.

CEPAL (Comisión Económica para América Latina y el Caribe) (2018a), Agenda 2030 y los Objetivos de Desarrollo Sostenible: una oportunidad para América Latina y el Caribe (LC/G.2681/Rev.2), Santiago, enero.

(2018b), Centroamérica y la República Dominicana: evolución económica en 2017 y perspectivas para 2018. Balance Preliminar (LC/MEX/TS.2018/3), Ciudad de México, febrero.

(2017), Posibles efectos económicos y sociales de la profundización de la Unión Aduanera entre Guatemala y Honduras (LC/TS.2017/53), Santiago, junio.

(2011), La economía del cambio climático en Centroamérica. Reporte técnico 2011 (LC/MEX/L.1016), Ciudad de México, julio.

(2000), La fuerza de la nueva integración centroamericana: convergencias y divergencias de la política fiscal y monetaria (LC/MEX/L.443), Ciudad de México, septiembre. (1999), La conformación del Área de Libre Comercio de las Américas (ALCA): aspectos institucionales y comerciales (LC/MEX/L.405-LC/MEX/R.678), Ciudad de México, octubre.

(1998), El pacto fiscal: fortalezas, debilidades y desafíos, Libros de la CEPAL, N 47 (LC/G.1997/REV.1-P), Santiago, Comisión Económica para América Latina y el Caribe (CEPAL).

(1984), Informe de la Primera Reunión de Ministros de Finanzas o de Hacienda de Centroamérica (E/CEPAL/CCE/L.419), Ciudad de México, octubre.

COSEFIN (Consejo de Ministros de Hacienda o Finanzas de Centroamérica, Panamá y la República Dominicana) (2012), Reglamento de Organización y Funcionamiento del COSEFIN, Punta Cana, 25 de julio.

Cuevas, M. A. (2008), "Evolución reciente del sistema financiero de Centroamérica y retos planteados para la política de competencia", documento para discusión, II Foro Centroamericano de Competencia, Antiguo Cuscatlán, 26-27 de junio. 
Espitia, G. (2004), Descentralización fiscal en Centroamérica: estudio comparativo, San Salvador, Conferencia Centroamericana por la Descentralización del Estado y el Desarrollo Local (CONFEDELCA)/ Deutsche Gesellschaft für Internationale Zusammenarbeit (GIZ)/Diputación de Barcelona.

Fuentes, J. (2017), Institucionalidad y perspectivas, COSEFIN (Consejo de Ministros de Hacienda o Finanzas de Centroamérica, Panamá y la República Dominicana), marzo. (2006), "Retos de la política fiscal en Centroamérica", serie Estudios y PerspectivasSede Subregional de la CEPAL en México, Nº 64 (LC/L.2646-P-LC/MEX/L.719/ Rev.2), Ciudad de México, Comisión Económica para América Latina y el Caribe (CEPAL), noviembre.

Funes, O. (2011), "Retos de la Unión Aduanera en Centroamérica", serie Estudios y Perspectivas-Sede Subregional de la CEPAL en México, N 131 (LC/L.3401-LC/ MEX/L.1036), Ciudad de México, Comisión Económica para América Latina y el Caribe (CEPAL), octubre.

Guerra-Borges, A. (2010), “Integración económica centroamericana: situación actual y conjeturas sobre sus perspectivas", Aldea Mundo, vol. 15, $\mathrm{N}^{\circ} 30$.

Hernández, R. y C. Schatan (2002), "Políticas de competencia y de regulación en el istmo Centroamericano", serie Estudios y Perspectivas-Sede Subregional de la CEPAL en México, N 11 (LC/MEX/L.544-LC/L.1806-P), Ciudad de México, Comisión Económica para América Latina y el Caribe (CEPAL), diciembre.

ICEFI (Instituto Centroamericano de Estudios Fiscales) (2018), Perfiles Macrofiscales de Centroamérica, $\mathrm{N}^{\circ}$ 9, enero.

(2016), Panorama de la politica fiscal de Centroamérica. Quinto Informe Estado de la Región [en línea] https://estadonacion.or.cr/files/biblioteca_virtual/ centroamerica/005/Panorama-Economico/ICEFIInformefinalrevisado.pdf. (2012), La política fiscal de Centroamérica en tiempos de crisis, Guatemala, Instituto Centroamericano de Estudios Fiscales.

Kim, J. y L. Papi (2005), "La integración regional y los regímenes cambiarios", América Central: integración global y cooperación regional, M. Rodlauer y A. Schipke (eds.), Occasional Paper, $\mathrm{N}^{\circ}$ 243, Washington, D.C., Fondo Monetario Internacional (FMI).

Medina, A. (2016), “Centroamérica: la política fiscal en 2015 y 2016”, Observatorio Fiscal, $\mathrm{N}^{\circ} 32$ [en línea] https:/ / www.icefi.org/sites/default/files/observatorio_ fiscal_no_32_epoca_ii.pdf.

OCDE (Organización de Cooperación y Desarrollo Económicos) (2006), "La región mesoamericana: sureste de México y América Central”, Estudios Territoriales de la OCDE.

OMC (Organización Mundial del Comercio) (s/f), "La OMC y los Objetivos de Desarrollo Sostenible", [en línea] https:/ /www.wto.org/spanish/thewto_s/ coher_s/sdgs_s/sdgs_s.htm.

Patten, C. y otros (2003), La integración centroamericana: realidad y perspectivas. El proceso de integración centroamericano y el papel de la Unión Europea, Bélgica, Comisión Europea.

Paunovic, I. (2005), “El Tratado de Libre Comercio Centroamérica-Estados Unidos: implicaciones fiscales para los países centroamericanos", serie Estudios y PerspectivasSede Subregional de la CEPAL en México, №34 (LC/L.2315-P), Ciudad de México, Comisión Económica para América Latina y el Caribe (CEPAL), mayo.

Paunovic, I. y J. Martínez (2003), “El impacto fiscal del CAFTA en los países centroamericanos", Comisión Económica para América Latina y el Caribe (CEPAL), diciembre. 
Pellandra, A. y J. Fuentes (2011), "El estado actual de la integración en Centroamérica”, series Estudios y Perspectivas-Sede Subregional de la CEPAL en México, N ${ }^{\circ} 129$ (LC/L.3360-LC/MEX/L.1017), Ciudad de México, Comisión Económica para América Latina y el Caribe (CEPAL), agosto.

Puchet, J. y F. Torres (2000), “Las finanzas públicas y la política fiscal en las economías de Centroamérica durante los años noventa y perspectivas de corto y mediano plazo", serie Política Fiscal, N 98 (LC/L.1028-P), Santiago, Comisión Económica para América Latina y el Caribe (CEPAL), marzo.

Rivas, J. e I. Paunovic (2005), "Implicaciones fiscales del área de libre comercio de las américas para los países de Centroamérica", documento de trabajo, Comisión Económica para América Latina y el Caribe (CEPAL)/Organismo Canadiense de Desarrollo Internacional (CIDA).

Rodlauer, M. y A. Schipke (eds.) (2005), “Centroamérica: integración mundial y cooperación regional", Occasional Paper, $\mathrm{N}^{\circ}$ 243, Washington, D.C., Fondo Monetario Internacional (FMI).

Rueda-Junquera, F. (2013), “Acuerdo de Asociación Unión Europea-Centroamérica: oportunidades y riesgos (I)", 13 de marzo [en línea] http:/ / www.condistintosacentos. com/acuerdo-de-asociacion-union-europea-centroamerica-oportunidades-yriesgos-i/.

Van Beers, C. y H. Linnemann (1991), "Commodity composition of trade in manufactures and South-South trade potential", The Journal of Development Studies, vol. 27, N 4 .

Vegh, C., Lederman, D. y F. Bennett (2017), "Leaning against the wind: fiscal policy in Latin America and the Caribbean in a Historical Perspective", Latin American and the Caribbean Semiannual Report, Banco Mundial, abril.

Villagómez, F. (2011), Centroamérica y República Dominicana: estudio sobre la posibilidad de implementar un indicador de balance estructural como instrumento de política fiscal (LC/MEX/L.1046), Ciudad de México, Comisión Económica para América Latina y el Caribe (CEPAL).

Zapata, R. y E. Pérez (2001), “Pasado, presente y futuro del proceso de integración centroamericano", serie Estudios y Perspectivas-Sede Subregional de la CEPAL en México, No 6 (LC/L.1643-P LC/MEX/L.500), Ciudad de México, Comisión Económica para América Latina y el Caribe (CEPAL), noviembre. 

Capítulo VIII

\section{Infraestructura logística y movilidad: las arterias de la integración centroamericana}

Gabriel Pérez-Salas

Ricardo J. Sánchez

\section{Introducción}

La integración de América Latina y el Caribe es un proceso multidimensional, que abarca no solo las temáticas económicas y comerciales, sino también las políticas, sociales, culturales y ambientales (CEPAL, 2014). Si bien la integración política, comercial y económica ha sufrido variadas vicisitudes y crisis a lo largo de las décadas pasadas, la integración física regional, es decir, la interconexión de la infraestructura económica y de los servicios que la aprovechan, ha logrado mantenerse a lo largo del tiempo. Incluso ha avanzado en períodos de grandes controversias políticas y crisis económicas, al punto de constituirse en una de las bases sobre la que se afianza el resto del proceso integracionista (CEPAL, 2009).

La Comisión Económica para América Latina y el Caribe (CEPAL) ha desempeñado siempre un rol preponderante en la integración física centroamericana. Desde su tercer período de sesiones, celebrado en junio de 1950, recomendó a los Gobiernos latinoamericanos que, al formular programas y adoptar medidas de fomento económico, "tengan en cuenta las posibilidades de expansión de la demanda mediante el intercambio recíproco, a fin de lograr una mejor integración de sus economías y un más elevado 
desarrollo de su productividad y de su ingreso real"1. Como respuesta, los países centroamericanos pidieron a la CEPAL que actuara como secretaría técnica para la integración centroamericana. De este modo, el programa de integración económica dejó de tener un énfasis casi exclusivo en el comercio, como hasta ese momento, y comenzó a incorporar la planificación coordinada de las actividades productivas y del transporte propuesta por la CEPAL (Fuentes, 1973). Posteriormente, en 1960, se plantea la importancia de las redes de infraestructura para la integración regional. Se establece que, para coronar con éxito la Asociación Latinoamericana de Libre Comercio (ALALC) (actualmente Asociación Latinoamericana de Integración (ALADI)), es fundamental elaborar una política regional de transporte y energía que favorezca la adecuada integración económica regional (Brown, 1966).

En las últimas décadas, la región centroamericana ha dado nuevos pasos trascendentales en la integración física regional, tanto por la reciente promulgación de su política marco centroamericana de logística y movilidad como por los grandes avances que ha realizado el Sistema de Interconexión Eléctrica de los Países de América Central (SIEPAC) (véase el capítulo IX). Estos elementos, sin duda, constituyen un hito importante en el proceso de integración y la génesis de la ruta conducente al desarrollo de una infraestructura integral para la región (SIECA, 2018).

En el presente capítulo se analizan las principales características del proceso llevado a cabo por la región con miras a la promulgación de la política marco de logística y movilidad de Centroamérica realizada con apoyo de la CEPAL. Se destacan, sobre todo, las fortalezas del proceso, las lecciones aprendidas, así como los elementos aún pendientes para alcanzar una plena integración logística en la región².

\section{A. Importancia de la infraestructura para los procesos de integración regional}

La infraestructura constituye un elemento central del sistema económico, social y territorial de un país. No solo permite la materialización de flujos de bienes, servicios y personas, sino que también constituye un elemento fundamental para brindar la conectividad necesaria con miras a asegurar el acceso a los servicios básicos de salud y educación y al mercado del trabajo de una forma segura y accesible para lograr un desarrollo sostenible en su sentido más amplio (Rozas y Sánchez, 2004).

Véase la resolución sobre desarrollo económico y política anticíclica del 20 de junio de 1950 (E/CN.12/194).

2 A efectos de este capítulo, la denominación "Centroamérica" se refiere a los países miembros del Sistema de la Integración Centroamericana (SICA): Belice, Costa Rica, El Salvador, Guatemala, Honduras, Nicaragua, Panamá y la República Dominicana, a menos que expresamente se indique otra cosa. 
En virtud de las exigencias de una mayor competitividad en los mercados internacionales y del desarrollo económico, los países de la región han requerido ampliar y modernizar su infraestructura de forma acorde a las nuevas necesidades y estándares tecnológicos internacionales. Sin embargo, esta modernización se ha centrado principalmente en obras orientadas al comercio exterior (por ejemplo, puertos, aeropuertos o grandes corredores viales) y se han descuidado las infraestructuras interiores. Esto no solo ha provocado una degradación progresiva de la cobertura y la calidad de vida de la población, sino que ha representado la pérdida de una excelente oportunidad para la implementación eficaz de políticas públicas, el pleno logro de metas de desarrollo sostenible y la concreción de los propios objetivos de la igualdad.

En el caso de la región centroamericana, la base de datos INFRALATAM muestra que los países están invirtiendo alrededor del 1\% de su producto interno bruto (PIB) nacional en el sector del transporte 3 . Sin embargo, para hacer frente a la demanda esperada en el período 2016-2030, deberían invertir anualmente alrededor del 2,2\% de su PIB en infraestructura del transporte, incluido el gasto en mantenimiento y reparaciones rutinarias de las obras.

Es importante tener presente que en estos valores no necesariamente se toman en cuenta las mejoras de diseño ni los nuevos materiales y tecnologías. Tampoco se consideran las nuevas inversiones asociadas a la resiliencia, la adaptación y la mitigación del cambio climático, a las que se hace referencia en las metas de los Objetivos de Desarrollo Sostenible (ODS) establecidos en la Agenda 2030 para el Desarrollo Sostenible (véase el cuadro VIII.1).

\section{Cuadro VIII.1 \\ Centroamérica y México: inversión promedio en el sector del transporte, 2008-2015 \\ (En porcentajes del PIB nacional)}

\begin{tabular}{lc}
\hline País & Inversión en transporte \\
\hline Belice & 0,96 \\
\hline Costa Rica & 1,25 \\
\hline El Salvador & 0,93 \\
\hline Guatemala & 1,23 \\
\hline Honduras & 2,21 \\
\hline México & 0,77 \\
\hline Nicaragua & 1,99 \\
\hline Panamá & 3,68 \\
\hline República Dominicana & 1,32 \\
\hline
\end{tabular}

Fuente: Comisión Económica para América Latina y el Caribe (CEPAL), sobre la base de Datos de Inversión en Infraestructura Económica (INFRALATAM), 2018 [en línea] http://infralatam.info/.

INFRALATAM es una iniciativa del Banco Interamericano de Desarrollo (BID), el Banco de Desarrollo de América Latina (CAF) y la CEPAL con miras a crear un banco de datos de inversión pública y privada en infraestructura económica, realizada por los países de América Latina y el Caribe. Véase [en línea] http://infralatam.info/. 
Cuando el análisis de la inversión se realiza por tipo de infraestructura, como se muestra en el gráfico VIII.1, se observa que en la mayoría de los países las infraestructuras viales concentran un porcentaje considerable de la inversión total (pública y privada), con una participación que va desde el 76\% de la inversión total en Honduras hasta el $98 \%$ en el caso de Belice. Un caso especial es el de Panamá, donde el 59\% de la inversión acumulada en el período 2008-2015 corresponde a obras portuarias y marítimas. Sin embargo, es importante tener presente que en este período se registran las obras de ampliación del Canal de Panamá, por lo que, de omitirse esta inversión, el comportamiento del país sería similar al del resto de la región.

\section{Gráfico VIII.1 \\ Centroamérica (7 países) y México: inversión promedio por tipo de infraestructura de transporte, 2008-2015 \\ (En porcentajes del PIB nacional)}

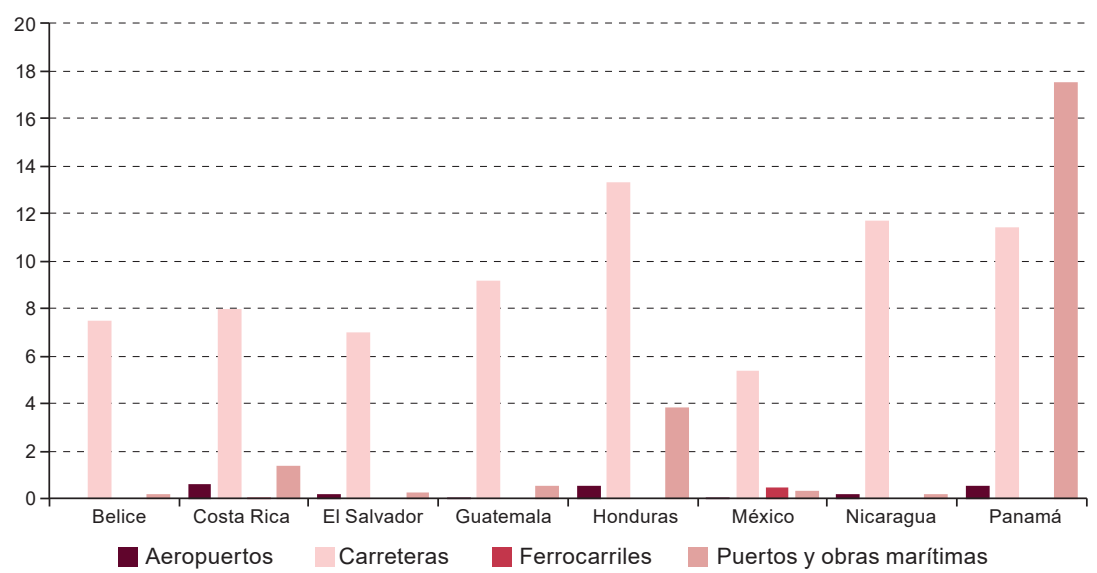

Fuente: Comisión Económica para América Latina y el Caribe (CEPAL), sobre la base de Datos de Inversión en Infraestructura Económica (INFRALATAM), 2018 [en línea] http://infralatam.info/.

Debido a la magnitud del déficit de infraestructura en la región, estas inversiones son insuficientes para ampliar la capacidad y asegurar el mantenimiento y actualización de las vías con la incorporación de nuevos estándares de diseño y seguridad que mejoren la calidad y la cobertura territorial de los servicios. Preocupa especialmente la falta de inversiones para mejorar la conectividad con el territorio, sobre todo con las zonas rurales y más alejadas de las grandes urbes, puesto que vastas zonas del territorio aún poseen dotaciones de infraestructura económica disímiles, con tiempos de tránsito muy altos o servicios ineficientes e inseguros debido a la escasa infraestructura disponible. Esto es muy pertinente en el actual contexto de demanda creciente de servicios de movilidad y logística urbana, en el que, además del precio, la población exige servicios puntuales, seguros y eficientes, tanto en los núcleos urbanos como en el ámbito rural. 
Por otra parte, pese a la gran inversión realizada en comparación con el resto de las infraestructuras, la infraestructura vial se concentra principalmente en los corredores principales (carreteras) y las zonas urbanas. Se destina muy poco a la ampliación y mantenimiento de las vías secundarias, caminos interiores o puentes rurales, que resultan fundamentales para la conectividad social y la competitividad de las cadenas logísticas de recursos naturales, como se analiza más adelante.

En los puertos y aeropuertos de la región, el crecimiento de los volúmenes de tráfico internacional, tanto de carga como de pasajeros, respectivamente, provoca una gran presión sobre la infraestructura disponible. En términos generales, esa situación se está resolviendo mediante un uso más productivo de las inversiones históricas, la optimización de procesos y la incorporación de mayor tecnología, de la mano de la inversión privada. Sin embargo, la continua demanda de mayor velocidad de operación, aranceles competitivos y servicios de valor añadido, junto al incremento del tamaño promedio de los equipos de transporte, hacen que la demanda de nueva infraestructura requiera mayores instalaciones. Incluso es posible que sea necesario reubicar estos recintos, lo que no solo puede entrañar un cuello de botella logístico, sino también una fuente importante de conflictividad debido al traslado de estas actividades fuera de los márgenes tradicionales de la región.

En cuanto al cruce de fronteras terrestres, se observan algunas mejoras en la infraestructura física, e incluso existen controles integrados entre algunos países. Sin embargo, la logística centroamericana adolece de la falta de obras de apoyo a las exportaciones, como frigoríficos y zonas de consolidación, descarga, descanso o control fitosanitario, que funcionen de forma expedita y segura para la carga. También se ve afectada por una escasa infraestructura tecnológica, que no permite la coordinación óptima de las actividades entre los componentes de la cadena logística. Asimismo, las discrepancias regulatorias de un país a otro encarecen el comercio y dificultan el surgimiento de encadenamientos productivos interregionales. La seguridad logística es otro elemento de importancia, ya que la interrupción de una cadena de suministro, ya sea por actos delictivos, falta de inventario o cualquier fenómeno natural que imposibilite la distribución de productos, no solo provoca pérdidas económicas por esa falla en particular, sino que tiene un efecto de propagación al resto de la cadena logística.

El apoyo de las nuevas tecnologías para la visibilidad de la cadena logística es muy incipiente en Centroamérica, lo que puede ralentizar la entrada de otras tecnologías disruptivas como la tecnología de cadenas de bloque (blockchain), la Internet de las cosas, la inteligencia artificial, la automatización y la robótica, tecnologías que ya están siendo utilizadas en el sector logístico internacional y que inevitablemente provocarán cambios profundos en toda la cadena logística. Por ello es fundamental que la planificación logística, 
así como los actores regionales del sector, incorporen prontamente estas herramientas, no solo para solucionar los tradicionales problemas del sector logístico, sino además para crear nuevas oportunidades de negocios, favorecer la transformación productiva y aumentar la competitividad de la región.

\section{B. Desde el concepto tradicional de transporte hacia un concepto más avanzado de logística y movilidad}

El establecimiento de los Objetivos de Desarrollo Sostenible lleva necesariamente a una revisión profunda de algunos conceptos y términos vinculados al sector del transporte. La separación entre la infraestructura y sus servicios, entre los distintos modos de transporte o entre el transporte de carga y de pasajeros responde solo a una necesidad operativa. Por ese motivo, al concebir una visión nacional y regional de estos temas que promueva un desarrollo sostenible, se deberían considerar de forma conjunta todos los ámbitos geográficos, las operaciones y los sujetos involucrados o influenciados por las decisiones relacionadas con las políticas de transporte, sin importar si se trata de pasajeros o carga, o si estos flujos ocurren en el ámbito urbano, rural o de larga distancia. Los conceptos de logística y movilidad engloban esa riqueza semántica y, por ello, deben ser parte del vocabulario básico de las políticas públicas en materias que tradicionalmente se han visto en distintos ejes programáticos, según el modo, el ámbito o el sujeto de las operaciones de transporte.

El concepto moderno de logística dista bastante de la idea de compra, mantenimiento y transporte de pertrechos que le dio origen. Pese a ello, aún persiste en diversos sectores la opinión de que la logística es un tema únicamente vinculado a la distribución de mercaderías y la optimización de inventarios propia del sector privado. Por el contrario, debido a los profundos cambios acontecidos en la economía global y en los sistemas de producción y distribución, la logística es un elemento central de la competitividad del sector agropecuario, la minería, la industria y el comercio. Forma parte de la gestión de la cadena de suministros que planifica, implementa y controla el flujo de bienes, servicios e información desde el punto de origen al de consumo, con el objetivo de satisfacer de forma eficaz y eficiente las exigencias de los consumidores.

Por logística se entiende la provisión de servicios de infraestructura, la producción, la facilitación del movimiento de mercancías, la distribución de bienes y la regulación de servicios e información a lo largo de la cadena global. En este concepto se incluyen tanto las actividades logísticas propias del sector privado como la acción del Estado y sus políticas públicas de diseño, 
provisión, facilitación y regulación de la actividad. Según esta definición, en una política de logística se deberían considerar de manera integrada y sostenible las necesidades de infraestructura física, junto con la provisión de los servicios y la distribución y regulación de flujos comerciales y de transporte, dentro de cierto marco de objetivos de política económica y organización territorial. Tal enfoque permitiría realizar una provisión eficiente y sostenible de bienes de uso público e interés estratégico, como lo son la infraestructura económica y los servicios que la aprovechan. De este modo se maximiza el aporte de dichos servicios a la mejora de la productividad de los factores, a la competitividad de las economías, el correspondiente desarrollo social y la mitigación de las externalidades negativas.

De manera similar, el concepto de movilidad viene a sustituir el concepto tradicional del transporte de pasajeros. Se entiende por movilidad la provisión de servicios que resuelvan eficientemente las distintas necesidades de transporte de cada segmento de la población de una forma digna, oportuna, confiable, eficiente, segura y sostenible, independientemente del modo de transporte utilizado. Este concepto incorpora, desde el principio, los requisitos de calidad de los servicios ofrecidos, es decir, su accesibilidad económica y física, seguridad, mitigación de las externalidades negativas surgidas, consideraciones de género e inclusión de usuarios con movilidad reducida. Según este concepto, el Estado tiene la obligación indeclinable de asegurar la accesibilidad de su población a servicios de transporte de calidad razonable, a un precio al alcance de todo ciudadano, y con un costo aceptable para la comunidad (Pérez-Salas y Sánchez, 2010).

Históricamente, las políticas públicas de infraestructura y transporte en América Latina se han diseñado, implementado y regulado pensando en modos específicos de transporte. Así, por ejemplo, es común observar la existencia (o demanda) de una política portuaria, de transporte marítimo, política vial o, a veces, de fomento del transporte ferroviario o la marina mercante, por nombrar solo algunas. Esta forma de ver el transporte ha hecho que surja una visión disociada de los servicios de infraestructura, con lo que la acción del Estado se diluye en múltiples iniciativas, muchas veces inconexas y por tanto ineficientes, relacionadas con los servicios de infraestructura. En el plano regional, esta concepción favoreció además la competencia entre modos de transporte en desmedro de soluciones complementarias que favorecieran la competitividad y la productividad de la economía. Esto explica, en parte, la distribución modal poco eficiente e insostenible que existe en la región, en la que el sector automotor predomina sobre otras opciones modales más apropiadas, teniendo en cuenta las distancias y el tipo de mercancías que la región produce y comercializa. A modo de comparación, cabe señalar que la participación del sector del transporte por carretera en América Latina es 15 veces mayor que en los Estados Unidos (CAF/CEPAL/OCDE, 2013). 
El cambio requerido para hacer frente a los nuevos desafíos logísticos y de movilidad sostenible impone la necesidad de una modificación paradigmática de la concepción y el diseño de las políticas públicas sectoriales. Es preciso dejar de pensar en modos de transporte que utilizan infraestructuras aisladas y comenzar a pensar en sistemas de logística y movilidad integrados. Con ese fin, es fundamental aplicar el concepto de comodalidad, que debe entenderse como la utilización óptima de cada medio de transporte y su combinación con otros, de manera que el trayecto completo resulte eficiente y sostenible de acuerdo con las necesidades particulares del servicio a prestar y la distancia a recorrer. El enfoque comodal posee grandes ventajas en términos de la reducción de emisiones (cumplimiento del indicador 9.4.1 de los ODS) en comparación con un sistema unimodal, pues permite implementar simultáneamente acciones que favorecen la sostenibilidad ambiental y social, al mismo tiempo que contribuyen al aumento de la competitividad económica (Kim y Van Wee, 2009).

Tanto la logística como la movilidad sostenibles requieren una infraestructura física y tecnológica que favorezca la integración operativa y arancelaria de los distintos modos. La entrega de información oportuna y confiable al usuario mediante sistemas inteligentes de transporte permite que este decida cuál es el modo de transporte más conveniente para resolver su necesidad. A ese efecto, se requiere el apoyo de herramientas de regulación para poder operar cabalmente, mediante la introducción de normas técnicas y económicas que conformen un mecanismo regulador y de control. Al mismo tiempo, se deben introducir mecanismos de señales de precios que permitan penalizar, compensar o incentivar determinados comportamientos de los usuarios a fin de estimular el cambio modal y alcanzar un equilibrio entre los modos de transporte que coadyuve a optimizar el uso de los recursos. En el ámbito regional, esto implica, además, dejar de pensar en redes de infraestructura modales y promover la integración de infraestructuras logísticas. A este fin, han de combinarse las infraestructuras viales, ferroviarias, fluviales, aéreas y marítimas, al mismo tiempo que se facilitan los procedimientos físicos y regulatorios para cambiar de un modo al otro, según cuáles sean las necesidades particulares de cada operación logística o de usuario.

\section{Políticas públicas integradas y sostenibles de logística y movilidad}

Mediante los conceptos de "logística, "movilidad" y "comodalidad" se busca facilitar el abordaje integral de una gran variedad de temas vinculados al desplazamiento de bienes y personas. De esta forma se intenta superar las limitaciones sectoriales y de modelos de los conceptos más tradicionales, con el fin de lograr una visión más moderna y holística de los servicios de 
transporte en todos los ámbitos geográficos (urbano, interurbano, regional e internacional). También es fundamental incorporar nuevos criterios en las políticas sectoriales. En los estudios y trabajos realizados sobre el terreno por la CEPAL en los últimos años, se ha detectado que el debilitamiento del papel del Estado en las décadas pasadas ha tenido un efecto en la merma del uso de instrumentos y herramientas de planeamiento estratégico, lo que se ha traducido en dos problemas esenciales:

i) La alta dispersión y multiplicidad de visiones públicas con respecto a la infraestructura y los servicios, y la consecuente falta de integralidad en el abordaje de las políticas en sus diferentes procesos (concepción, diseño, implementación y seguimiento, fiscalización y evaluación).

ii) La debilidad o ausencia de criterios amplios de sostenibilidad (que comprenden tanto el ámbito económico como el social, institucional y medioambiental) en la concepción de las políticas de los servicios de infraestructura, sobre todo en lo que se refiere al transporte, es decir, la logística y la movilidad.

A fin de solucionar estas deficiencias, se ha propuesto a los países de la región establecer una visión sostenible de largo plazo y una institucionalidad adecuada que incluya marcos normativos y regulatorios eficaces, así como instrumentos de fiscalización apropiados, y que potencie la consideración de dichos principios como política de Estado. Ello implica el alineamiento de los objetivos del sector de la logística y la movilidad con una visión nacional y regional, que incluya tanto la infraestructura como los servicios y considere todos los modos de transporte en un mismo proceso de análisis para la toma de decisiones, así como la existencia de una planificación y ejecución coordinadas de acciones entre los agentes públicos, privados y de la sociedad civil.

La importancia de incorporar la visión integrada de las políticas de logística y movilidad se basa en la necesidad de promover una mejora y fortalecimiento de la institucionalidad en Centroamérica y en toda América Latina. Con ese fin, ha de incrementarse la coordinación y la coherencia dentro del propio Estado y consolidarse la relación con el sector privado mediante marcos regulatorios modernos que contengan un equilibrio entre planeamiento, evaluación, capacidad y maduración de las inversiones. El elemento principal deberá ser el desarrollo integral de la economía, en el que no solo se insertan los aspectos financieros, sino también los servicios de la infraestructura, la logística y la movilidad, que son fundamentales para impulsar el desarrollo de la región.

En consecuencia, consolidar a nivel nacional una política integrada de logística y movilidad coordinada regionalmente constituye la alternativa más viable para alcanzar el objetivo de lograr que la circulación de mercaderías 
y personas se desarrolle en forma eficiente, competitiva y segura. De esa manera se favorece la productividad, la competitividad y la economía del país, así como la inclusión social de toda la población, tal como se analizará en la sección siguiente.

\section{La integración regional como opción de desarrollo sostenible}

La integración regional también permite alcanzar mayores beneficios en materia de competitividad que los que se obtendrían de forma individual (CEPAL, 2012; véanse los capítulos II y IX de este libro). La integración de los mercados regionales permite lograr un mayor grado de especialización productiva y promover las ventajas competitivas en los mercados regionales y globales. Además, contribuye a:

- Agrandar el mercado y con ello, reducir los costos medios, ampliar la red de proveedores y ganar experiencia antes de internacionalizar las operaciones.

- Aumentar la competitividad nacional, mediante un incremento de la competencia y un mejor aprovechamiento de los encadenamientos productivos regionales y del potencial comercial intrarregional.

- Promover el comercio de manufacturas y los encadenamientos productivos, de forma que se preserven los sectores básicos de la economía y se reduzca la exposición a la volatilidad de la relación de intercambio (BID/Banco Mundial/CEPAL, 2010).

- Mejorar la capacidad de negociación en los foros internacionales en comparación con lo que se lograría individualmente en negociaciones bilaterales complejas.

- Incrementar la dotación de infraestructura y la calidad de los servicios prestados, mediante la reducción de las externalidades negativas, producto de un uso más racional y eficiente de la infraestructura y los servicios modales que la utilizan.

- Promover el aumento del flujo comercial y financiero asociado a una ampliación de los mercados gracias a la integración. Ello también produce beneficios sociales $y$, consecuentemente, una mayor cohesión en el ámbito regional. Por ejemplo, una de las formas de resolver el déficit de mano de obra calificada (así como de profesionales en algunos sectores de la logística) que condiciona la expansión económica de un país es mediante el aumento de la movilidad del capital humano dentro de una subregión. De este modo, quienes emigran tendrán la oportunidad de mejorar sus condiciones laborales y ofrecer mayores oportunidades a sus familias. 
En particular, la integración regional de infraestructuras económicas representa una solución alternativa y a menor costo para cerrar la brecha de infraestructura analizada en secciones anteriores. Esto se debe a que la integración y la especialización de algunas infraestructuras para la prestación de servicios subregionales (puertos, aeropuertos, integración energética o de servicios de telecomunicaciones) permitirían alcanzar un mismo nivel de servicio, en términos de cobertura y calidad, con una menor inversión y a un menor costo de operación, gracias a las economías de red. Permitiría además brindar y asegurar un suministro continuo y seguro para las economías participantes. De este modo también se conseguiría en la red una redundancia necesaria ante fenómenos naturales extremos o pérdidas de conectividad, lo que sería difícil de lograr de forma individual con un costo competitivo. Por último, así se liberarían recursos públicos que podrían dedicarse al gasto social o a otros sectores de la economía nacional.

En el caso particular de Centroamérica, la integración regional tiene la ventaja adicional de que podría contribuir a resolver estos desafíos al desacoplar el crecimiento económico del aumento de las externalidades negativas y consolidar un cambio estructural con igualdad, en consonancia con lo que se plantea en los Objetivos de la Agenda 2030 para el Desarrollo Sostenible. Por ejemplo, las obras realizadas por los países en el corredor del Pacífico de la Red Internacional de Carreteras Mesoamericanas (RICAM), por donde transita el $95 \%$ de su comercio, han permitido reducir el tiempo de traslado entre Panamá y México de 190 a 54 horas. La velocidad media ha aumentado de $17 \mathrm{~km} / \mathrm{h}$ a $60 \mathrm{~km} / \mathrm{h}$, al mismo tiempo que se han reducido la siniestralidad vial y las emisiones asociadas al transporte.

Otro de los hechos destacados en la región guarda relación con la incipiente ampliación en curso de las opciones modales existentes, con miras a aumentar la eficiencia energética de las operaciones logísticas y fomentar proyectos de infraestructura regional que sean resilientes y adaptados al cambio climático. Para ello, los Estados, con apoyo de las distintas iniciativas de integración existentes, los organismos multilaterales y la cooperación internacional, se proponen mejorar la conectividad regional no solamente mediante carreteras, como ha sido la tónica hasta ahora, sino con otras modalidades como el transporte marítimo de corta distancia y el uso de transbordadores de carga y pasajeros, así como la posibilidad de reactivar la red ferroviaria centroamericana. Estos proyectos son estratégicos para el desarrollo de la región, pues permitirían modificar la actual orientación unimodal de las inversiones y comenzar a brindar servicios comodales, tal como se analizó en la sección anterior. Con este cambio de paradigma se podría diseñar una red de servicios regionales que combine e integre las infraestructuras presentes y futuras en función de mejorar la movilidad 
de personas y la logística de carga, con lo que se reducirían los costos de operación y mantenimiento, al mismo tiempo que las externalidades negativas sociales y ambientales que fueran surgiendo.

Otro de los impactos potenciales de este tipo de proyectos regionales es que podrían propiciar el cambio en el enfoque imperante de competencia en el mercado subregional por una modalidad de "colaboración en competencia" (en inglés, para expresar este concepto de forma más sintética, se ha acuñado el término coopetition). Esta modalidad promueve un sistema colaborativo dentro de la región que favorezca el intercambio de información y coadyuve a la elaboración de estrategias comunes de mantenimiento y compra de insumos, servicios de promoción, aseguramiento, capacitación, entre otras cosas, en beneficio de la región como conjunto. Lo anterior no va en desmedro de la natural vocación de competencia y especialización productiva entre los actores, sino que facilita la cooperación y refuerza el espíritu integracionista.

Un ámbito de aplicación de esa medida, que redundaría en grandes beneficios para la región, es la cooperación para el fortalecimiento de estructuras profesionales que gestionen de manera integral y moderna los servicios de transporte y logística. Ello potenciaría la capacidad de detectar y aprovechar las mejores prácticas logísticas internacionales y las oportunidades que representa la tecnología para el sector. Los países de la región tienen escasez de mano de obra calificada en temas de logística, lo que hace que sea difícil atender las nuevas exigencias de servicios de valor añadido, así como la incorporación de nuevas tecnologías e innovación en los servicios ofrecidos a la carga. Algunas esferas prioritarias en cuanto a la formación de conocimiento y habilidades para la profesionalización del sector serían la gestión empresarial en temas de tráfico, costos, recursos humanos y administración; técnicas de conducción eficiente y seguridad operativa para el manejo de cargas peligrosas, ahorro de combustible y respeto de las normas medioambientales. Además, es fundamental desarrollar habilidades personales que mejoren la motivación y el compromiso.

En consecuencia, la integración de la infraestructura a nivel regional constituye un tema estratégico con miras a potenciar el crecimiento y alcanzar mayores niveles de desarrollo en la región centroamericana, gracias a las cortas distancias y las escasas barreras culturales y lingüísticas existentes. Este cambio no solo permitiría resolver a un menor costo la brecha de infraestructura, sino que favorecería una mayor rentabilidad social de la inversión total (tanto pública como privada) al alinear mejor los intereses público-privados con el principio de equidad intergeneracional. De igual forma, en la medida en que la infraestructura se dimensione y diseñe debidamente para un uso compartido, se podría no solo aumentar la competitividad de las industrias (mediante la reducción del costo logístico), sino también gestionar mejor las externalidades negativas sobre la población y el territorio. Con ese fin, se 
podrían aplicar las soluciones técnicas que sean factibles por las eventuales economías de escala, de ámbito o aglomeración que el uso compartido de la infraestructura produjese. En este contexto, una alternativa para incrementar la inversión y que daría un impulso a la transformación productiva consiste en promover un uso compartido de la infraestructura logística, tanto por las empresas extractivas como por otros sectores económicos nacionales y de otros países (Halland y otros, 2015).

El Columbia Center on Sustainable Investment (CCSI) destaca la necesidad de que las nuevas obras o la rehabilitación de las existentes con el fin antes descrito estén debidamente coordinadas y conectadas con los planes de desarrollo territorial y de infraestructuras futuras, tanto en el ámbito nacional como subregional. De este modo se busca determinar las sinergias operacionales y verificar el cumplimiento de las condiciones técnicas necesarias para las empresas, además de que el diseño de la infraestructura sirva como bien público para un uso compartido por otros sectores de la sociedad. En ese sentido, resulta crítico favorecer y fortalecer los vínculos entre los grandes proyectos de infraestructura y la producción local. Ello es necesario incluso para mantener la propia sostenibilidad de esos proyectos, debido a las economías de escala y los encadenamientos que podrían lograrse (Toledano y otros, 2014).

Junto con estos aspectos técnicos es fundamental seguir profundizando los procesos políticos y cultivar la confianza entre los distintos países a fin de avanzar paulatinamente hacia un funcionamiento como espacio integrado, donde la infraestructura sea la hebra que conecte y posibilite la integración plena de los distintos territorios y sus habitantes. La creación de un organismo regulador ad hoc, que sea independiente y esté bien estructurado para el tipo de tareas que debe cumplir, resulta crucial para la gestión de una infraestructura de uso regional. Este ente tendría que mediar con agilidad ante las eventuales disputas entre participantes en el sistema y proceder de manera transparente en cuanto a la fijación de tarifas de acceso y operación que aseguren el acceso competitivo de nuevos actores y la no discriminación entre actores de diverso tamaño o que ofrezcan distintos tipos de productos. Un aspecto importante es que, independientemente de la forma de operación seleccionada o del tipo de infraestructura a implementar, el Estado no debe perder de vista la visión de largo plazo. Para ello debe asegurar desde el inicio los derechos de paso o servidumbres asociados a otras infraestructuras de uso compartido que pudiesen desarrollarse en el futuro (por ejemplo, fibra óptica, líneas eléctricas y oleoductos).

La CEPAL ha estado desarrollando una serie de estudios con el objetivo de caracterizar la infraestructura regional y brindar a los países orientaciones que los ayuden a mejorar sus políticas públicas y planes de inversión. Entre otras cosas, se propone la incorporación de acciones tendientes a aumentar la 
eficiencia, productividad, resiliencia y sostenibilidad de las infraestructuras y servicios logísticos. La introducción temprana de estas mejoras e innovaciones permitirán a la región reducir costos u ofrecer ventajas competitivas en determinados segmentos de mercado, al mismo tiempo que se minimizan las externalidades negativas de la actividad, como pueden ser la huella de carbono, la huella hídrica o las dificultades que afectan la eficiencia energética de los servicios. Todos estos elementos, además de reflejarse en el precio de los servicios, pueden servir como diferenciadores en mercados de mayor poder adquisitivo y conciencia socioambiental.

La reducción de la brecha de infraestructura es una condición necesaria, aunque no suficiente, para el desarrollo sostenible de la región. No solamente se requiere invertir más, sino hacerlo de mejor forma e incorporando criterios de sostenibilidad en su sentido más amplio. Con miras a solucionar estas deficiencias y alcanzar los ODS, la CEPAL ha planteado la necesidad de una nueva gobernanza de la infraestructura. La intención es abordar de manera integrada y sostenible la infraestructura y los flujos de servicios que la utilizan, como la única forma de garantizar el progreso y el bienestar y calidad de vida de sus usuarios finales, actuales y futuros (Jaimurzina y Sánchez, 2017). De este modo, la integración de infraestructuras logísticas se alza como una opción real frente al cierre de brechas y que contribuya al desarrollo sostenible. En particular, la integración de las infraestructuras de transporte y energía a nivel subregional tendría un efecto favorable en un conjunto de aspectos, entre los que destacan:

- La realización efectiva de la integración económica, comercial y política, mediante la promoción, financiamiento, construcción u operación de obras de integración física con miras a prestar servicios logísticos regionales, favoreciendo con ello una visión de más largo plazo sobre los procesos de integración.

- La solución progresiva y de manera conjunta de problemas que son comunes, junto con la creación o reorganización de cadenas productivas, una inserción más competitiva en los grandes mercados del mundo, el desarrollo descentralizado y la disminución de los costos comerciales y de distribución.

- Un desarrollo sostenible con mayor equidad social, así como la disminución de las asimetrías entre los países y dentro de ellos, mediante la participación de los gobiernos locales y el sector privado.

Para avanzar a ese respecto, los países deben coordinar las obras de infraestructura y armonizar los procedimientos técnicos y normativos con miras a favorecer la complementariedad entre las distintas economías. De ese modo podrían reducir los costos de operación y las externalidades negativas provocadas sobre el medio ambiente y la sociedad. En este sentido, la CEPAL ha resaltado la necesidad de alinear la concepción, diseño, ejecución, 
seguimiento, fiscalización y evaluación de las políticas de infraestructura y servicios conexos con la maximización de sus efectos en relación con el desarrollo. Esto podría lograrse mediante una política integrada y sostenible de logística y movilidad con una perspectiva regional (Pérez-Salas, 2008; Cipoletta, Pérez-Salas y Sánchez, 2010), que permita resolver los problemas de provisión de infraestructura y servicios. Muy en especial, sería necesario resolver las fallas u obstáculos institucionales y regulatorios, tanto en la conducción de las políticas como en la organización de los mercados que surgen de la alta dispersión y multiplicidad de visiones públicas con respecto a la infraestructura económica y los servicios en sus diferentes procesos (concepción, diseño, implementación y seguimiento, fiscalización y evaluación).

\section{E. Servicios logísticos y cadenas de valor vinculadas a los productos primarios}

En muchos países de la región, la explotación y la comercialización de los productos primarios siguen siendo la principal fuente de ingresos y motor de crecimiento. Por ese motivo, y ante la necesidad imperante de impulsar la diversificación productiva mediante un cambio estructural progresivo en estos países (CEPAL, 2016), no son pocas las instituciones que han visto en la participación en las cadenas globales de valor una herramienta para alcanzar dicho objetivo. Sin embargo, para que estas cadenas de valor se materialicen y funcionen de manera eficiente y competitiva se requiere, entre otros factores, el soporte físico y tecnológico que brinda la logística. Ello plantea ineludiblemente la necesidad de una gestión diferente de la infraestructura logística de la región, puesto que la existente fue diseñada para exportar grandes volúmenes al menor costo y en el menor tiempo posibles, sin ninguna consideración que favoreciera los encadenamientos productivos ni una adecuada gestión de las externalidades negativas. La proporción de exportaciones intensivas en logística o sensibles al tiempo en América Latina es, en promedio, prácticamente tres veces más elevada que en las economías de la Organización de Cooperación y Desarrollo Económicos (OCDE) (CAF/CEPAL/OCDE, 2013). De ahí la importancia que reviste para la región propiciar una adecuada logística para los productos primarios, ya que la falta de infraestructura o los altos costos logísticos imperantes dificultan la creación de encadenamientos productivos o la actividad de reexportación con valor añadido.

En muchos países de la región, su inserción efectiva en las cadenas globales de valor es una condición vital para su desarrollo sostenible de cara al futuro. Esto se debe a las múltiples ventajas que presentan las cadenas globales de valor en lo que se refiere a promover el comercio de manufacturas 
con valor añadido, aumentar el empleo de calidad, equilibrar la demanda al mismo tiempo que se preservan los sectores básicos de la economía, reducir la exposición a la volatilidad cambiaria y favorecer la inversión en sectores estratégicos. Sin embargo, las cadenas globales de valor se estructuran en función de las características del recurso, así como de la velocidad, calidad, flexibilidad y costo de la cadena completa. Por ende, la capacidad de entrada de una empresa local en una de estas redes no depende únicamente de su desempeño individual, sino de su recorrido histórico-social, su ubicación geográfica y la calidad de la infraestructura disponible (Muñoz Fernández y Pérez-Salas, 2017).

Más aún, gran parte de la infraestructura pública utilizada para el transporte de estos recursos naturales es deficiente y produce grandes externalidades negativas sobre la población y el medio ambiente. La infraestructura de uso privado, en muchos casos, es una barrera de entrada para otros actores productivos y no propicia mayores mejoras de la conectividad con el territorio. Esto dificulta la creación de economías de escala, de red y de aglomeración que pudieran alcanzarse en torno a la logística de los recursos naturales. Todos estos elementos limitan la captación de valor añadido, imposibilitan el logro de efectos positivos sobre otros sectores de la economía, incrementan las externalidades y reducen significativamente los impactos sociales positivos esperados de la extracción de la riqueza asociada a los recursos naturales, sobre todo aquellos asociados a industrias extractivas no renovables o agrícolas. En ese sentido resulta crucial que el diseño, el trazado, la propiedad y las regulaciones técnicas y económicas de la infraestructura estén diseñados para un uso compartido no discriminativo entre diversos sectores o empresas de distintos tamaños.

La CEPAL ha planteado la necesidad de fortalecer la integración productiva de la región mediante la creación de cadenas de valor que profundicen el mercado regional y favorezcan la innovación y la generación de empleo de calidad e inclusivo. La integración física no solo tiene un papel estructurante del proceso de integración regional, sino que le brinda el sustento físico, tecnológico y regulatorio necesario para materializar los intercambios de bienes y servicios que dan origen al comercio intrarregional. Por esta razón, es fundamental fortalecer la capacidad de los gobiernos en lo que se refiere al papel de la logística, mediante acciones que mejoren el diseño y la implementación de infraestructuras logísticas sostenibles. Con ese fin han de promoverse cambios en las políticas y regulaciones que permitan una efectiva integración productiva y la creación de cadenas de valor subregionales competitivas e inclusivas. En este contexto, el aprovechamiento de las ventajas de la integración logística centroamericana se plantea como una forma tangible para lograr un importante avance operativo en la cooperación regional, pues permitiría reducir los costos logísticos y las externalidades negativas de la actividad sobre la población y el medio ambiente. 


\section{F. El proceso de construcción de la política marco en Centroamérica}

Como se ha visto en las secciones anteriores, una adecuada integración de las infraestructuras logísticas y de movilidad, así como la formalización de estructuras regulatorias y de acción pública (a partir de los elementos constitutivos de políticas comunes), permiten alcanzar un mayor grado de especialización productiva y desarrollar ventajas competitivas en los mercados regionales y globales, con grandes beneficios sociales y ambientales. A fin de aprovechar este potencial, resulta fundamental cultivar la confianza política de largo plazo, cerrar las brechas de la integración y lograr un importante avance operativo en la cooperación para el desarrollo de la competitividad regional. En vista de todo lo anterior, la CEPAL propició una estrategia regional de integración que ayudara a sus países miembros a establecer mecanismos de diálogo político para encontrar soluciones atingentes a las realidades actuales de los países y de ese modo:

- integrarse de manera más eficiente y de forma sostenible mediante criterios comunes y coordinados entre los países;

- actualizar y modernizar los procesos de concepción, planificación, ejecución y seguimiento de sus políticas de provisión de infraestructura y regulación de servicios, y

- concertar una visión de largo plazo y definir un plan de inversiones regionales, tanto para la nueva infraestructura como para el mantenimiento de la existente.

Tal como sucede con las políticas nacionales, la CEPAL ha promovido la estructuración de un diálogo permanente entre los distintos niveles de gobierno y los representantes del sector privado y la sociedad civil, bajo una modalidad de mejora continua. Con esa modalidad se va avanzando hacia niveles de mayor consenso e integrando nuevas preocupaciones que surgen a partir de cambios geopolíticos, de infraestructura, tecnológicos o exógenos a la región, pero que afectan su estrategia de desarrollo e integración regional. Por ello, además de respetar los tiempos institucionales, y de reconocer y valorar las diferencias existentes en cuanto a los modelos legítimos de desarrollo aplicados por cada sociedad, se requiere una estructura capaz de anticipar grandes cambios a fin de propiciar el diálogo político y la toma de decisiones oportunas para alcanzar los resultados esperados, tanto en el plano nacional como en el regional.

La política marco regional en materia de movilidad y logística surge en 2008 en la Unidad de Servicios de Infraestructura de la División de Recursos Naturales e Infraestructura de la CEPAL. Se trataba de una propuesta orientada al fortalecimiento institucional de los ministerios sectoriales de transporte y obras públicas de la región, en respuesta a los mandatos conferidos a la CEPAL 
por la Décima Cumbre de Jefes de Estado y de Gobierno del Mecanismo de Diálogo y Concertación de Tuxtla, celebrada en junio de 2008. En esa ocasión, los jefes de Estado solicitaron a la CEPAL que diseñara una serie de actividades de investigación y fortalecimiento institucional en coordinación con la Comisión Técnica Regional de Transporte (CTRT) del Proyecto Mesoamérica, a fin de mejorar la competitividad e inserción internacional de los países de la región en un contexto de cooperación regional.

En el marco de ese mandato, la CEPAL promovió la importancia de la logística y la movilidad al más alto nivel político en cada país, desde los ministros sectoriales involucrados con el sector de la logística y la movilidad hasta el nivel presidencial, en algunos casos, como forma de asegurar un compromiso político de largo alcance con los resultados técnicos y cimentar las bases de confianza necesarias para la implementación del proceso. A fines de 2010, la CEPAL comenzó a esbozar las primeras ideas sobre la necesidad de una política integrada y sostenible en la región en su documento "Políticas integradas de infraestructura, transporte y logística: experiencias internacionales y propuestas iniciales" (Cipoletta, Pérez-Salas y Sánchez, 2010). Esa publicación muestra que los países que han tenido éxito en la implementación de políticas de logística han sido los que han contado con el liderazgo efectivo y permanente de sus más altas autoridades en la promoción del cambio y la búsqueda de soluciones a las dificultades que han ido surgiendo en la implementación. También han sido los países donde la apropiación de todos los estamentos del Estado (incluido el Poder Legislativo) resulta fundamental para alcanzar consensos de largo plazo con otros sectores de la economía.

En diciembre de 2013, en la Reunión de Ministros de Transporte de Mesoamérica, la CEPAL presentó un nuevo documento titulado "Bases para la formulación de una política de logística y movilidad en Mesoamérica" (Sánchez y Pérez-Salas, 2013), que aportó un marco general respecto de la formulación de políticas nacionales de logística y movilidad con pautas comunes para los países mesoamericanos ${ }^{4}$. En él se destaca la necesidad de avanzar progresivamente hacia una completa integración, de manera que se reconozcan $\mathrm{y}$ valoren las diferencias existentes sobre el modelo de sociedad buscado y se articulen las distintas iniciativas y visiones nacionales en torno a un ideal de convergencia (Altomonte, Pérez-Salas y Sánchez, 2016).

De forma paralela, en la XXXIII Reunión del Consejo Sectorial de Ministros de Transporte de Centroamérica (COMITRAN) de la Secretaría de Integración Económica Centroamericana (SIECA), realizada en Managua en agosto de 2014, los ministros centroamericanos solicitaron el apoyo de la CEPAL para la redacción de un documento marco de políticas públicas de

Se refiere a los países que conforman el Proyecto de Integración y Desarrollo de Mesoamérica: Belice, Colombia, Costa Rica, El Salvador, Guatemala, Honduras, México, Nicaragua, Panamá y la República Dominicana. 
carácter regional, en materia de movilidad y logística, así como el diseño y la organización de talleres nacionales con miras a la elaboración de políticas integradas y sostenibles de logística y movilidad que se pudieran proyectar hacia una política común para la región. A la luz de este nuevo mandato, la Unidad de Servicios de Infraestructura comenzó a realizar sobre el terreno una serie de talleres nacionales con el sector público y representantes del sector privado y de la sociedad civil de cada uno de los países de Centroamérica 5 . Su objetivo era difundir el proceso y sentar las bases para que la logística y la movilidad fueran parte de una política de Estado de largo plazo, comprometida con la integración regional. En este proceso, se logró establecer un consenso sobre los principios de integralidad y sostenibilidad que sustentan la política regional. Sobre esa base, se podrían priorizar, financiar y promover acciones que favorecieran la complementariedad entre las distintas economías y, de ese modo, contribuir a la competitividad y el bienestar de la región.

Dado que las resoluciones del COMITRAN son vinculantes, la política marco dejaba el ámbito técnico que tenía hasta ese instante y comenzaba a formar parte del andamiaje regional de la integración regional vinculante en el marco de la SIECA y el SICA. Se dio comienzo así a un período de gran dinamismo, caracterizado por el interés del COMITRAN por avanzar seriamente en el tema. En las reuniones del COMITRAN de los años subsiguientes, los ministros sectoriales exigieron avances palpables en la política marco. Los aportes realizados por la CEPAL con miras al diseño y adopción de una política regional de logística y movilidad quedaron plasmados en el documento "Políticas de logística y movilidad para el desarrollo sostenible y la integración regional: marco conceptual y experiencia regional" (Jaimurzina, Pérez-Salas y Sánchez, 2015). En él se ofreció un conjunto de recomendaciones para una política nacional de logística y movilidad, así como su coordinación a nivel centroamericano, en las que se tenía en cuenta la situación particular de los países de la región y la convergencia con las otras iniciativas de integración existentes en América Latina y el Caribe. Durante este período, fue posible alcanzar un consenso relativamente amplio sobre los principios que regirían la política regional. La principal motivación de los países para sumarse a este esfuerzo regional fue la búsqueda de mejoras en la competitividad de la economía con miras a incrementar los niveles de bienestar de la población, en un marco de desarrollo sostenible. El acompañamiento de las instituciones regionales en este proceso, así como de los organismos multilaterales de desarrollo, fue fundamental para brindar asesoría y resolver los problemas

El primer taller nacional se realizó en Managua (30 de septiembre y 1 de octubre de 2014); luego se realizaron otros en San Salvador (22 y 23 de octubre de 2014) y Tegucigalpa (18 y 19 de noviembre de 2014). Posteriormente se realizaron talleres nacionales en San José (21 y 22 de abril de 2015), en la ciudad de Panamá (26 y 27 de mayo de 2015) y en Ciudad de Guatemala (27 y 28 de mayo de 2015). Véase información detallada de cada uno de estos talleres en Pérez-Salas (2018). 
de coordinación y articulación de iniciativas a nivel nacional, de manera que luego se pudieran priorizar y elevar a un nivel regional.

Durante la XV Cumbre de Jefes de Estado y de Gobierno del Mecanismo de Diálogo y Concertación de Tuxtla, celebrada en Antigua (Guatemala) en junio de 2015, los presidentes y jefes de Estado decidieron asignar la más alta prioridad a la logística y la movilidad como elementos fundamentales de su estrategia de desarrollo y de integración regional, en línea con las recomendaciones realizadas por la CEPAL. A finales de ese año y durante la XXXV Reunión del Consejo Sectorial de Ministros de Transporte de Centroamérica (COMITRAN), celebrada en San Salvador el 22 de octubre de 2015, los ministros allí reunidos recibieron el documento "Política Marco Regional de Movilidad y Logística: perfil" (COMITRAN, 2015), que luego se presentaría en la Cumbre de Jefes de Estado y de Gobierno del SICA, celebrada el 18 de diciembre de ese mismo año, donde se aprobó en líneas generales el perfil de la política marco de movilidad y logística.

A partir de ese momento, la política marco registró un nuevo hito integracionista, pues dejó de ser un esfuerzo sectorial de transporte al incorporarse a sus trabajos el Consejo de Ministros de Integración Económica (COMIECO) y el Consejo de Ministros de Hacienda o Finanzas de Centroamérica, Panamá y República Dominicana (COSEFIN). De este modo surgió la primera acción concreta de coordinación y trabajo intersectorial, esfuerzo que, en definitiva, terminaría dando origen a la primera política intersectorial en Centroamérica.

El 19 de abril de 2018, en la sede de la Secretaría General del Sistema de la Integración Centroamericana (SG-SICA) en la ciudad de San Salvador, se procedió al lanzamiento oficial de la Política Marco Regional de Movilidad y Logística de Centroamérica. Era un documento que había sido aprobado por los jefes de Estado y de Gobierno de los países miembros del Sistema de la Integración Centroamericana el 14 de diciembre de 2017, en la ciudad de Panamá. En la versión final de la Política Marco se destaca la colaboración recibida de la CEPAL y el Banco Interamericano de Desarrollo (BID) 6 .

\section{G. Lecciones aprendidas del proceso centroamericano}

El lanzamiento de la política marco de logística y movilidad de Centroamérica es un hito trascendental en el proceso de integración centroamericana. Esta política puede llegar a ser una de las principales herramientas para la transformación productiva sostenible en la medida en que los países la adopten y la conviertan

Véase [en línea] http:/ /www.sica.int/noticias/centroamerica-lanza-politica-marco-regional-demovilidad-y-logistica-de-centroamerica_1_112637.html. 
en acciones concretas. El principal hallazgo del proceso es que la política marco ha sido fruto de una serie de trabajos sinérgicos de los ministros sectoriales de transporte, finanzas y economía, además de aportes del sector privado y la sociedad civil de los distintos países de la región. En esas labores se ha contado con el apoyo técnico y financiero de la CEPAL, el BID, la Agencia Mexicana de Cooperación Internacional para el Desarrollo (AMEXCID), la Agencia de Cooperación Internacional del Japón (JICA) y otras múltiples instancias $\mathrm{y}$ organismos donantes que participaron en este emprendimiento regional.

Un aspecto destacable del proceso es el hecho de que se ha propiciado un diálogo público-privado para la coordinación intersectorial. Ese diálogo permitió aprovechar sinergias con otras políticas públicas y favorecer la construcción de una visión de Estado de largo plazo sobre la importancia de la logística y la movilidad para alcanzar un desarrollo más sostenible, con equidad intergeneracional. Lo anterior es especialmente importante dado que la infraestructura, la provisión y la regulación de servicios de transporte, tanto de personas (movilidad) como de carga (logística), se caracterizan por su entorno altamente cambiante y el hecho de que contribuyen al surgimiento de grandes presiones sociales. Por esta razón, resulta fundamental crear mecanismos formales que coadyuven al monitoreo constante del contexto en que se insertan. Esto permitiría producir oportunamente los cambios necesarios para el cumplimiento cabal de los objetivos trazados bajo una modalidad de mejora continua. Para sustentar este proceso también es clave que los países cuenten con un conjunto de indicadores sectoriales que permitan monitorear el avance de las medidas y sus distintos componentes. Sobre esa base se podría obtener información para la toma de decisiones y la evaluación de los resultados y compromisos asumidos. Es fundamental para ello construir un sistema de indicadores que posibiliten el monitoreo y evaluación de la política a nivel regional. La CEPAL ha presentado una propuesta metodológica para medir el progreso en algunas iniciativas de integración regional, con especial énfasis en el ámbito de la integración de infraestructura logísticas.

La experiencia centroamericana muestra también que las normativas y regulaciones técnicas regionales se pueden ir construyendo de forma progresiva. Los primeros pasos pueden consistir en normativas regionales sobre tamaños y pesos máximos, entre otros aspectos técnicos, en el caso del transporte por carretera. Luego se pueden abordar los temas de regulación de la actividad, como los requisitos de ingreso y formación profesional para brindar servicios regionales, la antigüedad máxima de las flotas de transporte, los requisitos de seguridad, o de trazabilidad logística, entre otros. Por último, se puede llegar a construir un sistema regulatorio regional que permita elaborar directrices sobre regulaciones técnicas y económicas para el fomento de la competencia a nivel centroamericano, la promoción de inversiones estratégicas y la adopción de medidas orientadas a una redistribución modal de la carga y los pasajeros. Por ejemplo, en la Unión Europea se contemplan 
acciones específicas encaminadas a fomentar la competencia en todos los ámbitos de los servicios de transporte, incluida la libre prestación de esos servicios entre los Estados miembros.

Entre los puntos a mejorar destacan la urgencia de fomentar una mayor participación de la sociedad civil en estos procesos, y de recopilar necesidades y visiones adicionales sobre el tipo de ciudad y de consumo deseado. Del mismo modo, debería reforzarse la participación de los centros de investigación y universidades nacionales a fin de aprovechar plenamente su potencial innovador, como ocurre en otras experiencias internacionales analizadas por la CEPAL. El liderazgo político, así como la importancia relativa dada a la logística y movilidad, difería de un país a otro. Además, los cambios en los gabinetes a veces provocaban un retroceso considerable del acervo de conocimiento y compromisos acumulados. Dicho en otras palabras, es importante que la logística forme parte de una política de Estado de largo plazo y no dependa de la agenda de un ministro en particular. Por último, desde el punto de vista de la sostenibilidad de las acciones es un requisito fundamental la creación de instancias de diálogo reales entre los Estados, así como la promoción de la participación y apropiación del proceso por parte del sector privado y todos los segmentos de la sociedad.

\section{H. Conclusiones}

Una política de logística y movilidad coordinada a nivel subregional representa una enorme oportunidad de mejorar la eficiencia logística y la conectividad que brindan los servicios de movilidad, a un costo mucho menor de lo que significaría brindar un servicio de la misma calidad de forma individual. La logística y movilidad adquieren así una importancia estratégica, sobre todo en cuanto a la planificación y gestión de las infraestructuras y el diseño de redes logísticas con criterio regional. En ese sentido, es preciso desarrollar terminales que operen a una escala que las torne eficientes y atractivas, además de tener una conexión adecuada con la economía global y las redes internas. Para que la política marco sea una verdadera herramienta de desarrollo regional, se requiere una serie de acciones y reformas que establezcan un proceso que permita avanzar progresivamente en su implementación.

Entre estas acciones, cabe destacar las siguientes como prioritarias y urgentes:

- Fortalecer las instancias de coordinación entre los países como aspecto central en la consecución de una mejor integración, sobre todo en lo que se refiere a la evaluación y financiamiento de infraestructuras especializadas para prestar servicios regionales. Cuanto más se logre avanzar en el ámbito institucional, más se podrá fortalecer la integración y potenciar sus beneficios.

- Incorporar al sector privado y la sociedad civil como actores relevantes del proceso a fin de asegurar la implementación y 
el compromiso de largo plazo. Esto es fundamental si se desea promover la adopción de medidas concretas que plasmen el espíritu de la política marco en una verdadera herramienta de desarrollo, independiente de los gobiernos de turno y del nivel de compromiso que estos tengan con la integración regional. Sin ese respaldo transversal, se corre el riesgo de que la política se convierta en un mero documento que no estaría respaldado por acciones encaminadas a su implementación. Entre otros aspectos a desarrollar, es necesario resolver el tema del financiamiento y la organización de los mercados regionales, además de superar fallas regulatorias y de funcionamiento de las asociaciones público-privadas, establecer normativas regionales y buscar convergencias regulatorias.

- Establecer metodologías y procedimientos que permitan priorizar y financiar infraestructuras subregionales, con una perspectiva que favorezca la complementariedad entre las distintas economías. De ese modo, se podrían reducir los costos de operación, así como las externalidades negativas provocadas sobre el medio ambiente y la sociedad. Dentro de esta propuesta vale destacar una serie de acciones, tales como la creación de un sistema de planeamiento y de toma de decisiones que permitan adecuar la nueva infraestructura al modelo actual de desarrollo, diseñadas en función de las necesidades de la economía y del bienestar de sus habitantes. En este ámbito, resulta fundamental analizar la institucionalidad y la contabilidad regulatoria, así como las condiciones de funcionamiento y maduración de los mercados. Ello contribuiría a mejorar la manera en que los Estados planifican, evalúan, monitorean y fiscalizan las obras públicas y las concesiones orientadas a la maximización del beneficio social.

- Financiar obras internacionales: buena parte del financiamiento de la infraestructura se realiza mediante préstamos que muchas veces dificultan la aplicación de una perspectiva integral sobre el territorio y los servicios de infraestructura. Por ello es importante consensuar con los países una estrategia regional de integración que reconozca y valore las diferencias existentes sobre el modelo de sociedad imperante $y$, al mismo tiempo, sea capaz de articular las distintas normativas y regulaciones técnicas y económicas en torno a un ideal de convergencia que fomente la integración logística y productiva.

La CEPAL ha puesto de manifiesto la necesidad de fortalecer los avances alcanzados en materia de liberalización comercial. Esto podría lograrse mediante el perfeccionamiento de los procesos de integración regional, así como la armonización y la integración de los tratados comerciales vigentes. Las ineficiencias asociadas a fallas en la cobertura y la calidad de la infraestructura física, así como a la ausencia de armonización en materia regulatoria, constituyen una limitación determinante para la competitividad y el desarrollo sostenible de la región. De igual forma, la planificación de 
infraestructuras con una perspectiva de largo plazo y una inversión sectorial estable permite acompañar eficientemente la transformación productiva, y lograr una mejor adaptación a los cambios económicos, y a las nuevas preocupaciones sociales y ambientales que surgen con el desarrollo (Pérez-Salas, 2017).

La magnitud del déficit de infraestructura, así como su importancia creciente en las políticas de desarrollo, hacen necesario que los países analicen los principales aspectos involucrados en la evolución de la inversión en infraestructura y de los servicios provistos, tanto en forma pública como privada. Ello implica la necesidad de conocer en detalle las fortalezas y debilidades de los distintos mecanismos de asociación público-privada. Es preciso considerar que las inversiones deben contemplar no solo la expansión de la capacidad, sino también su mantenimiento, resiliencia y adaptación al cambio climático. Hay que tener presente que los eventuales recortes presupuestarios en estos aspectos suelen agravar los problemas derivados del uso intensivo o excesivo de la infraestructura existente. Por otro lado, es fundamental el fortalecimiento institucional tanto en la esfera técnica (es decir, en las metodologías y la rigurosidad de las evaluaciones) como en el ámbito político, sobre todo en la formulación de proyectos y en la toma de decisiones respecto de su selección y la correspondiente inversión.

Conviene advertir que, si bien se prevén considerables beneficios económicos y sociales para el conjunto de la sociedad, el proceso de integración regional, física y comercial provocará normalmente cambios significativos en la prioridad social y localización de las inversiones, cuyo despliegue podría diferir sensiblemente de las definiciones contenidas en las respectivas políticas nacionales. Se trata de una consecuencia lógica y normal de todo proceso de integración: la asignación entre los países miembros de los costos y beneficios del nuevo inventario de proyectos conjuntos constituye una materia central de las negociaciones políticas que a la postre tendrán como resultado una mayor unidad regional. Sin embargo, la idea de transferir parte de la soberanía nacional a instancias supranacionales que coordinen las distintas regulaciones técnicas y económicas del sector de la logística y la movilidad representa un reto mayor. Es de esperar que las complicaciones en la articulación de estas medidas no sean menores.

También podrían aparecer grupos de presión que busquen evitar la convergencia regulatoria por parte de algunos sectores de la economía nacional que se ven favorecidos por las actuales asimetrías o por los vacíos regulatorios a nivel nacional y que, por tanto, se verán perjudicados al modificarse las regulaciones y crearse un mercado ampliado que permita la entrada de nuevos actores en el sector. Del mismo modo, alcanzar consenso sobre cuáles deben ser los proyectos prioritarios y dónde deben localizarse será cada vez más difícil, en la medida en que vayan saliendo adelante los proyectos de los grandes corredores logísticos. Con ese fin, se debería incorporar progresivamente al planeamiento de la infraestructura regional 
la concepción de redes de servicios de infraestructura, para ir avanzando de forma decidida desde la integración física hacia una integración productiva y logística más efectiva.

El camino de la integración debe ser una parte esencial del proceso de mejora de las políticas relacionadas con servicios de infraestructura que ayuden a los países a alcanzar un desarrollo más sostenible y lograr una integración más eficiente. En ese sentido, se requiere dar inicio a un nuevo diálogo que acelere y fortalezca los procesos de integración regional, dotándolos de una visión de largo plazo, independientemente de las crisis coyunturales (de confianza o económicas) que se puedan enfrentar. En dicho diálogo se deberían tener debidamente en cuenta las asimetrías estructurales que puedan existir entre territorios y países, de modo que se aprovechen todas las ventajas de una integración plena y sostenible.

\section{Bibliografía}

Altomonte, H., G. Pérez-Salas y R. Sánchez (2016), “Un nuevo diálogo para la integración de las infraestructuras económicas de América Latina y el Caribe", Desarrollo e integración en América Latina (LC/G.2674), Santiago.

BID (Banco Interamericano de Desarrollo)/Banco Mundial/CEPAL (Comisión Económica para América Latina y el Caribe) (2010), "Cómo reducir las brechas de integración: escenarios y recomendaciones de políticas para promover la infraestructura física y reducir los costes del comercio intrarregional", nota de discusión de políticas presentada en la Tercera Reunión de Ministros de Hacienda de América Latina y el Caribe, Lima, 28 de mayo.

Brown, R. (1966), Transport and the Economic Integration of South America, Washington, D.C., The Brookings Institution.

CAF/CEPAL/OCDE (Banco de Desarrollo de América Latina/Comisión Económica para América Latina y el Caribe/Organización de Cooperación y Desarrollo Económicos) (2013), Perspectivas Económicas de América Latina 2014: logística y competitividad para el desarrollo (LC/G.2575), París.

CEPAL (Comisión Económica para América Latina y el Caribe) (2016), Horizontes 2030: la igualdad en el centro del desarrollo sostenible (LC/G.2660/Rev.1), Santiago. (2014), Integración regional: hacia una estrategia de cadenas de valor inclusivas (LC/G.2594(SES.35/11)), Santiago.

(2012), UNASUR: infraestructura para la integración regional (LC/L.3408), Santiago. (2009), "Infraestructura física e integración regional", Boletín $F A L, \mathrm{~N}^{\circ} 280$, Santiago, Comisión Económica para América Latina y el Caribe (CEPAL), diciembre.

Cipoletta, G., G. Pérez-Salas y R. Sánchez (2010), “Políticas integradas de infraestructura, transporte y logística: experiencias internacionales y propuestas iniciales", serie Recursos Naturales e Infraestructura, No 150 (LC/L.3226-P), Santiago, Comisión Económica para América Latina y el Caribe (CEPAL), mayo.

COMITRAN (Consejo Sectorial de Ministros de Transporte de Centroamérica) (2015), "Política Marco Regional de Movilidad y Logística: perfil", documento presentado en la XXXV Reunión del COMITRAN, San Salvador, 22 de octubre.

Fuentes, A. (1973), La creación de un mercado común: apuntes históricos sobre la experiencia centroamericana, Buenos Aires, Instituto para la Integración de América Latina (INTAL)/Banco Interamericano de Desarrollo (BID). 
Halland, H. y otros (2015), The Extractive Industries Sector: Essentials for Economists, Public Finance Professionals, and Policy Makers, Washington, D.C., Banco Mundial. Jaimurzina, A. y R. Sánchez (2017), “Gobernanza de la infraestructura para el desarrollo sostenible en América Latina y el Caribe: una apuesta inicial”, Boletín FAL, N 354, Santiago, Comisión Económica para América Latina y el Caribe (CEPAL), febrero. Jaimurzina, A., G. Pérez-Salas y R. Sánchez (2016), “Políticas de logística y movilidad para el desarrollo sostenible y la integración regional: marco conceptual y experiencia regional", Boletín FAL, N 345, Santiago, Comisión Económica para América Latina y el Caribe (CEPAL), enero.

(2015), "Políticas de logística y movilidad para el desarrollo sostenible y la integración regional", serie Recursos Naturales e Infraestructura, N 174 (LC/L.4107), Santiago, Comisión Económica para América Latina y el Caribe (CEPAL), noviembre.

Kim, N. y B. Van Wee (2009), "Assessment of CO2 emissions for truck-only and rail-based intermodal freight systems in Europe", Transportation Planning and Technology, vol. 32, $\mathrm{N}^{\mathrm{o}} 4$.

Muñoz Fernández, C. y G. Pérez-Salas (2017), “Reflexiones sobre el rol de la logística en la explotación sostenible de los recursos naturales en América Latina y el Caribe" Boletín FAL, N 357, Santiago, Comisión para América Latina y el Caribe (CEPAL), mayo.

Pérez-Salas, G. (2018), “Logística en Mesoamérica: resultados de los talleres de política e indicadores de integración logística 2017", Boletín FAL, No 364, Santiago, Comisión Económica para América Latina y el Caribe (CEPAL), abril.

(2017), "Institucionalidad y políticas de logística: lecciones para América Latina y el Caribe del proceso implementado por la República de Corea", serie Recursos Naturales e Infraestructura, N 185 (LC/TS.2017/126), Santiago, Comisión Económica para América Latina y el Caribe (CEPAL), diciembre. (2008), "La necesidad de establecer políticas integrales de infraestructura, transporte y logística", Boletín FAL, N² 263, Santiago, Comisión Económica para América Latina y el Caribe (CEPAL), julio.

Pérez-Salas, G. y R. Sánchez (2010), “Convergencia y divergencia en las políticas de transporte y movilidad en América Latina: ausencia de co-modalismo urbano", Boletín FAL, N 289, Santiago, Comisión Económica para América Latina y el Caribe (CEPAL), septiembre.

Rozas, P. y R. Sánchez (2004), “Desarrollo de infraestructura y crecimiento económico: revisión conceptual", serie Recursos Naturales e Infraestructura, No 75 (LC/L.2182-P), Santiago, Comisión Económica para América Latina y el Caribe (CEPAL), octubre.

Sánchez, R. y G. Pérez-Salas (2013), “Bases para la formulación de una política de logística y movilidad en Mesoamérica", documento presentado en la Reunión de Ministros de Transporte de Mesoamérica, San José, 4 de diciembre.

SIECA (Secretaría de Integración Económica Centroamericana) (2018), "Palabras del secretario general de la SIECA, en el lanzamiento de la Política Marco Regional de Movilidad y Logística", 19 de abril [en línea] http://www.sieca.int/index. $\mathrm{php} /$ news / palabras-del-secretario-general-de-la-sieca-en-el-lanzamiento-de-lapolitica-marco-regional-de-movilidad-y-logistica/.

Toledano, P. y otros (2014), A framework to approach shared use of mining-related infrastructure, Columbia Center on Sustainable Investment, Columbia University. 
Capítulo IX

\title{
La energía en la integración centroamericana
}

\author{
Víctor Hugo Ventura Ruiz
}

\section{Introducción}

En este capítulo se presenta una breve síntesis de la cooperación y asistencia técnica que la Comisión Económica para América Latina y el Caribe (CEPAL) ha proporcionado a los países centroamericanos en el ámbito de la energía. Los primeros subcomités y grupos de trabajo sobre energía, creados a finales de la década de 1950, tuvieron la tarea de promover el desarrollo de la electrificación y las fuentes renovables de energía, la conformación de redes eléctricas nacionales interconectadas y el aprovechamiento de la complementariedad de los sistemas nacionales. Entre 1976 y 1986 entraron en operación los enlaces eléctricos binacionales. En 1980, la CEPAL presentó el primer estudio sobre la interconexión eléctrica centroamericana, que sirvió de base para el desarrollo de planteamientos y emprendimientos posteriores que han permitido la conformación del primer mercado regional de electricidad de América Latina. Ha sido un largo proceso caracterizado siempre por la voluntad de cooperación entre las partes, lo que ha permitido realizar avances concretos aun en los períodos en que tuvieron lugar profundos conflictos políticos y sociales en varios países de la región. La CEPAL lideró la cooperación en materia de integración eléctrica hasta la década de 1980, cuando se incorporaron otros cooperantes y la banca multilateral de desarrollo para apoyar la construcción de la interconexión eléctrica regional, proyecto que se inauguró a finales de 2014. 
En materia de hidrocarburos, la cooperación de la CEPAL empezó en la década de 1970, cuando se produjeron los choques petroleros y surgió la preocupación por buscar mecanismos para reducir la vulnerabilidad de los países centroamericanos, incluida una regulación y supervisión efectiva para asegurar la eficiencia de las actividades en la cadena de suministro de hidrocarburos.

En el siglo XXI se incorporan dos países al proceso de la integración centroamericana (Belice y República Dominicana). La cooperación de la CEPAL se amplía al contexto de los ocho países que ahora conforman esta región. Se priorizan las iniciativas y acciones dirigidas a enfrentar la crisis de altos precios internacionales del petróleo que se produjo en el decenio 2003-2013. La Estrategia Energética Sustentable Centroamericana 2020, aprobada por los ocho países a finales de 2007, fue la respuesta regional. Esta estrategia estableció la ruta para el logro de un conjunto de objetivos que se pueden resumir en los siguientes: i) reducir la dependencia de los hidrocarburos; ii) aumentar la participación de las fuentes renovables; iii) reducir la emisión de gases de efecto invernadero; iv) aumentar la cobertura de energía eléctrica, y v) incrementar la eficiencia en la oferta y la demanda de energía. Actualmente, la CEPAL colabora con los países en la actualización de la estrategia energética, considerando las políticas y planes nacionales y los compromisos internacionales, en especial los establecidos en la Agenda 2030 para el Desarrollo Sostenible.

\section{A. La energía en la agenda de la Comisión Económica para América Latina y el Caribe}

En la Primera Reunión del Comité de Cooperación Económica del Istmo Centroamericano (CCE), órgano de consulta de la CEPAL ${ }^{1}$, celebrada en Tegucigalpa en agosto de 1952, el entonces Secretario Ejecutivo de la CEPAL, Raúl Prebisch, presentó un informe en que incluyó recomendaciones sobre el impulso necesario para el desarrollo energético. Prebisch enfatizó que sin suficiente disponibilidad de energía eléctrica no sería posible la industrialización y se vería frustrada la política de integración. En aquel entonces eran pocas las fuentes de energía hídrica en explotación y la generación de energía térmica requería la importación de combustibles, por lo que la política industrial de la integración exigía con apremio la realización de estudios para el desarrollo de nuevas fuentes de energía. La recomendación de la CEPAL apuntaba hacia la cooperación en materia de energía eléctrica y subrayaba que los estudios básicos y la capacitación de técnicos eran un medio fructífero para reforzar la política de integración (Pimentel, 2018). El CCE recomendó a los Gobiernos

El CCE tuvo amplia actividad en el siglo pasado y quedó en receso durante el presente siglo. 
centroamericanos que solicitaran a las Naciones Unidas asistencia técnica. En coordinación con la CEPAL y en consulta con los Gobiernos, esa asistencia se tradujo en un estudio de la industria eléctrica regional.

Las autoridades de la región acogieron con beneplácito esa recomendación ${ }^{2}$. En el marco del CCE se crearon los primeros subcomités y grupos de trabajo sobre energía. Estos comenzaron a promover el desarrollo de la electrificación y la cooperación y el aprovechamiento de la complementariedad de los sistemas nacionales, primero por medio de enlaces eléctricos binacionales y luego mediante una interconexión eléctrica regional entre seis países centroamericanos (Sistema de Interconexión Eléctrica de los Países de América Central (SIEPAC)). Este proyecto, de gran envergadura, finalizó en octubre de 2014.

En el ámbito petrolero, la cooperación de la CEPAL empieza en los años setenta, cuando ocurren los choques petroleros y se emprende la búsqueda de mecanismos que permitan reducir la vulnerabilidad de los países, incluida una regulación y supervisión efectiva para asegurar la eficiencia de las actividades en la cadena de suministro de hidrocarburos. Por su magnitud, la escalada de precios internacionales del petróleo registrada en el decenio 2003-2013 provocó grandes daños a las economías de los ocho países que conforman el Sistema de la Integración Centroamericana (SICA). Estos países requirieron el apoyo de la CEPAL para elaborar un Plan de Emergencia Energético (2003) y una estrategia energética sustentable. Esta última fue aprobada a finales de 2007 y en ella se establecieron metas que se deberían cumplir antes de 2020, que sirvieron para orientar la cooperación energética de los ocho países del SICA.

Por último, en iniciativas del Secretario General y de la Asamblea General de las Naciones Unidas (en particular, la iniciativa Energía Sostenible para Todos y la Agenda 2030 para el Desarrollo Sostenible) se ha definido la energía como uno de los pilares del desarrollo. En la actualidad esas iniciativas constituyen los ejes para la articulación de la cooperación energética que la CEPAL proporciona a los países.

En las páginas siguientes se resumen siete décadas de cooperación y asistencia técnica, que exhiben logros muy significativos. Se han definido tres subperíodos, que coinciden con hechos históricos relevantes para esta región: 1950-1979, 1980-1996 y 1997-2018 (o sea, hasta la actualidad). En el diagrama IX.1 se muestra un breve resumen de los principales acontecimientos e hitos.

\footnotetext{
A los efectos de este capítulo, al hablar de Centroamérica se hace referencia solamente a los seis países del istmo centroamericano que se adhirieron a la iniciativa integracionista durante la segunda mitad del siglo XX (de norte a sur: Guatemala, El Salvador, Honduras, Nicaragua, Costa Rica y Panamá). Al hacer referencia al Sistema de la Integración Centroamericana (SICA), se tiene en cuenta la conformación actual de dicho organismo, integrado por ocho países. En este caso, además de los seis ya mencionados, se incluyen Belice y la República Dominicana.
} 


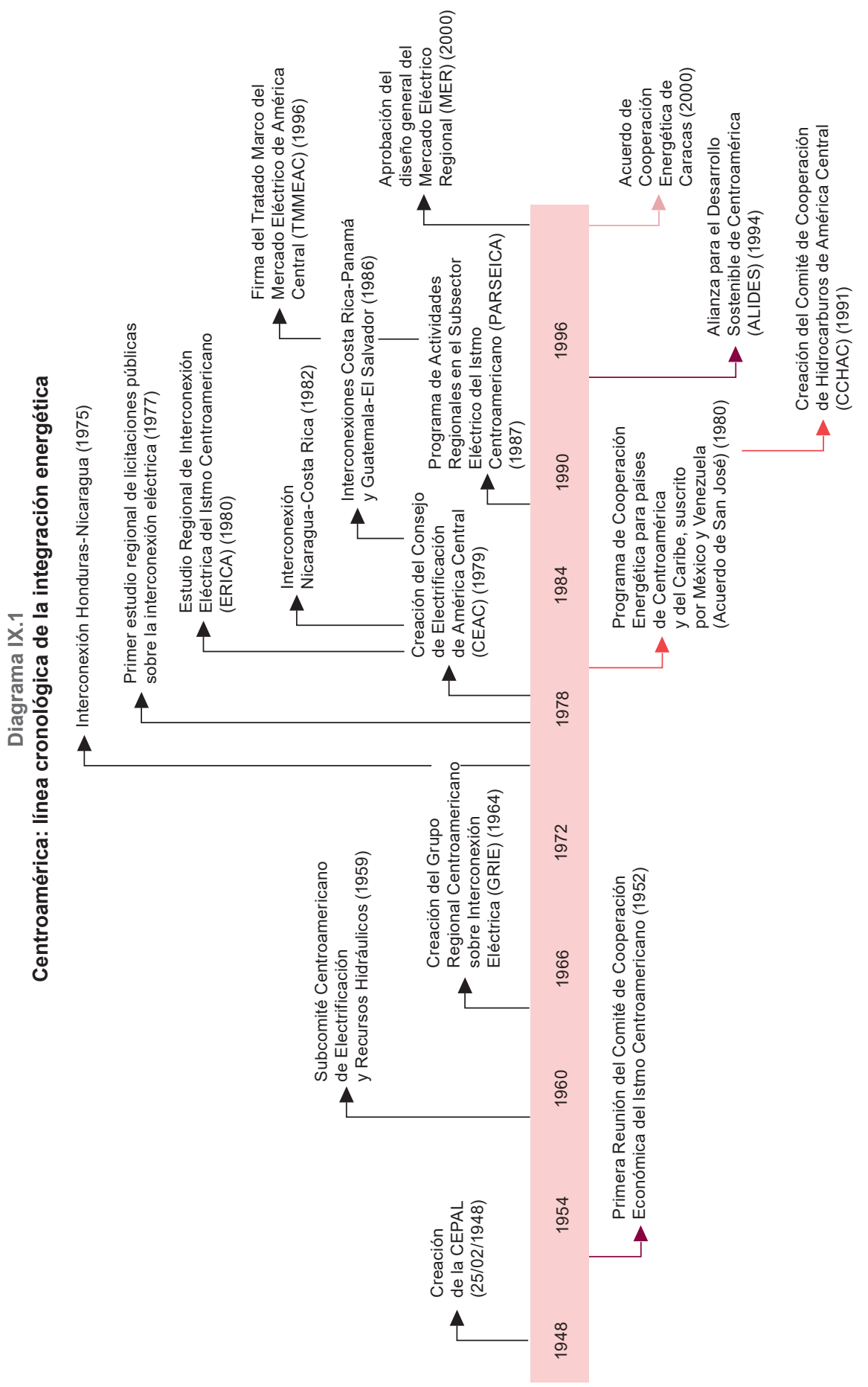




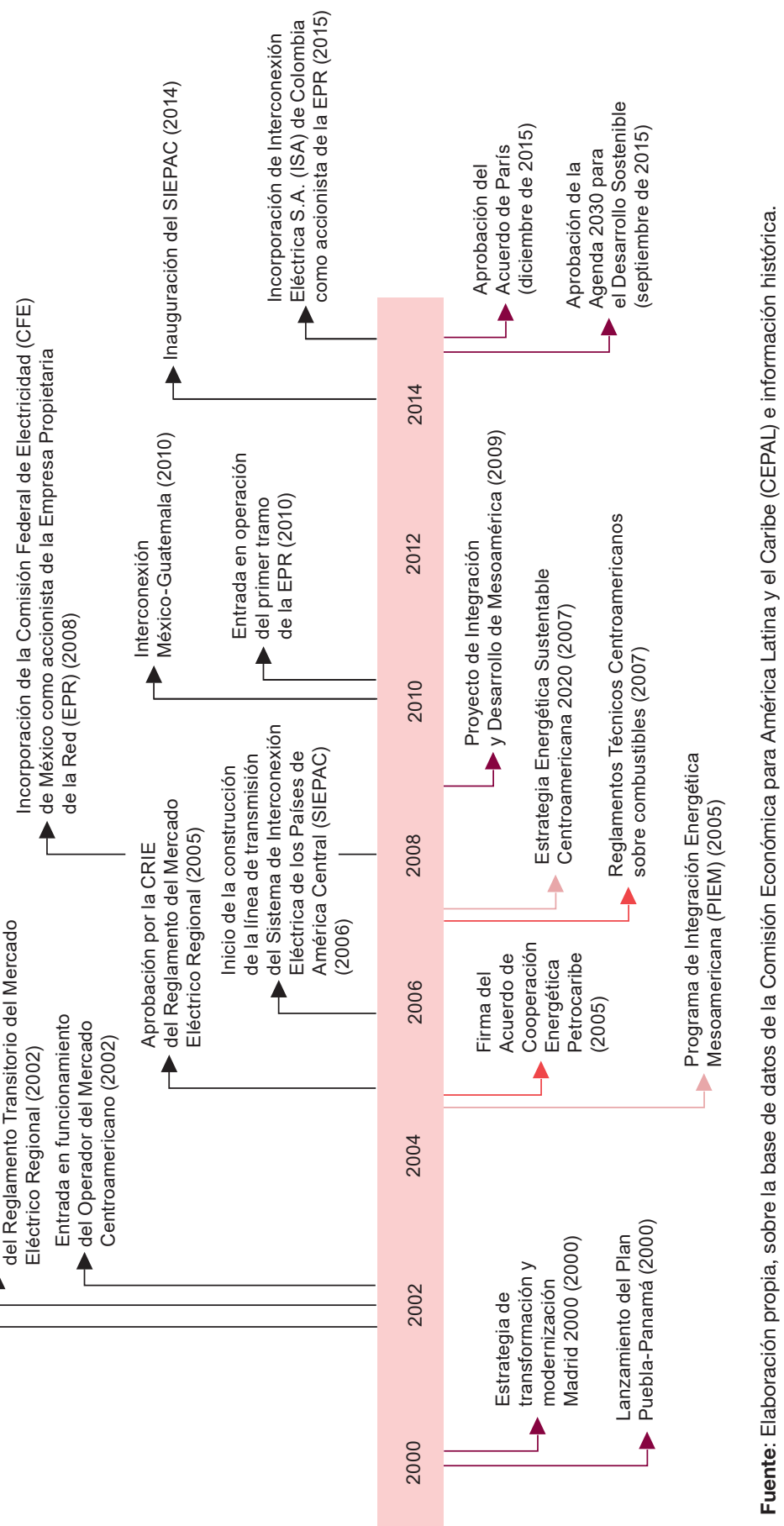




\section{B. El período 1950-1979}

La creación de la CEPAL y de su sede subregional en México coincidió con la finalización de un primer ciclo de desarrollo de la electricidad basado en concesiones a empresas privadas. En su mayor parte, estas empresas eran de carácter transnacional (por lo general, de capital estadounidense), recibían concesiones por un plazo de hasta 50 años y se dedicaban a prestar servicios en los principales centros urbanos. Privilegiaban la búsqueda de rentabilidad a corto plazo para garantizar el pago de dividendos a sus accionistas, por lo que escasearon las inversiones dirigidas al desarrollo hidroeléctrico y el desarrollo de sistemas de transmisión eléctrica. La sinergia rentista entre empresas eléctricas y petroleras empezaba a configurar un modelo que se complementaba, favoreciendo la instalación de centrales termoeléctricas que aprovechaban los excedentes de productos pesados de las refinerías, especialmente el combustóleo (combustible para calderas o fuel oil).

Cuando se inauguró la sede subregional de la CEPAL en México, el panorama energético de los países de la región se caracterizaba por muy bajas tasas de electrificación, aun en las zonas urbanas. También predominaba el bajo aprovechamiento del potencial hidroeléctrico y la alta utilización de las energías tradicionales (leña y otros residuos de biomasa). Los sistemas eléctricos locales solían ser pequeños y aislados. Escaseaba la infraestructura de transmisión eléctrica (con la consiguiente inexistencia de sistemas nacionales interconectados que permitieran aprovechar la diversidad y estacionalidad de la oferta y la demanda eléctrica). Por último, era notable la carencia, o la presencia incipiente y débil, de las recién creadas instituciones y empresas energéticas estatales.

Existía un consenso sobre la importancia de la electrificación para el desarrollo. Había evidencias de abundantes recursos hídricos y de la posibilidad de aprovechar otras fuentes renovables (como la geotermia), pero se requería un gran esfuerzo para desarrollar esas alternativas. También existía el convencimiento de que ese desarrollo solamente sería posible de la mano de empresas públicas ${ }^{3}$. En ese entonces comenzaba la Guerra Fría, con incidencia negativa en la región en las décadas de 1950 a 1990, en especial en

Como precedente estaban los ejemplos de México y los Estados Unidos. En el caso de México, bajo la presidencia de Lázaro Cárdenas, se aprobó en 1937 la Ley de la Comisión Federal de Electricidad, y en 1938 se nacionalizó la industria petrolera, con resultados muy positivos. En el caso de los Estados Unidos, se había creado en 1933 la Autoridad del Valle del Tennessee (TVA), con el objetivo de generar energía eléctrica y controlar el caudal del río Tennessee en una región que abarca siete estados. La TVA llegó a ser la mayor compañía pública de electricidad del continente. Por otra parte, también en los Estados Unidos, se fundó en 1942 la Asociación Nacional de Cooperativas Eléctricas Rurales (NRECA), organización que representa los intereses de más de 900 cooperativas eléctricas (de generación, transmisión y distribución). Esta Asociación está presente en 47 estados, presta servicio a más de 40 millones de personas (el $12 \%$ de la población) y posee el $42 \%$ de las líneas de distribución nacionales, que cubren tres cuartas partes del territorio estadounidense (véase [en línea] https://www.cooperative.com/nreca/). 
los procesos de desarrollo de los países del cuadrángulo norte, que sufrieron afectaciones en el sector energético ${ }^{4}$. Otros conflictos también afectaron a la región y su proceso de integración ${ }^{6}$. Sin embargo, debe resaltarse la contribución de la CEPAL y la continuidad de los comités y grupos de trabajo creados en el marco del CCE, que evitaron la paralización del proceso de integración. Aun en los años más álgidos de los conflictos armados, nunca se paralizaron las transacciones e intercambios de energía eléctrica entre los distintos países. De igual forma, continuó la marcha del fortalecimiento de la institucionalidad de la integración eléctrica y la infraestructura para mejorar la operación de los enlaces eléctricos binacionales.

En 1959, el CCE, durante su quinta reunión, creó el Subcomité Centroamericano de Electrificación y Recursos Hidráulicos (SCERH) 7 . Entre los temas encomendados a este Subcomité cabe mencionar los estudios de proyectos específicos de interconexión y desarrollo combinado de sistemas eléctricos entre distintos países, la evaluación de los recursos hídricos de la región, los estudios sobre regímenes tarifarios, el análisis de las experiencias relativas al financiamiento externo de las obras de electrificación, las propuestas encaminadas a armonizar diversos elementos técnicos y administrativos de los sistemas eléctricos, el programa de investigaciones sobre recursos hídricos (incluido el establecimiento de redes nacionales y regionales de estaciones hidrométricas e hidrometeorológicas), los estudios comparativos de costos de la energía eléctrica, el registro uniforme de cuentas para las empresas eléctricas y el desarrollo de estadísticas eléctricas.

En cumplimiento de esa agenda, se crearon los siguientes comités y grupos de trabajo en el seno del CCE: el SCERH, los grupos de trabajo binacionales sobre interconexión eléctrica (de norte a sur, GuatemalaEl Salvador, El Salvador-Honduras, Honduras-Nicaragua, NicaraguaCosta Rica y Costa Rica-Panamá), el Comité Regional de Recursos Hidráulicos (CRRH), en 1966, el Comité Regional de Normas Eléctricas (CRNE), en 1967, el Grupo Regional Centroamericano sobre Interconexión Eléctrica (GRIE) y

4 En las décadas de 1970 y 1980 se desarrollaron conflictos bélicos en Guatemala, El Salvador y Nicaragua. En Honduras, aunque el nivel de conflictividad fue menor, el territorio sirvió de base para ejércitos irregulares que interfirieron en los procesos de los países vecinos.

5 Nicaragua fue el país que tuvo la mayor afectación, derivada de la revolución sandinista (1979) y el movimiento contrarrevolucionario de los años ochenta. En el caso de Guatemala, como consecuencia de los sucesos de 1954, el país pospuso sus planes de desarrollo hidroeléctrico durante más de una década. De este modo se garantizó la protección frente a la competencia de la empresa eléctrica transnacional dominante y quedaron asegurados sus dividendos hasta que se extinguiera su concesión. En El Salvador, la infraestructura en general y las líneas y redes eléctricas resultaron seriamente dañadas durante el conflicto armado.

6 En especial, se refiere a la "Guerra de las 100 horas" (conflicto entre El Salvador y Honduras ocurrido en 1969). La construcción del enlace eléctrico binacional entre esos dos países se postergó alrededor de tres décadas.

7 En un inicio funcionó bajo el nombre de Subcomité Centroamericano de Electrificación, pero en su agenda siempre se incluyeron los recursos hídricos. 
el Grupo Regional sobre Tarifas Eléctricas (GRTE), ambos en 1968, el Grupo Regional sobre Recursos Hidráulicos (GRRH) y el Grupo Regional de Energía Geotérmica (GREG), en 1978. La CEPAL actuó como secretaría técnica de estos comités y grupos de trabajo. Salvo el CRRH, el resto ha dejado de operar y sus tareas han sido absorbidas por las nuevas entidades de la integración eléctrica regional ${ }^{8}$.

Durante los primeros 30 años, la CEPAL centró su atención en las iniciativas orientadas a desarrollar la infraestructura eléctrica (incluidas la electrificación rural y las fuentes de energía renovables), así como en el fortalecimiento de las empresas públicas de electricidad de reciente creación en los distintos países 9 . El primer desafío fue la construcción de una infraestructura eléctrica de transmisión que permitiera aprovechar los recursos naturales (sobre todo el potencial de las cuencas hídricas y la geotermia) y la conformación de los sistemas nacionales interconectados. La intención era poder transportar la energía de los centros de producción a los centros de consumo, aprovechando las estacionalidades y la diversidad de la demanda y la oferta eléctrica, a fin de reducir los costos del suministro de electricidad y garantizar la seguridad del suministro eléctrico. El segundo gran desafío lo planteaban las interconexiones eléctricas internacionales, que permitirían cosechar los beneficios de un desarrollo coordinado de los sistemas eléctricos y facilitarían la construcción de emprendimientos hidroeléctricos de mayor escala.

El primer gran choque petrolero (1973) tuvo repercusiones significativas en las economías de los países de la región, todos importadores de hidrocarburos ${ }^{10}$. Un segundo choque (1979) los alertó a buscar mecanismos

8 El Comité Regional de Recursos Hidráulicos (CRRH) está constituido por un Consejo Director, integrado a su vez por un miembro representante de cada uno de los Gobiernos de Belice, Costa Rica, El Salvador, Guatemala, Honduras, Nicaragua y Panamá. Estos miembros son los presidentes de los comités nacionales de meteorología y recursos hídricos de cada país. Su Secretaría Ejecutiva fue establecida en Costa Rica, en 1974. Fue la primera entidad del Comité de Cooperación Económica del Istmo Centroamericano en adquirir gestión independiente. Es un órgano especializado del SICA en los campos de la meteorología y el clima, la hidrología y los recursos hídricos e hidráulicos.

9 Los países centroamericanos crearon sus respectivas empresas públicas de electricidad entre 1940 y 1960: la Comisión Ejecutiva Hidroeléctrica del Río Lempa (CEL) de El Salvador fue creada en 1945; el Instituto Costarricense de Electricidad (ICE) en 1949; la Empresa Nacional de Energía Eléctrica (ENEE) de Honduras y la Empresa Nacional de Luz y Fuerza (ENALUF) de Nicaragua en 1957; el Instituto Nacional de Electrificación (INDE) de Guatemala en 1959, y el Instituto de Recursos Hidráulicos y Electrificación (IRHE) de Panamá en 1960.

10 A principios de los años setenta, después de un largo período de virtual estancamiento de los precios nominales del petróleo en el mercado internacional, los países miembros de la Organización de Países Exportadores de Petróleo (OPEP) decidieron intervenir para modificar los precios del petróleo crudo. Estos se incrementaron sustancialmente a partir de 1973. Los países miembros de la OPEP se aglutinaron en torno a objetivos comunes, en un marco de reivindicaciones tendientes a reordenar las relaciones económicas internacionales. A nivel mundial hubo una toma de conciencia de los riesgos que entrañaba la utilización indiscriminada de este recurso no renovable (CEPAL, 1981). 
para reducir los impactos ${ }^{11}$. La CEPAL elaboró estudios sobre las condiciones de abastecimiento de hidrocarburos a la región. Entre las medidas tomadas por los países cabe mencionar la movilización de recursos y financiamiento para desarrollar proyectos hidroeléctricos y geotérmicos de capacidad pequeña, mediana y grande, con lo que se logró diversificar la oferta y reducir la dependencia petrolera en el subsector eléctrico. Ello a su vez incrementó el endeudamiento (de las empresas eléctricas estatales y de los países). Desde el punto institucional, algunos Estados dieron los primeros pasos para conformar sus sectores de energía ${ }^{12}$.

Los principales resultados y progresos que se habían alcanzado al final de los años setenta se enumeran a continuación:

- Creación de los primeros grupos regionales encargados de analizar, estudiar y promover la integración eléctrica en la región centroamericana.

- Estudios de preinversión para el desarrollo de cuencas hidroenergéticas e interconexiones eléctricas binacionales, que servirían de base a la obtención del financiamiento necesario para la finalización de los estudios de preinversión, diseño, ingeniería y construcción de las obras.

- Construcción y operación de la primera interconexión eléctrica binacional (Honduras-Nicaragua, en 1976) y suscripción del primer contrato de compraventa de energía por parte de las empresas públicas de electricidad de los dos países.

- Establecimiento de tres enlaces binacionales con estudios de factibilidad finalizados ${ }^{13}$.

- Culminación de dos evaluaciones de prefactibilidad de la interconexión eléctrica centroamericana por parte de la CEPAL en el marco del CCE-GRIE. La primera (realizada entre 1974 y 1976, con apoyo de profesionales de las distintas empresas eléctricas nacionales y cooperación horizontal de la Comisión Federal de Electricidad de México (CFE)) mostraba beneficios

11 En 1978 ocurre una gran alteración a nivel mundial en el equilibrio entre la oferta y la demanda. Debido a un período de turbulencia política en la República Islámica del Irán y al aumento de la demanda al acelerarse el ritmo de recuperación económica internacional. A raíz de esto, en 1979 se produjeron cinco ajustes que incrementaron aproximadamente en un $40 \%$ el precio del petróleo con respecto a 1970.

12 En 1979, Panamá estableció la Comisión Nacional de Energía. En 1980, Costa Rica creó su Ministerio de Energía y Minas, y Nicaragua, el Instituto Nicaragüense de Energía (INE). Las dos primeras instituciones desaparecieron (o bien sus funciones fueron absorbidas por otra). La tercera subsiste, pero solo tiene funciones de ente regulador.

13 Salvo en el enlace El Salvador-Honduras (debido al conflicto binacional de 1969), en los restantes tres enlaces binacionales cuyas evaluaciones de prefactibilidad contaron con el apoyo de la CEPAL, los países avanzaron en la consecución de financiamiento, estudios de factibilidad e ingeniería y, en algunos casos, se preparaban las licitaciones y la construcción de las obras. Solo un enlace no fue considerado (el enlace Guatemala-Honduras), por decisión de las empresas públicas de los países involucrados. 
muy significativos, por lo que los países pidieron a la CEPAL que elaborara estudios con mayor nivel de detalle (CEPAL, 1977). En 1980, la CEPAL finalizó el Proyecto Regional de Interconexión Eléctrica Centroamericana, estudio que fue un hito para la integración eléctrica regional (véase el recuadro IX.1) y que sería la base para formular el SIEPAC en la siguiente década.

- Aprobación de la creación del Consejo de Electrificación de América Central (CEAC), en $1979^{14}$.

\title{
Recuadro IX.1 \\ EI Estudio Regional de Interconexión Eléctrica del Istmo Centroamericano
}

\begin{abstract}
Durante su cuarta reunión, celebrada a principios de 1977 en Panamá, el Grupo Regional Centroamericano sobre Interconexión Eléctrica (GRIE) encomendó a la CEPAL un estudio de prefactibilidad sobre las posibilidades a largo plazo de interconectar los sistemas eléctricos de la región. El objetivo del estudio era orientar las acciones que estaban realizando los países en forma bilateral y que sirviera de base en la formulación del programa general de integración eléctrica regional indicativa hasta el año 2000.
\end{abstract}

Ese mismo año, la CEPAL dio inicio al Estudio Regional de Interconexión Eléctrica del Istmo Centroamericano (ERICA), con el apoyo financiero del Banco Centroamericano de Integración Económica (BCIE), el Banco Interamericano de Desarrollo (BID) y el Programa de las Naciones Unidas para el Desarrollo (PNUD). También contó con la cooperación horizontal de los Gobiernos de Chile y México, por medio de la Empresa Nacional de Electricidad S. A. (ENDESA) y la Comisión Federal de Electricidad (CFE) (las respectivas entidades paraestatales de ambos países), así como del Organismo Internacional de Energía Atómica (OIEA) de las Naciones Unidas. Esas instituciones formularon metodologías de evaluación técnica, económica y financiera de las opciones de interconexión de los sistemas de electricidad. Otras instituciones mexicanas proporcionaron un valioso apoyo en especie . $^{\text {. }}$

La metodología utilizada se apoyó principalmente en el modelo WASP (Wien Automatic System Planning Package) del OIEA. Esta herramienta permite analizar, mediante técnicas de optimización dinámica, las posibles secuencias de adiciones de capacidad (a partir de una cartera de proyectos preseleccionada) para satisfacer la demanda de energía eléctrica y que, al mismo tiempo, cumplen los requisitos de confiabilidad del sistema y minimizan los costos de inversión y operación. El modelo WASP fue desarrollado en 1972 por la Autoridad del Valle de Tennessee (TVA) y el Laboratorio Nacional de Oak Ridge ${ }^{b}$. Ambos se encuentran en el estado de Tennessee (Estados Unidos) y su finalidad es satisfacer las necesidades del OIEA en cuanto al análisis de la competitividad de la energía nuclear en comparación con otras alternativas de expansión del sistema eléctrico. Se trataba de un modelo esencialmente termoeléctrico, por lo que fue necesario elaborar nuevas rutinas que permitieran simular con mayor fidelidad los proyectos hidroeléctricos. Ello dio lugar a la versión WASP-III (CEPAL, 1979), que luego pasó a ser una de las metodologías de mayor uso en el planeamiento de sistemas eléctricos en todo el mundo.

14 Durante la Sexta Reunión de los Presidentes y Gerentes de las Empresas Estatales de Energía Eléctrica del Istmo Centroamericano, celebrada en 1979 en Panamá, se propuso la creación del Consejo de Electrificación de América Central (CEAC) con el fin de promover la integración del sector eléctrico regional. Para su establecimiento faltaba aún la ratificación de Honduras y Guatemala. 
Recuadro IX.1 (conclusión)

Los resultados se complementaron con otros modelos de evaluación de inversiones y expansión de redes eléctricas utilizados por las empresas CFE y ENDESA. Posteriormente se llevaron a cabo estudios detallados de la operación de los sistemas eléctricos interconectados (flujos de carga, cortocircuito y estabilidades transitoria y dinámica, justificación del voltaje propuesto, aspectos del diseño de las líneas y subestaciones, costos detallados, despacho de carga y centro regional de operaciones), a cargo de la firma canadiense Montreal Engineering Company (MONENCO).

Se determinaron los costos y beneficios de la interconexión regional y las ventajas de la coordinación operativa. Además, se propuso un programa de inversiones y una hoja de ruta para avanzar en esa iniciativa integracionista. Así, a finales de los años setenta, la CEPAL proporcionaba a los países centroamericanos sólidas bases para iniciar la integración eléctrica de la región. En la actualidad, este ambicioso emprendimiento constituye el ejemplo sectorial integracionista de mayor avance en el hemisferio occidental.

Fuente:Elaboración propia, sobre la base de Comisión Económica para América Latina y el Caribe (CEPAL), Informe final del Estudio Regional de Interconexión Eléctrica del Istmo Centroamericano (ERICA), vol. I (CCE/SC.5/GRIE/VIII/3) y vol. II (E/CEPAL/CCE/SC.5/135), Ciudad de México, 1980.

a El Instituto Mexicano del Seguro Social (IMSS), la Secretaría de Agricultura y Recursos Hidráulicos (SARH) y el Instituto Nacional de Investigaciones Nucleares (ININ) permitieron la utilización de sus megacomputadoras, diseñadas para funcionar con lenguajes de alto nivel y lenguajes científicos de programación no disponibles en los países centroamericanos.

b El Laboratorio Nacional de Oak Ridge es una institución estadounidense especializada en ciencia y tecnología, bajo la jurisdicción del Departamento de Energía. Está orientado a la investigación básica y aplicada con miras a promover soluciones tecnológicas en áreas claves de la ciencia.

\section{El período 1980-1996}

En 1980 se desencadenó en América Latina una intensa crisis que dio comienzo a un complejo período de desequilibrios y ajustes. En la mayoría de los casos, estas situaciones hicieron que los países emprendieran reformas estructurales encaminadas a configurar economías más estables y más integradas al entorno internacional (CEPAL, 1996). En el ámbito centroamericano, la situación fue aún más grave: se registraron conflictos bélicos que asolaron a los países del cuadrángulo norte (Guatemala, El Salvador, Honduras y Nicaragua) y hubo serias desavenencias entre los Estados Unidos y Panamá, que desembocaron en sanciones comerciales y la invasión militar al segundo país (en diciembre de 1989). La paz y la estabilidad llegaron a Nicaragua cuando el movimiento contrarrevolucionario se disolvió a partir de 1990, después de las elecciones presidenciales celebradas en febrero de ese año. En El Salvador y Guatemala, se firmaron acuerdos de paz en enero de 1992 y diciembre de 1996, respectivamente.

En el decenio 1980-1989 el crecimiento promedio del producto interno bruto (PIB) fue de un 0,5\% anual, mientras que la tasa de crecimiento de la población fue del 2,7\%. En respuesta al aumento de los precios internacionales 
del petróleo en los años setenta, los países del istmo intensificaron los programas de desarrollo hidroeléctrico y geotérmico, con la construcción de nuevos proyectos que les permitirían reducir su dependencia del combustible importado. Estos proyectos requirieron cuantiosos préstamos externos, que fueron obtenidos por las empresas públicas de electricidad, con el aval de sus respectivos gobiernos. Como condición, se tendrían que alcanzar tasas de crecimiento superiores a las registradas. Además, se debía proporcionar acceso a financiamiento externo para continuar con los planes de expansión, realizarse ajustes periódicos, a tarifas acordes con las necesidades del subsector, e implementarse mejoras en el desempeño de las empresas de electricidad. Al no cumplirse las hipótesis anteriores, las empresas eléctricas en general se enfrentaron a serios problemas financieros. La magnitud de las inversiones ejecutadas en un marco de deterioro económico general de la región (que ocasionó grandes devaluaciones de sus monedas, salvo en el caso de Panamá) impidió el correspondiente incremento de los ingresos e hizo que el endeudamiento externo aumentara cada vez más (CEPAL,1992b).

Aun con un desempeño económico deficiente, el crecimiento de la demanda de energía (electricidad e hidrocarburos) casi siempre fue positivo (salvo en algunos años y casos específicos). De tal modo, en los primeros años de la década de 1990, el margen entre oferta y demanda de electricidad se fue estrechando de forma acelerada, en especial en países cuyos programas de expansión de nuevas centrales generadoras se habían paralizado. Esta situación desencadenó crisis de suministro de electricidad en Panamá y Nicaragua (1991), Guatemala y El Salvador (1992) y Honduras (1994) (CEPAL, 1992b). Ese panorama facilitó el arribo de inversiones privadas a la región y fue quizás el principal detonador de las reformas de la industria eléctrica que, con excepción de Costa Rica, se llevaron a cabo en los países de la región.

El sector petrolero siguió resintiendo los elevados precios del petróleo y sus derivados. Los sistemas de precios controlados y el escenario devaluatorio (con tipo de cambio fijo o mecanismos de "devaluación sucia") produjeron otros problemas. En algunos casos se llegó a situaciones de racionamiento en los mercados de combustibles. En apoyo a los países de la región, el 3 de agosto de 1980 los Presidentes de México y Venezuela suscribieron en Costa Rica el Programa de Cooperación Energética para países de Centroamérica y del Caribe (Acuerdo de San José). Por ese medio, los dos países petroleros pusieron a disposición de los países beneficiarios el suministro de hasta 160.000 barriles de petróleo diarios. Una parte de esas facturas se destinó a financiar proyectos de desarrollo.

Aun ante ese difícil panorama, la cooperación e integración energética de la región contó todo el tiempo con el apoyo de la CEPAL. Los principales resultados se resumen a continuación. 


\section{Avance de las interconexiones binacionales}

Durante los años ochenta entraron en operación tres enlaces eléctricos binacionales que se sumaron a la línea existente entre Honduras y Nicaragua, inaugurada en 1976. Fue un proceso gradual, resultado más de convenios bilaterales que de una planificación regional. A partir de 1986, en el istmo operaban dos bloques interconectados subregionales: el bloque norte, formado por Guatemala y El Salvador, y el bloque sur, conformado por los cuatro países restantes. Los intercambios se limitaban a la energía excedente, que no era posible almacenar en los embalses para su uso durante la estación seca. Durante los primeros años (1986-1988) los principales excedentes provenían de Honduras y Costa Rica (de los embalses Francisco Morazán y Arenal, respectivamente).

\section{El Plan Especial de Cooperación Económica para Centroamérica}

En la búsqueda de soluciones a los serios problemas que afectaban a la región, y en respuesta a los Acuerdos de Esquipulas, se recibió el apoyo unánime de la Asamblea General de las Naciones Unidas ${ }^{15}$. La Asamblea General pidió al Secretario General un Plan Especial de Cooperación Económica para Centroamérica (PEC). Esta iniciativa coadyuvaría a la reactivación del desarrollo social y económico sobre las bases de la diversificación de las exportaciones, el desarrollo rural y el aumento de la eficacia y la competitividad de la industria. Se consideraba urgente la inversión social para cerrar las brechas existentes, como parte de un modelo de desarrollo social que comprendiera tres elementos fundamentales: i) el restablecimiento de los servicios sociales de base; ii) el aumento de la producción y de la productividad de los sectores pobres de la población, y iii) la adopción de medidas de apoyo para el fortalecimiento de las instituciones, sobre todo a través de organismos de cooperación (Naciones Unidas, 1988). La CEPAL convocó al CCE y sus respectivos subcomités, elaboró perfiles de proyectos y convocó varias reuniones de cooperantes. Los sectores prioritarios fueron la energía y la agricultura. En el primer sector se obtuvieron los siguientes resultados concretos:

- Desarrollo Institucional e Integración Eléctrica Regional del Istmo Centroamericano (DIEICA). Esta iniciativa se llevó a cabo en dos fases. El Banco Mundial fungió como agencia ejecutora

\footnotetext{
15 "Procedimiento para establecer la paz firme y duradera en Centroamérica", suscrito en la Cumbre de Presidentes de Centroamérica, celebrada en Ciudad de Guatemala el 7 de agosto de 1987. Los Presidentes centroamericanos reconocieron el lazo inalienable que existía entre la paz y el desarrollo, y expresaron su intención de crear "un sistema de bienestar y justicia económica y social". A este efecto, acordaron negociar conjuntamente para recabar un apoyo económico extraordinario de la comunidad internacional.
} 
principal en ambos casos, y la CEPAL como agencia asociada. La primera fase tuvo como principales objetivos la reconstrucción y rehabilitación de redes eléctricas y subestaciones (muchas de ellas dañadas durante el conflicto armado), la rehabilitación de las centrales termoeléctricas, la electrificación rural, la creación de sistemas de comunicaciones y la realización de estudios de preinversión para centrales hidroeléctricas y geotérmicas. La segunda fase tuvo como objetivo identificar las áreas de las empresas eléctricas que requerían fortalecimiento institucional y financiero y definir aspectos encaminados a fortalecer el proceso de integración eléctrica regional.

- Apoyo e impulso de la operación coordinada de los sistemas eléctricos interconectados. Esta iniciativa tenía el objetivo de fortalecer los niveles técnicos de las empresas eléctricas estatales, sobre todo en los ámbitos de planeamiento y seguridad operativa, a fin de viabilizar las transacciones económicas de energía eléctrica y mejorar la operación de los sistemas eléctricos interconectados. Los principales resultados se obtuvieron por medio del Programa de Actividades Regionales en el Subsector Eléctrico del Istmo Centroamericano (PARSEICA) (véase el recuadro IX.2).

\section{Recuadro IX.2 \\ EI Programa de Actividades Regionales en el Subsector Eléctrico del Istmo Centroamericano}

La CEPAL elaboró este proyecto en el marco del PEC. Surgió como una de las respuestas a las mayores exigencias técnicas que planteaba a las empresas eléctricas la operación de una red integrada regionalmente. Tuvo como propósito reforzar la capacidad técnica de las empresas aludidas con el fin de lograr una operación más segura y económica de los sistemas interconectados nacionales y promover su operación integrada. El Programa de Actividades Regionales en el Subsector Eléctrico del Istmo Centroamericano (PARSEICA) incluyó las siguientes actividades: i) la instalación en cada empresa eléctrica de un simulador digital para realizar estudios de seguridad operativa; ii) el desarrollo e instalación en cada empresa eléctrica de modelos para optimizar la producción de las centrales de generación eléctrica y facilitar la concertación de intercambios entre países; iii) la adquisición e instalación de computadoras en cada empresa eléctrica con el fin de ejecutar modelos digitales de análisis de redes y planeamiento operativo, y iv) la capacitación de un grupo de profesionales de la región en seguridad y planeamiento operativos.

El presupuesto global del proyecto fue de 3,3 millones de dólares. El Banco Interamericano de Desarrollo (BID) financió alrededor de dos terceras partes de esa suma como cooperación técnica no reembolsable y el resto lo aportaron las seis empresas eléctricas, principalmente en especie. Por acuerdo de las correspondientes empresas de la región, la ejecución del proyecto corrió a cargo del Instituto Costarricense de Electricidad (ICE), que estableció a ese fin una unidad ejecutora ad hoc. El Grupo Regional Centroamericano sobre Interconexión Eléctrica (GRIE) cumplió la función de comité de dirección del proyecto.

Fuente: Elaboración propia. 


\section{Institucionalización del Consejo de Electrificación de América Central}

El subsector eléctrico de la región estaba formado por las empresas eléctricas estatales de los seis países ${ }^{16}$. El Consejo de Electrificación de América Central (CEAC) fue creado en 1979 por las autoridades de cuatro de esas empresas, decisión que luego fue avalada por las autoridades de las empresas de Guatemala y Honduras y ratificada por los Presidentes y Jefes de Estado en 1985. Durante el período 1985-1989, las asambleas legislativas aprobaron el convenio constitutivo del CEAC, con lo que quedó constituido dicho organismo como entidad de derecho internacional, con personalidad jurídica y patrimonio propios, así como plena capacidad para ejercer derechos y contraer obligaciones. La Secretaría Ejecutiva del CEAC comenzó a funcionar en agosto de 1989 en El Salvador y, a partir de entonces, la sede de dicha secretaría ha sido rotatoria, en períodos de dos años.

El CEAC es un organismo regional de cooperación, coordinación e integración cuya finalidad principal es mejorar el aprovechamiento de los recursos energéticos de los Estados miembros, por medio de una generación, transmisión y distribución de la energía eléctrica eficiente, racional y apropiada entre los países de Centroamérica. Entre sus objetivos se pueden citar: la promoción de la celebración de acuerdos bilaterales o multilaterales para la interconexión eléctrica entre los países, la ejecución de los estudios necesarios para lograr una mejor planificación y coordinación de las operaciones de interconexión y la obtención de capital financiero para el desarrollo de proyectos de producción, transporte o distribución de energía eléctrica (CEAC, 1989). Esas características del CEAC constituyeron uno de los puntos fuertes de los países en el proceso de integración eléctrica y conformación del mercado eléctrico regional, hasta llegar a la nueva institucionalidad que se confirmaría en la década de 2000. La CEPAL, como institución de cooperación técnica, ha acompañado al CEAC, sobre todo durante sus primeros años de funcionamiento.

\section{Relanzamiento de la interconexión eléctrica}

En 1987, en el marco de la celebración del quinto centenario del descubrimiento de América, la cooperación española retomó los estudios sobre la interconexión eléctrica centroamericana analizados por la CEPAL y propuso a los países un ambicioso proyecto de interconexión, con una línea troncal de $500 \mathrm{kV}$,

16 El Instituto Costarricense de Electricidad (ICE), la Comisión Ejecutiva Hidroeléctrica del Río Lempa (CEL) de El Salvador, el Instituto Nacional de Electrificación (INDE) de Guatemala, la Empresa Nacional de Energía Eléctrica (ENEE) de Honduras, el Instituto Nicaragüense de Energía (INE) y el Instituto de Recursos Hidráulicos y Electrificación (IRHE) de Panamá. 
que debería instalarse en los siguientes años e inaugurarse en $1992^{17}$. Es así como surge el SIEPAC. A solicitud de los países, la CEPAL participó activamente en la revisión de los estudios técnicos. Ello requirió amplias discusiones, sobre todo en lo referente al nivel de tensión del nuevo enlace y a la definición del mecanismo de organización y ejecución del proyecto. Los países iniciaban un proceso de transformación de sus sectores de energía que, salvo en el caso de Costa Rica, representó una nueva organización industrial que entrañaba la eliminación de los monopolios estatales. En el subsector eléctrico se abandonaba el modelo de comprador único y se introducía la competencia en el segmento de la producción de electricidad. Además, se creaban entes reguladores y mercados mayoristas de electricidad. Bajo este nuevo mecanismo de organización, la participación privada cobró especial importancia. Varios países comenzaron a liberalizar el mercado petrolero. Ello implicaba que también en el sector de hidrocarburos era necesario fortalecer la capacidad de supervisión y regulación.

En busca de apoyo y financiamiento, en 1992 se presentó el proyecto del SIEPAC a la comunidad internacional. El BID comenzó a brindar apoyo técnico y financiero para la actualización de los estudios de factibilidad. Mediante estos estudios se reafirmaron los importantes beneficios y se recomendó complementar las redes e interconexiones existentes con una línea troncal de transmisión longitudinal a los seis países de la región y su conexión con los sistemas nacionales en alrededor de 15 subestaciones, así como el refuerzo de las redes nacionales. También se sugirió un séptimo mercado eléctrico regional superpuesto a los seis mercados y sistemas eléctricos nacionales. Todos estos deben interactuar en forma paralela y coordinada, bajo la supervisión y monitoreo de entes regionales con suficiente autoridad para ello. Con esas conclusiones, los países de la región, junto con el BID y el Gobierno de España, decidieron aprobar el financiamiento de la línea del SIEPAC y de la constitución del Mercado Eléctrico Regional (MER) en marzo de 1997. El proyecto se puso en marcha en 2009 (una vez completados los procesos de aprobación, incluido el diseño del mercado eléctrico y el mecanismo organizativo regional) y fue finalizado en octubre de 2014. El costo total ascendió a alrededor de 500 millones de dólares (véase el mapa IX.1).

17 Del 19 al 23 de octubre de 1987 se llevó a cabo en Madrid la primera reunión con los responsables de las empresas eléctricas estatales del istmo centroamericano. El objetivo era lanzar y materializar la idea de construir una nueva línea de transmisión eléctrica. Esta reunión constituyó un hito en el proyecto, pues en ella se firmó el Primer Protocolo de Acuerdo del Proyecto de Interconexión Eléctrica Troncal de América Central (Echevarría y otros, 2017). 
Sistema de Interconexión Eléctrica de los Países de América Central (SIEPAC), 2018

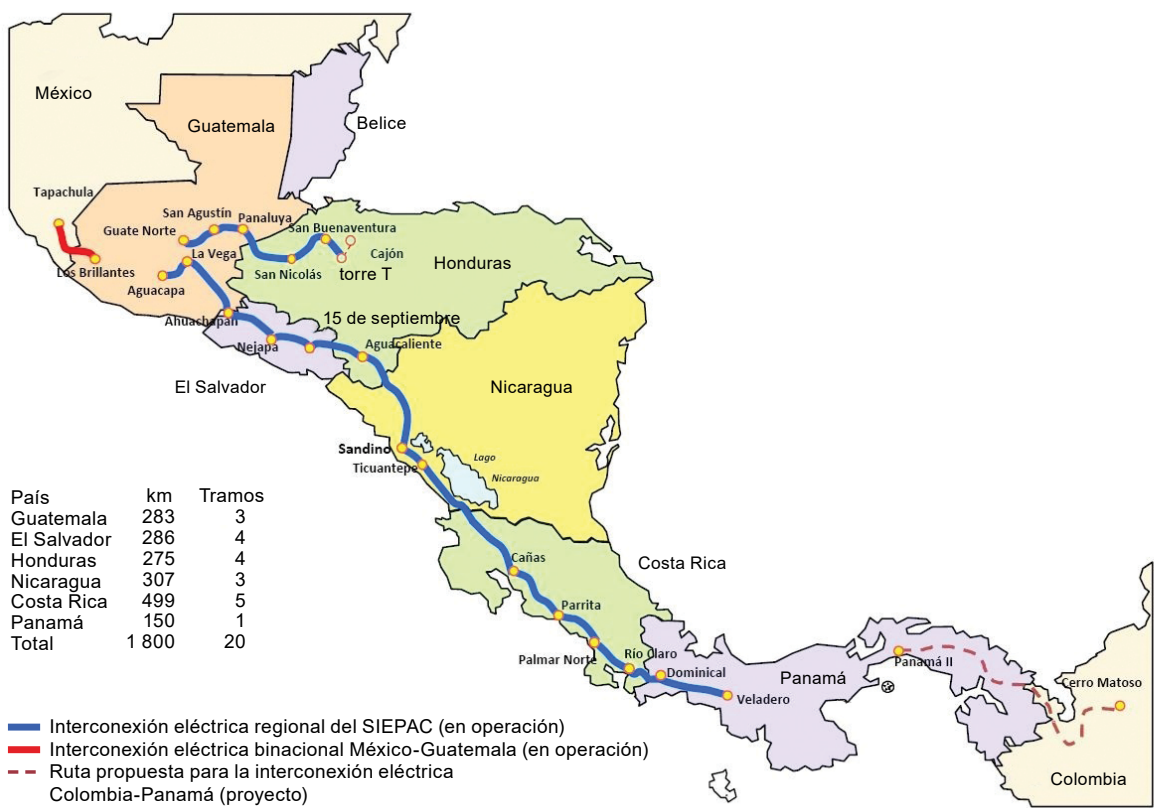

Fuente: Comisión Económica para América Latina y el Caribe (CEPAL), sobre la base de información del Sistema de Interconexión Eléctrica de los Países de América Central (SIEPAC).

\section{El Tratado Marco del Mercado Eléctrico de América Central}

El Tratado Marco del Mercado Eléctrico de América Central (TMMEAC) fue suscrito por los Presidentes de los seis países en diciembre de 1996 y ratificado por las respectivas asambleas legislativas. El Tratado estableció el marco jurídico necesario para la creación del MER y de los organismos regionales que le prestan apoyo. En él se considera la formación y el crecimiento gradual de un MER competitivo (basado en el trato recíproco y no discriminatorio, que contribuya al desarrollo sostenible de la región dentro de un marco de respeto y protección del medio ambiente) y se sientan las bases para abrir los mercados nacionales al intercambio regional, tanto en el acceso a la transmisión eléctrica como a las oportunidades de comprar y vender electricidad entre participantes de los diferentes países. En cuanto a la equidad social, uno de sus objetivos es propiciar que los beneficios lleguen a todos los habitantes de la región. Por su carácter de convenio internacional, el Tratado se ubica jerárquicamente por encima de las leyes nacionales y en segundo plano respecto a la Constitución de los países (Echevarría y otros, 2017). Fue necesario definir y aprobar un conjunto de interfaces regulatorias para asegurar una plena armonización entre las leyes y reglamentos nacionales y la legislación regional. 
Tras cuatro años de operación exitosa, los países han definido los desafíos actuales del MER y han elaborado una hoja de ruta para la expansión de la red eléctrica regional centroamericana (véase el recuadro IX. $3^{18}$ ).

\section{Recuadro IX.3}

\section{Desafíos actuales del Mercado Eléctrico Regional de Centroamérica}

La piedra angular para el desarrollo de este mercado fue la suscripción de su Tratado Marco (1996), que confiere autoridad, en el ámbito de la integración centroamericana, para la conformación de un mercado eléctrico regional superpuesto sobre los mercados nacionales de los seis países.

Desde 2002 comenzaron las transacciones regionales de electricidad, primero con reglas transitorias. Para 2013 se aplicaron reglamentos definitivos, que se han actualizado periódicamente con arreglo a las necesidades del mercado. En la actualidad, tras cuatro años de funcionamiento pleno, se observa que las transacciones regionales ya ascienden a más de $2.500 \mathrm{GWh}$ por año y se mantienen en un proceso continuo de crecimiento. Según diferentes estudios que se han realizado recientemente, los beneficios del comercio regional son superiores a los costos de funcionamiento y capital del MER, por lo que se concluye que este esfuerzo ha sido exitoso hasta la fecha.

Se espera que el MER siga creciendo en volumen y en beneficios para la región, para lo que se hace frente a los diferentes desafíos aún pendientes de atender. Las oportunidades de crecimiento se cifran en poder aumentar las transacciones a corto plazo, para las que aún hay espacio en las actuales redes de transmisión. La intención es completar los refuerzos nacionales de transmisión pendientes en algunos sectores y optimizar la armonización regulatoria entre el MER y los países miembros.

El mayor impulso sostenido de crecimiento se logrará cuando se hayan resuelto los desafíos pendientes para asegurar el uso del instrumento de contratos firmes a largo plazo, lo que a su vez permitirá el desarrollo de plantas de generación más grandes y de mayor eficiencia. También abrirá espacios regionales para impulsar las fuentes de energía renovables intermitentes.

Es necesario optimizar las condiciones para que los contratos firmes sean viables, tales como la garantía de que se podrá sostener a largo plazo una capacidad suficiente de transmisión regional. Para ello hay que establecer mecanismos que aseguren que tanto a nivel regional como nacional sea vinculante el mantenimiento de la capacidad de transmisión acordada entre los países en el contexto del MER.

La capacidad de transmisión comprometida entre los países es en la actualidad de $300 \mathrm{MW}$, pero se deberá incrementar en el futuro, cuando el crecimiento del mercado lo requiera y se justifique económicamente. La línea del SIEPAC se diseñó para poder añadirle un segundo circuito, con lo que se puede alcanzar, a costos razonables, una capacidad de cerca de $600 \mathrm{MW}$. Esto requerirá, además, que cada país incluya oportunamente en su propio sistema el respaldo que la capacidad regional requiera en su territorio.

Queda pendiente por definir si esta ampliación de capacidad debe hacerse a todo lo largo de la línea, o solo en aquellos tramos que muestren mayores transacciones, así como las fechas en que se justifique.

Estos desafíos para asegurar que el MER sea un mercado dinámico y en crecimiento continuo requerirán la introducción de algunos ajustes en la normativa vigente, para lo que se estudia un futuro Tercer Protocolo del Tratado Marco del Mercado Eléctrico de América Central, que se basa en planes estratégicos regionales que los entes regionales han desarrollado de forma conjunta desde 2015 .

De igual forma se analizan las opciones para posibles interconexiones extrarregionales con sistemas y mercados eléctricos de los países limítrofes con la región, todo en aras de incrementar la oportunidad de energía de menor costo y mayor seguridad de suministro.

Fuente: Elaboración propia.

18 El recuadro se elaboró sobre la base de información amablemente proporcionada por Teófilo de la Torre, especialista en materia del proceso de integración energética centroamericana. 


\section{Otros acontecimientos importantes de la integración energética regional}

\section{a) Otras interconexiones}

A inicios de la década de 1990, la CEPAL participó en dos importantes estudios de interconexión entre los países vecinos de Centroamérica, tanto del norte como del sur. En el estudio de prefactibilidad entre México y Guatemala se analizaron las opciones de interconexión de los sistemas de ambos países. Se pensó en prestar apoyo de esta manera al segundo país, sin descartar la posibilidad de que el enlace ofreciera seguridad energética a zonas del sureste mexicano (CEPAL, 1992a). Este proyecto fue retomado a inicios del presente siglo y se materializó en 2009, cuando se puso en marcha la operación del enlace entre México y Guatemala.

El segundo estudio fue elaborado en el marco del Grupo de los Tres (G-3), integrado por Colombia, México y Venezuela, que firmaron en 1994 un acuerdo de complementación económica con el propósito de crear una zona de libre comercio. El sector de la energía fue identificado como uno de los ejes de cooperación. Se planteó por primera vez un enlace mesoamericano, cuya evaluación se hizo con el apoyo del BID. Por diversas razones, la iniciativa del G-3 fue abandonada. Sin embargo, el estudio fue el primer planteamiento profundo en que se analizó el enlace Colombia-Panamá-Centroamérica. Este proyecto volvió a lanzarse como enlace binacional en los primeros años del presente siglo.

\section{b) Apoyo al subsector de los hidrocarburos}

Con la cooperación de Alemania, Italia y el BID, entre 1986 y 2004, la CEPAL ejecutó proyectos de asistencia técnica encaminados a mejorar las condiciones de abastecimiento de hidrocarburos a Centroamérica. Esas iniciativas permitieron reunir por primera vez a las autoridades del subsector petrolero de los países de la región. Se creó una importante base de datos que permitió a los países interesados hacer un análisis comparado de precios y costos de abastecimiento del crudo y sus derivados. De este modo pudieron adoptar medidas que les permitieran iniciar acciones para acceder a mejores precios, entre ellas, la exigencia a las transnacionales petroleras de referenciar los precios a los del mercado estadounidense de la costa del Golfo (con lo que se eliminaba la referencia a un mercado artificial denominado "posting Caribe" que encarecía injustificadamente los precios). La revisión de las rutas de los tanqueros, así como del tamaño de los envíos y de sus puertos de embarque y desembarque, fueron fundamentales para la determinación de costos eficientes de los fletes marítimos que se deberían reconocer en las fórmulas de precios de referencia (véase el mapa IX.2). Con esos antecedentes, a finales de 1991, el Foro Regional Energético de América Central (FREAC), una instancia que reunía a los ministros de energía de los 
países centroamericanos, creó el Comité de Cooperación de Hidrocarburos de América Central (CCHAC), primer grupo de trabajo regional en esta materia. El Comité ha seguido trabajando hasta la fecha y ha dado seguimiento a iniciativas clave en materia de hidrocarburos, incluido un monitoreo semanal de precios al consumidor final de los principales productos petroleros ${ }^{19}$.

\section{Mapa IX.2 \\ Países del Sistema de la Integración Centroamericana: principales rutas de abastecimiento de hidrocarburos}

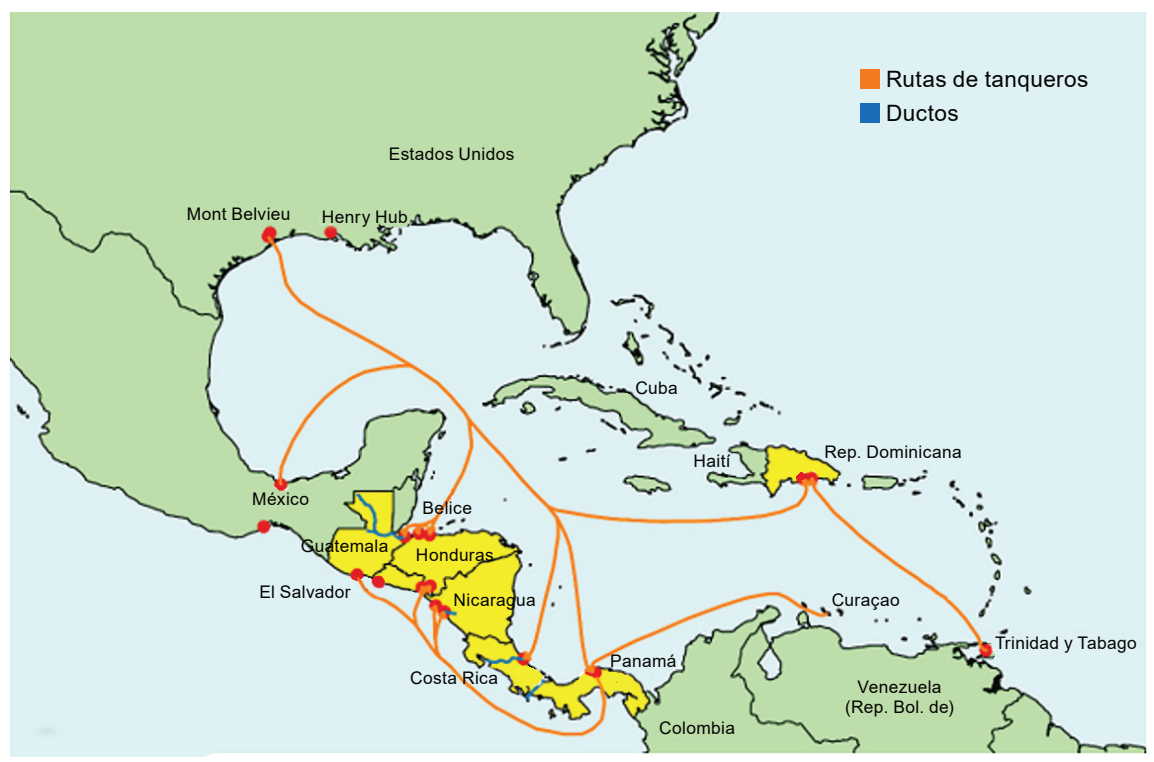

Fuente: Elaboración propia.

Fueron muy importantes los estudios orientados a la diversificación del suministro de hidrocarburos, en especial hacia el gas natural. En 1998 y 2002, la CEPAL presentó a los ministerios de energía y al CCHAC los primeros estudios sobre gasoductos regionales, desde México (CEPAL, 1998) y desde la República Bolivariana de Venezuela (Rodríguez, 2002). Esta idea ha recibido el apoyo de otros cooperantes, con evaluaciones en que se han considerado otras formas de suministro, sobre todo en forma de gas natural licuado $(\mathrm{GNL})^{20}$. Cabe mencionar que el gas natural permite alcanzar mayores niveles

19 El CCHAC fue creado durante la primera reunión del FREAC, en 1991. El FREAC fue la primera instancia ministerial sobre energía y tuvo una vida efímera, entre 1991 y 1996 . Actualmente se ha conformado el Consejo de Ministros de Energía del SICA, que también ha recibido apoyo de la CEPAL.

20. En el marco de la iniciativa Alianza de Energía y Clima de las Américas (ECPA) y con la cooperación de los Estados Unidos, se estudian mecanismos orientados a la regulación regional del gas natural. 
de eficiencia y una reducción sustancial de las emisiones, en comparación con las modalidades de generación termoeléctrica convencionales. Además, a mediano y largo plazo podría representar una opción atractiva para el transporte y la industria.

La revolución del gas de esquisto (shale gas) en los Estados Unidos, así como los excedentes y los bajos precios de ese recurso y la muy probable integración energética de los países de América del Norte, colocarían a los países del SICA en la frontera del mercado energético más grande y competitivo del mundo, situación que debería tener una incidencia positiva para la región. La República Dominicana recibe gas natural desde el inicio del presente siglo, lo que le ha reportado notables beneficios en el costo de su factura de hidrocarburos (CEPAL, 2017). En Centroamérica, los primeros embarques de este recurso energético comenzaron a llegar a inicios del segundo semestre de $2018^{21}$.

\section{c) Sistema de la Integración Centroamericana}

La constitución del SICA, en diciembre de 1991, trajo una nueva dinámica que se vería reflejada en importantes acuerdos en los temas relativos al medio ambiente ${ }^{22}$. El SICA mantiene una posición activa en cuanto a la movilización de recursos para proyectos de integración y apoyo al desarrollo e infraestructura de la región. Belice y la República Dominicana se adhirieron como miembros plenos en 2001 y 2013, respectivamente. En el caso de la CEPAL, esto supuso un reacomodo de sus actividades regionales para incluir a esos dos países.

\section{El período 1997-2018}

La asistencia técnica regional en temas de energía se ha mantenido, como resultado de la larga experiencia acumulada por la CEPAL y gracias a la posición geográfica de su sede subregional en México, desde donde este organismo ha podido articular la cooperación horizontal. La actual

${ }^{21}$ A inicios del presente siglo, los inversionistas privados presentaron los primeros proyectos de ciclos combinados con gas natural, que se instalarían en Puerto Cortés (Honduras) y prestarían servicio a los mercados de electricidad de El Salvador y Honduras. Dichas iniciativas no prosperaron, tal vez debido a la debilidad y poca madurez de los sistemas regulatorios. A comienzos de la segunda década del siglo XXI, dos países licitaron la compra de energía termoeléctrica, asignada a proyectos que utilizan gas natural. Se preveía que los primeros embarques de ese recurso energético llegaran a la región en agosto de 2018 (Panamá) y en 2021 (El Salvador).

22 Quizás el principal logro fue la Alianza para el Desarrollo Sostenible de Centroamérica (ALIDES), un acuerdo entre los presidentes de esa región firmado en 1994. Su finalidad era inducir un cambio progresivo en la calidad de vida del ser humano, que posibilitara el crecimiento económico con equidad social, así como la transformación de los métodos de producción y de los patrones de consumo, basados en el equilibrio ecológico. 
institucionalidad regional de la energía fue resultado, en buena medida, de las iniciativas y proyectos emprendidos por la CEPAL en el marco de mandatos de la Asamblea General de las Naciones Unidas (el CCE y el PEC). Por ese motivo, la CEPAL ha mantenido una vinculación estrecha con esos nuevos entes y ha sido llamada a cooperar tanto con el SICA como con los nuevos mecanismos de cooperación energética horizontal que han ido surgiendo, principalmente de los Estados Unidos, México y Venezuela (República Bolivariana de) ${ }^{23}$.

Durante este período, la agenda energética ha estado dominada por la implementación de las reformas del sector de la energía, tanto en la industria de la electricidad como en la de hidrocarburos. A nivel del subsector eléctrico, la temática principal ha estado relacionada con los mandatos emanados del Tratado Marco del Mercado Eléctrico de América Central (en especial, el financiamiento y construcción de la línea del SIEPAC y la conformación de los entes regionales de dicho mercado, lo que constituye el ejemplo más avanzado de integración sectorial del hemisferio occidental) y con la coordinación de los nuevos mecanismos de cooperación antes mencionados ${ }^{24}$. A partir de 2016 se ha incluido la Agenda 2030 para el Desarrollo Sostenible (aprobada por la Asamblea General de las Naciones Unidas en septiembre

23 Se refiere a la creación de nuevos mecanismos de cooperación petrolera impulsados por la República Bolivariana de Venezuela a partir de 2000 y 2005 (el Acuerdo de Cooperación Energética de Caracas y el Acuerdo de Cooperación Energética Petrocaribe, respectivamente), que marcarían el final de la cooperación de ese país con México en el marco del Acuerdo de San José, y al relanzamiento de la cooperación de México con sus vecinos del sur (el Plan Puebla-Panamá en 2000, el Programa de Integración Energética Mesoamericana, en 2005, y la consolidación de ambos en el Proyecto Mesoamérica, en 2008). Por parte de los Estados Unidos, figuran también las propuestas conocidas como Iniciativa Energética Hemisférica y Alianza Energía y Clima de las Américas (ECPA), lanzadas en 2001 y 2009, respectivamente.

24 Los estudios de factibilidad, ingeniería, diseño del mercado de electricidad y diseño de la institucionalidad fueron coordinados por el Consejo de Electrificación de América Central (CEAC) y por un comité de dirección conformado por delegados de los países, que incluyeron representantes de los ministerios de finanzas. Los organismos regionales establecidos en el Tratado Marco del MER y sus protocolos son: la Empresa Propietaria de la Red (EPR); la Comisión Regional de Interconexión Eléctrica (CRIE), encargada de la regulación del MER; el Ente Operador Regional (EOR), encargado de la operación del MER, y el Consejo Director del MER (CDMER), que es el responsable de impulsar el desarrollo del mercado regional y de adoptar las decisiones necesarias para lograr los objetivos y fines integrales del Tratado y sus protocolos. La EPR es una empresa multinacional que tuvo a su cargo la construcción del SIEPAC y actualmente presta servicios de transmisión eléctrica regional a los agentes registrados en el MER. El directorio de la EPR tiene representantes de las seis empresas públicas de electricidad de los países centroamericanos y de tres empresas extrarregionales (CFE de México, Interconexión Eléctrica, S. A. (ISA) de Colombia y Enel, una transnacional de origen europeo). Existe una undécima empresa regional (gemela de la EPR), la Red Centroamericana de Telecomunicaciones (REDCA), que es un operador neutral de servicios de transporte de banda ancha, sobre el cable de guarda de fibra óptica de la línea del SIEPAC. Lo anterior constituye el ejemplo más avanzado de integración multisectorial (energía-comunicaciones) del hemisferio occidental. 
de 2015), cuyo ODS 7 está dedicado a la energía, con mandatos, metas y desafíos muy claros respecto del acceso universal a los servicios modernos de energía, las fuentes renovables y la eficiencia energética.

Los altos precios del petróleo rompieron récords a partir de 2003. Junto con otros acontecimientos de implicaciones geopolíticas en la región, ese aumento de los precios marcaría un giro que tuvo consecuencias específicas en el sector energético de los países del SICA. A continuación se resumen las principales acciones y contribuciones de la CEPAL al desarrollo y la integración de la región en el sector a partir de 1997.

\section{Asistencia técnica a los países}

La asistencia técnica responde a las solicitudes que los países presentan a la CEPAL. En el ámbito de la energía, estas han tenido que ver por lo general con la formulación de políticas energéticas nacionales, la revisión de planes relacionados con el sector, las reformas (regulación energética, evaluación de modalidades de inversión privada y contratos de compraventa de energía), así como aspectos pertinentes a la formación de precios de suministro de los productos derivados del petróleo (gasolinas, diésel y gas licuado de petróleo), y las tarifas y costos de los servicios de electricidad. Esto último es una preocupación constante, dado el impacto que tienen los precios de los recursos energéticos en las actividades económicas, en el transporte y en la economía de las familias. A continuación se describen algunos resultados concretos.

\section{a) Bases de datos e informes estadísticos}

La CEPAL ha seguido desarrollando bases de datos regionales sobre energía y publica anualmente informes estadísticos muy completos sobre los subsectores de electricidad e hidrocarburos, que incluyen los ocho países del SICA. Además de medir el progreso de indicadores importantes para el desarrollo (por ejemplo, los avances en materia de electrificación y de energía renovables (véanse los gráficos IX.1 y IX.2)), también se informa sobre la evolución de las transacciones regionales de energía eléctrica (véase el gráfico IX.3) y algunos indicadores relacionados con la evolución de la competencia en el sector petrolero (véase el gráfico IX.4), como la participación por tipo de empresa y los índices de concentración, así como se presentan comparaciones (benchmarking) de los precios finales de la energía. Se trata de documentos muy demandados, tanto en el sector público como en el privado. 


\section{Gráfico IX.1}

Centroamérica: consumo de energía eléctrica por habitante, 1950-2016

(En kilovatios hora por habitante)

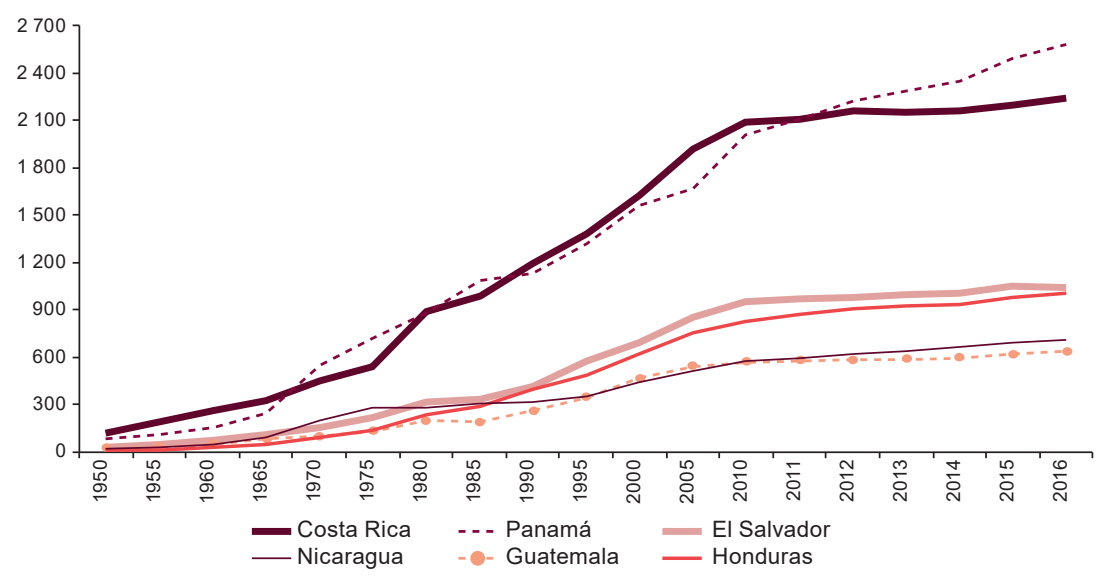

Fuente: Elaboración propia, sobre la base de informes oficiales.

Gráfico IX.2

Centroamérica: participación por fuente en la producción total de energía eléctrica, 1950-2017

(En gigavatios hora)

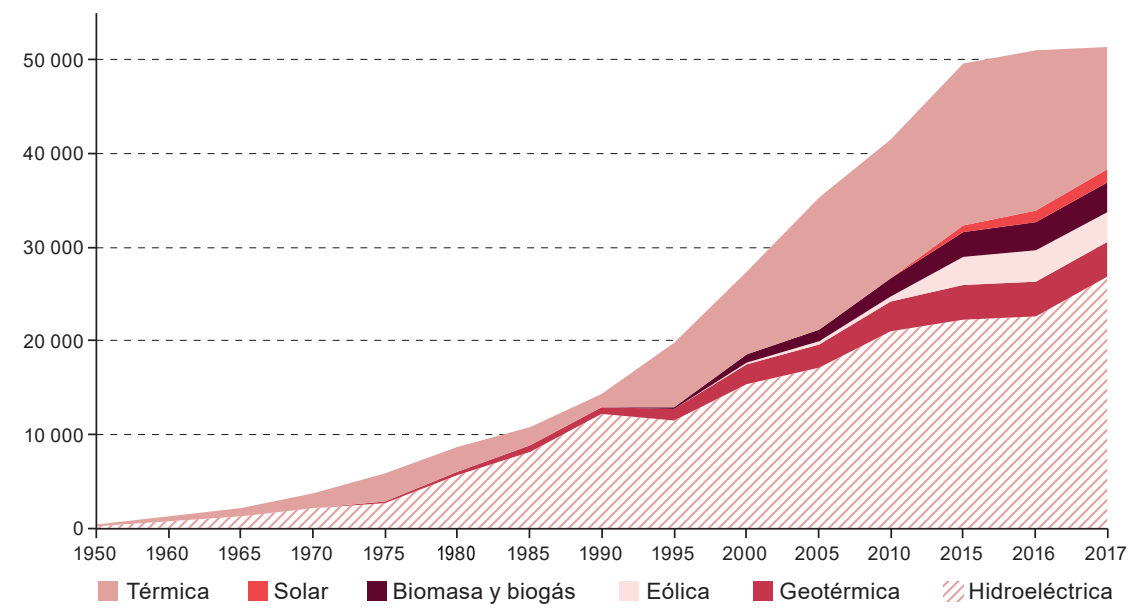

Fuente: Elaboración propia, sobre la base de informes oficiales. 


\section{Gráfico IX.3}

Centroamérica: importaciones y exportaciones de electricidad, 1976-2017 (En megavatios hora)

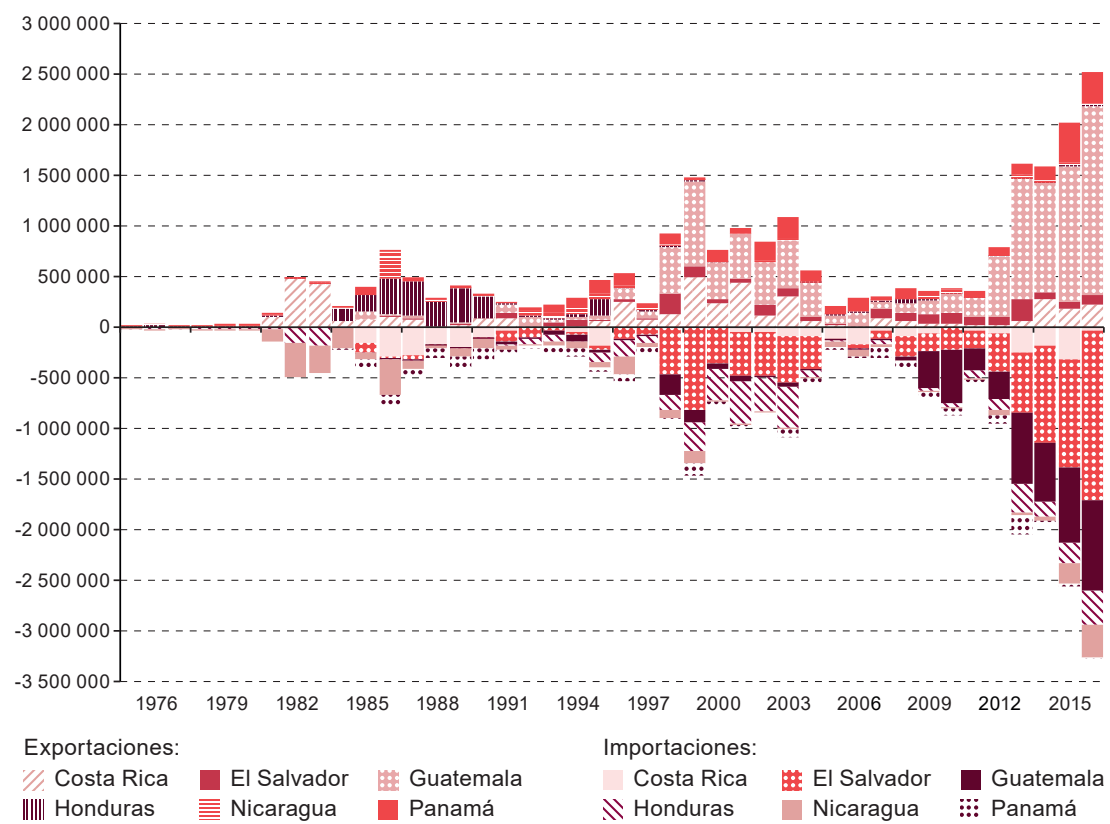

Fuente: Elaboración propia, sobre la base de informes oficiales.

\section{Gráfico IX.4}

Istmo centroamericano: participación por tipo de empresa e índices de concentración del mercado de diésel y gasolinas, 1996, 2006 y 2016

(En porcentajes e índice)

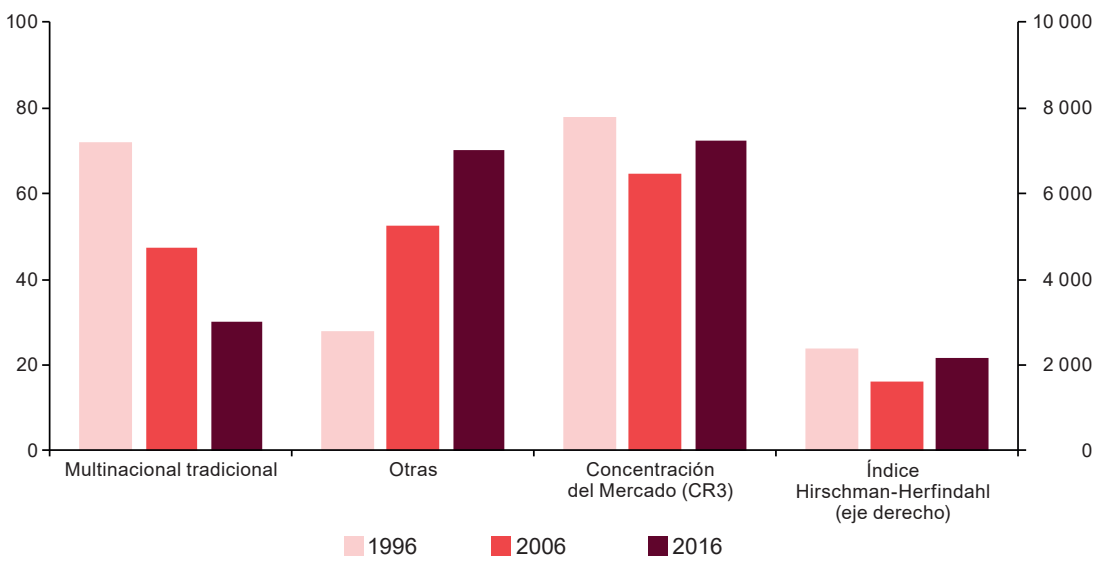

Fuente: Elaboración propia, sobre la base de informes oficiales.

a Los países incluidos son: Costa Rica, El Salvador, Guatemala, Honduras, Nicaragua y Panamá. 


\section{b) Hidrocarburos}

Las autoridades de los países del istmo han reconocido desde hace más de dos décadas la necesidad de armonizar el mercado de hidrocarburos. En 1994 se acordó preparar una estrategia centroamericana de combustibles, que fue elaborada por el CCHAC en 1995, con el apoyo de la CEPAL ${ }^{25}$. En 1996, los ministros de energía ordenaron que se implementara dicha estrategia $^{26}$. En apoyo a esa iniciativa se llevaron a cabo tres proyectos. El primero, financiado por el BID, mediante su Fondo Multilateral de Inversiones (FOMIN), estuvo encaminado a la armonización e integración del mercado de hidrocarburos y abarcó cuatro componentes: i) la elaboración de un plan de acción para el establecimiento del mercado de hidrocarburos regional; ii) la armonización de leyes, regulaciones y normas técnicas ambientales; iii) la convergencia de las políticas de precios de hidrocarburos, y iv) la promoción de proyectos de infraestructura regional. El segundo proyecto, financiado por Alemania, se dividió a su vez en dos componentes: i) el uso sostenible de hidrocarburos, y ii) la armonización de las normas aplicables al gas licuado de petróleo. El tercer proyecto contó con el apoyo de la cooperación italiana para la elaboración de dos estudios y la realización de evaluaciones sobre biocombustibles. Todas estas actividades tuvieron como contraparte las direcciones generales $u$ oficinas a cargo del subsector de hidrocarburos de los países centroamericanos y fueron ejecutadas por la sede subregional de la CEPAL en México (CEPAL, 2007a).

Los componentes de armonización de normas técnicas y ambientales en los proyectos antes citados han representado un gran apoyo para el proceso de la Unión Aduanera en lo que respecta a combustibles líquidos, infraestructura, gas licuado de petróleo (GLP) y otros factores ${ }^{27}$. En cuanto a la calidad de los combustibles utilizados en el transporte y atendiendo a la solicitud de las autoridades relacionadas con el medio ambiente y la energía y a los compromisos contraídos en foros internacionales, la CEPAL elaboró un estudio y una propuesta para la reducción del contenido de azufre en el diésel automotor (CEPAL, 2012) ${ }^{28}$. Dicha propuesta fue aprobada por los países, con compromisos y un calendario para mejorar la calidad del aire en las ciudades, que fue aprobado por los ministros de economía de la región. Este es un tema que adquiere relevancia debido a su vinculación con el ODS 3 y el ODS 11 (salud y ciudades y comunidades sostenibles), respectivamente.

En la $15^{\text {a }}$ Cumbre de Presidentes Centroamericanos, Costa Rica, agosto de 1994.

En la Novena Reunión del FREAC, Panamá, noviembre de 1991.

$27 \quad$ Al 30 de junio de 2007 se habían consensuado los Reglamentos Técnicos Centroamericanos (RTCA) de las gasolinas regular y superior, el diésel, el biodiésel, los cilindros portátiles para contener GLP, los aceites lubricantes para motores de gasolina y diésel, el transporte terrestre de hidrocarburos líquidos y GLP, los asfaltos, la gasolina de aviación y el keroseno. El proceso de actualización de las normas se vio frenado por las razones geopolíticas referidas en este capítulo.

28 En 2008, los ministros decidieron promover la reducción del contenido de azufre en los combustibles (16 Reunión del Foro de Ministros de Medio Ambiente de América Latina y el Caribe, Santo Domingo, 27 de enero a 1 de febrero de 2008). 


\section{c) Biomasa}

Los recursos energéticos tradicionales siguen registrando una utilización muy importante, sobre todo en las zonas rurales y en tres países de la subregión norte (Guatemala, Honduras y Nicaragua). En este ámbito, la CEPAL ha prestado apoyo con miras a mejorar los sistemas de información sobre la oferta y la demanda de biomasa, en su uso tradicional y moderno, en la agroindustria y como combustible sólido o gaseoso (biogás). En 2010, con apoyo de la cooperación alemana, la CEPAL realizó encuestas sobre el uso de la leña en Guatemala y Honduras. Considerando el compromiso contenido en el ODS 7, relacionado con la dotación de combustibles modernos para la cocción de alimentos en beneficio de toda la población y como energía renovable, la CEPAL impulsa el uso de una plataforma de información geoespacial para monitorear mejor y estimar el potencial de aprovechamiento sostenible de los recursos biomásicos, con especial atención a las zonas afectadas por el estrés forestal. Esto se ha enmarcado en un mecanismo de cooperación horizontal en que participan investigadores de la Universidad Nacional Autónoma de México (UNAM). Las plataformas referidas ya fueron entregadas a dos países (Honduras y República Dominicana) durante el primer semestre de 2018. Las versiones correspondientes a los restantes seis países del SICA se finalizarían durante el segundo semestre de 2018. Ello representa un avance importante para la región, pues facilita la evaluación transversal del ODS 7 con los restantes 16 Objetivos de Desarrollo Sostenible, sobre todo los referidos a la pobreza (ODS 1), la alimentación y la agricultura (ODS 2), la salud (ODS 3), el género (ODS 5), el agua y la gestión de cuencas (ODS 6) y los recursos agroforestales y el cambio climático (ODS 13).

\section{d) Eficiencia energética}

En respuesta al alza de los precios del petróleo, que comenzó a manifestarse en 2003, los ministros de energía de Centroamérica aprobaron en mayo de 2004 el Plan de Emergencia Energético, basado en una propuesta de la CEPAL. En ese plan se describieron en forma integral los primeros programas de eficiencia energética y se propugnó el uso de las fuentes de energía renovables y los biocombustibles. Luego la CEPAL impulsó el programa regional Base de Indicadores de Eficiencia Energética para América Latina y el Caribe (BIEE) con el objetivo de desarrollar indicadores que evalúen las políticas y programas de eficiencia energética y permitan analizar y comparar los resultados ${ }^{29}$. También se preparó una guía para formular planes sobre ese tema, que ha empezado a ser utilizada por los países (Navarro, 2017). Ambas constituyen poderosas herramientas para el

29 Este proyecto es una réplica del Programa ODYSSEE de la Comisión Europea, el cual reúne a representantes de los 28 Estados miembros de la Unión Europea más Noruega. Tiene como objetivo el seguimiento de las tendencias y medidas de eficiencia energética en Europa mediante herramientas en línea que incluyen bases de datos de consumo, indicadores de eficiencia energética y el seguimiento de los impactos de los programas nacionales implementados en cada país. 
monitoreo de los avances en eficiencia energética (que es uno de los ejes del ODS 7), así como los componentes conexos que figuran en las contribuciones previstas determinadas a nivel nacional (CPDN) presentadas por los países en el marco del Acuerdo de París sobre el cambio climático.

\section{e) Fuentes de energía renovables}

Las medidas adoptadas con miras a desarrollar estas fuentes de energía (entre ellas, las leyes que promueven su uso y otras medidas encaminadas a eliminar los obstáculos que se les interponen) permitieron que en los países centroamericanos se revirtiera la tendencia al decaimiento en la participación de las fuentes de energía renovables y se lograra un impulso positivo, con resultados que han sorprendido al mundo (véase el recuadro IX.2). Por otra parte, la CEPAL colabora con la Agencia Internacional de Energías Renovables (IRENA) para promover la iniciativa del Corredor Centroamericano de Energía Limpia.

\section{f) Nexo entre el agua, la energía y los alimentos}

El nexo entre el agua, la energía y los alimentos constituye una de las relaciones más importantes en la transversalización del ODS 6, el ODS 7 y el ODS 2. En 2016 se llevó a cabo una evaluación de la cuenca del río Reventazón en Costa Rica. Esta iniciativa revistió especial importancia debido a los conflictos e interrelaciones que se presentan y por el hecho de que dicha cuenca constituye la mayor fuente de energía eléctrica del país que, además, aporta el $85 \%$ de la producción de hortalizas y suple las necesidades de agua potable del $25 \%$ de la población de la Gran Área Metropolitana costarricense (Ballestero y López, 2017).

\section{La cooperación de México}

El Plan Puebla-Panamá (PPP) surgió en 2001 como una iniciativa de modernización y transformación de las regiones del sur y sureste de México y de los siete países del istmo centroamericano ${ }^{30}$. Mediante el PPP se intentaba lograr una integración económica que promoviera intercambios comerciales con pocas restricciones arancelarias, mejorara la infraestructura de la región, creara oportunidades de trabajo y aprovechara racionalmente los recursos, en aras de un desarrollo sostenible y equilibrado. El PPP se constituyó con ocho ejes, uno de los cuales correspondía a la interconexión eléctrica.

En 2005 se decidió priorizar los temas energéticos con el fin de paliar los efectos negativos de la gran escalada de precios del petróleo y tal vez por razones de orden geopolítico ${ }^{31}$. Esto dio lugar al Programa de Integración

El 15 de junio de 2001, en El Salvador, durante la Cumbre Extraordinaria de Jefes de Estado y de Gobierno del Mecanismo de Diálogo y Concertación de Tuxtla, se lanzó el PPP.

31 El enfrentamiento entre dos modelos antagónicos de cooperación hemisférica (el Área de Libre Comercio de las Américas (ALCA) y la Alianza Bolivariana para los Pueblos de Nuestra América (ALBA)). 
Energética Mesoamericana (PIEM). Se sumaron también a esta iniciativa Colombia y la República Dominicana. Su objetivo era compartir recursos, capacidad de producción, logística de transporte, mercados, tecnología y políticas de desarrollo sostenible en la región, a fin de coadyuvar al abasto de energía a precios competitivos y con sustento en el mercado. El PIEM incluía siete áreas de trabajo: i) una refinería en Centroamérica; ii) una planta generadora de energía eléctrica; iii) franquicias de distribución minorista de combustibles automotores (de Petróleos Mexicanos (Pemex)); iv) integración eléctrica México-Centroamérica; v) introducción del gas natural al istmo centroamericano; vi) fomento de las fuentes de energía renovables, y vii) promoción de la eficiencia energética.

En junio de 2008 se tomó la decisión de reestructurar las dos iniciativas (PPP y PIEM) y crear el Proyecto de Integración y Desarrollo de Mesoamérica o Proyecto Mesoamérica (PM), con cuyo fin se hicieron modificaciones estructurales al planteamiento original ${ }^{32}$. El PM está integrado por dos grandes ejes de trabajo: el económico y el social. El primer eje incluye la energía ${ }^{33}$.

Desde sus inicios, la CEPAL fue llamada a formar parte del grupo de apoyo interinstitucional de las tres iniciativas. Entre otros resultados específicos obtenidos en el área de energía se pueden mencionar: i) la construcción y puesta en marcha de la interconexión eléctrica México-Guatemala, a finales de 2009; ii) la evaluación preliminar de la interconexión eléctrica México -Guatemala-Centroamérica (Tovar y Ventura, 2016) y la instauración de la Comisión de Interconexión Eléctrica entre México y el SIEPAC (CIEMS), y iii) el inminente arribo del gas natural a Centroamérica y el consecuente inicio de las actividades preparatorias de los países para lograr un mejor uso de este recurso energético.

\section{La Estrategia Energética Sustentable Centroamericana 2020}

En 2005, las autoridades de energía y medio ambiente de los países centroamericanos solicitaron a la CEPAL la elaboración de una estrategia que cumpliera los compromisos asumidos por la región en la Cumbre de Johannesburgo $(\text { Río+10) })^{34}$. Posteriormente, las autoridades de los países

32 En la Décima Cumbre del Mecanismo de Diálogo y Concertación de Tuxtla, donde estuvieron presentes los jefes de Estado de los ocho países miembros, a los que se sumaron la República Dominicana, en calidad de Estado asociado del SICA, y Colombia (Tabasco (México), junio de 2008).

33 En el eje económico se consideran temas cruciales para el desarrollo de la infraestructura estratégica, la seguridad energética y la eficiencia del flujo de bienes y personas. En el eje social se abordan retos fundamentales en materia de salud pública, gestión del riesgo, seguridad alimentaria y vivienda, y se armoniza la información necesaria para prevenir daños causados por fenómenos de origen natural en Mesoamérica.

34 Primera Reunión Conjunta de ministros de energía y medio ambiente, San Pedro Sula (Honduras), febrero de 2005. 
avalaron los objetivos, medios, instrumentos y actividades de la Estrategia Energética Sustentable Centroamericana 2020 (Estrategia 2020), y encargaron a la sede subregional de la CEPAL en México que preparara un documento analítico con el fin de respaldar la estrategia, que fue aprobada en diciembre de $2007^{35}$. La Estrategia 2020 proporciona a los países una visión común de desarrollo e integración energética y establece metas con miras a los siguientes objetivos: i) reducir la dependencia de los hidrocarburos; ii) aumentar la participación de las fuentes renovables; iii) reducir la emisión de gases de efecto invernadero; iv) aumentar la cobertura de energía eléctrica, y v) aumentar la eficiencia de la oferta y la demanda de energía (CEPAL, 2007a). La estrategia ha servido como hoja de ruta al SICA y a las instituciones de la integración energética y como guía para el ordenamiento y complementación de la cooperación internacional. En casi todas las metas se registran importantes avances (véanse el gráfico IX.5 y el recuadro IX.4). La CEPAL forma parte del grupo de apoyo interinstitucional del SICA y de su Unidad de Coordinación Energética en cuanto al seguimiento de las actividades emprendidas en el marco de la Estrategia.

\section{Gráfico IX.5}

Países del Sistema de la Integración Centroamericana: evolución del índice de electrificación, 1960-2016

(En porcentajes y miles de habitantes)

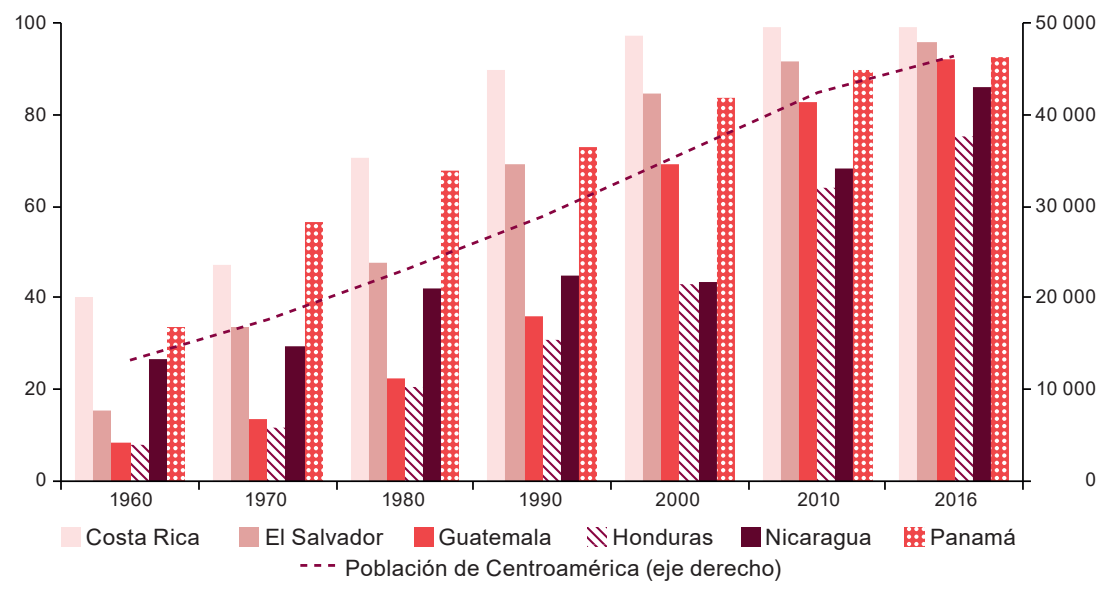

Fuente: Elaboración propia, sobre la base de informes oficiales.

35 La Estrategia fue aprobada por los ministros o responsables del sector energético de los países del SICA en una reunión celebrada en Ciudad de Guatemala en noviembre de 2007. Fue ratificada durante la $21^{\text {a }}$ Reunión Ordinaria de Jefes de Estado y de Gobierno de los Países del SICA, también celebrada en Ciudad de Guatemala, en diciembre de 2007. 
Actualmente, a solicitud del Consejo de Ministros de Energía del SICA, la CEPAL coordina la actualización de la estrategia energética regional centroamericana. Este trabajo se lleva a cabo en congruencia con los compromisos internacionales, en especial los establecidos en la Agenda 2030 para el Desarrollo Sostenible (por ejemplo, el ODS 7), la iniciativa de las Naciones Unidas conocida como Energía Sostenible para Todos y el Acuerdo de París (aprobado en el vigesimoprimer período de sesiones de la Conferencia de las Partes en la Convención Marco de las Naciones Unidas sobre el Cambio Climático, celebrado en París en diciembre de 2015).

\section{Recuadro IX.4 \\ La transición energética de Centroamérica}

A fin de reducir su vulnerabilidad a los choques petroleros, los países centroamericanos iniciaron un ciclo de expansión de las fuentes de energía renovables a partir de los primeros años del presente siglo. Implementaron leyes de promoción de esas fuentes de energía (que incluyen beneficios fiscales como la exoneración de aranceles de importación sobre los bienes de capital y la exoneración del impuesto sobre la renta durante los primeros años de operación del proyecto), así como licitaciones de tecnología que facilitaron el desarrollo de las fuentes de energía renovables convencionales y no convencionales (solar y eólica). A nivel regional, en 2007 se aprobó la Estrategia Energética Sustentable Centroamericana 2020 con una visión común de desarrollo e integración energética y metas que contribuyeran a reducir la dependencia de los hidrocarburos, aumentar la participación de las fuentes renovables, mermar la emisión de gases de efecto invernadero, aumentar la cobertura de energía eléctrica e incrementar la eficiencia energética.

Como resultado de esas acciones, ha aumentado sostenidamente la participación de la energía renovable en el total, hasta alcanzar el $67 \%$ de la producción de electricidad en 2016. Cabe destacar el crecimiento exponencial de las fuentes solar y eólica, con una capacidad instalada de $1.620 \mathrm{MW}$ y una producción de $4.500 \mathrm{GWh}$ de energía durante ese mismo año (un 9\% de la producción total). En Costa Rica, en 2016, se logró generar energía eléctrica totalmente renovable durante más de 300 días continuos, con lo que esas fuentes representaron más del $98 \%$ de su producción eléctrica (véanse los gráficos).

Según el tipo de tecnología renovable, las siguientes cifras muestran su relevancia en la producción de electricidad en 2016. En El Salvador la energía geotérmica representó más del $26 \%$; en Nicaragua, el $17 \%$ fue producido con fuentes eólicas; en Guatemala los ingenios azucareros aportaron el 16\% y, en Honduras, el $10 \%$ provino de la energía solar. La operación del SIEPAC permitió aumentar el comercio internacional de electricidad. En 2016, el volumen de transacciones internacionales (importaciones más exportaciones) alcanzó un récord cercano a 4,6 teravatios hora. Un $9 \%$ de la energía eléctrica producida se destinó al mercado regional.

Todos los países han tomado medidas para impulsar la eficiencia energética. Tres de ellos (Costa Rica, Nicaragua y Panamá) han aprobado leyes específicas sobre ese tema. De igual forma, han promovido cambios en los patrones de consumo de energía y la sustitución de recursos energéticos mediante la apertura de las redes de transmisión y distribución a las fuentes de energía renovables de pequeña escala (generación distribuida), así como el uso de automóviles eléctricos y de biocombustibles. 
Centroamérica: composición de la generación de energía, 2016

(en porcentajes)

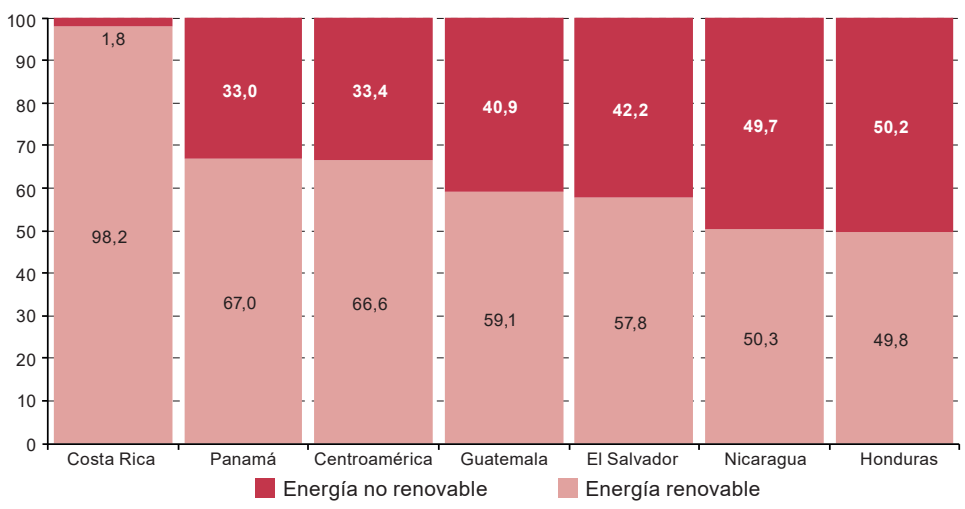

Fuente: Comisión Económica para América Latina y el Caribe (CEPAL), sobre la base de cifras oficiales.

Centroamérica: generación eléctrica a partir de las energías solar y eólica, 1995-2016

(en gigavatios hora)

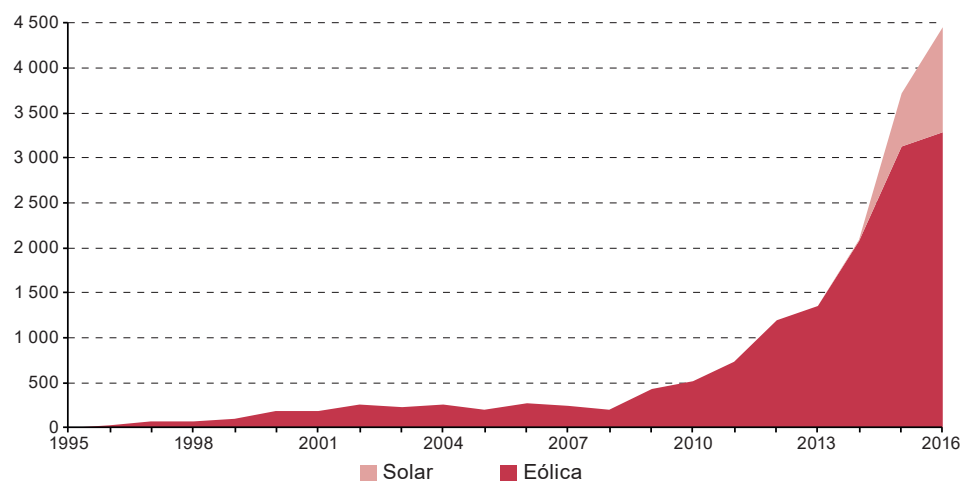

Fuente: Comisión Económica para América Latina y el Caribe (CEPAL), sobre la base de cifras oficiales.

Fuente:Comisión Económica para América Latina y el Caribe (CEPAL), sobre la base de M. Rojas Navarrete, Estadísticas del subsector eléctrico de los países del Sistema de la Integración Centroamericana (SICA), 2016 (LC/MEX/TS.2017/35), Ciudad de México, Comisión Económica para América Latina y el Caribe (CEPAL), sede subregional de la CEPAL en México, 2017. 


\section{E. Reflexiones finales: las tareas pendientes de la integración energética}

Durante las últimas siete décadas, los temas de cooperación e integración energética han estado presentes en las agendas de trabajo de los países centroamericanos. Las acciones e iniciativas emprendidas a este respecto pueden clasificarse en tres categorías: cooperación, complementariedad e integración. En función de su alcance geográfico, pueden agruparse como iniciativas binacionales, subregionales (con tres o más países), regionales (con los países del SICA), y extrarregionales (con participación de países socios como México, Venezuela (República Bolivariana de) y, recientemente, los Estados Unidos y otros).

La iniciativa de mayor alcance ha sido la interconexión eléctrica, que ha permitido cristalizar una infraestructura con valor de más de 500 millones de dólares y un mercado regional de electricidad en formación, que abarca a cerca de 46 millones de centroamericanos, junto con su institucionalización y gobernanza, que han implicado el establecimiento de cuatro entidades regionales. Además de las ventajas de la complementariedad que se han obtenido, los Estados están conscientes de que un escenario de integración posibilitaría la obtención de mayores beneficios. Por ello han comenzado a discutir la expansión de la interconexión (a partir del segundo circuito del SIEPAC), la plena armonización regulatoria de los mercados, los compromisos nacionales con miras a reforzar los sistemas de transporte nacional (y reservar la red del SIEPAC solo para el uso regional) y el aprovechamiento de las sinergias de la futura entrada del gas natural y las futuras conexiones, hacia el norte (México), hacia el sur (Colombia) y hacia otros Estados del SICA (Belice).

En el subsector petrolero, las iniciativas se han centrado en mecanismos de cooperación entre los países productores y los importadores. Se reconocen los aportes de dos grandes iniciativas: el Acuerdo de San José (1980-2007) y el Acuerdo de Cooperación Energética Petrocaribe (2005 a la fecha). Las limitaciones existentes en la infraestructura petrolera y las transformaciones ocurridas en las industrias de hidrocarburos, así como la mejora de las condiciones macroeconómicas y las nuevas modalidades de manejo de divisas, hicieron menos atractivo el Acuerdo de San José, cuyo uso empezó a mermar en la década de 1990. Petrocaribe enfrentó un primer obstáculo de tipo geopolítico que limitó el ingreso a nuevos miembros desde mayo de $2009^{36}$. El escenario de precios bajos del petróleo, que comenzó a manifestarse a partir de los últimos meses de 2014, ha reducido al mínimo las facilidades de Petrocaribe.

36 Un relevo presidencial y alteración del orden constitucional en uno de los países de la región, en mayo de 2009. 
En 2015 se aprobaron dos acuerdos de alcance global que en buena medida influirán en el programa del sistema de las Naciones Unidas y de los organismos de cooperación: la Agenda 2030 para el Desarrollo Sostenible y el Acuerdo de París. En ambos casos la energía cumple un papel fundamental. En la nueva visión de las iniciativas de integración energética no se pueden pasar por alto estos acuerdos. Tampoco se puede ignorar la transición y transformación energética que se está iniciando en el mundo, basada en cambios disruptivos relacionados con las tecnologías de la información, la generación distribuida, el almacenamiento de energía, la electromovilidad $\mathrm{y}$ las redes inteligentes.

Teniendo presente lo anterior, la CEPAL recomienda apoyar la integración energética como una forma de coadyuvar al cumplimiento del ODS 7 de la Agenda 2030 para el Desarrollo Sostenible. El papel central de la energía en la reducción de las emisiones de gases de efecto invernadero, y como catalizadora de un gran impulso ambiental, coadyuvará al desarrollo económico de las naciones y posibilitará una transición suave hacia economías bajas en carbono.

Todo lo anterior debe promoverse sin olvidar el apoyo a las iniciativas en curso, en especial la integración eléctrica de la región (véase el recuadro IX.3) y la conformación de un mercado regional de hidrocarburos que posibilite un abastecimiento eficiente a la región, sin los obstáculos y barreras que imponen las fronteras y las aduanas internacionales.

\section{Bibliografía}

Ballestero, M. y T. López, (2017), “El nexo entre el agua, la energía y la alimentación en Costa Rica: el caso de la cuenca alta del río Reventazón" (LC/TS.2017/105), serie Recursos Naturales e Infraestructura, $\mathrm{N}^{\circ} 182$ (LC/TS.2017/105), Santiago, Comisión Económica para América Latina y el Caribe (CEPAL), noviembre.

CEAC (Consejo de Electrificación de América Central) (1985), Convenio Constitutivo del Consejo Electrificación de América Central (CEAC), San José.

CEPAL (Comisión Económica para América Latina y el Caribe) (2017), Estadísticas del subsector eléctrico de los países del Sistema de la Integración Centroamericana (SICA), 2016 (LC/MEX/TS.2017/35), Ciudad de México, Comisión Económica para América Latina y el Caribe (CEPAL), diciembre.

(2013), Análisis del mercado eléctrico regional de Centroamérica y acciones para impulsar proyectos de generación nacional (LC/MEX/L.1096), Ciudad de México, febrero. (2012), Análisis de la reducción del azufre en el combustible diesel en El Salvador, Guatemala, Honduras y Nicaragua (LC/MEX/L.1083), Ciudad de México, noviembre. (2007a), Estrategia energética sustentable centroamericana 2020 (LC/MEX/L.828), Ciudad de México, noviembre.

(2007b), Perspectivas para el biodiesel en Centroamérica: Costa Rica, El Salvador, Guatemala y Honduras, (LC/MEX/L.791), Ciudad de México, agosto. 
(2007c), Diagnóstico preliminar de los aspectos agrícolas para la producción local de etanol a base de caña de azúcar en América Central (LC/MEX/L.767), Convenio CEPAL/República de Italia, Ciudad de México, marzo.

(2006), Istmo Centroamericano: diagnóstico de la industria petrolera (LC/MEX/L.685/ Rev.1), Ciudad de México, mayo.

(2000), Belice: escenarios para la integración eléctrica con los países vecinos (LC/MEX/R.762), Ciudad de México, agosto.

(1998), Gasoducto Regional México-Istmo Centroamericano. Resumen del estudio de prefactibilidad (LC/MEX/R.642), Ciudad de México, enero.

(1996), América Latina y el Caribe quince años después. De la década perdida a la transformación económica 1980-1995, Santiago, Fondo de Cultura Económica. (1992a), Interconexión eléctrica Guatemala-México: estudio preliminar (LC/MEX/R.357- (CCE/SC.5/GRIE/XVIII/3), junio.

(1992b), La crisis energética en América Central (LC/MEX/R.346-CCE/SC.5/ GRIE/XVIII/4), Ciudad de México, abril.

(1989), Informe de la Reunión Extraordinaria del Subcomité Centroamericano De Electrificación y Recursos Hidráulicos (LC/MEX/L.121 (CCE/SC.5/R.EX./1)), Ciudad de México, noviembre.

(1987), PARSEICA. Operación de sistemas eléctricos (parseica-oe) (LC/MEX/L.45 (CCE/SC.5/V/3)), febrero.

(1984), Lista de documentos del Subcomité de Electrificación y Recursos Hidráulicos y sus órganos subsidiarios (E/CEPAL/MEX/1984/L.6), Ciudad de México, enero. (1981), El impacto del incremento del precio de los hidrocarburos sobre las economías del Istmo Centroamericano (CEPAL/MEX/1036/Rev.1), Ciudad de México, enero. (1980a), Informe final del Estudio Regional de Interconexión Eléctrica del Istmo Centroamericano (ERICA), vol. I (CCE/SC.5/GRIE/VIII/3) y vol. II (E/CEPAL/ CCE/SC.5/135), Ciudad de México.

(1980b), Programa de inversiones para la alternativa A de interconexión eléctrica en el Istmo Centroamericano, 1984-1994 (CEPAL/MEX/SRNET/55), Ciudad de México, julio.

(1979), Modificaciones efectuadas al modelo WASP para mejorar la representación de las plantas hidroeléctricas (modelo WASPasp-3) (CEPAL/MEX/SRNET/13), Ciudad de México, marzo.

(1977), Informe de la Cuarta Reunión del Grupo Regional sobre Interconexión eléctrica (GRIE) (E/CEPAL/CCE/SG.5/119-CCE/SC.5/GRIE/IV/11/Rev.1), Panamá, marzo.

(1976), Informe de la Tercera Reunión del Grupo Regional sobre Interconexión Eléctrica (GRIE) (E/CEPAL/CCE/SC.5/109-CCE/SC.5/GRIE/III/7/Rev.1), Ciudad de México, mayo.

(1975), Informe de la Segunda Reunión del Grupo Regional sobre Interconexión Eléctrica (GRIE) (E/CEPAL/CCE/SC.5/105-CCE/SC.5/GRIE/II/4/Rev.1), San José.

(1972), "Istmo Centroamericano: análisis preliminar de las interconexiones de los sistemas eléctricos de Guatemala-El Salvador: El Salvador-Honduras; Nicaragua-Costa Rica y Costa Rica-Panamá" (E/CN.12/CCE/SC.5/87), Ciudad de México.

(1968), Informe de la Primera Reunión del Grupo Regional sobre Interconexión Eléctrica (GRIE), (E/CN.12/CCE/SC.5/63), mayo. 
Echevarría, C. y otros (2017), Integración eléctrica centroamericana: génesis, beneficios y prospectiva del Proyecto SIEPAC, Washington, D.C., Banco Interamericano de Desarrollo (BID).

MONENCO (Montreal Engineering Company) (1980a), Estudios de transmisión. Informe final (Volúmenes I, II y III), Montreal. (1980b), "Despacho de carga", Montreal.

Navarro, J. (2017), Propuesta metodológica para la elaboración de planes nacionales de eficiencia energética para los países del Sistema de Integración Centroamericana (SICA) (LC/MEX/TS.2017/3), Ciudad de México, Comisión Económica para América Latina y el Caribe (CEPAL), febrero.

Naciones Unidas (1988), "La situación en Centroamérica: amenazas a la paz y la seguridad internacionales e iniciativas de paz" (A/42/RES/231), mayo.

Pimentel, A. (2018), "La Integración Centroamericana desde sus orígenes hasta el Protocolo de Tegucigalpa, 1951-1991", Guatemala, inédito.

Rodríguez, V. (comp.) (2002), "Estudio de suministro de gas natural desde Venezuela y Colombia a Costa Rica y Panamá", serie Recursos Naturales e Infraestructura, N 40 (LC/L.1675-P-LC/MEX/L.515), Santiago, Comisión Económica para América Latina y el Caribe (CEPAL), junio.

Rojas, M. (2018), Estadísticas de producción de electricidad de los países del Sistema de la Integración Centroamericana (SICA). Datos preliminares a 2017 (LC/MEX/ TS.2018/15), Ciudad de México, Comisión Económica para América Latina y el Caribe (CEPAL), julio.

Torijano, E. (2017), Centroamérica y República Dominicana: estadísticas de hidrocarburos, 2016 (LC/MEX/TS.2017/33/Rev.1), Ciudad de México, Comisión Económica para América Latina y el Caribe (CEPAL), diciembre.

Tovar, J. y V. H. Ventura (2016), Análisis de opciones para incrementar las transacciones de energía eléctrica por la interconexión México-Guatemala-Centroamérica (LC/MEX/L.1210), Ciudad de México, Comisión Económica para América Latina y el Caribe (CEPAL), mayo. 


\section{Capítulo X \\ La respuesta al cambio climático: transversalización sectorial en el Sistema de la Integración Centroamericana}

Julie Lennox

\section{Introducción}

La alta exposición de los países del Sistema de la Integración Centroamericana (SICA) a los fenómenos climáticos y la gran vulnerabilidad de sus sociedades han colocado la respuesta a los fenómenos extremos y al cambio climático entre las prioridades de la integración. Este reto se ha reconocido en la región desde la década de 1990 y, en los últimos diez años, se ha vivido un proceso de formulación de políticas públicas y de transversalización del riesgo climático desde la institucionalidad ambiental hacia otros sectores claves como las finanzas, la agricultura, la salud y las obras públicas, entre otros, en los ámbitos nacional y regional.

En este capítulo se relata la experiencia interactiva de la Comisión Económica para América Latina y el Caribe (CEPAL), varias secretarías del SICA y los correspondientes ministerios a nivel nacional, en la que se buscó facilitar el proceso de transversalización del cambio climático. Entre los medios usados para ello se encuentran la generación de conocimiento técnico, el diálogo sobre las políticas públicas que se podrían aplicar, el fortalecimiento de las capacidades técnicas y la asesoría para instrumentar 
dichas políticas. La tesis principal es que el cambio climático representa una amenaza para la región del SICA, pero al mismo tiempo una oportunidad $\mathrm{y}$ un incentivo para transitar hacia un desarrollo sostenible e incluyente.

Frente a la brecha entre la sumatoria de las ofertas nacionales de reducción de las emisiones a nivel mundial y la meta de mantener el aumento de la temperatura mundial debajo de $\operatorname{los} 2{ }^{\circ} \mathrm{C}\left(\right.$ o $\left.1,5^{\circ} \mathrm{C}\right)$, urge redoblar los esfuerzos para lograr una adaptación sostenible e incluyente, continuando con la tarea de concientizar y formular políticas públicas, y atendiendo las demandas relativas a la instrumentación e implementación de estas. Lo anterior requiere una mayor articulación interinstitucional y el fortalecimiento de las capacidades técnicas.

Este capítulo está organizado en cuatro secciones: en la primera se expone la propuesta sobre cómo responder al cambio climático que se formuló en el marco de la iniciativa de la Economía del Cambio Climático en Centroamérica y la República Dominicana (ECC-CARD); en la segunda se describe cómo ha evolucionado y se ha implementado la iniciativa en la región del SICA desde 2008; en la tercera se señala la relación de la iniciativa con las instancias del SICA y el proceso de transversalización hacia tres sectores (finanzas, agricultura y salud), con resúmenes de las líneas de acción propuestas, y en la cuarta se concluye con las lecciones aprendidas.

\section{A. La región del SICA frente al cambio climático: propuesta de adaptación sostenible e incluyente}

La región del SICA es una de las más expuestas y vulnerables a los efectos adversos del cambio climático, por los siguientes motivos: al ser un istmo estrecho entre dos continentes y dos océanos, tiene extensas costas con áreas bajas; es una región afectada recurrentemente por las sequías, las lluvias intensas, los ciclones y el fenómeno de El Niño/Oscilación del Sur, así como por el aumento de la temperatura y los fenómenos hidrometeorológicos extremos, y alberga bosques y ecosistemas con gran biodiversidad y que enfrentan degradación y deforestación. En el Quinto Informe de Evaluación del Grupo Intergubernamental de Expertos sobre el Cambio Climático (IPCC) se informó sobre un amplio rango de efectos climáticos en la región centroamericana, en particular el aumento de la temperatura y el nivel del mar, el blanqueamiento de los corales, los fenómenos extremos, el atraso en el inicio de las lluvias, y la mayor irregularidad e intensidad de estas. También se informó acerca de riesgos relacionados con la producción de alimentos, la seguridad alimentaria, la hidroelectricidad y la salud (IPCC, 2014). En un informe anterior, el IPCC había señalado, con un nivel de confianza media, que hubo efectos antropogénicos que contribuyeron a intensificar la 
precipitación extrema a escala mundial y las sequías en algunas regiones, incluida Centroamérica, estas últimas debido a la reducción de la lluvia o al aumento de la evapotranspiración (IPCC, 2012).

Existen diferentes índices que ponen en evidencia el riesgo climático de la región. El índice de riesgo climático global de la organización Germanwatch correspondiente al período 1997-2016 indica que Honduras es el país del que se han informado los mayores efectos del clima, mientras que Nicaragua ocupa el puesto 4, la República Dominicana el 10, Guatemala el 11, El Salvador el 16, Belice el 27, Panamá el 95 y Costa Rica el 101. Según el mismo indicador anual, los países de la región a menudo se encuentran entre los de mayor riesgo: la República Dominicana ocupó el segundo lugar en 2004; Guatemala el primero y Honduras el séptimo en 2005; Nicaragua el tercero en 2007; Belice el noveno en 2008; El Salvador el primero en 2009; Guatemala el segundo y Honduras el quinto en 2010, y El Salvador el cuarto y Guatemala el noveno en 2011 (Harmeling y Bals, 2007; Harmeling, 2008, 2009, 2010, 2011 y 2012; Harmeling y Eckstein, 2013; Kreft y Eckstein, 2013; Kreft y otros, 2014 y 2015; Kreft, Eckstein y Melchior, 2016; Eckstein, Künzel y Schäfer, 2017).

En virtud de las evaluaciones de impacto realizadas por los gobiernos, la CEPAL y otras organizaciones regionales y de las Naciones Unidas, se ha generado un historial de pérdidas y daños causados por fenómenos extremos mayores en la región. Según la sumatoria de las evaluaciones de impacto de 19 fenómenos climáticos mayores ocurridos a partir de 1974, se estima que más de 150 millones de habitantes de la región han sido afectados. El monto de los daños acumulados - sin que la estimación sea exhaustiva respecto de toda la región- ascendería a más de 23.000 millones de dólares a precios de 2008. El 26\% de las pérdidas y daños se concentraron en el sector de la infraestructura y el $48 \%$ en los sectores productivos; entre estos últimos, el $66 \%$ de las pérdidas y daños correspondieron a la agricultura y el $12 \%$ al comercio (CEPAL, 2014; CEPAL/CAC/SICA, 2013b).

En el Monitor de Vulnerabilidad Climática de la Fundación DARA (2012) se han sintetizado investigaciones e información científica sobre el impacto mundial (incluidos las pérdidas y los beneficios) del cambio climático en 2010 y se ha realizado una proyección hacia 2030. La Fundación DARA realiza una valoración del costo humano y económico del impacto del cambio climático; además, estima los niveles de vulnerabilidad y los clasifica en cinco categorías: agudo, severo, alto, moderado y bajo. En 2010, el nivel de vulnerabilidad climática era moderado en Costa Rica, Guatemala, Nicaragua y Panamá, alto en la República Dominicana, severo en El Salvador y Honduras, y agudo en Belice. Hacia 2030, las condiciones de vulnerabilidad aumentarían y el nivel sería alto en Costa Rica, Guatemala y Nicaragua, severo en Panamá, y agudo en Belice, El Salvador, Honduras y la República Dominicana. 
La Universidad de Notre Dame utiliza el índice global de adaptación $\left(\right.$ NDGAIN) ${ }^{1}$ para estimar el nivel de vulnerabilidad al cambio climático de 180 países y la preparación de estos para hacerle frente ${ }^{2}$. Los países que ocupan los últimos lugares de la clasificación son los más vulnerables y menos preparados. En 2016 Honduras fue el país del SICA cuya capacidad de adaptación resultó ser la más baja, al ser clasificado en el lugar 122 entre 180 países. Le seguían Belice, en el lugar 121, Nicaragua, en el 115, Guatemala, en el 112, El Salvador, en el 104, la República Dominicana, en el 95, Panamá, en el 79, y Costa Rica, en el 61. De acuerdo con este índice, únicamente Costa Rica está mejor preparada y enfrenta menos retos; en el resto de los países hay grandes desafíos y urge actuar frente al cambio climático.

La región se caracteriza por una alta vulnerabilidad y a su vez contiene valiosos acervos naturales y culturales que ameritan y requieren ser preservados y valorados por su contribución al desarrollo de las generaciones actuales y futuras. Sus ecosistemas albergan aproximadamente el 7\% de la biodiversidad mundial (INBio, 2004) y forman parte de la zona de megadiversidad de Mesoamérica (Ramírez, 1983). A pesar de que estos acervos se están deteriorando debido el patrón de desarrollo, todavía prestan múltiples servicios ambientales, como fuentes silvestres de cultivos, polinización, control de plagas y regulación de la humedad, el ciclo hídrico y el clima local, entre otros. Asimismo, la población de la región, que es relativamente joven y tiene una gran diversidad cultural, étnica y de estilo de vida, constituye un tesoro que puede contribuir a dar respuesta al cambio climático.

Existen diversas iniciativas mediante las cuales se da seguimiento a las tendencias en materia de temperatura, tormentas tropicales, huracanes, inundaciones y sequías en la región. Entre esas iniciativas se encuentran el Foro del Clima de América Central — foro regional de aplicación de pronósticos climáticos a la seguridad alimentaria y nutricional-, la Base de Datos Internacional sobre Desastres (EM-DAT) y la Red de Sistemas de Alerta Temprana contra la Hambruna (FEWS NET). Además, en la iniciativa de la Economía del Cambio Climático en Centroamérica y la República Dominicana (ECC-CARD) y en otras, se ha estimado el impacto potencial del cambio climático en sectores de la región como los recursos hídricos, la agricultura, la biodiversidad, los bosques y la hidroelectricidad, y se han fomentado discusiones sobre las políticas públicas que se podrían aplicar para responder a esta amenaza.

\footnotetext{
Véase [en línea] https://gain.nd.edu/our-work/country-index/.

La vulnerabilidad se refiere a la exposición de los países al cambio climático, considerando los renglones alimentación, agua, salud, ecosistemas, hábitat humano e infraestructura. La preparación indica la capacidad de generar acciones de adaptación como respuesta a los fenómenos climáticos y sus efectos, con un enfoque que recae en la capacidad de los sectores económico, político y social para movilizar recursos financieros.
} 
La valorización económica realizada en el marco de la ECC-CARD evidenció que las consecuencias y los costos del cambio climático, en un escenario donde hubiera emisiones crecientes e inacción global (escenario A2), serían significativos y crecientes en el tiempo ${ }^{3}$. Los costos serían más elevados que los de un escenario en que se redujera la tasa de crecimiento de las emisiones (escenario B2) o los de un escenario en que las emisiones se estabilizaran y se redujeran significativamente, como se aspira a lograr en las negociaciones internacionales ${ }^{4}$. Así, los costos de la inacción frente al efecto de los fenómenos extremos y el cambio climático son demasiado altos si no se toman medidas ambiciosas e inmediatas para reducir las emisiones, sobre todo en los países emisores e históricamente responsables de la acumulación de las emisiones en la atmósfera (CEPAL, 2010 y 2012f).

En la región centroamericana, la presión de los rezagos sociales y económicos existentes y las restricciones presupuestarias podrían ser argumentos para posponer las medidas que es necesario adoptar frente al cambio climático. No obstante, las crecientes repercusiones de los fenómenos extremos, como la depresión tropical 12-E en 2011 y la intensificación de las sequías, muestran que se debe romper el círculo vicioso integrado por los efectos acumulados de las pérdidas, los daños y la reproducción de las vulnerabilidades frente a los fenómenos climáticos. Urge tomar mejores medidas para que la reconstrucción posterior a los desastres y la inversión pública se realicen de forma más robusta y resistente, con incentivos y requerimientos relativos a la reducción de las vulnerabilidades y la adaptación frente a la variabilidad climática actual y los cambios climáticos previstos.

Debido a que el cambio climático es una falla de mercado que repercute en la economía, no es posible tratarlo como responsabilidad exclusiva de las instituciones ambientales, sino como problema económico central y transversal con serias implicaciones fiscales, sociales y económicas. El cambio climático constituye un pasivo público contingente, que afectará las finanzas públicas en forma creciente. Hoy en día hay una mayor demanda financiera generada por el impacto de los fenómenos extremos como las sequías, los huracanes, las lluvias intensas y las inundaciones. Así, es urgente enfrentar de forma proactiva el desafío de los fenómenos extremos, la variabilidad y el cambio climático. De otro modo, la generación actual sufrirá mayores costos y deterioro a causa de los fenómenos extremos, y las generaciones futuras deberán pagar

El escenario A2 del IPCC sugiere un mundo muy heterogéneo y autosuficiente en el que se conservan las entidades locales, con un desarrollo económico orientado a las regiones; el crecimiento económico por habitante y el cambio tecnológico son más fragmentados y lentos que en otras líneas evolutivas.

4 El escenario B2 del IPCC sugiere un mundo en el que predominan las soluciones locales a la sostenibilidad económica, social y ambiental, con un nivel de desarrollo económico intermedio y cambio de tecnología. 
un costo muy elevado para adaptarse al cambio climático y por tener que realizar una transición tardía y caótica hacia economías sostenibles y con bajas emisiones de gases de efecto invernadero (GEI).

El cambio climático está magnificando las vulnerabilidades socioeconómicas de la región e incidirá cada vez más en su evolución económica. Se estima que Centroamérica produce solo una mínima parte de las emisiones de GEI del mundo: menos del 0,3\% de las emisiones sin cambio de uso de la tierra y menos del $0,8 \%$ de las emisiones brutas totales (CEPAL, 2011). Sin embargo, los efectos de la emisión de GEI son visibles en la región, dado que los factores dependientes del clima son decisivos para las actividades como la agricultura y la generación hidroeléctrica, así como para sus habitantes y ecosistemas.

En consideración a las condiciones de la región, los Gobiernos de los países del SICA han priorizado la adaptación y la reducción de la vulnerabilidad en sus políticas, así como las acciones nacionales y las negociaciones internacionales sobre cambio climático. En los últimos diez años, han participado activamente en la creación de la institucionalidad en el marco de la Convención Marco de las Naciones Unidas sobre el Cambio Climático (CMNUCC), para enfrentar los retos de la adaptación y de las pérdidas y daños asociados al cambio climático. También han participado en el Fondo Verde para el Clima, insistiendo en que se debe dar la misma prioridad a la adaptación que a la mitigación. Los países centroamericanos han formulado propuestas innovadoras e integradoras, como las siguientes: el enfoque de paisajes; la mitigación basada en la adaptación para reducir las emisiones debidas a la deforestación y la degradación forestal; la conservación de las reservas forestales de carbono, la gestión de los bosques de forma sostenible y el aumento de las reservas forestales de carbono en los países en desarrollo (REDD+); la perspectiva del "rostro humano" al cambio climático, y la alianza para la educación frente al cambio climático.

En el marco de la iniciativa de la ECC-CARD, los países del SICA consensuaron priorizar medidas y políticas públicas que contribuyeran a la adaptación, que estuvieran diseñadas explícitamente para asegurar una mejor inclusión y sostenibilidad, y en las que se incorporara la reducción de las vulnerabilidades. Dentro de ese marco prioritario, se confirma la necesidad de transitar hacia economías y sociedades sostenibles desde el punto de vista ambiental y con bajas emisiones de GEI. Dichas respuestas deben volverse parte integral de los planes de desarrollo nacional, y se debe hacer un esfuerzo especial para maximizar los cobeneficios y minimizar los costos intersectoriales de las acciones propuestas.

La experiencia acumulada en las últimas décadas demuestra la importancia de identificar los riesgos y las medidas apropiadas para diversos sectores en función de las metas de desarrollo establecidas, como la reducción 
de la pobreza, la gestión del agua, la agricultura, la seguridad alimentaria y nutricional, la protección de los ecosistemas, la seguridad y la eficiencia energéticas, el ordenamiento territorial y la prevención de desastres. Igualmente, se requieren políticas que faciliten la adopción de medidas vinculadas a las metas de desarrollo, por ejemplo, en los campos fiscal, comercial, tecnológico y educativo, y de la cooperación interinstitucional y regional o internacional (véase el diagrama X.1). Las múltiples vías de impacto del cambio climático y los múltiples retos asociados a la sostenibilidad y la reducción de las emisiones de GEI requieren un esfuerzo de articulación estratégica entre los planes y las instituciones sectoriales, para maximizar los cobeneficios de las medidas y minimizar sus costos y los posibles efectos adversos sobre otros sectores. Por último, un enfoque importante para maximizar los resultados es dar mayor atención a los bienes y servicios comunes que son públicos e intergeneracionales, como el clima, el agua, la seguridad alimentaria y energética, y el transporte público, entre otros.

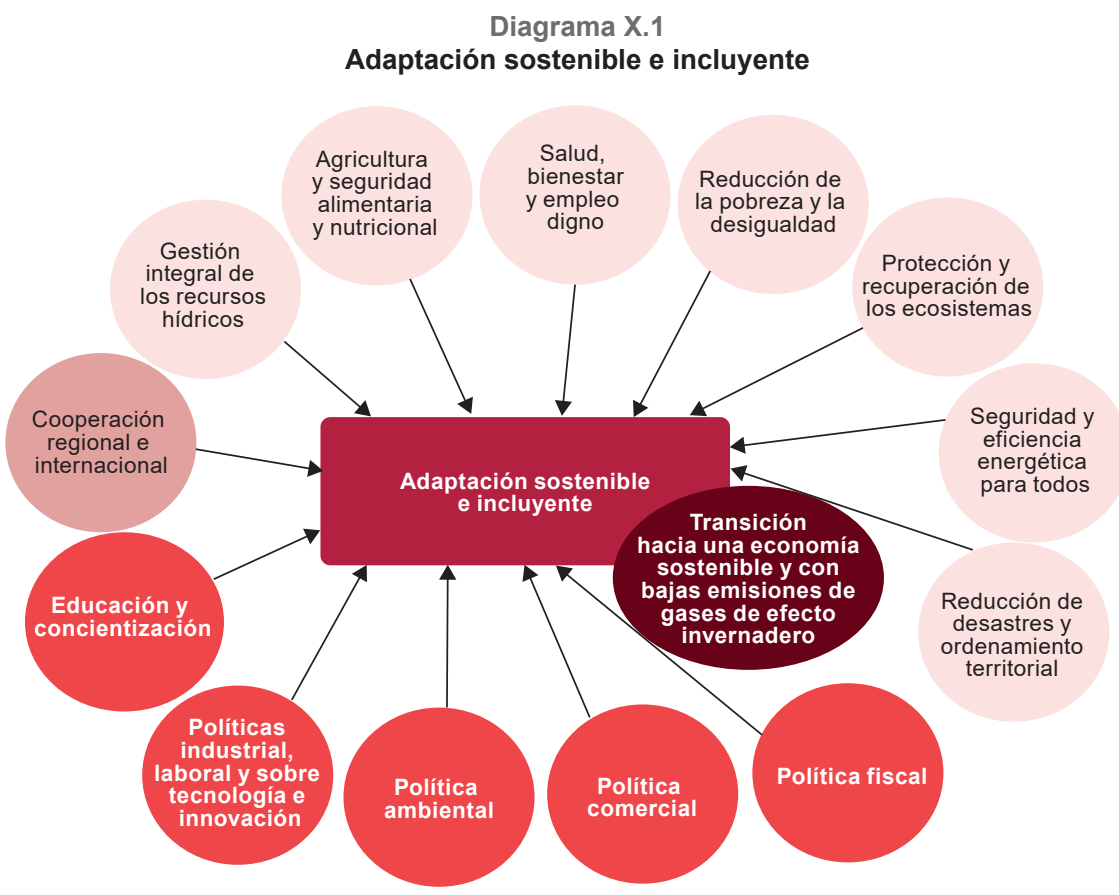

Fuente: Elaboración propia, sobre la base de la Iniciativa Economía del Cambio Climático en Centroamérica y la República Dominicana (ECC-CARD).

El avance del consenso internacional sobre la necesidad de transitar hacia modelos de desarrollo sostenible crea oportunidades para enfrentar el cambio climático. Los esfuerzos de la comunidad internacional durante varias 
décadas, cuyos principales hitos son la Cumbre para la Tierra de 1992 y la Conferencia de las Naciones Unidas sobre el Desarrollo Sostenible (Río+20) de 2012, se han cristalizado en los Objetivos de Desarrollo Sostenible (ODS), cuyo propósito es orientar las acciones de desarrollo de los países en el período 2015-2030. Entre ellos se encuentra el Objetivo 13 de acción urgente frente al cambio climático, que reafirma los acuerdos alcanzados en el marco de la CMNUCC. Un punto clave de este consenso es que dichos objetivos son interrelacionados e inseparables. Como se puntualiza en el Objetivo 17, para alcanzar los Objetivos de la Agenda 2030 para el Desarrollo Sostenible, es necesario mejorar de forma significativa la coordinación entre los sectores, las instituciones y las disciplinas.

La Agenda 2030 crea un marco para fomentar la adaptación sostenible e incluyente, con una transición hacia economías sostenibles desde el punto de vista ambiental y con bajas emisiones de GEI. Permite evidenciar el vínculo entre la reducción de las emisiones y la necesidad de evolucionar de forma urgente hacia patrones de producción y consumo cualitativamente más sostenibles e incluyentes. En el diagrama X.2 se muestran los ODS que están más relacionados con la propuesta de la adaptación sostenible e incluyente.

\section{Diagrama X.2}

Adaptación sostenible e incluyente y Objetivos de Desarrollo Sostenible (ODS)

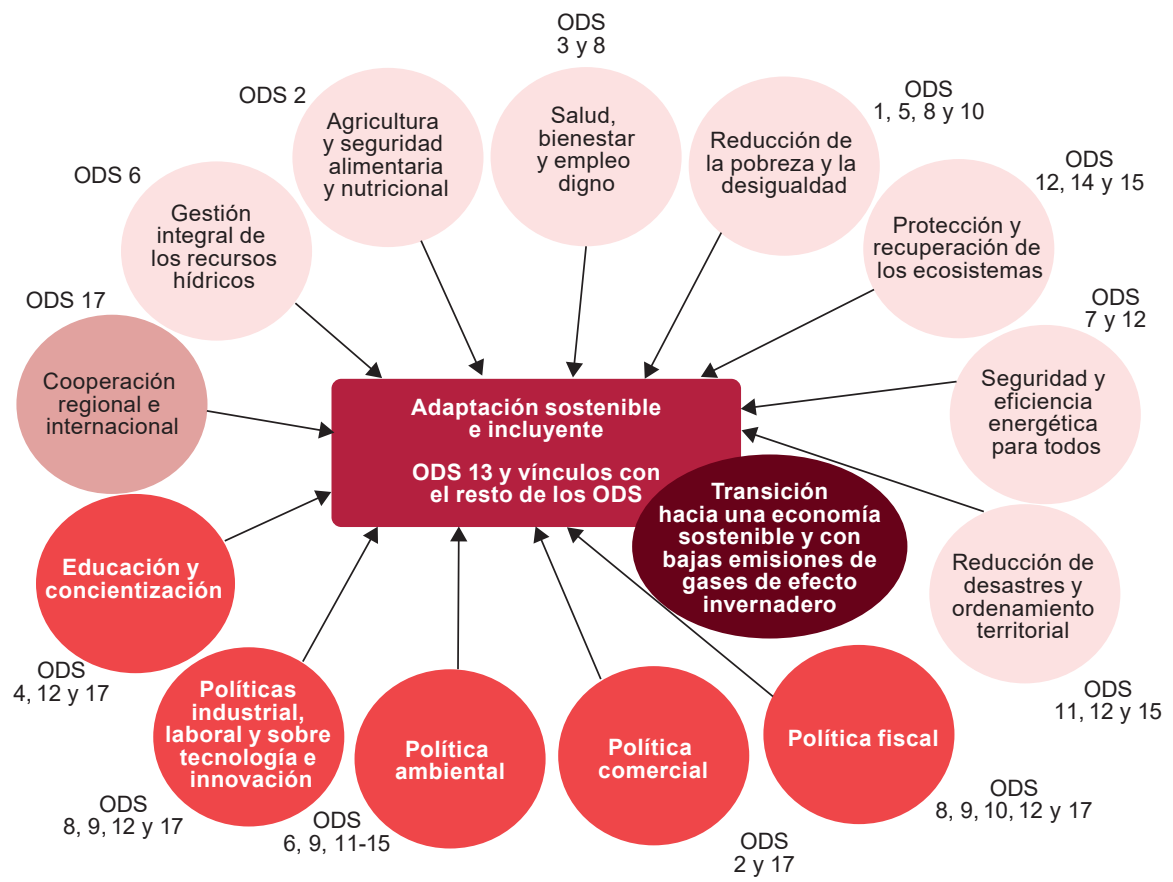

Fuente: Elaboración propia, sobre la base de la Iniciativa Economía del Cambio Climático en Centroamérica y la República Dominicana (ECC-CARD). 
Dos de estos Objetivos son poner fin a la pobreza en todas sus formas y en todo el mundo (Objetivo 1), y adoptar medidas urgentes para combatir el cambio climático y sus efectos (Objetivo 13). Además, una de las metas de este último es fortalecer la resiliencia y la capacidad de adaptación. Ambos objetivos son interdependientes entre sí y en relación con los demás, como el del hambre cero, la salud y el bienestar, la educación, el agua limpia y el trabajo decente, entre otros. La Agenda 2030 es el mayor esfuerzo que ha hecho la comunidad internacional para explicitar las estrechas relaciones que la reducción de la pobreza y la desigualdad tienen con el desarrollo sostenible y la respuesta al cambio climático (CEPAL, 2016a). Considerando que casi la mitad de la población centroamericana vive en condiciones de pobreza, es crucial vincular las respuestas al cambio climático con los programas de reducción de la pobreza y mejora de la calidad de vida y las oportunidades de la población. El economista Nicholas Stern señaló en la sede de la CEPAL (CEPAL, 2015a) que los dos retos que definirán la historia de este siglo son resolver el cambio climático y superar la pobreza, ambos íntimamente ligados. Si no se resuelve uno, no se resuelve el otro. No está de más recordar que en la CMNUCC se reconoce la relación entre la respuesta al cambio climático, el desarrollo sostenible y la erradicación de la pobreza.

En el marco de la CMNUCC, en 2015 los países miembros alcanzaron el Acuerdo de París, producto de arduas negociaciones. En este acuerdo se reconoce la Agenda 2030, en particular el derecho al desarrollo sostenible, la erradicación de la pobreza, la seguridad alimentaria, el trabajo digno y la integridad de los ecosistemas. Se resalta la necesidad de apoyar la adaptación y se mantiene el mecanismo de reducción y prevención de las pérdidas y los daños debidos a fenómenos extremos asociados al cambio climático. Se reconoce la necesidad de reducir significativamente las emisiones de GEI y de regresar a aproximadamente 40 gigatoneladas de emisiones anuales de $\mathrm{CO}_{2 \mathrm{e}}$ en 2030, para mantener el aumento de la temperatura por debajo de $2{ }^{\circ} \mathrm{C}$ sobre el nivel preindustrial. También se reconoce la necesidad de esforzarse para limitar dicho aumento a $1,5^{\circ} \mathrm{C}$. Se acuerda que cada país realizará esfuerzos ambiciosos para responder a dichos retos y presentará sus contribuciones previstas determinadas a nivel nacional (CPDN) (CMNUCC, 2015; IIDS, 2015).

Los países del SICA han insistido en la necesidad de reducir las emisiones mundiales de GEI para alcanzar un límite de $1,5^{\circ} \mathrm{C}$ en el aumento de la temperatura mundial con respecto a la época preindustrial. Los países centroamericanos están contribuyendo a reducir dichas emisiones en el marco de unas responsabilidades comunes pero diferenciadas, de sus capacidades y condiciones nacionales, y de un apoyo internacional favorable y previsible, que abarca los medios de implementación, como el financiamiento, el desarrollo y la transferencia de tecnología, y el fortalecimiento de las capacidades. Siete de los ocho países del SICA han presentado sus CPDN. Todos han contribuido a 
reducir las emisiones, y seis de ellos mencionan explícitamente sus agendas de adaptación y reducción de las pérdidas y los daños debidos a fenómenos extremos asociados al cambio climático.

En la actualidad, una gran parte de los países en desarrollo están elaborando planes nacionales de adaptación (PNAD), a menudo con referencia a sus planes nacionales de desarrollo y los ODS. De acuerdo con la información que figura en la página de la CMNUCC, Belice, la República Dominicana, Honduras y Costa Rica habían informado, hasta mediados de 2018, que estaban elaborando PNAD; Panamá y El Salvador, por su parte, se encontraban en el proceso preparatorio. Además, en abril de 2018, Costa Rica presentó su Política Nacional de Adaptación al Cambio Climático a nivel nacional (MINAE, 2018) y Guatemala inició los trabajos para elaborar su proyecto de integración de la agricultura en los PNAD, a fin de contribuir al fortalecimiento del Plan de Acción Nacional de Cambio Climático (PANCC) (FAO, 2017).

Además de plantear la necesidad y la urgencia de adaptarse, en el Acuerdo de París se hace un llamado a los países para que generen compromisos y mecanismos que permitan intensificar la reducción de las emisiones de GEI. Los países de la región del SICA prepararon inventarios de sus emisiones desde la década de 1990. Hasta la fecha se cuenta con información de los inventarios de 1994 y 2000 de todos los países. Sumando los ocho inventarios nacionales de 1994, por un lado, y los ocho de 2000, por el otro, se estima que las emisiones brutas pasaron de 265,3 millones a 342,5 millones de toneladas de GEI en ese período. Se informó que las absorciones fueron de 193,4 millones y 219,6 millones de toneladas de GEI en 1994 y 2000, respectivamente, y que las emisiones netas pasaron de 71,9 millones a 122,9 millones de toneladas de GEI en ese período. En 2000, el sector de la energía produjo el $44 \%$ de las emisiones netas, la agricultura, el 36\%, y el cambio de uso de la tierra, el 9\%. De la suma regional, ese mismo año Nicaragua representaba el $37 \%$ de las emisiones brutas y Honduras el $20 \%$; de las emisiones sin cambio de uso de la tierra, la República Dominicana emitía el 23\% y Guatemala el 18\%. Las emisiones netas de GEI de los ocho países representaban el 0,3\% de las emisiones globales.

Es importante recalcar que estos países ya contribuían con medidas anticipadas relativas a la reducción de las emisiones, en algunos casos, por medio de proyectos del mecanismo para un desarrollo limpio (MDL). Ahora, en el marco del Acuerdo de París, todos los países del SICA están formulando medidas de mitigación apropiadas para cada país (MMAP). La primera MMAP del sector agrícola a nivel mundial, NAMA Café de Costa Rica ${ }^{5}$, ya se encuentra en proceso de implementación; otras 15 medidas se encuentran en desarrollo, y se está buscando apoyo para la implementación de seis y la preparación de tres (CMNUCC, 2018).

Véase [en línea] http://www.namacafe.org/. 
La sumatoria de las contribuciones nacionales presentadas a la CMNUCC en el marco del Acuerdo de París, aun incluyendo las condicionadas a apoyos externos, darían como resultado una emisión anual de aproximadamente 52 a 57 gigatoneladas de $\mathrm{CO}_{2 e}$ en 2030. Ello implicaría una brecha de unas 12 a 17 gigatoneladas de $\mathrm{CO}_{2 \mathrm{e}}$ con respecto al nivel de emisiones necesario para que haya una probabilidad superior al $66 \%$ de que el aumento de la temperatura se mantenga por debajo de $2{ }^{\circ} \mathrm{C}$, según un informe preparado por la Secretaría de la CMNUCC (CMNUCC, 2016). Por lo tanto, a nivel internacional es urgente fijarse objetivos más ambiciosos respecto a la reducción de las emisiones y a la transición hacia economías en que estas sean bajas. A nivel de la región del SICA, se refuerza la urgencia y la prioridad de emprender medidas de adaptación.

En resumen, los cambios estructurales en la economía mundial, el Acuerdo de París en materia de cambio climático y la Agenda 2030 pueden aprovecharse para transitar hacia economías sostenibles e incluyentes. En este marco se deberán enfrentar retos como los siguientes: las formas de inserción en los mercados internacionales; las cadenas de producción y de comercio; la dependencia creciente respecto del consumo y la importación de hidrocarburos; la contaminación y las pérdidas para la salud pública; los problemas de alimentación, como el doble reto de la subnutrición y la obesidad; el uso ineficiente del agua y su contaminación, así como la degradación de los bosques y otros ecosistemas que brindan múltiples productos y servicios a la sociedad.

Se requiere un gran impulso ambiental que promueva la igualdad y la sostenibilidad, apoyado en políticas públicas coordinadas que desvinculen el desarrollo económico de las externalidades ambientales y mejoren la calidad de vida de la población con empleos y medios de vida dignos, así como bienes y servicios públicos de calidad que ofrezcan mayor cobertura. Los países miembros de la CEPAL aprobaron este planteamiento en su trigésimo sexto período de sesiones (CEPAL, 2016a).

Para enfrentar los retos mencionados, es necesario establecer pactos sociales sobre incentivos e inversiones que abran el camino al cambio estructural en la producción y el consumo, reduzcan el impacto del cambio climático y fomenten la transición hacia economías sostenibles desde el punto de vista ambiental. Entre los elementos clave se encuentran las políticas fiscales que generen un mejor equilibrio entre los bienes privados y los servicios públicos en la arquitectura del bienestar; una gobernanza más robusta de los recursos naturales y la preservación del ambiente, que incentive una matriz productiva y de consumo más diversificada y "verde"; un pacto social y laboral que potencie el ejercicio efectivo de los derechos humanos y la capacidad redistributiva del Estado, y una institucionalidad laboral más incluyente. Este esfuerzo requiere diversas medidas, como 
cambiar las normas de infraestructura, proteger las cuencas hidrológicas y las barreras costeras naturales, como los manglares, administrar mejor el uso del agua, y cambiar el diseño y la ubicación de los hogares, las comunidades y la infraestructura social (CEPAL, 2010 y 2016a).

\section{B. La iniciativa de la Economía del Cambio Climático en Centroamérica y la República Dominicana}

Desde la década de 1990, en la región del SICA se había manifestado interés por el desarrollo sostenible y preocupación por el cambio climático. En 1990, se constituyó la Comisión Centroamericana de Ambiente y Desarrollo (CCAD) con las autoridades ambientales de los países miembros. Todos ellos asumieron el compromiso de suscribir la Convención Marco de las Naciones Unidas sobre el Cambio Climático, adoptada en la Cumbre para la Tierra en 1992. En 1993, el Consejo de Ministros de Relaciones Exteriores del SICA suscribió el Convenio Regional sobre Cambios Climáticos, así como el Convenio Constitutivo del Centro de Coordinación para la Prevención de los Desastres Naturales en América Central (CEPREDENAC). Además, los Presidentes del SICA y el representante del Primer Ministro de Belice establecieron en 1994 la Alianza para el Desarrollo Sostenible de Centroamérica (ALIDES).

Los países centroamericanos han participado desde 1994 en las negociaciones de la Convención Marco de las Naciones Unidas sobre el Cambio Climático (CMNUCC), inicialmente con equipos centrados en los Ministerios de Ambiente. En 1999, los Presidentes y Jefes de Estado o sus representantes ante el SICA aprobaron el Marco Estratégico para la Reducción de Vulnerabilidades y Desastres Naturales en Centroamérica, que orientó el CEPREDENAC hacia la prevención. Otros instrumentos regionales significativos en aquellos años fueron el Foro Centroamericano y de República Dominicana de Agua Potable y Saneamiento (FOCARD-APS), la Estrategia Regional Agroambiental y de Salud (ERAS), y la Política Centroamericana de Gestión Integral de Riesgo de Desastres (PCGIR).

Por su parte, la CEPAL había enfocado su cooperación hasta finales de la década de 2000 en la agenda de desarrollo sostenible y la evaluación de desastres, incluidos los asociados a los fenómenos climáticos. En este último tema, el aporte comenzó en 1972, cuando se estimó el impacto del terremoto de Managua; en la actualidad, se han elaborado más de 20 informes con los países de la región. En dichas evaluaciones se estimaban los efectos que el desastre había tenido sobre los acervos (daños) y sobre los flujos (pérdidas y costos adicionales), en los sectores económicos y sociales y, en los últimos años, en el sector ambiental. Además, en ellas participaron múltiples instituciones nacionales y otras organizaciones de las Naciones Unidas. 
En muchos casos, con base en las evaluaciones se formularon propuestas de reconstrucción y reducción del riesgo, y los resultados se presentaron en reuniones con donantes. Sobre la base de la experiencia acumulada, se documentó la metodología y se realizó un proceso de capacitación de instituciones nacionales e internacionales para ampliar su uso (CEPAL, 2014).

La sede subregional de la CEPAL en México determinó, en su revisión estratégica de 2007, que enfrentar la amenaza climática iba más allá de reducir los riesgos de los fenómenos extremos, y que la preocupación manifestada por la región ameritaba explorar una posible cooperación en materia de cambio climático. En virtud de un proceso de discusión entre la CEPAL y el Comité Técnico de Cambio Climático de la CCAD, se propuso crear la iniciativa Economía del Cambio Climático en Centroamérica (ECC-CA), cuyo proyecto fue aprobado por los Ministros de Ambiente entre 2009 y 2012. Los objetivos acordados fueron los siguientes: alertar a los encargados de tomar decisiones y a las instituciones de sectores clave de Centroamérica, especialmente del sector fiscal, sobre la urgencia de enfrentar el reto del cambio climático, proporcionando estimaciones lo más robustas posible sobre los efectos potenciales de esta amenaza; propiciar la toma de decisiones y las acciones destinadas a reducir las vulnerabilidades y la pobreza asociadas a este fenómeno, y fomentar políticas públicas de adaptación y transición hacia economías más sostenibles y con bajas emisiones de GEI. En la iniciativa participaron Belice, Costa Rica, El Salvador, Guatemala, Honduras, Nicaragua y Panamá.

Desde el inicio se estructuró un proceso de cogestión técnica en el que participaba un Comité Técnico Regional conformado por delegados de los Ministerios de Ambiente y de Hacienda o Finanzas de los países socios, con la participación de las Secretarías Ejecutivas de la CCAD, el Consejo de Ministros de Hacienda o Finanzas de Centroamérica, Panamá y República Dominicana (COSEFIN) y la Secretaría de Integración Económica Centroamericana (SIECA). Se contempló la opción de realizar consultas y presentaciones ante los consejos ministeriales de la CCAD y el COSEFIN y, en la práctica, se llevaron a cabo diversas acciones de ese tipo con la CCAD. También se realizaron presentaciones de los resultados ante el Consejo Agropecuario Centroamericano (CAC) y el Consejo de Ministros de Salud de Centroamérica y República Dominicana (COMISCA), lo que permitió abrir agendas de trabajo con esos sectores y que estos participaran en el Comité Técnico Regional.

Más adelante, los socios prepararon y aprobaron, por medio del Comité Técnico Regional, una nueva propuesta de trabajo a la que se sumó la República Dominicana como país miembro pleno del SICA. Así, la iniciativa pasó a llamarse Economía del Cambio Climático en Centroamérica y la República Dominicana (ECC-CARD). Los países y la CEPAL se propusieron 
evaluar las consecuencias económicas y sociales del cambio climático, alertar sobre ellas e identificar medidas apropiadas de adaptación sostenible e incluyente, de mitigación en términos de desarrollo sostenible e inclusión social y económica, y de transición hacia una economía sostenible desde el punto de vista ambiental y con bajas emisiones. En el trabajo se plantearon opciones relativas a las políticas y su instrumentación, respecto de las áreas fiscales, ambientales, institucionales, agrícolas, de salud y de generación hidroeléctrica. En concordancia con el avance de la transversalización del tema, el Comité Técnico Regional aprobó componentes diseñados por tres grupos técnicos: fiscal (Secretaría Ejecutiva del COSEFIN); de agricultura y seguridad alimentaria y nutricional (GTCCGIR y Secretaría Ejecutiva del CAC), y de salud, integrado por la Comisión Técnica de Vigilancia de la Salud y Sistemas de Información (COTEVISI) y la Secretaría Ejecutiva del COMISCA.

La CEPAL y los socios regionales y nacionales diseñaron un método de gestión técnica participativa y de consulta, que comprendía determinar las necesidades y prioridades nacionales y regionales, diseñar proyectos, planes de trabajo y términos de referencia de los trabajos, y llevar a cabo la revisión técnica de los productos e informes. Además, los socios contribuyeron a los procesos de formular políticas con base empírica y fortalecer las capacidades técnicas. Este método hizo posible que diversas instituciones nacionales y regionales llevaran a cabo acciones conjuntas de acuerdo con sus necesidades y prioridades. También permitió reunir técnicos de diversas disciplinas e instituciones, y abrió oportunidades de cooperación con y entre los socios de diferentes sectores a nivel nacional y de las instancias sectoriales del SICA. Esta dinámica facilitó una rápida divulgación de los métodos de análisis y los resultados, y un mayor conocimiento sobre los resultados de cada país y de la región; además, creó un espacio entre técnicos de cambio climático en cuyos países había visiones divergentes sobre qué se debía priorizar: la adaptación o la mitigación.

A inicios de la segunda década de 2000 se había generado un mayor consenso sobre la prioridad de reducir las vulnerabilidades e implementar acciones de adaptación, sin escatimar oportunidades de transitar hacia economías más sostenibles desde el punto de vista ambiental, en particular de reducir las emisiones de GEI. Además, los Ministerios de Hacienda y de Ambiente comenzaron a explorar las implicaciones del cambio climático para la política fiscal, lo que supuso un aprendizaje en cuanto a los enfoques y el lenguaje de ambos sectores. Finalmente, hubo un proceso de integración de representantes del CAC y el COMISCA, por medio de sus Secretarías Ejecutivas y de los grupos técnicos que gestionaban los temas de cambio climático dentro de sus estructuras. 


\section{Experiencias de transversalización del cambio climático}

Los primeros trabajos de la iniciativa de la Economía del Cambio Climático en Centroamérica (ECC-CA) fueron utilizados principalmente por el sector ambiental. La CCAD se encontraba preparando su Estrategia Regional de Cambio Climático (ERCC), mandatada por los Jefes de Estado y de Gobierno en 2008. Los análisis de impacto generados en la iniciativa fueron utilizados para la sección de diagnóstico situacional de dicha estrategia (escenarios demográficos, macroeconómicos, de cambio de uso de la tierra, de energía y climáticos, impacto del cambio climático sobre los recursos hídricos, fenómenos extremos y valorización económica). Las políticas opcionales que había propuesto la iniciativa coincidieron con las propuestas de la ERCC, y entre las 15 acciones claves de esta última estaba la de continuar con la iniciativa.

Los resultados de la ECC-CA fueron presentados por los Ministros de Ambiente en procesos asociados a la CMNUCC. Se lanzó, por ejemplo, la primera publicación de la iniciativa, La economía del cambio climático en América Latina y el Caribe: sintesis 2010, en el acto paralelo que Centroamérica llevó a cabo en la XVI Conferencia de las Partes de la CMNUCC. Los resultados de la ECC-CA también fueron presentados en la XVII Conferencia de las Partes, en dos eventos paralelos organizados por la CEPAL con diversos socios. La CEPAL brindó acompañamiento técnico a la presidencia pro tempore de la CCAD en las negociaciones de 2011, a la delegación de El Salvador que en 2012 participó en las sesiones de coordinación de los países del SICA, y en cuatro mesas de negociación sobre adaptación y pérdidas y daños. Además, en el marco de la iniciativa, la CEPAL organizó cursos y sesiones de trabajo con diversos equipos de negociadores entre 2009 y 2016. Con base en la solicitud de la presidencia pro tempore de la CCAD - Ministerio de Medio Ambiente y Recursos Naturales (MARN) de El Salvador-, se preparó un análisis de la variabilidad climática histórica y actual, utilizando datos de las estaciones meteorológicas de la región. Dicho análisis fue presentado al Grupo Consultivo para la Reconstrucción y Transformación de América Central derivado de los efectos de la depresión tropical 12E en diciembre de 2011.

Entre los elementos que facilitaron el proceso de transversalización se encuentran los diversos mandatos sobre el cambio climático emitidos por las cumbres de Presidentes del SICA, así como la inclusión de la gestión integral del riesgo y la adaptación al cambio climático entre los cinco pilares del proceso de relanzamiento de la integración centroamericana en $2010^{6}$, y la reiteración del compromiso de combatir y erradicar el hambre y la desnutrición frente a diversas crisis, incluido el cambio climático, en 2012. Los Jefes de

Los pilares de la integración centroamericana son los siguientes: gestión integral del riesgo y adaptación al cambio climático, seguridad democrática regional, integración social, integración económica y fortalecimiento institucional. 
Estado y de Gobierno instruyeron a los consejos de ministros del SICA que elaboraran la agenda estratégica priorizada de sus sectores, teniendo como referente la Agenda 2030 para el Desarrollo Sostenible, así como un plan de acción para atender el impacto generado por el fenómeno de la sequía en la región. Finalmente, en 2017 se presentó la agenda estratégica priorizada del SICA, que incluía el pilar de la gestión integral del riesgo y la adaptación al cambio climático. Los objetivos de dicha agenda eran la gestión moderna, eficaz y sostenible de los recursos hídricos, la integración ambiental de la región para promover la adaptación y la mitigación de los efectos del cambio climático, la sostenibilidad de la biodiversidad y los sistemas terrestres y marinos, el acceso a las energías renovables y el uso de estas, así como la promoción de una agricultura regional sostenible, competitiva, incluyente y articulada.

Los delegados del Comité Técnico Regional de la ECC-CARD prepararon, en su reunión de 2017, las siguientes recomendaciones sobre las líneas de acción de la institucionalidad ambiental:

- continuar fomentando la adaptación multisectorial de forma sostenible, y promover la restauración y el aprecio de los ecosistemas y los recursos hídricos para el desarrollo de las sociedades, considerando especialmente los impactos del cambio climático;

- fomentar el uso de avances recientes en materia de climatología y escenarios de cambio climático;

- proponer y evaluar medidas de política pública en los ámbitos económico, social y ambiental, para hacer una transición hacia economías sostenibles desde el punto de vista ambiental, con el cobeneficio de reducir las emisiones de GEI;

- fomentar sistemas de información sectoriales y articulados entre sí;

- identificar las acciones que las diversas instituciones públicas, con sus respectivos presupuestos, hayan ejecutado en respuesta al cambio climático, a fin de evidenciar el esfuerzo público nacional $\mathrm{y}$ las potenciales sinergias, $\mathrm{y}$

- acompañar la labor del sector académico para desarrollar sus capacidades de investigación y de desarrollo curricular con referencia al cambio climático y el desarrollo sostenible.

En resumen, la institucionalidad ambiental del SICA ha mantenido una agenda propia de cambio climático y ha fomentado la transversalización hacia otros sectores, apoyada por los mandatos de los Presidentes y Jefes de Estado y por encuentros multisectoriales de la Secretaría General del SICA en esta materia. 


\section{Transversalización con los Ministerios de Hacienda o Finanzas y el COSEFIN}

En los primeros años de la iniciativa ECC-CA, la CEPAL y los Ministerios de Ambiente se acercaron a los Ministros de Hacienda o Finanzas para dialogar sobre la relevancia que el cambio climático tenía para la sostenibilidad fiscal. El impacto macroeconómico y fiscal de fenómenos extremos como el Huracán Mitch, las sequías en varios países de la región y el vínculo de la ECC-CA con el Informe Stern y su equipo facilitaron dicho diálogo. Progresivamente, se logró que se nombraran Delegados de los Ministerios de Hacienda o Finanzas para que participaran en el Comité Técnico Regional y en las discusiones técnicas, sobre todo en revisar la estimación del impacto del cambio climático en el producto interno bruto (PIB), así como en el uso de una tasa de descuento socioambiental.

En el marco del Comité Técnico Regional se aprobó un plan específico para fortalecer las capacidades técnicas de los funcionarios del sector fiscal, con énfasis en el análisis econométrico y el riesgo climático, la sostenibilidad fiscal y los mecanismos de seguros catastróficos y sectoriales. Dicho plan contó con el apoyo de la ECC-CA y de la Unidad de Economía del Cambio Climático de la División de Desarrollo Sostenible y Asentamientos Humanos de la CEPAL.

En la región se observaron avances significativos en materia de incorporación del cambio climático en el quehacer de los Ministerios de Hacienda. Entre dichos avances se cuentan los siguientes: la creación de unidades o encargados de cambio climático en el caso de Panamá, Guatemala y Honduras; el esfuerzo conjunto de los Ministerios de Ambiente y de Finanzas para incluir la variable del cambio climático en los planes anuales de los ministerios, en líneas presupuestarias etiquetadas para gastos relacionados con los fenómenos extremos; un acuerdo de canje de deuda para financiar gastos relacionados con el medio ambiente y el cambio climático en Guatemala; el trabajo con los Ministerios de Ambiente para establecer un fondo nacional de cambio climático en Guatemala y Honduras, y la firma de un acuerdo de cooperación entre el Ministerio de Medio Ambiente y Recursos Naturales y el Ministerio de Hacienda en El Salvador, con una agenda de trabajo técnico sobre cambio climático.

En el ámbito regional, el trabajo se facilitó con el fortalecimiento de la Secretaría Ejecutiva del COSEFIN y los mandatos específicos dirigidos a los Ministerios de Hacienda o Finanzas, que habían quedado plasmados en la Política Centroamericana de Gestión Integral de Riesgo de Desastres (PCGIR) de 2010 del CEPREDENAC. Eso creó un referente útil. En una iniciativa estratégica, el COSEFIN asumió el liderazgo del diseño y el establecimiento de un mecanismo de seguro soberano contra riesgos de catástrofes denominado 
CCRIF SPC. Además, con el apoyo de la Secretaría Ejecutiva del COSEFIN y la CEPAL, los Delegados de Hacienda profundizaron sus discusiones sobre la agenda sectorial y señalaron cinco áreas de desarrollo de la política fiscal para contribuir a la respuesta al cambio climático:

i) Fortalecimiento de las capacidades de los ministerios de Hacienda/ Finanzas para diseñar políticas de sostenibilidad fiscal que reduzcan los riesgos climáticos e incentiven la producción e infraestructura resiliente (incluido el análisis de subsidios, impuestos y exenciones).

ii) Fortalecimiento de capacidades en el diseño y la evaluación de proyectos de inversión pública (PIP) para fortalecer la resiliencia climática con los Ministerios encargados de infraestructura de salud y educación, transporte/vialidad, y energía (especialmente hidroeléctrica), incluyendo una valorización económica del riesgo climático desde la fase del diseño.

iii) Opciones para la formulación de presupuestos sectoriales para aumentar la resiliencia climática (integrado a iniciativas de presupuestación por resultados, cuando sea el caso).

iv) Programas de aseguramiento y gestión de riesgo a nivel del sector público y en sectores económicos como el agropecuario.

v) Mecanismos nacionales para gestionar y administrar el financiamiento climático internacional.

A partir de esta amplia agenda, se acordó enfocarse en implementar diversos cursos y seminarios sobre cómo robustecer los proyectos de inversión pública ante los riesgos de que ocurrieran fenómenos extremos y ante el cambio climático, lo que generó una mayor integración del tema en los ministerios. Del mismo modo, los socios pudieron vincular este reto con mandatos regionales, políticas nacionales y acuerdos internacionales. Dos de las prioridades que se propusieron en el Marco de Sendái para la Reducción del Riesgo de Desastres 2015-2030 son invertir en la reducción del riesgo de desastres para fomentar la resiliencia, e incrementar la preparación para los desastres mediante el principio de reconstruir mejor.

El robustecimiento de la inversión pública contribuirá a lograr los ODS de la Agenda 2030, a los que se ha adherido la comunidad internacional, incluidos los países del SICA. En particular, en el Objetivo 9 se propone construir y desarrollar infraestructura de calidad, confiable, sostenible y resiliente, aumentar la asistencia financiera y tecnológica a los países menos desarrollados, e incrementar de forma significativa el acceso a la tecnología de la información y las comunicaciones. Lo anterior se alinea con el Objetivo 13, entre cuyas metas se propone fortalecer la resiliencia y la capacidad de adaptación a las amenazas relacionadas con el clima y los fenómenos extremos en todos los países, e implementar el compromiso de 
los países desarrollados de movilizar conjuntamente 100.000 millones de dólares anuales hacia 2020, a fin de destinarlos a las necesidades de los países en desarrollo en el contexto del Fondo Verde para el Clima.

Como consecuencia de estas actividades, los socios prepararon una propuesta para fortalecer la política fiscal en los países miembros del COSEFIN y del SICA, identificando y aprovechando los cobeneficios de la sostenibilidad fiscal, la gestión integral de riesgos, la respuesta al cambio climático y la sostenibilidad ambiental, en el marco de los planes nacionales y sus políticas y estrategias regionales. Dicha propuesta fue presentada a los Ministros del COSEFIN, quienes respaldaron el proyecto y encargaron a su Secretaría Ejecutiva y a la CEPAL que hicieran una búsqueda de financiamiento internacional (resolución núm. 05-2017). Se acordó con dicha Secretaría mantener el grupo de Delegados de Hacienda de la ECC-CARD como referente técnico para dichos temas.

Esta área de trabajo fue incluida en la matriz de interés fiscal establecida por el COSEFIN y su Secretaría Ejecutiva con las siete áreas temáticas fiscales que ellos priorizaron. En el área de los riesgos fiscales se incluye continuar y ampliar las iniciativas de la ECC-CARD; en el área de la inversión pública se incluye la actividad estratégica de formar capacidades para integrar criterios relacionados con el riesgo climático en la formulación de proyectos de inversión pública; en el área de la administración tributaria se incluye una exploración que supone analizar reformas fiscales-ambientales, y, finalmente, en el área de los procesos presupuestarios se incluye homologar metodologías de costeo e introducir clasificadores presupuestarios de gastos vinculados a la gestión del riesgo climático (véanse COSEFIN, 2018, y el capítulo VII de la presente publicación).

En resumen, los Ministerios de Hacienda o Finanzas y el COSEFIN han integrado el cambio climático a su agenda de trabajo, han madurado su entendimiento al punto de identificar múltiples líneas de trabajo dentro de la política fiscal, y han enriquecido las discusiones regionales con la perspectiva fiscal. Se han creado o designado unidades o equipos responsables, y el grupo de delegados del Comité Técnico Regional de la ECC-CARD tiene un espacio de diálogo vinculado al COSEFIN con un plan de trabajo futuro aprobado por el Consejo de Ministros.

\section{Transversalización con los Ministerios de Agricultura y el CAC}

El Consejo Agropecuario Centroamericano (CAC) integró el cambio climático en su agenda de trabajo desde 2007. La CEPAL se acercó a la Secretaría Ejecutiva del CAC en 2011 y presentó los resultados de la ECC-CA en un seminario 
técnico sectorial y posteriormente en una reunión del CAC en 2012. En esa ocasión, los Ministros pidieron la cooperación de la CEPAL para elaborar una agenda de trabajo sobre este tema.

En el mismo año, los Ministros de Agricultura crearon el Grupo Técnico de Cambio Climático y Gestión Integral de Riesgos (GTCCGIR) y se llegó a un acuerdo con la CEPAL para formular de manera conjunta un programa de trabajo sobre el impacto potencial del cambio climático, la seguridad alimentaria y nutricional, y las opciones de aseguramiento contra riesgos climáticos. Paralelamente, se acordó un proyecto de desarrollo de sistemas de información e indicadores con el Comité Técnico Regional del CAC, constituido por asesores de los Ministros. Un elemento importante de los resultados obtenidos fue que la Secretaría Ejecutiva del CAC convocó a la CEPAL y a otras instituciones técnicas, como la Organización de las Naciones Unidas para la Alimentación y la Agricultura (FAO), el Instituto Interamericano de Cooperación para la Agricultura (IICA), el Centro Internacional de Agricultura Tropical (CIAT) y el Centro Agronómico Tropical de Investigación y Enseñanza (CATIE), entre otros, para coordinar la cooperación por medio de un Grupo Interagencial de Apoyo (GIA).

En los primeros análisis de este programa, se consideró el impacto potencial del cambio climático en el rendimiento de los granos básicos y el café, por departamentos de la región centroamericana. En el caso del café, se integraron los aportes de instituciones como el CIAT, el CATIE, el Centro de Investigación Agrícola para el Desarrollo Internacional (CIRAD), el Programa Cooperativo Regional para el Desarrollo Tecnológico y la Modernización de la Caficultura (PROMECAFE), el Instituto del Café de Costa Rica (ICAFE), la FAO y la Deutsche Gesellschaft für Internationale Zusammenarbeit (GIZ). En una discusión técnica se propusieron algunas líneas de acción, entre ellas, trabajar más con los pequeños productores, fortalecer las cadenas de valor, recolectar y usar más datos climáticos, diversificar la producción y los ingresos, desarrollar una propuesta integrada de servicios productivos y sociales, proporcionar incentivos económicos y fiscales, e invertir en infraestructura rural, entre otras.

En el tema de la seguridad alimentaria y nutricional, el COSEFIN encargó un plan de acción a la Secretaría Ejecutiva del CAC y sus grupos técnicos, con el acompañamiento del CIAT, la CEPAL, la FAO, el IICA, el Programa Mundial de Alimentos (PMA), el Organismo Internacional Regional de Sanidad Agropecuaria (OIRSA) y la Organización del Sector Pesquero y Acuícola del Istmo Centroamericano (OSPESCA), entre otros. La Secretaría Ejecutiva del CAC, la CEPAL y el Programa Regional de Seguridad Alimentaria y Nutricional para Centroamérica (PRESANCA) crearon un espacio para discutir los retos y oportunidades en seguridad alimentaria y nutricional en los países del SICA, integrando criterios de 
riesgo a la variabilidad y el cambio climáticos. Estas discusiones dieron lugar a publicaciones conjuntas sobre los retos y las oportunidades de la seguridad alimentaria y nutricional, coordinadas por la CEPAL con el apoyo de la Secretaría Ejecutiva del CAC y la SIECA, y sobre propuestas metodológicas y análisis iniciales relativos al impacto potencial del cambio climático en la seguridad alimentaria y nutricional y el sistema agroalimentario del SICA, con insumos técnicos preparados por el CIAT, el PRESANCA, el Instituto de Nutrición de Centroamérica y Panamá (INCAP), el IICA, la FAO, el CATIE y la CEPAL. Una de las recomendaciones más interesantes que emanó de este proceso fue que se fomentaran las respuestas a los retos de la seguridad alimentaria y nutricional en las que se tomaran en cuenta las oportunidades y los cobeneficios derivados de un enfoque sistémico, como el doble reto de la malnutrición, la reducción de las pérdidas poscosecha, y las acciones integradas de adaptación y mitigación de las emisiones de GEI.

El CAC apoyó un importante proyecto de desarrollo de seguros agropecuarios en la segunda mitad de la década de 2000, con la asistencia técnica del Banco Interamericano de Desarrollo (BID), el Banco Mundial, el Banco Centroamericano de Integración Económica (BCIE) y la Federación Interamericana de Empresas de Seguros (FIDES). Desde 2013, la CEPAL y la Secretaría Ejecutiva del CAC retomaron este reto con el apoyo del GTCCGIR, y establecieron una comunidad de práctica integrada por actores claves, como los Ministerios de Agricultura y expertos de instituciones públicas y privadas, nacionales, regionales e internacionales. Entre sus objetivos se contaban los siguientes: conocer los diversos esfuerzos que se habían realizado en la región, identificar las lecciones aprendidas y las mejores prácticas de otros países en desarrollo, y establecer líneas de acción para desarrollar seguros y microseguros agropecuarios y paquetes de servicios integrales en un marco amplio de gestión integral de los riesgos en la región centroamericana. Actualmente, la comunidad trabaja sobre la utilización de índices climáticos para diseñar seguros y sobre cómo vincular esos instrumentos con la perspectiva de brindar servicios integrales a los pequeños productores agropecuarios. La Secretaría Ejecutiva del CAC y la CEPAL han publicado de forma conjunta y regular informes sobre experiencias nacionales, regionales y extrarregionales, así como líneas potenciales de acción relativas a los seguros, incluidos los microseguros, en un marco de gestión integral del riesgo (CEPAL/CAC/SICA, 2013b y 2014). Paralelamente, la CEPAL ha cooperado con instituciones nacionales de Costa Rica, El Salvador, Guatemala y Panamá en el diseño de seguros agropecuarios ajustados a sus necesidades, y esas experiencias han sido compartidas en dicha comunidad de práctica.

La Secretaría Ejecutiva del CAC y la CEPAL reconocieron lo fundamental que es la gestión de la información para formular las políticas públicas, en particular la respuesta al cambio climático, y coordinaron un proyecto que tenía por objeto evaluar y generar planes de mejora de los sistemas de 
información nacional y regional con los socios correspondientes, y fortalecer las capacidades técnicas. El proyecto contó con recursos de la CEPAL y del Fondo Internacional de Desarrollo Agrícola (FIDA), y con la participación de los Ministerios de Agricultura, las oficinas nacionales de estadística, los bancos centrales y las oficinas de seguridad alimentaria y nutricional de los países del SICA. Sus resultados han quedado plasmados en un documento sobre los ODS y los retos del desarrollo rural en el SICA (CEPAL/CAC/ SICA, 2014) y en una propuesta para continuar con el fortalecimiento de los sistemas de información del sector, integrando variables climáticas. Además, se brindó asistencia técnica a la Secretaría Ejecutiva de Planificación Sectorial Agropecuaria (SEPSA) de Costa Rica en 2017, para contribuir a crear un sistema de información de variables de cambio climático y riesgo de desastres en el sector agropecuario. Este podría servir como caso piloto.

Este trabajo intenso alimentó la discusión entre los encargados de tomar decisiones y, en 2015, el CAC declaró su compromiso de impulsar una agricultura climáticamente inteligente y promover que la agricultura, como bien público regional, se adaptara al cambio climático. Luego de un proceso de planificación, este compromiso se concretó en 2017 con la aprobación, por parte de los Ministros del CAC, de la Estrategia de Agricultura Sostenible Adaptada al Clima (EASAC) para impulsar una agricultura más competitiva, inclusiva y sostenible adaptada a los efectos del cambio climático y de la variabilidad climática, que aumentara la productividad mediante la conservación y el uso sostenible y eficiente del agua, de la biodiversidad, del suelo y del bosque, con el fin de garantizar la seguridad alimentaria y nutricional (CAC/SICA, 2017, pág. 9). Asimismo, los Ministros extendieron la invitación a los organismos regionales e internacionales para que cooperaran en la implementación de la estrategia (CAC/SICA, 2017).

En lo que respecta a la incidencia internacional de esta Estrategia, varios Ministros presentaron y promovieron la nueva agenda de agricultura y cambio climático en diversos foros regionales e internacionales, incluida la XX Conferencia de las Partes en Lima y la XXI Conferencia de las Partes en París. Para la XXII Conferencia de las Partes en Marrakech, varios ministros del SICA participaron en un diálogo de alto nivel sobre agricultura y ambiente con ministros y viceministros de América Latina. Dicho diálogo, que la CEPAL fue invitada a moderar, fue organizado por el IICA y el Centro de Investigación Forestal Internacional (CIFOR), con el apoyo de la Secretaría Ejecutiva del CAC. Además, la CEPAL facilitó la participación de un ministro de la región del SICA en el evento paralelo de alto nivel de las Naciones Unidas sobre el hambre cero en un clima cambiante.

En 2017, la CEPAL y la Secretaría Ejecutiva del CAC diseñaron, con el apoyo del GTCCGIR y del Comité Técnico Regional, un nuevo programa de trabajo y una propuesta de financiamiento internacional destinados a 
fortalecer las capacidades técnicas nacionales y regionales de los países del SICA para implementar políticas públicas nacionales y la EASAC, particularmente a favor de los pequeños productores de zonas rurales y los consumidores de bajos ingresos. Ese año, la Secretaría Ejecutiva del CAC presentó los resultados de este programa de cooperación en la reunión del Comité Técnico Regional de la ECC-CARD, y los participantes recomendaron las siguientes líneas de acción:

- aprovechar las oportunidades de la Agenda 2030 para desarrollar sistemas agroalimentarios sostenibles y adaptados al clima;

- implementar la EASAC, con inclusión de los análisis técnicos y el fortalecimiento de las capacitaciones requeridas, los enfoques de extensión intensivos en conocimiento, la gestión integral de los riesgos y los seguros agropecuarios, y la articulación de los esfuerzos entre los actores;

- fortalecer los sistemas de información sobre variables de producción agropecuaria, seguridad alimentaria y nutricional, y desarrollo rural y climático, incluida la información geoespacial y el uso de tecnologías para capturarla;

- fomentar respuestas a los retos de la seguridad alimentaria y nutricional, en las que se tomen en cuenta las oportunidades y los cobeneficios derivados de un enfoque sistémico.

En resumen, en los últimos diez años los Ministerios de Agricultura del CAC han integrado el cambio climático en sus programas de trabajo, con múltiples líneas de labor y espacios de diálogo, y han coordinado colaboraciones con instituciones nacionales, con diversas instituciones de cooperación y con otras partes del SICA, como la SIECA, el PROMECAFE y el Programa de Sistemas de Información para la Resiliencia en Seguridad Alimentaria y Nutricional de la región del SICA (PROGRESAN-SICA).

\section{Transversalización con los Ministerios de Salud}

Desde el inicio de la ECC-CA, los delegados del Comité Técnico Regional identificaron al sector de la salud como prioridad. La CEPAL y el Secretario Ejecutivo del COMISCA acordaron en 2011 presentar a la Comisión Técnica de Vigilancia de la Salud y Sistemas de Información (COTEVISI) de este último y a los Ministros de Salud de Centroamérica los resultados de las dos primeras fases de la iniciativa. La consulta con la COTEVISI dio como resultado una propuesta titulada "Salud y cambio climático en los países de Centroamérica y la República Dominicana: respondiendo al riesgo climático en la salud humana", la cual se presentó al COMISCA en 2012.

Los Ministros de Salud instruyeron a la Secretaría Ejecutiva del COMISCA implementar esta iniciativa con la COTEVISI y el apoyo del Instituto Conmemorativo Gorgas de Estudios de la Salud de Panamá, el Instituto 
Nacional de Salud Pública de México (INSP), el Instituto de Meteorología de Cuba (INSMET), la Organización Panamericana de la Salud (OPS) y la CEPAL. En el marco de ese mandato, se organizaron planes de trabajo para analizar la relación histórica entre el clima y las enfermedades sensibles a ese factor, y se llevaron a cabo capacitaciones del tipo "aprender haciendo" en Costa Rica, El Salvador, Honduras, Nicaragua, Panamá y la República Dominicana. En 2016, se agregó el tema de la formulación de políticas públicas en respuesta al cambio climático en el sector de la salud, que se abordó con equipos nacionales de Costa Rica, Honduras y la República Dominicana. A raíz de este trabajo, el Ministerio de Salud de Costa Rica solicitó la asistencia técnica de la CEPAL a los efectos de elaborar una propuesta para el sector de la salud en el proceso de formulación de la Política Nacional de Adaptación al Cambio Climático, liderado por el Ministerio de Ambiente y Energía (MINAE) de dicho país.

Las recomendaciones dirigidas al sector, que emanaron de la reunión del Comité Técnico Regional de la ECC-CARD de 2017, fueron las siguientes: continuar con el fortalecimiento de las capacidades, integrando universidades y otros centros de investigación y ampliando el apoyo de organismos internacionales; desarrollar análisis y elaborar material de divulgación sobre el vínculo entre la contaminación del aire y los problemas de salud y sus costos; identificar las interrelaciones con otros sectores en los efectos del cambio climático sobre la salud; elaborar propuestas para integrar medidas de adaptación sostenible e incluyente en las políticas de salud e implementar un plan sectorial regional en respuesta al cambio climático.

Actualmente, la CEPAL y el COMISCA preparan una segunda publicación conjunta para divulgar los avances de los análisis, las propuestas y las novedades metodológicas; a tales efectos, realizan consultas con el COTEVISI y la OPS para acordar una nueva agenda de colaboración. En resumen, el COMISCA ha establecido su propia iniciativa en materia de salud y cambio climático, y la ha vinculado a su grupo técnico de la COTEVISI, donde se ha avanzado en el fortalecimiento de las capacidades técnicas analíticas y de formulación de políticas, con el apoyo de varias instituciones regionales e internacionales.

\section{Lecciones aprendidas y camino por recorrer}

El sistema de integración centroamericana ha proporcionado un marco de trabajo para impulsar acciones destinadas a combatir el cambio climático y adaptarse a él, ya que, en los consejos de ministros, las secretarías ejecutivas, los grupos de trabajo técnico y las políticas y estrategias regionales, se adoptan e impulsan dichas acciones. A nivel sustantivo, el cambio climático resalta las vulnerabilidades que los países comparten, así como las oportunidades 
de brindar una respuesta coordinada, especialmente en los campos de la gestión de las cuencas transnacionales, la seguridad alimentaria y energética, la gestión de riesgos y las negociaciones internacionales.

La combinación de acciones a nivel regional (particularmente en coordinación con las secretarías ejecutivas y los grupos técnicos de los consejos de ministros) y de otras concertadas con los socios nacionales para responder a sus prioridades en los mismos campos, permitió a la ECC-CARD aportar en ambos niveles, crear un circulo virtuoso y fomentar el aprendizaje y la cooperación sur-sur.

Cuando se inició el trabajo de la ECC-CARD, los Ministerios de Ambiente querían que se hiciera a la brevedad un análisis de la mejor calidad posible sobre el impacto y los costos potenciales, pero eran conscientes de la necesidad de involucrar a otros socios y de buscar el fortalecimiento de las capacidades técnicas. El Comité Técnico Regional consideró que no era posible dar la misma prioridad a estos elementos, dada la urgencia de producir resultados. Entonces se acordó priorizar el análisis oportuno y de calidad, con un proceso de cogestión, discusión y revisión técnica de los resultados. En los años más recientes, se ha puesto más atención al fortalecimiento de las capacidades, sobre todo de los métodos de análisis y del diálogo sobre las respuestas que se podrían dar en los sectores fiscal, agrícola y de la salud.

La ECC-CARD ha respondido a las demandas claves, desde la necesidad de llevar a cabo análisis básicos sobre el impacto potencial del cambio climático y la sensibilización de los sectores no ambientales, hasta la discusión de los enfoques que se podrían adoptar a la hora de responder y elaborar políticas públicas nacionales. El fortalecimiento de las capacidades técnicas, de diálogo y de articulación, así como la instrumentación, se perfilan como áreas emergentes prioritarias, atendiendo al reto de los efectos en las poblaciones vulnerables y las dificultades que la economía política presenta a propuestas como la reforma fiscal verde y la mayor inversión en bienes y servicios públicos comunes.

Igualmente, la propuesta consensuada de priorizar la adaptación sostenible e incluyente, dentro de la cual se promueve la transición hacia economías sostenibles desde el punto de vista ambiental y con bajas emisiones de GEI, evidencia una maduración del pensamiento que permitió superar la supuesta dicotomía entre mitigación y adaptación.

El trabajo de la iniciativa ha contribuido a llevar adelante un diálogo regular con los Ministros y con sus asesores y técnicos cercanos pertenecientes a los sectores que son relevantes para el cambio climático, a fin de discutir los resultados como insumos que los ayuden a tomar decisiones, y para identificar nuevas áreas de trabajo. Esta dinámica es importante a los efectos de promover una iniciativa que contribuya a que se formulen políticas basadas en evidencia. 
Por medio de este trabajo, la CEPAL, a través de la ECC-CARD, incursionó en un nuevo campo donde no siempre existían metodologías probadas, especialmente en contextos en que la información y los datos son limitados. Esto requirió esfuerzo técnico y flexibilidad para explorar, probar y discutir métodos y resultados, y, en algunos casos, volver a hacer el análisis. Además, por la naturaleza del tema, ha sido necesario reunir a técnicos de diversas disciplinas.

En los años recientes se conjugó la generación y la divulgación de nuevos conocimientos con el enfoque de fortalecer las capacidades técnicas, diseñando cada proceso emprendido con los socios de modo de combinar las distintas facetas y establecer espacios de capacitación técnica y reflexión sobre los resultados y las metodologías empleadas. Los funcionarios de los sectores participantes hicieron aportes y maduraron su entendimiento en las diversas áreas de sus competencias. Esto se ilustra sobre todo con la agenda de múltiples áreas de política fiscal elaborada por los Delegados de Hacienda del Comité Técnico Regional, y con el desarrollo de la EASAC en el sector agropecuario.

Hacia el futuro, se evidencia la importancia de que el sector académico se involucre más en el fortalecimiento de las capacidades, y de incrementar los esfuerzos para incorporar la ciencia y las opciones de respuesta al cambio climático en las diversas carreras universitarias y técnicas. También se debería generar mayor conocimiento e información relevante para formular políticas públicas, y procurar la participación y las acciones de los diversos sectores de la sociedad.

En la reunión del Comité Técnico Regional de la ECC-CARD de 2017, se propuso organizar una red técnico-académica sobre cambio climático en el SICA, aprovechando varias plataformas existentes, con la finalidad adicional de canalizar investigaciones que nutran los informes del IPCC y de fomentar la participación de científicos de la región en sus grupos de autores.

La iniciativa ECC-CARD se ha caracterizado por ser un proceso de cogestión técnica en el que la CEPAL participa y coordina las actividades en materia de cambio climático con las autoridades centroamericanas, tanto nacionales como regionales. También se ha caracterizado por facilitar espacios de diálogo y aprendizaje técnico entre diversas instituciones y sectores a nivel nacional y regional. Por ejemplo, se constató la importancia de contar con equipos multidisciplinarios e interinstitucionales en temas como el impacto potencial del cambio climático en la incidencia de las enfermedades, la relación entre el cambio climático y la seguridad alimentaria y nutricional, y el diseño de proyectos de inversión pública robustos frente a los retos del cambio climático y el desarrollo sostenible. 
El fortalecimiento de las capacidades y la cogestión técnica han sido claves en los resultados alcanzados; por ende, resulta importante reconocer y valorar el esfuerzo de todos los socios para gestionar iniciativas de esta forma, que es más extensa en cuanto al tiempo y más intensa respecto del involucramiento y el compromiso. La creación de una agenda futura, tanto a nivel de los grupos técnicos sectoriales como del Comité Técnico Regional de la ECC-CARD, supone el mismo proceso de gestión, evaluación y reflexión sobre los avances y los problemas, lo que da lugar a un ciclo virtuoso de acción-planificación-acción. En este sentido, es recomendable calcular un tiempo mayor para ejecutar las iniciativas que tienen estas características.

Los conocimientos generados en los procesos de gestión y aprendizaje técnicos han sido documentados en una serie de publicaciones, muchas de las cuales son conjuntas, y los actores de la región del SICA pueden acceder a ellas sin costo por Internet. Igualmente, los conocimientos y las respuestas generadas se han anclado en grupos técnicos conformados y consolidados, como es el caso de la COTEVISI del COMISCA y el GTCCGIR del CAC. En el caso del COSEFIN, el grupo de delegados de los Ministerios de Hacienda que participan en el Comité Técnico Regional contribuyó con la creación de una agenda técnica sobre política fiscal, inversión pública, cambio climático y desarrollo sostenible, que responde a la matriz de interés fiscal establecida por el Consejo. Esta agenda, plasmada en una propuesta técnica, ha sido respaldada por el Consejo y su Secretaría Ejecutiva, y servirá para abrir la discusión con los donantes.

En el caso del CAC, la cooperación con los ministerios, así como las comunidades de práctica que se convocaron para tratar los temas de la seguridad alimentaria y nutricional, el cambio climático y los seguros agropecuarios, coinciden con las prioridades plasmadas en la EASAC. El GTCCGIR de la Secretaría Ejecutiva del CAC y la CEPAL continúan trabajando conjuntamente y para los próximos años se prevén trabajos sobre el fortalecimiento de las capacidades para implementar la EASAC, lo que incluye componentes sobre la seguridad alimentaria y nutricional, la gestión de información agroclimática y el diseño de seguros agropecuarios desde la perspectiva de la gestión integral de los riesgos. 


\section{Bibliografía}

CAC/SICA (Consejo Agropecuario Centroamericano/Sistema de la Integración Centroamericana) (2017), "Estrategia agricultura sostenible adaptada al clima para la región del SICA (2018-2030)", San José [en línea] http://apps.iica.int/ observatorio-girsa / Content / Archivos / Publicaciones / Archivos / 10112017_ EstrategiaASAC-CAC.pdf.

CEPAL (Comisión Económica para América Latina y el Caribe) (2016a), Horizontes 2030: la igualdad en el centro del desarrollo sostenible (LC/G.2660/Rev.1), Santiago, julio. (2016b), Objetivos de Desarrollo Sostenible y retos del desarrollo rural en Centroamérica y la República Dominicana (LC/MEX/L.1205), Ciudad de México, febrero.

(2015a), “Nicholas Stern: 'La COP 21 de París debe ser el primer paso de muchos'", Santiago, 10 de octubre [en línea] https://www.cepal.org/es/ noticias/nicholas-stern-la-cop-21-paris-debe-ser-primer-paso-muchos.

(2015b), Microseguros agropecuarios y gestión integral de riesgos en Centroamérica y la República Dominicana: lineamientos estratégicos para su desarrollo y fortalecimiento (LC/MEX/L.1194), Ciudad de México, noviembre.

(2014), Manual para la evaluación de desastres (LC/L.3691), Santiago, febrero.

(2010), "La hora de la igualdad: brechas por cerrar, caminos por abrir. Síntesis" (LC/G.2433(SES.33/4)), Santiago, mayo.

CEPAL/CAC/SICA (Comisión Económica para América Latina y el Caribe/Consejo Agropecuario Centroamericano/Sistema de la Integración Centroamericana) (2014), Impactos potenciales del cambio climático sobre el café en Centroamérica (LC/MEX/L.1169), Ciudad de México, noviembre.

(2013a), Impactos potenciales del cambio climático sobre los granos básicos en Centroamérica, (LC/MEX/L.1123), Ciudad de México, noviembre.

(2013b), Gestión integral de riesgos y seguros agropecuarios en Centroamérica y la Republica Dominicana: situación actual y líneas de acción potenciales (LC/MEX/L.1122), Ciudad de México, noviembre.

CEPAL/SICA (Comisión Económica para América Latina y el Caribe/Sistema de la Integración Centroamericana) (2007), Estrategia energética sustentable centroamericana 2020 (LC/MEX/L.828), Ciudad de México, noviembre.

CEPAL (Comisión Económica para América Latina y el Caribe) y otros (2018), La economía del cambio climático en Guatemala: documento técnico 2018 (LC/MEX/ TS.2018/13), Ciudad de México, julio. (2017a), Impactos potenciales del cambio climático en el ámbito hidroeléctrico en Panamá y la República Dominicana (LC/MEX/TS.2017/28), Ciudad de México, noviembre. (2017b), La economía del cambio climático en Honduras: documento técnico 2017 (LC/MEX/TS.2017/26), Ciudad de México, octubre.

(2015), Cambio climático en Centroamérica: impactos potenciales y opciones de política pública (LC/MEX/L.1196), Ciudad de México, noviembre.

(2012a), La economía del cambio climático en Centroamérica: dos casos de impactos potenciales en la generación de hidroelectricidad. Serie técnica 2012 (LC/MEX/L.1070), Ciudad de México, octubre.

(2012b), “Variabilidad climática y eventos extremos en Centroamérica: reporte exploratorio", documento preparado para la XL Reunión Ordinaria de Jefes de Estado y de Gobierno de los Países del Sistema de Integración Centroamericana (SICA), Managua, 13 de diciembre, inédito. 
(2012c), La economía del cambio climático en Centroamérica: sintesis 2012 (LC/MEX/L.1076), Ciudad de México, octubre.

(2012d), La economía del cambio climático en Centroamérica: impactos potenciales en los patrones intraanuales y espaciales del clima. Serie técnica 2012 (LC/MEX/L.1073), Ciudad de México, septiembre.

(2012e), La economía del cambio climático en Centroamérica: impactos potenciales en la aridez y los meses secos. Serie técnica 2012 (LC/MEX/L.1074), Ciudad de México, octubre.

(2012f), La economía del cambio climático en Centroamérica: impactos potenciales en los ecosistemas. Serie técnica 2012 (LC/MEX/L.1077), Ciudad de México, octubre. (2012g), La economía del cambio climático en Centroamérica: evidencia de las enfermedades sensibles al clima. Serie técnica 2012 (LC/MEX/L.1069), Ciudad de México, octubre.

(2011), La economía del cambio climático en Centroamérica: reporte técnico 2011 (LC/MEX/L.1016), Ciudad de México, julio.

(2010), La economía del cambio climático en Centroamérica: síntesis 2010 (LC/MEX/L.978), Ciudad de México, noviembre.

CMNUCC (Convención Marco de las Naciones Unidas sobre el Cambio Climático) (2018) "Public NAMA", Bonn [base de datos en línea] http:/ / www4.unfccc.int/ sites/nama/SitePages/Country.aspx?CountryId=52.

(2016), "Aggregate effect of the intended nationally determined contributions: an update. Synthesis report by the secretariat" (FCCC/CP/2016/2), Bonn, mayo [en línea] http:/ / unfccc.int/resource/docs/2016/cop22/eng/02.pdf. (2015), "Aprobación del Acuerdo de París: propuesta del presidente. Proyecto de decisión -/CP.21" (FCCC/CP/2015/L.9), Bonn, diciembre [en línea] http:/ / unfccc.int/resource/docs/2015/cop21/spa/109s.pdf.

(2012), National Adaptation Plans: Technical Guidelines for the National Adaptation Plan Process, Bonn, diciembre.

COSEFIN (Consejo de Ministros de Hacienda o Finanzas de Centroamérica, Panamá y República Dominicana) (2018), “Plan de Trabajo Regional del COSEFIN: Matriz de Interés Fiscal (MIF)", documento preparado para el Seminario Regional sobre Instrumentos de Política Fiscal Verde, Cambio Climático y Sostenibilidad Ambiental, San José, 7 y 8 de noviembre [en línea] https:/ / www.cepal.org/sites / default/files/presentations/plan_de_trabajo_regional_del_cosefin.pdf.

Eckstein D., V. Künzel y L. Schäfer (2017), “Global Climate Risk Index 2018: who suffers most from extreme weather events? Weather-related loss events in 2016 and 1997 to 2016", Briefing Paper, Bonn, Germanwatch, noviembre.

FAO (Organización de las Naciones Unidas para la Alimentación y la Agricultura) (2017), "FAO y PNUD presentan proyecto para adaptación al cambio climático en Guatemala", Ciudad de Guatemala, 30 de noviembre [en línea] http:/ / www. fao.org/guatemala/noticias/detail-events/es/c/1070995/.

Fundación DARA (2012), "Methodology note: methodological documentation for the Climate Vulnerability Monitor", Madrid, inédito.

Harmeling, S. (2012), “Global Climate Risk Index 2012: who suffers most from extreme weather events? Weather-related loss events in 2010 and 1991 to 2010", Briefing Paper, Bonn, Germanwatch.

(2011), “Global Climate Risk Index 2011: who suffers most from extreme weather events? Weather-related loss events in 2009 and 1990 to 2009", Briefing Paper, Bonn, Germanwatch. 
(2010), "Global Climate Risk Index 2010: who is most vulnerable? Weatherrelated loss events since 1990 and how Copenhagen needs to respond", Briefing Paper, Bonn, Germanwatch.

(2009), “Global Climate Risk Index 2009: weather-related loss events and their impacts on countries in 2007 and in a long-term comparison", Briefing Paper, Bonn, Germanwatch.

(2008), “Global Climate Risk Index 2008: weather-related loss events and their impacts on countries in 2006 and in a long-term comparison", Briefing Paper, Bonn, Germanwatch.

Harmeling S. y C. Bals (2007), “Globaler Klima-Risiko-Index 2007: wetterbedingte schadensereignisse und ihre auswirkungen auf die staaten der welt in 2005 und im langjährigen vergleich", Briefing Paper, Bonn, Germanwatch.

Harmeling, S. y D. Eckstein (2013), “Global Climate Risk Index 2013: who suffers most from extreme weather events? Weather related loss events in 2011 and 1992 to 2011", Briefing Paper, Bonn, Germanwatch.

IIDS (Instituto Internacional para el Desarrollo Sostenible) (2015), "Summary of the Paris Climate Change Conference: 29 November-13 December 2015", Earth Negotiations Bulletin, vol. $12 \mathrm{~N}^{\circ}$ 663, Nueva York, 15 de diciembre [en línea] http: / / enb.iisd.org/download/pdf/enb12663e.pdf.

INBio (Instituto Nacional de Biodiversidad) (2004), Biodiversidad en Centroamérica, San José.

IPCC (Grupo Intergubernamental de Expertos sobre el Cambio Climático) (2014), "Central and South America", Climate Change 2014: Impacts, Adaptation, and Vulnerability. Part B: Regional Aspects. Working Group II Contribution to the IPCC Fifth Assessment Report, Cambridge, Cambridge University Press.

(2012), "Summary for policymakers", Managing the Risks of Extreme Events and Disasters to Advance Climate Change Adaptation, C. Field y otros (eds.), Cambridge, Cambridge University Press.

Kreft S. y D. Eckstein (2013), "Global Climate Risk Index 2014: who suffers most from extreme weather events? Weather-related loss events in 2012 and 1993 to 2012", Briefing Paper, Bonn, Germanwatch, noviembre.

Kreft S., D. Eckstein e I. Melchior (2016), “'Global Climate Risk Index 2017: who suffers most from extreme weather events? Weather-related loss events in 2015 and 1996 to 2015", Briefing Paper, Bonn, Germanwatch, noviembre.

Kreft, S. y otros (2015), "Global Climate Risk Index 2016: who suffers most from extreme weather events? Weather-related loss events in 2014 and 1995 to 2014", Briefing Paper, Bonn, Germanwatch, noviembre.

(2014), "Global Climate Risk Index 2015: who suffers most from extreme weather events? Weather-related loss events in 2013 and 1994 to 2013", Briefing Paper, Bonn, Germanwatch, noviembre.

Marroquín, H. (2017a), Factibilidad legal, regulatoria e institucional de la participación del Banco de Fomento Agropecuario de El Salvador en los seguros agropecuarios, incluyendo la sostenibilidad financiera y marco operativo (LC/MEX/L.1228), J. Iraheta (coord.), Ciudad de México, Comisión Económica para América Latina y el Caribe/Fondo Internacional de Desarrollo Agrícola/Banco de Fomento Agropecuario (CEPAL/ FIDA/BFA), enero. 
(2017b), Análisis de viabilidad legal, sostenibilidad financiera y operativa de una institución público-privada rectora de los seguros agropecuarios en Guatemala (LC/MEX/L.1234), J. Iraheta (coord.), Ciudad de México, Comisión Económica para América Latina y el Caribe/Fondo Internacional de Desarrollo Agrícola/ Ministerio de Agricultura Ganadería y Alimentación (CEPAL/FIDA/ MAGA), febrero.

(2017c), Análisis de factibilidad técnica para la implementación de seguros indexados contra las amenazas de sequía e inundación para los cultivos de arroz y maíz en Panamá (LC/MEX/TS.2017/4), J. Iraheta (coord.), Ciudad de México, Comisión Económica para América Latina y el Caribe/Fondo Internacional de Desarrollo Agrícola/Instituto de Seguro Agropecuario (CEPAL/FIDA/ISA), marzo.

MINAE (Ministerio de Ambiente y Energía) (2018), "Política Nacional de Adaptación al Cambio Climático", Decreto Ejecutivo, N 41.091, San José, 20 de abril.

Ramírez, P. (1983), "Estudio meteorológico de los veranillos en Costa Rica", Nota de Investigación, $\mathrm{N}^{\circ}$ 5, San José, Ministerio de Agricultura y Ganadería/Instituto Meteorológico Nacional (MAG/IMN).

Sánchez, L. y M. Juárez (2017), Análisis de viabilidad y estudios de oferta y demanda para el fortalecimiento de un seguro agropecuario sostenible e incluyente para los medianos y pequeños productores rurales en Costa Rica (LC/MEX/L.1226/Rev.1), J. Iraheta (coord.), Ciudad de México, Comisión Económica para América Latina y el Caribe (CEPAL)/Fondo Internacional de Desarrollo Agrícola (FIDA)/Instituto Nacional de Seguros (INS), enero. 



\title{
Capítulo XI \\ La dimensión social de la integración centroamericana
}

\author{
Humberto Soto de la Rosa \\ Maria Luisa Marinho \\ Citlalli Lamotte \\ Elsa Gutiérrez
}

\section{Introducción}

A mediados de la década de 1990, los países de Centroamérica firmaron el Tratado de la Integración Social Centroamericana (TISCA). Esto representó un hito que delimitó un antes y un después en la dimensión social del proceso de integración. En el momento de su firma, varios países de la región estaban saliendo de un período de inestabilidad económica y política. Tenían ante sí un horizonte de nuevos tiempos de paz y de consolidación democrática, derivados de los acuerdos de Esquipulas. Se encontraban en un momento propicio para plantearse el objetivo de transitar hacia la integración social.

Antes de 1995, no se observa un avance sustantivo en la incorporación de la dimensión social al proceso de integración centroamericano. Entre 1960 y 1980, dicho proceso estuvo centrado en la consolidación de un mercado común centroamericano, por lo que los avances en materia de integración social quedaron supeditados a los resultados de la integración económica. González resume estos avances como "el impacto social que ha tenido el crecimiento de una clase obrera más consciente de sus derechos y una clase 
gerencial que ha perdido, en parte, su fisonomía de clan familiar", es decir, un impacto marginal (González, 1988, pág. 320).

Durante este período, se crearon algunas instituciones que posteriormente han sido relevantes para la integración social, pero que no surgieron con ese propósito. Tal es el caso del Instituto de Nutrición de Centroamérica y Panamá (INCAP), fundado en 1947, y de la Coordinación Educativa Centroamericana (CEC), creada en 1975.

Durante la década de 1980, debido al escenario de conflictividad e inestabilidad económica y política, los avances en materia de integración social también se vieron acotados. Algunos de ellos se vislumbraban en la incorporación del ámbito cultural a la CEC en 1982 —con lo que la institución pasó a denominarse Coordinación Educativa y Cultural Centroamericana (CECC) - y en el inicio de la operación del Consejo de Ministras y Ministros de Trabajo de Centroamérica y República Dominicana en 1988. En contraste, la década de 1990 fue más beneficiosa para el proceso de integración social. A partir de la consolidación de la integración que se inició con la firma del Protocolo de Tegucigalpa, y que creó a su vez el Sistema de la Integración Centroamericana (SICA), se plantearon las bases de negociación que derivaron en la firma del TISCA en 1995.

Tras la rúbrica del TISCA, se registraron avances notorios en el proceso de integración social regional. Alcanzaron áreas del desarrollo complementarias a la educación o la salud, pues se expandieron a temas asociados a la inclusión social de grupos poblacionales, como la primera infancia, la juventud y las mujeres. También se ampliaron a otros sectores de desarrollo bajo una mirada regional, como sucedió en el caso del agua, el saneamiento y el trabajo. Los avances fueron graduales; se iniciaron con proyectos aislados que sentaron las bases para la conformación de estrategias y agendas regionales, que a su vez llegaron a incorporarse en las políticas regionales. Recientemente, el proceso se ha centrado en conciliar la retórica planteada por dichas políticas de índole regional con acciones más concretas orientadas a alcanzar la convergencia en materia de integración social.

Desde antes de la firma del TISCA en 1995, y también en los años posteriores, la Comisión Económica para América Latina y el Caribe (CEPAL) ha contribuido en distintos ámbitos a la evolución del proceso de la integración social centroamericana. Antes de la firma del TISCA, el aporte era de índole intelectual, a partir del análisis conceptual y metodológico que la CEPAL, desde su creación, había desarrollado en diversas temáticas como la educación, la salud, la seguridad alimentaria y la inserción laboral. Así, en la década de 1980, la CEPAL colocó el desarrollo social a un nivel de importancia similar al desarrollo económico. Esto encontró reflejo dentro del proceso centroamericano, sobre todo con la inclusión de la dimensión social como uno de sus ejes estratégicos. 
Durante la etapa de consolidación de las instancias institucionales, de 1995 en adelante, la CEPAL ha hecho otros tipos de aportaciones. Por ejemplo, ha presentado recomendaciones para una mejor configuración de la institucionalidad de la integración. Una vez consolidada dicha institucionalidad, ha realizado aportes directos en el marco del trabajo de los diversos consejos ministeriales y secretarías técnicas que conforman la institucionalidad social regional del sistema de integración. En este contexto, la CEPAL ha contribuido a la configuración de las políticas regionales propuestas en diversos ámbitos como la pobreza, la institucionalidad, la salud, la vivienda y la protección social, entre otros.

En este capítulo se exploran la trascendencia, los avances y los desafíos de la dimensión social del proceso de integración centroamericano. Se hace énfasis en la conformación de la institucionalidad para la integración social, así como su consolidación y su operatividad para abordar las temáticas de su competencia. Asimismo, se destacan los aportes de la CEPAL para hacer frente a los desafíos y potenciar las acciones regionales orientadas al incremento del bienestar social de la población, particularmente de cara al cumplimiento de la Agenda 2030 para el Desarrollo Sostenible.

\section{A. Institucionalidad de la integración social centroamericana}

Los esfuerzos en materia de integración social a nivel regional antes de 1990 fueron muy acotados en lo institucional. Se centraron en algunos sectores como la educación y la salud, en los que, mediante reuniones de consejos de ministros, se abordaron durante esos años problemáticas comunes, aunque sin establecerse estrategias sociales integradas ni institucionalizadas.

A raíz de la iniciativa planteada por la Comisión Regional de Asuntos Sociales (CRAS), creada en 1991 por acuerdo de la Declaración de San Salvador, los países centroamericanos firmaron la Alianza para el Desarrollo Sostenible (ALIDES) en 1994. Se establecieron así las bases para incluir la integración social en el proceso de integración regional desde una perspectiva institucional. Mediante la ALIDES, los países acordaron apoyar la formulación del TISCA que, como se mencionó, se firmó en 1995.

Con la firma del TISCA se planteó de manera más clara el objetivo de la integración social centroamericana. Se lo definió como la búsqueda de mayores oportunidades y mejor calidad de vida y de trabajo mediante la implementación de acciones que, bajo el principio de la cooperación mutua y el apoyo solidario, garantizaran el acceso de la población a los servicios básicos, al desarrollo y a la superación de los factores estructurales de la pobreza (SISCA, 2009d). 
El TISCA sentó las bases para el fortalecimiento de la institucionalidad regional en la dimensión social. Debido al modelo operacional propuesto para las instituciones regionales centroamericanas de integración, desde 1995 ha sido central la formación o consolidación de los consejos ministeriales sectoriales. Mediante sus reuniones periódicas y el acompañamiento de sus secretarías técnicas, han dado continuidad a las temáticas y mandatos en materia de integración social.

En el momento de la firma del TISCA, se encontraban operando diversos consejos ministeriales regionales, como los de educación y cultura, salud, trabajo, vivienda y deportes. Algunos se habían conformado recientemente, pues surgieron a raíz de la Declaración de San Salvador en 1991, mientras que otros tenían mayor trayectoria (véase el cuadro XI.1). Con el TISCA se plantea la necesidad de establecer un consejo de ministros coordinadores de las instancias sociales, el Consejo de la Integración Social Centroamericana (CIS), que articulara los esfuerzos de los diversos sectores hacia la convergencia del desarrollo social de los países de la región. Luego se crearon otros en respuesta a nuevas prioridades, como los consejos de ministros de agua potable y saneamiento y de la mujer. Estas iniciativas suman esfuerzos, pero también complejizan la labor coordinadora del CIS.

\section{Cuadro XI.1}

Consejos ministeriales sociales centroamericanos, según el año de inicio de sus funciones

\begin{tabular}{lc}
\hline Consejo ministerial & $\begin{array}{l}\text { Año de inicio } \\
\text { de funciones }\end{array}$ \\
\hline $\begin{array}{l}\text { Consejo de Ministros de Educación y Cultura de la Coordinación Educativa y Cultural } \\
\text { Centroamericana (CECC) }\end{array}$ & 1982 \\
\hline Consejo de Ministras y Ministros de Trabajo de Centroamérica y República Dominicana & 1988 \\
\hline $\begin{array}{l}\text { Consejo Centroamericano de Vivienda y Asentamientos Humanos (CCVAH) } \\
\text { Consejo de Ministros de Salud de Centroamérica (COMISCA) }\end{array}$ & 1991 \\
\hline \begin{tabular}{l} 
Consejo del Istmo Centroamericano de Deportes y Recreación (CODICADER) \\
\hline $\begin{array}{l}\text { Consejo de Instituciones de Seguridad Social de Centroamérica } \\
\text { y República Dominicana (CISSCAD) }\end{array}$
\end{tabular} & 1991 \\
\hline Consejo de la Integración Social Centroamericana (CIS) & 1992 \\
\hline $\begin{array}{l}\text { Consejo de Ministras de la Mujer de Centroamérica y República Dominicana (COMMCA) } \\
\text { bo }\end{array}$ & 2002 \\
\hline $\begin{array}{l}\text { Consejo Centroamericano y República Dominicana de Agua Potable } \\
\text { y Saneamiento (CONCARD-APS) }\end{array}$ & 2005 \\
\hline
\end{tabular}

Fuente: Elaboración propia, sobre la base de información oficial.

a No es un consejo ministerial, pero es de gran trascendencia en el contexto de la integración social regional.

b Fue creado en 2002, pero vino a incorporarse al Sistema de la Integración Social Centroamericana en 2005. 
No todos los consejos ministeriales han tenido asociada una secretaría técnica (véase el cuadro XI.2). Si bien la CECC, el Consejo de Ministros de Salud de Centroamérica (COMISCA), el Consejo Centroamericano y República Dominicana de Agua Potable y Saneamiento (CONCARD-APS), el Consejo de Ministras de la Mujer de Centroamérica y República Dominicana (COMMCA) y el CIS tienen sus propias secretarías, el Consejo Centroamericano de Vivienda y Asentamientos Humanos (CCVAH) y el Consejo del Istmo Centroamericano de Deportes y Recreación (CODICADER) recurren con ese fin a los servicios de la Secretaría de la Integración Social Centroamericana (SISCA). El Consejo de Ministras y Ministros de Trabajo de Centroamérica y República Dominicana tiene como secretaría a integrantes de la institución a cargo de la presidencia pro tempore con el apoyo de la Organización Internacional del Trabajo (OIT), en el marco de un acuerdo suscrito en 2014.

\section{Cuadro XI.2}

Secretarías técnicas de los consejos ministeriales sociales centroamericanos, según su año de inicio de operaciones

\begin{tabular}{lll}
\hline Consejo ministerial & Secretaría & $\begin{array}{l}\text { Año de creación } \\
\text { de la secretaría }\end{array}$ \\
\hline $\begin{array}{l}\text { Consejo de Ministros de Educación } \\
\text { y Cultura de la Coordinación Educativa } \\
\text { y Cultural Centroamericana (CECC) }\end{array}$ & $\begin{array}{l}\text { Secretaría General de la Coordinación } \\
\text { Educativa y Cultural Centroamericana } \\
\text { (SG-CECC) }\end{array}$ & 1982 \\
\hline $\begin{array}{l}\text { Consejo de Ministras y Ministros } \\
\text { de Trabajo de Centroamérica } \\
\text { y República Dominicana }\end{array}$ & $\begin{array}{l}\text { Presidencia pro tempore de turno } \\
\text { con el apoyo de la OIT }\end{array}$ & 1988 \\
\hline $\begin{array}{l}\text { Consejo de Ministros de Salud de } \\
\text { Centroamérica (COMISCA) }\end{array}$ & $\begin{array}{l}\text { Secretaría del Consejo de Ministros de } \\
\text { Salud de Centroamérica (SE-COMISCA) }\end{array}$ & 2007 \\
\hline $\begin{array}{l}\text { Consejo Centroamericano de Vivienda } \\
\text { y Asentamientos Humanos (CCVAH) }\end{array}$ & $\begin{array}{l}\text { Secretaría de Integración Social } \\
\text { Centroamericana (SISCA) }\end{array}$ & Desde 1999 \\
\hline $\begin{array}{l}\text { Consejo del Istmo Centroamericano de } \\
\text { Deportes y Recreación (CODICADER) }\end{array}$ & $\begin{array}{l}\text { Secretaría de la Integración Social } \\
\text { Centroamericana (SISCA) }\end{array}$ & Desde 2009 \\
\hline $\begin{array}{l}\text { Consejo de la Integración Social } \\
\text { Centroamericana (CIS) }\end{array}$ & $\begin{array}{l}\text { Secretaría de la Integración Social } \\
\text { Centroamericana (SISCA) }\end{array}$ & 1995 \\
\hline $\begin{array}{l}\text { Consejo Centroamericano y } \\
\text { República Dominicana de Agua Potable } \\
\text { y Saneamiento (CONCARD-APS) }\end{array}$ & $\begin{array}{l}\text { Secretaría Técnica del Foro } \\
\text { Centroamericano y República } \\
\text { Dominicana de Agua Potable } \\
\text { y Saneamiento (ST-FOCARD) }\end{array}$ & 2005 \\
\hline $\begin{array}{l}\text { Consejo de Ministras de la Mujer de } \\
\text { Centroamérica y República Dominicana } \\
\text { (COMMCA) }\end{array}$ & $\begin{array}{l}\text { Secretaría Técnica del Consejo de } \\
\text { Ministras de la Mujer de Centroamérica } \\
\text { y República Dominicana (ST-COMMCA) }\end{array}$ & \\
\hline
\end{tabular}

Fuente: Elaboración propia, sobre la base de información oficial.

En la búsqueda de mayor representatividad de todos los países en el modelo de integración, se establece la rotación de las presidencias pro tempore cada seis meses y la ubicación dispersa de las sedes de las secretarías por la región (véase el cuadro XI.3). 
Cuadro XI.3

Secretarías técnicas de los consejos ministeriales sociales centroamericanos, según su localización geográfica

\begin{tabular}{ll}
\hline Secretaría & Ciudad sede \\
\hline Secretaría de la Integración Social Centroamericana (SISCA) & Panamá \\
\hline $\begin{array}{l}\text { Secretaría General de la Coordinación Educativa y Cultural } \\
\text { Centroamericana (SG-CECC) }\end{array}$ & San José \\
\hline Secretaría del Consejo de Ministros de Salud de Centroamérica (SE-COMISCA) & San Salvador \\
\hline $\begin{array}{l}\text { Secretaría Técnica del Foro Centroamericano y República Dominicana de Agua } \\
\text { Potable y Saneamiento (ST-FOCARD) }\end{array}$ & San Salvador \\
\hline $\begin{array}{l}\text { Secretaría Técnica del Consejo de Ministras de la Mujer de Centroamérica } \\
\text { y República Dominicana (ST-COMMCA) }\end{array}$ & San Salvador \\
\hline
\end{tabular}

Fuente: Elaboración propia.

La institucionalidad del subsistema social de la Integración Centroamericana se complementa con el INCAP, el Banco Centroamericano de Integración Económica (BCIE), el Instituto Centroamericano de Administración Pública (ICAP) y la Comisión Centroamericana de Directores de Migración (OCAM).

En el ámbito de la conformación institucional de la integración regional, y sobre todo de la dimensión social, se destaca el análisis que aportaron la CEPAL y el Banco Interamericano de Desarrollo (BID) en 1996, con miras a realizar un diagnóstico de la institucionalidad centroamericana. Dicho trabajo se tradujo en diversas recomendaciones encaminadas a mejorar la propuesta planteada en el ámbito social. Fueron particularmente relevantes las recomendaciones de: i) puntualizar la naturaleza de una agenda regional en materia social correspondiente a la Secretaría de la Integración Social y el lugar que los ministros buscaban asignar a esa entidad, y ii) demostrar la eficacia de la Secretaría de la Integración Social mediante mayores flujos de información y otras tareas de coordinación sustantiva (CEPAL/BID, 1998). A partir de dichas recomendaciones, la SISCA ha buscado ejercer su papel de apoyo a la agenda regional de integración social bajo los mandatos de los encuentros presidenciales y de las reuniones de los consejos de ministros.

A continuación, se hace un breve recorrido por la historia de la institucionalidad previamente enumerada.

\section{Secretaría de la Integración Social Centroamericana}

Después de la firma y ratificación del TISCA por El Salvador, Guatemala, Nicaragua y Panamá, la Secretaría de la Integración Social Centroamericana (SISCA) comenzó sus funciones en 1997. En un principio se centró en acciones orientadas a la promoción de proyectos temáticos, en consolidarse a nivel de recursos humanos y financieros y en establecer una agenda con el CIS, con limitados avances sustantivos (Escrich y Quiteño, 2012). En ese período, 
la SISCA asumió el papel de Secretaría Técnica del Consejo de Ministros de Salud, con lo que durante unos años desempeñó un papel importante en proyectos asociados a los temas de salud. Esta situación se mantuvo hasta 2007, cuando el Consejo de Ministros de Salud constituyó su propia Secretaría Ejecutiva. Además, la SISCA asumió el papel de Secretaría Técnica del CCVAH.

En 2008 se reactivó el trabajo de la SISCA como Secretaría Técnica del CIS y se inició la búsqueda de coordinación multisectorial con las otras entidades de la integración social regional. Ello se materializó en una serie de acuerdos de entendimiento (alianzas) firmados con la SE-COMISCA, la ST-COMMCA y el INCAP, entre otras instancias. Además, con la anuencia del CIS, la SISCA impulsó la reactivación del CCVAH y el acercamiento con el CODICADER. A partir de esa fecha se convirtió en su Secretaría Ejecutiva (Escrich y Quiteño, 2012). La SISCA también impulsó la reactivación del Consejo de Ministras y Ministros de Trabajo de Centroamérica y República Dominicana, que hoy se encuentra muy activo, con el apoyo adicional de la OIT.

Actualmente, la SISCA tiene su sede en Panamá y promueve la articulación intersectorial, tanto entre las instituciones de los países como entre las entidades regionales del área social presentes en Centroamérica. Su propósito principal es desarrollar mecanismos de cooperación, gestión de conocimientos y gestión institucional con miras a la convergencia en políticas sociales. Todo esto lo hace a partir de temáticas centrales como la inclusión social y los derechos humanos, la vivienda y los asentamientos humanos, el deporte, la recreación y la cultura física.

La SISCA y la CEPAL firmaron un acuerdo de cooperación en 2010. Sobre esa base han colaborado en la elaboración de diagnósticos regionales y en la promoción de temáticas de interés regional en el ámbito de las reuniones del consejo de ministros.

\section{Secretaría General de la Coordinación Educativa y Cultural Centroamericana}

El principal antecedente de la Secretaría General de la Coordinación Educativa y Cultural Centroamericana (SG-CECC) es la Primera Reunión de Ministros de Educación de Centroamérica, realizada en 1975 en Guatemala. A partir de ese encuentro se constituyó la Coordinación Educativa Centroamericana (CEC) con el respaldo de la Organización de las Naciones Unidas para la Educación, la Ciencia y la Cultura (UNESCO). Sus funciones se ampliaron hasta incorporar el ámbito cultural en 1982 mediante la aprobación de la constitución de la Coordinación Educativa y Cultural Centroamericana (CECC) en la Octava Reunión de Ministros de Educación, con sede en Nicaragua. 
La SG-CECC en sus inicios se centraba en la organización de foros de Ministros de Educación con el objetivo de intercambiar experiencias y analizar problemas comunes. Sin embargo, las acciones de carácter regional solo comenzaron a ejecutarse en las dos últimas décadas del siglo XX. A partir de 2001, la SG-CECC ha mantenido un liderazgo en la implementación de programas y actividades regionales de diversa índole, tanto en aspectos educativos como culturales, que la CEPAL ha acompañado en varias ocasiones.

\section{Secretaría del Consejo de Ministros de Salud de Centroamérica}

Aunque el principal antecedente de la Secretaría del Consejo de Ministros de Salud (SE-COMISCA) fue la Primera Reunión de Ministros de Salud de Centroamérica y Panamá (1956), el Consejo de Ministros de Salud vino a establecerse en 1991 tras la firma de las Declaraciones de San Salvador y del Protocolo de Tegucigalpa y el TISCA, con el propósito de ejercer la rectoría del sector de la salud a nivel regional. En 2007, con el impulso central del BID, se creó su Secretaría Ejecutiva, previamente ejercida por la SISCA ${ }^{1}$. Esta ha centrado su labor en temáticas diversas vinculadas con la epidemiología, la mejora de los servicios de salud y uno de los rubros de mayor éxito dentro del proceso de integración regional en el ámbito social: la negociación para la adquisición conjunta de medicamentos. En años recientes, con el acompañamiento de la CEPAL, se ha dado impulso al análisis de los efectos del cambio climático en la salud.

\section{Secretaría Técnica del Consejo de Ministras de la Mujer de Centroamérica y República Dominicana}

La Secretaría Técnica del Consejo de Ministras de la Mujer de Centroamérica y República Dominicana (ST-COMMCA) es una instancia institucional regional de reciente creación. Desde su surgimiento en 2002, se ha especializado en promover la estrategia de equidad de género y de garantía de los derechos humanos de las mujeres. Responde a las necesidades emergentes relacionadas con las desigualdades entre hombres y mujeres en materia de acceso al desarrollo en los países de la región. A partir de 2005 se incorporó al Subsistema de la Integración Social. Desde entonces ha recibido un acompañamiento en sus esfuerzos por parte de la CEPAL.

La promoción de la compra conjunta de medicamentos como bien público regional tuvo un decidido apoyo del BID y consolidó las funciones de la SE-COMISCA. 


\section{Secretaría Técnica del Foro Centroamericano y República Dominicana de Agua y Saneamiento}

A principios del siglo XXI, las autoridades responsables del sector del agua potable y el saneamiento de Centroamérica y la República Dominicana plantearon la propuesta de establecer el Foro Centroamericano y República Dominicana de Agua Potable y Saneamiento (FOCARD-APS), que quedó inserto en el Subsistema de la Integración Social. El FOCARD-APS ha buscado mejorar la cobertura y la calidad de los servicios de agua potable y saneamiento, mediante el apoyo a acciones regionales orientadas a la gestión sostenible de los recursos.

\section{Otras instancias e instituciones}

El INCAP es una de las instituciones más antiguas en la región. Desde su creación, ha centrado sus esfuerzos en fortalecer la seguridad alimentaria desde la perspectiva del consumo. Es una entidad bien articulada con el resto de la institucionalidad regional.

La OCAM es otra instancia importante que ha adquirido relevancia en los últimos años. Si bien en su inicio tuvo como secretaría técnica a la Secretaría de Integración Económica Centroamericana (SIECA) (1990), a partir de 1999 esa función corresponde a la Organización Internacional para las Migraciones (OIM). Con el apoyo de la OIM, la Comisión prosigue su labor como mecanismo regional de coordinación, concertación y consulta para el tratamiento del fenómeno migratorio.

\section{B. Acciones realizadas a favor de la integración social centroamericana}

El entramado institucional descrito ha contribuido de diversas formas al proceso de integración social de la región. Los avances anteriores a 1990 no se asocian a dicha institucionalidad y son aislados en lo que a integración social regional se refiere. Durante la década de 1990, junto con la consolidación institucional y el establecimiento o reactivación de los consejos de ministros, se observó en cada una de las temáticas una evolución hacia la identificación de problemáticas comunes. Sin embargo, no había una visión muy clara desde la perspectiva de la integración propiamente dicha.

A partir de estos esfuerzos incipientes, en la década de 2000 el proceso de integración social se centra en la implementación de proyectos puntuales, varios de ellos relacionados con la educación y la salud, impulsados en el primer caso por la CECC y, en el segundo, por la SISCA en su calidad de Secretaría Técnica del COMISCA. De acuerdo con el cuarto informe del Estado de la Región en Desarrollo Humano Sostenible (PEN, 2011), una dificultad con que 
tropezaron estos proyectos consistió en que estos planes y estrategias carecían de antecedentes normativos o de referencias con las políticas nacionales. Tampoco contaban con elementos de seguimiento ni de sistematización para monitorear sus impactos.

En respuesta a estas necesidades, a fines de la década de 2000 comienzan a publicarse documentos normativos impulsados por los consejos ministeriales, en forma de estrategias o agendas regionales. Entre otros ejemplos, cabe mencionar la Agenda Estratégica Social del Sistema de la Integración Centroamericana, propuesta en 2008 por la SISCA; la Agenda Regional de Educación 2009-2011, promovida en 2009 por la CECC; la Estrategia Centroamericana de Vivienda y Asentamientos Humanos, impulsada en 2009 por el CCVAH, y la Estrategia Regional Agroambiental y de Salud, elaborada por el COMISCA en 2008, conjuntamente con otros consejos ministeriales regionales, como el de medio ambiente y el agropecuario (PEN, 2011). Estas agendas constituyeron importantes esfuerzos hacia la construcción de un planteamiento estratégico del proceso de integración que conduce en 2010 al relanzamiento de la integración centroamericana, a partir de una nueva forma de proceder en que la integración social era una de cinco grandes áreas estratégicas.

Las diversas instancias regionales han seguido elaborando agendas regionales, así como reglamentos y programas con la finalidad de ordenar el trabajo de los órganos del Sistema de Integración Social. De este modo se eleva el nivel de compromiso político, al trasladar los instrumentos de estrategias regionales a políticas regionales. Un ejemplo de ello es la aprobación de la Política de Seguridad Alimentaria y Nutricional de Centroamérica y República Dominicana (2012-2032), la Política Regional de Igualdad y Equidad de Género (2013-2025), la Política Regional de Salud (2015-2022) y la Política Educativa Centroamericana (2013-2030).

Los proyectos de cooperación también se han incrementado en diversas áreas temáticas gracias a un aumento de las fuentes de financiamiento. Diversas entidades han prestado su apoyo, de modo que han ido surgiendo proyectos con respaldo presupuestario del BID, el Programa de las Naciones Unidas para el Desarrollo (PNUD) y las entidades de cooperación bilateral de Alemania, España, los Estados Unidos, Finlandia, la provincia china de Taiwán, Suecia y la Unión Europea, entre otras. Los principales temas abordados han sido los de seguridad alimentaria y salud, integración social, promoción de alianzas público-privadas, igualdad y equidad de género, atención a la primera infancia, movilidad social, protección contra la trata y la explotación sexual, protección social e inclusión productiva con equidad, entre otros.

Durante estos años, la CEPAL ha acompañado a las instituciones de integración social mediante el apoyo a la gestión de agendas regionales, la promoción de temas emergentes y la elaboración de proyectos y programas 
concretos. A continuación, se hace una revisión de las acciones específicas de mayor relevancia según la temática abordada, como reflejo de los esfuerzos orientados a la integración social regional en salud, educación y cultura, integración social de grupos diversos, género, trabajo, vivienda, agua y saneamiento, seguridad alimentaria y deportes y recreación. Se hace especial énfasis en las contribuciones que ha realizado la CEPAL en cada uno de los temas a través de los años.

\section{Integración social regional}

Desde el primer proyecto temático que gestionó la SISCA en 1996, en el que se abordó la temática de las adolescentes y madres jóvenes solas, se han gestionado múltiples temas y acciones en el marco de la integración social. Al poco tiempo de iniciar su operación, el Consejo de Ministros de Desarrollo Social aprobó la propuesta de lineamientos de políticas y estrategias para el desarrollo y la integración social correspondiente al período 2000-2020, en que se establecieron metas para el primer decenio. En ese marco se implementaron acciones transfronterizas en el ámbito de la salud y la seguridad alimentaria y nutricional, como un componente de promoción de una política de desarrollo integral de los municipios fronterizos.

En el Segundo Informe sobre Desarrollo Humano en Centroamérica y Panamá, se señala que la XXII Reunión Ordinaria de Jefes de Estado y de Gobierno de Centroamérica, celebrada en 2002, se centró en temas de seguridad nutricional, clima y pobreza. En esa línea estratégica, en la denominada Declaración de San José se abordaron los temas de las nuevas responsabilidades de la SISCA (PNUD/Proyecto Estado de la Región, 2003).

Durante los años subsiguientes, el trabajo fue muy acotado, debido a la necesidad de fortalecer la institución. Uno de los avances de este período fue la elaboración, con el apoyo técnico del Fondo de las Naciones Unidas para la Infancia (UNICEF), de un plan de acción regional coordinado por el Foro Regional de la Familia, Niñez y Adolescencia, que fue aprobado en la $32^{a}$ Reunión de Ministros de la Integración Social Centroamericana (Managua, 15 de marzo de 2002).

La labor del CIS adquirió un nuevo dinamismo a partir de 2008, bajo el impulso de la SISCA. Se propuso una Agenda Estratégica Social del Sistema de la Integración Centroamericano que permitiera trabajar en acciones más concretas (CEPAL, 2013). Esa agenda fue aprobada por la $33^{\mathrm{a}}$ Reunión de Jefes de Estado y de Gobierno de los Países del SICA en 2008. A partir de ese momento, el CIS trabajó con miras a articular sus estrategias de acción, establecidas en el Planteamiento Estratégico de la Dimensión Social de la Integración Centroamericana del CIS. 
A partir de 2010, la CEPAL comienza a realizar un acompañamiento más cercano a la labor de la Secretaría de la Integración Social. Esto fue posible gracias a la firma de un convenio de colaboración que ha permitido prestar apoyo técnico en los ámbitos de la identificación de bienes públicos regionales, la atención a la primera infancia, la pobreza y protección social, la juventud y, más recientemente, el fortalecimiento institucional y la concreción de la Agenda 2030.

En el marco de esta colaboración se han definido varias agendas regionales, cuyos resultados se reflejan en el establecimiento de diversos planes. Entre estos se destacan el Plan Regional de Atención Integral a la Primera Infancia 2012-2021, el Plan de Acción Regional sobre Pobreza y Protección Social 2017-2020 y la instauración del Observatorio Centroamericano de Desarrollo Social (OCADES). Este último ha sido de gran utilidad en el seguimiento de los indicadores de la región y del Acuerdo Regional por el Eje Social de los Objetivos de Desarrollo Sostenible (ODS), que enmarca el trabajo regional orientado a la consecución de la Agenda 2030.

En 2018, los países del SICA aprobaron la Agenda Regional Intersectorial sobre Protección Social e Inclusión Productiva con Equidad 2018-2030 (ARIPSIP), mediante la que promoverán la implementación de políticas y programas encaminados a reducir las brechas sociales y la pobreza de cara a 2030. En esta agenda se enmarca la coordinación intersectorial para el desarrollo de estrategias orientadas a la reducción del hambre y la erradicación de la pobreza, y de la pobreza extrema, en la región del SICA. En el mismo año se contará también con el Programa de Integración y Reintegración de Niños y Jóvenes en Riesgo de Migración Irregular en Centroamérica (ALTERNATIVAS), con el apoyo técnico de la Deutsche Gesellschaft für Internationale Zusammenarbeit (GIZ), así como de la Organización de las Naciones Unidas para la Alimentación y la Agricultura (FAO), la SISCA, la CEPAL, la Oficina del Alto Comisionado de las Naciones Unidas para los Refugiados (ACNUR), el programa EUROsociAL y otros socios estratégicos. De este modo se busca atender la nueva configuración de la migración, uno de los temas emergentes más complejos (véase el recuadro XI.1).

Actualmente se encuentra en proceso de elaboración una hoja de ruta sobre el proyecto "Inclusión sociolaboral de las personas migrantes en Centroamérica", financiado por la Alianza para las Migraciones en Centroamérica y México (CAMMINA). Su coordinación está a cargo del OCADES y la Asesora Regional de Políticas Sociales de la SISCA. El proyecto tiene la finalidad de lograr la inserción sociolaboral de las personas migrantes a partir del contacto con diferentes socios, el establecimiento de mejores alianzas público-privadas, una mejor articulación de los esfuerzos a favor de su derecho de migrar de manera regular y segura, y el acceso a los medios y las oportunidades necesarios para garantizar su permanencia en sus lugares de origen. En estos procesos, la CEPAL ha mantenido un acompañamiento cercano, que se espera continúe en los años venideros. 


\title{
Recuadro XI.1 \\ Tendencias y desafíos relacionados con la migración en Centroamérica
}

\begin{abstract}
Debido al alto porcentaje de migraciones que se registra en los países de la región, la CEPAL ha analizado las principales tendencias y dinámicas migratorias en América Latina y el Caribe en el período comprendido entre 1970 y 2010 (Martínez, Cano y Soffia, 2014; Martínez y Orrego, 2016). Uno de sus principales énfasis ha estado en la migración intrarregional, es decir, los intercambios dentro de la región, que se han intensificado en los últimos 40 años. La CEPAL ha señalado que Centroamérica y el Caribe presentan los más altos niveles de emigrantes en comparación con el resto de la región, siendo Costa Rica el país que más migrantes recibe en relación con su población, los Estados Unidos el país que recibe el mayor volumen de migrantes latinoamericanos y caribeños, y México el país que presenta el mayor porcentaje de emigración en la región.

En el contexto actual, la CEPAL ha señalado un conjunto de problemáticas que se deberían atender a corto plazo. Entre ellas, cabe mencionar la situación de los niños migrantes no acompañados (cuyo número ha aumentado en Centroamérica en los últimos años), la migración irregular, las deportaciones, las normativas discrecionales, el acceso de los migrantes a la protección social y la portabilidad de derechos.
\end{abstract}

Frente a estas situaciones, la CEPAL enfatiza la necesidad de reconocer a los migrantes como sujetos de derechos (por ejemplo, del derecho a migrar), y urge a evitar las constantes violaciones que sufren a ese respecto en sus países de origen y destino y durante el tránsito entre ambos. Específicamente, la CEPAL ha elaborado directrices que articulan elementos de la gobernanza migratoria con el desarrollo de la infancia, ha enfatizado la importancia de la migración de retorno y la necesidad de contar con políticas específicas a ese fin y está llevando a cabo en Centroamérica un proyecto en torno a cómo utilizar las remesas de los migrantes para fortalecer el sector productivo de sus países de origen.

Fuente: Elaboración propia.

\section{Salud}

La integración regional en materia de salud tiene antecedentes de larga data. Como ya se mencionó, desde 1956 se realizan anualmente reuniones de Ministros de Salud centradas en el intercambio de experiencias y conocimientos sobre temas de interés común. Desde entonces, al incluirse el tema de la salud en los trabajos de la CEPAL, se reconocía la importancia del sector en el proceso de desarrollo económico, asociada a la potencialidad de una fuerza laboral saludable 2 . Los aportes de la CEPAL durante la década de 1950, que se centraban en las tasas de reproducción, natalidad y esperanza de vida, y en el énfasis del vínculo existente entre el proceso productivo y el nivel de bienestar, fueron retomados en algunas de esas reuniones ministeriales más recientes.

En 1948 se estableció una cooperación entre la CEPAL, la Organización Mundial de la Salud (OMS) y la OPS con el objetivo de estudiar el vínculo existente entre la economía y la salud pública. 
Posteriormente, la CEPAL promovió una visión diferente, pues incorporó los temas de la mortalidad, el déficit nutricional y la relación entre la salud y factores sociales como la pobreza, las divisiones geográficas y el nivel educacional. Esta visión se ve reflejada en la evolución del tema en la región centroamericana.

En 1984 se propone un Plan de Necesidades Prioritarias de Salud en Centroamérica y Panamá (PPS/CAP), impulsado por la Organización Panamericana de la Salud (OPS) en coordinación con los Ministerios de Salud y las instituciones de seguridad social. El plan estaba centrado en diversos elementos de la atención a la salud, varios de ellos coincidentes con la orientación de la CEPAL (fortalecimiento de servicios, medicamentos esenciales, recursos humanos, alimentación y nutrición, enfermedades tropicales, medio ambiente y salud, supervivencia infantil, entre otros) (Barillas, 2001). Durante los años subsiguientes se realizó un esfuerzo por atender necesidades de salud vinculadas a los conflictos armados, como el control de la malaria y la movilidad de los trabajadores de la salud (Cruz Peñate, 2001).

En la década de 1990, la CEPAL incorporó el análisis del vínculo entre la salud y la equidad ${ }^{3}$. Esto se basaba en la idea de que la salud era uno de los factores que incidían en la productividad y el consiguiente aumento de la competitividad internacional, lo que, a su vez, podía contribuir al logro de una mayor equidad social, al incorporar en el análisis a los grupos más vulnerables (CEPAL/OPS, 1994). Estas ideas se plasmaron en la segunda fase del plan conocido como Iniciativa de Salud de Centroamérica (ISCA), en que se reiteraba la importancia de la promoción de la salud, el control de las enfermedades y la atención a grupos vulnerables, teniendo en cuenta la atención a las necesidades derivadas de los conflictos. Posteriormente, se celebró la Primera Reunión del Sector Salud de Centroamérica y República Dominicana (RESSCAD), conformada por delegados de los Ministerios de Salud e instituciones de la seguridad social (Barillas, 2001). En 1995, el COMISCA, con el apoyo de la OPS y la SICA, lanzó el Programa de Acciones Inmediatas de Salud de Centroamérica (PAISCA). En este programa se abordaron temas nuevos, como el de la atención al sida y las enfermedades de transmisión sexual, además del desarrollo de sistemas de información en los ámbitos de la salud, el agua y el saneamiento (Barillas, 2001).

Ya en el siglo XXI, la CEPAL planteó la necesidad de promover la adopción de políticas sociales universales, solidarias y eficientes (CEPAL, 2000). En el ámbito de la salud, habría que avanzar hacia una cobertura universal y garantizada de los servicios, fortaleciendo la salud pública tradicional y el realce de la eficiencia y la reducción de los costos en la prestación de servicios (CEPAL, 2006).

En 1994, la CEPAL elaboró junto a la OPS una Propuesta sobre la Salud en la Transformación Productiva con Equidad (STPE). 
En esta misma época se aprobó el Proyecto Mesoamérica y se creó el Sistema Mesoamericano de Salud Pública (SMSP) con la finalidad de contribuir al fortalecimiento de los sistemas nacionales de salud. También se estableció el Instituto Mesoamericano de Salud Pública (IMSP) como órgano técnico del SMSP. El IMSP está compuesto por diversas instituciones académicas y tiene el objetivo de coordinar y desarrollar las actividades de cooperación multilateral que complementan las iniciativas del COMISCA. Además, se aprobó la agenda de salud impulsada por la XXIII Reunión del Sector Salud de Centroamérica y República Dominicana (RESSCAD). Dicha agenda tenía una vigencia de diez años (hasta 2018) y planteaba diez objetivos estratégicos que incluían temas como la instauración de políticas regionales de salud y la reducción de las desigualdades de acceso. En concordancia con esos objetivos, el COMISCA promovió diversos planes estratégicos regionales, entre los que cabe mencionar los referentes al VIH, la eliminación de la malaria, las enfermedades crónicas y el cáncer. Además, se establecieron diversas iniciativas con miras a abordar las prioridades de los países de la región en materia de salud.

Entre ellas se pueden destacar cuatro iniciativas de gran trascendencia:

i) el Acuerdo de cooperación técnica entre la SE-COMISCA y el BID para la prevención y control de la epidemia de influenza AH1N1 y otras enfermedades infecciosas (2010-2014), con el que se intentaba dar una respuesta adecuada y coordinada a nivel regional ante enfermedades comunes a la región;

ii) la Estrategia de Mejoramiento de la Gestión e Información Regional en Salud de la SE-COMISCA (2010-2013), que promovía el acceso a bajo costo a medicamentos e insumos de calidad y permitió consolidar el Modelo de Negociación Conjunta para la compra de medicamentos (un mecanismo regional de gran impacto orientado a reducir los precios de los medicamentos y los insumos para la salud) ${ }^{4}$;

iii) el proyecto "El fortalecimiento de las capacidades institucionales de la Secretaría Ejecutiva del COMISCA, para incidir estratégicamente en los cursos de acción en materia de salud como un determinante de la seguridad alimentaria y nutricional" (2013-2014), y

iv) el proyecto "Combate regional contra el VIH/sida en Centroamérica" (2012-2014), con el fin de implementar el plan estratégico regional para VIH/sida en la región mediante el apoyo a la investigación aplicada y a las iniciativas regionales sobre género, masculinidad, estigmatización y discriminación.

En 1975, la CEPAL elaboró para Centroamérica una propuesta de compra conjunta de fertilizantes, de gran similitud al proceso que, en el ámbito de la salud, se implementó 35 años después. 
También cabe destacar la labor realizada en un marco político regional que integra los principios de gobernanza en el ámbito de la salud. En 2014, se aprobó la Política Regional de Salud (2015-2022), financiada por el BID, la OPS y el Programa Regional de Seguridad Alimentaria y Nutricional para Centroamérica (PRESANCA) II. Esta política está dirigida por el COMISCA. En 2017 se estableció el proyecto "Asegurando a través de acciones de incidencia política el acceso universal a la salud y respeto de los derechos humanos en la respuesta al VIH en Centroamérica, para mejorar la calidad de vida de las personas con VIH". En el marco de la Agenda 2030, se implementa el proyecto "El sector salud en la agenda post 2015. Mejorando indicadores en salud en el marco de la Política Regional de Salud del SICA".

En estos últimos años, la CEPAL ha acompañado más de cerca el proceso de integración en materia de salud en los ámbitos de la vinculación con el medio ambiente, el cambio climático y los aspectos de seguridad alimentaria y nutricional. Se espera que esa relación se solidifique en el futuro, con el objetivo de apoyar el trabajo de articulación de las agendas regionales de salud con la Agenda 2030 y sus respectivas metas e indicadores. En concreto, la CEPAL ha trabajado con la Comisión Técnica de Vigilancia de la Salud y Sistemas de Información (COTEVISI) del COMISCA. Le ha prestado apoyo en lo tocante a la respuesta frente al mandato de los Ministros y la preparación de programas de fortalecimiento de la capacidad de análisis de vulnerabilidades en enfermedades sensibles al clima y escenarios de cambio climático (véase el capítulo X).

\section{Educación y cultura}

Los temas educativos han estado presentes en la agenda de la CEPAL desde sus inicios. La educación se ha considerado uno de los pilares que contribuyen a lograr el crecimiento, la equidad y la participación en la sociedad. Al igual que en el contexto de la integración social regional, hasta 1970, la educación se abordaba con temáticas puntuales, como el apoyo a los procesos de alfabetización, la ampliación de la cobertura del nivel básico y el acceso a la enseñanza de grupos particularmente excluidos, como los indígenas. Entre 1970 y 1990, la CEPAL planteó la necesidad de expandir el abordaje de la educación de modo que se incluyeran los vínculos entre la enseñanza y la estratificación social y los efectos de la educación preescolar en el ingreso al sistema formal. También propuso visibilizar la educación como consecuencia, y a la vez causa, de la exclusión. Esta evolución se reflejó en las instancias educativas regionales en Centroamérica.

Desde la Primera Reunión de Ministros de Educación de Centroamérica en 1975, la labor de la CECC se ha orientado a la integración de los esfuerzos educativos y culturales de la región. Se han abordado las temáticas tradicionales 
de analfabetismo y cobertura básica, pero también se han incorporado otros aspectos relativos a la inclusión, en paralelo a las propuestas intelectuales de la CEPAL.

Para inicios del siglo XXI, la CEPAL planteó la necesidad de expandir el financiamiento y el gasto educativo, y de conceder mayor importancia al tema de la transición de la escuela al mercado laboral, así como la calidad de la educación y la promoción de la educación en la primera infancia. Estas ideas tienen su correlato en el proceso de integración social regional. A partir de 2001, se dio inicio a una descentralización de las tareas educativas y culturales de la CECC, lo que se tradujo en que distintos países lideraron un programa o actividad regional específica. Así, por ejemplo, se ubicó la Red Centroamericana de Desarrollo Profesional e Investigación Docentes en Honduras y la revista Patrimonio Cultural Centroamericano en Guatemala, se firmó el Convenio de Colaboración con la Comisión Nacional de Libros de Texto Gratuitos de los Estados Unidos Mexicanos (2002) para elaborar un libro de texto de Historia del istmo centroamericano, y se establecieron convenios con la Asociación de las Televisiones Educativas y Culturales Iberoamericanas (ATEI), con el objetivo de impulsar el uso de la televisión, la radio y otras nuevas tecnologías de la información y la comunicación para la difusión de carácter educativo y cultural.

Además, se constituyó el Consejo Centroamericano de Acreditación de la Educación Superior, con la misión de establecer los requisitos necesarios y conceder reconocimiento a los organismos de acreditación que operen en la región para promover el mejoramiento de la calidad y la integración de la educación superior centroamericana. También se establecieron convenios promovidos por la CECC, relacionados con la mejora de la calidad de la educación y con la formación ocupacional y la inserción laboral. En 2007, en la $31^{a}$ Reunión de Jefes de Estado y de Gobierno de los Países del SICA, se aprobó el Decálogo Educativo 2021. En él se establecen las líneas de acción en materia educativa regional correspondientes al período 2007-2021, centradas en los temas de cobertura, calidad, eficacia e inversión. A partir de dicho instrumento, el Consejo de Ministros de Educación aprobó en 2009 la Agenda Regional de Educación 2009-2011, y en 2011 dio inicio al proyecto “FES/Educación 2011-2013", con fondos de la cooperación española.

A raíz de la formulación de los Objetivos de Desarrollo Sostenible, en 2016 se actualizó el Decálogo Educativo 2021 y se aprobó la Política Educativa Centroamericana (PEC) 2013-2030, con metas a mediano y largo plazo (2021 y 2030, respectivamente), y con un marco orientador basado en objetivos y acciones estratégicas acordadas entre los países de la región.

Algunos de los mayores logros en materia de integración cultural regional han sido la revista Patrimonio Cultural Centroamericano, la Antología Literaria Centroamericana, la Casa Centroamericana de la Cultura y la serie 
Culturas Populares Centroamericanas. Por su parte, en materia de integración educativa regional, son notorios los avances hacia la formación inicial de docentes de la educación primaria o básica y la promoción del Programa Regional Formación Ocupacional e Inserción Laboral y del Programa Regional de Mejora de la Calidad Educativa, así como la promoción del bachillerato internacional y del bachillerato académico centroamericano, la educación inclusiva y la educación intercultural bilingüe.

En este contexto, en años recientes, la CEPAL ha apoyado a la CECC en los procesos de apropiación de la Agenda 2030 y ha contribuido a la elaboración de los indicadores asociados a la Política Educativa Centroamericana, además de aspectos puntuales como la evaluación de los impactos de las políticas educativas a nivel medio y superior.

\section{Género}

La CEPAL ha apoyado los procesos relacionados con la perspectiva de género desde hace más de 40 años a través de las Conferencias Regionales sobre la Mujer de América Latina y el Caribe. Desde la primera conferencia, que se celebró en 1977, se planteó la necesidad de establecer medidas orientadas a lograr la integración de la mujer de manera activa en la vida política, económica, social y cultural de los países de la región. Los aportes intelectuales de la CEPAL en este ámbito han tenido también su reflejo en el proceso de incorporación de la temática de género en la dimensión regional centroamericana. La creación del Consejo de Ministras de la Mujer de Centroamérica y República Dominicana en 2002 es uno de los muy diversos logros impulsados por la Agenda Regional de Género, con el acompañamiento de la CEPAL.

Debido a lo reciente de su fundación, los avances logrados por el COMMCA remiten al período comprendido entre 2005 y la actualidad. Sus principales atribuciones son el impulso a los procesos de institucionalización de las políticas de igualdad y equidad de género y la propuesta de proyectos, tratados y convenios que contribuyan a garantizar los derechos de las mujeres. Las acciones más relevantes parten de la conformación de sus planes estratégicos, en los que se priorizan acciones y estrategias que se implementarían durante un tiempo determinado (COMISCA, 2014). El primero fue el Plan Estratégico 2006-2009, centrado en la necesidad de alcanzar la equidad de género con respecto a la autonomía económica, la salud integral y la participación política, además de promover el fortalecimiento institucional del COMMCA. En esta primera etapa se instala formalmente la Secretaría Técnica de la Mujer (STM-COMMCA), siendo este el logro más importante en el marco de dicho plan.

Por su parte, el Plan Estratégico 2009-2013 tuvo como ejes transversales la erradicación de la violencia contra las mujeres y la multiculturalidad. Se planteó la necesidad de dar continuidad a los esfuerzos encaminados a lograr 
la autonomía económica de las mujeres y aumentar su participación política, y se promovieron en especial el fortalecimiento institucional del COMMCA y la transversalización del género a todos los niveles de la estructura del SICA. En este período, se proclamó la Declaración de Panamá sobre Género, Integración y Desarrollo, se formularon 20 mandatos presidenciales relacionados con los derechos de las mujeres y la igualdad de género y se elaboraron acuerdos de los consejos de ministros. Además, se observó la presencia de iniciativas con enfoque de género en más de un $30 \%$ de los órganos e instituciones que conforman el SICA. Se aprobó la Política Regional de Igualdad y Equidad de Género (PRIEG) del SICA, con el apoyo de la provincia china de Taiwán, la Agencia Española de Cooperación Internacional para el Desarrollo (AECID), la GIZ, la Entidad de las Naciones Unidas para la Igualdad de Género y el Empoderamiento de las Mujeres (ONU-Mujeres), la Oficina Regional para América Latina y el Caribe del Fondo de Población de las Naciones Unidas (UNFPA), el PNUD y la OPS.

El COMMCA se encuentra a cargo del seguimiento de la PRIEG. Sobre la base de su plan estratégico más reciente (2014-2018), el COMMCA ha incorporado nuevos temas relacionados con la agenda de género nacional, regional e internacional. Entre ellos cabe mencionar las tecnologías de la información y comunicación, las encuestas sobre el uso del tiempo y los sistemas de gestión de la igualdad. De igual manera, se plantea la necesidad de fortalecer y expandir la transversalización de género en las diferentes entidades del SICA.

A lo largo de la hasta ahora breve existencia del COMMCA, la CEPAL, a través de su División de Asuntos de Género, ha acompañado técnicamente los esfuerzos de la Secretaría Técnica y del mismo Consejo con miras a avanzar en la transversalización del enfoque de género a nivel regional, así como en los temas del trabajo remunerado y no remunerado, la economía del cuidado, la fecundidad adolescente, el mercado laboral y la distribución del tiempo. Cabe destacar que la contribución a los procesos de integración en materia de perspectiva de género por parte de la CEPAL no se ha limitado a la relación con el COMMCA. Desde hace algunos años, se mantiene también una estrecha colaboración con la SIECA en el ámbito de la autonomía económica de las mujeres.

\section{Trabajo}

Desde su creación, la CEPAL ha hecho énfasis en la relevancia de promover el desarrollo del trabajo dentro del proceso de crecimiento económico, a partir de la búsqueda del incremento de la productividad. Con el paso del tiempo, el pensamiento de la CEPAL en esta materia se ha ido centrando en la importancia de que, además del incremento de la 
productividad, se enfatice la dimensión social del trabajo, subrayando el papel clave del acceso a empleo de calidad como un mecanismo fundamental de inserción social.

Los diagnósticos y propuestas con respecto a la centralidad del trabajo y su dimensión social, sobre todo en los ejes de inclusión social, educación y empleo, han influido en la visión que recientemente se ha incorporado en el proceso de integración. Lo anterior se evidencia con la reactivación del Consejo de Ministras y Ministros de Trabajo de Centroamérica y República Dominicana en 2005, y la implementación del Programa Regional de Formación Ocupacional e Inserción Laboral, la instauración de un comité de empleo y la creación del Observatorio Regional del Mercado Laboral de Centroamérica y República Dominicana en 2006 (Nicolau y Martín, 2006).

La labor realizada por la CEPAL en materia de certificación de competencias laborales como incentivo al incremento de la empleabilidad y la productividad de los trabajadores también ha tenido su reflejo regional. En 2008 se implementó un proyecto pionero de homologación de competencias laborales en el sector del turismo. Este daría pie a lo que más tarde se instauraría como una estrategia para la certificación homologada de competencias laborales, una labor promovida por la Red de Institutos de Formación Profesional de Centroamérica, Panamá, República Dominicana y Haití (REDIFP).

Por su parte, en la Agenda Estratégica Regional para Asuntos Laborales y de Trabajo del Sistema de Integración Centroamericana, impulsada por el Consejo, se establecieron las prioridades de crear mayores oportunidades de empleo productivo y trabajo decente, aumentar la cobertura, la eficacia y la sostenibilidad de la protección social, promover el cumplimiento efectivo de las normas, principios y derechos fundamentales en el trabajo, y fortalecer el tripartismo y el diálogo social.

Al analizar las prioridades en detalle, se observa que apenas en una ocasión se menciona la elaboración de estrategias conjuntas entre los Estados, y que la atención se centra principalmente en el nivel nacional y no en el regional. Por ello, en 2016 se elaboró un plan de acción regional basado en la Declaración de San José. En dicha declaración se establecieron, entre otras áreas temáticas prioritarias, la erradicación del trabajo infantil, el cumplimiento de la legislación laboral nacional e internacional, la política de empleo y gestión de la movilidad laboral, la formalización del empleo y los pisos de protección social y la profundización del diálogo social, con la aplicación de un criterio de igualdad de oportunidades y no discriminación con enfoque de género. También se destacó el interés del Consejo en la adopción de medidas conducentes a la implementación de la Recomendación sobre el VIH y el sida y el Mundo del Trabajo, 2010 (núm. 200) de la OIT. Además, se creó una plataforma virtual que busca el intercambio de información y 
buenas prácticas en materia de erradicación del trabajo infantil, así como de empleo y empleo juvenil, mediación laboral, formalización, protección social y cumplimiento de la legislación laboral.

Se puede apreciar un área de oportunidad de gran relevancia en temas laborales dentro de los esfuerzos conjuntos de la CEPAL y la SISCA. Entre otros ejemplos, cabe mencionar el trabajo que realiza la CEPAL con el objetivo de fortalecer el vínculo entre la educación, la capacitación técnico-profesional y el empleo. Este tema se ha incluido en la agenda regional de América Latina y el Caribe. Se impulsa un diálogo político con miras a fomentar pactos fiscales, sociales y laborales.

En la actualidad, la CEPAL enfatiza la importancia de la Agenda 2030, sobre todo el cumplimiento del Objetivo 8, mediante el fortalecimiento de instituciones laborales que protejan los derechos de los trabajadores (por ejemplo, frente al desempleo) y promuevan una alta calificación de la fuerza de trabajo (formación profesional y capacitación, adaptadas a las nuevas necesidades). Para ello, se requiere la implementación de reformas laborales en los países de la región mediante la elaboración de políticas públicas y la participación de los actores sociales (Isgut y Weller, 2016).

\section{Vivienda}

El tema de la vivienda ha sido abordado desde los inicios de la CEPAL como un elemento relevante del bienestar. En un principio, ello se enmarcaba en la visión de apoyar los procesos de construcción de vivienda y su mejoramiento como parte del proceso de creación de infraestructura a favor del desarrollo 5 . Luego, se le impartió una orientación más enfocada en la dimensión social. En la década de 1980, esa orientación se basó en el concepto de las necesidades básicas insatisfechas. En décadas posteriores se ha aplicado la óptica de que el entorno de vivienda es un espacio de ejercicio de un derecho humano y un elemento de inclusión social, que incorpora aspectos de calidad, gestión y ordenamiento territorial. Con esta última visión es que el sector de la vivienda se ha incorporado recientemente en el marco de la integración social de la región centroamericana.

Si bien el CCVAH comenzó sus operaciones a inicios de la década de 1990, fue en el año 2000 que se incorporó como ente rector del sector en la región del SICA, mediante el Acta de Guatemala. Así se formalizó su constitución y se le atribuyeron las funciones de normar el enfoque regional de ordenamiento territorial y desarrollo sostenible, vivienda y gestión del territorio urbano, cooperación internacional y cooperación horizontal. En esos años, la agenda del Consejo se concentró en proyectos puntuales.

Con el auspicio de la CEPAL, en 1957 se celebró una reunión en Costa Rica en que se analizó la problemática de la vivienda en Centroamérica. 
Luego, en 2009, se plantea la Estrategia Centroamericana de Vivienda y Asentamientos Humanos (ECVAH) 2009-2012, que fue actualizada en 2015 para el período 2014-2018, como instrumento regional en busca de la garantía del derecho constitucional al acceso a una vivienda digna. Durante el período 2009-2012, el trabajo se centró en la atención al déficit habitacional, la gestión de riesgos, el fortalecimiento institucional, el financiamiento, la gestión del conocimiento y el ordenamiento y desarrollo territorial. Para el período 2014-2018 se refrendaron las temáticas.

En años recientes, se aprobó la Agenda de Ordenamiento Territorial del CCVAH 2016-2020 (Agenda OT), con el objetivo de promover acciones regionales de ordenamiento territorial. Se reconocen en ella los retos comunes del cambio climático, el crecimiento urbano, la vulnerabilidad ante fenómenos naturales y la pérdida acelerada de los recursos naturales. Mediante esta agenda se busca establecer una hoja de ruta para llegar a un acuerdo político regional de ordenamiento territorial en Centroamérica que sea capaz de armonizar la conceptualización básica de ordenamiento territorial entre los países, junto a una articulación de las políticas públicas que se aplican en las zonas fronterizas o a nivel de toda la región. Se espera que la implementación de la agenda se traduzca en acciones regionales y nacionales, lo que representaría un paso importante en el tratamiento de estos temas a nivel regional.

En 2016 se aprobó también, con el impulso del CCVAH, la declaración regional Gestión en Red de Ciudades Intermedias, una Oportunidad para Centroamérica y la República Dominicana, que defiende la necesidad de apoyar el desarrollo endógeno de manera tal que la migración interna de las zonas rurales a las urbanas se realice hacia ciudades intermedias y no solamente hacia las principales urbes. Para ello, se propone el establecimiento de una red de ciudades intermedias que contribuya a la reducción de la pobreza y de las desigualdades entre los países. En concordancia con la Agenda 2030, ello facilitaría el trabajo conjunto para enfrentar problemáticas regionales, tales como el desempleo, el cambio climático, la seguridad alimentaria y el déficit de infraestructura de conectividad regional y fronteriza, mediante políticas, procesos y proyectos conjuntos. Además, el CCVAH ha suscrito diversos acuerdos de cooperación con órganos del SICA con miras a garantizar una gestión de asentamientos humanos, con carácter inclusivo y productivo.

Un segundo espacio institucional de integración regional en torno al tema de la vivienda se asocia con el eje social del Proyecto Mesoamérica y su Programa para el Desarrollo de la Vivienda Social en Centroamérica. Su objetivo es crear un mercado de financiamiento sostenible para la vivienda. A ese fin se ofrece asistencia técnica para desarrollar la capacidad institucional, así como financiamiento para la adquisición, mantenimiento, mejoramiento y ampliación de las viviendas, mediante la concesión de microcréditos, créditos de largo plazo y garantías. 
La labor de la CEPAL en materia de vivienda y ordenamiento territorial ha acompañado los avances planteados en la medida en que se ha realizado una vinculación directa con el Programa de las Naciones Unidas para los Asentamientos Humanos (ONU-Hábitat), organismo con el que se ha trabajado conjuntamente el tema en los países de la región. Se espera que en un futuro esta labor siga fortaleciéndose.

\section{Agua y saneamiento}

Entre 1950 y 1970, la CEPAL centró su trabajo relacionado con el agua principalmente en la gestión de los recursos hidráulicos, con un enfoque general y desde una perspectiva económica. Hubo algunos intentos por analizar la problemática del acceso al agua potable y el saneamiento, aunque subsumida como un aspecto de la vivienda. Después se inició una labor más decidida con relación al análisis del suministro de agua potable y saneamiento ambiental en Centroamérica y se propusieron diversas recomendaciones con miras a fortalecer la potencial cooperación regional en la materia (CEPAL, 1981). En 1998, la CEPAL publicó un documento con las principales recomendaciones de la Conferencia de las Naciones Unidas sobre el Agua celebrada en 1977, la Conferencia Internacional sobre el Agua y el Medio Ambiente: El desarrollo en la perspectiva del siglo XXI (1992) y la Conferencia Internacional sobre el Agua y el Desarrollo Sostenible (1998), con respecto a la gestión de los recursos hídricos en su totalidad, no solo el acceso agua potable (CEPAL, 1998). Estos aportes establecieron elementos relevantes que luego se han retomado en la incorporación de esta dimensión al proceso de integración social centroamericano.

Desde 2009, a raíz de la celebración de la Cumbre del Agua en el seno del Consejo Centroamericano y República Dominicana de Agua Potable y Saneamiento (CONCARD-APS), se registraron avances en el tema del agua potable y el saneamiento en la región en lo que se refiere a la estabilidad jurídica y política y la calidad en la prestación de esos servicios. A partir de ese momento, se inician acciones encaminadas a articular las políticas públicas y los marcos jurídicos regionales con el fin de lograr un nivel de convergencia en el acceso de dichos servicios. En 2011 se inician los trabajos con miras a elaborar líneas de base nacionales.

Finalmente, en 2013, por acuerdo de los Presidentes, se encomendó al FOCARD-APS que promoviera una agenda regional de saneamiento. En 2014 se firmó la Agenda Regional de Saneamiento 2014-2018, en cuya línea de normativa se planteó la Ley Marco Regional referente al Derecho Humano al Agua Potable y el Saneamiento. Años después se emitió la Declaración para el Reconocimiento y Atención a los Efectos del Cambio Climático en Sistemas de Agua Potable en los países del SICA. Se planteaba así la necesidad de abordar dentro de la agenda regional una temática emergente. 
En años recientes, la CEPAL ha aportado el conocimiento técnico adquirido en torno al tema del cambio climático en Centroamérica, así como la información necesaria para proyectar las necesidades y retos regionales en la materia (véase el capítulo X).

\section{Seguridad alimentaria}

En los primeros años de existencia del INCAP, antes de 1970, su labor se centró en la investigación asociada a las deficiencias de la alimentación y la nutrición. El énfasis de la investigación se centraba en los estudios de desnutrición de niños pequeños y en la formación de personal especializado en nutrición y ciencias de los alimentos. También en ese período se establecieron unidades de nutrición en cada uno de los países miembros. En ese sentido, el INCAP buscaba apoyar a cada país para que desarrollara su propia investigación y capacidades. Entre 1970 y 1990, se centró la atención en el fortalecimiento de programas de nutrición y su vínculo con la salud, así como el análisis de las múltiples causas de la desnutrición. Después de 1990, se planteó una reorientación con miras a atender un mandato de promoción de la seguridad alimentaria y nutricional. A partir de 1993, la labor se centra en promover el concepto de que todas las personas puedan gozar, en forma oportuna y permanente, de acceso físico, económico y social a los alimentos que necesitan, en calidad y cantidad, para su adecuado consumo y utilización biológica, con lo que se les garantizaría un estado de bienestar general propicio a su desarrollo.

En ese contexto, se inicia la proyección hacia un marco más estratégico, que se adopta en 2002 e incorpora los retos emergentes asociados a la inseguridad alimentaria y nutricional vinculada con las condiciones de sequía y con el cambio climático. De 2005 a 2012, se pusieron en marcha varias iniciativas. Tal es el caso del Programa Regional de Seguridad Alimentaria y Nutricional para Centroamérica (PRESANCA), financiado por la Unión Europea y la Secretaría General del Sistema de la Integración Centroamericana (SG-SICA) (2005), el Proyecto Mesoamérica con su subproyecto "Programa Mesoamérica sin Hambre" (2008), cuya finalidad era avanzar hacia la erradicación del hambre en Mesoamérica mediante marcos normativos y políticas públicas multisectoriales, en el marco de la línea de la Agenda 2030 y el Plan de Seguridad Alimentaria, Nutrición y Erradicación del Hambre 2025 de la Comunidad de Estados Latinoamericanos y Caribeños (CELAC), y de la Estrategia Regional de Seguridad Alimentaria y Nutricional financiada por la Unión Europea, la AECID, el PNUD y el Gobierno de Finlandia, y dirigido por el INCAP. De este modo surgieron el Programa Regional de Seguridad Alimentaria y Nutricional para Centroamérica (PRESANCA II) y la Política de Seguridad Alimentaria y Nutricional de Centroamérica y República Dominicana 2012-2032, cuyas instituciones encargadas son el Consejo Agropecuario Centroamericano (CAC), el COMISCA, el INCAP y la SISCA. 
Otros avances en la materia se reflejan en el establecimiento del Programa de Sistemas de Información para la Resiliencia en Seguridad Alimentaria y Nutricional de la Región del SICA (PROGRESAN-SICA) y del proyecto "Apoyo al incremento de la productividad y calidad de la producción de alimentos para contribuir a la seguridad alimentaria en Centroamérica y la República Dominicana", financiado por la provincia china de Taiwán y con el apoyo técnico y administrativo de la Secretaría Ejecutiva del CAC.

El INCAP, por su parte, recibió financiamiento de China para la implementación del proyecto "Promoción de la alimentación y nutrición de hogares rurales en la ventana de oportunidad de los mil días". Como estrategia para la reducción del hambre y la pobreza, este proyecto promueve el desarrollo agrícola familiar sostenible, en conglomerados de municipios de Belice, El Salvador, Guatemala, Honduras, Nicaragua y la República Dominicana que tienen alta prevalencia de desnutrición crónica.

La CEPAL ha acompañado diversos esfuerzos en el marco de la seguridad alimentaria con el CAC y el COMISCA, desde una visión basada en el fortalecimiento de la capacidad y la elaboración de insumos de base para la toma de decisiones.

\section{Deportes y recreación}

Desde su constitución en 1992, el Consejo del Istmo Centroamericano de Deportes y Recreación (CODICADER), órgano del SICA responsable de la política deportiva de la región, ha buscado promover la utilización del deporte como derecho humano, instrumento de política social y medio para contribuir a la integración entre los países miembros. Para ello, desde 1996 el Consejo celebra los Juegos Deportivos Estudiantiles Centroamericanos como una forma de contribuir a la integración, la solidaridad y la paz entre los países del istmo. La primera edición de estos juegos se realizó en sedes compartidas, de manera tal que en cada país se competía en un deporte específico. Desde 1999, se llevan a cabo en una sola sede.

En 2012, el CODICADER se propuso estructurar su estrategia en el Plan Estratégico 2012-2016, que se renovó para el período 2016-2020. Centra su acción en el fortalecimiento institucional, la gestión del conocimiento y la sensibilización sobre la importancia que tiene el deporte para la salud, la paz y la identidad centroamericana. Además, entre 2015 y 2016, la SISCA ejecutó el proyecto "Apoyo a la promoción de la educación física y del deporte para el fomento de la integración centroamericana", con la aprobación del CODICADER y con componentes vinculados al Plan Estratégico del CODICADER.

Cabe mencionar que, desde 1926, en la región también se celebran los Juegos Centroamericanos y del Caribe, a cargo de la Organización Deportiva Centroamericana y del Caribe (ODECABE). A pesar de tratarse 
de una organización de carácter regional, su misión ("desarrollar y proteger el deporte y el espíritu olímpico en los países afiliados"6) da a entender que no tiene como objetivo la integración regional.

La CEPAL ha abordado el tema en años recientes en el marco de los trabajos de inclusión social juvenil. Se basa en la consideración del deporte y el tiempo libre como derechos, sobre todo de los niños y los jóvenes, y en su importancia como actividades de reinserción social, por ejemplo, de jóvenes con antecedentes de violencia.

\section{Los retos y desafíos para mejorar el proceso de la integración social centroamericana}

Como se ha señalado, la institucionalidad de la dimensión social es muy compleja. Existe un entramado de consejos ministeriales, secretarías técnicas e instituciones de soporte que abordan muy diversas temáticas, como la protección social y la pobreza, la vivienda, la salud, la recreación, el trabajo, la educación, el agua y el saneamiento, el empoderamiento de la mujer, la nutrición y la administración pública. Esta situación plantea el gran reto de la articulación coherente con miras a lograr el fin común de incrementar el bienestar social de la población en la región. Este reto de coordinación se ha abordado reiteradamente en el transcurso de los últimos 20 años, mediante iniciativas como convenios o acuerdos de coordinación.

Algunas de las alianzas y coordinaciones referidas se han plasmado en acuerdos formales de entendimiento que intentan favorecer el abordaje multisectorial dentro del Sistema, lo que constituye un logro en la labor del binomio CIS-SISCA. Tal es el caso de las alianzas y acuerdos concertados con la SE-COMISCA, la ST-COMMCA y el INCAP. También ha sido relevante que la SISCA haya asumido el papel de Secretaría Técnica del CCVAH y del CODICADER, y que haya dado un impulso importante al restablecimiento del Consejo de Ministros y Ministras de Trabajo. Se trata de pasos iniciales hacia un proceso complejo de coordinación interinstitucional que, por ahora, tiene un correlato en la Agenda Regional Intersectorial sobre Protección Social e Inclusión Productiva con Equidad (ARIPSIP) 2018-2030.

Este reto se amplía ante la visión integral que plantea la Agenda 2030, según la cual sería necesario articular las acciones de otras instituciones vinculadas con el medio ambiente, el desarrollo de las zonas rurales y del sector agropecuario, así como el desarrollo económico en general, a fin de articular las labores con instancias como el CCAD, el CAC, la Estrategia Centroamericana de Desarrollo Rural Territorial (ECADERT) y la SIECA, entre otras.

Véase [en línea] http://www.odecabe.org/about-us/mision/. 
Existen elementos que añaden complejidad al reto de la coordinación, como la dispersión institucional en el ámbito geográfico, que dificulta la formulación de propuestas integrales de promoción de la dimensión social en el proceso de integración. También se plantea como un reto adicional el hecho de que las presidencias pro tempore cambien cada seis meses, lo que representa un desafío desde el punto de vista de la continuidad de las acciones y estrategias.

Más allá de esta dispersión institucional se ubican los retos de fortalecer las capacidades técnicas, financieras e institucionales encargadas de la promoción de la integración social regional. La breve historia de estas instituciones ha estado marcada por limitaciones financieras y falta de recursos, que se reflejan en la falta de capacidad institucional para materializar en acciones concretas la mayoría de los acuerdos. Es relevante la identificación de consejos de ministros que no tienen asociada una secretaría técnica propia. A pesar de las limitaciones de recursos, sería beneficioso que se crearan las secretarías faltantes para así atender de manera específica los temas respectivos.

Por su parte, en el ámbito de los acuerdos y voluntades, si bien se ha avanzado significativamente en varios rubros de la integración social regional, aún persisten diversas temáticas en las que se dificulta el consenso entre todos los países de la región. Tal es el caso del manejo de aspectos relativos a la movilidad humana que se reflejan, por ejemplo, en un reconocimiento limitado de las capacidades laborales y en la conservación de las prestaciones sociales. Lo mismo ocurre cuando se habla de hacer converger el desarrollo social en diversos rubros, como la educación, la salud, la vivienda y la protección social. Son retos que plantean un esfuerzo adicional de cara al futuro y en los que la CEPAL intentará contribuir con la asistencia técnica y el fortalecimiento de capacidades del funcionariado de las instituciones de la integración social regional.

\section{Conclusiones y recomendaciones}

El análisis histórico del proceso de integración social regional da cuenta de avances, pero también de retos y desafíos para los años venideros. Por una parte, se observa que en ciertos sectores se han registrado más avances que en otros. Por otra, se destaca que, en la búsqueda de la integración social regional, se ha logrado actuar de forma conjunta, y hasta cierto punto coordinada, en líneas de acción comunes. También cabe destacar que los acuerdos han permitido establecer ámbitos comunes de entendimiento, intercambio de experiencias, información y buenas prácticas. Sin embargo, en muchos casos estos acuerdos no se han materializado en una labor conjunta. Ello 
guarda relación con la fortaleza de la institucionalidad en cada dimensión, lo que a su vez se vincula con la cantidad de instrumentos que posee cada comisión o consejo.

En este sentido, se recomienda fortalecer el papel coordinador del Consejo de Integración Social. De este modo, en el marco de los planteamientos del TISCA, se podría articular una política regional sobre el proceso de integración centroamericana que oriente las acciones emprendidas en el ámbito social hacia un horizonte común. El marco propuesto por la Agenda 2030 para el Desarrollo Sostenible puede ser útil para configurar dicho proceso de articulación.

Es fundamental fortalecer la institucionalidad de la dimensión social y que los países miembros le proporcionen una financiación sólida, que luego se podría complementar con recursos de la cooperación internacional. Esta base financiera consolidaría a su vez la autonomía en la toma de decisiones y proporcionaría espacio para que cada consejo ministerial tenga su secretaría técnica, de modo que los temas se aborden de manera adecuada.

Por otra parte, es necesario dar continuidad a las acciones implementadas. Ello implica la necesidad de fortalecer los mecanismos de cooperación interministerial y la definición de desafíos comunes que permitan formular estrategias de mayor plazo, lo que facilitaría la continuidad de los trabajos a pesar de la rotación de las presidencias pro tempore.

Por último, se ha observado que la falta de continuidad plantea riesgos en lo que se refiere a mantener los logros alcanzados. Además, se reconoce la conveniencia de impulsar nuevos temas en la agenda común. Esto hace más imperativa la cooperación entre las instituciones, entre los países y con las entidades internacionales pertinentes. La CEPAL estará presente para apoyar este paso.

\section{Bibliografía}

AECI (Agencia Española de Cooperación Internacional) (2007), Programa de Cooperación Regional con Centroamérica. Adaptación al plan director de la cooperación española 2005-2008. Programación 2007-2008 [en línea] http://www.jerez.es/fileadmin/ Documentos/Participacion_Ciudadana/Cooperacion/Normativa_estatal/ PCRC_correccion_12_de_abril_071.pdf.

Barrillas, E. (2001), “Estudio sobre salud en Centroamérica en el marco del proceso de integración", documento preparado para el Segundo Informe sobre Desarrollo Humano en Centroamérica y Panamá, San José, Proyecto Estado de la Nación.

CECC (Consejo Educativo y Cultural Centroamericano) (2017), “38 Reunión Ordinaria del Consejo de Ministros de Educación y del Consejo de Ministros y Directores de Cultura de la CECC/SICA", Panamá, 4 de octubre [en línea] http:/ / ceducar. info/ceducar/recursos/biblioteca $\% 20$ online/Actas/ordinarias/38reunion $\% 20$ ordinaria/index.html. 
CEPAL (Comisión Económica para América Latina y el Caribe) (2013), Integración social en Centroamérica: situación al 2012, tendencias y propuestas (LC/MEX/L.1094), Ciudad de México.

(2006), La protección social de cara al futuro: acceso, financiamiento y solidaridad (LC/G.2294(SES.31/3)), Santiago.

(2000), Equidad, desarrollo y ciudadanía (LC/G.2071/REV.1-P), Santiago.

(1998), Recomendaciones de las reuniones internacionales sobre el agua: de Mar del Plata a París (LC/R.1865), Santiago.

(1981), Istmo centroamericano: experiencias recientes sobre cooperación horizontal en materia de suministro de agua potable y saneamiento ambiental (E/CEPAL/L.256), Ciudad de México.

CEPAL/BID (Comisión Económica para América Latina y el Caribe/Banco Interamericano de Desarrollo) (1998), La integración centroamericana y la institucionalidad regional, Ciudad de México[en línea] https:/ / repositorio.cepal.org/bitstream/ handle/11362/25301/1/S9800099_es.pdf.

CEPAL/OPS (Comisión Económica para América Latina y el Caribe/Organización Panamericana de la Salud) (1994), Salud, equidad y transformación productiva en América Latina y el Caribe (LC/G.1813(SES.25/18)), Cartagena de Indias.

CIS (Consejo de la Integración Social Centroamericana) (2017), “LXXI Reunión Ordinaria del Consejo de la Integración Social Centroamericana (CIS)", Heredia, 18 de mayo [en línea] http://www.sisca.int/centro-de-documentacion/4-cis /1-resoluciones/269-1xvi-reunion-ordinaria-cis-18-de-mayo-de-2017-presidenciapro-tempore-costa-rica/file.

CODICADER (Consejo del Istmo Centroamericano de Deportes y Recreación) (2015), Acta de la II Reunión de Comité Directivo del Consejo del Istmo Centroamericano de Deporte y Recreación (CODICADER), Managua, 20 y 21 de febrero [en línea] http:/ / www.ind.gob.ni/archivos/acta_reunion_codic_2015.pdf.

COMISCA (Consejo de Ministros de Salud de Centroamérica) (2018), "Resolución COMISCA 01-2018", 10 de abril [en línea] https://www.sica.int/busqueda/ busqueda_basica.aspx?IdCat=\&IdMod=3\&IdEnt=143.

(2014), Plan Estratégico de Transversalización Perspectiva de Género en Salud 2014-2018 en el marco del Plan de Salud de Centroamérica y República Dominicana [en línea] https: / / www.paho.org/hq/dmdocuments/2014/PETGS-COMISCA.pdf.

COMMCA (Consejo de Ministras de la Mujer de Centroamérica y República Dominicana) (2015), "Acta de XXXVI Reunión Ordinaria", Guatemala, 20 de enero [en línea] https: / / www.sica.int/Consulta/Documento.aspx?Idn=93161\&idm=1.

Consejo de Ministras y Ministros de Trabajo de Centroamérica y República Dominicana (2017), "Declaración de San Salvador", San Salvador, 7 de septiembre [en línea] http:/ / www.ilo.org/wcmsp5/groups/public/---americas/---ro-lima/---srosan_jose/documents/genericdocument/wcms_574677.pdf.

Cruz-Peñate, M. (2001), Salud e historia en Centroamérica: análisis de las reuniones del sector salud de Centroamérica y República Dominicana 1985-2000, Managua, Organización Panamericana de la Salud (OPS)/Ministerio de Salud de Nicaragua.

Escrich, A. e Y. Quiteño (2012), “Una mirada de la SISCA al proceso de la Integración Social Centroamericana", Revista de la Integración Social Centroamericana (RISCA), año 2, No 7.

Gómez, G. y J. Romero (2009), Desigualdad y exclusión social en Centroamérica: alternativas de políticas públicas. Caso de Nicaragua, Managua, Centro Interuniversitario de Estudios Latinoamericanos y Caribeños (CIELAC)/Friedrich Ebert Stiftung (FES) [en línea] http:/ /library.fes.de/pdf-files/bueros/nicaragua/07181.pdf. 
González, R. (1988), "Pasado y presente de la integración económica centroamericana", Centroamérica: el reto de la integración, Federación Liberal y Centrista de América Central y el Caribe, Guatemala.

Isgut, A. y J. Weller (eds.) (2016), Protección y formación: instituciones para mejorar la inserción laboral en América Latina y Asia, Libros de la CEPAL, N 140 (LC/G.2687-P), Santiago, Comisión Económica para América Latina y el Caribe (CEPAL).

Nicolau, I. y M. Martín (2006), Programa de Cooperación Regional con Centroamérica. Plan de Acción de Formación Ocupacional e Inserción Laboral, San José, Coordinación Educativa y Cultural Centroamericana.

Martínez, J., V. Cano y M. Soffia (2014), “Tendencias y patrones de la migración latinoamericana y caribeña hacia 2010 y desafíos para una agenda regional", serie Población y Desarrollo, № 109 (LC/L.3914), Santiago, Comisión Económica para América Latina y el Caribe (CEPAL), octubre.

Martínez, J. y C. Orrego (2016), “Nuevas tendencias y dinámicas migratorias en América Latina y el Caribe", serie Población y Desarrollo, N 114 (LC/L.4164), Santiago, Comisión Económica para América Latina y el Caribe (CEPAL), marzo.

ODECA (Organización de Estados Centroamericanos) (1991), Protocolo de Tegucigalpa a la Carta de la Organización de Estados Centroamericanos (ODECA), Tegucigalpa, 13 de diciembre.

(1951), Carta de la Organización de Estados Centroamericanos-Carta de San Salvador, San Salvador, 14 de octubre.

OEA (Organización de los Estados Americanos) (1993), Protocolo al Tratado General de Integración Económica Centroamericana (Protocolo de Guatemala), Guatemala, 29 de octubre.

(1960), Tratado General de Integración Económica Centroamericano, Managua, 13 de diciembre.

OIT (Organización Internacional del Trabajo) (1999), El proceso de la integración centroamericana en perspectiva, San José [en línea] http://www.ilo.org/public/ spanish/region/ampro/mdtsanjose/worker/integ_ca/final.htm.

PEN (Programa Estado de la Nación) (2011), Estado de la Región en Desarrollo Humano Sostenible 2010, San José.

PNUD (Programa de las Naciones Unidas para el Desarrollo)/Proyecto Estado de la Región (2003), "El desafío de la acción regional", Segundo Informe sobre Desarrollo Humano en Centroamérica y Panamá, San José.

SG-SICA (Secretaría General del Sistema de la Integración Centroamericana) (2011), Instrumentos jurídicos del Sistema de la Integración Centroamericana, tercera edición, Antiguo Cuscatlán, julio.

SISCA (Secretaría de la Integración Social Centroamericana) (2010), “El desafío de la crisis económica global para la integración social de los países miembros del SICA: impactos sociales, respuestas de política pública y recomendaciones de acción regional", serie Políticas Sociales, $N^{\circ} 1$, Antiguo Cuscatlán, febrero. (2009a), "Alianza para el Desarrollo Sostenible de Centroamérica (ALIDES)", serie Integración, San Salvador, junio.

(2009b), "Bases para una política social Centroamericana", serie Integración, San Salvador, junio.

(2009c), "Compendio de normativas y acuerdos sobre políticas de la integración social centroamericana", serie Integración, San Salvador, junio.

(2009d), "Tratado de la Integración Social Centroamericana (TISCA)", serie Integración, San Salvador, junio. 
Capítulo XII

\section{La integración centroamericana en materia de ciencia, tecnología e innovación}

Leda Peralta Quesada

Ramón Padilla Pérez

\section{Introducción}

En América Latina y el Caribe se enfrentan retos estructurales que han persistido a lo largo del tiempo y se han registrado pocos avances en cuanto a identificar e implementar soluciones sistémicas y sostenibles. Algunos de estos retos son la productividad baja y estancada, la dificultad para generar empleos de calidad, la infraestructura deficiente, la pobreza y la dificultad para responder a la creciente desigualdad, la brecha de género, las desigualdades territoriales y el deterioro ambiental. La pérdida de dinamismo y la inestabilidad del sistema económico, las desigualdades y las tensiones causadas por la concentración de la riqueza y de los ingresos, y el riesgo de que ocurra una crisis ambiental de grandes proporciones son fenómenos cada vez más visibles y presentes en el debate público (CEPAL, 2016).

A estas condiciones internas se suman grandes cambios mundiales que tienen efectos sobre el desarrollo, el comercio y los modelos productivos nacionales y regionales. Los cambios políticos y económicos vienen acompañados de retos sociales y ambientales, como el envejecimiento de la población, las crisis ambientales y el efecto de los desastres, así como de la Cuarta Revolución Industrial (Industria 4.0) o nueva revolución tecnológica, 
que evidencian la extensión y el efecto de los retos estructurales irresueltos y crean nuevos desafíos, pero también brindan oportunidades de modernizar e innovar los sistemas gubernamentales y productivos.

Este contexto y las oportunidades que brindan la revolución tecnológica y la innovación llaman a repensar el modelo productivo, con el que no se está logrando responder a los retos estructurales y a las nuevas demandas mundiales. Estos temas se reconocen en la Agenda 2030 para el Desarrollo Sostenible, cuyo objeto es lograr un mayor empleo productivo, promover la industrialización inclusiva y sostenible, y fomentar la innovación, resaltando la importancia del ámbito productivo para el desarrollo. Además, el acelerado cambio tecnológico y las disrupciones digitales están llamados a desempeñar un papel muy importante en el logro de los Objetivos de Desarrollo Sostenible (ODS). Los avances en genética, robótica, energías renovables, inteligencia artificial y otras tecnologías ofrecen grandes promesas en cuanto a erradicar la pobreza y promover el desarrollo sostenible (CEPAL, 2018b). La ciencia, la tecnología y la innovación (CTI), al permitir una mayor tasa de crecimiento basada en una mayor eficiencia y productividad, contribuyen a que se avance en la consecución de los objetivos de la Agenda 2030, como poner fin a la pobreza (Objetivo 1), garantizar una educación inclusiva (Objetivo 4) y promover un crecimiento económico sostenido (Objetivo 8), entre otros. De manera directa, ayudan a construir infraestructuras resilientes, promover la industrialización inclusiva y sostenible y fomentar la innovación (Objetivo 9), y a garantizar modalidades de consumo y producción sostenibles (Objetivo 12).

Ante estos retos y metas, la Comisión Económica para América Latina y el Caribe (CEPAL) ha propuesto un cambio estructural progresivo hacia un modelo sostenible con respecto al ambiente e intensivo en conocimientos y tecnología, que mediante la innovación permita aumentar la productividad y la competitividad, así como generar empleos de calidad. Se sugieren estos cambios profundos para modificar la composición del producto, el empleo y el patrón de inserción internacional, y así alejarse de modelos débilmente encadenados que tienen poco contenido tecnológico.

Una característica importante de la innovación y la generación de conocimientos científicos y tecnológicos es que rara vez ocurren de manera aislada, sino en espacios colaborativos e interactivos. En este sentido, la integración de Centroamérica en materia de ciencia, tecnología e innovación ofrece grandes oportunidades, especialmente con miras a responder a los retos de la nueva revolución tecnológica, muchos de los cuales trascienden fronteras, como la ciberseguridad, el uso de macrodatos para tomar decisiones, y la automatización de los puestos de trabajo. Además, dicha integración permitiría que las economías centroamericanas, que son pequeñas y abiertas, lograran economías de escala y se encadenaran a procesos regionales y mundiales de producción basados en el uso intensivo del conocimiento 
y la tecnología. La interacción entre los sistemas de innovación también incentiva la actualización tecnológica y el establecimiento de estándares de calidad comunes. En el ámbito público, fomenta la cooperación Sur-Sur para aprovechar las lecciones aprendidas y el camino recorrido por los países o territorios que han superado los retos estructurales que aquejan a la región. Es decir, la innovación demanda, pero también contribuye a modernizar y agilizar los aparatos estatales para que sean capaces de responder a las necesidades cambiantes y dinámicas del sector productivo.

Las políticas de CTI y desarrollo productivo de la subregión se han formulado e implementado desde ópticas en que se privilegian los objetivos nacionales y se desatienden las oportunidades y los retos subregionales, pese a que la innovación ofrece oportunidades para mejorar la productividad y la sofisticación de las economías, y abre espacios para integrarse. Además, el proceso de transversalizar la innovación hacia otros sectores se ha visto desacelerado por un enfoque de silos en que la innovación se sitúa en instituciones especializadas en CTI o similares, sin contemplar la gran cantidad de oportunidades que se crean en campos tan diversos como la agricultura, la descarbonización de las economías, la gestión del riesgo de desastres, la salud y el bienestar, y el aprovechamiento de los macrodatos, entre muchos otros.

El objetivo central de este capítulo es reflexionar sobre el proceso de integración centroamericana en materia de CTI en las tres décadas más recientes, con un enfoque particular en el aporte de la CEPAL al proceso.

El capítulo se divide en cinco secciones además de esta introducción. En la primera se ofrece un fundamento teórico y conceptual sobre la importancia de la integración regional en materia de CTI. En la segunda se sintetizan los avances en materia de integración, dentro del marco del Sistema de la Integración Centroamericana (SICA), así como por medio de organismos subregionales enfocados en la CTI y el desarrollo productivo. En la tercera y la cuarta se presentan algunas de las actividades que la CEPAL ha realizado para fortalecer el proceso de integración regional en materia de CTI, y en la quinta se exponen las conclusiones y las recomendaciones.

\section{A. Fundamento lógico de la integración en materia de ciencia, tecnología e innovación}

Entre los países centroamericanos hay un reconocimiento generalizado de lo importante que es la CTI para alcanzar mayores tasas de crecimiento económico. En diferente medida, en los planes nacionales de desarrollo se integra a la CTI como un elemento transversal o como un eje estratégico. Los gobiernos - mediante ministerios, viceministerios, secretarías y consejos- 
diseñan e implementan programas para fomentar la creación y la difusión de conocimientos científicos y tecnológicos, una mayor actividad innovadora en el sector empresarial y la interacción entre diversos componentes de los sistemas de innovación, entre otras acciones.

No obstante, los esfuerzos y los resultados aún son insuficientes (véase el cuadro XII.1). El gasto en investigación y desarrollo como porcentaje del producto interno bruto (PIB) se mantiene en un nivel muy bajo y prácticamente no se ha modificado en los últimos 15 años. Costa Rica es el único país de la subregión cuyo coeficiente supera el 0,5\% del PIB. Salvo en el caso de ese país, la labor encaminada a lograr que haya más titulados de grado e investigadores en ciencia y tecnología es muy inferior a la que se observa en economías grandes de América Latina. La brecha es enorme al comparar la subregión con los Estados Unidos o con algunos líderes mundiales en la materia, como la República de Corea y Suecia. En términos de resultados, medidos según el número de patentes solicitadas por residentes, las brechas también son muy significativas.

Esta insuficiencia de recursos destinados a la CTI en los países de la subregión se da en un contexto internacional que se caracteriza por una creciente segmentación de mercados, cadenas de valor y tecnologías que exige como respuesta la cooperación transnacional para crear sinergias y evitar la fragmentación. La presencia de economías de escala y de externalidades comunes en el campo de la CTI da espacio para formular políticas o iniciativas transnacionales, y las justifica, especialmente ante la necesidad de diseñar e implementar estrategias que demandan inversiones cuantiosas.

Las políticas nacionales de un país pueden tener efectos negativos y positivos en un país vecino, que normalmente no se tienen en cuenta en el proceso de toma de decisiones. Las externalidades positivas implican que la efectividad de la política ejecutada en el país A se reduce debido a los efectos positivos que tiene sobre el país B. Es decir, el país B se beneficia de las políticas del país $\mathrm{A}$, a pesar de no haber incurrido en ningún gasto por ello. De esta manera, los beneficios que obtiene el país $\mathrm{A}$, en términos de mayor competitividad, se ven erosionados. La descentralización o la falta de coordinación pueden conducir a que el esfuerzo del país A sea menor, a no ser que el país B coopere o pague por los beneficios (Pelkmans, 2006a).

A su vez, las economías de escala son el resultado de dos factores. Por un lado, cuando se aplican políticas similares en más de un país, puede ser eficiente transferir la administración de estas a un gobierno central (costos fijos de la administración pública). Por otro lado, cuando las políticas son costosas y tienen costos fijos altos, la integración puede generar beneficios. Las políticas pueden exigir grandes inversiones en infraestructura o equipos, por ejemplo, laboratorios de investigación o infraestructura de transporte, y las economías de escala pueden lograrse mediante proyectos transnacionales. 


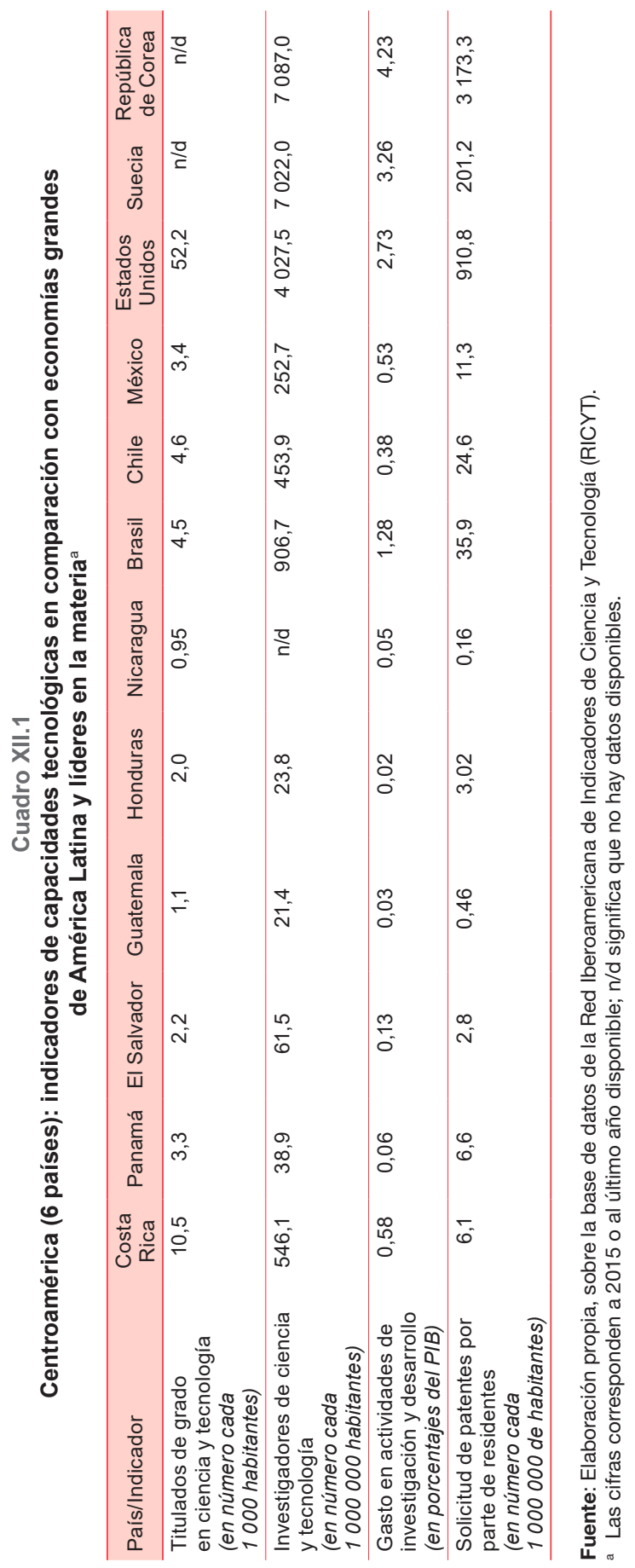


La integración puede ser más eficiente cuando se trata de proyectos grandes de investigación y desarrollo (I+D) y otras actividades de CTI que requieren inversiones significativas (economías técnicas de escala). Algunos proyectos de investigación son demasiado grandes y riesgosos para ser ejecutados por un solo país. A manera de ilustración, varios países europeos participan en la Organización Europea de Investigación Nuclear (CERN), el mayor laboratorio mundial de partículas físicas. Este es un claro ejemplo de los resultados que se pueden alcanzar al unir recursos provenientes de muchos países cooperantes. La coordinación transnacional de la investigación pública también puede mejorar la difusión del conocimiento entre los países y crear una mayor base de conocimiento regional con investigadores más especializados y menor duplicidad de proyectos. En la misma línea, la duplicación y la fragmentación de la I+D pública y privada entre países geográficamente vecinos podría abordarse mediante la integración transnacional (Van der Horst, Lejour y Straathof, 2006).

La integración de políticas de CTI también puede ser más eficiente si existen políticas nacionales con características similares, dado que se cubrirían una sola vez los costos fijos de administración, en lugar de que todos los países tengan que pagar dichos costos. El mismo argumento es válido en lo que respecta a la supervisión y la evaluación de los programas (Van der Horst, Lejour y Straathof, 2006). El intercambio de experiencias y buenas prácticas entre los responsables de las políticas nacionales es otra actividad que podría promoverse a nivel transnacional. De igual manera, se podrían lograr economías de escala significativas al crear un sistema común y transnacional de patentes, y coordinar normas y estándares.

Las externalidades de las políticas surgen cuando las acciones del gobierno de un país en materia de CTI tienen efectos no intencionales sobre otros países (Van der Horst, Lejour y Straathof, 2006). La interdependencia entre los países genera un libre flujo de conocimiento (externalidades) al que los destinatarios no han contribuido (Radosevic, White y Furlani, 2008). Estos flujos transfronterizos de conocimiento debilitan la relación entre el PIB y la inversión pública nacional en I+D (Van der Horst, Lejour y Straathof, 2006). La presencia de externalidades desincentiva el apoyo a la I+D por parte de los gobiernos nacionales, ya que hay algunos beneficios que los individuos y las organizaciones nacionales no pueden internalizar. Por ello, la integración transnacional de políticas puede dar lugar a mayores inversiones y mejores resultados. 


\section{B. Desarrollo histórico y estado actual de la integración centroamericana en materia de ciencia, tecnología e innovación}

El objetivo de esta sección es realizar un recuento histórico del proceso de integración centroamericana en materia de CTI. En la siguiente sección se examina el papel de la CEPAL en dicho proceso.

Pese a que en la subregión no ha habido una estrategia común para promover e integrar la CTI, sí se evidencian algunos esfuerzos iniciales por coordinar las actividades de I+D. Además, se ha aprovechado la institucionalidad del SICA y otros organismos regionales para promover la integración mediante políticas y diálogos sectoriales.

La información recopilada permite agrupar la labor de integración en materia de CTI en tres grandes áreas: i) coordinación regional para promover la CTI; ii) formulación de políticas públicas sectoriales para fomentar la integración, y iii) cooperación regional para impulsar la investigación. La primera se refiere específicamente a la experiencia de la Comisión para el Desarrollo Científico y Tecnológico de Centroamérica y Panamá (CTCAP), quizá el esfuerzo más ambicioso de integración en materia de CTI. El objetivo era convertir la CTCAP en el ente coordinador a los efectos de integrar y fortalecer el sistema subregional mediante la formulación, armonización e implementación de políticas. Sin embargo, la Comisión se ha visto afectada por los mismos retos que continúan repercutiendo en los sistemas nacionales de innovación, como los presupuestos limitados y variables, y las dificultades para llevar a cabo una tarea de coordinación.

No obstante, en la subregión se observan importantes logros en cuanto a la organización sectorial para promover la integración, especialmente mediante el trabajo de entidades como el Consejo Agropecuario Centroamericano (CAC) y el Centro Regional de Promoción de la Mipyme (CENPROMYPE). Estos han promovido la formulación de políticas sectoriales de integración resultantes de amplios procesos de diálogo, consenso e identificación de oportunidades comunes.

En cuanto a cooperar con el propósito de integrar la investigación, se ha aprovechado la institucionalidad de la integración para establecer centros especializados cuyo trabajo ha contribuido a transversalizar el tema y a aprovechar la CTI para fomentar el desarrollo sectorial. 


\section{Coordinación para promover la ciencia, la tecnología y la innovación}

En el área específica de las políticas relativas a la CTI, los primeros esfuerzos para lograr una mayor integración centroamericana se remontan a 1976, cuando se constituyó formalmente la CTCAP. En sus orígenes se consideró necesario contar con un mercado centroamericano de ciencia y tecnología, y tener una acción común en la materia. La estrecha vinculación que el desarrollo científico y tecnológico tiene con el crecimiento económico llevó a plantear la necesidad de crear un organismo que promoviera la formulación de políticas comunes de CTI. En sus primeros años, las actividades de la CTCAP se concentraron en tres áreas:

i) identificar, formular y promover proyectos de desarrollo tecnológico a nivel regional;

ii) coordinar a nivel regional las actividades nacionales de planeación científica y tecnológica, y

iii) formular propuestas de interés generalizado en asuntos que concernían directamente a todos los países (Nájera, 1984).

El objetivo principal de la CTCAP es fomentar los vínculos entre las diferentes organizaciones públicas nacionales de ciencia y tecnología. Entre sus actividades principales se encuentran las siguientes: gestionar la cooperación que se otorga a la subregión en ciencia y tecnología; identificar, proponer y elaborar proyectos subregionales, y conocer y discutir los temas relacionados con la ciencia y la tecnología que son relevantes para la subregión ${ }^{1}$.

La CTCAP ha pasado por diversas etapas, siempre sujeta a los recursos que los organismos de ciencia y tecnología le puedan brindar, dado que carece de personalidad jurídica y presupuesto propio, y por consiguiente no tiene infraestructura ni personal de tiempo completo. En algunos momentos ha recibido el impulso de los gobiernos que asumen la presidencia pro tempore $\mathrm{y}$, en otros, el financiamiento y el apoyo de organismos internacionales como el Banco Interamericano de Desarrollo (BID), la CEPAL y la Unión Europea. En junio de 2018 la CTCAP se encontraba en un impasse, sin un plan operativo vigente ni reuniones periódicas de sus miembros.

Pese a que las actividades de la CTCAP han recibido poco apoyo financiero de sus miembros, los organismos de cooperación internacional han contribuido al avance de algunos proyectos. A continuación se describen cuatro iniciativas de cooperación internacional que han dado impulso a la integración centroamericana en materia de CTI. 
En 1993, el BID estableció el Fondo Multilateral de Inversiones (FOMIN) como un laboratorio de innovación para promover el desarrollo mediante el apoyo al sector privado. Aunque el grueso de su trabajo se ha enfocado en la implementación de proyectos nacionales, también se han promovido proyectos regionales en temas que facilitan y promueven la innovación, como la mejora regulatoria y la inclusión financiera, la formación de jóvenes, y el apoyo a emprendimientos resilientes. Asimismo, el enfoque de su trabajo en tres ejes ha permitido transversalizar los beneficios de la innovación hacia áreas estratégicas para el desarrollo: la agricultura climáticamente inteligente, las ciudades inclusivas y la economía del conocimiento. Esto ha contribuido a que se adopte un enfoque amplio en las políticas de CTI existentes en la región.

Más recientemente, el BID ha establecido la Red de Innovación, Ciencia y Tecnología, que reúne a viceministros y altos funcionarios responsables de las políticas de CTI. Mediante la red se busca promover el intercambio de experiencias sobre políticas de CTI y reformas institucionales, así como explorar iniciativas de cooperación. La reciente creación y consolidación de políticas nacionales de CTI y sociedad del conocimiento evidencia la necesidad e importancia de este tipo de esfuerzos, que tienen por objeto construir capacidades para formular políticas públicas efectivas.

Merece la pena resaltar un proyecto destinado a promover la integración en la CTI, cuyo objetivo era crear una red regional de centros de desarrollo tecnológico. Esta cooperación técnica no reembolsable fue ejecutada por la CTCAP con el aporte del BID. Se elaboró un diagnóstico de 18 centros de investigación y desarrollo tecnológico de la subregión, su entorno institucional referido a las políticas de CTI, su relación con las empresas, la comercialización de tecnologías y la transferencia de resultados a los sectores sociales. Como resultado, en octubre de 2010 se constituyó la red de centros de investigación y desarrollo tecnológico y se elaboró un plan de acción cuya ejecución demandaba alrededor de 11 millones de dólares. Desafortunadamente no fue posible encontrar el financiamiento para ejecutarlo.

Por su parte, una iniciativa más reciente de la Unión Europea, que corresponde al período 2017-2018, tiene el objetivo de apoyar a los países de la subregión para que formulen políticas conjuntas de investigación e innovación con miras a cumplir los objetivos de desarrollo sostenible. Mediante un proceso participativo, los representantes de la subregión decidieron concentrarse en iniciativas que permitieran reducir los residuos de biomasa. En junio de 2018, las actividades que tenían previstas eran priorizar estrategias y buscar empresas centroamericanas y europeas que estuvieran dispuestas a invertir en las tecnologías identificadas. 


\section{Integración mediante políticas públicas sectoriales}

La integración sectorial ha avanzado gracias a los esfuerzos por establecer entidades especializadas que apoyen los procesos de integración mediante el fomento del diálogo y el debate, la formulación de políticas públicas y la construcción de capacidades institucionales. La labor del Consejo de Ministros de Integración Económica (COMIECO) y del CENPROMYPE ha contribuido a especializar sus respectivos sectores, y sus diálogos han promovido el avance en la integración de políticas y estrategias. Otro ejemplo es el CAC, organismo del SICA, que promueve una agricultura sostenible, competitiva $\mathrm{y}$ articulada a nivel regional.

El CENPROMYPE lideró la elaboración y adopción de la Estrategia Regional de Articulación Productiva Mipyme, que es uno de los más recientes esfuerzos por promover la integración productiva. La estrategia ha sido adoptada por todos los países de la subregión, y Costa Rica ha elaborado su Política de Desarrollo Productivo 2016-2050 a la luz de los principios y objetivos que se establecen en ella.

La estrategia está destinada a potenciar el comercio intrarregional y a incluir a las microempresas y pequeñas y medianas empresas (mipymes) en cadenas globales de valor mediante el fomento de la articulación interinstitucional e intersectorial. Asimismo, los esfuerzos de sofisticación productiva y adición de valor parten de la centralidad de la CTI para mejorar los productos y los procesos, y del aprovechamiento de las capacidades nacionales y regionales. Así, cobra relevancia el concepto de la triple hélice de la innovación (véase el diagrama XII.1)2.

Con el afán de coordinar el apoyo que se brinda a la subregión, la CEPAL también ha incorporado esta estrategia a sus iniciativas de integración productiva, las cuales se analizan con más detalle en la siguiente sección.

2 Desde el punto de vista de la CEPAL, la generación de conocimiento y la transferencia tecnológica son requisitos fundamentales para conseguir el cambio estructural progresivo que requiere la subregión. Las fuentes de desarrollo futuro están cada vez más ligadas a la innovación, que se sitúa como un elemento clave en la estrategia de desarrollo de los países. El modelo de la triple hélice muestra un cambio en la relación bilateral tradicional entre el sector privado y el gobierno, que define un nuevo paradigma donde la relación se hace tripartita al incluir a la academia y que supone la transición de sociedades industriales a sociedades del conocimiento. La tesis principal es que el potencial para el desarrollo económico dentro de una sociedad del conocimiento pasa por la importancia de las instituciones de investigación y desarrollo y de la simbiosis de elementos de las tres esferas para dar lugar a nuevos acuerdos institucionales y sociales que fomenten la producción, la transferencia y la aplicación del conocimiento (Garry, Parada y Salido, 2017). 


\section{Diagrama XII.1 \\ La triple hélice de la innovación}

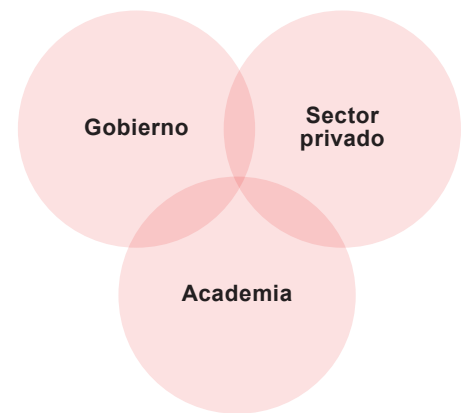

Fuente: Elaboración propia, sobre la base de H. Etzkowitz, "Enterprises from science: the origins of science-based regional economic development", Minerva, vol. 31, № 3, 1993.

Complementariamente, el COMIECO ha acordado apoyar las acciones de fomento realizadas por el CENPROMYPE, con el objetivo de ampliar las oportunidades de insertar las mipymes de la subregión en cadenas regionales y globales de valor (Acuerdo núm. 03-2015). Este apoyo se acompaña de la Estrategia Centroamericana de Facilitación del Comercio y Competitividad, que tiene por objeto establecer un entorno habilitador que promueva el intercambio intrarregional (Acuerdo núm. 01-2015).

\section{Cooperación para impulsar la investigación}

Además de la CTCAP, en Centroamérica hay diversos organismos regionales que promueven la integración regional en áreas relacionadas de manera directa e indirecta con el desarrollo productivo, científico y tecnológico, muchos de ellos especializados en el sector agropecuario y agroindustrial. Uno de los primeros esfuerzos en esta dirección fue establecer el Instituto Centroamericano de Investigación y Tecnología Industrial (ICAITI) para coordinar y priorizar la I+D subregional. Posteriormente se promovió el establecimiento de centros especializados, como el Instituto Centroamericano de Administración Pública (ICAP), el Instituto Interamericano de Cooperación para la Agricultura (IICA) o el Instituto de Nutrición de Centroamérica y Panamá (INCAP), entre otros, que desempeñan un papel activo en la creación de conocimiento, el fomento de debates y la formación de capital humano.

El ICAITI se creó en 1956 con el fin de promover la investigación para la integración. El instituto surgió a raíz de consideraciones sobre el estrecho vínculo que existe entre el desarrollo económico y el progreso técnico, y sobre el potencial de la subregión para aprovechar ese progreso a fin de desarrollarse. Entre sus principales finalidades se encontraban investigar la posibilidad de aprovechar los recursos naturales con vistas al desarrollo 
industrial, contribuir al mejoramiento de las técnicas industriales y los métodos de producción, fomentar la eficiencia industrial, y estudiar métodos tecnológicos adecuados a las condiciones de la subregión (CEPAL, 1955).

Dada la vocación agropecuaria y extractiva de las industrias centroamericanas, la investigación del ICAITI se abocó a estos temas, pero con un fuerte énfasis en promover la innovación, que se evidencia en los temas hacia los que se orientaron algunas investigaciones: utilización de desperdicios del café, elaboración de harinas instantáneas, recuperación del plomo de las baterías y extracción de aceites con ondas ultrasónicas. Además de la gran variedad de investigaciones, la elaboración de normas técnicas y especificaciones industriales que se aplicaran a nivel regional fue un aporte importante. Asimismo, se determinó que en Centroamérica había gran potencial para la industria farmacéutica, las fibras vegetales largas, los materiales de construcción y los productos alimenticios. La centralidad de las industrias en el enfoque del ICAITI permitió lograr importantes acercamientos con los sectores productivos y establecer un modelo incipiente de comercialización de servicios que, sin embargo, no alcanzó para mantener a flote las actividades del instituto.

El instituto recibió un gran impulso con la creación del Mercado Común Centroamericano, pero el debilitamiento del ritmo de expansión y la permanencia de estructuras industriales tradicionales afectaron su desempeño y relevancia. Aunque desde 1963 se exponían las dificultades que se enfrentaban para obtener financiamiento adecuado y estable, así como las limitaciones de sus cuadros técnicos, el ICAITI cerró sus puertas en 1998 por problemas financieros.

Las dificultades financieras y de coordinación que tuvo el ICAITI reflejan las condiciones similares que afrontan los sistemas nacionales de innovación. Sin embargo, merece rescatar dos pilares que parecen haber marcado las actividades del instituto: la centralidad de las industrias en sus actividades de investigación, y la comercialización de servicios. Estos pilares continúan exhibiendo debilidad en los sistemas nacionales de innovación, específicamente en los centros públicos de investigación, que tienden a realizar sus actividades de I+D sin vincularlas mucho con la industria y las prioridades productivas nacionales.

Por su parte, el Consejo Superior Universitario Centroamericano (CSUCA) cuenta con un Plan para la Integración Regional de la Educación Superior en Centroamérica y República Dominicana (2016). En el Plan se definen siete pilares prioritarios, entre los que se encuentra un programa de investigación, ciencia, tecnología e innovación para la integración y el desarrollo subregional, y un programa de integración de las funciones sustantivas de la universidad y de relación universidad-sociedad-estado. Quizá uno de los elementos más valiosos de este Plan sea la propuesta de 
elaborar y evaluar una agenda centroamericana de investigación. Crear esta agenda contribuiría a identificar oportunidades subregionales de innovación aprovechando ejercicios realizados recientemente, construir modelos de transferencia tecnológica y establecer esquemas de aprovechamiento compartido de la infraestructura de investigación.

\section{La contribución de la CEPAL a la integración en ciencia, tecnología e innovación}

Desde su creación, la CEPAL ha considerado la centralidad de la CTI como mecanismo de fomento del desarrollo, aunque durante su evolución ha adoptado distintos enfoques. Este pensamiento se inició con un énfasis en el progreso técnico y ha evolucionado hacia sociedades y economías basadas en el conocimiento, la tecnología y la innovación.

La ausencia de marcos institucionales y normativos habilitadores, o su debilidad, así como las carencias persistentes que se encuentran en los sistemas nacionales de innovación han desacelerado los esfuerzos de integración subregional. En este entorno, y entendiendo la innovación en su definición más amplia, la CEPAL ha trabajado para insertarla en sus áreas de trabajo y ha reconocido la transversalidad del tema y las diversas oportunidades de colaborar con los sectores sociales, ambientales y productivos. Por ello, ha trabajado de forma estrecha con los países de la región en temas como la digitalización y la penetración de las tecnologías de la información y las comunicaciones (TIC), la medición y el seguimiento de las políticas de innovación, la institucionalidad para la innovación, el desarrollo de consorcios productivos (clústeres), la innovación ecológica, el fomento de la innovación en las mipymes, la articulación institucional y los encadenamientos productivos, entre otros.

Esta labor ha contribuido a entender la CTI fuera de los silos de los ministerios y las instituciones especializadas en el tema y ha allanado el camino para transitar hacia sociedades basadas en el conocimiento. La concepción ampliada de la CTI y los esfuerzos por transversalizarla, combinados con los cambios tectónicos que la nueva revolución tecnológica ha provocado en el mundo, han permitido replantear el abordaje de esta materia e identificar oportunidades de desarrollo. Además, el fortalecimiento sectorial ha sentado las bases para llevar adelante proyectos subregionales que empiezan a florecer.

\section{Evolución del enfoque en ciencia, tecnología e innovación}

Pese a que existen pocos proyectos regionales y subregionales de promoción de la CTI, ha habido una gran cantidad de esfuerzos para fortalecer los sistemas nacionales de innovación, así como de iniciativas para transversalizar la 
innovación. En este sentido, es posible agrupar las contribuciones de la CEPAL en tres grandes áreas: i) modelo estructural para el desarrollo; ii) promoción de la CTI, y iii) transversalización de esta.

Las estructuras para el desarrollo se refieren a la identificación de modelos estructurales que permitan abordar los retos que supone el desarrollo de los países de la región. Estos retos han transitado desde la heterogeneidad y las brechas entre el centro y la periferia, hasta la inserción internacional mediante el uso intensivo del conocimiento y la tecnología. En estos modelos, la CTI ha desempeñado distintos roles y se la ha interpretado de distintas maneras, aunque siempre se ha reconocido su centralidad para promover el desarrollo.

Las ideas centrales de dichos modelos se han reflejado en iniciativas internas y en proyectos de asistencia técnica destinados a promover la CTI. Durante el período de la industrialización y la sustitución de importaciones, por ejemplo, la labor se concentró en fomentar la diversificación productiva mediante el aprovechamiento de las capacidades para investigar y promover la tecnificación, sobre todo de las industrias manufactureras. Posteriormente, la forma de entender este tema se ha ampliado para incluir esfuerzos por fortalecer los sistemas nacionales de CTI, cuyo objetivo final es la transición hacia sociedades y economías basadas en el conocimiento y la eficiencia, que logren encadenarse a los procesos productivos mundiales y agregarles valor. Esta transición, sumada al trabajo realizado con los países de la región, ha permitido perfilar temas estratégicos de intervención, como el fortalecimiento de la institucionalidad, la formulación de políticas públicas eficientes, el acceso al financiamiento y la internacionalización.

La CEPAL ha transversalizado la CTI en planes de trabajo y proyectos de asistencia técnica. Así, se observan diversas iniciativas destinadas a promover la innovación en áreas tan diversas como las siguientes: el cierre de las brechas de género en CTI; el acceso a las TIC y el uso de ellas; la innovación en las mipymes; los encadenamientos y la internacionalización, y la innovación ecológica.

En esta sección se analizan estos aportes desde una mirada temporal que ilustra la evolución del pensamiento y las actividades de la CEPAL, transitando desde un enfoque que se centraba en el progreso técnico hacia un entendimiento integral de la CTI para el desarrollo.

Entre las décadas de 1950 y 1970, y ante las características del modelo productivo centroamericano seguido a lo largo de un siglo, que se basaba en la exportación de bienes primarios y extractivos, la CEPAL insistió en la importancia de acortar las brechas entre centro y periferia. Para superar el modelo productivo de periferia, que dio como resultado un bajo nivel de diversificación e integración productivas, productividad dispar, escasa propensión a invertir en investigación, desarrollo e innovación, y atraso 
en el desarrollo de sectores difusores de tecnología, se debía hacer una transición hacia un modelo que promoviera el progreso técnico y una nueva forma de relacionarse con el mundo. Este modelo destinado a promover la industrialización iba acompañado de un proceso de integración de mercados para fomentar la sustitución de importaciones.

Como Secretaría del Comité de Cooperación Económica del Istmo Centroamericano, la CEPAL señaló la importancia de la cooperación subregional en el ámbito tecnológico como un elemento fundamental para la integración económica (CEPAL, 1955). En respuesta a ello, el Comité solicitó asistencia técnica para determinar la pertinencia de establecer un instituto regional de investigación, sentar las bases que permitieran crearlo, e identificar recursos para su funcionamiento. Ante el dictamen positivo de la CEPAL, en 1956 inició sus labores el ICAITI, al que ya nos hemos referido.

En la década de 1960 la CEPAL señaló de manera recurrente la necesidad de fortalecer la coordinación entre los organismos de alcance subregional, entre ellos, el Banco Centroamericano de Integración Económica (BCIE), el ICAITI y la Secretaría de Integración Económica Centroamericana (SIECA). Algunos retos que enfrentaban dichos organismos se referían a los siguientes temas: "a) el mejoramiento y capacitación de sus cuadros técnicos; b) a la relativa debilidad de los esfuerzos de promoción en los sectores o actividades de mayor importancia para la integración; c) la insuficiente coordinación y fortalecimiento recíproco de sus respectivos trabajos, y d) el desarrollo de nexos más estrechos con las instituciones gubernamentales de cada país" (CEPAL, 1965, pág. 2). Aunque se han logrado avances en la integración de la CTI y en los sistemas nacionales de innovación, el grueso de estos retos se mantiene hasta la fecha y continúa limitando las posibilidades de lograr la integración productiva y promover la innovación.

Pese a los esfuerzos por fomentar la industrialización y el aprovechamiento del progreso técnico como eje de desarrollo, primaron las iniciativas nacionales y los países intentaron especializarse en campos similares, lo que dio como resultado una oportunidad perdida en cuanto a la especialización productiva y un menor comercio intrarregional. Sumado a esto, los pocos avances alcanzados se debilitaron o eliminaron durante la crisis de la "década perdida" de 1980.

En la década de 1990 surge una nueva visión de regionalismo abierto, en la que se mantenía la importancia de la industrialización, pero se ponía énfasis en el fortalecimiento de las capacidades endógenas para establecer industrias tractoras que permitieran generar, acumular y difundir el progreso técnico. Resurge la importancia de los mercados internos y del comercio intrarregional para lograr la especialización y el encadenamiento productivo. Durante este período, la labor se orientó hacia la estabilización macroeconómica y la facilitación del comercio. El enfoque de atraer inversión 
extranjera directa (IED) y la creación de zonas francas representaron un entendimiento parcial del cambio tecnológico, al suponer que el comercio internacional y la atracción de empresas multinacionales sería una estrategia suficiente para alentar el desarrollo de las capacidades tecnológicas.

Ante la crisis financiera de 2008 y después de dos décadas de un modelo exportador que, aunque exitoso en materia comercial, no permitió lograr grandes avances en cuanto a la productividad y la generación de capacidades endógenas para crear valor e innovar, la CEPAL inició un proceso de replanteamiento del modelo de desarrollo que se seguía en la región. Como resultado de esta reflexión, se propuso un cambio estructural progresivo que suponía el uso intensivo de conocimientos y tecnología, así como la sostenibilidad ambiental, para aumentar la productividad y la competitividad, y generar empleos de calidad. Aunque desde sus inicios la CEPAL había manifestado la importancia del progreso técnico, en ese período se amplió el enfoque conceptual para integrar temas como el fortalecimiento institucional, la mejora de las capacidades técnicas e interpersonales, la especialización industrial y el desarrollo rural, con las mipymes en el corazón de las estrategias y los sectores productivos nacionales.

\section{Hacia un sistema regional de innovación}

En 2011 y 2012, la CEPAL, con el apoyo financiero de la Deutsche Gesellschaft für Internationale Zusammenarbeit (GIZ), brindó asistencia técnica a los países de la subregión mediante el proyecto Hacia un Sistema Regional de Innovación. Su objetivo principal fue fortalecer la integración centroamericana en temas de CTI, como mecanismo para incrementar las capacidades de cada país y potenciar el impacto de la CTI en su desarrollo económico y social.

Las actividades del proyecto se dividieron en tres etapas. En la primera, la CEPAL elaboró un análisis sobre los beneficios potenciales de una mayor integración centroamericana en materia de CTI y estudió casos exitosos en otras regiones del mundo. Paralelamente, se elaboró un marco conceptual y metodológico para estudiar sistemas de innovación en Centroamérica. En una primera reunión que se llevó a cabo en San José (Costa Rica), a la que asistieron representantes de los organismos de ciencia y tecnología de la subregión, se discutió la importancia de aumentar la cooperación en la materia.

La segunda etapa consistió en elaborar estudios nacionales sobre los sistemas agroindustriales de innovación. En los estudios se identificaron algunas fortalezas y debilidades que eran comunes a los países ${ }^{3}$. Por el lado de las fortalezas, se señalaron las siguientes: i) organizaciones (empresas, universidades, centros de investigación y organizaciones gubernamentales, entre otros) que interactuaban en el marco de sistemas de innovación emergentes;

El siguiente análisis de los sistemas de innovación está basado en Padilla (2013). 
ii) base de conocimientos en el sector productivo y en universidades y centros de investigación, sobre sectores específicos como la agroindustria; iii) amplia oferta de programas académicos de educación superior; iv) sector empresarial que competía en mercados locales e internacionales; v) marco institucional de apoyo a las actividades de CTI; vi) laboratorios de investigación que trabajaban en temas prioritarios nacionales, y vii) amplia red de organizaciones que facilitaban la difusión y la absorción de conocimientos.

Por otro lado, las principales debilidades identificadas fueron las siguientes: i) sector industrial dominado por empresas con baja productividad, mano de obra poco calificada y escaso empeño en invertir en innovación; ii) relaciones entre empresas que eran principalmente de carácter comercial y, en menor medida, de intercambio y creación de conocimientos; iii) enseñanza de grado universitario concentrada en las ciencias sociales y escasa formación de posgrado; iv) relación universidad-empresa concentrada en la formación y el flujo de recursos humanos, con escasa orientación a la difusión y generación de innovaciones y con limitada transferencia de conocimientos; v) pocos recursos dedicados a la investigación en las universidades; vi) actividades de investigación que solían carecer de objetivos concretos orientados hacia el mercado; vii) insuficientes recursos públicos destinados a fomentar la CTI y la articulación entre componentes; viii) falta de coordinación a nivel nacional entre las políticas llevadas a cabo por diversos organismos públicos; ix) débil sistema financiero de apoyo a la innovación, y x) falta de recolección sistemática y periódica de indicadores de capacidades tecnológicas, así como de ejercicios de monitoreo y evaluación de políticas de CTI.

No obstante, en el interior de la subregión se observaron disparidades evidentes en cuanto a la solidez del marco institucional, el diseño y la ejecución de políticas públicas, los recursos humanos y financieros destinados a la CTI, la calidad de la investigación y la enseñanza, y la capacidad innovadora de las empresas, entre otros. Es posible clasificar a los países centroamericanos en tres grupos:

i) Costa Rica y Panamá destacan por su compromiso político y financiero con las actividades de CTI. La innovación es un componente fundamental de los planes nacionales y la visión de desarrollo de largo plazo, y hay instituciones que trascienden los cambios de gobierno. Los instrumentos de política pública en CTI abarcan una amplia variedad de temas y sectores. También hay políticas e infraestructura para fomentar la vinculación entre los actores del sistema, como oficinas de transferencia tecnológica, incubadoras de empresas y fondos que promueven la vinculación. Costa Rica, en particular, cuenta con un sistema educativo de alto nivel, incluso en comparación con los países desarrollados. Se observa un mayor consenso en la sociedad en general sobre la importancia de la CTI para el desarrollo. No obstante, como 
se mencionó anteriormente, existe una distancia importante con los países desarrollados y con los líderes de América Latina, como el Brasil y Chile, en términos de recursos invertidos y resultados obtenidos.

ii) El Salvador y Guatemala se encuentran en un punto intermedio en la subregión. Sobresalen iniciativas recientes destinadas a fortalecer las instituciones, así como las capacidades y las relaciones de los componentes del sistema. Existe espacio para fortalecer la presencia de la CTI en una estrategia nacional de desarrollo que vaya de la mano de un mayor compromiso financiero público. También hay oportunidades para ampliar el alcance de la política pública de CTI hacia instrumentos que promuevan mayor interacción entre los componentes del sistema y que estén más orientados a los resultados.

iii) En Honduras y Nicaragua hay un camino más largo por recorrer. Las instituciones y políticas de CTI pueden fortalecerse de manera que sean parte integral de una visión nacional de desarrollo y trasciendan los gobiernos. Es necesario ampliar los recursos financieros nacionales (públicos y privados), para reducir la dependencia de la cooperación internacional. Las capacidades tecnológicas y de innovación están concentradas en pocos sectores (por ejemplo, el agropecuario y el agroindustrial).

En lo que respecta a los sistemas de innovación de cada país de la subregión, los agrícolas y agroindustriales mostraban una mayor solidez y concentraban una parte significativa de la capacidad tecnológica y productiva de cada uno de los países.

La tercera etapa del proyecto Hacia un Sistema Regional de Innovación consistió en formular propuestas para promover una mayor integración centroamericana en la CTI. Las líneas estratégicas se debatieron y aprobaron en la LXIII Reunión Ordinaria de la CTCAP, celebrada los días 21 y 22 de abril de 2012 en Tegucigalpa (Honduras). Al término de la reunión, los países miembros de la CTCAP firmaron una carta en la que se solicitó apoyo para implementar líneas estratégicas, pero se sigue a la espera de encontrar financiamiento para avanzar, lo que de nuevo pone de manifiesto la debilidad de la CTI a nivel subregional. Las tres líneas estratégicas priorizadas son las siguientes ${ }^{4}$ :

i) Crear un fondo regional de apoyo a la CTI

Las experiencias de la Unión Europea y los países del Mercado Común del Sur (MERCOSUR) ofrecen puntos de referencia para la organización y el funcionamiento de un fondo regional centroamericano destinado a la CTI. La

Las siguientes líneas se tomaron de Padilla (2013). 
estructura organizacional del fondo podría ser la de un consorcio públicoprivado internacional que contribuyera al desarrollo de programas y proyectos dirigidos a fortalecer la integración subregional en CTI. El fondo se conformaría con la participación de las agencias de la cooperación internacional que actúan en la subregión, delegados de los gobiernos nacionales, representantes de grandes grupos empresariales que trabajan en Centroamérica, rectores de instituciones de educación superior con experiencia previa en el manejo de fondos para la investigación, y directores de centros de investigación con experiencia en vinculación con el sector productivo. Además, se contaría con la participación de la CTCAP, que facilitaría la implementación de las decisiones adoptadas.

Para crear y poner en funcionamiento el fondo subregional, se propone organizar talleres y seminarios que den lugar a acuerdos sobre una agenda de trabajo. De manera preliminar, se sugiere que el fondo subregional incluya los siguientes ejes básicos:

- Apoyar convocatorias de contenido sectorial asociadas a las prioridades estratégicas de la subregión (agroproductivas, de salud y de medio ambiente), cuyos proyectos constituyan una oportunidad para mejorar la formación de equipos de investigación multidisciplinarios, con vinculación efectiva con el sector productivo y en los que participen organizaciones basadas en diversos países de la subregión. Mediante la aplicación de técnicas prospectivas se establecerán las preferencias para financiar iniciativas que respondan a las necesidades socioeconómicas de la subregión.

- Apoyar de manera directa proyectos de I+D, articulando la acción de grandes empresas, mipymes, universidades, centros de investigación y organizaciones de la sociedad civil que estimulen la inserción de investigadores en las empresas para llevar a cabo tareas de $\mathrm{I}+\mathrm{D}$. Un requisito para la conformación de equipos es la participación de organizaciones basadas en diversos países de la subregión.

- Fomentar y apoyar convocatorias para la creación de empresas de base tecnológica y apoyar la formación de capital de riesgo.

- Financiar seminarios para universidades, centros de investigación y empresas privadas sobre derechos de propiedad intelectual y transferencia de conocimientos a la sociedad, con énfasis en la creación, gestión y evaluación de oficinas de transferencia tecnológica.

- Financiar posgrados vinculados con el desarrollo de áreas estratégicas para la subregión, cuyo diseño atendería tanto a indicadores de calidad científica y académica, como de empleo y retorno de la formación en el mercado de trabajo. 


\section{ii) Fortalecer la calidad y pertinencia de la investigación en el sector agroproductivo}

Los centros de investigación relacionados con el sector agroproductivo en Centroamérica tienen, en general, las siguientes debilidades: pocos cuentan con la capacidad de realizar investigaciones complejas; hay una insuficiente vinculación entre ellos, y con las universidades y el sector productivo, y existen problemas para financiar sus actividades.

El desarrollo de esta línea estratégica exige formular convocatorias para formar grupos de investigación con carácter multidisciplinario y transnacional que aborden las prioridades estratégicas de desarrollo y que contribuyan a una integración más efectiva. El fortalecimiento de la investigación está ligado al aumento del número de investigadores para afrontar los desafíos del crecimiento económico con mayor igualdad. Los países centroamericanos necesitan una masa de recursos humanos calificados en ciencias e ingeniería para incorporar al sistema productivo y alimentar el desarrollo del sistema público de investigación.

Se requiere formular una política de incentivos a la investigación, considerando la labor científica realizada individualmente y en grupo: publicaciones, formación, participación en redes de conocimiento a nivel regional y nacional, servicios de asesoría a empresas o sectores productivos, y patentes. Un aspecto fundamental que se deberá encarar a nivel subregional y nacional es cómo establecer una política de incentivos que dirija los esfuerzos en CTI a problemas relevantes para el desarrollo y contribuya a construir capacidades en los países con trayectorias académicas más débiles $\mathrm{y}$ fragmentadas.

La creación de redes interinstitucionales por áreas de conocimiento facilitaría los flujos de comunicación entre los investigadores. Su desarrollo supondría una base de apoyo y de interacción necesaria para innovar en nuevas modalidades de investigación. La organización de seminarios regionales sobre las perspectivas de crecimiento de los diferentes ámbitos de conocimiento a nivel internacional y de la subregión contribuiría a crear la confianza, la comunicación y el interés por desarrollar actividades de investigación y difusión conectadas con prioridades nacionales.

La participación en redes temáticas transnacionales (por áreas del conocimiento y con carácter multidisciplinario) permitiría sistematizar los conocimientos más avanzados en las áreas seleccionadas, con información relevante como las investigaciones realizadas en el país y la subregión, la actualización de los posgrados existentes y los alcances obtenidos en el desarrollo de las investigaciones. 
La integración de estudiantes de posgrado en la actividad de las redes temáticas transnacionales fomentaría la transferencia de conocimientos, la movilidad y la creatividad de los investigadores y los jóvenes egresados para asociarse en grupos interinstitucionales orientados a resolver problemas en áreas prioritarias para los países y la subregión en su conjunto.

\section{iii) Crear un clúster agroproductivo transnacional}

La creación de aglomeraciones agroproductivas consolidará un espacio para formalizar la colaboración público-privada en cada país y a nivel subregional. Las aglomeraciones productivas constituyen la base a partir de la que se estructuran acciones con los siguientes fines: fomentar la demanda de conocimientos, apoyar la modernización empresarial en innovación, favorecer cambios regulatorios que estrechen la vinculación y la movilidad entre los diferentes agentes (universidades y centros de investigación, empresas y organizaciones intermedias), y crear nuevas modalidades de transferencia de los conocimientos (formales y tácitos). La creación de aglomeraciones agroproductivas transnacionales favorecerá un cambio estructural de la subregión hacia productos y procesos con mayor valor agregado y contenido tecnológico.

La articulación productiva es una apuesta para desarrollar la capacidad de innovación y constituye una solución operativa a las debilidades y carencias competitivas detectadas anteriormente. Se propone también fomentar la oferta de servicios tecnológicos y de I+D de los centros de investigación a las mipymes. La creación de capacidades en el sistema productivo actuará para mejorar los niveles de competencia tecnológica y acceso a la información.

\section{Desarrollo productivo}

De manera complementaria a las iniciativas enfocadas específicamente en la CTI, la CEPAL ha llevado a cabo diversos esfuerzos para promover el desarrollo productivo, que tienen en el centro el cambio tecnológico. En años recientes, la sede subregional de la CEPAL en México ha trabajado en estrecha colaboración con ministerios de economía, industria y comercio exterior para diseñar estrategias que permitan fortalecer las cadenas de valor. En el manual publicado en 2016 se sistematiza la metodología utilizada (Padilla y Oddone, 2016).

Las cadenas de valor a las que se prestó apoyo pertenecen a diversos sectores económicos: actividades primarias (tomate y chile verde, hortalizas de exportación, camarón de cultivo, miel, papaya); servicios (turismo rural), y actividades industriales (textiles, lácteos, embutidos). Para obtener más detalles sobre las cadenas, véanse Padilla (2013 y 2017), Padilla y Oddone (2016), y Garry, Parada y Salido (2017). 
A nivel subregional, es importante reconocer el acercamiento entre la CEPAL, el CENPROMYPE y la SIECA, que dio como resultado la elaboración de una propuesta metodológica de articulación productiva y cadenas regionales de valor para la subregión del SICA. La propuesta se construye sobre la experiencia acumulada por la CEPAL en la ejecución de iniciativas de alcance nacional, y en ella se aprovechan oportunidades para lograr la integración productiva, específicamente la Estrategia Regional de Articulación Productiva Mipyme, elaborada por el CENPROMYPE.

Gracias al trabajo conjunto, esta metodología se encontraba en proceso de implementación en el segundo semestre de 2018 (véase el capítulo V), partiendo de la experiencia acumulada por la CEPAL que, en coordinación con el CAC, hizo el diagnóstico de la cadena regional de lácteos. En el primer semestre de 2018, el CENPROMYPE inició un proceso de fortalecimiento de la cadena regional de valor de la pesca, al tiempo que la CEPAL y la SIECA elaboraron un programa de trabajo conjunto para fortalecer diversas cadenas regionales de valor. También hay que subrayar que la CEPAL empezó, en el segundo semestre de 2018, un proceso de fortalecimiento de la cadena de valor de la industria de la animación digital en tres países mesoamericanos. Estos proyectos tienen el objetivo de articular las capacidades productivas nacionales y potenciarlas mediante sinergias y economías de escala subregionales.

\section{Conferencias y órganos subsidiarios de la CEPAL}

Como parte de su mandato, la CEPAL cuenta con órganos intergubernamentales permanentes que examinan diversas temáticas de las políticas públicas de la región, facilitan la cooperación y el aprendizaje entre pares a partir de experiencias comparadas, adoptan consensos regionales en sus respectivas áreas de competencia y formulan mandatos para la Secretaría Ejecutiva de la Comisión. En materia de CTI, se destacan a continuación dos iniciativas.

\section{Conferencia de Ciencia, Innovación y Tecnologías de la Información y las Comunicaciones}

La Conferencia de Ciencia, Innovación y Tecnologías de la Información y las Comunicaciones fue creada en 2012 mediante la resolución 672(XXXIV) de la CEPAL y la resolución 2012/35 del Consejo Económico y Social. Por medio de ella se busca promover el desarrollo y el mejoramiento de las políticas nacionales de ciencia, tecnología e innovación, y las relacionadas con el avance de la sociedad de la información y del conocimiento.

La Conferencia responde a la necesidad de crear un espacio permanente de diálogo político y técnico del más alto nivel sobre ciencia, innovación y tecnologías de la información y las comunicaciones que permita coordinar 
acciones e intercambiar conocimientos para mejorar la calidad y la efectividad de las políticas en esta materia, además de fortalecer el papel de la ciencia y la tecnología como instrumentos fundamentales de la reforma estructural, el proceso de diversificación productiva y la modernización y competitividad de las economías de América Latina y el Caribe (CEPAL, 2017).

Considerando la amplitud de los temas, los países acordaron organizar su trabajo en tres grandes áreas:

i) Promover la formación de recursos humanos, impulsando programas regionales e internacionales de cooperación con el objetivo de fomentar las capacidades científico-tecnológicas.

ii) Fomentar el intercambio de experiencias y la generación de conocimiento a la hora de diseñar políticas sobre CTI, incluidas las tecnologías de la información y de las comunicaciones.

iii) Facilitar la coordinación y cooperación entre los países miembros de la Conferencia.

Se continúa con el trabajo histórico destinado a mejorar las capacidades para formular políticas públicas integrales y eficientes, aprovechando la cooperación Sur-Sur y el intercambio de experiencias. Asimismo, se mantiene la centralidad de crear capacidades endógenas para la innovación, y se insiste en la necesidad de mejorar la coordinación. En un afán por mejorar la coordinación y las sinergias, se ha dado una convergencia natural entre la Conferencia y la Agenda Digital para América Latina y el Caribe (que se describe a continuación), y esta última se ha convertido en un espacio central de intercambio de experiencias y búsqueda de ideas y soluciones a problemas comunes.

\section{Agenda Digital para América Latina y el Caribe}

La Conferencia Ministerial sobre la Sociedad de la Información de América Latina y el Caribe surge a raíz de un diálogo regional sobre la sociedad de la información y del conocimiento, en el que los países afirmaron su voluntad de diseñar e implementar programas para el acceso y uso de las tecnologías de la información y las comunicaciones (TIC). Su principal objetivo es diseñar e implementar programas para el acceso y uso de las TIC en la región.

Dado que el acceso a las TIC y el uso de ellas es uno de los pilares fundamentales de la transformación del conocimiento y la tecnología en innovación, la CEPAL ha liderado el diálogo latinoamericano en estos temas. Ya en 2003, con el apoyo de la CEPAL y en el marco de la Conferencia Ministerial Regional de América Latina y el Caribe preparatoria para la segunda fase de la Cumbre Mundial sobre la Sociedad de la Información, los países de la región iniciaron un proceso de diálogo político que en 2005 dio lugar a la aprobación del Plan de Acción sobre la Sociedad de la Información de América Latina y el Caribe 
(eLAC2007) en Río de Janeiro (Brasil). Posteriormente se aprobó el Plan de Acción eLAC2010 en 2008 en San Salvador, el Plan de Acción eLAC2015 en 2010 en Lima, el Plan de Trabajo 2013-2015 para la Implementación del Plan de Acción sobre la Sociedad de la Información y del Conocimiento para América Latina y el Caribe (eLAC2015) en 2013 en Montevideo, y la Agenda Digital para América Latina y el Caribe (eLAC2018) en 2015 en Ciudad de México (CEPAL, 2018a) y en 2018 en Cartagena de Indias (Colombia) (eLAC2020).

La Agenda Digital para América Latina y el Caribe (eLAC2020) tiene por objeto ser un instrumento catalizador para coordinar los esfuerzos de cooperación regional en materia digital, y se estructura en siete áreas de acción (CEPAL, 2018a):

i) Infraestructura digital

ii) Transformación digital y economía digital

iii) Mercado digital regional

iv) Gobierno digital

v) Cultura, inclusión y habilidades digitales

vi) Tecnologías emergentes para el desarrollo sostenible

vii) Gobernanza para la sociedad de la información

Merece la pena examinar la propuesta de la CEPAL de crear un mercado digital regional con el objetivo de construir una estrategia que permita reducir las barreras que dificultan el intercambio de bienes y servicios en línea, aumentando la calidad de la oferta y reduciendo los costos. En este sentido, se proponen cinco ejes principales de trabajo:

i) Facilitar el movimiento de bienes, servicios y capital vinculado a la industria digital en el ámbito latinoamericano.

ii) Promover el acceso expedito y sencillo a los bienes y servicios, en un esquema intrarregional de libre competencia, sin restricciones ni barreras arbitrarias (incluye el teletrabajo).

iii) Proteger de forma adecuada al consumidor y los datos personales, independientemente de su nacionalidad o lugar de residencia.

iv) Revisar el régimen fiscal que se aplica a los servicios digitales intrarregionales y extrarregionales.

v) Lograr una regulación convergente y armonizada en que la normativa que se aplica a los servicios equivalentes sea compatible, independientemente del país o el tipo de red o tecnología 5 .

Constituir un mercado único digital permitiría aprovechar economías de escala y de red mediante el desarrollo de redes y plataformas digitales, el aumento de la conectividad de las personas y las empresas, y el intercambio de bienes y servicios en línea. Sin embargo, primero es necesario superar

\footnotetext{
Véase [en línea] https://www.cepal.org/sites/default/files/pages/files/fact_sheet_mdr-final.pdf.
} 
algunas trabas persistentes, como la falta de coordinación en materia de estándares y regulación, las carencias en infraestructura y transporte de mercancías, las deficiencias en los servicios de logística, y la poca penetración de los medios de pago en línea (CEPAL, 2016).

Aunque el tema que convoca a los países al espacio de diálogo creado por la Agenda Digital para América Latina y el Caribe es solo una parte de la CTI, la evolución de la agenda demuestra un enfoque destinado a construir sociedades del conocimiento. La amplitud de la agenda permite incorporar temas relevantes para la CTI, como la infraestructura y la construcción de capacidades. Asimismo, se cuenta con una agenda seria de consolidación y mejora de la gobernanza sectorial. Esto implica fortalecer la institucionalidad y las capacidades de las entidades rectoras y ejecutoras, mejorar los marcos normativos, y promover la coherencia y la articulación normativa para transversalizar la CTI. De esta manera, este espacio puede llegar a convertirse en un líder y un catalizador de la transición hacia economías basadas en el uso intensivo de conocimientos y tecnología.

La Conferencia de Ciencia, Innovación y Tecnologías de la Información y las Comunicaciones y la Agenda Digital para América Latina y el Caribe han permitido delinear prioridades estratégicas para la región, y se han convertido en espacios de pensamiento, replanteamiento y búsqueda de oportunidades de mejorar, especialmente aprovechando las experiencias de los países latinoamericanos. Dado que ambas tienden a convocar a los mismos actores nacionales y regionales, y en vista de la similitud de sus agendas, el espacio creado por la Agenda Digital para América Latina y el Caribe se ha convertido en la principal plataforma de intercambio de los países. Su dinamismo y la confianza creada entre sus participantes ofrecen un espacio ideal para promover una agenda regional y consensuada sobre el aprovechamiento de la CTI para fomentar el desarrollo sostenible.

\section{E. Conclusiones}

La evolución de la integración centroamericana en CTI presenta similitudes con el desarrollo de los sistemas nacionales de innovación. Se observa un amplio consenso sobre su importancia y los beneficios que genera para el desarrollo económico y social, y en la subregión se han identificado áreas estratégicas con potencial para innovar. Además, se ha avanzado en la formulación de políticas públicas integrales que han tenido por objeto fomentar una transición hacia sociedades del conocimiento. Pese a esto, a nivel nacional y subregional se continúan enfrentando una serie de retos, entre ellos la continuidad y la calidad de las políticas de innovación, la articulación entre los componentes de los sistemas de innovación, la calidad y la orientación de los recursos humanos, la vinculación entre la industria y 
la academia, el acceso al financiamiento, y la recolección y el uso de datos. Así, aunque existen políticas y visiones destinadas a fomentar la CTI, hay diversos obstáculos que han dificultado y dificultan su implementación y continuidad.

Si bien la CEPAL ha trabajado con los países de la subregión para abordar los principales problemas que enfrentan los sistemas de innovación, los avances no han sido suficientes. Aunque ha contribuido a fortalecer la capacidad de formular políticas públicas integrales que den visibilidad a la gran cantidad de sinergias potenciales entre la CTI y todos los componentes sociales, económicos y ambientales, la implementación y la efectividad de esas políticas requieren mayor atención. Se continúa evidenciando la dificultad de articular en el interior de los sistemas de innovación, la pérdida de oportunidades de establecer vínculos con los sectores estratégicos, el poco aprovechamiento de las capacidades locales y regionales para la investigación, la desvinculación entre las agendas académicas y productivas de investigación, desarrollo e innovación, y las dificultades para acceder al financiamiento, a lo que se suman las brechas de género y las territoriales.

La persistencia de estos retos es un desafío que la CEPAL enfrenta. Se mantiene un llamado permanente al fortalecimiento institucional de los sistemas nacionales de innovación, promoviendo sinergias entre los componentes de dichos sistemas y convocando a que se hagan inversiones sostenidas y eficientes. También es imperativo mejorar la coordinación de las agendas de investigación, desarrollo e innovación y de los proyectos de asistencia técnica entre los organismos regionales e internacionales que apoyan la integración.

En este sentido, el trabajo realizado en el marco de la Conferencia de Ciencia, Innovación y Tecnologías de la Información y las Comunicaciones y la Agenda Digital para América Latina y el Caribe ha fomentado la interacción entre los países, ha permitido identificar oportunidades comunes de investigación, desarrollo e innovación y, en general, ha promovido la integración regional en CTI. Estos espacios de diálogo, consenso y aprendizaje crean oportunidades para profundizar el trabajo realizado hasta el momento y hallar espacios de transversalización y trabajo multisectorial.

El desarrollo de la CTI también da lugar a oportunidades de abordar retos y prioridades subregionales. Además, es un elemento indispensable a los efectos de cumplir la Agenda 2030 para el Desarrollo Sostenible y sus ODS, en particular mediante el acceso al conocimiento, la promoción de la salud, la seguridad alimentaria, el uso de energías renovables, la mitigación del cambio climático, la gestión del riesgo de desastres y la generación de empleos de calidad que garanticen un aumento real de los ingresos de los trabajadores (CEPAL, 2017). 
El aprovechamiento de la CTI y la creación de sinergias tienen dos vertientes de apoyo al desarrollo. Por un lado, el uso intensivo del conocimiento y la tecnología permite crear respuestas a los problemas sociales, económicos y ambientales persistentes. Estas respuestas van desde formular políticas públicas eficientes y crear capacidades institucionales hasta implementar proyectos nacionales e intersectoriales para promover la innovación. Por otro lado, y considerando que un 95\% del parque industrial regional está compuesto por mipymes, también se crean oportunidades de negocio y crecimiento para empresas innovadoras o de base tecnológica que busquen responder a estos retos.

Es importante estudiar estas oportunidades y priorizar los espacios de gran potencial para la subregión. Por ejemplo, se ha avanzado de forma significativa en la integración energética y en algunos aspectos del manejo ambiental. Estos avances se explican ampliamente en los capítulos IX y X de este libro. Merece la pena recordar que ellos se han logrado gracias a las innovaciones tecnológicas y de los procesos, así como a las sociales. En el mercado energético centroamericano se ha logrado una importante sofisticación tecnológica, y el Sistema de Interconexión Eléctrica de los Países de América Central (SIEPAC) es un ejemplo excelente de cómo promover la articulación subregional mediante innovaciones sociales en la gobernanza sectorial con múltiples países. Por otra parte, a nivel ambiental se cuenta con redes hidrometeorológicas compartidas y se ha logrado el manejo transfronterizo de las cuencas. Ambas iniciativas llaman a utilizar la CTI para mejorar el acceso a los datos y su aprovechamiento a la hora de tomar decisiones, sobre todo al formular políticas públicas y estrategias en temas como la conservación ambiental, la resiliencia productiva y de las mipymes, la planificación territorial o las estrategias de fomento agroproductivo sensibles al cambio climático. Asimismo, se abre un nuevo espacio de integración, mediante la creación de un mercado digital regional que asegure la competencia efectiva, proteja los derechos de los consumidores, genere confianza y seguridad, y promueva estándares comunes e interoperabilidad para desarrollar economías digitales.

Desde la década de 1960 se ha reconocido que el sector agroalimentario también tiene gran potencial, y esto se ha visto reflejado en las oportunidades que presenta la Estrategia Regional de Articulación Productiva Mipyme, que fue elaborada por el CENPROMYPE y aprobada por sus países miembros. Pese a este reconocimiento y a las fortalezas de este subsistema de innovación, sobre todo de sus centros de investigación, los esfuerzos siguen siendo meramente nacionales, con pocos asomos subregionales.

Mediante el cambio estructural progresivo propuesto por la CEPAL se busca promover los encadenamientos productivos de manera de aumentar la escala de las actividades productivas locales, mejorar su productividad y (re)especializarlas en áreas con alto potencial para agregar valor. Este 
enfoque ha dado como resultado la reciente publicación de una propuesta metodológica de articulación productiva y cadenas regionales de valor en la subregión del SICA, que fue elaborada mediante un esfuerzo conjunto de la CEPAL, el CENPROMYPE y la SIECA. Por un lado, se evidencia la necesidad de mejorar la coordinación entre los organismos que apoyan la integración, así como el impulso por lograrlo. Por otra parte, se hace posible la aplicación de metodologías consensuadas en temas tan diversos como la pesca (CENPROMYPE) y la animación digital (CEPAL), pero con el objetivo común de articular y agregar valor.

Las dificultades que se enfrentan en la subregión a la hora de implementar y dar seguimiento a las políticas públicas y los programas llaman a pensar en mecanismos creativos e innovadores que permitan articular y aprovechar las capacidades existentes. La metodología de fortalecimiento de las cadenas de valor es un excelente ejemplo de una innovación que tiene por objeto mejorar la articulación de sus componentes y fortalecer su gobernanza. Además, la metodología se caracteriza por formar redes de colaboración y confianza que trascienden proyectos, fomentan el trabajo multisectorial y profundizan la transversalidad de la CTI.

\section{Bibliografía}

CEPAL (Comisión Económica para América Latina y el Caribe) (2018a), "Agenda Digital para América Latina y el Caribe (eLAC 2020)”, documento presentado en la Sexta Conferencia Ministerial sobre la Sociedad de la Información de América Latina y el Caribe, Cartagena de Indias, 18 a 20 de abril [en línea] https: / / conferenciaelac. cepal.org/6/sites/elac2020/files/cmsi.6_agenda_digital.pdf.

(2018b), “La tecnología y la innovación son fundamentales para la implementación de la Agenda 2030 en América Latina y el Caribe", Santiago, 18 de julio [en línea] https: / / www.cepal.org/es / comunicados/la-tecnologia-la-innovacion-sonfundamentales-la-implementacion-la-agenda-2030-america.

(2018c), "Mercado regional digital: aspectos estratégicos", Documentos de Proyectos (LC/TS.2018/30), Santiago, abril.

(2017), "Informe de la Segunda Reunión de la Conferencia de Ciencia, Innovación y Tecnologías de la Información y las Comunicaciones de la Comisión Económica para América Latina y el Caribe" (LC/L.4276), Santiago, enero [en línea] http:/ / repositorio.cepal.org/bitstream/handle/11362/40870/S1601336_es.pdf.

(2016), "La CEPAL impulsa la creación de un mercado digital regional en América Latina y el Caribe", Santiago, 22 de junio [en línea] https:/ /www. cepal.org/es/comunicados/la-cepal-impulsa-la-creacion-un-mercado-digitalregional-america-latina-caribe.

(1965), "Organización institucional de la integración" (CEPAL/MEX/14), Ciudad de México, octubre [en línea] https: / / repositorio.cepal.org/bitstream/ handle/11362/23414/CEPALmex14_es.pdf. 
(1955), “Instituto Centroamericano de Investigación y Tecnología Industrial: 6 (CCE) Resolución aprobada el 7 de mayo de 1955" (E/CN.12/CCE/21), Informe del Comité de Cooperación Económica del Istmo Centroamericano (E/CN.12/ CCE/29), San Salvador, mayo.

Garry, S., Á. Parada, y J. Salido (2017), “Incorporación de mayor valor en la cadena de la miel y productos derivados de la colmena en el Pacífico Central, Costa Rica", Documentos de Proyectos (LC/MEX/TS.2017/23), Santiago, Comisión Económica para América Latina y el Caribe (CEPAL), septiembre.

Nájera, R. (1984), “Mecanismos institucionales para el desarrollo científico-tecnológico del Istmo Centroamericano", inédito.

Padilla, R. (ed.) (2017), Politica industrial rural y fortalecimiento de cadenas de valor, Libros de la CEPAL, Nº 145 (LC/PUB.2017/11-P), Santiago, Comisión Económica para América Latina y el Caribe (CEPAL), junio. (2013), Sistemas de innovación en Centroamérica: fortalecimiento a través de la integración regional, Libros de la CEPAL, N 118 (LC/G.2559-P), Santiago, Comisión Económica para América Latina y el Caribe (CEPAL), febrero.

Padilla, R. y N. Oddone (2016), Manual para el fortalecimiento de cadenas de valor (LC/MEX/L.1218), Santiago, Comisión Económica para América Latina y el Caribe (CEPAL), octubre.

Pelkmans, J. (2006a), "Testing for subsidiarity", Bruges European Economic Policy Briefing, $\mathrm{N}^{\circ} 13$, Bruges, College of Europe, febrero. (2006b), "European industrial policy", Bruges European Economic Policy Briefing, $\mathrm{N}^{\circ} 15$, Bruges, College of Europe, julio.

Radosevic, S., M. White y A. Furlani (2008), Complementarities Between Regional, National and EU Support Instruments, Bruselas, Comisión Europea, junio.

Van der Horst, A., A. Lejour y B. Straathof (2006), "Innovation policy: Europe or the Member States", CPB Document, N 132, La Haya, noviembre. 

Capítulo XIII

\title{
A modo de conclusión: con la mirada puesta en el futuro de la integración
}

\author{
Hugo E. Beteta \\ Jorge Mario Martínez Piva
}

El proceso de integración centroamericana ha estado muy ligado a la propia historia de la Comisión Económica para América Latina y el Caribe (CEPAL) debido al cercano acompañamiento técnico e intelectual que brindó esta institución. En su septuagésimo aniversario, la CEPAL publica este libro en el que se analiza el proceso de integración centroamericana desde aquellas áreas en las que colabora con la región, subrayando los avances más importantes y los desafíos más urgentes.

Este libro tiene como principal objeto analizar algunos de los aportes más relevantes de la CEPAL al proceso de integración centroamericana. Si bien existen muchas áreas en las cuales la CEPAL ha realizado diversos aportes durante la historia de la integración - como en los temas vinculados a la integración financiera, el desarrollo turístico y el fortalecimiento de capacidades de modelización macroeconómica-, en este trabajo no fue posible abordarlas todas y se revisan solo aquellas que cuentan con una agenda de colaboración más reciente.

En el libro se da cuenta de que existen bienes públicos regionales sobre los que resulta más provechosa la acción conjunta, y estos se presentan agrupados de manera resumida en estas conclusiones. En la sección A se repasan las acciones de trabajo en las que actualmente la CEPAL colabora 
con el proceso de integración, en tanto que en la sección B se describen algunos de los desafíos más apremiantes que enfrenta la región. Con este libro cepalino sobre la integración centroamericana se busca arrojar luz sobre algunas áreas de este proceso de integración y subrayar su relevancia como instrumento de desarrollo.

\section{A. Avances y acciones de trabajo identificadas}

Para la CEPAL, el desarrollo se alcanza mediante un cambio estructural progresivo en el cual la igualdad está en el centro del esfuerzo desarrollador. Las políticas de desarrollo productivo forman parte del conjunto de instrumentos para el cambio estructural que inciden sobre estructuras económicas poco dinámicas, poco diversificadas y de escaso valor agregado, hasta lograr un cambio en la composición de la producción, incrementando su valor.

El cambio estructural progresivo requiere de dos tipos de eficiencia dinámica que impulsan trayectorias de más rápido crecimiento de la productividad, la producción y el empleo. La primera es la llamada "eficiencia schumpeteriana", que permite la creciente presencia de sectores intensivos en conocimientos, con alta difusión de capacidades hacia el conjunto de la economía, y que lideran el proceso de innovación e incrementos de productividad, tanto dentro del propio sector como hacia otros sectores. La segunda es la "eficiencia keynesiana", que se enfoca en el dinamismo de la demanda de los bienes producidos en un país, de manera que se centren en los que tienen una demanda en rápido crecimiento que estimula a las empresas a aumentar la inversión y la producción (CEPAL, 2012).

Centroamérica requiere de niveles más altos de eficiencia dinámica, tanto schumpeteriana como keynesiana, para que se fortalezcan sectores dinámicos desde el punto de vista tecnológico y de la demanda. Este cambio estructural es costoso y para las economías pequeñas y abiertas supone un reto doble, ya que están más expuestas al comercio internacional, con una mayor competencia y reglas comerciales que limitan el número de políticas industriales a las que se puede echar mano, y tienen mercados internos pequeños que dificultan poder alcanzar las economías de escala necesarias para el desarrollo de industrias eficientes.

El proceso de integración centroamericana crea espacios idóneos para actuar conjuntamente en áreas en las que existen bienes públicos regionales y sobre las que resulta más provechosa la acción conjunta que la individual. En estas áreas es posible diseñar políticas para el cambio estructural progresivo, y la CEPAL ha ofrecido apoyo a los países de la región en el diseño de dichas políticas. En este libro se han analizado varias de estas políticas: la integración comercial, las cadenas regionales de valor, la unión aduanera, la logística y la 
movilidad, las matrices de insumo-producto como instrumentos analíticos para la integración, la integración energética, la respuesta ante el cambio climático, la coordinación fiscal, la dimensión social de la integración y la relevancia de la ciencia, la tecnología y la innovación.

El primer espacio de trabajo fue el comercial, que ofreció un mercado ampliado para las industrias de la región y que ha sido sumamente aprovechado en el proceso industrializador de la región. Si bien el comercio intrarregional sigue concentrado en sectores de baja y mediana intensidad tecnológica, ha logrado crear cadenas productivas regionales basadas en las eficiencias productivas de países vecinos.

Las cadenas de valor regionales subrayan la existencia de un creciente comercio intraindustrial en Centroamérica y el reto de incrementar tanto los flujos comerciales intrarregionales, como su valor agregado. El diseño de una metodología para el fortalecimiento de las cadenas de valor regionales propuesto por la CEPAL, conjuntamente con diversos organismos de la integración centroamericana, facilitará que el desarrollo de estas cadenas se traduzca en cambios en su estructura y que procuren productos y servicios de mayor valor.

Sin embargo, el proceso de integración centroamericana tiene pendiente la profundización de medidas - tanto logísticas y de infraestructura, como legales y administrativas para la creación de una unión aduaneraque faciliten el comercio intrarregional. En cuanto a la unión aduanera, El Salvador, Guatemala y Honduras han dado pasos significativos y la CEPAL ha estimado, a través de modelos de equilibrio general, cuantiosas ganancias en el crecimiento del PIB, el comercio y el bienestar, así como en materia de recaudación fiscal. Más relevante aun es que las estimaciones indican que el impacto positivo sería mayor si la unión aduanera se extendiera a todos los países que actualmente forman parte de la integración económica centroamericana.

Una política de logística y movilidad subregional ofrece una enorme oportunidad para mejorar la eficiencia y la conectividad que brindan los servicios de movilidad, a un costo menor de lo que significaría un servicio de la misma calidad ofrecido de manera individual. La CEPAL ha señalado que la logística y la movilidad tienen una importancia estratégica tanto para la planificación y gestión de las infraestructuras, como para el diseño de redes logísticas con criterio regional y que tengan una escala que las torne eficientes y atractivas, conectadas adecuadamente con la economía global y con las redes internas. En este libro se ha insistido en la importancia de acompañar los procesos de integración regional de la planificación de infraestructuras con una mirada de largo plazo y una inversión sectorial estable que facilite la transformación productiva (Pérez-Salas, 2017). 
Con miras a proveer más y mejores instrumentos de análisis sobre la integración regional, la CEPAL ha analizado la generación de valor agregado y empleo a partir de las exportaciones en algunos países centroamericanos y en la República Dominicana. El enfoque, basado en matrices de insumo-producto nacionales, cuantifica la importancia del comercio internacional para estos países $\mathrm{y}$, en particular, la relevancia del comercio intrarregional centroamericano. Mediante el uso del modelo de insumo-producto, analizando el valor agregado generado por las exportaciones y el empleo inducido por estas, es posible estimar el cociente de valor agregado por ocupado que se interpreta como un indicador de la productividad laboral. Esta herramienta permite analizar el valor agregado por sector, diferenciando el sector exportador e incluso el que exporta a terceros mercados y al mercado centroamericano, y resaltando que Centroamérica constituye el segundo destino más importante de los países estudiados en la generación de valor agregado, precedido por los Estados Unidos. Más aun, el valor agregado por ocupado incorporado en las exportaciones dirigidas a Centroamérica es mayor que el registrado en las exportaciones destinadas a los Estados Unidos, lo que sugiere una generación de empleo de mayor calidad en las exportaciones intracentroamericanas.

El cambio estructural progresivo puede tener una expresión significativa en Centroamérica a la luz del análisis que permiten las matrices de insumoproducto. Se identifican sectores con potencial de incorporar mayor valor agregado en las exportaciones, o con efectos significativos en la generación de empleo o en la creación de ocupaciones de mejor calidad, y, por tanto, mayor productividad. Esta evidencia permite diseñar una política industrial que encause a la región hacia las transformaciones necesarias para la irrupción de nuevas actividades productivas, de alta demanda internacional, y el reforzamiento de otras con alto progreso técnico y cuidado del medio ambiente.

La política productiva regional tiene su expresión en diversas actividades y en acciones de coordinación de políticas públicas. Con el énfasis puesto en el cambio estructural progresivo, la CEPAL apoya la integración energética centroamericana como una forma de coadyuvar al cumplimiento de los Objetivos de Desarrollo Sostenible (ODS). Por una parte, se impulsaría la eficiencia productiva de diversos sectores, al tiempo que se podrían reducir las emisiones de gases de efecto invernadero, y, por la otra, la integración energética podría ser un elemento central del gran impulso ambiental propuesto por la CEPAL: aprovechar la necesidad de cambiar la matriz energética y el patrón de producción para promover una nueva política industrial basada en un keynesianismo ambiental.

El gran impulso ambiental abre la posibilidad no solo a una política productiva, sino también a la coordinación de políticas frente al cambio climático que tanto amenaza a Centroamérica. El sistema de integración centroamericana proporciona un marco de trabajo con acciones para 
combatir y para adaptarse al cambio climático, ya que las diversas instancias públicas adoptan e impulsan trabajos con visión local, nacional y regional. El cambio climático resalta las vulnerabilidades compartidas de los países, así como las oportunidades de respuesta coordinada, subrayando el valor del trabajo regional.

Si bien el proceso de integración centroamericana ha madurado su trabajo en algunas áreas de acción común, en otras, como en la coordinación fiscal y la dimensión social, aún es posible profundizar las acciones conjuntas. En materia fiscal, la integración centroamericana tiene una incipiente política de coordinación. El Consejo de Ministros de Hacienda o Finanzas de Centroamérica, Panamá y la República Dominicana (COSEFIN) registra avances en la coordinación de procedimientos y regulaciones aduaneras, así como en la armonización de normas, pero no ha logrado adelantos en materia de coordinación de incentivos fiscales a la inversión extranjera directa y ha avanzado a un ritmo lento en los esfuerzos para lograr una coordinación e integración fiscal. Si bien el COSEFIN surgió de las preocupaciones hacendarias derivadas de los acuerdos comerciales, su paulatina consolidación le ha permitido conocer y generar acuerdos más allá de los tributarios. Es de esperar que la creciente integración regional conduzca a una mayor coordinación fiscal y a la consolidación de la institucionalidad relacionada con este tema.

La integración social centroamericana muestra notables avances, pero también presenta retos para los próximos años. Se destaca que se ha logrado avanzar en una acción conjunta en algunos temas sociales, identificando líneas de acción comunes y logrando algún grado de trabajo coordinado. Esto se ha traducido en acuerdos que establecen entendimientos e intercambios de experiencias, información y buenas prácticas. Sin embargo, los diversos consejos y comisiones tienen distintos niveles de fortaleza institucional, así como distinta cantidad de instrumentos de acción, por lo que los resultados de sus trabajos a nivel regional son dispares. Por esta razón, la CEPAL ha recomendado el fortalecimiento del papel coordinador del Consejo de la Integración Social Centroamericana (CIS), con miras a articular una política regional de la dimensión social. Además, el marco propuesto por las Naciones Unidas en la Agenda 2030 para el Desarrollo Sostenible es oportuno y puede articular dicho proceso.

El cambio estructural progresivo propuesto por la CEPAL tiene uno de sus pilares fundamentales en la ciencia, la tecnología y la innovación. Se propone un tránsito hacia una economía basada en sectores intensivos en conocimientos que lideren el proceso de innovación, e incrementos de productividad, con efectos positivos en el resto de los sectores de la economía.

Existe amplio consenso sobre la importancia de la inversión en ciencia, tecnología e innovación, y Centroamérica ha identificado áreas estratégicas con potencial para innovar, tanto a nivel regional como nacional. Los países 
de la región también han avanzado en la formulación de políticas públicas nacionales integrales que fomenten una transición hacia sociedades del conocimiento. Sin embargo, persisten retos para diseñar esas políticas con alcance regional y asegurar su continuidad y calidad, su articulación entre componentes de los sistemas de innovación, la calidad y orientación de los recursos humanos, la vinculación entre la industria y el sector académico, el acceso al financiamiento, y la recolección y el uso de datos. La CEPAL propone acciones regionales para fomentar la ciencia, la tecnología y la innovación con políticas regionales que maximicen los recursos de innovación instalados en la región y pongan énfasis en sectores de interés regional. De igual modo, ha impulsado la creación de un mercado digital regional que genere confianza y seguridad, y promueva estándares comunes y una interoperabilidad para el desarrollo de economías digitales en la región.

La CEPAL seguirá trabajando con los países de la subregión en la búsqueda de acciones regionales para abordar los principales problemas de los sistemas de innovación, y contribuir al fortalecimiento de la capacidad de formulación de políticas públicas integrales que visibilicen las múltiples sinergias potenciales entre la ciencia, la tecnología y la innovación y los componentes sociales, económicos y ambientales. Se proponen más esfuerzos de articulación dentro de los sistemas de innovación y una mayor vinculación con sectores estratégicos, como el energético y el alimentario.

\section{B. Cambios tectónicos}

Es importante reinterpretar el papel de la integración centroamericana en un mundo donde existen profundos cambios que pueden mover los cimientos que históricamente han sostenido la integración en la región. La apuesta por un cambio estructural progresivo, en un marco de respeto al multilateralismo y a las reglas internacionales, facilitaría el cumplimiento de las metas de los ODS y el desarrollo económico y social de países pequeños como los centroamericanos. Sin embargo, este cambio estructural se da en un contexto internacional que condiciona la política económica de la región, le da oportunidades, pero también le plantea retos.

El ejercicio de reinterpretación del papel de la integración comienza por la identificación de los cambios y los retos a los que se enfrenta la región centroamericana en el siglo XXI. Los principales cambios profundos, o cambios tectónicos como los llama la CEPAL (2016), que afectan a la región centroamericana son: la consolidación de China como potencia, la evolución de los megaacuerdos comerciales, el auge del nacionalismo económico y la relación de la región con los Estados Unidos, el cambio demográfico y la migración, la sostenibilidad del desarrollo y el cambio climático, y la nueva 
revolución tecnológica. Todos estos cambios están transformando y retando a la economía mundial, redefiniendo la posición de los países y alterando el balance de poder entre los bloques económicos. La posición de los países pequeños, como los centroamericanos, es doblemente frágil frente a estos cambios: por una parte, son economías muy abiertas que han logrado una profunda integración en procesos productivos globales a través del comercio y la inversión, y, por la otra, son economías pequeñas cuyos márgenes de acción son reducidos.

\section{La consolidación de China como potencia económica y geopolítica}

La capacidad de China para incorporar progreso técnico y cambiar su estructura productiva le ha permitido reducir la brecha del PIB per cápita con respecto a los países más avanzados. Su crecimiento económico se benefició con la estrategia de relocalización productiva que llevan a cabo las corporaciones multinacionales en una amplia gama de industrias y servicios hacia regiones con menores costos de producción. Esto le permitió colocarse en el centro de muchas cadenas globales de valor.

China se convirtió en pocas décadas en el principal exportador y el segundo importador mundial de bienes y servicios, y se transformó en un gran importador de materias primas. La participación de la inversión china en países que cuentan con grandes dotaciones de recursos naturales aumenta la posibilidad de que se transformen en fuertes competidores de América Latina y el Caribe en importantes mercados agrícolas y de minerales. Para la región centroamericana, especializada en la exportación de manufacturas hacia el mercado de los Estados Unidos, la creciente presencia china en este país amenaza buena parte de su producción exportadora. Más aun, las crecientes importaciones chinas en Centroamérica han irrumpido en algunas cadenas regionales de valor que se consideraban maduras, como la textil y la industria del plástico.

El mundo se reordena ante el nuevo actor global que representa China y los países centroamericanos, que por muchos años mantuvieron lazos diplomáticos con la provincia china de Taiwán, han comenzado a replantearse sus relaciones con China y con Asia en general. Centroamérica, al igual que México y los países sudamericanos de la costa del Pacífico, se ha aproximado más a los Estados Unidos y ha celebrado acuerdos de libre comercio con ese país, en un intento por participar en su gran mercado interno. Sin embargo, no solo muchas industrias de China han ganado cuota de mercado en los Estados Unidos en detrimento de las industrias centroamericanas, sino que las propuestas económicas nacionalistas de los Estados Unidos obligan a replantearse esas estrategias comerciales. 
Es necesario, entonces, redefinir los términos de la relación con China para impulsar un nuevo estilo de desarrollo de la región. Centroamérica debe reflexionar sobre las condiciones para negociar y para buscar las oportunidades que pueden surgir de sus relaciones con China. Las dificultades del escenario internacional y las crecientes amenazas a los mecanismos de administración del comercio hacen necesario un esfuerzo para explorar las potencialidades de una mayor relación con países asiáticos, al tiempo que se fortalecen los mecanismos de integración regional.

Por otra parte, el éxito de China a la hora de reducir brechas de ingresos y capacidades con respecto a las economías avanzadas deja importantes lecciones a Centroamérica y hace evidente la urgencia del cambio estructural. China mostró que la diversificación de la oferta supone el desarrollo de nuevas habilidades y conocimientos, lo que requiere cambios profundos en las capacidades tecnológicas. Sin embargo, también es necesario aprender que se deben evitar los elementos negativos asociados a esta experiencia de desarrollo reciente: su impacto en los niveles de contaminación y el notorio incremento de la desigualdad.

\section{Los megaacuerdos crean mercados megarregionales}

Desde los años noventa, el mundo vivió un auge de los mecanismos de liberalización comercial, más allá de la creación de la Organización Mundial del Comercio (OMC), especialmente a través de la profundización de diversos acuerdos de integración comercial y la firma de múltiples tratados de libre comercio. Centroamérica ha participado activamente en estos mecanismos (véase el capítulo III) y ha alineado sus políticas de desarrollo con las políticas de desarrollo de mercados externos.

En los últimos tiempos han surgido iniciativas comerciales de enorme impacto potencial por el tamaño de las economías involucradas. Debido a los cambios recientes en la política comercial de los Estados Unidos, varios proyectos en los que participaba este país han quedado en suspenso (como es el caso de la Asociación Transatlántica de Comercio e Inversión (TTIP)) o han sido firmados con la ausencia de los Estados Unidos, a la espera de que más adelante se una (como sucedió con el Acuerdo de Asociación Transpacífico (TPP), ahora llamado Tratado Integral y Progresista de Asociación Transpacífico (CPTPP)).

Los acuerdos megarregionales tienen un fuerte impacto en las estrategias de inserción internacional de los países centroamericanos, lo que podría llevarlos a asumir sus estándares y normas comerciales, e incluso es posible que algunos países de la región busquen acercarse a dichos acuerdos. 
Como la irrupción de China, los megaacuerdos tienen aspectos positivos y negativos cuando se los mira desde la perspectiva de los bienes públicos globales y la Agenda 2030 para el Desarrollo Sostenible. Del lado positivo, es posible que estas negociaciones ayuden a definir estándares ambientales y sociales convergentes con los ODS. Del lado negativo, el debilitamiento del multilateralismo y la formación de megaacuerdos entre poderosos actores que, de hecho, ya tienen un alto nivel de integración, abren la posibilidad de un descenso del poder de negociación de los países en desarrollo. Los megaacuerdos no consideran los problemas específicos de las economías en desarrollo en cuanto al acceso a la tecnología, la reducción de brechas y la presencia en el mercado internacional. De esa forma, tenderían a reducir los espacios de política de fomento productivo disponibles para la región.

Es posible que en el futuro se configuren tres niveles de gobernanza del comercio internacional: i) la OMC en la regulación de los temas tradicionales; ii) los acuerdos megarregionales en los nuevos temas asociados a las cadenas de valor, los servicios, los estándares y la propiedad intelectual, y iii) las iniciativas de integración regional. Este sería un escenario negativo para la construcción de un sistema multilateral de comercio que contemple los intereses de las economías en desarrollo. El fenómeno megarregional desafía a América Latina y el Caribe a profundizar su proceso de integración como herramienta para mejorar su inserción en la economía mundial y la obliga a tener un papel mucho más proactivo en el debate mundial. Los cambios en las agendas de negociación internacional obligan a los países centroamericanos a reflexionar en bloque sobre los mecanismos de acción regional para que su voz sea escuchada y puedan sacar provecho del comercio global y de la profundidad de su propia integración regional.

\section{El auge del nacionalismo económico y los vínculos con los Estados Unidos}

Para regiones pequeñas y abiertas como la centroamericana, que ha buscado crecer mediante el fortalecimiento del mercado regional y de sus vínculos con mercados dinámicos externos, el creciente nacionalismo económico de algunos de sus socios, en especial de los Estados Unidos, presenta un desafío mayúsculo.

Los Estados Unidos son la principal fuente de inversión extranjera de los países centroamericanos, y para la mayoría de ellos constituyen el principal destino de sus exportaciones y el principal origen de sus importaciones. Entre ellos existen diversas cadenas de producción muy entrelazadas en diversos eslabones: en las industrias textil y de confección, automotriz, de aparatos médicos y farmacéutica, y en cadenas de servicios (como el turismo, los servicios logísticos, los servicios financieros y otros). Las relaciones entre 
Centroamérica y los Estados Unidos se han institucionalizado a través de acuerdos comerciales, tanto en el marco de la OMC, como a través del Tratado de Libre Comercio entre República Dominicana, Centroamérica y los Estados Unidos, lo que se suponía que creaba un entorno de estabilidad en los mercados. Sin embargo, la creciente incertidumbre sobre la estabilidad de los acuerdos con los Estados Unidos, incluso en el marco multilateral, pone presión en la estrategia de desarrollo centroamericana y hace que gane importancia la profundización del comercio intrarregional y la búsqueda de otros socios comerciales para la diversificación del destino de las exportaciones.

El sistema multilateral de comercio y los mismos acuerdos comerciales que se creía que daban estabilidad a las relaciones comerciales y de inversión entre países han comenzado a recibir señales preocupantes, sobre todo desde los Estados Unidos. Este país ha obligado a una renegociación del tratado de libre comercio que tenía con México y el Canadá, y ha impuesto a diversos socios comerciales medidas que rozan con la legalidad de los acuerdos. Los países centroamericanos deben defender el comercio regido por normas y evitar que este se rija por el poder político, ya que en ese escenario su posición se vería muy debilitada. Las alianzas regionales para participar en el debate global y las posiciones comunes en estos temas son necesarias para tener una voz relevante. Hay que explorar vías como el acercamiento y los procesos de convergencia entre la integración centroamericana y otros acuerdos regionales, como el Mercado Común del Sur (MERCOSUR) y la Alianza del Pacífico. Del mismo modo, se debe procurar el fortalecimiento de acuerdos comerciales con otros socios y el lanzamiento de nuevos acuerdos en los que primen los principios de no discriminación a través del trato nacional y el principio de nación más favorecida, la reciprocidad, la transparencia, los mecanismos de solución de controversias y válvulas de escape para momentos de crisis. Sería mejor aún si la región introduce en los acuerdos comerciales nuevos elementos que permitan vincular mejor el comercio con el desarrollo, como podría ser una actualización del principio de trato especial y diferenciado, normas sobre transferencia de tecnologías y disciplinas sobre los subsidios.

Otro reto importante que la región centroamericana enfrenta en su relación con los Estados Unidos es el escalamiento en las cadenas de valor con las que la región se vincula con ese país. La especialización en la maquila, si bien ha permitido diversificar la canasta exportadora y fortalecer la estructura industrial, mantiene a la región centroamericana enfocada en eslabones productivos de baja productividad e intensivos en mano de obra. La región se integra a las cadenas productivas ofreciendo un recurso del que tiene abundancia relativa: la mano de obra. La transformación productiva requiere que se transite hacia sectores con una demanda más dinámica de mayor intensidad tecnológica. La agregación de valor y el escalamiento en la 
cadena de valor dependerá de ambos elementos. El vínculo con el mercado estadounidense puede ser una oportunidad para lograrlo, pero aún es difícil vislumbrar la superación de la relación centro-periferia ente ambos.

\section{La población envejece y muchos jóvenes emigran}

Aunque en Centroamérica las sociedades aún son mayoritariamente jóvenes, se distingue un cambio en la distribución de la edad de las poblaciones nacionales vinculado al descenso de la fecundidad y a la mayor longevidad, que ha llevado al progresivo envejecimiento de la población. La transición de sociedades con predominio de jóvenes a sociedades con predominio de personas mayores tiene repercusiones sobre el consumo, pues estos usan más servicios médicos que la población en general. Así, el envejecimiento de la población implica que un mayor porcentaje del PIB se gastará en atención de la salud. La importancia del peso de la atención de la salud en la economía y su financiamiento aumentará rápidamente en los próximos años y profundizará los retos que Centroamérica enfrenta para asegurar la cobertura de salud y de ingresos a su población mayor.

Por otra parte, Centroamérica es una región con altas tasas de emigración, sobre todo hacia los Estados Unidos, donde reside el 78\% de los migrantes centroamericanos, pero también hacia el interior de la propia región. En los países del Triángulo del Norte Centroamericano (El Salvador, Guatemala y Honduras), los flujos de emigración superan los de inmigración. En Costa Rica y Panamá, la inmigración es más relevante como efecto de la gran inmigración nicaragüense en el primero y de la atracción migratoria asociada a las inversiones en infraestructura y construcción en el segundo.

La política restrictiva para el ingreso de migrantes y las deportaciones masivas que ha implementado el Gobierno de los Estados Unidos a partir de la segunda mitad de la década de 2000, que han superado los 840.000 migrantes provenientes de los países del Triángulo del Norte Centroamericano (Canales y Rojas, 2018), imponen serios retos. Aunque los países han puesto en marcha varias iniciativas ante esta situación, enfrentan diversas necesidades, como el apoyo psicosocial y la reinserción laboral en un mercado laboral de bajos salarios.

Los flujos migratorios requieren propuestas regionales y diálogos con países extrarregionales, como México y los Estados Unidos, ya que ningún país puede enfrentar estos retos aisladamente. Se trata de gestionar de manera conjunta una gobernanza de la migración para que esta sea ordenada y regular, y para que se contemple todo el ciclo del proceso (origen, tránsito, destino y retorno). 


\section{La sostenibilidad del desarrollo y el cambio climático}

El patrón de desarrollo que ha seguido el mundo hasta el día de hoy es insostenible y ha producido cambios en el clima que se consideran la mayor falla del mercado de todos los tiempos. Los países centroamericanos deben tomar medidas prontas para adaptarse al cambio climático y para incluir la variable ambiental en sus planes de desarrollo, incluso en sus propuestas de política económica para la transformación productiva. Todos los modelos predictivos sobre el comportamiento del clima en los distintos escenarios climáticos muestran que la región centroamericana será una de las más afectadas a nivel mundial por eventos extremos y, por lo tanto, debe prepararse.

Las economías centroamericanas deben acelerar su crecimiento para reducir las brechas de ingreso con respecto a las economías desarrolladas, pero esto solo sería sostenible con un cambio profundo del estilo de desarrollo. Ello supone un proceso simultáneo de construcción de nuevas capacidades y acortamiento de la brecha tecnológica, sin el cual es imposible conciliar empleo, crecimiento y protección ambiental. Se trata de sacar provecho de la necesidad de un cambio en el patrón de desarrollo para generar un gran impulso ambiental. Se requiere el diseño de nuevas políticas económicas, tanto positivas (incentivos) como negativas (desincentivos), que influyan sobre la estructura de rentabilidades para favorecer un nuevo estilo de desarrollo.

Centroamérica enfrenta el reto de moverse hacia un patrón de crecimiento que combine el progreso técnico, la igualdad y la sostenibilidad ambiental, y para ello debe construir capacidades para generar las innovaciones requeridas para el desacople entre crecimiento y emisión. Una economía con pocas capacidades tecnológicas y escaso capital humano, como la que tiene actualmente la región centroamericana, no será capaz de cuidar el medio ambiente ni adaptarse al cambio climático.

Las acciones que la región puede emprender son mucho más efectivas si se hacen de manera conjunta, como región, tanto en lo que respecta a las negociaciones en diversos foros mundiales y regionales, como a las medidas de adaptación y mitigación. El espacio para la cooperación con otros países latinoamericanos también es enorme $\mathrm{y}$, por lo tanto, hay ventanas de oportunidad para profundizar la integración regional en áreas distintas a las tradicionales, como el comercio o la infraestructura.

\section{La nueva revolución tecnológica}

El ritmo de las innovaciones y de su acceso al mercado, así como la obsolescencia de productos y hasta de sectores, se ha acelerado muchísimo en las últimas dos décadas. Las brechas entre los países líderes en materia de innovación y los seguidores, como los de Centroamérica, tiende a ensancharse, y las políticas 
de innovación centroamericanas aun no pueden responder efectivamente a este reto. En este sentido, es importante apreciar que la integración regional ofrece sinergias y economías de escala que permitirían competir en algunos sectores con fuerte presencia de la nueva revolución tecnológica (véase el capítulo XII).

La competitividad y el crecimiento de los países dependerán, en gran medida, de su integración a la infraestructura digital mundial y de que puedan sacar provecho de las innovaciones en áreas prometedoras como la nanotecnología y la biotecnología. Esta transición requiere un cambio radical en la forma de abordar la innovación y la visión que se tiene de la ciencia y la tecnología en Centroamérica. Los retos para desarrollar el ecosistema digital y mejorar su infraestructura, el capital humano y el entorno empresarial, así como las capacidades de investigación y adaptación tecnológica, son enormes.

Los estándares globales en materia digital (la regulación de flujos de datos, los derechos de propiedad intelectual, y la seguridad y privacidad) y los altos costos de investigación y desarrollo en los nuevos y prometedores sectores intensivos en conocimientos podrían atenderse mejor desde la actuación conjunta de los países centroamericanos. Tanto en el marco de las negociaciones donde se discuten los estándares globales en materia digital, como en la decisión de invertir en laboratorios, proyectos y aplicaciones científicas en áreas como la biotecnología, la actuación en bloque puede marcar la diferencia.

\section{A modo de cierre}

En este libro se han subrayado algunos de los desafíos de la integración centroamericana en áreas en las que la CEPAL trabaja con los países de la región. Algunos de esos desafíos son muy relevantes por su vinculación con el cambio estructural progresivo, por lo que se consideran críticos para el desarrollo de Centroamérica. Debido a que estos desafíos se vinculan entre sí, atender algunos de ellos generaría condiciones positivas en el resto, de manera circular y progresiva.

En este trabajo se ha puesto énfasis en los retos en los que la actuación conjunta de los países centroamericanos sería mucho más beneficiosa que el trabajo individual de cada uno. Se trata de actuar, fortalecer o crear bienes públicos regionales en los que la CEPAL, así como las propias instituciones regionales, podría realizar importantes aportes, profundizando las acciones comunes centroamericanas. De igual modo, se han identificado áreas emergentes en las que el trabajo en conjunto será importante, como es el caso de la adaptación y mitigación al cambio climático y el creciente peso de la tecnología y la investigación en el desarrollo económico. 
Por último, se debe señalar que en esta publicación se ha identificado la necesidad de profundizar en futuros trabajos la reflexión sobre la importancia de fortalecer las capacidades técnicas, de articulación y de instrumentación de las políticas por parte de las instituciones regionales. Esto implicará abordar la relevancia de dotar a las instituciones del financiamiento que les permita hacer su trabajo de manera independiente, permanente y técnicamente sólida.

Desde la CEPAL se continuará apoyando la propuesta de desarrollo e integración de Centroamérica, con la confianza de que el trabajo realizado hasta el día de hoy en la región, y el que está por venir, contribuirán a la implementación de los Objetivos de Desarrollo Sostenible que las Naciones Unidas y los Estados se han propuesto para 2030.

\section{Bibliografía}

Canales, A. y M. Rojas (2018), "Panorama de la migración internacional en México y Centroamérica", serie Población y Desarrollo, No 124 (LC/TS.2018/42), Santiago, Comisión Económica para América Latina y el Caribe (CEPAL).

CEPAL (Comisión Económica para América Latina y el Caribe) (2018), Desarrollo, integración e igualdad: la respuesta de Centroamérica a la crisis de la globalización (LC/PUB.2018/19), Santiago.

(2016), Horizontes 2030: la igualdad en el centro del desarrollo sostenible (LC/G.2660/Rev.1), Santiago, julio.

(2012), Cambio estructural para la igualdad: una visión integrada del desarrollo (LC/G.2524(SES.34/3)), Santiago.

Pérez-Salas, G. (2017), “Institucionalidad y políticas de logística: lecciones para América Latina y el Caribe del proceso implementado por la República de Corea", serie Recursos Naturales e Infraestructura, No 185 (LC/TS.2017/126), Santiago, Comisión Económica para América Latina y el Caribe (CEPAL), diciembre. 


\section{Publicaciones recientes de la CEPAL ECLAC recent publications}

\section{www.cepal.org/publicaciones}

Informes Anuales/Annual Reports

También disponibles para años anteriores/Issues for previous years also available

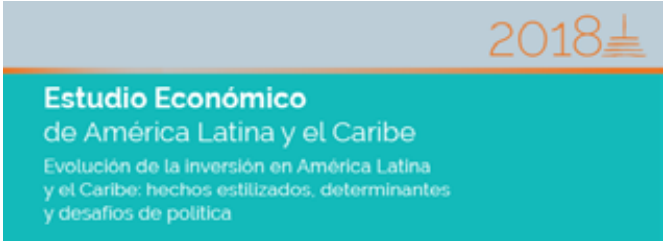

Estudio Económico de América Latina y el Caribe 2018 Economic Survey of Latin America and the Caribbean 2018

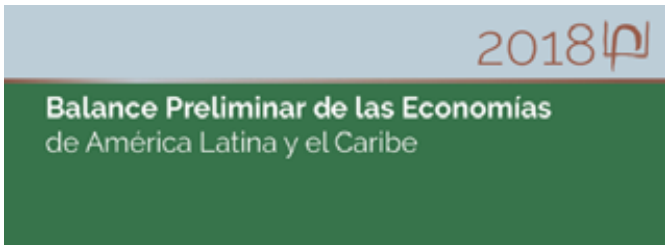

Balance Preliminar de las Economías de América Latina y el Caribe 2018

Preliminary Overview of the Economies of Latin America and the Caribbean 2018

\section{8橉}

Panorama Social

de América Latina

Panorama Social de América Latina 2018

Social Panorama of Latin America 2018

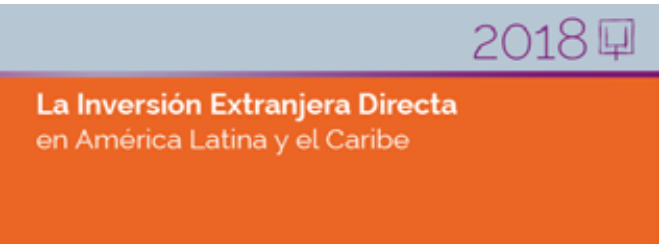

La Inversión Extranjera Directa en América Latina y el Caribe 2018

Foreign Direct Investment in Latin America and the Caribbean 2018

\section{8}

\section{Anuario Estadistico}

de América Latina y el Caribe

Statistical Yearboo $h$

for Latin America and the Caribbean

Anuario Estadístico de América Latina y el Caribe 2018 Statistical Yearbook for Latin America and the Caribbean 2018

\section{8 曲}

Perspectivas del Comercio Internacional de América Latina y el Caribe

Las tensiones comerciales exigen

una mayor intogración regional

Perspectivas del Comercio Internacional de América Latina y el Caribe 2018

International Trade Outlook for Latin America and the Caribbean 2018 


\section{El Pensamiento de la CEPAL/ECLAC Thinking}

Desarrollo e igualdad: el pensamiento de la CEPAL en su séptimo decenio. Textos seleccionados del período 2008-2018

La ineficiencia de la desigualdad

The Inefficiency of Inequality

Horizontes 2030: la igualdad en el centro del desarrollo sostenible Horizons 2030: Equality at the centre of sustainable development

Horizontes 2030: a igualdade no centro do desenvolvimento sustentável

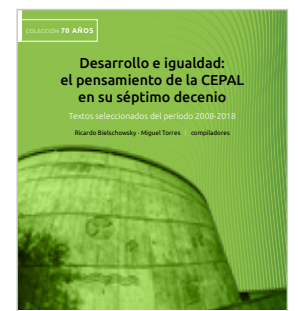

(6)

\section{Libros y Documentos Institucionales/Institutional Books and Documents}

Acuerdo Regional sobre el Acceso a la Información, la Participación Pública y el Acceso a la Justicia en Asuntos Ambientales en América Latina y el Caribe Regional Agreement on Access to Information, Public Participation and Justice in Environmental Matters in Latin America and the Caribbean

Hacia una agenda regional de desarrollo social inclusivo: bases y propuesta inicial ATowards a regional agenda for inclusive social development: bases and initial proposal

\section{Libros de la CEPAL/ECLAC Books}

Logros y desafíos de la integración centroamericana: aportes de la CEPAL

Envejecimiento, personas mayores y Agenda 2030 para el Desarrollo Sostenible: perspectiva regional y de derechos humanos

La inclusión financiera para la inserción productiva y el papel de la banca de desarrollo

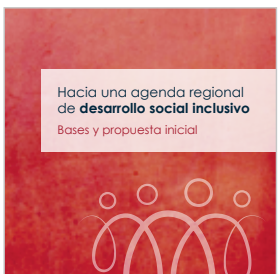

(6)
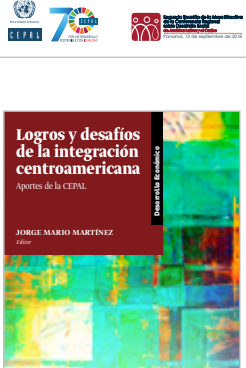

(2)
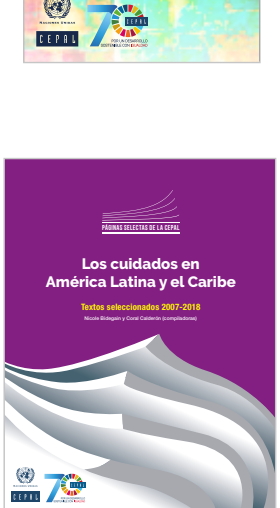

\section{Páginas Selectas de la CEPAL/ECLAC Select Pages}

Los cuidados en América Latina y el Caribe. Textos seleccionados 2007-2018

Empleo en América Latina y el Caribe. Textos seleccionados 2006-2017

Desarrollo inclusivo en América Latina. Textos seleccionados 2009-2016 
Revista CEPAL/CEPAL Review

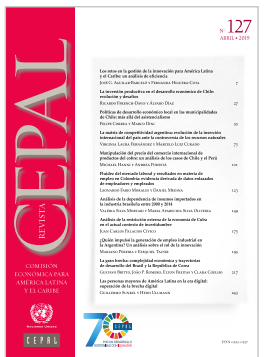

Notas de Población

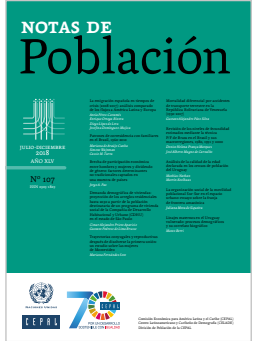

Documentos de Proyectos Project Documents

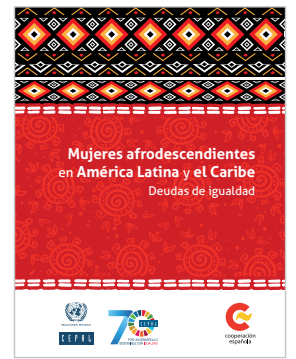

Coediciones/Co-editions

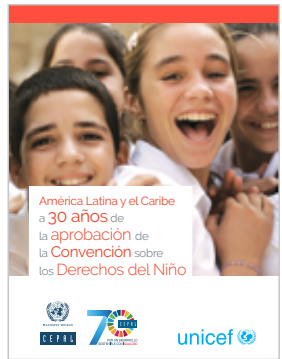

Series de la CEPAL/ECLAC Series

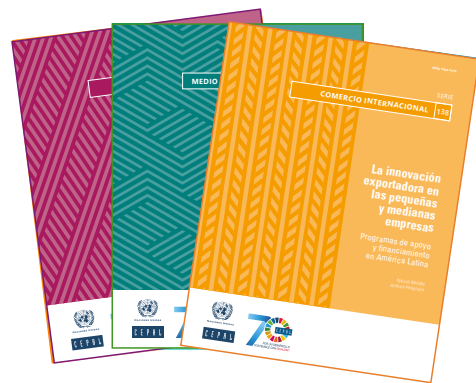

Observatorio Demográfico

Demographic Observatory

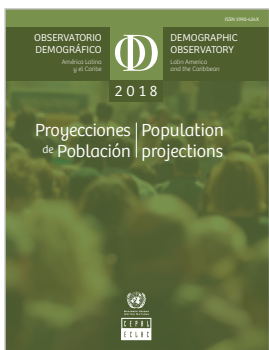

Metodologías de la CEPAL

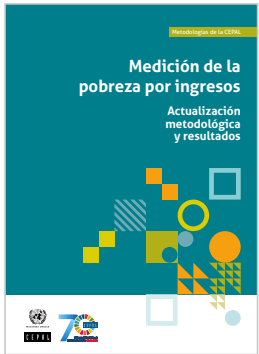

Copublicaciones/Co-publications

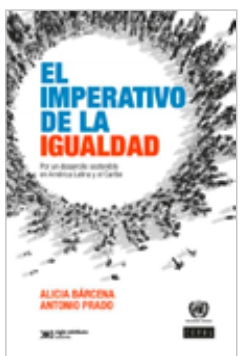





\section{Logros y desafíos}

de la integración centroamericana

El proyecto de integración centroamericana empezó en 1951 de la mano de las propuestas intelectuales y el apoyo técnico de la Comisión Económica para América Latina y el Caribe (CEPAL). Desde entonces, la CEPAL ha trabajado con los países centroamericanos en la elaboración de propuestas para su desarrollo, entrelazadas con el planteamiento de integración regional.

En su septuagésimo aniversario, la CEPAL publica este libro sobre la integración centroamericana, poniendo énfasis en las áreas en las que colabora con la región, y subraya los avances más importantes y los desafíos para el futuro. En esta publicación se hace un inventario del aporte de la CEPAL al proceso de integración centroamericana y se muestra su relevancia como instrumento de desarrollo.

La CEPAL quiere contribuir a la permanente renovación de la propuesta de desarrollo e integración para Centroamérica, con énfasis en el cambio estructural progresivo que se puede impulsar desde diversos frentes que se abordan en este libro: el sector social, la energía, los retos del cambio climático, la infraestructura, la coordinación fiscal, el comercio, la integración productiva y la innovación. Estas nuevas ideas se construyen sobre la fructífera experiencia histórica y vislumbran nuevas áreas de colaboración con la integración centroamericana. 